

\section{Blaggow \\ University Iibrary}

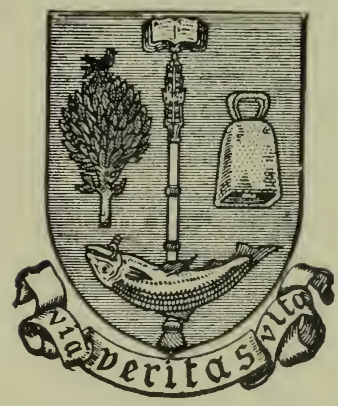

$$
\begin{array}{r}
R Q B O 58 \\
R Q 3200 \\
299
\end{array}
$$

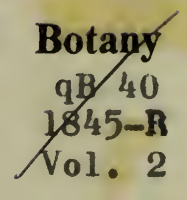





\section{PHYTOGRAPHIE}

\section{MÉDICALE,}

HISTOIRE DES SUBSTANCES HEROÏQUES

\section{ET DES POISONS}

TIRES DU REGNE VEGETAL,

\section{Par JOSEPH ROQUeS.}

NOUVELLE ÉDITION ENTIEREMENT REFONDUE, Et publiée en $\bar{a}$ vol. in-8 ${ }^{\circ}$, beau papier velin, DE CHACUN 550 a 600 PAgRS.

A vec un Atlas gr. in $-4^{\circ}$, de 150 planches coloriées.

20

TOME SECONI).

(2)

IPAIRIS

EIOUARD GARNOT, LIBRAIRE, NED PATER SIIXT-ANDRE-DES-ARCS , 7 .

1845. 


\section{dibTh Then
.118.mon}

GLAGGOW VAIVER SITY

LISPARY: 


\title{
PHYTOGRAPHIE MEDICALE.
}

\author{
CONVOLVULACÉES. \\ CONVOLVULACE AE. \\ Convolvulacece. - Juss.
}

\section{LISERON. CONVOLVULUS.}

Calice à cinq découpures. Corolle en cloche, à limbe plissé, entier ou à cinq angles. Étamines rapprochées, inégales. Ovaire ceint à la base d'un corps glanduleux; stigmate à deux lobes. Capsule à deux, trois ou quatre loges, renfermant chacune une ou deux graines.

\section{LISERON DES CHAMPS. CONVOLVULUS ARVENSIS.}

Convolvulus arvensis. Lins. Spec. 218. DC. Fl. Fr. 2745.

\section{(Planche 5o.)}

Sa tige fine et flexible rampe à terre lorsqu'elle est sans appui, ou bien elle s'élève en grimpant sur les plantes de son voisinage, autour desquelles elle s'en-

11. 
tortille. Les feuilles sont alternes, lisses, sagittées, portées sur de courts pétioles. Les fleurs sont blanches, roses ou purpurines, quelquefois panachées, solitaires, soutenues par de longs pédoncules, et munies de deux petites bractées éloignées du calice. On rencontre fréquemment cette petite plante dans les vignes, dans les champs, et dans tous les lieux cultivés. Ses fleurs répandent une odeur suave; elles se ferment au coucher du soleil, et ne se rouvrent que le lendemain.

\section{LISERON DES HATES. CONVOLVULUS}

\section{SEPIUM.}

Convolvulus sepium. Linn. Spec. 218. DC. FI. Fr. 2744.

Fl. Dan. t. 458.

Cette espèce, qu'on rencontre partout dans la campagne, surtout au milieu des haies et des buissons, charme les regards par ses belles corolles du blanc le plus pur. Ses tiges, grêles, cannelées, sarmenteuses, garnies de feuilles cordiformes et hastées, s'entrelacent dans les épines, se roulent autour des arbustes, dont elles embrassent étroitement les rameaux, ou montent en grimpant sur la cime des arbres. Les fleurs sont grandes, blanches, portées sur des pédoncules tétragones, solitaires, et munies, à peu de distance de leur calice, de deux bractées opposées, en forme de cœur.

Ce grand liseron couvre la rive droite de l'Oise, près de L'Ile-Adam. C'est un charmant spectacle de voir ses blanches corolles se fermer peu à peu, aussitôt que le soleil quitte l'horizon.

Lorsqu'on blesse les tiges de ces deux liserons, il en 
découle un suc d'abord douceâtre, puis âcre et amer. Ce suc contient un principe gommo-résineux qui exerce une action spéciale sur les organes digestifs. Haller, Coste, Willemet, Burtin, Gilibert, Bodard, pensent qu'on.peut substituer ces plantes indigènes, et surtout le grand liseron, à la scammonée d'Orient. Le suc des racines, des tiges et des feuilles, réduit en extrait et pris à la dose d'un scrupule, produit un effet cathartique assez intense. Les auteurs de la Matière médicale indigène l'ont prescrit avec avantage à plusieurs hydropiques. Le docteur Bodard, qui lui donne le nom de scammonée d'Europe, l'a également administré à la dose de dix, quinze, vingt et trente grains, selon l'âge et la constitution du malade, et il a presque toujours obtenu un effet purgatif sans irritation. Une forte décoction de feuilles fraîches manifeste la même propriété. A la campagne, où l'on manque souvent des secours ordinaires, on pourrait employer utilement ces plantes, qu'on trouve partout dans la belle saison. Séchées à l'ombre, elles conservent encore leurs vertus.

Décoction purgative. Prenez une ou deux poignćes de tiges, feuilles et fleurs du liseron des haies ; faites bouillir pendant un quart d'heure dans huit ou dix onces d'eau, et ajoutez une bonne cuillerée de miel. C'est un purgatif assez doux qui peut figurer utilement dans la médecine domestique. On peut employer de la même manière le liseron des champs. Les feuilles séchées à l'ombre conservent leurs propriétés et purgent très-bien; on les donne en décoction à la dose de deux ou trois gros dans une tasse de bouillon aux herbes. 
Les feuilles fraîches de ces deux liserons, pilées et appliquées en cataplasme sur les tumeurs indolentes, sur les plaies, sur les vieux ulcères, les raniment et les disposent à la guérison.

\section{LISERON JALAP. CONVOLVULUS JALAPA.}

Convolvulus jalapa. Linn. Mant. 43. Dese. Ann. Mus. 2. t. 40, 41. Kern. Hort. V. 11. t. 125.

(Planche 51.)

Ce liseron exotique a une racine tubéreuse, d'un volume considérable. Les tiges qui naissent de cette racine sont très-longues, volubiles, garnies de feuilles d'un vert obscur, alternes, pétiolées, plus ou moins anguleuses, arrondies, presque cordiformes. Les fleurs sont grandes, solitaires, soutenues par des pédoncules qui naissent de l'aisselle des feuilles. La corolle est grande, campaniforme, blanche, teinte de pourpre dans le milieu.

Le jalap croît dans l'Amérique espagnole, aux environs de La Vera-Cruz; iltire son nom de Xalapa, ville du Mexique, d'où on l'apporta en Europe vers l'an ı6 бо. La racine fraîche est d'un blanc jaunâtre et remplie d'un suc laiteux. Celle qu'on trouve dans le commerce est ordinairement divisée en fragmens orbiculaires, compactes, rugueux, noirâtres en dehors, d'un gris foncé intérieurement, marbrés, résineux, d'une odeur un peu nauséabonde, d'une saveur amère, âcre et mordicante. 
ANALYSE CHIMIQUE.

Cartheuser s'était livré, il y a bien long-temps, à l'examen chimique du jalap, et il avait obtenu d'une once de cette racine, une demi-once de principe gommeux ou extractif, et deux scrupules de résine. Nous devons à M.M. Planche, Henry et Cadet-Gassicourt, un travail plus complet sur les principes chimiques de cette substance végétale. D'après leurs recherches, le jalap contient de la résine, un extrait gommeux, de l'amidon, de l'albumine, divers sels, des traces d'àcide acétique, de matière sucrée et de matière colorante.

M. Chevallier a extrait du jalap une substance blanche pulvérulente, qui avait été déjà signalée par M. Hume fils sous le nom de jalapine. On l'obtient en traitant le jalap par l'acide acétique; on filtre la solution acide, et on précipite par l'alcali volatil.

\section{PROPRIÉTÉS DÉLÉTÈRES.}

Les expériences tentées sur les animaux par M. Cadet-Gassicourt prouvent que c'est au principe résineux que le jalap doit son action irritante. Un demi-gros de résine introduit dans l'estomac d'un vieux chien a produit, deux heures après, quelques vomissemens de matières muqueuses, plus tard, de l'abattement, de la soif et des convulsions; l'animal est mort cinq jours après. La membrane muqueuse de l'estomac et du duodénum a offert, sur différens points, des traces évidentes d'inflammation.

Un chirurgien administra quinze grains de jalap it un de ses malades qui se plaignait d'un embarras gas-: 
trique. Ce médicament produisit une irritation violente, des évacuations copieuses, des faiblesses, des anxiétés, des douleurs fixes et atroces dans le basventre, avec fièvre, céphalalgie, tintement d'oreilles, etc.

Une jeune fille ayaṇt pris un bol préparé avec la crême de tartre et quatorze grains de résine de jalap, éprouva une superpurgation suivie de lipothymie et de douleurs abdominales d'une violence extrême; la tête et les membres inférieurs étaient aussi douloureux. Ces symptômes se prolongèrent pendant cinq ou six jours ; ils furent enfin dissipés par les hypnotiques et les cordiaux. (Ephemer. med.-phys. german. decur. 2, ann. 7.$)$

Ce recueil académique renferme quelques autres faits semblables. Le niême remède a donné lieu à des convulsions épileptiques qui se sont renouvelées pendant plusieurs semaines. Une autre fois douze grains de résine, incorporés dans le sirop de roses, ont causé des tranchées horribles; les mucilagineux, les corps gras, ont mis fin à cet accident.

\section{Propriétés médicales.}

Plus une substance est riche en propriétés actives, plus il faut la manier avec prudence. Cette réflexion s'applique aux médicamens tirés de la famille des convolvulacées, et particulièrement au jalap, dont on fait un si grand abus. Électuaires, pilules, poudres, teintures, toutes les formes ont été épuisées en faveur de cette drogue exotique par les médicastres et les charlatans, qui ne voient partout que des humeurs sura- 
bondantes, des amas de glaires, et pour qui l'art de guérir n'est absolument que l'art de purger. Qu'on cesse de nous vanter ces guérisons extraordinaires d'obstructions, de dartres, de migraines, de rhumatismes, etc., opérées par la teinture alcoholique de jalap, et surtout par cette composition pernicieuse qui, depuis quelques années, inonde nos villes et nos campagnes. Je regarde ces remèdes offerts par des mains empiriques à la crédulité du peuple comme de véritables poisons qui agissent avec une extrême violence, ou qui minent sourdement les entrailles. En effet, la plupart des maladies que je viens de désigner se trouvant fréquemment liées avec une surexcitation ou une phlogose latente, soit des intestins, soit des autres viscères abdominaux, le jalap et les purgatifs résineux du même genre pourraient-ils ne pas ranimer encore ces foyers d'irritation? Pour quelques succès, sans doute très-rares, sur combien de maux l'humanité n'a-t-elle point à gémir! On trouve dans la Revuce médicale, et dans la Gazette de santé, rédigée par mon savant ami le docteur Miquel, des faits qui constatent jusqu’à la dernière évidence l'activité délétère de ces purgatifs drastiques.

Cependant je suis bien éloigné de vouloir proscrire l'usage du jalap. Cette substance est précieuse en ce qu'elle provoque une purgation presque toujours constante. Employée par un médecin instruit, elle produira d'excellens effets dans ces maladies lentes des organes digestifs où il faut réveiller le ton affaibli des viscères, et vaincre une constipation opiniâtre. Elle aura également du succès dans certaines hydropisies. 
passives qui demandent quelquefois des évacuans énergiques. On y aura recours pour exciter une irritation révulsive sur la surface intestinale, dans les affections comateuses, dans certaines maladies des organes de la respiration, etc. On le donnera aussi, mais à petites doses, aux enfans d'un tempérament muqueux, tourmentés par les vers.

Les purgatifs énergiques, parmi lesquels nous devons ranger le jalap, ont joui et jouissent encore, malgré toutes les opinions systématiques, d'une réputation justement méritée. C'est à leur action vive et profonde sur l'organisme qu'il faut attribuer ces effets salutaires et inattendus qui se font remarquer dans quelques cas de maladies vainement combattues par d'autres remèdes. L'ébranlement imprimé aux solides et aux fluides va retentir dans tout le système; les organes qui entretiennent avec le tube digestif des rapports de sensibilité et de sympathie, répondent en quelque sorte à cet appel; les forces de la vie se réveillent, et peu à peu l'harmonie se rétablit dans les fonctions. C'est ainsi qu'on peut expliquer quelques cures heureuses qu'on a obtenues du fameux remède de Leroy; mais les praticiens sages usent sobrement de ces moyens de perturbation : ils savent fort bien que si la nature triomphe quelquefois, le plus souvent elle succombe dans cette lutte violente. Tous ces remèdes actifs seront toujours, dans les mains des ignorans et des empiriques, un instrument de dommage; les gens du monde ne doivent jamais y avoir recours sans avoir pris l'avis d'un médecin éclairé.

Bien qu'on ait abusé des purgatifs dans le traitement 
des scrophules, à une époque où l'humorisme ne voyait qu'un virus spécifique à expulser, il n'est pas moins vrai qu'ils sont d'un grand secours dans ce genre de maladie : on a même employé avec un succès incontestable des préparations où l'on a jeté pêle-mêle toute sorte d'évacuans. Le professeur Baumes faisait grand cas d'un remède de ce genre, les pilules de Janin.

Hufeland recommande spécialement l'usage du jalap à la dose de quatre à six grains, avec un peu de magnésie. Ce mélange convient aux enfans scrophuleux, dont les intestins sont farcis de mucosités; il fait cesser la toux, les mauvaises digestions, l'empâtement du ventre, et autres symptômes qui compliquent si souvent la maladie strumeuse. D'après ce médecin expérimenté, la matière médicale ne possède pas de plus puissans résolutifs que les substances résineuses mélangées avec les extraits amers et les sels neutres. Il dit que l'art a beaucoup perdu de sa puissance en condamnant d'une manière trop générale l'emploi du jalap et autres évacuans gommo-résineux : aussi n'est-il pas rare de voir les empiriques les plus absolus réussir dans les cas où les médecins dogmatiques échouent journellement. Ces médicamens énergiques ne débarrassent pas seulement les intestins des mucosités qu'ils renferment, ils relèvent encore le ton et les fonctions du système lymphatique, et la maladie présente bientôt un aspect plus satisfaisant. Les minoratifs et les doux résolutifs ont une action trop faible lorsque le système est frappé d'une sorte de stupeur et d'inertie.

M. le docteur Baudelocque, dans ses Études sur laffection scrophuleuse, excellent ouvrage qui a paru 
nouvellement, a fort bien apprécié l'action médicamenteuse des purgatifs.

"Dès que l'on a placé un scrophuleux dans des conditions atmosphériques convenables, tous les moyens que l'on emploie doivent avoir pour but d'accélérer le mouvement de composition et de décomposition de nos organes; c'est l'effet que produisent les évacuans, et surtout les purgatifs. 'Toutes les fois qu'une déperdition de liquide a eu lieu, l'organisme tend à la réparer, et, pour cela, l'absorption acquiert plus d'énergie. Lorsqu'un purgatif a déterminé d'abondantes évacuations, il a diminué la partie séreuse du sang, ainsi que l'a fort bien démontré le docteur Balzac. La réparation du sérum se fait avec des matériaux mieux élaborés, qui modifient avantageusement le sang, les humeurs, et par suite la composition des organes. On parvient ainsi, par des évacuations successives, répétées à des distances convenables, à rendre beaucoup plus rapide le renouvellement de tout le corps, à changer entièrement la constitution, à faire disparaitre jusqu'aux dernières traces de l'affection scrophuleuse. Telles sont les vues qui m'ont dirigé dans l'emploi des évacuans, pour l'administration desquels il faut d'ailleurs avoir égard à l'état des organes de la digestion.) (Baudelocede, Études sur la maladie scrophuleuse, page 512.)

Les purgatifs ont également joui d'une grande vogue dans le traitement des maladies goutteuses. Alexandre de Tralles ne les conseille pas seulement pendantl'attaque, il veut encore qu'on les répète tous les deux ou trois mois. Frédéric Hoffmann assure avoir éprouvé 
sur lui-même leurs effets salutaires dès l'invasion de la douleur, et il les recommande aux jeunes médecins; il est vrai qu'il a soin de n'employer que les plus doux. Mais Sydenham, qui avait beaucoup mieux étudié la nature de la goutte, pense au contraire que tous les purgatifs sont nuisibles, soit qu'on les emploie pendant l'accès afin de l'affaiblir et d'en abréger le cours, ou à la fin du paroxisme pour emporter le reste de la maladie, soit dans les intervalles des attaques afin de prévenir le retour de la goutte. " J'ai éprouvé, dit-il, sur les autres et sur moi-même, que la purgation ne fait alors qu'augmenter le mal au lieu de le guérir. Je connais des goutteux qui se purgeaient régulièrement, non-seulement au printemps et en automne, mais encore chaque mois, et même chaque semaine, sans qu'aucun d'eux ait jamais pu se délivrer de la goutte : bien loin de là, elle est devenue plus cruelle et plus terrible que s'ils n'avaient fait aucun remède. "

Cette manière de proscrire un genre entier de médicamens dans toutes les phases de la goutte, nous paraît trop rigoureuse. Il est des cas où il est utile et même indispensable d'avoir recours aux purgatifs, surtout vers la fin de l'attaque; c'est lorsqu'il se manifeste des signes de pléthore bilieuse ou muqueuse, que l'appétit se perd, que les évacuations intestinales sont difficiles ou irrégulières, etc. Dans ces circonstances, quelques petites doses de jalap et de crême de tartre produisent les meilleurs effets. Nous avons souvent donne cette purgation, et toujours sans le moindre accident. Lorsque l'irritation arthritique menace 
la tête ou les organes pulmonaires, et que les topiques, tels que les sinapismes, les vésicatoires, sont inefficaces, les évacuans énergiques peuvent encore être employés pour détourner cette périlleuse métastase.

Mais nous ne saurions approuver l'usage qu'on fait des purgatifs, soit pour éloigner les attaques de la goutte, soit pour les combattre lorsqu'elles sont décidées et régulières. Les douleurs arthritiques peuvent bien s'adoucir ou se dissiper par les évacuans, mais on ne saurait extirper la goutte avec ces remèdes. La goutte est dans tout l'organisme; elle n'est point seulement dans le doigt qui souffre; vous pourriez l'amputer, vous ne guéririez pas pour cela la maladie. Ainsi la douleur, la rougeur, la tumeur, ne sont point la goutte, mais bien ses produits, comme le disait Van Helmont : Non quod dolet, quodque tumet, vel ardet, podagra est, sed hujus sunt producta.

Il y a plus : en troublant l'ordre des mouvemens. naturels, on expose des parties plus nobles, plus essentielles à la vie, et l'on a vu des goutteux mourir presque subitement après avoir pris un purgatif.

Le jalap et la scammonée sont d'un usage vulgaire dans l'œedème, dans l'hydropisie. Les charlatans, qui se sont emparés de ces substances, les administrent avec hardiesse, et en obtiennent quelquefois d'heureux résultats; mais lorsque le malade est dévoré par la fièvre, qu'il est très-faible et d'une sensibilité vive, lorsque les viscères sont atteints d'une inflammation chronique, ces remèdes sont de véritables poisons.

Une femme âgée d'environ cinquante ans, d'une constitution nerveuse, était affectée d'une hydropisie 
ascite avec œedème des membres inférieurs. Son médecin lui avait prescrit quelques laxatifs et un régime végétal. Fatiguée de la lenteur de ce traitement, et voulant guérir à tout prix, elle prend l'élixir purgatif de Leroy : les premières doses produisent des évacuations excessives, et l'enflure diminue. Ce début l'encourage : elle en avale une nouvelle dose, qui la fait vomir et la purge violemment; elle est saisie de convulsions, et elle tombe à terre; sa faiblesse est extrême. Les évacuations continuent pendant toute la journée; elles sont séreuses et sanguinolentes. Le ventre est horriblement distendu et sensible.

Consulté par le mari de cette dame, je prescris un julep anodin pour la nuit, et je condamne formellement l'usage de la drogue empoisonnée. Les douleurs s'apaisent, grâce aux gouttes de laudanum que contient le julep, et la malade dort quelques heures. Trompée par ce calme de la nuit, qu'elle attribue au remède Leroy, elle veut malgré mes conseils en prendre encore quelques doses : dans huit ou dix jours elle $y$ renoncera si elle n'est point guérie. L'odème, qui avait d'abord un peu diminué, augmente de volume; il survient de l'oppression, de la fièvre et une soif ardente. Cependant la malade en prend à sept heures du matin une nouvelle dose; ce sera la dernière : les évacuations sont suivies d'une anxiété extrême, d'évanouissemens, de délire, de sueurs froides : elle expire avant la fin du jour.

Ces funestes accidens, dont tous les praticiens pourraient citer des exemples, ne doivent pourtant pas faire oublier les services que rendent journelle- 
ment les purgatifs, et surtout les drastiques, dans les affections œedémateuses. On sait que Sydenham les maniait avec une grande habileté : ils sont même quelquefois très-utiles dans l'hydropisie dépendant des maladies du coeur; et le professeur Laennec ne craignait pas d'y avoir recours. On doit d'autant moins craindre de les employer, que leur répétition diminue souvent l'énergie des contractions du coeur, tout aussi efficacement que la saignée elle-même; et lors même qu'il n'existe aucune trace d'hydropisie, si les premières saignées ne soulagent pas le malade, un ou deux purgatifs rendent souvent la suivante plus utile. Tous les purgatifs peuvent être administrés avec avantage dans la diathèse séreuse qui dépend des maladies du. cour; mais les drastiques qui purgent sous un petit volume sont préférables. Sous ce rapport encore, les médecins désespèrent trop souvent du salut de leurs malades, et abandonnent quelquefois à une mort certaine des hommes à qui on eût pu rendre une existence supportable pour plusieurs années. Laennec nous dit que Corvisart, qui n'était pourtant pas un praticien timide, a commis lui-même une fois cette faute.

Un notaire de ses amis était attaqué depuis plusieurs années d'une maladie du cour, et depuis quelque temps d'ascite et d'une leuco-phlegmatie universelle, contre laquelle les saignées, les diurétiques et quelques purgatifs furent tout-à-fait inutiles. Corvisart pensa que la mort était inévitable, et en prévint les parens du malade. Quelques jours après on leur parla d'un charlatan qui avait fait de merveilleuses cures d'hydropisie. Cet homme, qu'on alla chercher dans 
un cabaret des faubourgs, fit prendre au malade une poudre fortement drastique, dans deux onces d'eaude-vie. Ce médicament produisit plus de vingt évacuations alvines, et dès-lors les urines redevinrent un peu plus abondantes. Le même moyen, répété tous les jours pendant plus d'une semaine, eut chaque jour des effets plus marqués, et la diathèse séreuse disparut complètement. Le malade a encore vécu dix ans dans un état de santé très-supportable.

J'ai plus d'une fois constaté les avantages des purgatifs, et particulièrement du jalap uni au calomel, dans ces toux opiniâtres qui succèdent à la coqueluche, et qui résistent aux préparations de belladone, aux calmans pris à l'intérieur, et à tous les irritans de la peau. On sait que la coqueluche est une maladie trèsréfractaire, que dans le cours du traitement on donne presque toujours des boissons gommeuses et sucrées, dẹs loochs, du laitage et autres corps gras, qui finissent par engouer les voies digestives : alors l'appétit se perd; les enfans tombent dans une sorte d'inertie et de langueur; ils ont le visage bouffi, d'un jaune terne; le pourtour des yeux d'une couleur plombée, l'haleine chaude. La langue muqueuse. Les quintes de toux deviennent plus fréquentes, surtout le soir et le matin; les membranes pulmonaires s'irritent de plus en plus: toutes ces secousses répétées réagissent sur le poumon, et il survient des désordres irrémédiables. Donnez quelques petites doses de jalap et de calomel, et tout cet appareil de symptômes se dissipe quelquefois d'une manière très-prompte. La dose de ces substances réunies est de quatre, cinq et six grains, 
suivant l'âge des enfins; on augmente la dose pour les adultes. Lorsqu'on a attendu trop long-temps, et que le mal est grave, ce remède est encore utile, mais il faut l'administrer quatre, cinq et six fois, en mettant deux, trois et quatre jours d'intervalle entre chaque prise; on prescrit ensuite une décoction légère de quinquina et un régime restaurant.

En exposant les propriétés du jalap, nous ne devons pas oublier sa vertu puissante contre les vers; tous les praticiens ont pu la vérifier, surtout chez les enfans d'un tempérament muqueux. On l'administre à la dose de six, huit, douze et quinze grains, qu'on triture avec un peu de sucre : la valériane ajoute à son action vermifuge. Ce mélange convient spécialement lorsqu'il se manifeste quelques symptômes nerveux.

Le jalap s'administre sous différentes formes. Lorsqu'on veut produire un effet cathartique, la dose est de vingt à trente grains, qu'on donne à la fois, ou mieux encore par fractions de huit ou dix grains, d'heure en heure, mais il faut qu'il soit récemment pulvérisé; sa poudre perd beaucoup de son action en vieillissant. La résine obtenue par l'alcohol est beaucoup plus irritante; la dose est de six à douze grains, qu'on incorpore dans une petite quantité de sucre, de jaune d'œuf, de mucilage ou de sirop, pour que ses molécules ne puissent s'attacher à la surface des intestins. Dans les prescriptions magistrales, on combine le jalap avec d'autres substances purgatives, telles que le calomel, la crême de tartre, la rhubarbe, la gratiole, etc.; et on compose avec plusieurs de ces agens réunis des poudres ou des bols vermifuges d'une grande 
efficacité. Quelquefois on l'associe aux absorbans et aux amers, à la magnésie, à la gentiane, au quinquina, à la cannelle, afin de débarrasser le conduit intestinal, et d'exciter en même temps ses forces toniques.

Poudre de jalap composée. Prenez, jalap en poudre, magnésie, de chaque, demi-gros; cannelle fine, quinze grains; mêlez et triturez exactement. On donne depuis quatre jusqu'à six et huit grains de cette poudre, une ou deux fois par jour, aux enfans affectés d'engorgement du mésentère avec atonie dominante; elle est préférable à tous les prétendus fondans, qui sont d'un faible secours contre ces maladies opiniâtres.

Poudre purgative pour un adulte. Prenez; résine de jalap, dix grains; oleo-saccharum de fenouil, vingt grains; triturez avec soin, et donnez cette poudre en une seule dose dans une petite tasse de café.

Émulsion purgative. Prenez, résine de jalap, dix à quinze grains; faites dissoudre en triturant dans deux onces de lait d'amandes; et ajoutez, eau distillée de cannelle, demi-once; sucre, quantité suffisante. Cette émulsion, ainsi que la poudre précédente, évacue assez bien les personnes qui éprouvent une répugnance invincible pour les purgatifs ordinaires.

Électuaire hydragogue. Prenez, rob de genièvre, deux onces; jalap, scammonée d'Alep, de chaque trois gros; semences d'anis, un gros; sirop de rhubarbe, quantité suffisante pour former un électuaire, qu'on administre à la dose de deux ou trois gros dans les hydropisies où les purgatifs sont indiqués.

Savon résineux de jalap. Prenez, résine de jalap, sa-

11. 
von officinal, de chaque, parties égales; triturez exactement avec un peu d'esprit de vin rectifié, jusqu'à ce que le mélange soit intime; ensuite, faites évaporer à une douce chaleur jusqu'à consistance d'extrait. La dose est de dix à vingt grains, qu'on triture avec un peu d'eau de cannelle, en y mêlant peu à peu une once et demie d'huile d'amandes douces. On donne, toutes les heures, aux adultes une cuillerée à bouche de cette mixture, et aux enfans une petite cuillerée. La résine de jalap, ainsi réunie au savon et à une substance oléagineuse, perd sa qualité irritante, et purge avec beaucoup de douceur. Elle est très-propre à combattre la diathèse vermineuse, les constipations opiniâtres et la physconie sans lésion organique. Cette composition est aussi efficace et plus sûre que l'huile de ricin, qui est souvent sophistiquée et très-âcre.

On peut former des pilules de quatre grains chacune avec le savon résineux de jalap. On en prend deux le soir en se couchant, et deux le matin à jeun en buvant par-dessus quelques gorgées d'eau pure ou légèrement sucrée. Elles conviennent aux personnes habituées à la bonne chère, et qui ont quelquefois besoin de stimuler et de débarrasser le tube digestif. Ce remède est bien préférable aux fameux grains de santé qui ont eu tant de vogue, et que les charlatans ont voulu remplacer par des pilules stomachiques, digestives, etc.

Mixture vermifuge et purgative de Storck. Prenez, sel polichreste (tartrate de potasse et de soude), jalap en poudre, valériane sauvage, de chaque, un gros; oxymel scillitique, quatre onces : mêlez. La dose est 
d'une cuillerée à bouche pour les adultes, et d'une petite cuillerée pour les enfans. On prend cette dose à sept et à neuf heures du matin, en buvant immédiatement après une tasse de thé ou de bouillon de veau. C'est un excellent remède contre les vers. Il a quelquefois guéri des ophthalmies rebelles, des symptômes d'amaurose provenant d'un foyer vermineux.

Teinture hydragogue de Sydenham. Prenez, jalap pilé grossièrement, demi-once; scammonée, trois gros; feuilles de séné, deux onces; réglisse, semences d'anis, de chaque, demi-once; sommités d'absinthe et feuilles de sauge, de chaque, une poignée : faites infuser à froid dans trois livres d'eau-de-vie, et ne passez la liqueur que lorsque vous voudrez en faire usage. La dose est d'une cuillerée le soir à l'heure du sommeil, et de deux autres le lendemain matin. On augmente ou l'on diminue les doses suivant l'effet du remède.

\section{LISERON SCAMMONÉE. CONVOLVULUS SCAMMONIA.}

Convolvulus scammonia. Linn. Spec. 281. - Scammonia Syriaca. Вачн. Pin. 294.

\section{(Planche 52.)}

Le liseron-scammonée a une racine fusiforme, trèsépaisse, charnue, pleine d'un suc laiteux. Les tiges qui s'échappent de cette racine sont grêles, grimpantes, garnies dans toute leur longueur de feuilles triangulaires, à base taillée en forme de flèche, pointues, lisses, d'un vert clair, attachées à de longs pétioles. 
Les pédoncules qui portent les fleurs sont garnis de deux petites bractées ouvertes. Le calice a des folioles obtuses, un peu échancrées à leur sommet; la corolle est grande, évasée en forme de cloche, d'une couleur blanche mélangée de jaune ou de pourpre. Cette plante croît dans plusieurs contrées de l'Asie, et particulièrement dans la Syrie, aux environs d'Alep.

C'est à l'aide d'incisions pratiquées sur la racine, qu'on obtient cette substance gommo-résineuse, connue dans les pharmacies sous le nom de scammonée. On en distingue deux sortes : celle d'Alep ou de Syrie, et celle de Smyrne. La première est légère, friable, d'un gris cendré, d'une cassure brillante; elle contient, d'après l'analyse de Bouillon-la-Grange et Vogel, soixante parties de résine, trois de gomme, deux d'extrait, et trente-cinq de débris végétaux. Celle de Smyrne est beaucoup moins pure, plus compacte, plus foncée en couleur, plus difficile à réduire en poudre; elle fournit beaucoup moins de résine, plus de gomme, et une grande quantité de matière terreuse. On croit qu'elle est extraite de plusieurs végétaux de la famille des Apocynées.

\section{PROPRIÉTÉS DÉLÉTÈrEs.}

La scammonée a une odeur nauséabonde qui lui est propre, une saveur âcre et amère; elle est peu soluble dans l'eau, mais elle se dissont facilement dans l'alcohol, qui prend alors une couleur jaune brunâtre. L'action irritante qu'elle exerce sur le canal alimentaire l'assimile aux poisons drastiques. En effet, elle produit à haute dose des déjections alvines répétées, quelque- 
fois teintes de sang, un ténesme douloureux, des coliques violentes, et l'inflammation des intestins. D'après Van Swieten, elle excite des évacuations d'une odeur cadavéreuse, et cause une prompte dissolution du sang, qu'elle réduit en sérosité. Scammonii $S y$ riaci lacryma, ingesta corpori humano, in putridam aquam solvit humores, solutos per alvum evacuat. (Comment. in Boerh., aphor.) Barthez pense qu'elle agit alors par une impression vénéneuse sur le principe de vie qui anime le sang et les humeurs. Du reste, aucun fait ne prouve cette prétendue décomposition produite par la scammonée.

On doit rarement l'administrer aux personnes d'un tempérament irritable, bilieux ou sanguin. Ainsi que la résine de jalap, elle peut donner lieu à une superpurgation, à un spasme violent des organes gastriques.

\section{MÉTHODE CURATIVE.}

On cherche à calmer ces accidens par des boissons adoucissantes, et surtout par l'opium. Il n'existe point de méthode plus prompte et plus efficace lorsqu'elle est employée à temps; elle calme l'irritation douloureuse, et prévient ainsi la phlogose qui en est la suite. En pareil cas, on peut donner avec confiance la mixture suivante : prenez, huile d'olive ou d'amandes douces, trois onces; mucilage de gomme arabique, sirop de pavot, de chaque, une once; laudanum de Sydenham, vingt gouttes. La dose est d'une cuillerée à bouche, de quart d'heure en quart d'heure; on éloigne un peu les doses lorsque les douleurs et les évacuations diminuent. 
PROPRIÉTÉS MÉdiCALES.

Les Grees et les Arabes ont parfaitement connu la scammonée; nos humoristes ell ont fait un abus condamnable; nos physiologistes modernes ne l'emploient jamais; elle produit néanmoins, dans quelques maladies chroniques, des effets inattendus. On cite des fièvres intermittentes rebelles, des céphalalgies, des ophthalmies opiniâtres, des épanchemens lymphatiques, des leucorrhées, qui ont cédé à ce purgatif énergique. La surface intestinale, irritée par ses molécules, devient alors un centre de fluxion qui exerce une influence remarquable sur les organes primitivement affectés. Ces secousses, si on les renouvelle avec sagesse, intervertissent l'ordre habituel des mouvemens, font naître de nouvelles impressions, et produisent ainsi un effet révulsif très-salutaire. Les personnes qui ont la fibre molle, la sensibilité obtuse, se trouvent fort bien de ce purgatif; mais on doit en user sobrement, ainsi que du jalap, dans les climats chands, où l'homme est affecté des plus légères irritations : lorsque les purgatifs sont indiqués, il faut préférer alors les tamarins, la crême de tartre, et autres laxatifs d'une nature rafiaîchissante. Les vieillards, les personnes délicates, les indigens, supportent aussi avec peine les purgatifs résineux, qui les jettent dans une grande faiblesse, après avoir donné lieu à des évacuations prolongées.

Les anciens avaient cherché à modifier l'action irritante de la scammonée en l'imprégnant de vapeurs sulphureuses, en y ajoutant du suc de coing, de ré- 
glisse, etc; nous ne nous arrêterons point à ces préparations surannées qu'on ne retrouve plus dans nos formulaires. Aujourd'hui on administre simplement la scammonée triturée avec du sucre, avec la gomme arabique, avec des amandes, ou bien réunie à d'autres substances purgatives. A la dose de dix à quinze grains, elle évacue assez bien les individus d'une complexion ordinaire; il en faut vingt-cinq ou trente grains pour les tempéramens robustes. Lorsqu'on l'administre à faibles doses, elle purge pen, mais elle excite l'action des glandes, et elle agit alors comme un remède fondant, altérant, ainsi qu'on le disait dans l'ancienne école.

Ses effets thérapeutiques se rapprochent de ceux du jalap, et plusieurs praticiens combinent ces deux substances. Van Swieten nous apprend que Boerhaave mêlait la scammonée à l'antimoine diaphorétique; qu'il recommandait ce mélange comme un bon préservatif contre la goutte, et qu'il le faisait répéter tous les trois mois. Celeberrimus Boerhaavius amico suo Bassando, podagrico jam veterano, in litteris adillum datis suasit, ut singulo trimestri tale purgans sumeret. (Van Swieten, Comment. de Podagrâ, tome 4.)

Nous répèterons ici que les drastiques sont rarement utiles dans la goutte; que si dans quelques circonstances ils soulagent les goutteux adonnés à la bonne chère et chargés de mauvais sucs, ils sont toujours nuisibles aux sujets nerveux, irritables, et d'une constitution sèche.

La scammonée fait partie d'une foule de préparations anciennes; elle entre dans les pilules cochées 
les pilules dorées, les pilules fétides, le pilules de Beloste; dans plusieurs électuaires hydragogues, etc. La plupart de ces médicamens, fort peu usités aujourd'hui, ne sont pourtant pas tous à dédaigner; ils agissent vivement sur l'appareil digestif, sur le foie, la rate et autres viscères abdominaux ; produisent une révulsion puissante et salutaire dans quelques cas de céphalalgie, d'ophthalmie, etc. On les a administrés avec non moins d'avantage dans l'hydropisie, dans les maladies de la peau et un grand nombre d'autres affections chroniques et opiniâtres.

Parmi les formules les plus simples, nous citerons un mélange dont Finke faisait un fréquent usage dans les maladies bilieuses anomales.

Poudre résolutive de Finke. Prenez, diagrède sulphuré, huit grains; calomel ou muriate de mercure doux, trois grains; mêlez, pour une poudre à prendre tous les matins à jeun, plusieurs jours de suite. On boit par dessus une tasse de bouillon de veau. Cette poudre convient dans les embarras intestinaux et dans-l'engorgement du foie, dont elle excite les sécrétions languissantes; elle ne produit d'ailleurs aucune salivation. Le docteur Sainte-Marie l'a administrée avec beaucoup de succès dans plusieurs épidémies de fièvre bilieuse. Aucune méthode thérapeutique n'a mieux répondu à ses vues que l'application des sangsues sur la région épigastrique, l'emploi de la poudre de Finke tous les matins, et une dose modérée de sirop de pavot tous les soirs.

Pastilles purgatives. Prenez, résine de scammonée d'Alep, six grains; teinturealcoholiquede séné, quarante 
gouttes; carbonate de magnésie, un gros ; sucre blanc en poudre très-fine, deux gros et demi; réglisse en poudre très-fine, huit grains ; gomme adragante, cinq grains; essence d'anis, une très-petite goutte; sirop de violette, quantité suffisante pour le mucilage : faites suivant l'art huit pastilles.

Elles conviennent particulièrement aux personnes sujettes aux régurgitations acides et à celles qui sont incommodées par des flatuosités. Alors, si l'on veut seulement combattre ces accidens, sans produire d'effet purgatif bien marqué, il suffit d'en prendre une ou deux le matin à jeun, et l'on aura encore par là l'avantage d'entretenir la liberté du ventre. Mais pour obtenir une véritable purgation, il faut prendre les huit pastilles, trois d'abord, trois autres au bout d'un quart d'heure, et les deux dernières un quart d'heure après. On les mâche, et l'on avale à chaque prise une cuillerée de bouillon. Lorsque la purgation commence, on la seconde en buvant par intervalles trois ou quatre tasses de thé léger ou de bouillon de veau.

Les docteurs Cottereau et Haas ont fréquemment employé ces pastilles dans leur pratique, et toujours avec succès. Les femmes et les enfans, qu'on évacue avec tant de difficulté, prendront ce purgatif sans répugnance.

Avant de terminer cet article, arrêtons-nous un instant sur quelques préparations qui ont joui d'une grande vogue dans les annales de la médecine empirique; nous dirons ensuite un mot de quelques autres médicamens que nous devons aux charlatans contemporains. 
Cornachini, médecin de Pise, a été l'inventeur d'une poudre qui consiste dans un mélange de scammonée, de crême de tartre et d'antimoine diaphorétique. Elle a été tour à tour désignée sous les noms de poudre Cornachini, poudre du comte de Warwick, poudre de tribus, poudre des trois diables. On s'en sert encore quelquefois, et on la donne depuis douze grains jusqu'à un gros. Van Swieten la recommande contre les fièvres intermittentes rebelles; il faut l'administrer quelques heures avant le paroxysme. Lautter a observé que ce remède dissipait quelquefois la fièvre sans provoquer la purgation. A la vérité les purgatifs drastiques peuvent supprimer une fièvre intermittente en excitant une sorte de trouble dans tout le système, en changeant ou en modifiant cette disposition particulière qui prépare et ramène les accès; mais une semblable méthode n'est pas sans danger; il faut l'abandonner aux empiriques.

Nous devons une poudre non moins fameuse à Ailhaud, médecin provençal, qui fit avec ce remède une fortune considérable. C'est un mélange de scammonée, de jalap et de suie : la suie n'est là que pour masquer les autres ingrédiens. La gazette d'Avignon inscrivait périodiquement les miracles de cette poudre, et les révélait aux châteaux, aux couvens, aux presbytères, etc. On la disait excellente pour évacuer les humeurs surabondantes ou viciées; le sang, la bile, l'atrabile, la pituite, les glaires. Elle guérissait l'apoplexie, la paralysie, l'hydropisie, la goutte, le rhumatisme, la gravelle; enfin elle convenait à toutes les maladies. Les seigneurs et les curés de village, les 
propriétaires ruraux en étaient abondamment pourvus, afin de n'en pas manquer dans les circonstances graves. Le règne de cette drogue a duré plus de cinquante ans. La poudre d'Ailhaud a fait un mal affreux, parce qu'on l'appliquait indistinctement à toutes sortes de maladies; eh bien! le temps seul a pu en faire justice. Il faut au public des remèdes énergiques qui l'agitent et le purgent, qui le guérissent ou le tuent promptement.

La réputation de ces poudres s'étant usée peu à peu, de nouveaux industriels sont venus nous offrir à peu près les mêmes remèdes sous des noms différens. Les uns y ont joint l'émétique, les autres la gomme-gutte, afin d'en augmenter la force. On connait notre opinion sur le remède de Leroy; nous en avons assez dit sur cette mauvaise drogue qui a enfanté l'élixir anti-glaireux et le toni-purgatif.

L'élixir anti-glaireux n'est pas moins nuisible: c'est un composé de substances drastiques et d'alcohol. On le distribue dans les villages, dans les hameaux, où les violens purgatifs sont encore plus pernicieux que dans les villes, parce que la plupart des habitans des campagnes, livrés à de rudes travaux qui les exténuent, usant d'un régime alimentaire peu substantiel, reçoivent un plus grand dommage de l'emploi des drastiques.

Le toni-purgatif a paru presque en même temps; il faisait aussi son tour de France; il ravageait nos bourgs, nos villages; mais sa fortune baisse depuis que son inventeur n'est plus là pour le faire prospérer. Un remède toni-purgatif! C'est pourtant avec un nom faux, ridicule et barbare qu'on attire ces pauvres ma- 
lades qui sont bien-aises d'être à la fois purgés et fortifiés. Toutes ces antithèses médicales ne sauraient faire naitre le moindre doute dans leur esprit : une annonce emphatique leur a garanti les effets du remède! Mais, chose déplorable! on a vu des chefs de corps, des colonels, des chefs d'atelier, imposer, pour ainsi dire, ces mauvaises préparations à leurs soldats, à leurs ouvriers, comme des médicamens merveilleux.

Tous les médecins qui ont étudié et observé leur action physiologique ne peuvent que les ranger parmi les poisons. Quelques succès ne prouvent rien; les drastiques administrés sans choix ni méthode produiront presque toujours les plus funestes effets.Cependant on distribue au public des bouteilles entières de ces élixirs dont quelques cuillerées suffisent pour tuer un malade. On a vu une infinité de malheureux qui dès les premières doses ont été pris d'une gastro-entérite mortelle; d'autres, réduits à vivre d'un peu de bouillon et de lait, ont traîné un vie languissante pendant plusieurs années; d'autres ont conservé dans le système nerveux une susceptibilité telle, que le plus léger mouvement, la moindre intempérance de l'air, leur causent des douleurs, des spasmes et un malaise universel.

Certes, la médecine et la pharmacie, professions si honorables et si utiles qui exigent de longues études et de grands sacrifices, ne sauraient plus long-temps résister aux empiétemens du charlatanisme, et elles sont menacées d'une ruine prochaine, si quelque loi tutélaire ne vient bientôt à leur secours. On se plaint de l'insuffisance des hôpitaux; des personnes riches 
et charitables créent de nouveaux refuges pour les ouvriers malades; mais que l'autorité proscrive toutes ces drogues qui ruinent la santé des classes laborieuses et les réduisent à l'état de misère, il y aura souvent des places vides dans les hospices.

\section{LISERON TURBITH. CONVOLVULUS TURPETHUM.}

Convolvulus turpethum. Linn. Spec. 221. Blackw. t. 397.

- Convolvulus alatus, maximus. Herm. Lugd. 177.

t. 178.179 .

Ce liseron a des racines ligneuses peu ramifiées, recouvertes d'une écorce brune et épaisse : elles s'enfoncent en serpentant dans la terre, à la profondeur de cinq ou six pieds, et laissent fluer, lorsqu'on les brise, un suc laiteux et gluant. Du collet de ces racines s'élèvent des tiges grêles, sarmenteuses, qui rampent à terre ou grimpent sur les arbrisseaux et les arbres voisins. Les feuilles sont anguleuses, crénelées, pointues, molles, couvertes d'un duvet soyeux et blanchâtre, portées sur des pétioles ailés, creusés en gouttière. Les fleurs sont axillaires, pédonculées, environnées, presque immédiatement au-dessous du calice, de deux bractées ovales, qui leur servent d'involucre. Les corolles ont la forme et la grandeur du liseron des haies.

On trouve cette plante dans les Indes Orientales, it Ceylan, à la côte de Malabar, eic. Elle se plaît dans les lieux ombragés et humides. Les racines fraîches ont un goût d'abord douceâtre, ensuite piquant et nau- 
séabond. Lorsqu'on les blesse, il en découle un suc abondant et visqueux qui devient jaunâtre en s'épaississant, et manifeste une saveur également nauséeuse et mordicante. Ces racines nous parviennent, desséchées, par la voie du commerce; elles sont brunes au dehors, blanchâtres intérieurement, presque inodores, imprégnẻes d'une gomme-résine âcre et drastique.

Les médecins arabes employaient fréquemment cette espèce de liseron, mais à peine figure-t-il aujourd'hui dans la matière médicale. Il est éminemment cathartique dans son pays natal, tandis qu'en Europe ses effets médicinaux sont très-variables parce qu'il est presque toujours sophistiqué : tantôt il purge faiblement, et tantôt avec une extrême violence.

\section{LISERON MÉCHOACAN. CONVOLVULUS $M E C H O A C A N N A$.}

Convolvulus mechoacanna. Lisw. Mat. med. 56. RAy. Hist. plant. 1. 723 .

Il est originaire du Brésil et du Mexique, d'où il fut transporté en Europe vers le commencement du xvi siècle. Sa racine est épaisse, rameuse, brune en dehors, blanchâtre intérieurement, résineuse et lactescente; elle pousse des tiges sarmenteuses, rampantes, garnies de vrilles, et de feuilles cordiformes d'un vert foncé. Les fleurs sont en cloche, d'un bleu rosé, ou purpurines.

Ce liseron est laiteux comme les espèces précédentes; mais ses racines sont moins résineuses, moins actives ; elles ont fourni à M. Félix Cadet-Gassicourt une fécule amylacée, de l'albumine, un principe huileux so- 
luble dansl'alcohol rectifié, etc. On administrait autrefois le méchoacan aux personnes délicates et irritables; on le donnait surtout aux enfans qui étaient tourmentés par les vers; mais son action est faible et incertaine, ce qui l'a fait tomber dans l'oubli. On le trouve quelquefois mêlé avec la racine de bryone; alors il purge violemment.

\section{LISERON SOLDANELLE. CONVOLVULUS SOLDANELLA.}

Convolvulus soldanella. Linn. Spec. 226. Scop. Fl. Carn. t. $1 . n^{\circ} 222$. DC. Fl. Fr. 2748.

Ses tiges sont grêles, rameuses, couchées sur la terre, garnies de feuilles pétiolées, réniformes ou un peu échancrées au sommet et d'un vert luisant. Les fleurs, portées sur des pédicelles axillaires, ont un calice entouré par deux bractées ovales, et une corolle grande, évasée, de couleur purpurine : elles forment une sorte de cloche presque quadrangulaire, s'ouvrent le matin, et se referment dans l'après-midi, pour s'épanouir de nouveau le lendemain.

Cette plante, qui porte le nom vulgaire de chou marin, croît dans les lieux sablonneux, le long des côtes, - depuis Nice jusqu'en Belgique. 'Toutes ses parties épanchent un suc résineux, îcre et amer, qui a beaucoup d'analogie avec celui du liseron scammonée, et qui purge vivement. La racine a fourni à M. Planche un extrait gommeux, une résine verte, des substances salines et une matière ligneuse.

Le suc de la plante fraîche est un puissant hydrago- 
gue qu'on peut administrer par petites cuillerées dans du bouillon aux herbes ou du bouillon gras. La racine desséchée perd en grande partie sa saveur, mais elle conserve son action purgative. La dose est de vingt à trente grains, qu'on mêle avec du miel. Suivant Murray, quelques auteurs la prescrivent depuis un gros jusqu'à quatre. Ces doses sont évidemment trop fortes, si la racine a été desséchée avec soin, car elles pourraient enflammer les tuniques digestives. Au reste, on a tort de négliger cette plante indigène, et elle doit être replacée parmi les médicamens héroïques. On devrait même la multiplier dans les sites où elle croît spontanément.

Il est peu de genres qui montrent autant d'analogie entre leurs propriétés physiques et leurs vertus médicamenteuses que le genre Liseron. Outre les espèces que nous avons décrites, on en compte beaucoup d'autres qui sont également douées de propriétés purgatives. Nous nous contenterons de citer le liseron maritime (convolvulus maritimus), qui croît dans les Indes et au Brésil; le liseron à gros fiuit (convolvulus macrocarpus), qu'on emploie comme purgatif à la Martinique; le liseron panduriforme (convolvulus panduratus), espèce usuelle aux État-Unis; le liseron à grosse racine (convolvulus macrorhizos), qui sert également de purgatif à Saint -Domingue; enfin le liseron des rives (convolvulus littoralis), espèce à suc laiteux qui croît aux Antilles. Ces divers liserons et quelques autres que nous passons sous silence, contiennent une matière gommo-résineuse qui excite vivement les tuniques digestives, et produit dans certains cas les 
bons et les mauvais effets des remèdes hydragogues.

Toutes ces espèces exotiques peuvent se remplacer par nos liserons, surtout par ceux qui naissent dans nos provinces méridionales. C'est là, sous l'influence du soleil, que les propriétés des plantes se perfectionnent, que leurs principes deviennent plus actifs, leurs sucs plus résineux.

Je le revois enfin ce ciel du Midi; je respire les parfums de ces rians coteaux que je parcourais dans mes jeunes années. Au milieu des beaux paysages qui charment ma vue, mon sang se réchauffe, mon cour se ranime, mes vieux souvenirs se réveillent. Je reconnais ce vallon si étroit, mais si joli, d'où s'échappe un air pur et suave, et ce ruisseau et ce bois touffu qui le suivent dans ses gracieux détours en répandant partout une fraîcheur vivifiante.

\section{...... In vialle reduclá}

Seclusum nemus et virgulta sunantia sylvis.

Quelle ineffable harmonie entre ce frémissement de l'air, et ce vallon, et ce bocage et ce ruisseau! O douce paix! c'est ici ton asile. Lorsque, après une course botanique, j'observe les richesses que j'ai amassées; que sous l'abri d'un bouquet de chênes, tout près d'une onde qui murmure, je repose mon corps fatigué et livre mon âme aux délices de la rêverie, que peut-il manquer à mon bonheur?

Les fleurs printanières ont perdu leur éclat; des gousses naissantes, des corolles flétries, annoncent l'accomplissement de leur destinée; mais la nature ne 
peut se lasser de produire, elle ouvre son sein, une infinité d'herbes aromatiques jonchent la terre. C'est l'ivette musquée, c'est la sarriette des mon tagnes, c'est la camomille valentine avec sa tige empourprée, le romarin avec son petit feuillage demi-vert. Ici, le grand plantain m'offre sa tige toute nue et sa charmante aigrette, composée d'un faisceau d'étamines de la plus douce nuance. Là, au milieu d'un groupe d'arbrisseaux divers, une belle plante étale ses corolles de neige: c'est le liseron des haies, indolent parasite qui se fait balancer par les brises dans un berceau de verdure. Plus loin, faible et sans appui, le petit liseron rampe sur la pelouse où il épanche son doux parfum. Le vulgaire méprise et foule aux pieds cette herbe modeste, qui est pourtant un chef-d'œuvre sorti des mains de la nature. Qu'il est joli, ce petit entonnoir blanc qu'elle a nuancé de rose et plissé avec grâce, pour qu'il se ferme le soir, et se rouvre le matin aux premiers rayons du jour! Le monde végétal a aussi ses heures de repos; mais c'est le sommeil des champs, sommeil paisible et doux qui n'a point de mauvais réveil. 


\section{GENTIANÉES. GENTIANEAE.}

\section{Gentianea. Juss.}

\section{GENTIANE. GENTIANA.}

Calice à cinq lobes Corolle de forme variée, en cloche, en entonnoir ou en roue, à quatre ou cinq divisions. Cinq étamines insérées sur le tube de la corolle. Ovaire surmonté de deux stigmates. Capsule à une loge, à deux valves.

GENTIANE JAUNE. GENTIANA LUTEA.

Gentiana litea. Linn. Spec. 329. DC. Fl. Fr. 2761. Lapeyr. Hist. Plant. Pyr. 132. Balb. Fl. Lyon. 1. 482.

\section{(Planche 53.)}

Sa tige est droite, simple, cylindrique, très-élevée. Ses feuilles sont grandes, ovales, embrassantes, d'un vert pâle, à plusieurs nervures; les inférieures sont un peu rétrécies en pétiole. Les fleurs sont nombreuses, verticillées autour de la tige dans les aisselles des feuilles supérieures; elles ont un calice membraneux, déjeté d'un seul côté; une corolle d'un jaune éclatant, en forme de roue, profondément découpée en lanières étroites, terminées en pointe. L'ovaire, qui ressemble à une espèce de massue verdâtre, est surmonté de deux stigmates. Cette espèce est connue 
sous le nom de grande gentiane: on la trouve aux environs de Lyon, dans les prairies du Pilat et de 'Tarare; sur la lisière des bois de Châtillon, en Bourgogne; dans les pâturaģes montueux des Pyrénées, des Vosges et de l'Auvergne. Mais c'est dans les hautes prairies des Alpes helvétiques que le botaniste aime à saluer cette superbe plante (I). C'est là qu'elle se montre dans toute sa beauté primitive : reléguée dans

(1) Dans ces imposantes solitudes oì la nature a pour ainsi dire s'assemblé ses prodiges, on rencontre à chaque pas l'élégante soldanelle, l'anémone à fleur de narcisse, le rhododendron étalant au bont de ses rameaux toujours verts la pourpre délicate de ses bouquets, et la reine des plantes des montagnes, la gentiane à corolle d'or. Mais quelle admirable perspective vient charmer le regard! quelle variété d'accidens! que de scènes magunifiques! Là de vastes et antiques forêts dont la teinte sombre se dessine sur les collines; des glaces éternelles qui scintillent comme le diamant sur la cime des monts; des torrens qui roulent avec fracas, et dont l'écho redit les longs mugissemens dans les profondes vallées. Ici, des arbres parés de verdure agitant leur tendre tt mobile feuillage à còté de noirs sapins, de vénérables chênes, mutilés, rompus par l'orage ou vieillis par le temps; des rochers, des ruines, des grottes, que mille arbrisseaux décorent avec une pompe sauvage. Plus loin, des coteaux rians et fertiles, des pâturages peuplés d'innombrables troupeaux, des cités, des villages épars dans les montagnes ; partout des sites ravissans, un air vif et pur, des eaux limpides, des émanations balsamiques qui renouvellent la vie et doublent l'existence; quel spectacle pour l'homme sensible! quelle source d'inspiration et d'enthousiasme pour le pein tre et le poëte! A l'aspect de tant d'objets sublimes, l'esprit s'élève et s'épure ; un charne inconnu pénètre l'âme, la remplit des plus nobles pensées. Ces passions turbulentes qui naissent au milieu des discordes civiles, ces désirs dévorans, ces tristes soucis qui rampent dans la poussière de la terre, tout cela s'évanouit comme un songe devant les merveilles de cette puissance immuable, éternelle, qui a formé la nature, ct répandu partout le mouvement et la vie. 
les jardins des curieux, elle languit, et semble regretter sa patrie.

La gentiane jaune recèle dans sa racine des vertus nombreuses et énergiques. Cette racine est épaisse, fort longue, marquée par des rides annulaires trèsrapprochées, brune en dehors, jaunâtre intérieurement, d'une texture spongieuse, d'une saveur extrêmement amère.

\section{ANALYSE CHIMIQUE.}

D'après les recherches ingénieuses de MM. Henri et Caventou, la racine de gentiane contient un principe amer cristallin, qui doit être rangé parmi les principes immédiats des végétaux. Ce principe, désigné par ces chimistes sous le nom de gentianin, est d'une belle couleur jaune, sans odeur, d'une amertume de gentiane très-prononcée. Il se dissout très-facilement dans l'éther et l'alcohol, et se sépare, par l'évaporation spontanée, sous forme de petites aiguilles cristallines jaunes. L'eau bouillante en dissout une certaine quantité, l'eau froide beaucoup moins, cependant elle devient très-amère. Outre le principe amer, la gentiane contient un principe odorant très-fugace, une matière analogue à la glu, une matière huileuse verdâtre fixe, un acide organique libre, du sucre incristallisable, de la gomme, une matière colorante fauve, et du ligneux.

M. Planche a reconnu dans l'eau distillée de cette racine un principe volatil qui agit fortement sur le cerveau, produit des nausées et une sorte d'ivresse. 


\section{PROPRIÉtÉS MÉdICALES.}

Suivant Pline; c'est à Gentius, roi d'lllyrie, que nous devons la connaissance des propriétés de la gentiane. Mais est-il besoin d'invoquer le témoignage de l'antiquité, lorsqu'il s'agit d'une plante qui réunit les suffrages des praticiens modernes? En effet, il n'est point de substance amère qui combatte avec plus de succès l'atonie des tissus vivans. Aussi est-elle généralement employée dans les débilités gastriques, dans l'anorexie, les langueurs d'estomac, les flatuosités, les aigreurs qui résultent de digestions mal élaborées ; dans les diarrhées qui se prolongent ou se reproduisent sous l'influence de l'atonie intestinale, et dans plusieurs autres affections lentes qui reconnaissent pour cause la faiblesse des appareils organiques.

Avant la découverte da quinquina, la racine de gentiane occupait le premier rang parmi les fébrifuges indigènes; quelques enthousiastes lui ont même attribué de nos jours une vertu plus puissante que celle de l'écorce du Pérou, parce qu'elle a guéri des fièvres qui avaient résisté à ce précieux médicament. Sans nous arrêter à cet éloge marqué au coin de l'exagération, nous conviendrons que la gentiane dissipe assez souvent les fièvres intermittentes simples; mais nous dirons aussi qu'une confiance aveugle en cette plante pourrait avoir des suites funestes, si l'on avait à traiter une fièvre accompagnée de symptômes pernicieux. Le quinquina sera toujours en pareil cas le remède par excellence : la chimie moderne, qui nous avait fait espérer, dans la substance alcaline isolée de cette 
écorce, une arme non moins puissante et plus facile à manier, paraît avoir accompli sa promesse ; il ne s'agit plus que de multiplier les expériences ( 1 ). Revenons à la gentiane. Sa vertu fébrifuge dépend beaucoup du sol où elle a été recueillie; celle qui croît dans les montagnes, et surtout dans les Alpes, est douée d'une action plus marquée, plus énergique. Les paysans de ces contrées s'en servent depuis long-temps avec un plein succès. Dans certains cas, il est utile d'y joindre une substance aromatique, comme l'écorce d'orange, la cannelle, l'absinthe, la valériane. Cette combinaison se digère beaucoup mieux; elle est d'ailleurs très-appropriée à l'inertie profonde de l'appareil gastrique. Les fièvres quartes très-opiniâtres qui sévissent sous le règne d'une température froide et humide ont quelquefois cédé à une semblable médication.

C'est à tort qque dans certains ouvrages de matière médicale la gentiane est désignée comme un moyen spécifique contre le scrophule. Nous ne connaissons aucune substance qui soit douée d'une semblable vertu. La thérapeutique de cette affection rebelle repose essentiellement sur l'examen approfondi de ses causes et de ses complications. Notre plante est utile aux scrophuleux dont le système est dans un véritable état de relâchement et de faiblesse, qui ont le teint pâle, la peau froide, bouffie, les glandes lymphatiques engor-

(1) Nous écrivions ces lignes en 1821; notre espoir n'a pas été déçu, et les faits recueillis jusqu'à ce jour sont innombrables. Honneur aux chimistes et aux médecins qui ont les premiers constaté la vertu fébrifuge des principes immédiats du quinquina. 
grées, avec des écoulemens muqueux et une sorte de langueur des fonctions nutritives. On a opposé avec succès à cet état pathologique l'élixir amer de Peyrilhe; mais il est impossible de dire combien cette préparation a été funeste à une époque où l’on ne voyait dans les maladies strumeuses que l'atonie radicale du système lymphatique. L'élixir de gentiane, le houblon, les vins les plus généreux, les alimens les plus riches en substance nutritive, composaient tout le traitement. On ne tenait aucun compte de la constitution individuelle; on n'examinait point s'il y avait une surexcitation intérieure : en sorte que les malades dont l'état morbide était compliqué d'une inflammation locale, ou de quelque suppuration lente des viscères, étaient bientôt dévorés d'une espèce de consomption qui les conduisait rapidement au tombeau. Les praticiens attentifs avaient souvent observé ces graves erreurs; mais il était réservé aux auteurs modernes de rectifier cette partie si essentielle de la thérapeutique (1). Le docteur Pujol y a puissamment contribué par ses beaux mémoires sur les inflammations chroniques et sur les maladies du système lymphatique; toutefois il faut convenir que c'est le professeur Broussais qui a ramené l'attention générale sur l'inflammation des tissus; les

(1) M. le docteur Baudelocque, s'appuyant de sa propre expérience et en même temps de l'autorité du professeur Dupuytren, blâme avec raison, dans ses Études sur le scrophule, l'usage banal de l'élixir de Peyrilhe. Lorsque nous nous élevions contre cette méthode peu rationnelle, les médecins de Paris ne songeaient guèrc à la modifier. Au reste, c'est l'abus et non l'usage des stimulans que nous blâmons. 
services qu'il a rendus à la science seraient inappréciables, si ses partisans fanatiques n'abusaient point de sa doctrine.

La gentiane n'est pas moins utile pour prévenir cek affaiblissement général du système qui amène le rachitis ; mais il faut que ce moyen prophylactique soit employé en temps opportun. On seconde ses effets corroborans par un bon régime, par des frictions pratiquées sur l'épine dorsale et sur les membres avec des flanelles sèches ou imprégnées de vapeurs aromatiques. Il est essentiel d'observer que le rachitis se lie très-souvent avec l'engorgement des glandes mésentériques; lorsque cette complication est accompagnée d'une chaleur fébrile, d'un sentiment douloureux à la région abdominale, quel que soit d'ailleurs l'état de faiblesse, il faut être réservé sur l'usage de la gentiane, des toniques et des excitans.

L'observation a quelquefois constaté les avantages de cette plante dans le traitement des maladies arthritiques. Les vieux goutteux, les individus d'une constitution faible, dont l'estomac a perdu ses facultés toniques, qui sont tourmentés par une goutte vague, par des flatuosités incommodes, trouvent du soulagement dans l'emploi de la gentiane et de ses préparations. Ces remèdes, en rétablissant les fonctions digestives, en corroborant tout l'organisme, éloignent les attaques, préviennent les anomalies de la goutte et ses métastases sur les viscères; mais leur abus peut avoir des suites fâcheuses. On les prend d'abord à faibles doses, qu'on élève peu à peu, et on les suspend de temps en temps pour ne pas habituer l'estomac à leur 
impression. La gentiane est un des ingrédiens de la poudre arthritique du codex de Paris, également connue sous le nom de poudre du duc de Portland. Cullen a signalé les funestes effets de cette composition; ceux qui en ont fait un long usage en Angleterre ont été délivrés de la goutte, mais ils ont succombé à des hydropisies, à des attaques d'asthme, d'apoplexie, etc. Cadogan assure que, dans l'espace de six ans, il a vu périr un grand nombre de goutteux qui avaient employé le même remède. Gaubius cite un fait semblable. Un homme de quarante ans, d'un tempérament extrêmement bilieux, depuis long-temps sujet à des attaques de goutte, en fut entièrement délivré après avoir fait usage pendant dix-huit mois de la poudre du duc de Portland; mais il éprouva bientôt après une difficulté de respirer qui s'aggrava de jour en jour, et il succomba à une maladie organique du poumon. Il est certain que la gentiane et les amers sont nuisibles aux goutteux doués d'une sensibilité extrême. L'abus de ces médicamens peut appeler la goutte sur l'estomac, les intestins, le poumon, etc., en provoquant un mouvement fluxionnaire sur ces organes irrités.

C'est en automne et surtout au printemps que la goutte, encore latente dans toute l'économie, cherche à faire irruption sur les membres. Cette remarque n'avait point échappé à Hippocrate ri à quelques autres anciens auteurs. Lucien, qui a décrit les caractères de la goutte avec tant d'esprit et d'originalité, dit qu'elle se montre lorsque l'orme se couvre de fleurs, et que le merle chante sur ses rameaux : 
Sed quandò ulmi vere tener flos abunilat, E't argula cantat in ramis merula: Tunc per membra aculum telum haret mystis, Obscurum, latens, subiens recessus artuum.

Les goutteux éprouvent alors une sorte de malaise, des irritations, des spasmes qui se concentrent tantôt sur la poitrine, tantôt sur l'appareil digestif. Ces symptômes sont presque toujours le prélude d'une attaque. Un régime doux, un exercice modéré, des pédiluves, des frictions avec de la flanelle sur les membres où la goutte se porte habituellement, mais surtout une vie réglée, voilà le secret d'avoir un paroxisme régulier, moins long et moins douloureux. Malheureusement on veut le faire avorter à tout prix, et comme les remèdes antigoutteux abondent, on peut choisir entre la teinture de gentiane ou l'essence de gayac, entre les poudres toniques ou l'élixir purgatif. Avec ces méthodes perturbatrices, la matière arthritique se jette sur les organes intérieurs, y développe des inflammations vives et souvent mortelles. Les goutteux forment une classe nombreuse et riche; ils craignent les longues attaques, et surtout la douleur qui les accompagne. Comment résister aux charlatans qui les obsèdent, depuis la capitale de l'Armagnac jusqu'à Paris, leur montrant le remède qui doit les soulager à l'instant, et les délivrer pour toujours de la goutte, cette cruelle ennemie de leurs plaisirs et de leurs jouissances.

Le médecin éclairé et consciencieux n'a promis que du soulagement; encore a-t-il voulu des soins, des privations, un régime assez sévère. L'empirique, dédaignant toutes les ressources diététiques, promet une 
guérison prompte et radicale; trois mille cures alfichées sur tous les murs garantissent sa promesse. Riches goutteux, pourriez-vous hésiter un seul instant?... Le savoir modeste se retire; l'ignorance et la cupidité prennent sa place.

On donne la gentiane en substance pulvérisée à la dose de dix, quinze et vingt grains, lorsqu'on veut simplement exciter le ton du système gastrique. L'eau, le vin et l'alcohol s'emparent de ses principes actifs; elle est le principal ingrédient de la teinture de Whytt, de l'élixir amer de Peyrilhe, etc., dont la formule se trouve dans tous les dispensaires, et qu'on administre par cuillerées. On associe la gentiane aux fébrifuges, aux toniques, aux excitans, tels que le quinquina, les fleurs de camomille, les préparations de fer, le cachou, l'angélique, l'absinthe, l'écorce d'orange, etc. L'extrait est d'un usage fréquent dans les prescriptions magistrales; la dose est de dix à vingt grains, qu'on peut faire dissoudre dans du vin de Madère, dans l'eau distillée de cannelle ou de menthe poivrée. Cette solution est très-utile pour dissiper l'état de faiblesse qui accompagne les longues convalescences.

Électuaire de gentiane. Prenez, racine degentiane, fleurs de camomille romaine réduites en poudre, de chaque une once; limaille de fer porphyrisée, deux gros; miel blanc, suffisante quantité pour former un électuaire, qu'on prescrit à la dose d'un gros toutes les quatre heures, dans les fièvres intermittentes automnales revêtues d'un caractère asthénique; dans la leucorrhée, l'aménorrhée, la chlorose avec faiblesse des organes assimilateurs. On fait prendre immédiatement 
après chaque dose une petite tasse d'infusion de camomille ou de petite centaurée.

$V$ in de gentiane composé. Prenez, racine de gentiane, deux onces; angélique, sommités d'absinthe sèches, de chaque une once; vin blanc de France, deux livres; alcohol, quatre onces. Faites macérer pendant quatre jours et filtrez la liqueur. On donne de temps en temps une ou deux cuillerées de ce vin pour combattre la diathèse muqueuse, si favorable au développement des vers; pour ranimer l'énergie vitale dans les affections strumeuses, scorbutiques, rhumatismales, goutteuses, etc.

Mixture diffusible. Prenez, teinture de racine de gentiane, de quinquina, d'écorce d'orange, de badiane, de chaque deux onces. Mêlez. Cette potion, composée de différentes teintures alcoholiques, doit être employée dans la dyspepsie muqueuse, maladie assez ordinaire chez les personnes douées d'un tempérament lymphatique, ou qui habitent des lieux humides. L'habitude que certains hommes contractent de boire des liqueurs fortes, habitude que des travaux pénibles et la rigueur du climat justifient jusqu'à un certain point, doit en faire varier les doses. Mais ce médicament pourrait être très-préjudiciable dans nos contrées méridionales, et chez les tempéramens biliososanguins, nerveux ou bilieux. La dose ordinaire est d'une cuillerée à bouche avant chaque repas. Nous avons extrait cette préparation de la pharmacologie magistrale de M. le docteur Fiévée, ouvrage estimable où les praticiens trouveront un grand nombre d'excellentes formules. 
Poudre antigoutteuse du duc de P'ortland. Prenez, parties égales de racine de gentiane jaune et de racine d'aristoloche ronde; de sommités de germandrée, d'ivette et de petite centaurée. Réduisez séparément en poudre chaque substance desséchée avec soin, et les mêlez ensuite pour l'usage.

On prend un gros de cette poudre, le matin à jeun, dans un peu d'eau et de vin, dans du bouillon ou dans du thé. Il faut en continuer l'usage pendant trois mois sans interruption. On diminue la dose d'un quart les trois mois suivans, et on en prend seulement un demigros pendant six autres mois. L'année suivante, il suffit d'en prendre seulement un demi-gros tous les deux jours.

Nous avons donné plus haut notre avis sur cette composition, qui ne peut être profitable qu'aux goutteux d'un tempérament froid, inerte et lymphatique; encore est-il dangereux de soumettre aussi long-temps les organes à l'action d'un pareil remède. Il vaut mieux le cesser, et le reprendre de temps en temps s'il fait dubien.

Tous les végétaux qui constituent le genre gentiane sont doués d'une vertu amère et tonique; nous ne ferons connaître que les espèces les plus remarquables.

\section{GENTIANE PURPURINE. GENTIIANA PURPUREA.}

Gentiana purpurea. Lins. Spec. 22\% DC. Fl. Fr. 2763. Froel. Gent. $n^{\circ} 2$.

Sa racine, horizontale, épaisse et ligneuse, pousse une tige droite, lisse, cylindrique, haute d'environ 
deux pieds. Les feuilles sont ovales, lancéolées, à cinq nervures. Les fleurs forment le plus souvent deux vèrticilles axillaires; elles sont grandes, campaniformes, à six lobes arrondis, jaunâtres en dehors, d'un pourpre foncéa la partie inférieure du limbe, souvent ponctuées en dedans. Le calice est en forme de spathe membraneuse, fendu d'un côté, déjeté de l'autre, souvent écliancré au sommet, égal à la moitié de la longueur de la corolle.

Cette belle plante croît dans les Pyrénées et dans les Alpes; elle varie pour les teintes de la corolle, qui est quelquefois rose ou pourpre sans aucune ponctuation, et même blanche.

Les habitans des Alpes font usage de cette espèce de gentiane, qui possède toutes les propriétés médicales de la gentiane jaune; elle est également usuelle en Norwège et en Allemagne.

GENTIANE PONGTUÉE. GENTIANA PUNCTATA.

Gentiana punctala. Linv.' Spec. 329. DC. FI. Fr. 2765. J ${ }_{\mathrm{ACQ}}$. Fl. Austr. t. 28.

Cette espèce a une racine divisée en plusieurs souches. Il naît de chaque souche une tige droite, cylindrique, haute d'un pied à un pied et demi au plus. Les feuilles inférieures sont ovales, pointues, rétrécies en pétiole vers leur base; les feuilles caulinaires sont lancéolées; les unes et les autres glabres et marquées de nervures. Les fleurs sont presque sessiles et disposées en verticilles axillaires. La corolle est campanulée, longue d'un pouce, jaunâtre, tachetée de 
points noirs, divisée en dix lobes obtus. Le calice est très-court, à six lobes inégaux, irréguliers.

On trouve cette plante dans les Alpes du Dauphiné et de la Suisse, dans les Pyrénées, dans les montagnes de l'Autriche et du Piémont. Elle est également employée comme tonique et fébrifuge.

\section{GENTIANE CROISETTE. GENTIANA CRUCIATA.}

Gentiana cruciata. Lrnn. Spec. 334. DC. Fl. Fr. $276 \%$. Chev. Fl. Par. 3. 510.

Sa tige est cylindrique, rougeâtre, haute de six à huit pouces, très-garnie de feuilles, ordinairement un peu couchée à sa base. Les feuilles sont lancéolées, glabres et un peu nerveuses; chaque paire forme, en se réunissant, une gaîne lâche qui enveloppe la tige de distance en distance. Les fleurs sont tubulées, légèrement campanulées, à quatre divisions, presque sessiles, et disposées en verticilles au sommet de la tige; le verticille terminal est le plus considérable; l'inférieur n'offre souvent que deux fleurs opposées. La corolle est d'un beau bleu à son orifice, peu colorée extérieurement.

La gentiane croisette croît en France et en Allemagne, dans les pâturages secs et montagneux. On la trouve aux environs de Lyon, à Fontaines, à MontCindre, etc.; à Compiègne, à Fontainebleau, à SaintGermain. Sa racine est très-amère; on s'en sert dans les campagnes à titre de fébrifuge. 
GENTIANE A COURTE TIGE. GENTIANA ACAULIS.

Gentiana acaulis. Linn. Spec. 330. DC. FI. Fr. 2770. J ACQ. Fl. Austr. t. 135. Lapeyr. Hist. Plant. Pyr. 1. 134.

Sa racine ligneuse pousse une ou deux tiges trèsbasses, portant une seule fleur. Les feuilles radicales sont larges, ovales, lancéolées, à trois nervures, et couchées sur la terre, où elles forment une rosette; les feuilles caulinaires sont plus étroites, rangées par paires opposées en croix. La fleur est très-grande, en forme de cloche, d'un superbe bleu, ponctuée intérieurement. Cette espèce offre plusieurs variétés, relativement à la hauteur de la tige, à la largeur des feuilles et à la nuance de la fleur.

Elle est commune dans les prairies des Pyrénées et des Alpes du Jura; on la trouve aussi dans les montagnes du Dauphiné. On lui attribue les vertus des espèces congénères.

\section{GENTIANE PNEUMONANTHE. GENTIANA}

\section{PNEUMONANTHE.}

Gentiana pneumonanthe. Lins. Spec. 330. DC. FI. Fr. 2769. Fl. Dan. t. 269.

Cette espèce a une tige haute de dix à douze pouces, ordinairement simple, quelquefois ramifiée, d'un violet rougeâtre à la base. Les feuilles sont opposées, un peu réunies par la base, étroites, obtuses à leur extrémité. Les fleurs sont grandes, campaniformes, 
droites, presque sessiles, d'un bleu d'azur magnifique, disposées en petit nombre au sommet de la tige et dans les aisselles des feuilles supérieures; elles sont munies, à la base, de deux petites feuilles jouant le rôle de bractées. Les étamines sont réunies en un faisceau autour de l'ovaire.

On trouve cette plante dans les lieux humides et marécageux; elle est assez commune à Montmorency, à Saint-Gratien, à Saint-Léger, etc. Nous l'avons observée en septembre dans les prés humides qui s'étendent au pied de la montagne du Dévézou (Aveyron) : le sol en était couvert. Il ne faut rien moins que l'aspect d'une jolie plante, pour vous faire oublier un instant ce lieu sauvage et plein de tristesse. Nous avons goûté les feuilles et les racines; elles sont d'une grande amertume.

\section{GENTIANE D'ALLEMAGNE. GENTIANA GERMANICA.}

Gentiana germanica. WiLd. Spec. 1. 1346. Ghev. Fl. Par. 3. 510. Lapeyr. Hist. Plant. Pyr. 1. 136.

Sa tige est droite, très-rameuse, haute de six à huit pouces; les feuilles radicales sont en spatule, les caulinaires sessiles, oblongues, rétrécies en pointe vers le sommet. Les fleurs, disposées le long de la tige et des rameaux qu'elles terminent, forment une sorte de panicule ample, et sont portées sur des pédoncules assez longs : elles ont un calice à cinq lobes égaux entre eux; une corolle d'un bleu vif, en forme d'entonnoir, à large tube, à cinq lobes lancéolés. Il n'y a quelquefois que 
quatre divisions à la corolle et au calice; mais cette irrégularité ne se présente que sur une ou deux fleurs du même individu, tandis que "dans les autres on compte cinq divisions.

Cette plante fleurit en août et septembre; on la trouve dans les prés et sur les pelouses. M. Chevallier l'a cueillie à Villers-Coterets, à Compiègne, à Saint-Germain; Lapeyrouse, dans les pâturages des Pyrénées, à Vieille dans la vallée d'Aran, et à Campsaure-de-Luchon.

Elle possède les vertus médicamenteuses du genre, et on peut la substituer aux gentianes dont nous venons de tracer les principaux caractères. La gentiane amarelle (gentiana amarella), la gentiane des champs (gentiana campestris), la gentiane printanière (gentiana verna), ont, avec toutes ces espèces, la plus grande analogie de propriétés.

\section{CHIRONIE. CHIRONIA.}

Corolle en entonnoir, à cinq lobes. Étamines insérées sur le tube; anthères oblongues, droites, tortillées après la fécondation. Capsule à deux loges formées par les bords rentrans des valves.

\section{CHIRONIE CENTAURÉE. CHIRONIA CENTAUREA.}

Chironia centaurium. SмIтн. FI. Brit. 1. 257. DC. FI. Fr. 2780. Woodw. Med. bot. t. 15\% - Gentiana centaurium. Lins. Spec. 332.

Cette plante, si renommée pour sa vertu fébrifuge, a une tige droite, élancée, haute de quinze à dix-huit pouces, un peu tétragone, divisée au sommet en ra- 
meaux opposés, formant une sorte de corymbe. Les feuilles sont ovales, un peu allongées, marquées de trois nervures. Les fleurs sont sessiles, d'une odeur douce et d'une couleur rosée ou purpurine. Elle croît en juillet et août au bord des bois et des prairies, le long des haies, etc. Mon frère, Victor Roques, a observé une variété à fleurs blanches, assez commune sur les pelouses sèches de Puylaurens (Tarn).

Tout le monde connaît cette plante fraîche et jolie qui porte le nom de petite centaurée. Linné en avait fait une gentiane; les botanistes qui sont venus après lui l'ont rangée, les uns dans le genre Chironia, les autres dans le genre Erythreea. Je préfère le nom de chironie à cause des vertus antifébriles de la plante, et par respect pour la mémoire du centaure Chiron, l'un des premiers inventeurs de 'la médecine et de la botanique. Mon esprit se complaît dans ces vieilles traditions; d'ailleurs, à force de changer la nomenclature déjà reçue, on ne fait qu'embarrasser la science, et au lieu de la rajeunir et d'en hâter les progrès, on rend ses abords plus difficiles.

$\mathrm{Au}$ reste, cette herbe bienfaisante a reçu les éloges des médecins de tous les siècles; son amertume spéciale lui a fait donner par ceux du moyen âge le nom de fel terrce (fiel de terre). Nous ne répèterons pas ici toutes les merveilles opérées par la petite centaurée. Un médecin du Nord, Samuel Sedelius (1), les a consi-

(1) Wedel a aussi disserté sur les vertus de cette plante ( $D e$ centaurio minori: Iena, 1713); quelques auteurs français ont confondu ces deux noms, et ont attribué à celui-ci l'ouvrage du premier. 
guées dans un singulier livre, imprimé à Francfort en r694, ayant pour titre: Centcuurium minus, auroque majus. Ce n'est point une panacée universelle, comme le pensait ce bon Allemand; mais c'est un bon remède pour ranimer, pour corroborer l'action affaiblie de l'appareil digestif, pour dissiper les accès fébriles qui ne sont pas sous la dépendance de quelque irritation viscérale ou de quelque inflammation chronique. A la campagne, où l'on n'a pas toujours sous la main du sulfate de quinine, on peut employer une forte infusion de cette plante pour guérir les fièvres intermittentes simples; cette infusion est plus active si l'on y mêle quelque substance aromatique, comme les feuilles de sauge, les fleurs de camomille, etc. Nous l'avons quelquefois administrée ainsi, et nous nous rappelons que, dans une circonstance, ce remède a enlevé des accès de fièvre qui avaient résisté à plusieurs onces de quinquina. Nous devons observer ici que les racines et les feuilles de la petite centaurée sont plus amères et plus efficaces que les fleurs. 


\section{MÉNIANTHE. MENIANTHES.}

Calice à cinq divisions profondes. Corolle en entonnoir, à cinq lobes ovales, barbus intérieurement. Cinq étamines attachées au tube de la corolle. Stigmate en tête sillonnée. Capsule globuleuse à une loge ; semences nombreuses, attachées longitudinalement au milieu des valves.

\section{MÉNIANTHE TRÈFLE D'EAU. MENIAN'THES} TRIFOLIATA.

Menianthes trifoliata. Linn. Spec. 208. DC. Fl. Fr. 2757.

\section{(Planche 54.)}

C'est une fort jolie plante qu'on rencontre dans les lieux humides et marécageux de l'Europe, et que nous avons observée aux environs de Paris, à Villed'Avray; elle croît aussi aux environs de Lyon. Sa tige cylindrique, un peu rampante, se termine par un épi de fleurs qui naissent de l'aisselle d'une bractée très-courte et pointue. Les feuilles sont radicales, peu nombreuses, soutenues par de longs pétioles, et composées de trois folioles ovoïdes, d'un beau vert. Les fleurs sont blanches, teintes de rose, trois fois plus grandes que le calice. La corolle est glabre en dehors, barbue intérieurement.

Le trèfle d'eau n'a qu'une odeur herbacée, mais il est d'une grande amertume. D'après Trommsdorf, le suc exprimé des tiges et des feuilles contient une matière féculente, composée d'albumine et de résine verte; un extractif amer azoté, une matière animale, une gomme brune, de l'acide malique, de l'acétate de po- 
tasse, une fécule blanche', soluble dans l'eau bouillante, qui se précipite par le refroidissement.

\section{PROPRIÉTÉS MÉdicALES.}

Cette plante est digne de figurer à côté des gentianes par sa propriété amère et corroborante. On y a recours lorsqu'on veut ranimer l'état languissant des organes gastriques, rendre les digestions plus faciles, plus régulières, dissiper des accès fébriles, des tuméfactions abdominales, des bouffissures, des diarrhées, des affections lentes fomentées par une atonie morbifique. On a observé que le trèfle d'eau produisait aussi d'heureux effets dans le traitement des maladies dartreuses. M. le professetr Richerand (Nosographie chirurgicale) en conseille le suc mêlé avec celui de fumeterre, à la dose de deux ou trois onces, dans une pinte de petit-lait, pour combattre les taches hépatiques disséminées sur la surface du corps, et dont l'apparition se fait principalement remarquer au printemps et durant l'été. Comıme ces éruptions dépendent fréquemment d'un flux hémorrhoïdal avorté, il faut y joindre l'application réitérée des sangsues à l'anus, et l'usage de quelques pilules aloétiques, amères, afin d'entretenir la liberté des évacuations alvines. On prend en même temps quelques bains domestiques dans lesquels on fait dissoudre une à deux onces de foie de soufre.

Parmi les plantes amères conseillées contre les affections arthritiques qui se présentent avec une sorte de langueur générale, on retrouve encore notre ménianthe; mais il faut l'administrer de manière à ne point fatiguer l'estomac : car à forte dose il irrite ce 
viscère, et produit même le vomissement. On corrige sa qualité nauséeuse en y joignant quelque substance aromatique, comme la menthe, l'écorce d'orange, etc. Il faut varier ces combinaisons, les donner à des doses modérées, les seconder par les secours del'hygiène, les suspendre de temps en temps, ou les cesser entièrement, s'il survient des symptômes d'irritation. C'est le seul moyen de les rendre utiles, et d'éviter les inconvéniens qu'on attribue à l'usage prolongé des amers.

On emploie les feuilles de ménianthe sous la forme de poudre et d'extrait, à la dose de dix à vingt grains. L'eau, le vin et l'alcohol se chargent de ses principes médicamenteux; on prépare avec ces liquides des décoctions, des infusions et des teintures amères trèsénergiques. On donne le suc de la plante fraîche isolé ou uni aux sucs amers et antiscorbutiques à la dose d'une à deux onces. D'après Cartheuser, ce suc, mêlé avec la poudre de tormentille jusqu'à la consistance pilulaire, produit les mêmes effets que le quinquina. Il y a de l'exagération dans cet éloge; toutefois on ne sáurait méconnaitre l'activité fébrifuge qui résulte du mẻlange des amers et des toniques avec les astringens. Le ménianthe est cultivé dans quelques pays pour les usages économiques; on s'en sert en Angleterre pour préparer la bière commune, où elle remplace le houblon. 


\section{VILLARSIE. VILLARSIA.}

Calice à cinq divisions profondes. Corolle en roue à cinq lobes arrondis et ciliés. Cinq étamines. Un style très-court terminé par un stigmate à deux lobes crénelés. Capsule uniloculaire, polysperme. Semences membraneuses et ciliées sur leurs bords, attachées le long des sutures des valves.

\section{VILLARSIE NYMPHOIDE. VILLARSIA NYMPHOIDES.}

Villarsia nymphoides. Vent. Choix n ${ }^{\circ}$ 9. p. 2. DC. Fl. Fr. 2758. Chev. Fl. Par. 3. 508. - Menianthes nymphoides. Linn. Spec. 20\%. Fl. Dan. t. 339.

Cette plante s'élève à la surface de l'eau, où elle flotte comme les nénuphars. Ses tiges se composent de rejets cylindriques, allongés, garnis cà et là de feuilles arrondies, cordiformes, et de faisceaux de fleurs inégalement pédonculées : ces fleurs, disposées en ombelle, nagent également sur l'eau; leurs corolles sont grandes, jaunes et ciliées sur les bords.

Elle se plait dans les rivières, dans les étangs; on la trouve dans presque tout le nord de la France; elle croît dans la Seine, aux environs de Paris, sur les rives de la Sarthe, dans le canal d'Orléans, etc. Sa place est marquée, parmi les végétaux amers et antiscorbutiques, à côté du trèfle d'eau et des gentianes. Toutes ces plantes ont entre elles les plus grands rapports de forme, de structure et de propriétés. 


\section{SPIGÉLIE. SPIGELIA.}

Calice à cinq divisions profondes. Corolle en entonnoir; limbe ouvert à cinq divisions égales. Cinq étamines. Ovaire à deux lobés; un style persistant; un stigmate simple. Capsule à une loge, à deux valves.

\section{SPIGÉLIE ANTHELMINTHIQUE. SPIGELIA}

\section{ANTHELMIA.}

Spigelia anthelmia. LinN. Amen. Acad. 5. 133. t. 2.

\section{(Planche 55.)}

Sa tige est droite, cylindrique, herbacée, glabre, haute d'environ un pied. Ses feuilles sont opposées, sessiles, lancéolées, entières, aiguës à leur sommet. La tige et les rameaux se terminent par quatre feuilles opposées en croix, plus grandes que les autres, d'où naissent deux grappes de fleurs un peu grêles, munies de bractées. Le calice offre cinq découpures aiguës; la corolle est composée de cinq lobes d'une nuance jaunâtre. Cette plante croît à Cayenne, au Brésil et dans plusieurs autres contrées de l'Amérique méridionale.

\section{SPIGÉLIE DU MARYLAND. SPIGELIA MARYLANDICA.}

Spigelia marylandica. Linn. Syst. Veğ. 166. Catesb. Carol.

2. t. 78. Kerv. Gen. Plant. vol. 3. Icon.

\section{(Planche 56.)}

Cette brillante espèce abonde dans les bois humides de l'Amérique septentrionale. Elle se distingue par ses 
fleurs d'un rouge de feu, par sa tige droite, quadrangulaire, garnie de feuilles opposées, sessiles, ovales, terminées en pointe, et d'un joli vert. Les fleurs sont unilatérales, presque sessiles, disposées en épi au sommet de la tige. Le calice est à cinq divisions presque filiformes, persistantes; la corolle est en entonnoir, longue d'environ un pouce, d'un rouge vif en dehors, d'une couleur orangée en dedans, à cinq découpures lancéolées, ouvertes.

Aucun travail chimique n'a été entrepris sur ces deux plantes; toutefois elles paraissent recéler un principe nauséeux, amer, qui les rapproche des poisons. On a même imposé à la première le nom de Brinvilliers (I). Au rapport de Puinh, elles attaquent l'une et l'autre l'appareil nerveux, causent des vertiges, la dilatation des pupilles, étc. Suivant Chalmers, cité par Murray, la spigélie du Maryland, administrée à forte dose, a produit l'obscurcissement de la vue, des convulsions et la mort. Cependant on a beaucoup prôné en Europe ces deux plantes contre les affectionsvermineuses. Linné a surtout fait l'éloge de la première espèce dans le cinquième volume des Amonitates academica. Les nombreuses expériences faites en Amérique par le docteur Browne constatent en effet son action éminemment vermifuge; en Suède, une femme a été délivrée de treize vers lombricoïdes qui la tourmentaient horriblement. Le docteur Dahlberg donnait cette plante

(1) On a voulu faire de la marquise de Brinxilliers une autre Locuste; nous ne prétendons point qu'elle fût innocente, mais elle n'avait certainement pas les profondes connaissances qu'on lui a prètées dans l'art de préparer les poisons. 
en poudre à la dose de vingt grains, deux ou trois fois par jour, et en infusion jusqu'à deux ou trois gros ; il continuait ainsi pendant une ou deux semaines en interposant un laxatif tous les quatre jours. Le docteur Home a confirmé par de nouveaux essais les expériences qui avaient été tentées aux États-Unis sur la spigélie du Maryland par Linning, Garden et Chalmers. Gilibert, avec le secours de cette même plante, a guéri un enfant de dix ans en proie à des convulsions occasionées par un foyer vermineux.

Browne faisait bouillir deux petites poignées de spigélie anthelminthique dans deux livres d'eau réduites à moitié, et il ajoutait à la colature du sucre et du jus de citron; la dose de ce remède était de deux à quatre onces, matin et soir, pendant trois jours de suite. Il prescrivait en même temps quelques lavemens pour entraîner les vers. Cette boisson faisait dormir comme l'opium; mais le malade, en s'éveillant, était gai, avait les yeux animés. (The civil and natural History of Jamaica.) Linning emploie particulièrement la racine de spigélie du Maryland; il la donne en poudre à la dose de dix à douze grains, et en infusion à la dose d'un scrupule aux enfans d'environ trois ans. On prend ce remède matin et soir pendant plusieurs jours; lorsqu'il ne produit point d'effet laxatif, il convient de donner de temps en temps quelques grains de calomel.

Ces plantes sont rarement employées en France. Malgré leur qualité vermifuge, nous pensons qu'on doit être circonspect sur leur usage, surtout à l'égard des enfans d'un âge encore tendre. D'après l'aveu de Linning et de Brocklesby, elles peuvent exciter un pro- 
fond assoupissement, des vertiges et autres symptòmes fầcheux. Bergius, qui a souvent employé la spigélie du Maryland, a également signalé son action narcotique, et Van Swieten regarde l'autre espèce comme un remède dangereux pour les enfans. Satis autem patet, omnia hac valida remedia magnâ cum cautelâ tantùm adhiberi posse, et vix locum habere in teneris infantibus unquìm. (Comment. in BоErн., aphor., tome 4, page 656.) Il résulte de ce qui vient d'être dit, que ces médicamens, administrés à hautes doses, peuvent produire les phénomènes propres aux poisons narcotiques âcres. Nous ne pouvons que renvoyer à notre introduction, page 27 , où nous avons tracé les moyens thérapeutiques qui conviennent à ce genre d'empoisonnement. 


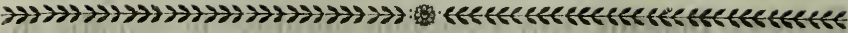

\title{
APOCYNÉES. APOCYNEAE.
}

\author{
Apocynede. Juss.
}

\section{NÉRIUM. NERIUM.}

Calice à cinq divisions. Corolle en entonnoir ; tube insensiblement dilaté, portant à son orifice cinq appendices découpés en deux ou plusieurs lobes; limbe à cinq divisions obtuses et obliques. Anthères en fer de flèche, conniventes, terminées par un filet coloré. Style simple, stigmate tronqué, porté sur un rebord annulaire. Follicules grêles, allougés, contenant un grand nombre de semences couronnées de poils.

NÉRIUM LAURIER-ROSE. NERIUM OLEANDER.

Nerium oleander. Linn. Spec. 305. DC. Fl. Fr. 2788.

(Planche 57.)

Tout le monde connaît ce charmant arbuste qui, dans la belle saison, orne nos jardins, nos terrasses, nos promenades; mais bien des gens ignorent ses qualités pernicieuses. Sa tige, haute de six à huit pieds, se divise en plusieurs rameaux verdâtres, longs, flexibles et redressés. Ses feuilles sont opposées, souvent ternées, longues, étroites, fermes, lancéolées, pointues, permanentes, d'un vert foncé, et marquées en dessous par une forte nervure longitudinale. Ses fleurs s'élèvent 
en magnifiques corymbes à l'extrémité des rameaux; elles sont d'un rose plus ou moins vif, et quelquefois blanches. On trouve le laurier-rose dans l'Europe australe, où il croît spontanément; il abonde dans l'île de Crète, surle bord des ruisseaux et dans tous les lieux frais. (Sonnini, Voyage en Grèce.) On le retrouve sur les bords de l'Eurotas et dans tous les marais du Péloponèse. (PovQueville, Voyage en Morée.) Il embellit les rivages du Guadalquivir, le Bétis des anciens. (FÉE, Flore de Virgile.)

Dioscoride et Galien ont connu le laurier-rose et ses qualités malfaisantes; Apulée l'a surtout décrit avec beaucoup de précision dans son Ane d'or, livre 4. C'est le rhododendron de Pline. Suivant ce naturaliste, il est un poison pour les bêtes de somme, les chèvres et les brebis, Jumentis, caprisque et ovibus venenum est. (Hist. nat., lib. 16, cap. 20.)

PROPRIÉTÉS DÉLÉtĖRS.

Les expériences des modernes ont confirmé l'observation des anciens : les chevaux, les, ânes, les mulets, les chèvres, les moutons, les chiens, etc., succombent sous l'influence délétère de cet arbuste, qui recèle dans toutes ses parties un principe vireux, âcre et volatil. Ses divers produits, l'infusion, la décoction des feuilles et des rameaux, l'eau distillée, l'extrait des feuilles, sont vénéneux.

Un fait recueilli par Morgagni prouve șon action prompte et funeste sur l'homme : le suc des feuilles, mêlé avec du vin, occasiona à une femme de soixante ans des vomissemens affreux, suivis de syncope et 
d'aphonie. Son pouls était petit, faible, tendu; ses lèvres noires : elle mourut neuf heures après avoir avalé ce poison. Le corps était violet postérieurement depuis la tête jusqu'aux pieds; la partie antérieure était dans l'état naturel. Le ventre n'était point météorisé; il conservait un peu de chaleur, ainsi que la poitrine, bien qu'il se fût déjà écoulé dix-sept heures depuis la mort. Les vaisseaux sanguins de l'estomac, des intestins et de l'épiploon étaient très-distendus. L'estomac et le duodénum contenaient une petite quantité d'un liquide verdâtre; on ne remarquait aucune altération dans les membranes. La face postérieure du poumon droit était rouge et adhérente; le poumon gauche était flétri. Tous les autres viscères de la poitrine et du bas-ventre étaient d'ailleurs dans l'état naturel. (MorGAGNI, de sedibus et causis morborum, epist. 59.)

On rapporte que des soldats français périrent dans l'île de Corse, où le laurier-rose est très-commun, pour avoir mangé des volailles qu'ils avaient fait rôtir avec des branches de cet arbuste. Plenck a inséré dans sa Toxicologie un fait semblable, extrait du Traité des Poisons de Libautius.

Le 29 mars 1829 , une jeune veuve avait pris une forte décoction de feuilles de laurier-rose, qu'on lui avait indiquée comme un emménagogue efficace. Quelques instans après elle fut prise de nausées et de vomissemens accompagnés d'une céphalalgie violente, d'entéralgie avec un sentiment de feu à la gorge, d'angoisses, de convulsions et de fréquens évanouissemens. Le pouls était concentré, intermittent, presque éteint. On lui donna d'abord une certaine quantité de lait qui fut 
presque aussitôt rejeté. M. le docteur Martini, appelé environ trois quarts d'heure après l'empoisonnement, fit prendre à la malade environ trente grains d'ipécacuanha en trois doses, et puis une nouvelle dose de dix grains dans une émulsion de gomme arabique. Ce vomitif agit merveilleusement, et dissipa peu à peu tous les symptômes graves. Le lendemain, quelques lavemens et une solution de sulfate de magnésie complétèrent la guérison. (Larber, sui Funghi Saggio generale.)

M. Loiseleur-Deslongchamps dit qu'un malade, à qui l'on avait conseillé trois grains de laurier-rose en poudre, en ayant pris douze grainsà la fois, eut des vomissemens abondans et douloureux, accompagnés d'éblouissemens, de défaillances et de sueurs froides. Une grande quantité d'eau sucrée et une potion éthérée calmèrent tous ces accidens. Ce médecin a essayé sur lui-même l'extrait des feuilles; il a commencé par de petites doses, et successivement il a fini par en prendre dix grains. Alors il a perdu l'appétit; il a éprouvé une courbature douloureuse dans les membres, une débilitẻ musculaire très-prononcée, avec un malaise universel.

Les phénomènes suscités par le laurier-rose sont ceux des poisons narcotiques âcres. On y remédie par les boissons délayantes, par des potions émétisées, si le malade n'a point vomi. On passe ensuite à une méthode émolliente ou tonique, suivant l'état d'irritation ou de faiblesse. 
PROPRIÉTÉS MÉDicales.

Cet arbuste n'est plus consacré aux usages médicinaux. On employait autrefois en topique la décoction des feuilles pour exciter le système dermoïde, dans les cas de dartres et de gales rebelles; on a même essayé intérieurement l'extrait contre ces mêmes affections. Ceux qui voudront se livrer à de nouveaux essais ne doivent pas oublier que les divers produits obtenus du laurier-rose sont de violens poisons, non-seulement pris à l'intérieur, mais encore appliqués sur la peau, et à plus forte raison si cet organe se trouve ulcéré. La poudre des feuilles, employée pour exciter la membrane olfactive, est un puissant sternutatoire, qui peut également donner lieu à de graves accidens. Les propriétés délétères de ces arbustes s'exaltent dans les pays chauds; ceux qu'on cultive dans le Nord sont moins vénéneux. Ils varient pour la nuance de la fleur; il y en a à fleurs blanches, à fleurs couleur de chair, à fleurs panachées.

Le nérium odorant est aussi une très-belle espèce qu'on cultive dans les jardins, mais elle est plus petite et plus délicate; ses fleurs sont odorantes, d'un rose plus ou moins vif, ou blanches. Cet arbuste, originaire de l'Inde, est également délétère. 


\section{APOGYN. APOCYNUM.}

Calice très-petit, à cinq divisions. Corolle campanulée, à cinq lobes roulés en dehors. Ovaire entouré de cinq corps glanduleux. Anthères conniventes, bifides à leur base. Style très-court; stigmate large. Follicules longs et aigus. Semences couronnées d'une longue aigrette.

\section{APOCYN GOBE-MOUCHE. APOCYNUM ANDROS AEMIFOLIUM.}

Apocynum androscemifolium. Lins. - Apocynum canadense. Bocc. Sic. 35. t. 16. f. 3.

Originaire du Canada et de la Virginie, cet apocyn se distingue par ses bouquets de fleurs d'une nuance purpurine. Sa tige rougeâtre, rameuse, haute d'environ deux pieds, se divise en rameaux garnis de feuilles opposées, ovales, pointues, portées sur de courts pétioles, vertes en dessus, d'une couleur plus pâle en dessous, légèrement pubescentes en leurs bords et sur leurs nervures postérieures. Les fleurs naissent en bouquets ombelliformes aux sommets de la tige et des rameaux; elles sont d'un rouge plus ou moins foncé en dehors, blanches intérieurement. On cultive cette jolie plante pour la décoration des jardins. Elle est remplie d'un suc laiteux très-caustique, qui enflamme et ulcère la peau. Ses émanations ont quelquefois produit le gonflement de la face et des mains.

Les fleurs de cette espèce exsudent une liqueur mielleuse qui attire les mouches; mais à peine ces insectes ont-ils insinué leur trompe entre les corpuscules glan- 
duleux qui entourent l'ovaire, qu'ils se trouvent pris comme dans un piége. On trouve souvent deux ou trois mouches engagées dans la même fleur.

\section{APOGYN A FLEURS HERBACÉES. APOCYNUM $C A N N A B I N U M$.}

Apocynum cannabinum. Lins. - Apocynum canadense. Moris. Hist. 3. 609. t. 3. f. 14.

Ses tiges sont herbacées, rougeâtres, pubescentes dans leur partie supérieure, hautes d'environ trois pieds, garnies de feuilles ovales, vertes en dessus avec quelques poils rares, blanchâtres et cotonneuses en dessous. Les fleurs sont petites, d'une couleur herbacée ou d'un vert blanchâtre, disposées en corymbe, et soutenues par des pédoncules pubescens. Les fruits sont longs, très-grêles, presque semblables à des aiguilles.

Cette plante, qu'on cultive au Jardin du Roi, est également imprégnée d'un suc laiteux très-âcre. Plenck l'a rangée parmi les poisons, ainsi que l'apocyn maritime (apocynum Venetım. Lins.). Cette dernière espèce croît en Italie, aux environs de Venise et dans les îles Adriatiques; elle a des feuilles oblongues, saliciformes, finement dentées et d'un joli vert. Ses fleurs sont purpurines, blanches dans une variété, disposées en bouquets lâches au sommet des rameaux. L'apocyn maritime répand une odeur forte, nauséeuse; ses feuilles tuent les chiens, les loups, les renards, etc. 
CYNANQUE. CYNANCHUM.

Calice très-petit, à cinq dents. Corolle presque en roue; limbe plane à cinq divisions longues et linéaires. Centre de la fleur occupé par un corps cylindrique, oblong, droit et denté. Anthères adnées à la face interne des filamens. Style très-peu apparent; deux stigmates. Follicules oblongs et aigus.

\section{CYNANQUE DE MONTPELLIER. CYNANCHUM}

\section{MONSPELIACUM.}

Cynanchum monspeliacum. Lins. Spec. 311. DC. Fl. Fr. 2789. J AcQ. $_{\text {. Plant. Rar. t. } 340 .}$

D'une racine longue et traçante s'élèvent des tiges herbacées, cylindriques, sarmenteuses, volubiles et pleines d'un suc laiteux. Les feuilles sont pétiolées, arrondies, cordiformes, un peu pointues et veinées. Les. fleurs sont blanchâtres, attachées à des pédoncules rameux, disposées en corymbes latéraux ; la corolle offre six divisions allongées, étroites et très-ouvertes.

On trouve cette plante aux environs de Montpelliẹ: et de Narbonne, dans les terrains sablonneux. Elle se. reproduit sous une variété dont les feuilles sont moins. larges, plus pointues, et les pédoncules communs plus allongés. On en obtient un suc gommo-résineux qu'on substitue quelquefois à la scammonée de Syrie, mais qui est moins énergique : ce suc épaissi porte le nom de scammonée de Montpellier. 
CYNANQUE DROITE. CYNANCHUM ERECTUM.

Cynanchum erectum. Lins. Spec. 311. J J $\mathrm{JCQ}$. Hort.

Vind. t. 38.

Cette espèce a des tiges droites, glabres, un peu rameuses, hautes d'environ trois pieds. Ses feuilles sont opposées, pétiolées, cordiformes, pointues, d'un vert un peu glauque. Ses fleurs sont nombreuses, blanches, disposées en corymbes latéraux, lâches, situés vers la partie supérieure des tiges. La corolle est divisée profondément en lanières oblongues, un peu obtuses, s'ouvrant en étoile. Cette plante est originaire de la Syrie; elle contient un suc laiteux très-âcre, d'une qualité drastique.

Au rapport de Puinh (materia venenaria), un demigros defeuilles a produit sur un chien des vomissemens, des convulsions et la mort, bien que l'animal eût rejeté le poison.

Quelques autres végétaux appartenant au mêmegenre se font également remarquer par leur énergie. Le cynanchum viminale, espèce volubile, dont la tige est nue, filiforme, contient un suc très-caustique. Le cynanchum arguel de Delille purge avec violence; ses feuilles servent à sophistiquer le séné d'Égypte. Le cynanchum vomitorium et le cynanchum tomentosum de Lamarck manifestent des propriétés analogues à celles de l'ipécacuanha, et remplacent dans divers pays cette racine. 


\section{PÉRIPLOCA. PERIPLOCA.}

Calice à cinq dents. Corolle à cinq divisions profondes et ouvertes. Cinq filamens alternes avec les divisions. Semences aigrettées.

\section{PÉRIPLOCA DE GRÉCE. PERIPLOCA GRAECA.}

Periploca grieca. Linn. Spec. 309. Duham. Arbr. 2. t. 11.

Ses tiges volubiles, hautes de vingt à trente pieds, se divisent en rameaux minces, souvent entrelacés les uns dans les antres, garnis de feuilles ovales, aiguës à leur sommet et d'un vert luisant. Les fleurs sont disposées en petits corymbes axillaires, d'un pourpre foncé, d'une odeur nauséeuse; la corolle est garnie intérieurement et sur ses bords de poils courts, blanchâtres, très-serrés.

Cet arbrisseau est depuis quelque temps répandı dars nos bosquets, où son beau feuillage sert à couvrir les murs, à former des tonnelles et des berceaux. Ses feuilles sont vénéneuses pour les chiens et les loups. On les recueille en Syrie pour les mêler au vrai séné, qui acquiert alors des propriétés très-actives et purge avec violence.

Le périploca à feuilles étroites (periploca angustifolia), autre arbrisseau d'ornement, à fleurs blanches au centre et largement bordées de pourpre, est également vénéneux.

Le périploca scammonée (periploca scammonium) est encore un arbrisseau grimpant qui croît en Égypte, et qui fournit un suc laiteux très-âcre. Ce suc bruni et 
épaissi par la dessiccation est la scammonée de Smyrne, purgatif drastique et dangereux.

\section{ASCLÉPIAS. ASCLEPIAS.}

Calice petit, à cinq dents. Corolle en roue, à cinq lobes ouverts et réfléchis. Cinq appendices en forme de cornets s'inclinant vers le centre de la fleur. Etamines larges, forniant un tube pentagone autour du stigmate, et portant clacune intérieurement une anthère à deux loges. Deux ovaires surmontés d'un seul stigmate pentagone. Follicules oblongs, aigus, souvent renflés, contenant des semences couronnées d'aigrettes.

\section{ASCLÉPIAS DOMPTE-VENIN. ASCLEPIAS VINCETOXICUM.}

Asclepias vincetoxicum. Lrnv. Spec. 314. DC. FI. Fr. 2790. Fl. Dan. t. 849 .

\section{(Planche 58.)}

De sa racine horizontale, noueuse, chargée d'une multitude de fibres, s'élève une tige simple, faible, cylindrique, haute d'environ un pied, portant des feuilles opposées, ovales, pointues, un peu cordiformes, pétiolées, d'un vert foncé en dessus, d'un reflet plus pâle en dessous. Les fleurs sont disposées par petits bouquets pédonculés dans les aisselles supérieures des feuilles et au sommet de la tige. La corolle est d'un tissu compacte, blanche, avec une légère teinte verdâtre. Cette plante habite les lieux incultes, les bois secs et sablonneux; elle est assez commune aux environs de Paris.

La racine fraîche du dompte-venin manifeste une 
odeur forte, nauséeuse, une saveur âcre ; son suc passe pour délétère. Elle fournit un principe gommo-résineux, un principe volatil âcre, et de l'oxalate de chaux. Haller et Bulliard regardent cette plante comme vénéneuse ; suivant ce dernier, elle aurait excité de violens vomissemens. Je ne sais s'il existe des faits qui prouvent son action malfaisante; mais je pense qu'on doit la tenir pour suspecteà cause de ses affinités avec d'autres espèces dangereuses.

La dénomination hyperbolique de cet asclépias annonce les grandes vertus que des naturalistes et des médecins peu exacts lui ont jadis attribuées. Les principes âcres et stimulans que renferme sa racine peuvent la rendre diaphorétique dans quelques circonstances; mais qui voudrait en faire usage contre les maladies ataxiques, la peste, l'hydrophobie, d'après l'autorité de Tragus, de Chomel, et autres auteurs surannés?

\section{ASCLÉPIAS DE SYRIE. ASCLEPIAS SYRIACA.}

Asclepias Syriaca. Linn. Spec. 313. DC. Fl. Fr. 2792.

\section{(Planche 59.)}

Originaire de l'Orient, cette espèce s'élève à la hauteur de deux à trois pieds sur une tige droite, simple, verdâtre, parsemée de points d'un pourpre obscur vers la base. Les feuilles sont larges, ovales, opposées, vertes en dessous, cotonneuses en dessus. Les fleurs sont disposées au sommet de la tige en ombelles penchées et bien garnies. La corolle est rougeâtre ou blanchâtre, tout-̇̇-fait réfléchie sur le calice. Les follicules 
sont remplis d'une espèce de coton très-fin, blanc, soyeux, ce qui a fait donner à cette plante le nom d' $a$ pocyn à la ouate. On la cultive dans nos jardins, où elle s'acclimate parfaitement.

L'asclépias de Syrie contient un suc laiteux trèsâcre, drastique, délétère pour les loups, les renards, les chiens, etc. Les fleurs répandent une odeur pénétrante, qu'on ne peut respirer long-temps sans être incommodé.

L'asclepias gigantea, qui porte de grandes et belles fleurs d'un jaune safrané, disposées en ombelle à l'extrémité de la tige, est aussi un poison irritant. Ses feuilles sont remplies d'une liqueur laiteuse qui a produit, à la dose d'une demi-once, les plus violens symptômes. L'asclepias procera, l'asclepias curassavica, provoquent le vomissement, et sont employés dans divers pays à la place de l'ipécacuanha. L'asclepias decumbens est escharotique, cathartique. (Coxe, the American Dispensatory.)

L'asclepias nigra de Linné paraît avoir de grands rapports avec l'apocyn des anciens, que Galien et Dioscoride rangent parmi les poisons. Celui-ci fait périr les loups, les panthères, les renards, les chiens, après avoir paralysé les extrémités postérieures. D'après Pline, il est mortel pour tous les quadrupèdes.

Cette espèce a une tige un peu grimpante, des feuilles ovales, lancéolées, des bouquets de fleurs d'un pourpre noirâtre, et des semences semblables à celles du domptevenin ; elle croît dans les provinces méridionales de la France. Son suc est lactescent, jaunâtre et d'une grande âcreté. 
La famille des apocynées compte quelques autres genres de plantes dont on a observé les effets irritans.

L'écorce, les feuilles et les fruits du cerberc ahouai, du cerbera manghas, du cerbera thevetia, passent pour d'affreux poisons; ces arbres exotiques distillent une liqueur laiteuse très-corrosive.

On cultive en France le cerbera manghas. C'est un arbrisseau à tige droite, rameuse, à feuilles ovales, lisses et veinées. Les fleurs sont grandes, fort belles, et d'une odeur suave; le limbe est d'un blanc pur, la gorge d'un rouge cramoisi.

Le plumeria rubra, magnifiquement représenté dans l'Hortus de Kerner, tab. 3r , est drastique et puissamment délétère; son suc brûle le linge comme l'acide nitrique.

L'echites suberecta produit la gastrodynie, des nausées, des efforts de vomissemens répétés, des convulsions générales et la mort; son suc, administré à la dose de deux gros, a fait périr un chien dans l'espace de huit minutes. (Puinh.)

Enfin on trouve dans les genres Cameraria, Taberncemontana, Stapelia, des plantes fétides et vénéneuses.

MÉTHODE CURATIVE.

Les propriétés actives des apocynées résident principalement dans un suc laiteux, âcre, irritant, plus ou moins caustique et amer. La plupart de ces végétaux exercent une action véhémente sur le canal alimentaire, provoquent des évacuations douloureuses et prolongées à la manière des drastiques. Quelquefois ils 
portent une influence spéciale sur le système nerveux, produisent des convulsions, des spasmes variés, un état de stupeur, etc. Ces divers accidens réclament des méthodes curatives sagement combinées. On donnera des boissons tièdes, abondantes, afin de faire rejeter le poison; et, si elles ne suffisent point, on administrera un vomitif. La surexcitation du canal alimentaire, les douleurs vives doivent faire proscrire le tartre émétique, l'ipécacuanha et autres évacuans; il faut se borner aux boissons adoucissantes souvent répétées, aux clystères émolliens, aux fomentations anodines. On ne se hâtera point d'administrer les acides, l'eau vinaigrée, à moins qu'il ne survienue un état de stupeur. Les symptômes nerveux avec faiblesse demandent l'usage de l'éther, des antispasmodiques et des excitans modérés. Les saignées générales ou locales ne doivent être pratiquées que dans les cas d'inflammation ou de congestion vive de quelque organe; leur imprudent emploi peut donner lieu à une asthénie mortelle, parce que les poisons attaquent d'une manière directe les forces de la vie.

Nous quittons un groupe de végétaux malfaisans pour entrer tout à l'heure dans une famille non moins riche en poisons tous originaires de l'Inde; mais que le lecteur veuille bien auparavant faire ici, avec nous, une courte station, et recevoir avec indulgence un faible souvenir des Pyrénées. S’il daigne nous suivre par la pensée dans ces belles montagnes, il entendra de loin les mugissemens du Gave, et il n'aura à craindre ni l'ouragan ni les avalanches. 
PYRÉNÉEs. VALLÉE d'ARGELÈs.

Nous arrivons à Tarbes à dix heures du soir. Mon coeur bat d'impatience, et je goûte à peine quelques instans de sommeil. Aux premiers bruits du matin, je suis debout, et je parcours rapidement la ville, qu'arrosent de nombreux ruisseaux. A six heures, nous voici déjà dans la plaine, aspirant avec délice l'air vif et salubre qui s'échappe des Pyrénées. Rien n'égale la richesse de cette plaine, où de magnifiques champs de maïs, de belles prairies, des fruits de toute espèce et des eaux limpides charment tour à tour les yeux.

Nous suivons la route de Lourdes, laissant à gauche celle de Bagnères. Encore quelques instans, et la vallée d'Argelès va nous sourire. La voilà qui s'ouvre; peu à peu elle se déploie, elle s'évase, elle s'arrondit, et forme une espèce de bassin chaudement éclairé par les rayons du soleil. Sur le fond légèrement vaporeux de l'horizon se dessinent de hautes montagnes, élançant jusqu'aux nues leurs pyramides étincelantes de neige. O l'admirable perspective! ô la délicieuse vallée! Mes yeux ne peuvent se lasser de contempler ces champs fertiles qui la couvrent, ces hosquets qui la parfument, ces pelouses riantes qui l'embellissent, ces ruisseaux respleudissans de lumière qui la traversent en répandant partout la vie et la fécondité; ces hameaux, ces charmans villagres disposés en amphithéâtre sur les flancs de la montagne ; ces nuages argentés qui courent sur un ciel d'azur et se balancent majestueusement au-dessus des rochers; ces sites pittoresques, ces collines avec leurs mouvemens divers, là sombres et arides, ici 
pleines de fraîcheur et de grâce ; ces bois vigoureux qui descendent de la crête des monts jusqu'aux bords du Gave, où ils forment des voûtes de la plus belle verdure.

Je laisse mon cheval et mon guide dans la vallée pour aller visiter l'abbaye de Saint-Savin, assise gracieusement à droite sur le versant de la colline. Là m'attendaient de nouvelles impressions, une vue plus admirable encore. Que j'aime ce site enchanteur! quel pieux et doux recueillement inspire cette chapelle gothique ainsi rapprochée du ciel! quels souvenirs elle réveille! quels sentimens elle fait naître! Des frênes, des chataigniers, des hêtres l'ombragent de leurs rameaux touffus. Les brises du soir y font entendre leur ineffable murmure, où se mêlent les chants des pasteurs, les sonnettes des troupeaux et le bruit des torrens que les échos propagent au loin dans la vallée. Oui, je crois voir errer sous ces frais ombrages l'homme souffrant, prêt à se rendre aux sources minérales. C'est là que, sous l'inspiration de la foi, le cœur rempli d'amour et d'espérance, il adresse au ciel sa fervente prière; c'est là qu'il lui demande ce calme moral, sans lequel les douleurs physiques ne sauraient s'adoucir; c'est là, dans ce temple champêtre, qu'il vient accomplir son vœu au retour des eaux... Ils sont passés ces jours de nos simples aïeux; une philosophie hautaine les a flétris de ses amères dérisions.

Je descends au village de Pierrefite, où je retrouve mon guide. Nous prenous le chemin de Saint-Sauveur en suivant les sinuosités d'une gorge ténébreuse. Ici tout se rembrunit, tout prend une physionomie sévère. 
Quel contraste avec les lieux charmans que nous ve-nons de quitter! L'élévation et l'âpreté des monts, l'escarpement des rochers, leur aspect sombre et menaçant, le silence qui plane sur les hauteurs, tandis que le Gave s'agite et gronde dans un abîme ; quelques faibles rayons de lumière qui tremblent dans cette imposante solitude; voilà un spectacle impossible à décrire, une sorte d'harmonie sauvage qui remplit l'âme d'un mélange d'admiration et de terreur dont le souvenir ne saurait s'effacer.

Au milieu des quartiers de roche que les torrens ont arrachés de la montagne, et qui sont venus bondir sur la route, l'hellébore pied de griffon étale son feuillage verdâtre et profondément incisé : ses fétides exhalaisons, mêlées à l'odeur forte que répandent des masses de buis éparses çà et là, font sur mes sens une impression fầcheuse. Hâtons-nous de fuir ces tristes lieux. Mais voici des plantes amies qui viennent nous sourire : c'est la clématite, arbuste chéri des voyageurs, qui fait flotter sa blonde chevelure an milieu des buissons; c'est la valériane des Pyrénées avec sa taille svelte, que couronnent des bouquets de fleurs du plus doux incarnat. Enfin la plaine de Luz se dessine avec ses prairies, ses ruisseaux, ses champs parfaitement cultivés.

Un chemin d'un aspect romantique me conduit à Saint-Sauveur, lieu charmant où s'élève un groupe d'élégantes maisons, au milieu de la plus fraîche verdure. Je parcours tous ces petits sentiers qui sont comme suspendus au-dessus de la rive gauche du Gave; ces allées mystérieuses, témoins discrets des plus doux 
épanchemens. Là je repose délicieusement ma vue sur les beaux sites, sur les odoriférans bocages qui m'entourent. Un charme indéfinissable pénètre mon âme, la remplit et la transporte; je marche, j'admire, je rêve au milieu du calme le plus parfait. Ah! je voudrais passer ici, non quelques heures, mais ma vie entière, dans cette paix du cceur qui me fait oublier toutes les misères humaines. Sans parler de la douce température des eaux de Saint-Sauveur, de leurs vertus bienfaisantes contre ces irritations, ces anomalies nerveuses, maux bizarres et trop souvent réfractaires it toutes les ressources de l'art, que ne doit-on pas attendre de l'air pur et frais qu'on y respire (1)?

Mais, au milieu de ces impressions délectables, le soleil dorait à peine de ses rayons mourans les flancs supérieurs des rochers; les ombres descendaient dans la plaine, où régnait une teinte donce et vaporeuse, tandis que la lune apparaissait sur les hauteurs avec son disque redoublant de clarté à mesure que l'incarnat du couchant pâlissait dans les airs. Je quitte avec peine cette charmante solitude, et je gagne lentement le village de Luz. Là, tout près d'une vieille église, je trouve un gite passable et un souper frugal qui me

(1) Lisez M. le docteur Bourdon, si vous voulez savoir quels sont les maux que les bains de Saint-Sauveur peuvent dompter ou adoucir. Son livre est particulièrement consacré aux eaux minérales de France et d'Allemagine. Vous y trouverez les renseignemens les plus exacts sur leurs vertus et leur emploi, les conseils les plus sages touchant l'hygiène que vous devez suivre pendant la saison des eaux, et tout cela écrit d'un style clair, spirituel, attrayant. 
MÉDICALE.

paraît délicieux, grâce aux fatigues d'une longue journée. Bientôt le dieu des songes vient se balancer sur ma paupière; il m'entoure de ses plus doux pavots, et je m'endors au bruit du Gave qui retentit au pied de mon gîte.

11. 


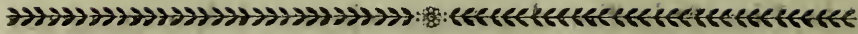

\section{STRYCHNEES. STRYCHNEAE.}

\author{
Strychnece. DC.
}

\section{STRYCHNOS. STRYCHNOS.}

Calice à cinq divisions caduques. Corolle tubulée, à cinq lobes. Cinq étamines. Un style terminé par un stigmate un peu èpais. Baie globuleuse ou ovale, pulpeuse, à une seule loge, recouverte par une écorce fragile et crustacée Semences orbiculaires, attachées à un placenta central.

\section{STRYGHNOS NOIX VOMIQUE. STRYCHNOS} NUX VOMICA.

Strychnos nux vomica. Linn. Spec. 271. - Caniram.

Rheed. Hort. Mal. 1. 67. t. 37.

\section{(Planche 6o.)}

C'est un arbre d'une grosseur médiocre, dont les branches se divisent en rameaux cylindriques, lisses et verdâtres. Les feuilles sont opposées, soutenues par de courts pétioles, arrondies, pointues à leur sommet, entières, d'un vert sombre, et marquées en dessous par cinq nervures saillantes. Les fleurs sont disposées en petits corymbes à l'extrémité des rameaux. La corolle est d'un blanc jaunâtre, tubulée, ventrue, à cinq lobes aigus, réfléchis; les étamines sont à peine sail- 
lantes hors du tube. Les fruits sont des baies globuleuses, d'un jaune doré, de la grosseur d'une orange, à une seule loge renfermant plusieurs semences. Cet arbre croît à Ceylan, à la côte de Coromandel et au Malabar, où il est connu sous le nom indien de caniram. Les Anglais l'appellent poison-nut, noix-poison; ce nom lui convient beaucoup mieux que celui de noix vomique, car le vomissement est le moindre de ses effets.

Les semences que renferment les fruits de cette espèce de strychnos portent lenom de noix vomiques; elles sont orbiculaires, aplaties, ombiliquées, recouvertes d'un épiderme gris et soyeux; le périsperme est d'une consistance dure et cornée, d'une amertume intense.

\section{ANALYSE CHIMIQUE.}

La noix vomique a fixé dans ces derniers temps l'attention des chimistes. M. Braconnot a trouvé dans cette graine une matière cornée végétale très-abondante, une huile verte, butyreuse, une matière animalisée extrêmement amère, etc. M. Desportes a obtenu avec le principe amer une matière colorante jaune, une matière végéto-animale, du surmalate de chaux, de la gomme et une fécule amylacée. Mais l'analyse de la noix vomique s'est encore perfectionnée par les nouvelles recherches de MM. Pelletier et Caventou; ces chimistes y ont découvert un principe alcalin très-vénéneux qui a reçu le nom de strychnine. Cette substance s'offre sous la forme de cristaux microscopiques; elle est blanche, grenue, inodore, d'une amertume excessive, presque insoluble dans l'eau, 
très-soluble dans l'alcohol et les huiles volatiles : elle forme, par sa combinaison avec les acides, des composés salins qui sont plus solubles que leur base. Le principe alcalin se trouve uni, dans la noix vomique, à un nouvel acide qui a été désigné sous le nom d'acide igasurique.

\section{PROPRIÉTÉS DÉLÉTÈRES,}

On a fait de nombreuses expériences sur les animaux pour constater les propriétés vénéneuses de la noix vomique. Gesner, De Heyde, Courten, Wepfer, Brunner, Loss, Hillefeld, Bonnet, etc., ont empoisonné avec cette substance des chiens, des chats, des renards, des loups, des lapins, plusieurs espèces d'oiseaux, etc. Sa composition chimique étant aujourd'hui mieux connue, on a pu varier les épreuves, et on a beaucoup mieux apprécié son action délétère sur l'économie animale. Parmi les médecins qui ont repris nouvellement ce genre d'expérimentation, et qui s'y sont le plus distingués, nous devons citer MM. Desportes, Magendie, Delille, Orfila, Ségalas, Alibert, Vallin et Sandras.

D'après les expériences de MM. Desportes, Magendie et Delille, la noix vomique, sa décoction, son extrait aqueux, son extrait résineux, mêlés avec les alimens; ou introduits dans la plèvre, dans le péritoine, dans la veine jugulaire, dans le tissu des muscles, agissent avec violence sur les chiens, les chats, les lapins, etc. Frappés de convulsions tétaniques, ces animaux succombent à une sorte d'asphyxie dans un très-court espace de temps. L'extrait alcoholique est surtout promptement délétère. Lorsqu'on touche l'ani- 
mal soumis à l'action de cette substance, il éprouve une secousse semblable à une forte commotion électrique. Suivant M. Magendie, un seul grain fait périr un chien d'une taille ordinaire. D'après les expériences de M. Barthélemy, six ou sept grains suffisent pour empoisonner un loup.

MM. Pelletier et Caventou ont constaté, par des expériences qui leur sont propres, que l'action délétère de la noix vomique réside spécialement dans la strychnine. Un demi-grain de cette substance, soufflé dans la gueule d'un lapin, lui a donné des convulsions en deux minutes, et la mort trois minutes après. La même dose, introduite dans une incision faite au dos d'un autre lapin, a produitle même résultat dans l'espace de trois minutes et demie. L'huile grasse de la noix vomique, administrée à la dose de deux grains, a fait périr des chats de convulsions tétaniques au bout de dix minutes. Les mêmes chimistes se sont assurés que les effets délétères de cette huile étaient dus à la présence de la strychnine. Dépouillée du principe alcalin, elle s'est montrée absolument inerte.

M. le docteur Sandras a fait avaler à une chatte jeune et très-forte trois quarts de grain de strychnine. D'abord l'animal n'a rien offert d'extraordinaire, excepté qu'une écume assez abondante lui sortait de la gueule. A sept minutes, convulsions dans la patte de devant du côté droit. La chatte se dresse sur le bout de ses ongles comme si elle marchait sur un sol brûlant; en même temps, sa colonne vertébrale se courbe et s'arrondit en arrière; ses yeux prennent une expression tantôt menaçante, et tantôt profondément effrayée. A 
cettepremière attaque succède une minute de calme, interrompu assez fréquemment par quelques convulsions. partielles. A huit minutes, l'animal tombe sur le côté, tantôt agité de convulsions générales et cloniques, et tantôt dans une sorte de tétanos. Alors le cou est violemment renversé en arrière, et contracté dans toutes ses parties; la tête est fléchie sur le cou, le dos convexe, le ventre durci par la contraction de ses muscles larges; les pattes de devant sont dans un état de demiflexion, mais raides, et celles de derrière allongées et contractées avec tant de violence, qu'on peut à deux reprises prendre l'animal par le bout de ses pattes et le lever horizontalement tout d'une pièce, comme s'il était gelé. Une première fois ce tétanos dure à peu près une demi-minute. La respiration, qui pendant ce temps avait été momentanément suspendue, reprend alors, mais forcée, accélérée et bruyante; les yeux, auparavant alternativement fermés avec force ou ouverts et brillans, semblent devoir rester ouverts, et l'animal paraît revenir à lui et reprendre ses sens. Un bruit subit renouvelle le tétanos; la même succession de symptômes recommence, puis tout à coup une raideur plus grande se manifeste, les yeux se ferment avec violence, et l'animal expire. Lalangue, collée au palais, et les lèvres, n'ont nullement noirci pendant le tétanos; l'animal a uriné abondamment, et les urines sortent encore un quart d'heure après la mort. Immédiatement ses membres cessent d'être contractés. Deux heures après la raideur cadavérique s'en était emparée.

L'écume de la gueule ne présente aucune trace de strychnine. L'autopsie ne montre aucun désordre dans 
les voies digestives; la membrane muqueuse gastrique est plissée et enduite d'un liquide gluant d'un goût douceâtre. Le seul désordreappréciable, et encore étaitil très-peu marqué, c'était une teinte rougeâtre répandue dans toute la substance grise des moelles allongée et épinière.

M. Sandras a répété les mêmes expériences un grand nombre de fois sur différens animaux, des chiens, des lapins, des cabiais, des oiseaux de différentes espèces, et toujours avec des résultats analogues. Mais il a rarement vu cette teinte violacée qui, dit-on, se répand sur les gencives et la langue pendant les accès de tétanos. (Gazette médicale de Paris, mai 1830 .)

Suivant quelques physiologistes, la noix vomique détermine la mort en enflammant les tissus gastriques; d'autres pensent que c'est en agissant directement sur les nerfs. M. Ségalas, qui a fait un grand nombre d'expériences sur plusieurs espèces d'animaux, compare la propriété de la strychnine à celle d'une forte décharge électrique (I). On est, au reste, généralement d'accord queles divers produits de la noix vomique exercent une action spéciale sur la moelle de l'épine, bien que, dans

(1) M. Ségalas a observé que les poisons qui, comme l'acétate de morphine, ont une action spéciale sur le cerveau, opèrent, proportion gardée relativement au volume du corps, avec plus d'énergie chez l'homme que chez les chiens, les cabiais et les lapins; tandis que les substances telles que la strychnine, dont l'action s'exerce sur la moelle épinière, produisent plus d'effet chez ces derniers que chez les premiers. Cela tiendrait-il au développement du cerveau, qui, eu égard au volume du corps, est bien plus grand chez l'homme que chez les mammifères dont il s'agit, au lieu que la condition contraire se remarque pour la moelle de l'épine? 
quelques circonstances particulières, on ait trouvé d'autres organes profondément altérés.

En effet après la mort les divers tissus offrent rarement des traces d'inflammation; cependant, selon Wepfer, ce poison a quelquefois gangrené l'estomac et les intestins. M. le docteur Coze a trouvé les voies alimentaires noirâtres, phlogosées dans toute leur étendue, sur un chien à qui il avait donné de fortes doses d'extrait alcoholique. M. Dupuy, professeur à l'école vétérinaire d'Alfort, qui a éprouvé la noix vomique sur des chevaux, a aussi remarqué des taches violettes, des points rougeâtres sur les membranes de l'estomac et des intestins. Enfin M. le docteur J. Cloquet, à la suite d'un empoisonnement par cette substance, a trouvé dans l'estomac un liquide muqueux sanguinolent, d'une couleur brunâtre; la surface intérieure de cet organe présentait dans divers points une teinte variant du rouge au noir foncé. Le duodénum contenait un liquide jaunâtre muqueux; il était manifestement phlogosé.

Une femme âgée d'environ cinquante ans, d'une. faible constitution, était hémiplégique à son entrée à l'Hôtel-Dieu, à la fin d'août I 819 . Elle prit pendant plusieurs jours un grain d'extrait résineux de noix vomique, sans en éprouver d'effet. Ensuite on augmenta la dose, et on lui confia trois pilules, qu'elle devait prendre dans la journée à de grands intervalles. Ayant eu l'imprudence de les réunir en un bol, et d'avaler le tout à la fois, il lui survint des accès de tétanos extrêmement violens. Trois grains d'extrait suffirent pour développer une gastro-entérite, qui devint mortelle en 
trois jours, malgré les secours les mieux entendus. $\Lambda$ l'ouverture du cadavre, on trouva l'estomac fortement enflammé, mais le foyer principal des accidens était dans les intestins, violets et comme gangrenés en plusieurs endroits; on les déchirait avec facilité. Les gros intestins avaient peu souffert. On ne trouva rien de particulier dans les autres organes; seulement les poumons étaient gorgés d'une assez grande quantité de sang noirâtre ; leur tissu parut plus rouge qu'à l'ordinaire. Il y avait peu de sérosité dans les ventricules cérébraux. (Remarques sur la noix vomique considérée comme médicament, parF. M. CozE, Journal universel des sciences médicales, novembre $18 \mathrm{rg}$.)

Mathiole, dans son Commentaire sur Dioscoride, rapporte qu'une vieille femme fut empoisonnée pour avoir mangé du fromage dans lequel on avait incorporé de la râpure de noix vomique pour tuer les rats.

Un jeune homme âgé de vingt-six ans fut atteint d'hémiplégie du côté gauche sans cause connue. A son entrée à l'Hôtel-Dieu, on lui administra l'extrait alcoholique de noix vomique. On lui en confia six grains, qu'il devait prendre en trois fois; mais il eut l'imprévoyance d'avaler le tout à la fois. Aussitôt il éprouva des attaques de tétanos très-fortes, avec douleur à l'estomac et sentiment d'une espèce de barre qui lui eût serré fortement la poitrine dans le lieu correspondant aux attaches du diaphragme; enfin une hémoptysie très-abondante, qui ne céda qu'aux saignées répétées.

Il n'y a pas long-temps que deux grains de strychnine ont causé instantanément la mort, à l'hôpital de la 
Charité. Ce médicament avait été prescrit à une malade; il fut donné par mégarde à une vieille femme qui succomba au bout de deux minutes.

\section{PROPRIÉTÉS MÉDICALES.}

Malgré les effets délétères de la noix vomique, Wiel, médecin allemand, l'a recommandée, il y a plus d'un demi-siècle, dans quelques affections rebelles, telles que le scorbut, l'hydropisie, la goutte, le rhumatisme, les dartres, les vieux ulcères, etc. Cet auteur se vante d'avoir obtenu à la longue les plus heureux résultats de ce remède énergique. (Dissert. de usu nucis vomica , 1772.) On a également essayé la noix vomique contre l'hypochondrie, l'hystérie, les fièvres intermittentes, la dysenterie, etc. Mais n'avons-nous pas des moyens moins suspects à opposer $\dot{a}$ ces diverses affections? D’après Hoffmann, une jeune fille à qui l'on avait donné trente grains de noix vomique en deux doses pour la délivrer d'une fièvre quarte rebelle, mourut après avoir éprouvé une anxiété extrême et de vains efforts pour vomir. Le docteur Niemann, qui a quelquefois employél'extrait alcoholique dissous dans un véhicule gommeux, dit avoir été obligé d'abandonner ce remède à cause des accidens qu'il faisait naître. (Pharm. bat., tome I, page I69.) Suivant le docteur Rademacher (Libellus de dy senteriâ, Colonice, r8o6), ce remède a quelquefois produit de violens vomissemens et une telle faiblesse, qu'un de ses malades a couru le plus grand danger. D'après les faits que cet auteur a recueillis, l'extrait de noix vomique n'a produit de bons effets qu'en le combinant avec la teinture d'opium. 
Ce n'est que dans ces derniers temps que l'action médicale de cette substance a été justement appréciée. A la tête des médecins qui l'ont soumise à des épreuves cliniques, nous placerons M. Fouquier comme en ayant fait une application spéciale au traitement de la paralysie. Le résultat de ses recherches a été consigné dans un excellent mémoire qui a paru en ${ }_{1} 8 \mathrm{I} 6$. Témoin des effets incertains et le plus souvent inefficaces des autres moyens proposés contre cette maladie, notre habile professeur a su mettre à profit le symptôme le plus redoutable que fait naître la noix vomique. Ainsi, c'est en excitant une sorte de tétanos artificiel qu'il est parvenu à guérir un grand nombre de paralytiques. L'action de ce remède commence ordinairement une demiheure après son ingestion; mais il est des malades qui n'en éprouvent les effets qu'au bout de plusieurs heures. Selon que la dose est plus ou moins considérable, les muscles soumis à l'empire de la volonté, ou du moins les muscles paralysés, sont saisis d'une contraction forte et permanente. Ce spasme se développe d'une manière imperceptible, et s'établit en même temps dans toutes les parties qu'il doit affecter; il s'élève bientôt, et le plus souvent en quelques minutes, au point de rigidité qu'il doit atteindre. Cet état a tous les caractères d'un véritable tétanos; il incommode ordinairement si peu les paralytiques, que la plupart peuvent dormir pendant qu'ils en sont affectés, mais il devient douloureux durant les exacerbations. Celles-ci n'ont lieu que dans les cas où le spasme parvient à un certain degré d'intensité; elles consistent en contractions plus violentes, et font éprouver des commotions brusques et 
passagères plus ou moins fréquentes; elles survieunent tout-à-coup sans cause apparente, ou bien à l'occasion de quelque mouvement imprimé au malade, ou exercé par lui. Ces exacerbations, qui prouvent l'énergie du remède, ajoutent ordinairement à son efficacité. Mais la puissance médicinale de cette substance ne se manifeste pas toujours de la même manière; quelquefois ce n'est qu'un serrement de poitrine, un sentiment d'oppression incommode, ou bien un tressaillement soudain et instantané, ou bien encore une sensation de chaleur vive, ou une exaltation considérable de la sensibilité dans les parties malades.

D'autres fois ce sont des fourmillemens et des picotemens douloureux, des battemens, des tiraillemens qui annoncent l'action secrète et salutaire de la noix vomique. Indépendamment de ces phénomènes, son usage augmente l'appétit et rend les évacuations alvines plus rares. Elle occasione, même à faible dose, une sorte d'ivresse à quelques paralytiques; elle entraîne des accidens lorsqu'elle est administrée sans règle et sans mesure. Alors il survient un tétanos général; la difficulté de parler, d'avaler, de respirer, une anxiété pénible; le malade s'agite, se tourmente, s'effraie; son cour palpite, tout son corps est baigné de sueur. Cet appareil menaçant est sans danger ; bientôt le calme se rétablit de lui-même, le spasme se dissipe par degrés, un sentiment de fatigue douloureuse lui succède. En renouvelant pendant un certain temps ces phénomènes, le malade s'aperçoit que la volonté reprend de l'empire sur les parties paralysées. La sensibilité et la chaleur augmentent en même temps que les 
mouvenıens deviennent moins pénibles, moins bornés, moins incertains; mais ces heureux résultats se font quelquefois attendre long-temps. (FovQuier, Mémoire sur l'emploi de la noix vomique dans le traitement de la paralysie.)

D'après les expériences du professeur Fodéré, la noix vomique, employée en substance et en extrait, n’a offert que des effets purement sédatifs caractérisés par un ralentissement dans la respiration et dans la circulation. Chez un paralytique, le pouls, qui offrait d'abord soixante-douze pulsations, s'est ralenti au point de ne plus en offrir que trente; et le ralentissement devenait tel, qu'on a dû employer les cordiaux. M. Fodéré pense que la noix vomique est douée d'une propriété sédative plus prononcée que celle de la digitale pourprée. D'un autre côté, M. le baron Larrey accuse cette substance d'augmenter la phlegmasie des membranes nerveuses; il a remarqué que ses effets étaient constamment pernicieux, et il voudrait que son usage fût proscrit. Ces deux autorités sont bien imposantes sans doute; mais les faits recueillis par M. le professeur Fouquier et quelques autres médecins non moins recommandables, sont trop nombreux et trop concluans pour qu'on doive renoncer à un moyen aussi énergique.

M. Sandras a observé que l'emploi de la strychnine était beaucoup plus salutaire dans le traitement de la paraplégie et des paralysies locales, que dans celui de l'hémiplégie; que ce médicament réussissait beaucoup mieux lorsque la maladie se développait lentement et avec une sorte de régularité.

Une femme entra à l'Hôtel-Dieu avec une paralysie 
presque complète des extrémités inférieures. Cela avait commencé cinq ou six mois avant l'époque où elle s'était déterminée à venir à l'hôpital. C'étaient d'abord des engourdissemens, des fourmillemens, avec une grande faiblesse de ces extrémités. Lors de son entrée, il lui était impossible de se soutenir sur les jambes, qui avaient cependant conservé leur sensibilité. On lui prescrivit la strychnine en commençant par $2 / 8$ de grain, et, en trois semaines, cette femme fut complètement rétablie, et put se servir de sajambe comme avant l'époque où elle avait commencé à en perdre l'usage.

Un jeune homme avait pris, deux jours de suite, deux gros par jour de résine de copahu; il lui survint une gastro-entérite qui guérit toute seule en peu de jours; mais, en même temps, l'action du copahu avait déterminé une paralysie de la vessie qui ne guérit point. On fut obligé plusieurs jours de suite de sonder le malade, dont la vessie avait perdu à la fois et la sensibilité et la contractilité. Ce ne fut qu'au bout de sept à huit jours qu'on s'avisa de lui donner de la strychnine à la dose de $1 / 8$ à $2 / 8$ par jour. La sensibilité et la contractilité de la vessie revinrent dès-lors peu à peu, et, au bout de trois semaines, cet organe avait repris toutes ses fonctions.

Un homme âgé de soixante-trois ans fit une chute sur la tête et fut paralysé des deux mains et d'une partie des avant-bras. On lui fit prendre la strychnine à l'intérieur; à plusieurs reprises, on appliqua des vésicatoires sur tous les points des avant-bras et des mains, et on les pansa avec un ou deux grains de strychnine. Ce traitement dura plus d'une année, mais le malade fut 
guéri. Il ne lui resta qu'un peu de difficulté à ouvrir les doigts avec promptitude. Quand on se relâchait sur l'emploi de la strychnine, les progrès de la guérison s'arrêtaient, et il fallait promptement revenir à l'usage de ce médicament, soit à l'intérieur, soit surtout à l'extérieur.

Cette observation prouve jusqu'à l'évidence l'efficacité de la strychnine, car il est à peu près certain, à en juger par les cașanalogues que la science possède, que le malade n'aurait jamais guéri sans elle.

M. le docteur Edwards a guéri par la noix vomique une amaurose avec paralysie de la paupière supérieure. M. le docteur Magendie a vu de très-bons effets de la même substance dans l'affaiblissement marqué des organes génitaux, dans l'incontinence d'urine, etc. Il a aussi employẻ la résine de noix vomique pour les estomacs paresseux, et des débilités extrêmes avec tendance irrésistible au repos.

Maintenant, si nous voulons ajouter foi à l'homœopathie, elle nous dira que la noix vomique, administrée d'après sa méthode, dissipe à l'instant toutes ces crampes, tous ces spasmes, toutes ces affections erratiques de la tête et du bas-ventre, ces dégoûts, ces aigreurs, ces constipations, ces vomissemens; enfin tous ces phénomènes morbifiques qui tourmentent notre existence, et qui se jouent de nos remédes calmans, de nos potions à la fleur d'orange. Il n'y a au reste aucun danger à en faire l'essai, car aucun malade ne mourra empoisonné pour avoir pris un décillionième de grain de noix vomique.

On donne la noix vomique en substance pulvérisée à 
la dose de trois ou quatre grains, qu'on répète plusieurs fois dans la journée. L'extrait alcoholique a des vertus plus puissantes; la dose est de deux grains, qu'on renouvelle aussi trois ou quatre fois en vingtquatre heures. Pour éviter les accidens, il faut commencer par une ou deux prises, et juger par les résultats si l'on doit ou non les multiplier. Dans le cours du traitement, on aura soin de suspendre de temps en temps le remède; mais alors on recommencera par de faibles doses. On prépare avec une once d'alcohol et trois grains d'extrait sec de noix vomique une teinture qu'on administre à la dose de dix, quinze et vingt gouttes.

M. le docteur Magendie a proposé de remplacer les extraits de noix vomique par la strychnine, à raison de ses propriétés constantes et de l'uniformité de son action. On la réduit en pilules de la manière suivante : prenez, strychnine bien pure, deux grains; conserve le rose, un demi-gros; mêlez exactement, et faites vingt-quatre pilules bien égales et argentées. N'oublions pàs que cette substance agit avec une intensité extrême, et qu'un huitième de grain a quelquefois suffi pour tuer un chien de forte taille. Il faut une main bien délicate pour manier une arme aussi dangereuse.

La méthode ïatraleptique, ou endermique, comme on dit aujourd'hui, nous paraît un des meilleurs moyens d'administrer la strychnine. M. le docteur Miquel, ancien chef de clinique à l'hôpital de la Charité, en a fait nouvellement une heureuse application à l'amaurose. Nous nous empressons de communiquer à nos 
lecteurs quelques fragmens que cet habile praticien a bien voulu détacher d'un mémoire qu'il se propose de publier incessamment.

\section{DE L'EMPLOI DE LA STRYCHNINE DANS LE TRAITEMENT DE L'AMaUrose.}

L'amaurose est, de toutes les maladies de l'organe de la vision, la plus grave et la plus rebelle. Sous l'influence de causes variées et le plus ordinairement insaisissables, l'neil est frappé de cécité et néanmoins conserve toute sa transparence; aucun phénomène insolite n'a souvent précédé la catastrophe, et s'il a été remarqué quelques symptômes préliminaires ou concomitans, ils ont été si fugaces, que raisonnablement ils ne peuvent devenir la base d'indications thérapeuttiques. Cependant la personne est aveugle.

Le médecin invoque à son aide tous les moyens dérivatifs; il emploie les purgatifs, les cautères, le séton à la nuque, etc.; il échone. Il se rattache à l'idée que l'amaurose est liée à une cause spécifique, qu'elle tient à une syphilis mal guérie, à un principe dartreux, rhumatismal, goutteux; il la combat par les remèdes propres à ces affections; il échoue le plus souvent encore; et le malade, réputé par lui incurable, est condamné à être privé à jamais de la lumière du soleil.

C'est donc un service immense à rendre à l'humanité que de proclamer que la moitié au moins de ces aveugles par amaurose, abandonnés des médecins, peuvent recouvrer la faculté de voir.

Je n'oserais pas me prononcer d'une manière aussi II. 
formelle, si des faits assez nombreux et des plus concluans ne m'avaient révélé la puissance du traitement par la strychnine dans les cas de cette nature.

L'action de l'extrait de noix vomique et de strychnine surtout est des plus énergiques; elle se porte principalement et peut-être uniquement sur la pulpe nerveuse de la moelle épinière et détermine des contractions plus ou moins violentes de tous les muscles; de telle sorte que les sujets qui sont soumis à ces médicamens, ont des secousses involontaires et comme galvaniques des membres. Cette action, portée à un plus haut point, amène le trismus et peut même aller jusqu'au tétanos. Cette propriété a été mise à profit dans le traitement des paralysies, et il serait facile de citer un grand nombre de guérisons dues uniquement à ce moyen.

Il était rationnel de penser que l'amaurose idiopathique pure, celle qui tient uniquement à la paralysie des nerfs optiques, recevrait une impression salutaire du traitement par la strychnine, si l'on pouvait diriger l'action de ce médicament sur le nerf paralysé; mais comment y parvenir? Administrée à l'intérieur comme dans les paralysies ordinaires, l'ensemble del'organisme en reçoit bien l'influence, mais l'effet spécial sur le nerf optique n'a point lieu.

La méthode endermique, c'est-à-dire le médicament introduit par la pean dénudée, s'offrait naturellement à l'esprit. A son aide il était possible d'agir presque immédiatement sur le nerf affecté. C'est ce procédé que j'ai adopté depuis quatre ans, à l'imitation d'un médecin d'Édimbourg qui en a eu la première idée; 
et j'ai eu depuis lors des succès tellement inespérés, que je n'hésite pas à considérer cette méthode, que j’ai beaucoup perfectionnée, comme la seule ressource qui reste à la plupart des amaurotiques pour recouvrer la vue.

Ne m'occupant pas d'une manière spéciale des maladies des yeux, je n'ai pu recueillir un grand nombre d'observations relatives au traitement de l'amaurose par la strychnine; mais cependant leur importance est telle qu'elles ne peuvent laisser aucun doute dans les esprits.

Sur sept amaurotiques aveugles que j'ai soumis à ma méthode, trois ont recouvré la vue complètement; deux, qui ne voyaient le jour qu'imparfaitement, sont assez clairvoyans pour se conduire et même pour lire de gros caractères; les deux derniers n'ont éprouvé aucune amélioration.

Des trois personnes guéries, la première était un horloger aveugle depuis dix-huit mois. En deux mois et demi de traitement il a recouvré la vue de la manière la plus complète; et depuis le mois d'avril ı 833, époque de la guérison, il a repris son état d'horloger: c'est prouver qu'il a aujourd'huila vue la meilleure. Le second cas est encore fort important. Un compositeur d'imprimerie était à peu près aveugle depuis deux ans; grâce à cette méthode, il a repris aujourd'hui son état. Les deux malades qui n'ont été qu'incomplètement guéris, sont deux dames, dont l'une, habitant le Havre, est fille d'un des premiers horlogers du Palais-Royal. Quand j'ai commencé le traitement, elle y voyait à peine pour se conduire, et, depuis neuf ans, elle n'avait ni lu ni écrit; aujourd'hui elle écrit à sa famille 
d'une manière assez nette. L'amélioration qu'elle a obtenue ne s'est pas démentie depuis deux ans. Les deux sujets qui n'ont retiré aucun avantage de la strychnine, sont un ancien notaire de Paris, âgé de quarante-trois ans, et un perruquier de la rue Montmartre, âgé d'une soixantaine d'années.

Il m'est impossible d'indiquer ici toutes les particularités d'un traitement qui, en raison du médicament. actif qui en fait la base, et de l'importance de l'organe sur lequel il agit, demande de fréquentes modifications, suivant les incidens qui se présentent; néanmoins je vais tâcher d'iudiquer de mon mieux la marche que j'ai suivie.

Avant de commencer le traitement, il faut s'assurer que les humeurs de l'œil sont parfaitement transparentes, et que le malade distingue au moins d'un œil la lumière des ténèbres. Cette dernière condition est indispensable; si elle n'existe pas, il est, je crois, inutile d'employer la strychnine, elle n'aura aucun résultat. La perception de la lumière par un seul œil suffit; car M. Roussel, l'horloger dont j'ai parlé, et qui était dans ce cas, a recouvré complètement la vue de l'œil gauche, quoiqu'il ne pût distinguer de ce côté la flamme d'une bougie placée à un pouce de l'organe.

Ces circonstances favorables une fois établies, je commence le traitement par une application de douze à quinze sangsues derrière l'oreille du côté que je veux d'abord attaquer; si le sujet est pléthorique et disposé aux congestions cérébrales, j'applique les sangsues à l'anus. Dans tous les cas aussi, je purge préalablement ces malades avec une once d'huile de ricin. 
Ensuite j'applique sur la tempe du même côté un vésicatoire de quinze lignes de diamètre que je laisse jusqu'au lendemain.

C'est cette plaie bien nette et bien rosée qui va servir de moyen d'introduction à la strychnine; il est donc de la plus haute importance de la conserver dans un état convenable à l'absorption.

On ne se douterait pas que c'est là une des grandes difficultés que j'ai rencontrées dans mon traitement, et que ce n'est qu'à force de tâtonnemens que je suis parvenu à la vaincre. En effet, la strychnine en poudre, comme je l'employai d'abord, déterminait en peu d'heures sur la plaie une fausse membrane épaisse fortement adhérente; de sorte qu'un second pansement était șans nul effet, et que pour redonner à la plaie la propriété absorbante, j'étais obligé de réappliquer l'emplâtre vésicatoire tous les deux jours sur la même partie. J'essayai alors de mêler la strychnine avec la pommade de garou; même inconvénient avait lieu. Il en fut de même, quoiqu'à un moindre degré, en remplaçant une portion de la pommade de garou par du cérat. Je ne suis parvenu à peu près à mon but qu'en faisant préalablement dissoudre la strychnine avec une petite quantité d'alcohol. Voici la formule de la pommade que j'emploie, et dont les proportions doivent être rigoureusement suivies. Prenez, pommade épispastique ou au garou, un gros et un scrupule; cérat de Galien, un gros et deux scrupules; strychnine dissoute dans q. s. d'alcohol, quatre grains : faites une pomniade bien homogène.

Les pansemens sont faits le matin et le soir avec 
douze grains de cette pommade étendue sur une feuille de poirée ou de papier brouillard. Les quantités de garou et de cérat doivent être invariables; mais on augmente, selon le besoin et successivement, la dose de la strychnine, d'un grain chaque fois. Le plus haut que jel'ai portée a été à dix grains.

Aussitôt après le pansement et dès le premier jour, le malade reçoit l'influence de la strychnine; et déjà au troisième ou quatrième jour on peut avoir quelque indice sur le résultat probable du traitement. Le premier effet que l'on remarque est le sentiment d'étincelles plus ou moins nombreuses et actives dans le fond des deux yeux, et surtout dans l'oeil du côté où est placé le vésicatoire. Ces étincelles sont d'une haute importance; si elles n'existaient pas, on devrait mal augurer du succès du traitement. La quantité des étincelles est aussi une chose digne de remarque : elles sont quelquefois noirâtres, d'autres fois blanches ou rouges. Les étincelles rouges sont les plus avantageuses. Il ne faudrait pas pourtant qu'elles fussent d'abord trop éclatantes, car alors il faudrait se hâter de modérer l'action du remède, soit en diminuant la quantité de la pommade, soit en ne faisant qu'un pansement par jour.

Il survient dans le cours du traitement des incidens sur lesquels il faut arrêter l'attention. Ce sont des douleurs de tête occupant plus particulièrement la région occipitale ou le sommet de la tête, une raideur de la mâchoire, et de la difficulté dans le mouvement des membres inférieurs; si ces symptômes sont passagers, s'ils ne sont point portés à un degré trop élevé, il ne faut point en tenir compte. Dans le cas contraire, on 
interrompra la pommade de strychnine pendant un jour, et on appliquera sur la plaie un huitième de grain ou un quart de grain d'hydroclorate de morphine. Ce seul moyen m'a toujours réussi.

J'ai pour habitude, pendant tout le traitement, d'agir légèrement et d'une manière continue sur le canal intestinal, au moyen de pilules composées avec deux grains de calomel et quatre grains de résine de jalap. On prend ces pilules le soir en se couchant. Si, à la longue, le calomel avait une action sur la bouche, on le remplacerait par un ou deux grains d'extrait d'aloès.

Quelquefois les étincelles, qui ont été abondantes les premiers jours, se suppriment, et ne reviennent pas en augmentant la quantité de strychnine; il faut alors joindre au traitement des frictions sur le sourcil et la paupière inférieure avec une teinture de strychnine fortement chargée. Si, malgré cette addition, les étincelles se suppriment encore, je me suis bien trouvé d'un vomitif. Après les secousses qu'il détermine, les étincelles recommencent et continuent. Chez deux malades, j'ai été obligé de recourir trois fois au vomitif (qui se compose de deux grains de tartre stibié), pendant la durée du traitement.

Quand le malade a un wil meilleur que l'autre, il faut commencer le traitement par celui-là; toujours le mauvais œil s'améliore, et même quelquefois on n'est pas obligé de l'attaquer directement. Cette circonstance heureuse a eu lieu chez un de mes malades.

J'ai remarqué, et je ne suis point le seul, que le séton à la nuque, le moxa aux tempes, étaient plus nuisibles qu'utiles dans les cas d'amaurose idiopathique; 
ce que je puis dire, c'est que les deux malades qui n'ont éprouvé aucune amélioration de mon traitement avaient été martyrisés par ces moyens.

Je ne dois pas oublier de dire que, malgré les modifications que j’ai fait subir à ma pommade, je ne suis pas parvenu complètement à empêcher la formation des fausses membranes. Il s'en forme une mince et molle à la suite de chaque pansement: il faut avoir soin de l'enlever chaque fois qu'on renouvelle la pommade, ce qui est facile à pratiquer.

Au reste, le praticien doit panser lui-même le malade tous les jours, et ne pas perdre de vue que l'attention la plus minutieuse doit être apportée à ce traitement, qui, mal administré, peut être dangereux.

Le genre strychnos fournit un autre végétal non moins vénéneux, qui croît aux Indes orientales, aux îles Philippines, à la Cochinchine; c'est le strychnos Ignatii de Lamark, ou l'ignatia amara de Wildenow. M. Aubert du Petit-Thouars le désigne sous le nom de caniram de Saint-Ignace; il a tous les caractères d'un strychnos. Les fruits renferment des semences irrégulières, plus ou moins anguleuses, brunes, un peu ridées à leur surface, d'une substance cornée intérieurement, et d'une saveur éminemment amère.

Cette graine, connue sous le nom de fève de saint Ignace, se compose des mêmes principes que la noix vomique; ses propriétés actives et délétères sont dues à la présence de la strychnine ; elle est un violent poison pour l'homme et pour un grand nombre d'animaux. Sauvages rapporte (Nosol. méthod.) qu'un étu- 
diant ayant pris, pour faire un essai, quarante grains de fève de saint Ignace, fut saisi de convulsions avec cardialgie. On lui administra tous les quarts d'heure six gouttes d'alcali volatil dans un véhicule convenable, et il fut guéri.

Ainsi que la noix vomique, cette substance figure dans la matière médicale. On a particulièrement signalé sa vertu fébrifuge; et, d'après l'assertion de Lewis, deux grains ont produit le même effet qu'une once de quinquina. Desbois de Rochefort dit également qu'elle a été employée à Paris avec succès contre les fièvres quartes rebelles; mais il se hâte d'ajouter qu'elle a l'inconvénient d'attaquer les nerfs, d'exciter le délire, et même une folie opiniâtre. Ces graines font la base d'un remède de charlatan, connu sous le nom d'eau de Polissart, et jadis très-accrédité dans le traitement de la goutte; c'est une espèce de teinture alcoholique qui excite des convulsions, purge quelquefois avec violence, et fait disparaître momentanément les accès. Desbois de Rochefort dit avoir connu des malades qui sont morts pendant son opération.

J'ai été témoin, il y a quelques années, d'une senblable catastrophe à l'hôtel Coquillière. Un vieux goutteux, qui depuis long-temps faisait usage de cette préparation, et qui avait éprouvé, en arrivant à Paris, les premiers signes d'une attaque, en prit une cueillerée à dix heures du matin et une autre à midi. Peu de temps après il survint des évacuations nombreuses, avec des mouvemens convulsifs et une suffocation des plus violentes. A cinq heures du soir le malade avait cessé de vivre. Les pédiluves irritans, les sinapismes, rien 
ne put rappeler l'irritation goutteuse aux extrémités. Ces accidens démontrent combien il est dangereux d'intervertir l'ordre des mouvemens naturels par des moyens violens. Les purgatifs drastiques, et surtout le remède de Leroy, qu'on emploie aussi pour s'opposer à l'invasion de la goutte, doivent faire nécessairement beaucoup de victimes.

Je ne parlerai point de l'action vermifuge de ces graines; nous avons des remèdes plus sûrs et non moins efficaces auxquels on donmera sans doute la préférence. Leur extrait alcoholique attaque le système nerveux avec une violence extrême; il est encore plus actif que l'extrait de noix vomique.

Un autre poison végétal sur lequel on n'avait encore que des notions inexactes, a été apporté de l'île de Java par M. Leschenault; c'est l'upas-tieuté, dont se servent les naturels du pays pour empoisonner leurs flèches. Il provient d'un arbrisseau sarmenteux qui appartient au genre strychnos, et à qui M. Leschenault a donné le nom de strychnos tieuté. Cet arbrisseau, qu'on appelle tsettik, croît uniquement dans les solitudes de Blanbangan. M. Lesson, qui a fait le voyage autour du monde sur la corvette la Coquille, en a apporté quelques fragmens. La racine, recouverte d'un épiderme fin, uni, couleur de rouille, est blanchâtre intérieurement. La tige est revêtue d'une écorce blanche, rugueuse, où abonde un petit cryptogame noir du genre opegrapha; le bois en est poreux et d'un blanc jaunâtre.

L'upas-tieuté est un suc extractif d'une amertume extrême, d'une couleur brune, de consistance de mé- 
lasse; on le conserve dans de petits tuyaux de bambou. D'après les belles expériences de MM. Delille et Magendie, l'upas-tieuté, ainsi que la noix vomique et la fève de saint Ignace, est un stimulant énergique de la moelle épinière. A très-petite dose, il cause la mort en déterminant une contraction tétanique prolongée de tous les muscles auxquels la moelle de l'épine fournit des nerfs : contraction qui suspend nécessairement la respiration et produit l'asphixie. L'analogie botanique, qui existe entre cette plante et les végétaux congénères, fait présumer que ses qualités vénéneuses sont dues à la présence de la strychnine.

Suivant Foersch, médecin de la compagnie hollandaise des Indes orientales, l'arbre qui produit ce poison croît dans l'île de Java, à environ vingt-sept lieues de Batavia; il est appelé en langue malaise bohonupas. Étant à Soura-Charta, résidence de l'empereur, au mois de février i 776 , il dit avoir assistéà l'exécution de treize femmes de ce monarque, convaincues d'infidélité. On les conduisit à onze heures du matin sur la place vis-à-vis le palais. Le juge fit passer au-dessus de leur tête la sentence qui les condamnait. On leur présenta ensuite le Coran pour leur faire jurer que cette sentence était juste; ce qu'elles firent en mettant une main sur le livre et l'autre sur la poitrine, et levant les yeux au ciel. Ensuite le bourreau procéda à l'exécution de la manière suivante. On avait dressé treize poteaux; on y attacha les coupables. Elles restèrent dans cette situation, mêlant leurs prières à celles des assistans, jusqu'à ce que, le juge ayant donné le signal, le bourreau les piqua au sein avec une lancette trempée 
dans la résine de l'upas. A l'instant elles éprouvèrent un tremblement suivi de convulsions, et six minutes après elles avaient cessé de vivre. Elles avaient la peau couverte de taches livides; leur visage était enflé, leur teint bleuâtre, leurs yeux jaunes.

Désirant faire lui-même quelques expériences, le docteur Foersch se procura, avec beaucoup de peine, quelques grains de bohon-upas, qu'il fit dissoudre dans de l'arack : il piqua avec une lancette trempée dans ce poison des chiens et d'autres animaux; tous moururent dans des convulsions en moins de treize minutes. Les effets du poison, introduit dans les voies alimentaires, furent les mêmes. Un chien à qui il en donna un quart de grain, fut attaqué de convulsions sept minutes après, et mourut au bout d'une demi-heure. L'estomac et les intestins étaient très-enflammés.

Il existe sur la côte de Macassar un arbre appelé cadjoé-upas, dont le poison agit à peu près de même; mais ses effets ne sont pas si terribles. (Mélanges de littérature étrangère, tome I, page 63.)

Ce poison paraît être l'upas-antiar. de M. Leschenault; il est produit par un arbre de la famille des urticées, et ne doit pas être confondu avec l'upas-tieuté; nous en parlerons plus tard.

Les sauvages de la Guyane et des autres contrées de l'Amérique possèdent quelques autres poisons, tels que le ticunas, le woorara, le curare, etc., qu'on rapporte à des lianes appartenant à la famille des strychnées ou à celle des apocynées; toutefois, MM. de Humboldı et Bonpland, qui nous ont donné des détails curieux sur ces redoutables toxiques, n'ont pu 
déterminer leur véritable origine. On sait senlement que les Indiens s'en servent pour empoisonner leurs armes de chasse et de guerre. Leur action sur le système animal a beaucoup d'analogie avec celle de l'upas-tieuté.

Voici, au reste, quelques nouveaux renseignemens sur le poison américain nommé woorara ou wourali; ils sont extraits de la relation d'un voyage récent de M. Waterton dans l'Amérique du sud.

Au fond des déserts du Démérary et de l'Esséquébo, bien loin de tous les établissemens européens, il existe une tribu d'Indiens, connue sousle nom de Macouchi. Quoique tous les sauvages qui vivent entre le fleuve des Amazones et l'Orénoque fassent usage du wourali, les Macouchis savent lui donner un degré d'énergie particulier.

On a beaucoup parlé des prodigieux effets de ce poison : quelques personnes ont soutenu qu'ils étaient presque instantanés, lorsqu'une portion quelconque en était introduite dans le sang. D'autres ont dit, au contraire, qu'ils n'avaient pas assez de force pour tuer un animal de la taille d'un homme. Les premiers ont eu le tort d'ajouter trop de confiance à des contes merveilleux; les seconds ont fait leurs expériences avec des poisons d'une qualité inférieure, ou n'ont pas eu assez de flèches empoisonnées. Voici d'abord la manière de préparer le wourali :

Lorsque l'Indien veut préparer son poison, il commence par aller à la recherche d'une espèce de vigne qui croît dans ces déserts, et qu'on nomme wourali. C'est de cette vigne qu'il emprunte son nom, et c'est 
elle qui en forme le principal ingrédient. Il se procure ensuite une racine d'un goût très-amer, puis deux espèces de plantes bulbeuses qui contiennent un suc verdâtre ou glutineux. Après cela, il parcourt la forêt pour avoir deux espèces de fourmis : une de ces fourmis est noire et très-grosse, et sa piqûre est si venimeuse, qu'elle donne la fièvre; l'autre est une petite fourmi rouge qui pique comme une aiguille, et qui place son nid sous la feuille d'un buisson. Il introduit aussi dans la composition une certaine quantité du plus fort poivre indien, qu'il cultive pour cela autour de sa cabane, et il y ajoute des dents pilées du serpent labarri et du connacouhi dont il fait provision; car , toutes les fois qu'il tue un serpent, il en arrache les dents pour les conserver. Ce mélange est ensuite placé sur le feu, et quand il commence à bouillir, l'Indien y verse une nouvelle infusion de la vigne nommée wourali, et il enlève l'écume avec une feuille. Cette décoction est laissée sur le feu jusqu'au moment où elle prend l'aspect d'un sirop épais, d'un brun foncé; alors on y trempe des flèches pour en éprouver la force. Lorsqu'elle a le degré de cuisson nécessaire, on la retire, et on la verse dans un petit vase de fabrication indienne, qu'on recouvre de deux feuilles et d'un morceau de peau de daim attaché avec une corde. On place ce vase dans la partie la plus sèche de la hutte, et on le met de temps en temps sur le feu, pour empêcher les effets de l'humidité.

C'est dans cette composition qu' on trempe les flèches qu'on veut rendre empoisonnées.

Voyons maintenant comment agit le poison. L'ani- 
mal qui en a été atteint tombe dans une espèce de sommeil léthargique, et la mort survient d'une manière si douce, que le blessé ne parait éprouver d'autre peine que la douleur momentanée qu'il a ressentie lorsque le trait l'a pénétré.

"Nous en essayâmes la force, dit M. Waterton, sur un chien de taille moyenne, et nous lui fîmes une blessure à la cuisse, afin qu'aucun organe essentiel ne pût être atteint. Au bout de trois ou quatre minutes, il commença à éprouver les effets du poison; il flairait tout ce qui était autour de lui sur le sol, et regardait fixement la partie blessée. Bientôt après il chancela, et se coucha pour ne plus se relever. Il aboya une fois, sans paraître ressentir de douleur : ses cris étaient sourds et faibles. Il plaça sa tête entre ses quatre pattes, puis, la soulevant un peu, il la laissa retomber de côté. Son œil devint fixe, et de temps en temps ses extrémités étaient agitées de mouvemens convulsifs. Tantôt les battemens de son cceur semblaient être arrêtés, tantôt ils étaient forts et rapides; ces pulsations se prolongeaient encore, quoique faiblement, lorsque déjà tous les autres organes paraissaient saisis par la mort. ")

Une seconde expérience fut faite sur un aï ou paresseux à trois doigts. Blessé à la jambe, et déposé sur le sol à peu de distance d'une table, il parvint à s'en rapprocher, et se cramponna à un de ses pieds, comme s'il eût voulu y monter; mais ce fut son dernier effort. La vie se détruisait rapidement, et cet animal, organisé de manière à résister à la mort sous mille formes différentes, n'a pu résister au wourali. D'abord, une 
des jambes de devant lâcha prise, et tomba de côté sans mouvement; l'autre ne tarda pas à tomber de la même manière. Les deux jambes de devant ayant perdu leur force, tout son corps se courba, et il plaça sa tête entre ses pattes de derrière, qui continuaient à adhérer à la table. Lorsque le poison eut atteint celles-ci, il glissa par terre, mais si doucement, que si vous eussiez ignoré qu'il avait été blessé par un trait empoisonné, vous n'auriez jamais cru qu'il était mourant. Sa bouche était fermée; il n'y avait autour ni écume, ni salive. Point de soubresauts dans les tendons, ni le moindre trouble dans la respiration. Dix minutes après avoir reçu la blessure, il fit un mouvement, et, dans l'instant qui suivit, la dernière étincelle de vie s'échappa.

Voilà deux preuves incontestables des effets de ce poison, la mort du chien et celle du paresseux. Mais comme aucun de ces animaux n'était de forte dimension, il serait encore permis de douter de son action sur les animaux d'une taille plus considérable, sans le fait que nous allons rapporter.

Un gros bœuf, du poids de neuf cents à mille livres, fut attaché à un pieu par une corde assez longue pour lui laisser la faculté d'aller et de venir. On tira trois flèches sur lui : deux lui percèrent transversalement les naseaux. Le poison agit au bout de quatre minutes. Comme s'il eût senti qu'il allait tomber, le bœuf commença par se tenir ferme sur ses jambes, et il resta tranquille pendant environ quatorze minutes. Il se mit alors à flairer le sol, et fit un pas ou deux, chancela, s'affaissa sur la terre, et resta étendu de côté. Son œịl, 
qui était vif quelques minutes auparavant, devint fixe et sombre, et quoiqu'on approchât la main tout auprès, comme pour le frapper, sa paupière ne faisait aucun mouvement. Ses jambes éprouvaient des mouvemens convulsifs, et sa tête se soulevait de temps à autre. Sa respiration était pénible, et sa bouche remplie d'écume. Les soubresauts des tendons s'affaiblirent graduellement; le train postérieur se paralysa, et, deux minutes après, la tête et les jambes de devant cessèrent de se mouvoir. Rien n'annonçait plus la présence de la vie, que les battemens toujours plus faibles du cœur. Vingt-cinq minutes après avoir reçu les blessures, l'animal avait cessé d'exister. Sa viande était très-tendre et très-savoureuse.

Cette dernière circonstance de l'innocuité de la viande des animaux tués par le wourali est assez remarquable, et elle explique pourquoi les Indiens vont à la chasse armés de traits ainsi empoisonnés, qu'ils lancent avec leur sarbacane jusqu'à trois cents pieds de haut. Quelquefois l'oiseau blessé reste d'abord dans l'arbre où il a été atteint, et, au bout de trois minutes, il tombe au pied du chasseur. D'autrefois il s'envole; mais il ne saurait aller loin ; et quoique, en général, les convulsions et la mort n'arrivent qu'en trois minutes, cependant il tombe immédiatement dans une stupeur qui se manifeste par la répugnance qu'il parait éprouverà se mouvoir.

Le strychnos colubrinum, d'après Roxburgh, ne diffère point du strychnos nux vomica; son bois, qu'on appelle bois de couleuvre, est très-vénéneux, et ses effets ont beaucoup d'analogie avec ceux de la 
noix vomique. Quelques auteurs ont également rapporté la fausse angusture à un arbre du groupe des strychnées; mais il paraît qu'on ignore encore à quel végétal elle appartient. Nous parlerons de ces écorces en traitant de l'angusture vraie.

L'empoisonnement produit par les plantes de la famille des Strychnées offre les symptômes suivans : malaise général, chaleur à l'épigastre, nausées, tremblemens, commotions musculaires, raideur tétanique du tronc et de ses extrémités, se renouvelant à des intervalles plus ou moins rapprochés, soit spontanément, soit par le contact d'une partie quelconque du corps, par le bruit ou par des menaces adressées au malade. Lorsque ces attaques se prolongent, il survient un tétanos universel, une anxiété douloureuse, une difficulté extrême de respirer, l'insensibilité du pouls, des sueurs froides et la mort. La strychnine surtout agit avec une extrême violence, et la mort est pour ainsi dire instantanée.

MÉTHODE CURATIVE.

Il résulte de plusieurs expériences communiquées à l'Académie des Sciences par M. le docteur Donné, que le chlore, l'iode ou le brome neutralisent l'action vénéneuse de la strychnine et autres alcalis végétaux. Ces substances, ingérées séparément, mais à peu de distance l'une de l'autre, se combinent entre elles et forment des chlorures, des iodures ou des bromures. Les animaux auxquels ce jeune et habile expérimentateur a donné un grain de strychnine pure (un demigrain suffit pour causer la mort d'un chien ordinaire), 
ont toujours été sauvés, quand, immédiatement après, il leur a administré la teinture d'iode.

Dans les premiers instans de l'empoisonnement, on pourrait essayer cette teinture, qui, plus tard, serait impuissante, les molécules délétères étant déjà absorbées. L'alcali volatil a été administré avec succès, tous les quarts d'heure, à la dose de cinq ou six gouttes dans trois ou quatre cuillerées d'eau sucrée, dans un cas d'empoisonnement par la f'ève de Saint-Ignace. Ce fait, rapporté par Sauvages, ne doit pas être dédaigné.

Parmi les moyens ordinaires, on place les émétiques et les purgatifs; on donne immédiatement après des boissons mucilagineuses. Lorsqu'on a débarrassé les voies alimentaires, on peut administrer tous les quarts d'heure quelques cuillerées d'une potion préparée avec deux onces d'infusion de fleurs de tilleul, une once de sirop simple, demi-once d'essence de térébenthine, et deux gros d'éther. On a conseillé la trachéotomie et l'insufflation de l'air dans les poumons, afin de prévenir l'asphyxie; mais il est nécessaire de continuer l'insuflation pendant plusieurs heures pour en obtenir du succès. Si l'empoisonnement a eu lieu par suite d'une blessure faite aux membres, il faut promptement cautériser la plaie et pratiquer une ligature au-dessus de l'endroit blessé. On a également proposé des saignées abondantes, pour dissiper les accidens produits par ces poisons; mais, si elles éloignent les spasmes musculaires, elles peuvent également provoquer une adynamie mortelle. Ce moyen thérapeutique convient rarement aux personnes d'un âge avancé ou d'une constitution débile. 
Le sucre, qu'on avait d'abord regardé comme le contre-poison des flèches américaines (Voyage de la Condamine), est maintenant tout-à-fait oublié. Nous lisons cependant dans le Traité des arbres résineux de Duplessy, que le sucre brut, donné à fortes doses, a sauvé plusieurs animaux sur lesquels on avait fait des expériences avec ces traits empoisonnés.

pyrénées, barèges, vallée de campan.

Nous avions dit adieu au riant bassin de Luz; nous partions pour Barèges en suivant la rive gauche $d u$ Bastan. L'aube du jour éclairait à peine de ses teintes veloutées la cime des monts, l'air était pur et suave, le temps magnifique. L'heureuse disposition de mon âme donnait à ces lieux solitaires et sauvages un charme rarement senti par ceux qui les ont parcourus ou décrits. Ils n'ont vu que la nudité des rochers; ils n'ont éprouvé qu'une sorte d'horreur dans cette gorge dominée par des pics presque inaccessibles, sans cesse menacée par les orages et les avalanches; et, au milieu de ce triste spectacle, ils ont à peine jeté un regard sur ces hautes prairies qui bordent la route de Barèges, où croît une foule d'arbustes et de plantes de tonte espèce. L'homme est ainsi fait : un sentiment pénible ferme son cœur à tout ce qui pourrait le consoler ou le distraire. Et puis n'a-t-on pas dans ces montagnes des eaux minérales efficaces contre les maux les plus rebelles ou les plus hideux?

Barèges n'a qu'une rue principale, mais elle est spacieuse, propre, ornée de beaux hôtels où les màlades 
et les curieux sont parfaitement servis. On y trouve d'ailleurs des médecins habiles, et des chaises à porteurs pour les éclopés qui, de toutes parts, viennent aux eaux.

En quittant ce lieu pour atteindre le col du Tourmata, vous voyez à droite un joli bois de hêtres qui s'étend jusqu'au sommet de la montagne; et sur le plateau, vous avez une belle promenade et une fontaine qui épanche une eau délicieuse. Là, sous des berceaux de verdure, ceux que les eaux ont guéris vont quelquefois célébrer leur convalescence par des repas champêtres.

Nous suivons le sentier tracé à travers la montagne sur un sol aride et rocailleux, où nos regards sont pourtant égayés par quelques jolies plantes. Nous cueillons la trolle d'Europe, élevant sa tête globuleuse, où rayonne l'or le plus pur; à ses pieds rampe la violette des Pyrénées, fleur charmante que la nature a semée aux bords du chemin et jusqu'au milieu des rochers, pour embellir ce triste passage. Ici on coupe, là on fane les regains dont la senteur m'enivre. A gauche, sur les flancs des montagnes, apparaissent des granges, quelques champs cultivés, et des lambeaux de prairies où les troupeaux semblent suspendus. Nous rencontrons à chaque instant des paysannes, la tête couverte d'unc sorte de cape, qui portent à Barèges du lait tout fumant. Mais bientôt plus de granges, plus de troupeaux, plus de végétation, plus de culture; on voit seulement de loin en loin quelques chétives cabanes de bergers. Une vaste solitude plane sur ces hauteurs où tout est froid et immobile. Le silence qui y règne n'est troublé que par l'écho des torrens; c'est une région désolée, un 
véritable désert. Lorsqu'on est parvenu au sommet de la montagne, la vue s'égare sur une immense perspective, surtout si on la reporte sur les lieux qu'on vient de quitter. Barèges est comme perdu dans la profondeur des ravins, et áu milieu des masses de rochers qui l'entourent; mais aux confins de l'horizon s'élèvent plusieurs pics, dont la crête, couverte de neiges éternelles, semble se confondre avec l'azur des cieux.

On descend par une pente rapide, sillonnée d'excavations, où le torrent mugit pour annoncer les cascades de Tramesaigues. Là je contemple le fameux pic du Midi avec son cône gigantesque; ici une forêt de sapins étale sa sombre verdure; partout des ruisseaux, des torrens, des cascades s'échappent du flanc des montagnes pour alimenter et grossir le Gave. Voici l'hellébore à fleurs vertes, poison violent; le houx frelon avec son feuillage luisant et rustique; la digitale pourprée qui ouvre tardivement ses longs tubes pour récréer ces lieux déserts; le rhododendron ferrugineux, privé de ses belles fleurs de carmin, mais tapissant les rochers et les bords du Gave de ses rosettes toujours verdoyantes.

Quelques huttes se montrent çà et là. Des hommes simples, courbés vers la terre, déchirent son sein pour lui confier plus tard les semences qui doivent les nourrir. Au milieu d'un si pénible labeur, leur pain n'est jamais trempé de larmes; leur âme ne connaît ni crainte, ni chagrin, ni remords. Leur visage, brûlé par le soleil, porte l'empreinte d'une vertueuse résignation; et puis, une modeste croix, plantée sur un petit tertre, les encourage, les fortifie, leur pro- 
met une meilleure destinée. Il faut être bien cruel pour tenter d'arracher de ces cœurs naïfs des croyances qui répandent sur toute leur vie un charme si doux.

Peu à peu le paysage prend un aspect plus riant; nous touchons aux belles prairies de Gripp, à ses ombrages frais. $\mathrm{O}$ la charmante station après avoir parcouru des sentiers si âpres, des lieux si sauvages! Une femme alerte et empressée nous offre en souriant des truites qu'on vient de pêcher dans le Gave, du beurre frais, et du lait qui exhale le parfum des pâturages. Après quelques instans de repos, nous voilà sur la route qui mène à Sainte-Marie. Ici commence la vallée de Campan. Que de grâce, que de fraîcheur! Quelles eaux, quelle végétation, quel enchantement! De toutes parts coulent des ruisseaux si purs, si limpides, qu'on est tenté à chaque instant de se pencher pour se rafrầchir la bouche de leur onde cristalline.

Plus on avance vers Bagnères, et plus la physionomie du paysage devient riante et poétique. Comme on aime à contempler ce beau ciel, ces frais pâturages, ces charmans bosquets, ces jardins, ces chaumières, ces contours si moelleux des collines qui s'élèvent sur la rive gauche de l'Adour! Et ces troupeaux qui paissent I'herbe fleurie, et ces femmes qui vous apportent des jattes d'un lait écumant, et ces enfans qui vous offrent à chaque pas de petits cailloux taillés à facettes, qu'ils vendent quelquefois chèrement à quelque naîf étranger! "Monsieur! monsieur! voici des minéraux; voyez comme ils sont jolis. Mais venez plutôt voir la grotte, elle est bien curieuse: je vais vous y conduire, si vous le voulez; en quelque minutes nous y 
sommes. " Comment ne pas se laisser séduire par de petits enfans dont l'allure est si sémillante, le parler si doux!

Différent des autres gaves dont le cours est si retentissant, si rapide, l'Adour promène paisiblement ses ondes diaphanes dans un lit bordé des plus beaux arbres; et, comme pour donner plus de prix à cet admirable paysage, la nature a posé sur la rive droite le pic de Lhyéris, avec ses formes arides et ses teintes sombres.

A l'entrée de Bagnères, une avenue, plantée de peupliers, de tilleuls et de frênes, vous conduit aux bains de Salut. Oh! que ce doux nom fait de bien à l'âme! comme il fait vibrer un cœur souffrant! Il faut à l'homme, être si faible, si mobile, quelque chose de prestigieux qui lui donne de l'espoir, qui lui inspire de la confiance. Ici vous avez des promenades pittoresques, des sites ravissans, des ombrages voluptueux, de nombreux ruisseaux qui murmurent; vous croyez errer dans les sentiers fleuris de l'Élysée. En visitant les bains de Salut, nous avons rencontré une femme encore jeune, mais amaigrie, triste et décolorée ; une belle fille, au teint de rose, lui donnait le bras, et la promenait doucement dans un lieu solitaire. On eût dit une de ces ombres malheureuses que Virgile nous peint sur les rives du Styx, dans le Champ des Pleurs, Lugentes Campi. Aurions-nous deviné la cause de son mal? $\mathrm{Ah}$ ! puisse-t-elle retrouver la paix du coewr dans les Pyrénées! 


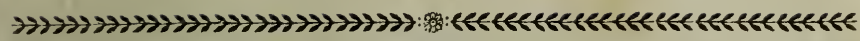

\section{RHODORACÉES. RHODORACEAE.}

Rhodoracece. Vent. - Ericece. Juss.

\section{RHODODENDRON. RHODODENDRON.}

Calice à cinq divisions profondes. Corolle en entonnoir, divisée en cinq lobes ouverts. Dix étamines insérées à la base de la corolle; filamens inclinés. Capsule à cinq loges.

\section{RHODODENDRON FERRUGINEUX.}

\section{RHODODENDRON FERRUGINEUM.}

Rhododendron ferrugineum. Linn. Spec. 562. DC. FI. FI. 2796. LA Peyr. Hist. Plant. Pyr. 1. 220. J AcQ. Fl. Austr. t. 255 .

\section{(Planche 6r.)}

Haute de deux à trois pieds, sa tige ligneuse se divise en rameaux un peu tortus, garnis, dans leur partie supérieure, de feuilles ovales, lancéolées, lisses, d'un vert brillant à leur face supérieure, teintes en dessous d'une couleur de rouille, un peu roulées en leurs bords et soutenues par de courts pétioles. Les fleurs sont purpurines ou rougeâtres, disposées en bouquets à l'extrémité des rameaux. La corolle est en entonnoir, un peu courbée, tachée vers la base de points ferrugineux. 
Ce rhododendron aime les lieux secs et découverts : on le trouve dans les Pyrénées et sur toute la chaîne des Alpes; il couvre la crête des montagnes de la grande Chartreuse en Dauphiné. Je l'ai observé à la descente du col de Tourmalet, sur les deux rives du Gave; il y est si abondant et si vivace que le sol est comme recouvert d'un tapis de verdure. Je l'ai également cueilli dans les Pyrénées orientales, au pied du Canigou. On le cultive dans les jardins sous le nom de laurier-rose des Alpes.

Tous les végétaux du genre rhododendron sont vénéneux. Les fleurs de celui-ci exhalent une odeur vireuse; les feuilles, d'une saveur amère et très-âcre, sont funestes aux bestiaux. Ainsi que les poisons narcotiques âcres, toute la plante produit la stupeur, des tremblemens, des vertiges, des douleurs d'entrailles, etc.

On a cependant essayé cet arbuste dans les dartres et les affections arthritiques rebelles; mais ancune observation exacte ne nous apprend si cet essai a été heureux. On donneles fleurs et les feuilles en infusion ou en décoction, à la dose d'un ou deux gros pour une livre de véhicule. Nous ne conseillons à aucun goutteux d'en faire usage. 


\section{RIIODOIENDRON PONTIQUE. RHODODENDRON PONTICUM.}

Rhododendron Ponticum. WILd. Spec. 2. 606. JACQ. Ic. Plant. rar. t. 78.

(Planche 62.)

Cet arbrisseau, plus élevé que le précédent, se fait remarquer dans nos bosquets par la couleur brillante de ses fleurs. Ses rameaux sont droits, cylindriques, un peu rougeâtres, ornés de feuilles longues de cinq à six pouces, lancéolées, rétrécies à leur base, persistantes, d'un beau vert en dessus, plus pâles en dessous, soutenues par des pétioles courts et épais. Ses fleurs, d'une couleur purpurine ou d'un violet tendre, forment une belle grappe au sommet des rameaux. La corolle est grande, campanulée, divisée à son limbe en cinq découpures profondes. Cette belle espèce a plusieurs variétés qu'on cultive en Europe, et qu'on voit maintenant dans presque tous nos jardins; elle croît en Asie, sur les côtes de la mer Noire et aux environs de Trébisonde.

D'après Tournefort ( $V$ oyage au Levant), les fleurs de cet arbrisseau sont malfaisantes; le miel puisé par les abeilles, sur ces fleurs, donne des vertiges et des nausées. Dioscoride dit aussi qu'autour d'Héraclée, dans le royaume de Pont, le miel, en certains temps de l'année, rend insensés ceux qui en font usage; ce qu'il faut attribuer aux fleurs sur lesquelles les abeilles le récoltent. Suivant Pline, il est des années où le miel 
est également vénéneux dans le même pays : "Ceux qui en ont mangé se couchent à terre, cherchent le frais, ont des sueurs abondantes. Qui edêre, abjiciunt se humi, refrigerationem qucerentes : nam et sudore diffluunt. " C'est sans doute ce miel malfaisant qui jeta la consternation dans l'armée des Grecs lorsqu'elle vint camper aux environs de Trébisonde. Xénophon raconte que les soldats qui en mangèrent une grande quantité eurent de violentes évacuations suivies de délire. Les moins malades ressemblaient à des gens ivres; les autres étaient furieux ou moribonds. On voyait la terre jonchée de corps comme après une défaite. Personne néanmoins n'en mourut, et les accidens cessèrent le lendemain.

Quelques naturalistes pensent que les abeilles avaient puisé ce miel sur l'azalée pontique (azalea pontica, Lıv.), plante narcotique et vénéneuse qui croît aussi aux environs de Trébisonde, et appartient à la même famille.M. Lemaire-Lisancourt observe fort bien, dans le Journal de Botanique de M. Desvaux, que les abeilles ne changent presque pas la nature du nectar qu'elles puisent dans les fleurs. Ainsi le miel peut devenir purgatif, astringent, vénéneux , etc., suivant les plantes sur lesquelles il a été recueilli par ces insectes. Les miels de l'ancienne Colchide, pays fertile en végétaux nuisibles, sont bien différens du miel du mont Hymette, où croissent abondamment la sauge, le thym, le serpolet et autres plantes aromatiques. De même le miel qui vient de l'ouest et du nord n'est point comparable à celui du Gâtinais et du midi de la France. 


\section{RHODODENDRON A FLEURS JAUNES.}

\section{RHODODENDRON CHRYSANTHUM.}

Rhododendron chrysanthum. Linn. Suppl. 237. GMeL. Sibér. 4. 121. t. 54.

(Planche 63.)

Cette plante croît sur les hautes montagnes de la Sibérie. Ses tiges se divisent en rameaux nombreux, glabres, de couleur brune, garnis de feuilles alternes ovales, ridées, vertes en dessus, roussâtres en dessous, entières et un peu roulées en leurs bords, marquées de nervures réticulées. On remarque, dans toute la longueur des rameaux, des stipules en forme d'écailles, d'une couleur de rouille. Les fleurs sont grandes, d'un beau jaune, disposées en corymbes terminaux. La corolle est campanulée, presque en roue. Les capsules sont ovales, inclinées sur leur pédoncule.

Les feuilles de cet arbuste manifestent une saveur âcre mêlée d'amertume. A forte dose, elles agissent à la manière des drastiques, causent des tremblemens, des vertiges, une anxiété douloureuse, une chaleur brûlante dans l'œsophage, des tranchées, et l'inflammation du canal alimentaire. D'après Pallas, la décoction concentrée des rameaux et des feuilles excite la fièvre, une soif ardente, et une sorte d'ivresse suivie de la perte des sens. Les Cosaques font cependant usage de cet arbrisseau dans toutes sortes de rhumatismes et dans les douleurs de membres chroniques. Après quelques doses de ce remède, et quelquefois 
même après la première, les parties affectées se trouvent en un meilleur état. (Voyages dans plusieurs provinces de l'empire de Russic.)

Le docteur Metternich a fait usage du rhododendron chrysanthum en poudre contre les affections goutteuses opiniâtres, depuis dix jusqu'à quarante grains par jour, en trois ou quatre prises, se réglant d'après la constitution et la sensibilité du malade, et augmentant graduellement les doses. Cette poudre doit être continuée pendant plusieurs semaines, et quelquefois plus long-temps, pour obtenir l'effet désiré. Elle agit puissamment sur la masse des fluides, et donne une odeur toute particulière à la sueur. Le même médecin l'a également employée, avec un heureux succès, dans quelques cas de douleurs rhumatismales, avec fièvre et gonflement des pieds et des mains. Weismantel a guéri avec le rhododendron une paralysie presque universelle survenue à la suite d'une affection goutteuse.

Infusion de rhododendron chrysanthum. Prenez, feuilles desséchées, et récoltées lorsque l'arbuste est en pleine floraison, depuis deux gros jusqu'à demionce; faites infuser dans douze onces d'eau bouillante pendant vingt-quatre heures. Ce reméde excite des sueurs abondantes; on en donne deux ou trois demitasses par jour, dans les maladies goutteuses et rhumatismales revêtues d'un caractère chronique. On peut employer de la même manière la décoction des tiges et des feuilles. 


\section{RHODODENDRON A GRANDES FLEURS.}

\section{RHODODENDRON MAXIMUM.}

Rododendron maximum. Wild. Spec. 2. 606. Kern. Hort. v. 16 . t. 190 .

Ce bel arbrisseau, originaire du Canada et de la Virginie, s'élève à cinq ou six pieds de hauteur. Ses rameaux sont garnis de feuilles pétiolées, coriaces, ovales, aiguës à leur sommet, d'un vert foncé et luisant en dessus, roussâtres en dessous, un peu roulées à leurs bords. Les fleurs sont grandes, rouges, disposées en corymbes à l'extrémité des rameaux.

On le cultive dans les jardins, où il se reproduit sous deux variétés : l'une à fleurs blanches, l'autre à fleurs d'un rose tendre. Toutes ses parties exhalent une odeur forte et vireuse. Suivant Coxe, on l'emploie, aux États-Unis, dans les rhumatismes chroniques.

Pallas a décrit et figuré dans la Flore de Russie quelques autres espèces non moins remarquables, entre autres: le rhododendron de Daourie (rhododendron Dauricum), arbrisseau à fleurs terminales, grandes, violettes ou d'un rose pourpré; le rhododendron du Kamtschatka (rhododendron Camtschaticum), à fleurs campanulées, presque en roue, d'une belle couleur de rose. Le rhododendron du Caucase (rhododendron Caucasicum), à feuilles tomenteuses en dessous, à corolles blanches ou rougeâtres.

Ces arbrisseaux, introduits maintenant dans les jardins des curieux, jouissent de propriétés très-énergiques. 


\section{KALMIA. KALMIA.}

Calice à cinq divisions. Corolle en soucoupe, creusée intérieurement de dix fossettes. Dix étamines insérées à la base de la corolle. Un style. Capsule polysperme à cinq valves, à cinq loges.

\section{KALMIA A LARGES FEUILLES. KALMIA}

\section{LATIFOLIA.}

Kalmia latifolia. Linn. Spec. 560. Trew. Plant. Sel. t. 38 . f. 1 .

C'est un charmant arbrisseau de cinq à sept pieds, formant un buisson très-rameux et toujours vert. Ses feuilles sont nombreuses, coriaces, ovales, elliptiques, d'un vert foncé. Ses fleurs, d'un rouge brillant, sont disposées en manière de corymbe au sommet des rameaux. Elles s'épanouissent en juin et pendant une grande partie de l'été.

Cette espèce, qu'on cultive en pleine terre dans notre climat, nous vient de l'Amérique septentrionale. Ses feuilles sont vénéneuses, surtout pour les animaux domestiques, les chevaux, les bœufs, les moutons, etc. On a cependant remarqué que les cerfs s'en nourrissaient.

Le Kalmia à feuilles étroites (kalmia angustifolia) a des feuilles petites, ternées; des fleurs d'un rouge vif, disposées en corymbe axillaire. Il est également vénéneux.

Toutes les espèces appartenant au genre Rhododendron et au genre Kalmia, ont des propriétés délétères; il est d'autant plus essentiel de les signaler, qu'elles 
sont admises dans nos jardins comme plantes d'ornement. Elles causent la céphalalgie, l'ivresse, le délire, des vertiges, des vomissemens, des superpurgations, etc. La matière médicale s'est déjà enrichie de quelques espèces; mais, en attendant qu'un plus grand nombre de faits nous ait éclairés sur leur action thérapeutique, il convient de les essayer avec prudence. Les accidens qu'ils font naitre réclament les mêmes moyens que les poisons narcotiques âcres; savoir, les vomitifs, employés dans les premiers momens, ensuite les boissons mucilagineuses et sédatives.

\section{LÉDUM. LEDUM.}

Calice très-petit, à cinq dents. Corolle divisée jusqu'à la base en cinq pétales. Cinq à dix étamines, insérées à la base du calice. Capsule surmontée du style, à cinq loges, à cinq valves, s'ouvrant de bas en haut. Cinq placenta filiformes adhérant au sommet de l'axe central, et penchés chacun dans une loge.

\section{LÉDUM DES MARAIS. LEDUM PALUSTRE.}

Ledum palustre. Linn. Spec. 561. DG. Fl. Fr. 2795. Fl. Dan. t. 1031.

Sa tige, peu élevée, se divise en rameaux flexibles, velus, d'une couleur roussâtre. Ses feuilles sont alternes, persistantes, presque sessiles, étroites, lancéolées, roulées sur leurs bords, vertes à leur face supérieure, chargées en dessous de poils entrelacés, de couleur de rouille. Les fleurs sont pédonculées, d'un blanc pur, disposées en ombelles sessiles. Ce petit arbrisseau croît dans les lieux ombragés et marécageux 
de l'Europe septentrionale; il est quelquefois désigné sous le nom de romarin sauvage.

Le lédum des marais, dans sa pleine floraison, répand au loin une odeur forte, pénétrante; lorsqu'on la respire pendant quelque temps, la tête devient pesante, vertigineuse. Ses feuilles sont amères, un peu nauséabondes et narcotiques; elles fournissent un extrait aqueux , d'abord douceâtre, ensuite amer, styptique; un extrait résineux d'une grande amertume, et une huile empyreumatique d'une odeur extrêmement fétide. Prises à haute dose, ces feuilles peuvent susciter des phénomènes graves, des vertiges, des tremblemens, une violente céphalalgie. Dans quelques parties du Nord, on les fait entrer dans la fabrication de la bière; mais alors cette boisson acquiert une qualité malfaisante. On frotte aussi les troupeaux avec une forte décoction ıles mêmes feuilles pour faire périr la vermine.

Cet arbuste, admis dans la pharmacopée de Russie et dans celle de Suède, n'est point usité en France; il est pourtant doué de propriétés actives, et s'il fallait s'en rapporter aux éloges qu'il a reçus dans une thèse soutenue par Westring, sous la présidence de Linné, il nous offrirait un remède spécifique contre la toux convulsive et les maladies cutanées les plus réfractaires. Hartman et Wahlin, après l'emploi d'un vomitif, prescrivent l'infusion des feuilles, coupée avec du lait, contre la coqueluche. Odhélius a aussi publié, dans les mémoires de l'académie de Stockholm, plusieurs observations qui constatent les succès de ce remède dans plusieurs cas de lèpre. D'autres médecins ont eu à s'en louer dans le traitement des dartres, des affections sy- 
philitiques rebelles au mercure, des rhumatismes invétérés.

Infusion de romarin sauvage ou lédum des marais. Prenez, feuilles et sommités des jeunes rameaux, demi-once; eau bouillante, une livre : laissez infuser pendant une heure dans un vase clos. La dose, pour les adultes, est d'une à trois onces, qu'on répète deux ou trois fois dans le jour. On en donne une cuillerée à bouche aux enfans affectés de toux convulsive. D'après Berger, ce remède, continué pendant quelque temps, a produit des effets salutaires dans la lèpre. On emploie aussi extérieurement la décoction aqueuse, avec laquelle on fait des lotions sur les parties malades.

La famille des bruyères, confondue par quelques botanistes avec celle des rhodoracées, renferme aussi quelques plantes âcres et narcotiques.

\section{ANDROMÈDE. ANDROMEDA.}

Calice très-petit, à cinq divisions. Corolle en grelot ou en tube, à cinq lobes. Dix étamines; anthères s'ouvrant par le sommet; filets attachés à la base de la corolle. Un style. Capsule polysperme, à cinq valves et à cinq loges.

\section{ANDROMĖDE DE VIRGINIE. ANDROMEDA} MARIANA.

Andromeda Mariana. Desf. Arbr. 1. 256. Duнам. Ed. Nov. t. $3 \%$.

C'est un joli arbrisseau qui s'élève en buisson de deux à quatre pieds. Ses feuilles sont tantôt ovales, tantôt plus allongées, d'un vert luisant en dessus, 
ponctuées et veinées en dessous, et soutenues par des pétioles courts. Les fleurs sont campanulées, grandes, d'une couleur blanchâtre, et disposées en grappes latérales.

Cette plante nous vient du Maryland et de la Virginie; on la cultive à l'ombre dans les jardins. La décoction des feuilles est stimulante et très-âcre; on l'emploie en topique contre la teigne faveuse et les dartres.

On a proposé les feuilles du Gaulthéria du Canada (Gaultheria procumbens) comme succédanées du thé; elles sont âcres, narcotiques, et n'ont aucune des qualités qui distinguent le thé de la Chine. 


\section{LOBÉLIACÉES. LOBELIACE AE.}

Lobeliacea. Juss._Campanulacece. DEsf.

\section{LOBÉLIE. LOBELIA.}

Calice à cinq dents. Corolle irrégulière ; tube plus long que le calice, fendu longitudinalement en dessus; limbe à deux lèvres, à cinq lobes. Cinq étamines à anthères réunies en tube. Stigmate ordinairement simple. Capsule ovoïde à deux ou trois loges, s'ouvrant par le sommet.

\section{LOBÉLIE BRULANTE. LOBELIA URENS.}

Lobelia urens. Linn. Spec. 1321. DC. Fl. Fr. 2870. Engl. Bot. 953.

(Planche 64.)

Cette plante a une tige droite, simple, quelquefois un peu rameuse, haute d'environ un pied et demi. Ses feuilles radicales sont ovoïdes, en forme de spatule; celles de la tige, lancéolées, sessiles, un peu écartées les unes des autres. Toutes sont glabres, légèrement dentées, et d'un joli vert. Ses fleurs, attachées à de courts pédoncules, et disposées en grappe terminale, ont une corolle d'un bleu tendre, comme labiée, avec deux taches blanchâtres à son orifice. On trouve cette lobélie dans les bois, dans les landes, dans les terrains 
marécageux; elle croît dans plusieurs départemens de la France, aux environs de Paris, de Fontainebleau, de Nantes, etc.

Ainsi que les euphorbes, elle contient un suc laiteux d'une âcreté extrême. Toutes ses parties, et particulièrement la racine, irritent et enflamment les voies alimentaires. L'infusion des tiges et des feuilles produit une espèce de choléra-morbus accompagné d'une anxiété douloureuse et de convulsions. On combat ces accidens par des boissons mucilagineuses, le lait pris en abondance, des lavemens émolliens et l'opium. Malgré l'opinion du docteur Bodard, nous pensons que cette plante est peu propre à remplacer l'espèce suivante:

\section{LOBELIE SYPHILITIQUE, LOBELIA} SYPHILITICA.

Lobelia syphilitica. Lins. Amen. Acad. 4. 527. JAcQ.

Ic. Plant. rar. t. 597.

(Planche 65.)

Cultivée dans quelques jardins, la lobélie syphilitique se fait remarquer par l'élégance de son port et par les jolies fleurs dont elle est couverte. Sa tige simple, anguleuse, chargée de poils, s'élève à la hauteur d'environ deux pieds. Sesfeuilles sont alternes, ovales, lancéolées, sessiles, vertes, un peu rudes et légèrement dentées. Les fleurs sont axillaires, solitaires, d'un bleu transparent, et portées sur des pédoncules très-courts. La corolle est velue en dehors; sa lèvre 
inférieure offre un palais à deux gibbosités. Cette espèce croît sur les bords des rivières, et dans les bois de l'Amérique septentrionale.

La lobélie syphilitique est beaucoup moins âcre que l'espèce précédente; cependant sa décoction, prise à haute dose, produit des évacuations douloureuses et peut enflammer les organes gastriques.

D'après Kalm et Bartram, elle est employée dans l'Amérique septentrionale comme un puissant remède contre la syphilis. On fait bouillir une poignée de la racine sèche dans douze livres d'eau, jusqu'à réduction d'un tiers, et l'on prend chaque jour deux ou trois verres de cette décoction. On augmente ensuite progressivement les doses; et, lorsque le remède excite une trop forte purgation, on le suspend pendant deux ou trois jours; on prend en même temps des bains chauds, et l'on s'impose un régime sévère. On dit que la lobélie syphilitique est aussi eflicace dans ce pays que le mercure l'est en Europe; ce dont il est permis de douter. Cependant, lorsque la maladie vénérienne est rebelle aux préparations mercurielles, il est possible que cette plante produise de bons effets.

\section{LOBÉLIE A LONGUES FLEURS. LOBELIA LONGIFLORA.}

Lobelia longiflora. Lins. J⿳亠口冋Q. Hort. Vind. t. $2 \%$.

Sa tige est rameuse, herbacée, hérissée de poils courts, haute d'environ un pied. Ses feuilles sont lancéolées, irrégulièrement dentées, molles, un peu velues en dessous. Les fleurs sont axillaires, attachées à des 
pédoncules courts et pubescens; la corolle est blanche, à tube filiforme, long de trois à quatre pouces, et à limbe ouvert en étoile, presque régulier.

Cette espèce croît à la Jamaïque, à Saint-Domingue, etc. , surles bords des ruisseaux ; on la cultive au Jardin du Roi. C'est un poison des plus caustiques et des plus subtils. Ses émanations sont tellement délétères, suivant Jacquin, qu'on est saisi d'une extrême oppression de poitrine lorsqu'on les respire pendant quelques instans. Introduite dans l'estomac, cette plante produit des vomissemens affreux que rien ne peut apaiser. Après la mort, on trouve les intestins enflammés et gangrenés.

Le père Feuillée nous apprend que la lobélie du Chili (Lobelia Tupa) n'est pas moins pernicieuse. Le lait qui s'écoule de la racine et des tiges est un poison mortel, et l'odeur des fleurs excite de violens vomissemens.

Tous les végétaux de cette tribu sont remplis d'un suc laiteux plus ou moins âcre. Nous n'en exceptons pas même la lobélie cardinale (Lobelia cardinalis), espèce originaire de la Virginie, qui se fait remarquer dans nos jardins par ses grappes de fleurs d'un pourpre éclatant. On dit néanmoins que sa racine sert de vermifuge aux sauvages de l'Amérique septentrionale.

D'après Cutler et John Andrew, le Lobelia inflata, espèce également indigène de l'Amérique septentrionale, a une vertu antispasmodique. Le premier de ces médecins dit avoir été guéri d'un asthme à l'aide de cette plante dont les propriétés résident dans un principe âcre et volatil. 
M. Bidault a employé les feuilles desséchées et pulvérisées, à la dose de dix à vingt grains, pour exciter le vomissement. Les semences sont douées de la même propriété. Mais, d'après l'observation de Coxe, cette même poudre, administrée à la dose d'une cuillerée à café par un charlatan, a produit des symptômes fầcheux.

M. S. Colboun, professeur de matière médicale au collége Jefferson, à Philadelphie, a obtenu de cette plante un principe âcre exerçant sur la gorge une action irritante qui persiste pendant un certain temps et qui exige des ablutions fréquentes. Ce principe, qu'il désigne sous le nom de Lobéline, se dissout parfaitement dans l'alcohol.

La lobélie brûlante, qui croît dans nos départemens, contient probablement des principes analogues. Mais ne nous pressons pas trop d'introduire toutes ces plantes âcres dans la matière médicale; nous avons des vomitifs plus doux et des antispasmodiques moins suspects. 


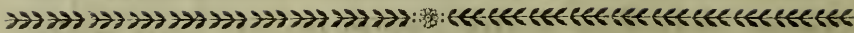

\section{COMPOSÉES. COMPOSITAE.}

Compositce. Adans. Linn. DG. - Synantherece. Cass. - Cichoracece, cynarocephala et corymbiferce. Juss.

Fanille nombreuse, excellente, où les vertus sont héréditaires. Elle est formée de plusieurs tribus, toutes riches en plantes curieuses, utiles et salubres; a peine si l'on peut y compter une ou deux espèces d'une qualité suspecte. Que notre monde n'est-il ainsi composé? A leur tête apparaissent les artémises, d'une vive amertume; les camomilles, ornement de la pelouse et du parterre, avec leurs essences éthérées; les matricaires, d'un arome puissant ; les laitues rafraichissantes , qui apaisent les irritations mondaines, calment la colère de l'homme bilieux; les chicorées, qui réveillent l'appétit blasé du gourmand, dissipent les sombres vapeurs de l'hypochondre.

Viennent ensuite la centaurée étoilée, végétal revêche, habitant les terrains arides, incultes, et dont les houpes de pourpre nous font oublier un instant les calices épineux; la centaurée bénite, plante si recherchée de nos pères, dont les vertus merveilleuses sont inscrites dans nos vieux livres; le chardon laineux, véritable géant au milieu des faibles herbes qui bor- 
dent les champs, tout velu, tout hérissé d'épines, et prêt à se défendre contre les atlaques du sobre quadrupède qui en fait ses délices. J'aime l'attitude imposante, la beauté mâle et austère de ce végétal que le passant méprise; j'aime ses grandes feuilles onduleuses, en forme de lyre, ses fleurs sphériques, teintes d'un pourpre foncé. Et cette jolie vergerette du Canada, qui a déserté, il y a plusieurs siècles, sa patrie, a traversé les mers, portée sur l'aile des vents, pour venir en Europe, où elle a laissé partout de nombreux rejetons.

Que vois-je sur le penchant rocailleux du coteau? N'est-ce pas la belle carline étalant ses fleurs rayonnantes d'or et de carmin? C'est ainsi qu'elle s'épanouit par un beau jour; mais que les vents se déchaînent, que le ciel devienne nuageux, aussitôt elle se contracte, elle se resserre; on dirait qu'elle a peur de la pluie ou de l'orage. Mystérieux et charmant baromètre!

Le diligent pissenlit se réveille et s'ouvre à cinq heures du matin, à huit heures du soir il s'endort et ferme sa fleur. Le salsifis des prés, plus matinal encore, s'épanouit à quatre heures, à dix il est endormi. Le souci des champs, plus paresseux, s'ouvre beaucoup plus tard, mais il veille jusqu'à dix heures du soir ( $\mathrm{t}$ ).

Je vois avec plaisir cette horloge vivante :

Ce n'est plus ce contour où l'aiguille mouvante

Chemine tristement le long d'un triste mur;

C'est un cadran semé d'or, de pourpre et d'azur,

(1) C'est d'après l'observation attentive et souvent renouvelée de ces plantes, que l'immortel Linné avait établi son horloge de Flore. En effet, plusieurs espèces de léontodon, la laitue, les laitrons, la piloselle, le salsifis, le souci des champs, celui 
Où d'un air plus riant, en robe diaprée, Les filles du printemps mesurant la durée, Ou nous marquant les jours, les heures, les instans, Dans un cercle de fleurs ont enchaîné le temps.

DewLu, Les Trois Règnes.

\section{§I. CHICORACÉES. CHICORACEAE.}

\section{LAITUE. $\quad L A C T U C A$.}

Involucre oblong, imbriqué, à plusieurs folioles inégales, pointues, membraneuses sur les bords. Réceptacle ponctué, glabre. Aigrette soyeuse, pédiculée.

\section{LAITUE VIREUSE. LACTUCA VIROSA.}

Lactuca virosa. Linn. Spec. 1119. DC. Fl. Fr. 2888.

(Planche 65.)

Sa tige est droite, rameuse, feuillée, blanchâtre, hérissée de petites épines, haute de trois ou quatre pieds. Ses feuilles sont alternes, éparses, oblongues, amplexicaules à leur base, un peu spatulées, glabres, d'un vert glauque, inégalement dentées, épineuses sur leurs bords, ainsi que sur leur côte postérieure. Ses

d'Afrique, etc., s'ouvrent et se ferment à des heures réglées. Cette dernière plante est même météorique, et peut servir de baromètre. Elle s'ouvre constamment à sept heures du matin , et reste ouverte jusqu'à quatre, si le temps doit être sec; il faut au contraire s'attendre à la pluie, si sa fleur ne s'épanouit point, ou si €lle se ferme avant son heure accoutumée.

La plupart des graines de la famille des composées sont couronnées d'une aigrette soyeuse et volatile qui les transporte quelquefois à de grandes distarices. On peut expliquer ainsi les voyages. et les migrations de quelques-unes de ces plantes. 
fleurs sont d'une couleur jaunâtre, visqueuses, disposées en grappes menues, peu garnies à l'extrémité des tiges et des rameaux. On rencontre cette plante dans les lieux incultes et sauvages, dans les haies, sur le bord des chemins, etc.

Toutes ses parties sont remplies d'un suc lactescent, visqueux, âcre, amer, d'une odeur nauséabonde. Un gros de ce suc occasiona au savant botaniste Gilibert des étourdissemens, des nausées, des anxiétés, avec cardialgie. La nuit fut troublée par des rêves effrayans et un fréquent réveil en sursaut. Les expériences tentées sur les animaux avec l'extrait de la plante prouvent qu'il agit sur le système nerveux à la manière des narcotiques : il a quelques rapports avec l'opium, mais on ne saurait comparer les vertus de ces deux substances.

Cependant cet extrait, préparé avec le suc de la plante fraîche, a mérité des éloges dans quelques affections pectorales d'un caractère nerveux. Suivant le docteur Schlesinger, de Francfort-sur-l'Oder, c'est un remède pour ainsi dire spécifique contre l'angine et le spasme de la poitrine ; il le donne, mêlé avec du sucre, à la dose de deux grains, ou dissous dans une eau distillée; cette dose doit être répétée plusieurs fois dans la journée. Collin l'avait déjà prescrit à très-haute dose, et avec un grand succès, contre les hydropisies avec engorgement des viscères abdominaux. Stoll le recommande aussi dans les mêmes affections; mais Quarin se plaint de son peu d'efficacité.

J'ai moi-même faitl'essai del'extrait de laitue vireuse dans les irritations de poitrine, dans les attaques 
d'asthme, dans certains cas de phthisie, de catarrhe chronique du poumon, et je lui ai véritablement reconnu une action sédative; mais j’ai été souvent obligé de l'abandonner pour recourir à l'opium ou à l'extrait des solanées, dont les propriétés m'ont toujours paru plus constantes.

La meilleure manière de préparer cet extrait consiste à rapprocher au bain-marie le suc qui distille des blessures faites à la plante. Celui qu'on obtient par la décoction est beaucoup plus faible. La dose est de deux grains, qu'on répète toutes les deux heures. Schlesinger le donne sous la forme de poudre, en y mêlant un demi-grain de digitale pourprée, cinqgrains de sucre blanc, et dix grains de gomme arabique. Il fait également dissoudre huit grains du même extrait dans un gros d'eau de cannelle vineuse, dont il donne quinze ou vingt gouttes de deux en deux heures. Un malade qui avait déjà le râle, fut sauvé en prenant chaque demiheure quinze gouttes de la composition suivante.

Teinture de laitue vireuse. Prenez, feuilles de laitue vireuse, une once; macis, un gros; esprit de vin, eau distillée, de chaque quatre onces : faites digérer pendant quelques jours, et filtrez avec expression.

A l'aide de ces préparations, il a combattu efficacement l'asthme convulsif, et dissipé d'une manière durable les suffocations périodiques très-rapprochées. 
LAITUE SAUVAGE. LACT'UCA SYLVES'TRIS.

Lactuca sylvestris. DC. FI. Fr. 2887. - Lactuca scariola. Linn. Spec. 1119.

Cette espèce, très-voisine de la laitue vireuse, s'élève sur une tige cylindrique, dure, blanchâtre, un peu épineuse à la partie inférieure. Les feuilles sont lisses, embrassantes, verticales, découpées en lobes profonds, d'un vert jaunâtre, garnies d'épines sur les bords ainsi qu'au-dessous de la nervure principale. Les fleurs sont petites, d'un jaune pâle, disposées en panicules allongées.

On la rencontre en été dans les terrains incultes et pierreux, au bord des chemins et des vignes. Elle est vireuse et narcotique comme l'espèce précédente dont elle diffère par ses feuilles sinuées ou pinnatifides. Il ne faut point la confondre avec la plante que les jardiniers nomment scariole; celle-ci est une varićté de la chicorée endive.

La laitue cultivée (lactuca sativa) n'est point dépourvue non plus de propriétés anodines. Son suc, son eau distillée et sa décoction sont légèrement narcotiques. Le docteur Scudamore, dans son Traité de la goutte, vante la vertu soporifique du lactucarium, sorte d'extrait obtenu par l'évaporation à l'air libre du suc de la plante. Il doit au professeur Duncan Senior la connaissance de cette préparation, qu'il recommande comme un doux sédatif, propre à diminuer la toux, à favoriser le sommeil et à soulager la douleur, ayant été témoin de son mode d'action dans un grand nombre de circonstances. 
M. le docteur François, et après lui un grand nombre de praticiens ont répété les expériences de MM.Duncan et Scudamore avec plus ou moins de succès. En général, l'extrait de laitue, désigné aujourd'hui sous le nom de thridace, est une préparation fort utile dans quelques affections nerveuses; mais qu'on se garde bien d'oublier les vertus héroïques de l'opium lorsque des symptômes graves demandent un sédatif promptement efficace.

Une dame très-nerveuse éprouva, six heures après un déjeîner léger, des coliques atroces et des crampes doutloureuses dans les membres inférieurs. Cet état dura jusqu'à neuf heures du soir, malgré l'application des topiques émolliens et de trente sangsues autour de l'ombilic. A six heures il y eut un peu de calme, mais point de sommeil; on administra huit grains de thridace en deux doses. Vers minuit les tranchées et fût contractions spasmodiques reparurent avec la même violence; le pouls était faible et intermittent, la face d'une pâleur effrayante. D'après notre conseil, on administra à une heure du matin quinze gouttes de laudanum liquide de Sydenham dans un peu de sirop de menthe et d'eau de fleur d'orange. La même dose est répétée au bout de vingt minutes, et à deux heures la malade s'endormit dans le calme le plus parfait. Le lendemain matin il ne lui restait qu'un peu de faiblesse et le souvenir de ses souffrances.

On pourrait, au reste, prouver par d'autres faits que la thridace s'est montrée utile là où l'opium et les autres narcotiques avaient aggravé la maladie.

Pour obtenir le principe calmant de la laitue connu 
sous le nom de thridace, il faut récolter la plante dans les premiers momens de la floraison; c'est alors qu'elle jouit de toute sa vigueur. On rejette les feuilles; on pile les tiges et les branches dans un mortier de marbre, et on les soumet à la presse afin d'en extraire le suc. On filtre ensuite ce suc pour le dépouiller de la clorophile, et on le fait évaporer à l'étuve ou au bain-marie, par une chaleur toujours au-dessous de quarante degrés de Réaumur. Aussitôt que l'évaporation est terminée, on retire le résidu, qui s'enlève par écailles ou fragmens bruns, durs, cassans, qu'il faut placer promptement dans des flacons bien bouchés; car la thridace est trèsavide d'humidité, et s'empare rapidement de celle de l'atmosphère: alors elle redevient molle.

On donne la thridace à la dose de deux à trois grains dans un véhicule peu étendu, et mieux encore sous la forme de pilules; mais cette dose pour un adulte est rarement suffisante; il faut la répéter une et deux fois, en mettant une demi-heure d'intervalle entre les doses. Ce médicament est employé comme un doux sédatif dans les insomnies opiniâtres, les spasmes nerveux, l'hypochondrie, les irritations pulmonaires. Il produit néanmoins dans quelques circonstances une sorte de malaise, d'anxiété, et même de stupeur, à la manière des narcotiques. Nous croyons que la préparation des Anglais connue sous le nom de lactucarium est plus active que la thridace; elle est d'ailleurs plus simple et plus facile, puisqu'il suffit de faire évaporer à l'air libre le suc qui découle des incisions qu'on a pratiquées sur la tige de la plante.

La laitue cultivée est peu active au printemps; son II. 
suc est alors composé en grande partie d'eau et de nucilage qu'anime faiblement un léger principe amer; mais vers le mois de juillet, à l'époque de sa floraison, ce même suc se concentre, le mucilage diminue, le principe amer s'exalte, et les propriétés de la plante se rapprochent alors de celles de la laitue sauvage. Voilà pourquoi le suc exprimé de la laitue lorsqu'elle n'est pas encore montée convient beaucoup mieux que l'extrait aux sujets très-irritables qui ont besoin d'être calmés et rafraîchis. On peut le donner avec un grand avantage dans les cas d'hypochondrie et à la suite des gastrites chroniques, à la dose de trois ou quatre onces dans autant de petit-lait. Les bains et un régime végétal secondent à merveille les effets de ce remède , qui doit être pris tous les matins à jeun en deux doses, et continué pendant plusieurs semaines.

On ne saurait croire combien l'usage de cette plante potagère favorise les fonctions intestinales chez les personnes qui ont habituellement les entrailles échauffées. Martial loue avec raison sa vertu lubrifiante :

Prima tibi dabilur ventri lactuca movendo Utilis.

C'est avec le secours de la laitue des jardins et des bains froids que Musa guérit Auguste d'une hypochondrie extrêmement grave. Outre des sommes considérables, l'empereur lui donna le droit de porter l'anneau d'or; et, ce qui devait surtout flatter un homme sensible à la gloire de son art, les médecins furent exemp- tés de tout impôt.

La laitue était fort estimée des anciens; ses propriétés culinaires ont été célébrées par Martial, Horace, 
Virgile, etc. : Grataque nobilium requies lactucaciborum. Elle tempère la chaleur intérieure produite par les alimens de haut goût ou par les mets trop succulens. Lorsque l'estomac la digère bien, elle donne des nuits calmes et répand dans les veines une agréable fraîcheur. Nous la conseillons aux personnes irritables, mélancoliques, ou douées d'un tempérament bilioso-sanguin; aux hommes qui ont perdu le repos et qui éprouvent une sorte d'exaltation maladive causée par des travaux intellectuels, par des entreprises difficiles.

A Rome la laitue fut d'abord servie à la fin du souper; plus tard elle parut au premier service, comme nous l'apprend Martial :

Claudere quac conas lactuca solebat avorum, Dic mihi cur nostras inchoal illa dapes?

"Vous me mettez en dépense pour vous donner à souper, dit Pline le jeune à Septilius Clarus, et vous me manquez. J'avais pourtant préparé à chacun une laitue, trois escargots, deux œufs, un gâteau, du vin miellé et de la neige. Nous avions des olives d'Andalousie, des courges, des échalottes, et mille autres mets aussi délicats. Vous auriez eu à choisir d'un comédien, d'un lutteur ou d'un musicien, ou même, admirez ma profusion, vous les auriez eus tous ensemble. Mais vous avez mieux aimé, chez je ne sais qui, des huîtres, des fressures de porc, des poissons rares et des danses espagnoles. Je saurai vous en punir, je ne vous dis pas comment."

Pline avait heureusement beaucoup d'esprit et des manières attrayantes. Il ne fallait rien moins que cela pour faire oublier ses mauvais soupers. Horace qui était 
tout aussi spirituel, mais surtout bien plus friand, dit que la laitue ne convient point aux buveurs. Mêlée avec le vin elle surnage et s'aigrit dans l'estomac : Lactuca innatat acri post vinum stomacho.

En effet il est des personnes qui la digèrent difficilement, surtout lorsqu'elle est crue. Mais est-il vrai que ce légume affaiblisse la vertu prolifique? On l'a dit anciennement et quelques modernes l'ont répété, sans founir aucun fait à l'appui de cette assertion. Les gens du peuple mangent beaucoup de laitues en salade, c'est même leur principal repas pendant une grande partie de l'été, et cependant on ne voit pas diminuer le nombre de leurs enfans.

\section{CRÉPIS. CREPIS.}

Involucre lâche, sillonné et ventru à la base. Réceptacle nu. Aigrette blanche, sessile.

\section{CRÉPIS RONCINÉ. CREPIS LACERA.}

Crepis lacera. Tenore. Silloge Plant. vasc. 403.

Cette espèce de crépis a une racine épaisse, allongée et jaunâtre; une tige simple, lisse, anguleuse, farineuse à la base. Les feuilles caulinaires sont légèrement velues, les feuilles radicales roncinées, divisées en lobes profonds, presque deux fois pinnatifides. Les fleurs sont blanches, disposées en épi; elles s'épanouissent en été.

On donne à cette plante, assez commune dans les montagnes d'Italie, les noms de cicoriella, lattugaccio selvaggio, angina. Suivant M. Tenore, elle est remplie d'un suc laiteux très-âcre et très-délétère. On a vu 
périr misérablement plusieurs personnes qui avaient fait usage de bouillons où cette herbe avait été mêlée à d'autres chicoracées.

Plusieurs habitans d'un village de la commune d'Arienzo, dans la Terre de Labour, mańgèrent de cette espèce de crépis qu'ils avaient cueillie croyant que c'était de la chicorée sauvage. Le premier qui en ressentit les pernicieux effets était un enfant de trois ans qui mourut en deux jours. Treize autres individus furent pareillement empoisonnés, et, malgré tous les secours de l'art, quatre d'entre eux succombèrent presque en même temps. Lorsque la nouvelle de cet événement affreux se répandit dans le voisinage, les autres malades étaient moribonds. A l'autopsie on trouva une inflammation profonde dans les intestins. (Grors. delle due Sic., maggio 1827.)

Nous avons extrait cette observation del'Enchiridio di Tossicologia de M. le professeur Delle Chiaje.

Ce fait est d'autant plus intéressant sous le rapport de l'hygiène publique, qu'on n'avait signalé jusqu'ici comme vénéneuse aucune plante du groupe des chicoracées, excepté la laitue vireuse ou sauvage. Je ne sais si je me trompe, mais le crépis lacéré de Tenore pourrait bien n'être pas la seule espèce délétère; une autre chicoracée me parait au moins suspecte, si elle n'est pas nuisible, à cause de l'odeur forte d'amande amère qu'elle exhale; c'est le crépis fétide de Linné (barkhausia foetida. DC.). Cette espèce a aussi des feuilles profondément découpées, des fleurs composées de fleurons jaunes, rougeâtres extérieurement.; elle est commune en été au bord des champs. 
§II. CYNAROCÉPHALES.

CYNAROCEPHALE.

\section{CARTHAME. CARTHAMUS.}

Involucre ventru à la base, imbriqué d'écailles épineuses. Fleurons hermaphrodites Réceptacle garni de paillettes. Graines dépourvues d'aigrette.

\section{GARTHAME DES TEINTURIERS. CARTHAMUS} TINCTORIUS.

Carthamus tinctorius. Lins. Spec. 1162. DC. Fl. Fr. 3002. Lam. Illustr. t. 661. f. 3.

Sa tige est droite, cylindrique, blanchâtre, rameuse au sommet, haute d'environ un pied et demi. Les feuilles caulinaires sont éparses, ovales, embrassantes, pointues, veinées, bordées de quelques dents épineuses; les feuilles radicales sont oblongues, rétrécies à la base. Les fleurs sont terminales, solitaires, d'un rouge de safran, toutes flosculeuses et hermaphrodites : les écailles de l'involucre sont foliacées et épineuses; les graines dépourvues d'aigrette.

Cette plante tinctoriale et économique est originaire de l'Orient; on la cultive en France, dans nos départemens méridionaux. Ses graines renferment, outre une substance farineuse, un principe amer, âcre et nauséabond qui est un violent purgatif pour l'homme; mais les perroquets les mangent avec avidité et s'en engraissent sans être purgés, ce qui leur a fait donner le nom de graine de perroquets. 


\section{ONOPORDON. ONOPORDUM.}

Involucre ventru, composé d'écailles oblongues, épineuses. Réceptacle ponctué. Graines comprimées, rugueuses en travers, couronnées d'une aigrette caduque.

\section{ONOPORDON ACANTHE. ONOPORDUM ACANTHIUM.}

Onopordum acanthium. Linn. Spec. 1158. DC. Fl. Fr. 3005. Fl. Dan. t. 909.

Cette plante, haute de trois à quatre pieds, et recouverte d'un duvet cotonneux d'un blanc de neige, se divise en rameaux épineux et étalés, qui se terminent chacun par une grosse fleur purpurine ou blanche. Les feuilles sont grandes, ovales, sinuées, anguleuses, blanchâtres et garnies d'épines : dans une variété, elles sont vertes et tomenteuses. Elle fleurit en juillet, et croît dans les lieux incultes, au bord des chemins, au milieu des décombres. On l'appelle vulgairement pédane, épine blanche, chardon acanthin. Sa calathide est bonneà manger comme celle des artichauts.

Des auteurs graves et dignes de foi attestent la vertu anticancéreuse de cette plante. Stahl a guéri en quatorze jours, avec le suc des feuilles appliqué en topique, un cancer de la face qui avait résisté à bon nombre d'autres remèdes. Borel a guéri également un cancer des narines; Timmerman un ulcère de même nature, qui avait déja rongé une partie du visage. Goelick a employé ce topique avec un égal succès, chez une femme qui avait un carcinome à la partie latérale gauche du 
cou, et chez un homme affecté de la même maladie a la lèvre supérieure. D'après Eller, deux femmes ont été également guéries d'un ulcère cancroïde de la face. Vater et Mohring citent des faits semblables.

Ces détails sont connus : ils ont été consignés dans divers recueils, et Murray les a reproduits dans son Apparatus médicaminuın, mais je doute qu'ils aient été mûrement examinés. C'est assez l'usage de dédaigner les moyens simples et faciles; mais pourquoi ne pas les essayer dans certains maux dont la chirurgie, armée du fer et du feu, triomphe si rarement?

Au reste, on ne s'est nullement occupé de la composition chimique de cette plante, qui n'est ni âcre ni amère. Par quel principe agit-elle sur le cancer? Je ne sais; mais les faits sont là pour tempérer mon scepticisme. On emploie les feuilles pilées, ou leur suc imbibé de charpie. Ce topique doit être renouvelé matin et soir.

\section{CENTAURÉE. CENTAURËA.}

Involucre imbriqué d'écailles épineuses, foliacées ou ciliées. Fleurons extérieurs stériles et plus grands que ceux du centre. Réceptacle garni de paillettes soyeuses. Graines à ombilic latéral.

\section{CENTAURÉE CHAUSSE-TRAPE. CENTAUREA CALCITRAPA.}

Centaurea calcitrapa. LinN. Spec. 129\%. DC. Fl. Fr. 3054.

Sa tige est velue, striée, rameuse, et comme en corymbe dans sa partie supérieure. Ses feuilles sont verdâtres, molles, pinnatifides, à découpures étroites, écartées et dentées; les radicales sont en lyre, avec un 
lobe terminal élargi. Les fleurs sont sessiles, terminales, d'un pourpre plus ou moins vif, environnées de bractées à leur base; les épines de l'involucre sont jaunes et fort grandes.

Cette plante abonde en été dans les lieux stériles et pierreux, au bord des chemins. On la désigne sous le nom de chardon étoilé, de chausse-trape. En effet, son calice épineux ressemble parfaitement à une chaussetrape, machine de guerre à plusieurs pointes, qui servait à arrêter la marche de la cavalerie.

M. Figuier, professeur de chimie à Montpellier, qui a examiné sa composition intime, en a obtenu une matière résiniforme, une substance animalisée, de la gomme, divers sels, une matière colorante verte, et une petite quantité d'acide.

Depuis long-temps la chaússe-trape figure parmi les plantes amères et fébrifuges. Sa réputation n'est point usurpée ; car elle guérit aussi bien que les autres amers indigènes les fièvres intermittentes simples. Nous avons employé très-souvent à la campagne, et presque toujours avec succès, la décoction des feuilles, des fleurs et des racines. Le suc de la plante est encore plus actif, si on en donne quatre ou cinq onces quelques instans avant le frisson.

\section{CENTAURÉE CHARDON-BÉNI. CENTAUREA BENEDICTA.}

Centaurea benedicta. Linn. Spec. 1296. DC. FI. Fr. 3058.

Cette espèce pousse des tiges rougeâtres, laineuses , branchues, hautes d'environ un pied et demi. Lesfeuilles 
soni oblongues, dentées, velues, d'un vert clair, traversées par une nervure blanche, et à peine demi-décurrentes; les inférieures sont sinuées et presque ailées. Les fleurs sont jaunes, terminales, entourées de bractées, et remarquables par leur involucre, dont les épines sont rameuses et jaunâtres.

Elle est originaire des provinces méridionales; on la cultive dans les jardins pour les usages médicinaux.

Ainsi que l'espèce précédente, le chardon-béni est. imprégné de principes amers qui rendent son usage recommandable dans les mêmes circonstances. Sa puissance médicamenteuse se rapproche de celle des gentianes et du trèfle d'eau. On peut donc l'employer pour relever le ton des voies digestives, pour dissiper les fièvres intermittentes qui ne tiennent pas à une lésion profonde du système nerveux. Nous nous garderons bien de répéter ici les éloges outrés qu'on trouve dans nos vieux livres, touchant les vertus de cette plante dans la pleurésie, la pneumonie, les fièvres malignes, et autres maladies graves. Qui ne sait que les amers et les toniques sont presque toujours nuisibles dans ces affections diverses? La médecine domestique, qui a si long-temps abusé et qui abuse encore de ce genre de médicamens, a grandement besoin d'être réformée.

On administre le chardon-béni en poudre, en extrait, en infusion aqueuse et vineuse. Ces préparations, et surtout l'infusion des sommités fleuries, produisent d'abord un effet émétique. Il est nécessaire de débuter par de faibles doses. 


\section{§ III. CORYMBIFÈRES. CORYMBIFERAE.}

\section{VERGERETTE. ERIGERON.}

Involucre oblong, imbriqué. Fleurs radiées; fleurons hermaphrodites; demi-fleurons femelles, nombreux, linéaires. Aigrette simple.

VERGERETTE ACRE. ERIGERON ACRE.

Erigercn acre. Linn. Spec. 1211. DC. Fl. Fr. 3131.

Sa racine, dure et ligneuse, pousse des tiges droites, fermes, garnies de poils rudes, ramenses, hautes de huit à dix pouces. Les feuilles sont éparses, sessiles, oblongues, lancéolées, hispides comme les tiges. Les fleurs sont nombreuses, bleues ou rougeâtres, portées sur des pédoncules feuillés, ordinairement uniflores. Les graines sont couronnées par une aigrette rude, de couleur rousse.

Cette plante est commune dans les lieux arides et rocailleux ; elle fleurit en juillet. Les fleurs contiennent un principe amer et irritant. Quelques médecins naturalistes, qui ont une sorte de prédilection pour les remèdes simples, les prescrivent dans les affections catarrhales du poumon.

La vergerette du Canada (erigeron canadense), espèce si commune dans les terrains sablonneux, qu'on reconnaîtà sa tige pyramidale hérissée de poils, à ses petites grappes defleurs axillaires d'un jaunedoré, possède les mêmes vertus. Ses fleurs sont même préférables; car, outre une saveur légèrement amère, elles laissent dans. 
la bouche une sensation de fraîcheur analogue à celle de l'éther ou de la menthe poivrée. On les fait sécher, et on les donne en infusion théiforme dans quelques cas d'hypochondrie et d'hystérie. Cette infusion, sucrée comme le thé, a un goût fort agréable.

Nous observerons néanmoins que deux autres espèces ont été signalées comme dangereuses : ce sont la vergerette fétide (erigeron graveolens) et la vergerette visqueuse (erigeron viscosum); elles ont l'une et l'autre des feuilles hispides et gluantes qui répandent une odeur forte quand on les froisse. D'après Puinh, ces deux plantes sont âcres, narcotiques, et font périr les chèvres qui s'en nourrissent.

\section{CAMOMILLE. ANTHEMIS.}

Involucre à folioles imbriquées, presque égales, scarieuses sur les bords. Fleurs radiées; fleurons hermaphrodites; demi-fleurons femelles, fertiles, lancéolés, nombreux. Réceptacle convexe, garni de paillettes. Semences couronnées par une membrane entière ou dentée.

\section{GAMOMILLE ROMAINE. ANTHEMIS NOBILIS.}

Anthemis nobilis. Lrnn. Spec. 1260. DC. Fl. Fr. 3259. Chev. Fl. Par. 3. 575.

Sa racine ligneuse et un peu rampante pousse des tiges hautes de huit à neuf pouces, rameuses, faibles et un peu couchées. Les feuilles sont pinnatifides, à découpures linéaires, un peu courtes et aiguës, recouvertes d'un léger duvet et d'un vert pâle. Les fleurs sont terminales et solitaires; le disque est jaune, le 
rayon d'un blanc argenté. La variété qu'on cultive a des fleurs doubles et tout-à-fait blanches.

Cette plante croît dans les pâturages secs; on la trouve sur les pelouses des bois à Meudon, à Versailles, à Ville-d'Avray, etc. Ses fleurs, d'une saveur chaude et amère, exhalent une odeur forte, aromatique, pénétrante; elles fournissent une huile essentielle de couleur bleue, du camphre, un principe résineux et du tannin. On a tort d'employer les fleurs doubles, qui sont moins aromatiques.

Il n'est pas de médicament simple qui soit d'un usage aussi vulgaire que la camomille. Hypochondrie, hystérie, céphalalgie, accès fébriles, indigestions, inappétence, faiblesse d'estomac, aigreurs, flatuosités, refroidissement, diarrhée, choléra, tous ces maux de nature et de causes si diverses ont été tour à tour attaqués avec cette herbe aromatique. Certes, nous ne saurions blâmer l'usage de la camomille, lorsque les organes se trouvent dans un véritable état de langueur, comme cela a lieu assez souvent chez les femmes délicates et hystériques, chez les hommes livrés à des méditations profondes, sujets à des spasmes, à des migraines provenant de digestions laborieuses et incomplètes; l'indication de ce remède nous paraît alors assez précise, et son emploi peut être suivi d'un soulagement immédiat, ainsi que tous les médecins ont pul'observer. Quelques tasses d'une infusion légère de ces fleurs remettent alors le malade, le raniment, font cesser ces bâillemens, ces flatuosités si incommodes; calment ce malaise, ces oppressions qui le tourmentent. Ce que nous blâmons, c'est l'abus qu'on 
en fait journellement pour dissiper une foule de symptômes qui dépendent de quelque irritation viscérale chronique, et qui s'exaspèrent par l'emploi des boissons stimulantes. Une douleur profonde dans quelque point de la région abdominale, l'aridité ou la rougeur de la langue, un pouls plus ou moins fébrile, repoussent ce genre de remède.

L'affreuse épidémie de 1832 avait donné une grande vogue à la camomille; tout le monde voulait en avoir une certaine provision en réserve en cas d'accident. L'infusion théiforme des fleurs a été utile dans quelques cholérines, ou au début du choléra, pour ranimer les fonctions de la peau, et seconder les effets d'une méthode stimulante; mais dans la période active du choléra, lorsque la diarrhée ou des vomissemens douloureux et opiniâtres attestaient une phlegmasie plus ou moins profonde de l'appareil gastrique, la camomille, la menthe et autres remèdes aromatiques ont été évidemment nuisibles.

La camomille romaine nous paraît surtout convenir dans les fièvres intermittentes simples qui se développent au printemps. On administre les fleurs en infusion ou en poudre; mais l'infusion doit être très-chargée lorsqu'on veut interrompre l'accès fébrile. La poudre récente des fleurs cueillies dans l'année est beaucoup plus active. Il faut en donner cinq ou six prises de vingt grains chacune pendant l'intervalle des accès, ayant soin de faire prendre la dernière une heure avant le frisson; le meilleur véhicule, c'est le vin. Lorsque la fièvre a cédé, il est nécessaire de continuer encore pendant quelques jours l'usage de la camomille. 
On doit donner la préférence à la camomille à fleurs simples, parce qu'elle est plus aromatique, la recueillir dans l'année, et ne la réduire en poudre qu'au moment où l'on veut en faire usage.

Nous signalerons en passant une espèce congénère non moins énergique : c'est la camomille cotule (anthemis cotula). On la reconnaît aisément à son odeur fétide, à sa tige rameuse et diffuse, à ses feuilles deux fois pinnatifides, à découpures linéaires, parsemées de quelques poils courts; à ses fleurs nombreuses, blanchâtres, formant un corymbe irrégulier. Elle est fort commune dans les terrains incultes, et porte les noms de maroute, de camomille puante. Beaucoup moins agréable que la camomille romaine, elle a pourtant une vertu excitante très-marquée. Elle a été recommandée comme fébrifuge, emménagogue et antispamodique; mais on ne s'en sert guère aujourd'hui qu'à l'extérieur: on en prépare des cataplasmes, des fomentations, des bains aromatiques pour remédier à l'atonie musculaire, pour ranimer les ulcères scrophuleux, etc. 


\section{ARMOISE. ARTEMISIA.}

Involucre ovoïde ou globuleux, imbriqué d'écailles serrées. Fleurons du disque nombreux, hermaphrodites, à cinq dents; ceux de la circonférence peu nombreux, entiers, femelles, fertiles. Réceptacle nu ou hérissé de poils. Semences dépourvues d'aigrette.

ARMOISE ABSINTHE. ARTEMISIA ABSINTHIUM.

Artemisia absinthium. Linn. Spec. 1188. DG. Fl. Fr. 3226.

(Planche 66.)

C'est une herbe vivace, dont les tiges rameuses, feuillées, blanchâtres, ont deux ou trois pieds de hauteur. Les feuilles sont alternes, pétiolées, larges, molles, d'un vert argenté, surtout en dessous, très-découpées, deux ou trois fois ailées. Les fleurs sont nombreuses, jaunâtres, disposées au sommet des rameaux en grappes unilatérales et feuillées; les involucres sont cotonneux, demi-globuleux et pendans; le réceptacle est garni de poils. Cette plante est connue sous le nom d'absinthe, de grande absinthe, d'armoise amère : on la rencontre dans les terrains arides et incultes de l'Europe tempérée.

La grande absinthe exhale une odeur forte, presque narcotique. Ses propriétés actives résident spécialement dans un principe résineux très-amer, et dans une huile volatile qui a la couleur de l'émeraude. Il est peu de plantes dont les vertus soient aussi bien établies. A la ville, à la campagne, partout on connaît l'action stomachique de l'absinthe; et depuis long-temps elle 
jouit d'une réputation pour ainsi dire populaire. L'eau, la bière, le vin, l'alcohol, s'emparent de ses principes médicinaux. Ces divers liquides portent sur l'organisme une impression à la fois stimulante et tonique, excitent et corroborent tous les tissus, accélèrent la circulation, augmentent la chaleur animale, provoquent la diaphorèse, etc. Pris avec modération, ils combattent l'inertie, la faiblesse de l'estomac et des intestins, aiguisent l'appétit, favorisent la digestion, dissipent les flatuosités.

Les fièvres intermittentes qui s'accompagnent de symptômes peu graves, cèdent à l'action stimulante et tonique de l'absinthe. J'en ai fait un fréquent et heureux emploi dans les hôpitaux militaires, où nous manquions quelquefois de quinquina de bonne qualité. Assez souvent je la mêlais avec les fleurs de camomille romaine : ces deux plantes réunies iont une vertu.fébrifuge très-remarquable.

On a souvent recours aux préparations d'absinthe pour combattre cette langueur cachectique connue sous le nom de chlorose ou pâles couleur's. Elles conviennent spécialement lorsqu'il existe une faiblesse générale, lorsque l'utérus est dans un état d'inertie qui s'oppose aux mouvemens hémorrhagiques. Observons néanmoins que la chlorose qui se manifeste chez les jeunes filles, à l'époque de la nubilité, dépend trèssouvent d'uné irritation de la matrice; que cet état cède aux remèdes tempérans, aux demi-bains, aux antiphlogistiques; tandis que l'absinthe, les toniques, les emménagogues, peuvent provoquer une inflammation mortelle. On fait un grand usage de l'absinthe II. 
dans le traitement de la leucorrhée; son action tonique dissipe assez promptement les langueurs d'estomac qui accompagnent cette affection morbifique. Mais nous ferons également remarquer que, chez les femmes d'une constitution faible et en même temps irritable, ces écoulemens muqueux sont rarement exempts d'un état fébrile, d'une sensation pénible, comme douloureuse, dans les lombes et dans la région abdominale; que ces symptômes, lorsqu'ils se prolongent, sont l'indice de quelque phlogose latente, soit de l'utérus, soit des viscères circonvoisins, et qu'ils contr'indiquent formellement l'usage de l'absinthe, des amers et des excitans.

Les praticiens prescrivent également cette plante dans quelques hydropisies. C'est en ranimant l'action languissante des reins et de tout le système urinaire, qu'elle a quelquefois dompté des anasarques rebelles à d'autres moyens. Le docteur Calès, mon collègue à l'armée des Pyrénées, fut pris d'un nedème universel à la suite d'une maladie ataxique qui l'avait réduit à un état de faiblesse extrême. Après avoir employé vainement les plus puissans diurétiques, il se mit à l'usage d'une forte infusion d'absinthe dans du vin blanc. Ce remède, continué pendant l'espace d'un mois, dissipa entièrement l'enflure et remonta le système des forces. On conseille aussi l'absinthe contre la dyspepsie goutteuse, le scorbut, les affections lymphatiques, etc. Elle a surtout une action très-puissante sur les vers; mais son emploi devient nuisible quand la diathèse vermineuse se complique de l'irritation des intestins.

On administre rarement l'absinthe en substance; 
mais on emploie fréquemment son extrait, sa teinture alcoholique, son infusion aqueuse on vineuse. On trouve aussi dans les officines un sirop, une conserve, une eau distillée et une huile volatile : tous ces divers produits se distinguent par des facultés plus ou moins excitantes. Le vin d'absinthe est surtout un remède énergique contre l'aménorrhée entretenue par une débilité générale; on le donne à la dose d'une à deux onces, qu'on répète deux ou trois fois par jour. Le peuple et les charlatans l'emploient dans tous les cas de suppression des règles et des lochies. J'ai vu périr d'une entérite des plus violentes une jeune fille trèsrobuste à laquelle on l'avait administré à haute dose pendant huit jours, afin de rappeler le flux menstruel.

On emploie aussi l'absınthe à l'extérieur; on en prépare des fomentations, des bains, des fumigations aromatiques. En Angleterre on la substitue fréquemment au houblon, dans la fabrication de la bière; mais on a remarqué que cette boisson était alors plus enivrante.

$V$ in d'absinthe. Prenez, feuilles sèches d'absinthe, une once; vin blanc, deux livres : laissez infuser à froid, pendant deux jours, dans un vase hermétiquement fermé. Le vermouth, liqueur stomachique fort estimée, n'est autre chose que du vin de Hongrie dans lequel on a fait infuser de l'absinthe. On en prend un petit verre le matin à jeun, et autant avant le repas.

Teinture d'absinthe. Prenez, sommités d'absinthe, trois gros; sucre, demi-once; alcohol, cinq onces : faites digérer pendant quinze jours, passez et filtrez 
la liqueur. La dose est d'une cuillerée à café dans deux onces de vin blanc.

L'extrait d'absinthe de Suisse est encore une liqueur très-excitante où l'on fait entrer plusieurs substances aromatiques, et qu'on colore avec du suc d'épinards.

'Toutes ces liqueurs sont recommandées, à petites doses, contre les langueurs d'estomac, les flatuosités, l'inappétence, la chlorose, la suppression menstruelle, etc.

Nous avons assez signalé les dangers de ces médicamens énergiques dans les irritations viscérales, nous n'y reviendrons point; mais nous devons avertir ceux qui auraient envie de se faire gourmands, que l'usage habituel des préparations d'absinthe et autres boissons stimulantes engendre des maux sans nombre. Toutes ces teintures si recherchées excitent, en effet l'estomac, le rendent plus actif, lui impriment une force nouvelle; mais cette excitation factice dégénère bientôt chez les uns en une langueur générale; provoque chez les autres des gastrites, dès spasmes variés, et une mobilité nerveuse qui fait d'un homme une petite femme à vapeurs.

Nous connaissons des littérateurs pleins d'esprit et de verve, mais dans un état habituel de souffrance, qui croient trouver une sorte de ressource dans les liqueurs alcoholiques. Eh bien, un petit verre vous suffit aujourd'hui; demain il vous en faudra deux; puis il faudra doubler encore la dose, ou bien le gaster, dont vous avez fait un paresseux, refusera toute espèce de service. Ceux qui se livrent aux travaux de l'esprit ne savent peut-être pas que les tiraillemens, les fai- 
blesses, les langueurs d'estomac dérivent presque toujours du cerveau, dont l'excitation réagit sans cesse sur les organes digestifs. Laisser reposer l'esprit, agiter le corps, vivre avec tempérance, voilà le traitement le plus rationnel, le plus sûr.

Mais si l'on persiste dans ce pernicieux régime, il n'y aura que les plus forts excitans qui pourront tirer pour un instant l'estomac de son inertie; il deviendra exigeant, capricieux; de nouvelles saveurs, des mets extraordinaires ne sauraient vaincre ses 'dégoûts toujours croissans. Aujourd'hui il demandera de la glace pilée, demain du kirsch ou du madère, un autre jour de l'extrait d'absinthe.

C'est aux hommes intelligens, spirituels, ornement du monde social, que nos conseils s'adressent, et non aux gourmands de profession, classe égoïste, indocile, dont toutes les sensations résident dans le ventre. Ceux-ci n'ont point d'oreilles, ils ne sauraient nous entendre; leurs entrailles toujours avides, comme dit Sénèque ( $\mathrm{I}$ ), dépeuplent la mer et la terre. Cuisiniers, courèz au milieu des feux; étudiez leurs besoins, leurs désirs; aiguillonnez leur appétit blasé! Que le grand et le petit four travaillent sans cesse; que les vins se multiplient; que les mets se succèdent, qu'ils varient de forme, de goût, de couleur ; et, s'il le faut, que tou-

(1) Je me souviens d'avoir entendu vanter un ragoût fameux, dans lequel un gourmand, pour accélérer sa ruine, avait fait entrer tout ce que les gens les plus fastueux auraient pu consommer successivement à leur table pendant toute une semaine. Les coquilles de Vénus, les spondyles et les huîtres étaient entremêlés d'oursins, supportés sur un plancher de surmulets hachés et privés d'arêtes. (SÉnèQue, lettre $\mathrm{XCV}$.) 
tes les saveurs soient confondues en une seule; qu'on allie dans un seul plat ce qui ferait l'ornement de plusieurs services; enfin, que ces gourmands soient rassassiés, qu'ils célèbrent leurs propres funérailles, et que leur destinée s'accomplisse.

Presque toutes les espèces dont se compose le genre artemisia possèdent des propriétés analogues. Elles sont plus ou moins imprégnées de principes aromatiques et résineux, et on les remplace les unes par les autres. Nous ne citerons que les plus remarquables.

Armoise des glaciers (artemisia glacialis). Cette espèce, revêtue d'un duvet soyeux et brillant, a des 'feuilles découpées en quatre ou cinq lobes multifides, et des fleurs jaunes, assez grandes, ramassées en bouquet à l'extrémité des tiges. Elle croît dans les Alpes, dans le voisinage des glaciers. Les montagnards lui donnent le nom de petit genipi blanc.

Cette petite plante répand un parfum délicieux. Ses feuilles sont amères et aromatiques; on les prend en infusion pour exciter les sueurs.

L'armoise des rochers (artemisia rupestris), porte également le nom de genipi, et possède à peu près les mêmes vertus. Les habitans des Alpes emploient ces deux espèces dans les maladies aiguës, et principalement dans la pleurésie. Cette méthode, dont se plaignait le célèbre Tissot, est évidemment meurtrière dans les inflammations.

Armoise pontique. Artemisia pontica. On la reconnaît à ses feuilles blanchâtres, soyeuses, finement découpées; à ses fleurs petites, globuleuses et disposées en panicule terminale. On la désigne sous le nom de 
petite absinthe, d'absinthe romaine. Elle croît abondamment sur les bords du Pont-Euxin :

Cana priüs gelido desint absinthia Ponto.

Ovid.

On la rencontre aussi dans les montagnes du Piémont et dans le Jura. Moins tonique et moins amère, elle est plus stimulante et plus agréable que la grande absinthe, à laquelle d'ailleurs on la substitue. On la cultive dans les jardins.

Armoise du Valais. Artemisia vallesiaca. Elle est toute couverte d'un duvet épais et blanchâtre. Les feuilles sont trilobées, à lanières étroites et linéaires. Les fleurs sont disposées en panicule droite et rameuse; les involucres sont légèrement scarieux, et renferment de trois à six fleurons hermaphrodites d'un jaune rougeâtre. Cette espèce croît dans les lieux les plus chauds des Alpes, dans le Valais, dans le val d'Aoste; elle est très-aromatique et très-excitante. On la récolte dans son pays natal pour remplacer la grande absinthe, à laquelle on la préfère.

Armoise maritime. Artemisia maritima. Elle est également chargée d'un coton blanc et fin. Ses tiges sont hautes, très-rameuses, garnies de feuilles multifides, à découpures linéaires; ses fleurs petites, pendantes, nombreuses, d'une couleur jaunâtre, et disposées en grappes terminales. Cette plante croît sur les bords de la mer, depuis la Provence jusqu'en Belgique. Elle est aromatique et d'une saveur amère qui n'est point désagréable. Les Anglais en font un fréquent usage. 
ARMOISE COMMUNE. ARTEMISIA VULGARIS,

Artemisia vulgaris. Linn. Spec. 1188. CG. Fl. Fr, 1188. B

Cette espèce a des tiges hautes d'environ trois pieds, cylindriques, cannelées; glabres, quelquefois un pèu velues et rougeâtres. Ses feuilles sont pínnatifides et incisées, vertes en-dessus, blanchâtres et tomenteuses en-dessous. Les fleurs sont rougeâtres et disposées en petits épis latéraux qui naissent dans les aisselles des feuilles supérieures, et qui tous ensemble forment de longues grappes terminales.

\% On la rencontre dans les lieux incultes, dans les décombres, au bord des chemins. Lorsqu'on froisse les feuilles entre les doigts, elles exhalent une odeur forte et aromatique. M. Braconnot en a obtenu une matière amère animalisée et une huile odorante.

Les anciens, Hippocrate, Galien èt Dioscoride avaient attribué à l'armoise une action emménagogue puissante. Les modernés lui ont aussi reconna une propriété excitante, et beaucoup de médecins y ont encore recours lorsque la menstruation' est irrégulière, difficile ou supprimée. Mais nous devons observer que son usage ne peut être utile qu'autant que cet état est entretenu par l'inertie de l'utérus ou par une faiblesse générale. L'armoise agit alors à la manière des substances aromatiques, de la camomille, de la matricaire, de l'absinthe et autres végétaux stimulans auxquels on l'associe même afin d'augmenter son action médicamenteuse. Il m'est souvent arrivé de la donner 
en infusion avec le safran, et j'ai eu à me louer de ce mélange. On fait infuser une pincée d'armoise et un scrupule de safran dans deux tasses d'eau bouillante, et on donne le matin à jeun cette boisson édulcorée avec du sucre, après avoir fait prendre à la malade un pédiluve simple. On continue ce remède pendant cinq ou six jours, et on le suspend pour le reprendre à l'époque présumée de la menstruation.

Mais l'aménorrhée, suite d'une débilité organique, est beaucoup moins fréquente qu'on ne pense; elle est bien plus souvent le résultat d'une congestion sanguine, d'une irritation plus ou moins vive, soit de l'utérus, soit des organes voisins; et alors les véritables emménagogues sont les antiphlogistiques, les saignées générales ou locales pratiquées avec mesure, les bains et une diète en harmonie avec cet état d'irritation.

Une maladie d'une solution autrement difficile, l'épilepsie, a été combattue avec quelque succès, en Allemagne, par l'usage de la racine d'armoise. C'est au docteur Burdach, de 'Triebel, près de Sorau, qu'on doit cette découverte. Comme nous manquons de méthodes rationnelles pour triompher d'une affection aussi grave, nous ne saurions dédaigner un moyen empirique dont l'expérience a constaté les effets salutaires. M. Burdach recommande de récolter l'armoise en automne, de la faire sécher à l'ombre et de ne la pulvériser qu'au moment de s'en servir. Environ une demi-heure avant l'accès, lorsqu'il peut le prévoir, il donne à un adulte une cuillerée à café (environ un gros) de cette poudre dans un peu de bière chaude. 
Le malade se met au lit, se couvre bien, et boit de la bière légère, très-chaude. La sueur ne tarde pas à s'établir, et le malade sort du lit quand elle cesse de couler.

Le docteur Burdach assure que la première dose procure déjà du soulagement et qu'elle suffit même quelquufois pour opérer une cure radicale. Il faut meltre un jour d'intervalle entre les doses. Des expériences ont été faites à l'institut polyclinique de Berlin, sur dix épileptiques; trois furent guéris plus ou moins promptement; trois furent soulagés, puisque les accès devinrent plus éloignés et plus faibles; chez les quatre autres on n'observa aucun effet.

Une femme de quarante-un ans, ayant fait plusieurs campagnes avec son mari, qui était soldat, devint hystérique à la paix, lorsqu'elle fut réduite à un genre de vie sédentaire. Deux avortemens, des chagrins, des inquiétudes, et des désordres de la menstruation, vinrent encore aggraver cet état. Les accès hystériques parurent d'abord avec les symptômes ordinaires, hémicrânie, vomissement, coliques, globe hystérique, évanouissemens, etc. Mais depuis six mois, il s'y était joint des convulsions très-analogues à celles de l'épilepsie, à cette différence près qu'il n'y avait point d'état soporeux. Commechacun de ces accès était amené par un sentiment de malaise et d'agitation, on fit prendre de la racine d'armoise, le 16 avril, à onze heures du soir, au moment où les prodromes d'un accès se déclarèrent. Il s'établit dans la nuit une sueur abondante qui dura jusqu'au matin. La malade ne dormit pas une minute; elle changea de linge le matin et 
se sentit fort soulagée. Cependant, le 17 avril, vers deux heures après midi, elle eut tout à coup un accès d'épilepsie, auquel en succéda un second tout aussi violent, une heure après; la malade tomba ensuite dans un sommeil profond qui dụra jusqu'au lendemain matin. Soixante-douze heures après la prise de la première dose, on en donna une seconde, aussi dans de la bière chaude. Bientôt il s'établit une sueur générale, abondante et fétide, et le matin, un flux d'urine colorée en jaune, mais non sédimenteuse. La malade se trouva soulagée, et au mois de mai suivant, ,il n'avait pas encore reparu d'accès. Le 6 mai, elle sortit de l'hôpital. Depuis deux ans, elle jouit d'une santé parfaite et n'ajamais ressentid'attaque d'épilepsie.

Une fille de dix-sept ans, épileptique depuis cinq, par suite de mauvais traitemens et de coups recus sur la tête, avait tous les jours un accès qui paraissait régulièrement à la même heure. Une seule dose d'armoise, qui fut suivie d'une sueur légère, suffit pour la guérir.

Une fille de dix-huit ans était atteinte, depuis deux ans, d'une épilepsie qui s'aggravait sans cesse, de manière qu'on comptait souvent douze accès par jour. Après que la malade eut pris trois doses d'armoise, le nombre des accès se trouva réduit à deux par jour, de courte durée. La malade n'a pas été suivie plus longtemps.

Un homme de vingt-neuf ans, atteint, depuis quatre ans, d'une épilepsie périodique, occasionée par une chute dans l'eau, fut radicalement guéri par deux doses d'armoise. 
Un homme de trente-six ans, un peu idiot, éprouvait, depuis son enfance, deux accès au moins d'épilepsie par semaine. Trois doses d'armoise suffirent pour éloigner tellement les accès, qu'il n'en eut plus qu'un seul par mois. Depuis lors, une forte dose, prise par mois, supprima ce dernier accès lui-même.

Une fille de seize ans fut atteinte d'épilepsie, sans cause connue, à l'époque de la puberté. Elle avait ordinairement un accès toutes les quarante-huit heures. Une seule dose d'armoise la guérit radicalement. (Journal der praktirchen heiskunde, avril 1824.)

De nouveaux faits, recueillis depuis cette époque par M. Burdach, sont venus confirmer l'efficacité de la racine d'armoise contre l'épilepsie. Ce médecin a observé une différence śurprenante entre le nombre des guérisons qui ont eu lieu dans le canton qu'il habite, et celui des succès obtenus dans d'autres endroits. En effet dans son pays, sur vingt malades, deux seulement n'ont pas éprouvé de soulagement notable après l'usage de la racine d'armoise, tandis qu'ailleurs la proportion a été inverse; ce qu'il attribue à une mauvaise préparation du médicament, lequel n’a pu déterminer cette sueur abondante qui suit constamment son usage. M. Burdach pense que le pronostic et le traitement de l'épilepsie doivent reposer non sur la eause présumable ou sur le siége hypothétique de cette maladie, mais sur la considération de ses intermissions ou de sa périodicité. Ainsi, il est une espèce d'épilepsie dont les accès reviennent tous les jours une et même plusieurs fois; c'est celle que la racine d'armoise combat avec le plus de succès, et cela d'autant mieux que les convul- 
sions sont plus violentes, et que les accès sont assez rapprochés pour que le malade n'ait pas le temps de revenir complètement à lui dans leurs intervalles. M. Burdach ne connaitt pas de cas de ce genre dans lequel l'armoise n'ait pas parfaitement réussi.

Une autre espèce d'épilepsie, caractérisée parłe retour quotidien de deux accès, un le matin et un autre le soir, se montre surtout chez les enfans de cinq à quinze ans. Les attaques sont peu intenses et s'annoncent par des tiraillemens dans les pieds; le paroxisme présente les symptômes des affections vermineuses, et les anthelmintiques demeurent sans effet. Cette forme réclame l'emploi de la racine d'armoise, qui ne tarde pas à être suivi d'une diminution dans la violence et dans la durée des attaques, puis de leur cessation complète: on doit après celle-ci continuer eucore le traitement pendant quelques semaines, d'autant que l'armoise ne provoque pas une transpiration aussi forte que dans le cas précédent. La dose de ce médicament peutêtre portée très-haut chez les jeunes gens qui n'ont pas encore atteint leur quinzième année. Les bains tièdes légèrement aromatisés contribuentà la guérison.

Une troisième espèce, ou l'épilepsie nocturne, est caractérisée par le retour irrégulier des attaques tous les dix ou quinze jours, et ordinairement après minuit; celles-ci sont annoncées le jour auparavant par une susceptibilité très-grande, par l'abattement, ou, chez quelques sujets, par une grande activité morale, interrompue par un besoin passager de dormir, survenant à des heures où le malade n'en a pas l'habitude. Ce dernier ne remarque pas ordinairement les prodromes dont 
il ignore en outre la valeur; d'autres fois il la connaît et tombe dans le désespoir. Cette forme, qui s'observe le plus souvent chez les jeunes gens de dix-sept à vingt-cinq ans, est plus aggravéc, très-momentanément il est vrai, qu'améliorée par la racine d'armoise. Une autre espèce d'épilepsie, que ce médicament modifie à peine, est celle qu'on observe chez les hommes, et dont les attaques très-violentes reviennent toutes les six ou huit semaines, se suivent à courts intervalles pendant deux ou trois fois vingt-quatre heures, et sont accompagnées d'une très-forte transpiration.

Les enfans à la mamelle supportent très-bien la racine d'armoise; on ne doit pas être trop réservé à leur égard pourles doses de ce médicament, qui combat avec avantage chez eux toutes les affections spasmodiques plus ou moins semblables à l'épilepsie. M. Burdach assure que dans ces cas l'armoise est réellement un spécifique. Lorsque la vie du malade est en danger, il y joint le musc ou d'autres moyens; hors cette circonstance, la racine d'armoise suffit et réussit seule, lors même qu'il existe quelques signes de diathèse inflammatoire.

Il a obtenu de très-bons effets de ce remède chez les jeunes filles de douze à quinze ans atteintes d'accidens épileptiformes qui dépendaient des efforts de la nature pour établir la menstruation. Il avoue néanmoins qu'il n'a pas été aussi heureux cliez les femmes plus âgées, lorsque les accidens épileptiqnes, compliqués d'ailleurs d'aménorrhée et datant souvent de la même époque que celle-ci, étaient survenus après la première menstruation.

M. le docteur Schoenbeck a employé également avec 
succès la même racine, à la dose de deux à quatre gros, peu de temps avant ou immédiatement après l'accès. Un épileptique a été guéri; et l'état de six autres a été assez amélioré pour n'avoir plus que des accès rares, réduits d'ailleurs à des évanouissemens courts et pas-sagers.

\section{ARNICA. ARNICA.}

Involucre à plusieurs folioles égales sur un ou deux rangs. Fleurons du disque hermaphrodites, demi-fleurons de la circonférence munis de cinq filamens stériles. Toutes les semences également munies d'aigrettes.

ARNICA DES MONTAGNES. ARNICA MONTANA.

Arnica montana. Linn. Spec. 1245. DC. Fl. Fr. 3198.

Lapeyr. Hist. Plant. Pyr. 2. 524. B BLb. Fl. Lyon. 1. 389.

Duв. Fl. Orl. 913.

\section{(Planche 67.)}

Sa tige est cylindrique, légèrement velue, haute d'environ un pied, simple et uniflore; quelquefois elle se divise, et porte plusieurs fleurs. Les feuilles radicales sont oblongues, lancéolées, rétrécies en pétiole; celles de la tige, presque toujours au nombre de quatre, sont opposées deux à deux. Les fleurs sont grandes, d'un jaune d'or, solitaires à l'extrémité de la tige ou des rameaux. Cette plante croît dans les prairies des Alpes, des Pyrénées, des Vosges, etc. On la trouve aussi aux environs de Lyon, dans les prairies de Pilat, dans la forêt d'Orléans et dans les bois de la Sologne.

L'arniça est un des végétaux indigènes les plus éner- 
giques. Les fleurs et la racine exhalent une odeur vive, aromatique ; leur saveur est âcre et amère. D'après l'examen chimique de MM. Chevallier et Lassaigne, les fleurs contiennent une résine ayant l'odeur de l'arnica; une matière amère nauséabonde, ressemblant à la matière vomitive du cytise; de l'acide gallique; une matière colorante jaune; de l'albumine; de la gomme et divers sels. (Journal de pharmacie, juin 18 i.9.)

Un soldat de la garde royale, tourmenté de palpitations de coeur et d'une agitation convulsive du bras droit, fut mis à l'usage d'une décoction de fleurs d'ainica. Le premier verre provoqua des nausées, et bientôt après une sorte de frémissement général, avec des tiraillemens qui se prolongeaient dans les membres jusqu'à l'extrémité des doigts. Ces phénomènes étaient accompagnés d'une sorte de sensation que le malade ne pouvait exprimer; les jambes exécutaient aussi des mouvemens involontaires. La poitrine ne se soulevait qu'avec peine; les muscles de cette cavité étaient dans un état de contraction fixe qui s'opposait à l'exercice des mouvemens mécaniques de la respiration. (Barbier, Traité de Mat. méd.)

\section{PROPKIÉTÉS MÉdICALES.}

Les médecins qui se sont anciennement occupés de cette plante la regardaient comme un spécifique contre les contusions, les meurtrissures provenant de chutes graves. Ils avaient remarqué que la décoction des fleurs, prise intérieurement, occasionait des douleurs vives dans les parties contuses, des anxiétés, des nausées, des hémorrhagies, des déjections sanguinolentes, et 
quelquefois le délire. (Schut, De viribus arnica.) Nous ne contestons point les effets salutaires de l'arnica dans quelques affections de l'encéphale à la suite de chutes violentes; mais il faut savoir en restreindre l'usage, et surtout s'en abstenir lorsque la dureté du pouls, la chaleur fébrile, l'irritation prononcée de quelques viscères annoncent un état de congestion, une phlogose imminente.

L'impression vive et prompte que cette plante exerce sur l'appareil nerveux a sans doute déterminé quelques praticiens à la prescrire dans le traitement de la paralysie. D'après les observations de M. Collin, elle a dissipé des tremblemens, des convulsions, des affections paralytiques et autres accidens nerveux. Sousl'influence de ce puissant remède, les malades éprouvaient des douleurs dans les yeux, une sorte de fourmillement dans les membres, des tiraillemens, une chaleur vive, qui étaient presque toujours d'un heureux présage. Observons néanmoins que l'usage de l'arnica n'est point admissible dans les cas d'irritation ou de congestion sanguine de l'encéphale; or, la paralysie offre très-souvent ce caractère chez les vieillards d'un fort tempérament. Ce n'est qu'après avoir remédié à la cause primitive par des saignées générales et locales qu'on peūt avoir recours à cette plante héroïque.

M. 'Théodore Martell, négociant, âgé de soixantehuit ans, d'une constitution forte, d'un tempérament lymphatico-sanguin, devint hémiplégique du côté gauche à la suite d'une attaque d'apoplexie. Des évacuations sanguines suivies d'un éméto-cathartique, de l'application successive de plusieurs vésicatoires, etc. , 
avaient débarrassé la tète; mais les mouvemens involontaires des membres étaient entièrement abolis. Cet état durait depuis plusieurs semáines, et M. le professeur Boyer, qui, dans les premiers jours de l'attaque, avait vu le malade avec moi, avait porté un pronostic défavorable. Peu satisfait des remèdes employés jusqu'alors, je prescrivis à M. Martell une décoction de fleurs d'arnica légèrement sucrée. On lui en donnait trois onces toutes les quatre heures, et on ajoutait à chaque dose deux cuillerées d'une forte infusion des mêmes fleurs. L'usage de ce remède fut constamment suivi de nausées et d'un sentiment d'ardeur à l'épigastre, que quelques cuillerées d'une potion éthérée faisaient promptement disparaître. On continua l'arnica pendant trois semaines, sans en obtenir un amendement sensible; cependant on remarqua peu à peu plus de chaleur dans les membres paralysés. Le malade éprouvait de temps en temps des contractions spasmodiques : d'abord il put remuer faiblement les orteils; ensuite la sensibilité et le mouvement se rétablirent d'une manière progressive dans toute l'étendue des parties affectées. Au bout d'environ trois mois, M. Martell put se promener seul dans sa chambre; et, peu de temps après, il fut en état de reprendre le cours de ses affaires. Cette observation et quelques autres faits analogues démontrent la puissance médicatrice de l'arnica contre la paralysie, dont la cause réside spécialement dans une atonie nerveuse.

D'après le témoignage de Collin, l'arnica a dissipé des fièvres intermittentes d'une nature grave. Aaskow, Deiman, Voltelen ont également constaté son 
action fébrifuge. Stoll a combattu des fièvres quartes à l'aide d'un électuaire préparé avec-les fleurs d'arnica et le sirop d'écorce d'orange; il en donnait gros comme une muscade quatre fois par jour. Cette dose excitait une cardialgie supportable; mais les malades qui en prenaient davantage éprouvaient bientôt après des douleurs violentes d'estomac, des sueurs visqueuses, froides, avec un pouls grand, plein et très-lent. Toutefois l'opium calmait la cardialgie d'une manière aussi sûre que prompte. D'après l'observation de Stoll, ceux qui souffraient davantage de l'estomac étaient beaucoup plus tôt guéris. Qui largiores florum doses absumebant, ventriculo graviùs dolebant, sed multò citius sanabantur ex febre. (Rat. med., pars tertia.) M. le docteur Double a employé avec succès la décoction des fleurs, seule ou légèrement rougie avec du vin, chez deux individus pauvres et attaqués d'une fièvre tierce. Ils présentaient, dans le principe, de légers symptômes de complication gastrique, qui devenaient surtout sensibles dès l'invasion de l'accès. Après avoir fait usage, l'un pendant neuf jours, l'autre pendant onze, de la décoction d'arnica, la fièvre a dispara, aussi bien que les symptômes de gastricité. (Journal général de médecine, tome 2 亿.)

Stoll a beaucoup contribué à répandre l'usage de l'arnica dans le traitement des affections typhoïdes, et personne n'ignore combien les sectateurs de Brown ont abusé de ce médicament énergique. L'illustre médecin de Vienne l'administrait dans les fièvres putrides, lorsque les viscères étaient exempts d'inflammation, ou lorsque celle-ci avait été dissipée, lorsque le pouls 
était à peu près naturel, et que cependant le malade était faible, stupide, très-abattu, en proie à un délire sourd, dans un état de somnolence, etc. On a recours à l'arnica dans le traitement des affections muqueuses compliquées d'adynamie et d'ataxie; elle est particulièrement indiquée lorsque le pouls est petit, faible, tremblotant, avec torpeur et prostration du système musculaire. M. le docteur Mercier, médecin à Rochefort (Puy-de-Dôme), a signalé ses vertus dans plusieurs cas de fièvre muqueuse adynamique avec suspension de la sécrétion des urines. Ce remède, donné en substance et en décoction, a combattu avec un grand succèsl'assoupissement, la dépression des forces, qui était extrême, et la débilité pour ainsi dire paralytique de l'appareil urinaire. Conférez le $33^{\mathrm{e}}$ volume du Journal général de médecine, page 386.

Mais qu'on ne se hâte point d'administrer l'arnica; les spasmes, les soubresauts des tendons, les mouvemens convulsifs et autres lésions de la sensibilité ne dépendent pas toujours d'une faiblesse réelle, mais plutôt d'un état trompeur de débilité ou d'une oppression momentanée des forces vitales, qui se montre souvent dans les fièvres adynamiques et ataxiques. Autant ce médicament devient salutaire pour remédier à quelques accidens graves qui se manifestent vers la fin de ces pyrexies, autant son usage prématuré est nuisible lorsqu'il existe un éréthisme général, ou bien une irritation locale qui n'a pas été combattue par des moyens convenables. On doit surtout opposer l'arnica à ces diarrhées énervantes, à ces flux dysentériques opiniâtres qui, dans la troisième période du typhus, me- 
nacent d'éteindre entièrement les forces de la vie.

On a recommandé l'arnica contre les toux convulsives, la coqueluche, la dyspnée asthmatique, les catarrhes, la péripneumonie, etc. Il est à peine nécessaire d'observer que ces maladies sont presque toujours. marquées, du moins dans le principe, par un excès d'irritation quidoit faire craindre tous les remèdes stimulans. C'est ainsi que l'usage prématuré de l'arnica, dans les affections pulmonaires, peut les convertir en phthisie ; mais, dans l'état avancé des catarrhes, lorsque l'expectoration devient difficile, et que le poumon est surchargé de matières muqueuses, on peut prescrire avec confiance ce remède énergique; on le donne en décoction ou en infusion avec les espèces pectorales. Cette boisson, administrée à doses nauséeuses, continuée avec persévérance, et secondée par l'application des vésicatoires sur le thorax, a quelquefois vaincu les catarrhes les plus opiniâtres. L'emploi de l'arnica n'est pas moins précieux dans quelques cas de péripneumonie, lorsque les forces vitales sont abattues au point de faire craindre que la crise ne soit imparfaite ou nulle, ce qui arrive fréquemment dans les péripneumonies ataxiques. On administre alors l'infusion ou la décoction des fleurs avec l'extrait de quinquina; cette composition excite le système général des forces, ranime l'action pulmonaire, et favorise l'expectoration.

Cette plante a été célébrée par Barthez dans le traitement de la goutte. Je pense qu'on peut prescrire l'arnica, dans quelques affections goutteuses, pour favoriser les sueurs critiques, lorsque la nature paraît choisir ce mode de solution; mais il faut bien se garder 
d'y avoir recours durant l'irritation de la maladie. Ces sueurs, que- l'art s'efforce de provoquer par des remèdes excitans, augmentent l'irritation générale; elles peuvent même, suivant la remarque judicieuse de M. le docteur Double, susciter une attaque d'apoplexie, en donnant lieu à une direction vicieuse des mouvemens vers la tête. Voyez la Séméiologie générale, publiée par ce célèbre praticien, tome 3 , page $33_{2}$.

Enfin le docteur Schüt, qui a longuememt disserté sur l'arnica, lui attribue bien d'autres propriétés que nous passons sous silence; nous dirons seulement que dans les maladies asthéniques, dans le typhus putride, dans la dysenterie avec prostration des forces et tendance à la gangrène, cette plante, méthodiquement administrée, a souvent produit les plus heureux effets. Tout ce qu'on a pu dire contre l'usage des stimulans ne saurait anéantir les faits recueillis par les médecins les plus distingués de l'Europe. Les antiphlogistiques, si vantés aujourd'hui dans le traitement des fièvres putrides et du typhus, peuvent sans doute être couronnés de succès pendant la période d'irritation; mais, lorsque les facultés vitales et organiques sont frappées d'adynamie, soit par îeffet d'un poison septique, soit par l'abus d'une méthode énervante, persister dans l'emploi des mêmes moyens, c'est vouloir éteindre le dernier souflle de vie.

On donne quelquefois l'arnica en substance, à la dose de dix à trente grains; mais plus souvent en infusion ou en décoction édulcorée avec un sirop agréable. On emploie les fleurs et la racine depuis un gros jusqu'à demi-once pour une livre de véhicule. L'extrait, 
préparé avec les fleurs, se prescril depuis vingt grains jusqu'à un gros. On peut combiner utilement ces diverses préparations avec le vin, l'éther sulfurique, le quinquina, le camphre, la valériane, etc.

Poudre de racine d'arnica composée. Prenez, racine d'arnica, vingt grains; camphre, quatre grains. Préparez douze poudres semblables. On en donne une toutes les trois heures, dans le typhus dysentérique, pour combattre la prostration des forces et la tendance à la décomposition des humeurs.

Infusion de fleurs d'arnica composée. Prenez, fleurs d'arnica, racine de valériane, de chaque deux gros. Faites infuser, à vase fermé, dans dix onces d'eau bouillante. Ajoutezà la colature, eau de menthe poivrée, deux onces; sirop simple, une once; éther alcoholisé, un gros; teinture d'opium, quinze ou vingt gouttes. On administre cette potion par cuillerées, dans la deuxième et troisième période des affections putrides, pour soutenir les mouvemens salutaires de la nature, et remédier à l'état nerveux caractérisé par le désordre et l'affaiblissement des forces vitales. 


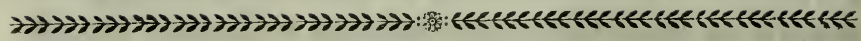

\section{VALÉRIANÉES. VALERIANE E.}

\section{Valerianea. DC.}

Hier encore la chaleur était accablante, on respirait à peine. Les pluies du soir et de la nuit ont versé des trésors sur la campagne; l'herbe des prés est rafraîchie, et les trèfles étincellent de perles liquides.

Quittons les prairies de Vanvres. Voici les collines de Meudon, où la valériane sauvage nous appelle...... Je l'aperçois déjà toute radieuse, s'élevant comme un trait au-dessus des gazons qui bordent un épais taillis : j'admire les petits bouquets blancs et roses qui ornent sa tête, mélange charmant où la nature a mis toute sa grâce. Une plante rustique se montre à quelques pas de la valériane; c'est l'euphorbe des bois, distillant aux feux du soleil sa liqueur laiteuse. La pourpre de sa tige contraste durement avec son feuillage : n'y touchez pas, c'est un poison.

Mais quelle odeur suave vient ravir mes sens! Herbe modeste, précieux don de la Providence, je reconnais tes fruits si vermeils, si délicieux, si frais; je. les vois briller à travers le feuillage qui leur sert d'abri, et je crois les cueillir encore dans les bois des Pyrénées, au bord du torrent, entre les rochers tapissés de mousse. Comme après les fatigues de la journée je savourais leur 
ambroisie dans ces hautes régions où l'air est si pur, le ciel si beau! Ineffables souvenirs de mes jeunes années, courses champêtres, études de la nature, doux repos de l'esprit et du cœur, vous me charmez encore à l'automne de ma vie!

\section{VALERIANE. VALERIANA.}

Calice très-petit, presque entier, se déroulant, dans la maturité, en une aigrette sessile et plumeuse. Corolle tubulée, à cinq lobes inégaux. Étamines rarement solitaires, le plus souvent au nombre de trois. Un à trois stigmates. Une graine recouverte et couronnée par le calice.

\section{VALÉRIANE OFFICINALE. VALERIANA OFFICINALIS}

Valeriana officinalis. Linn. Spec. 45. DC. FI. Fr. 3315. Lapeyr. Hist. Plant. Pyr. 1. 18. Chev. Fl. Par. 3. 601. Fl. Dan. t. 570.

\section{(Planche 69.)}

C'est une jolie plante, qu'on rencontre au printemps dans les lieux un peu humides, dans les prairies, sur la lisière des bois. On lui donne le nom de valériane sauvage, pour la distinguer d'une autre espèce qu'on cultive dans les jardins. Presque simple, cylindrique, cannelée et un peu velue, sa tige s'élève à la hauteur de trois ou quatre pieds. Ses feuilles sont toutes ailées, à folioles pointues, pubescentes, dentées en leurs bords et d'un joli vert. Ses fleurs exhalent une odeur douce; elles sont d'un blanc mélangé de rose, disposées en panicule au sommet de la tige et des rameaux. Une va- 
riété se fait remarquer par ses feuilles luisantes et d'un vert foncé ou noirâtre.

Cette espèce est assez commune aux environs de Paris, à Meudon, dans la vallée de Chevreuse, etc. Je l'ai observée à Barèges, dans la plaine de Luz, et dans la vallée de Campan, sur la rive gauche de l'Adour.

La racine de valériane se compose d'un faisceau de fibres, d'une couleur fauve en dehors, d'un blanc jaunâtre intérieurement, exhalant une odeur forte, diffusible, permanente; d'une saveur âcre, amère, un peu nauséeuse. M. Trommsdorff, professeur de chimie à Erfürt, qui a procédé à l'analyse de cette racine, en a obtenu un principe particulier soluble dans l'eau, insoluble dans l'éther et dans l'alcohol, de la résine noire, une huile volatile verdâtre d'une odeur pénétrante et camphrée, de l'extrait gommeux et de la fécule.

L'impression vive et soudaine que cette substance produit sur certains animaux, et notamment sur les chats; les étourdissemens, l'état de vertige et d'ivresse qu'on éprouve lorsqu'on respire pendant quelque temps l'air chargé de ses émanations, démontrent son influence physiologique sur le cerveau et sur les nerfs. Prise intérieurement, la ṿalériane excite l'appareil gastrique, produit un sentiment de chaleur dans l'estomac, anime la circulation, augmente la fréquence du pouls, ainsi que la faculté exhalante de la peau. Si l'on contịue l'usage de ce médicament, ou si l'on en prend de fortes doses, on éprouve bientôt une sorte de malaise, de l'oppression, et un resserrement pénible dans la région précordiale; il survient de l'agitation, des spasmes, des éblouissemens, et autres phénomènes nerveux. 
PROPRIÉTÉS MÉDICALES.

La valériane sauvage, inconnue à nos pères, tient depuis quelque temps un rang très-distingué dans la matière médicale. Son usage est particulièrement consacré au traitement des névroses. Le botaniste Fabius Columna l'essaya le premier sur lui-même vers la fin du $\mathrm{xvI}^{\mathrm{e}}$ siècle pour se délivrer de l'épilepsie. Mais quel est son mode d'action dans les maladies spasmodiques? Ses effets salutaires sont-ils dus à une vertu stimulante, ou bien à une faculté sédative? L'école italienne lui attribue une propriété contre-stimulante ou déprimante, tandis qu'en France, en Allemagne, en Angleterre, on la met au nombre des remèdes excitans. Mais ici, comme dans beaucoup d'autres cas, il faut abandonner toute espèce de théorie pour interroger l'expérience, et s'en rapporter purement au témoignage des faits. Ainsi, sans nous perdre dans des explications superflues, qui ne pourraient satisfaire les bons esprits, nous dirons que la valériane paraît douée d'une vertu nervine spécifique, et que son usage a souvent prospéré dans ces altérations nerveuses où le principe sensitif réagit d'une manière insolite contre les impressions qu'il éprouve. Une de ces lésions, qui s'annonce par des signes si alarmans qu'un célèbre médecin de l'antiquité la comparait à un taureau en fureur, l'épilepsie (I), a cédé à l'emploi méthodique de ce remède, d'après les assertions de Mead, Tissot, Dehaën, etc. Plus récemment, le docteur Chrichton, médecin de l'empereur de Rus-

(1) Arétée de Cappadoce a dessiné les traits de cette déplorable maladie avec une vigueur de pinceau inimitable. Lucrèce, dans 
sie, a triomphé, avec la valériane, d'une épilepsie qui, pendant sept ans, avait résisté à tous les autres secours de la thérapeutique.

Une jeune fille, atteinte depuis dix ans d'une affection nerveuse accompagnée de symptômes épileptiques, a été délivrée dans l'espace d'un mois par le même moyen. M. le docteur Macartan, médecin distingué, qui a opéré cette guérison, donnait trois fois par jour à la malade un scrupule de racine, de valériane en poudre. Elle n'a point eu de rechute, et elle jouit depuis plusieurs années de la plus parfaite santé. Gilibert a également guéri trois épileptiques avec ce médicament, administré à haute dose, en substance pulvérisée et en infusion vineuse.

Mais nous ne pouvons nous dissimuler que d'autres praticiens non moins estimables ont obtenu peu de succès de la valériane. Au reste, lorsqu'on veut faire usage de cette substance nervine, il faut préalablement examiner s'il n'existe point d'autres indications à remplir. Le sujet est-il pléthorique, d'une constitution forte, il faut lui prescrire des bains, des évacuations sanguines, des boissons tempérantes, du petit-lait, un

son Poème de la nature des choses, a également tracé de l'épilepsie un tableau digne d'un grand peintre.

Quin etiam subitâ vi morbi scepè coactus Ante oculos aliquis nostros, ut fulminis ictu, Concidit, et spumas agit, ingemit et tremit artus : Decipit, extentat nervos, torquetü, anhelat: Inconstanter et in jactando membra fatigat : Nimirum, quia vis morbi distracta per artus Turbat agens animam: spumantes ut in cequore salso $V$ entorum validis fervescunt viribus undae.

(Lvcriti, de Nalura rerum, lib. 3.) 
régime rafraîchissant. Lorsqu'il existe des signes évidens d'un embarras bilieux ou gastrique, l'emploi des vomitifs et des évacuans devient indispensable avant d'avoir recours à la valériane. M. le professeur Baumes (Traité des convulsions dans l'enfance) avoue qu'ayant donné ce remède à un enfant de neuf ans atteint de convulsions épileptiques, et qui avait besoin d'être beaucoup purgé, la maladie empira tellement, qu'il désespéra ensuite, pendant plus de quatre mois, de pouvoir lui rendre la santé. Les attaques d'épilepsie, qui auparavant étaient incomplètes, se convertirent en accès très-violens. Après plusieurs évacuations et un peu de repos, M. Baumes parvint à le guérir avec le même remède qui avait d'abord aggravé son état. Il n'appartient qu'aux grands maîtres de reconnaitre leurs fautes, de les avouer avec candeur, et de savoir les réparer. Un praticien vulgaire n'eût point manqué d'accuser la valériane de son insuccès. Du reste, tous les nervins sont inutiles lorsque l'épilepsie est entretenue par quelque lésion organique ou par des affections morales profondes, et l'on pense bien que celle qui succède à la suppression d'une hémorrhagie ou à la répercussion d'un exanthème demande d'autres moyens ( 1 ).

(1) Les charlatans, et même certaines familles, d'ailleurs fort honorables, possèdent des remèdes secrets qui ont, dans quelques cas, dissipé l'épilepsie en agitant violemment tout l'organisme. C'est ainsi qu'un empirique des environs de Lyon traitait et guérissait quelquefois ce mal affreux. Sainte-Marie rapporte qu'il n'exigeait son salaire que deux ans après le traitement, et lorsque la cure paraissait confirmée; qu'il passait nême des contrats pardevant notaire avec ceux dont il entreprenait la guérison à ces conditions. Son secret consistait en une poudre qu'il faisait pren- 
La valériane a été également éprouvée contre la paralysie, l'hystérie, la chorée ou danse de Saint-Guy, la migraine, et une foule d'autres accidens nerveux. Elle a quelquefois guéri ou soulagé ces maux, souvent elle les a aggravés. On peut fonder quelque espoir sur ce médicament lorsque l'affection nerveuse s'accompagne d'un état de débilité qu'on reconnait à la lenteur du pouls, à la mollesse des chairs, et surtout à une langueur générale peinte dans tous les traits de la physionomie. Lorsque ces symptômes prédominent, la valériane, unie au quinquina, produit quelquefois des effets admirables; tandis que cette médication tonique est fortement contre-indiquée par la mobilité des nerfs, jointe à une irritation excessive ou à un état imminent de phlogose. C'est ici que la méthode jadis si vantée du docteur Pomme a de grands succès, et l'on a vu l'hystérie, l'hypochondrie, des affections convulsives que la valériane et les nervins stimulans avaient portées à un très-baut degré de violence, céder au simple usage des bains et des boissons tempérantes; ce qui prouve d'une manière incontestable que le traitement méthodique de ces maladies repose entièrement sur la connaissance des causes qui les excitent, les entretiennent ou les reproduisent. Les indications relatives à l'état

dre le matin; mais le malade devait garder le lit tout le jour, car en restant debout il aurait couru le risque de s'assommer. En effet, de nombreux et violens accès d'épilepsie avaient lieu pendant vingt-quatre heures. Il se trouvait le lendemain dans un affaissement extrême avec stupeur ou délire; là se terminait le traitement et l'opération du remède. Le malade était délivré de son níal pour plusieurs années, quelquefois même pour toujours. 
d'irritation ou d'atonie de l'appareil nerveux ne sont d'ailleurs très-souvent que secondaires, et le médecin ne doit s'en occuper que lorsque la cause primitive a été combattue par des remèdes convenables.

Mais les propriétés actives de la valériane brillent surtout dans les affections convulsives entretenues par un foyer vermineux; et l'on a vu des mouvemens épileptiques, des spasmes, des tremblemens, des convulsions générales, la cardialgie, la catalepsie et autres phénomènes nerveux occasionés par la présence des vers, céder parfois d'une manière très-prompte à ce précieux médicament, qui a le double avantage de faire périr ou d'expulser ces insectes par son principe amer et fétide, et de réprimer en même temps la mobilité nerveuse par sa vertu antispasmodique. Dans la plupart de ces affections sympathiques, suscitées par la diathèse vermineuse, la valériane emprunte une nouvelle force de son union avec le camphre, le jalap, le calomel. Associée à cette dernière substance, elle a triomphé, dans un court espace de temps, d'une maladie vermineuse invétérée qui avait réduit un jeune homme à un état voisin de la démence.

Pendant son enfance, M. $\mathrm{E}^{* * * *}$ avait été singulièrement tourmenté par lès vers, et depuis environ deux ans il était sujet à des palpitations de cœur, à des terreurs continuelles Son sommeil était pénible et presque toujours accompagné de rêves effrayans. Plusieurs fois la nuit il s'éveillait en sursaut, et il poussait des cris lamentables, croyant voir un spectre prêt à le saisir. Après plusieurs traitemens, qui n'avaient eu aucun succès, je lui conseillai des bols préparés avec la valé- 
riane en poudre et le muriate de mercure doux. Ce remède fut suivi, le troisième jour, de l'expulsion de plusieurs vers lombricoïdes. Huit jours après, le malade en rendit encore cinq ou six avec une grande quantité de matières muqueuses. On continua le remède, et on donna en même temps des clystères préparés avec une forte infusion de valériane et de l'huile de camomille; mais on ne voyait plus de vers dans les déjections. Un matin, après avoir pris un lavement de valériane, le malade rendit un paquet de vers entrelacés, au nombre de dix-huit. De jour en jour, on vit la santé du jeune homme s'améliorer d'une manière notable. Les palpitations étaient moins fréquentes, le sommeil beaucoup plus tranquille. Après quelques jours de repos, je fis recommencer le traitement; on donna stous les trois jours dix-huit grains de valériane et six grains de muriate de mercure doux réduits en bols, avec un peu de miel. Cette préparation, continuée pendant quelques semaines, détruisit tout-à-fait le foyer vermineux. Le malade éprouvait seulement de la faiblesse, et il digérait avec difficulté. Le vin de quinquina le rétablit entièrement.

Outre les symptômes nerveux, il est encore d'autres signes qui peuvent faire soupçonner la présence des vers. Les enfans tourmentés par ces insectes ont assez souvent les glandes salivaires engorgées et la bouche pleine d'eau. 'Tissot dit avoir observé plusieurs fois une sorte d'aphonie d'origine vermineuse. Une petite fille de six ans éprouvait périodiquement une extinction de voix accompagnée de délire; ces attaques, qui duraient plusieurs heures, s'étaient renouvelées plus de vingt 
fois pendant le cours d'une année. Ce célèbre praticien, ayant examiné son état avec attention, ne douta point que les vers n'en fussent la cause. La valériane lui parut le vermifuge le mieux indiqué dans cette circonstance. La petite malade fut en effet radicalement guérie par ce remède.

Pechlin nous a fait connaître uneanomalie singulière de la sensibilité produite par la présence des vers. Un jeune homme montra, pendant toute la durée d'une maladie vermineuse, une mémoire prodigieuse et un génie élevé; à sa guérison il redevint un sujet fort ordinaire.

La vertu antifébrile de la valériane a été constatée par plusieurs médecins à une époque où la guerre maritime avait rendu le quinquina d'une cherté excessive. D'après les observations recueillies par $\mathbf{M}$. le docteur Vaidy dans les hôpitaux de Berlin, elle a dissipé en peu de jours des fièvres intermittentes de tous les types, et dont la plupart étaient anciennes. La dose ordinaire était d'un à trois gros, pris en deux ou trois fois, le jour de l'apyrexie, et d'un à deux gros le jour de l'accès. M. Vaidy'a quelquefois ajouté un grain d'opium par gros de poudre de valériane. M. le docteur Desparanches, qui a également employé cette plante comme fébrifuge, dit qu'il l'a trouvée peu inférieure au quinquina. Je n'ai jamais prescrit la valériane seule; mais j'ai acquis la certitude que certaines fièvres intermittentes, accompagnées de symptômes nerveux, cédaient plus facilement à l'action du quinquina lorsqu'on y joignait la valériane.

Passons maintenantà un autre ordre de fièvres, bien 
que leur existence soit vivement contestée par la nouvelle école, et prouvons que la valériane est douée de vertus puissantes dans les maladies qui offrent un caractère adynamique et ataxique. Ici les autorités ne nous manquent point, et nous pouvons opposer aux physiologistes des hommes dont la pratique vaste et lumineuse est universellement appréciée. Dans l'état avancé, et même dès la deuxième période de ces pyrexies, c'està-dire lorsque des signes évidens de faiblesse ont remplacé l'état d'irritation; lorsque le désordre de l'appareil nerveux est uni à la prostration des forces, et surtout lorsque l'adynamie et l'ataxie sont dues à une influence miasmatique, la valériane est sans contredit un des médicamens les plus salutaires. On ne doit pas même hésiter à prescrire cette substance, ainsi que les autres excitans volatils, dès le début et pendant la première période des fièvres putrides et nerveuses, lorsqu'elles s'annoncent avec tous les symptômes de l'abattement et de la faiblesse. C'est ainsi que le professeur Hufeland a employé avec un grand succès la méthode stimulante pendant tout le cours des fièvres nerveuses qui ont régné en Prusse dans l'hiver de 1807 . Cet habile praticien administrait ordinairement une infusion de valériane animée avec l'éther alcoholisé et l'acétate d'ammoniaque. Mais, dans un degré plus avancé de la maladie, il était indispensable d’augmenter les doses de cette médication excitante.

Pierre Frank, Hecker, Hildenbrand, Smith, Barthez, Baumes, Pinel, etc., recommandent l'emploi de la valériane pendant la période adynamique et nerveuse des affections fébriles, en y joignant, les uns 
le quinquina, le camphre, le musc, la serpentaire de Virginie; les autres, l'arnica, l'opium et l'ammoniaque. On sait combien la présence des vers peut altérer la marche des fièvres putrides, en excitant des symptômes graves, des spasmes, des convulsions, le hoquet, la cardialgie et autres accidens nerveux ( $\mathrm{I}$ ). Cette complication vermineuse, qui ajoute au danger de la maladie, est combattue avec succès par la valériane unie au camphre. Enfin les préparations de valériane sont indiquées vers la fin du typhus, lorsqu'on aperçoit une tendance aux sueurs critiques; lorsque la peau, auparavant sèche, s'humecte, se détend d'une manière sensible. Ces médicamens deviennent alors des sudorifiques très-efficaces.

Mais on tomberait dans une erreur bien grave, si l'on croyait pouvoir placer la valériane dans le traitement de toutes les maladies adynamiques et ataxiques. Ces pyrexies, surtout dans leur premier stade, offrent très-souvent des symptômes inflammatoires, des phlegmasies locales, ou un état d'irritation vive, qu'on doit chercher à combattre par une méthode débilitante. Toutefois, dans le véritable typhus des camps et des prisons, gardez-vous bien d'abuser des antiphlogistiques : la période d'irritation est d'une courte durée, et la dépression des forces, qui quelquefois lui succède

(1) Forestus a observé une phrénésie produite par des vers, et qui régna épidémiquement en France dans l'année 1545. Les malades se plaignaient d'une vive céphalalgie, et de chaleur à la région lombaire; ils étaient privés de sommeil, en proie au délire le plus violent, ou plongés dans un état comateux. (Observ., lib. 7.) 
d'une manière très-prompte, vient bientôt réclamer d'autres secours que les boissons émollientes et l'application des sangsues. Les symptômes nerveux contre-indiquent également l'emploi de la valériane et autres remèdes excitans, quand ils dépendent d'une phlegmasie gastrique ou d'une congestion cérébrale. Dans les cas douteux, il faut prendre en considération l'état de vigueur ou de faiblesse du sujet, la saison de l'année, et le caractère de l'épidémie régnante.

Les propriétés de la valériane dépendent, en grande partie, du sol où elle est récoltée. Il faut choisir, pour les usages médicinaux, celle qui croît sur les collines exposées aux rayons du soleil, et non celle qu'on trouve sur les bords humides des ruisseaux. Dresky (Dissert. de valer. officin.) recommande de la cueillir vers la fin d'avril ou au commencement de mai, de la faire sécher à l'ombre, de la conserver dans des vases bouchés, et de la renouveler tous les ans. En vieillissant, ses principes aromatiques s'envolent. Nous ajouterons qu'il faut ne la pulvériser qu'au moment d'en faire usage, si l'on veut qu'elle jouisse de toute son énergie. D'après Joseph Frank, elle remplace parfaitement l'aristoloche serpentaire.

On donne la racine pulvérisée, depuis quinze ou vingt grains jusqu'à un gros, une ou plusieurs fois par jour; on y ajoute un peu de macis ou de cannelle, pour en masquer la saveur désagréable. Dans les affections nerveuses graves, il faut en élever hardiment les doses, si l'on veut obtenir des succès. Donnée à la dose d'une demi-once, deux fois par jour, elle a dissipé une catalepsie qui avait résisté à de plus faibles doses. 
Quarin en prescrivait jusqu'à six gros par jour; Herz en donnait demi-once à la fois, et réitérait cette dose trois ou quatre fois dans les vingt-quatre heures.

L'eau, le vii et l'alcohol s'emparent des principes actifs de la valériane. L'infusion aqueuse est fréquemment employée : d'autres prescrivent la décoction; mais alors une partie de l'huile essentielle s'envole. En mêlant ces deux produits, on conserve tous les principes chimiques de la plante. La dose est de deux ou trois gros et plus pour une livre de véhicule. On peut ajouter à la colature de l'eau de menthe poivrée ou quelque autre excitant diffusible. L'extrait de valeriane est peu usité; ou peut le prescrire à la dose de vingt ou trente grains. Suivant Dresky, l'extrait alcoholique conserve l'odeur et le goût de la plante; l'extrait aqueux est beaucoup moins actif.

La teinture alcoholique simple de valériane, la teinture éthérée et la teinture ammoniacée sont des médicamens d'une grande énergie. La teinture de valériane éthérée de Trommsdorff se prépare en faisant digérer à une douce chaleur une once de racine de valériane en poudre dans six onces d'alcohol; on ajoute ensuite à la colature deux onces d'éther sulfurique. Pour préparer la teinture de valériane ammoniacée ou volatile, on fait digérer à froid, pendant quatre jours, deux onces de poudre de valériane dans douze onces d'esprit d'ammoniaqne. Ces compositions se prescrivent dans les affections nerveuses, convulsives, hystériques, à la dose de trente ou quarante gouttes et plus, qu'on mêle avec une demi-tasse d'infusion de fleurs de camomille, de feuilles de menthe ou d'oranger. 
Infusion de valériane composée. Prenez, racine de valériane en poudre, une once; cannelle de Ceylan, un gros: faites infuser pendant une heure dans dix onces d'eau bouillante; passez et ajoutez à la colature, alcohol de menthe, une once et demie; teinture de valériane ammoniacée, demi-once ; sirop simple, une once. Cette potion stimulante se donne par cuillerées, d'heure en heure, dans le traitement du typhus nerveux ou ataxique, avec prostration des forces, 'soubresauts des tendons, tremblemens musculaires, etc.

Gouttes excitantes du professeur Hecker. Prenez, essence de valériane, éther alcoholisé, de chaque deux gros; teinture thébaïque, un gros. On en donne, toutes les heures, de vingt à trente gouttes, dans deux onces d'infusion de valériane ou d'arnica.

Ces préparations ne doivent point être prescrites au commencement des fièvres putrides et nerveuses, lorsque le pouls est plein et fréquent, le visage animé, l'urine rare, ardente; elles seraient alors pernicieuses. Mais il ne faut pas non plus attendre que la prostration des forces soit parvenue à un très-haut degré; et il est nécessaire de renouveler souvent et d'augmenter peu à peu les doses, parce que leur impression stimulante s'émousse et s'épuise bientôt sur des organes frappés d'une débilité profonde.

Poudre vermifuge. Prenez, racine de valériane nouvellement pulvérisée, demi-gros; calomel, huit grains : mêlez, et divisez en trois doses à prendre de deux en deux heures. Cette poudre m'a parfaitement réussi dans les affections spasmodiques causées par la présence des vers. On augmente ou on diminue la 
dose des ingrédiens, suivant l'âge du malade. La combinaison de la valériane avec le calomel ne convient pas seulement dans les affections vermineuses de l'enfance, mais encore dans les maladies convulsives de cet âge, qui se montrent très-souvent liées à la surabondance des fluides muqueux.

Pilules antispasmodiques. Prenez, extrait de valériane, camphre, castoréum, assa-fotida, de chaque un gros; extrait d'opium, douze grains : mêlez, et formez soixante-douze pilules, à prendre une le matin à jeun et une autre le soir. M. le docteur Blaud a dissipé avec ces pilules une affection convulsive connue sous le nom de chorée ou danse de Saint-Guy. Il a donné successivement jusqu’à douze de ces pilules, distribuées en trois prises dans le courant de la journée; et il est revenu par gradation aux doses primitives. En dix jours, ce traitement a été couronné de succès sur trois malades. (Nouvelle bibliothèque médicale, décembre 1825.)

\section{VALÉRIANE PHU. VALERIANA PHU.}

Valeriana phu. Lins. Spec. 45. DC. FI. Fr. 3316.

Lapeyr. Plant. Pyr. 1. 18.

De sa racine épaisse, presque fusiforme, s'élève une tige droite, creuse, un peu branchue, haute de deux on trois pieds. Les feuilles radicales sont pétiolées, ovales, les unes tout-à-fait simples, les autres lobées à leur base; les feuilles supérieures de la tige sont ailées, composées de folioles lancéolées, pointues et un peu décurrentes. Les fleurs sont blanches ou rougeâtres, 
disposées au sommet de la tige et des rameaux en panicule peu étalée.

Cette plante croît dans les Pyrénées, dans les montagnes de l'Alsace et dans la Silésie; M. Poiret l'a observée sur les côtes de Barbarie, dans les environs de La Calle. On la cultive dans les parterres. Sa racine exhale une odeur forte, pénétrante, analogue à celle de la valériane sauvage. De Haën n'employait que cette espèce dans sa pratique. Les paysans de la Sibérie la donnent à leurs enfans atteints d'épilepsie ou d'autres maladies convulsives.

\section{VALÉRIANE NARD-CELTIQUE. VALERIANA CELTICA.}

Valeriana celtica. Linn. Spec. 46. DC. FI. Fr. 3322. $\mathrm{J}_{\mathrm{ACQ}}$. Collect. 1. p. 24. t. 1.

Sa racine, brune, écailleuse, horizontale, donne naissance à une tige menue, simple, cylindrique, haute de quatre à six pouces. Les feuilles radicales sont oblongues, pointues, entières, rétrécies et prolongées en pétiole à leur base; les feuilles canlinaires, au nombre de deux à quatre, opposées, sessiles et linéaires. Les fleurs sont disposées en grappe allongée, quelquefois composée de trois ou quatre verticilles sessiles, quelquefois formée de rameaux opposés.

Cette plante croît sur les rochers des Hautes-Alpes, dans le Valais, le Piémont, au mont Cenis, etc. Ses feuilles et le port de sa tige la font ressembler à une petite graminée. C'est le nard-celtique des Romains; Virgile, dans sa cinquième églogue, lui donne le 
nom de saliunca humilis. (Voyez la Flore de Virgile, par M. Fée, dans la Collection des classiques latins.)

Sa racine a une odeur très-forte, une saveur aromatique, âcre, légèrement amère. Très-usitée anciennement, on l'emploie fort peu aujourd'hui, bien qu'elle possède des propriétés actives. Elle est, dit-on, fort estimée en Afrique, où l'on trouve son parfum si délicieux, qu'on en compose une pommade cosmétique.

La valériane diö̈que (valeriana dioica), la valériane rouge (valeriana rubra), la valériane des montagnes (valeriana montana), sont également aromatiques, et leurs vertus se rapprochent de celles des autres espèces. 


\section{RUBIACÉES. RUBIACEAE.}

Rubiacece. Juss. DC.

\section{QUINQUINA. CINCHONA.}

Calice turbiné à cinq dents. Corolle tubulée, à cinq divisions plus ou moins étroites, souvent plus courtes que le tube, la plupart velues à leur sommet. Étamines ordinairenent au nombre de cinq, à filamens très-courts, insérés vers le milieu du tube de la corolle; anthères allongées, tantôt saillantes, plus souvent renfermées dans la corolle. Ovaire presque ovale, surmonté d'un style de la longueur de la corolle, et terminé par un stigmate épais, oblong, simple ou légèrement bifide. Capsule oblongue, couronnée par le calice, à deux valves courbées en dedans à leurs bords, se séparant, à l'époque de la maturité, en deux parties ou comme en deux capsules. Semences oblongues, comprimées, à rebords membraneux, attachées à un réceptacle central.

\section{QUINQUINA CONDAMINE. CINCHONA COND AMINEA.}

Cinchona condaminea. Humb. et Bonpl. Plant. aquin. 1. 33.

t. 10. - Cinchona officinalis. Linn. Syst. veg. ed. 10. p. 929.

(Planche 7o.)

C'est un arbre d'un port élégant, qui croît au Pérou, sur la pente des montagnes, près de Loxa et d'Ayavaca. Ses rameaux sont opposés, recouverts d'une écorce d'un gris verdâtre, et marqués de cicatrice après la chute des feuilles; les inférieurs ont 
une disposition horizontale; les autres se relèvent à leur extrémité. Ses feuilles sont ovales, lancéolées, munies de glandes, d'un vert luisant en-dessus, marquées en-dessous de plusieurs nervures, dont la principale et la plus saillante est ordinairement d'une belle couleur rouge. On remarque dans chacune de ces nervures un très-petit enfoncement qui renferme une liqueur cristalline très-astringente. Les pétioles sont courts, aplatis d'un côté, convexes de l'autre, avec deux stipules aiguës et caduques à leur base.

Les fleurs, teintes de rose et d'une odeur suave, forment une panicule terminale, étalée, à ramifications ordinairement trichotomes. Les pédoncules, légèrement pubescens, offrent à leur base et vers leur milieu de petites bractées opposées, aiguës. Le calice est presque pentagone, un peu hérissé, à cinq dents ovales, acuminées, ouvertes. La corolle est infundibuliforme, à tube rouge, garni de poils soyeux, à limbe divisé en cinq découpures aiguës plus courtes que le tube, ciliées au sommet et aux bords. Les étamines sont courtes, à filets égaux, attachés au fond du tube; les anthères linéaires deux fois plus longues que la partie libre des filets. L'ovaire est rond, un peu déprimé, rougeâtre, adhérent au calice. Le style, droit, épais, un peu plus long que le tube, se termine par un stigmate légèrement bifide. La capsule est ovale, oblongue, couronnée par le calice, marquée longitudinalement de deux sutures opposées, à deux valves et à deux loges, renfermant un grand nombre de semences de forme lenticulaire, bordées d'une membrane laciniée. 
Cette espèce de quinquina est connue sous le nom de quinquina gris ou quinquina loxa. L'écorce fraîche est d'un gris cendré, remplie d'un suc jaunâtre qui en découle aussitôt qu'on la blesse. L'écorce sèche est mince, cylindrique, bien roulée, recouverte de petites crevasses transverses, d'une couleur grisâtre en dehors, d'nn rouge pâle intérieurement. Sa cassure est nette, son odeur peu sensible, sa saveur astringente et amère. Le quinquina loxa, devenu très-rare, est regardé en Espagne comme le plus énergique et le plus efficace contre les fièvres intermittentes.

Le cinchona scrobiculata de MM. de Humboldt et Bonpland a beaucoup d'analogie avec le cinchona condaminea; il en diffère par le tronc, qui est plus élevé; par les feuilles, d'une plus grande dimension; et par les anthères, toujours plus courtes que la partie libre des filets. Les écorces de cette plante sont trèsestimées, et l'on en fait un grand commerce sous le nom de quina fina.

\section{QUINQUINA A FEUILLES LANCÉOLÉES.}

\section{CINCHONA LANCIFOLIA.}

Cinchona lancifolia. Murss. Périod. Santa-Fé. 465. - Cinchona angustifolia. Ruız. Quinou. Suppl. p. 21. - Cinchona nitida. R. et Pav. Fl. Peruv. 2. t. 191.

(Planche 7 r.)

Cette espèce, toujours solitaire sur les pentes escarpées des Andes, s'élève à la hauteur de trente à 
quarante-cinq pieds. Ses rameaux sont couverts d'une écorce d'un brun pourpre, lisse, ou creusée de fentes transversales et obliques, souvent marquée de cicatrices provenant de la chute des feuilles. Celles-ci sont opposées, pétiolées, ovales, en forme de lance, longues d'environ deux pouces, veinées, d'un vert pâle, toujours lisses, sans scrobicules et sans glandes. Ses fleurs sont rougeâtres, disposées au sommet des rameaux en panicule ouverte et trichotome, avec des pédoncules parsemés d'un léger duvet. La corolle est divisée à son limbe en cinq découpures aiguës, tomenteuses en dedans, plus courtes que le tube. La capsule est oblongue, glabre, parsemée de stries peu apparentes.

L'écorce que fournit cet arbre porte le nom de quinquina orangé; elle est roulée en tubes gros et épais, d'une substance compacte et dure, d'une cassure fibreuse. Sa surface est brune, rugueuse, fendillée transversalement, couverte de lichens grisâtres. La couleur intérieure de l'écorce est d'un jaune foncé, presque fauve; son odeur est légèrement aromatique, sa saveur très-amère, mais peu astringente. Ce quinquina est fort rare; il recèle, d'après Mutis, la vertu fébrifuge par excellence. Son principe aromatique le fait employer de préférence dans le traitement des fièvres accompagnées de symptômes nerveux. D'après l'opinion de Zea, de M. de Humboldt, et autres célèbres naturalistes, le cinchona nitida, le cinchona lanceolata, et le cinchona rosea de la Flore péruvienne, ne sont que des variétés du cinchona lancifolia. 
Le cinchona nitida, découvert par Ruiz en ${ }^{2}$ 80, a un tronc stolonifère, et des pédoncules multiflores. Son écorce est regardée comme un excellent fébrifuge; elle ressemble à celle du lancifolia de Mutis.

Le cinchona lanceolata a une ample panicule et des fleurs disposées presqu'en corymbe, avec un calice pourpré, une corolle d'un rose vif, à limbe velu, et des anthères hispides à leur base. Ses feuilles sont oblongues, lancéolées, glabres, traversées par des veines pourpres. Son écorce, brune, chagrinée, parsemée de cryptogames grisâtres, porte le nom de cascarilla amarilla, de Mugna; elle est jaunâtre intérieurement et d'une saveur très-amère.

Le cinchona rosea, décrit par Ruiz et Pavon, croît dans les forêts des Andes, aux environs de San-Antonio de Playa-Grande. C'est un arbre peu élevé', dont les rameaux quadrangulaires sont garnis de feuilles oblongues, acuminées, glabres et luisantes, avec desstipules purpurines situéesà la base despétioles. Ses fleurs forment une panicule droite, terminale; les pédoncules sont étalés, comprimés et pubescens. Le calice est de couleur purpurine; la corolle rosée, d'environ quatre lignes de longueur. Le tube court, légèrement courbé, glabre à son orifice, s'évase en un limbe tomenteux à cinq divisions ovales. Les étamines sont velues à leur base, les anthères bifides et un peu saillantes. Son écorce est brune, lisse, de couleur chocolat intérieurement, d'une saveur ligneuse, styptique, mais peu amère. 


\section{QUINQUINA PUBESCENT. CINCHONA PUBESCENS.}

Cinchona pubescens. $\mathrm{V}_{\mathrm{AHL}}$ Act. Soc. Hist. Nat. HafN.

1. 19. t. 2.

(Planche 72.)

Ce quinquina s'élève, sur un tronc droit, à quinze ou vingt pieds de hauteur. Ses rameaux, pubescens à leur partie supérieure, se garnissent de feuilles pétiolées, ovales, quelquefois cordiformes, velues, à nervures fortes et parallèles. La configuration de ces feuilles varie singulièrement dans les différens individus et quelquefois sur la même plante. La panicule est terminale, pubescente, garnie de fleurs nombreuses, blanches en dedans, rouges en dehors, avec de petites bractées à la base des divisions des pédoncules. Le calice est coloré, à cinq dents aiguës, adhérent à l'ovaire dans presque toute son étendue. La corolle est tomenteuse, à cinq divisions ovales, parsemées de poils blanchâtres; son tube renferme cinq étamines dont les filets sont très-courts. La capsule est cylindrique, glabre, longue d'un pouce, un peu rétrécie vers la base.

On rencontre cet arbre dans les Andes et les forêts chaudes du Pérou. Ses écorces constituent le quinquina jaune royal ou quinquina calisaya; elles sont larges, peu roulées, d'un tissu fin et serré, d'un jaune foncé intérieurement, imitant la couleur de la cannelle. Leur arome est peu sensible; mais elles manifestent une saveur éminemment amère. Ce quinquina, d'ail- 
leurs très-estimé, est souvent confondu avec plusieurs espèces ou variétés différentes.

Quelques botanistes regardent le cinchona hirsuta, le cinchona purpurea et le cinchona ovata, de Ruiz et Pavon, comme des variétés du précédent. Les écorces du cinchona purpurea sont aujourd'hui très-répandues par la voie du commerce; elles sont d'un jaune rougeâtre et d'une amertume très-remarquable.

\section{QUINQUINA A FEUILLES OBLONGUES.}

\section{CINCHONA OBLONGIFOLIA.}

Cinchona oblongifolia. Murss. Aцiв. Fièvr. pern. t. 4. Cinchona grandifolia. Porr. Encycl. 6. 38.

(Planche 73.)

C'est un très-grand arbre qui croît au Pérou, dans les bois des Andes, au voisinage des torrens et dans les forêts de Santa-Fé de Bogota. Les jeunes rameaux sont quadrangulaires, rougeâtres, garnis de feuilles amples, ovales, glabres, d'un vert luisant en-dessus, plus pâle en dessous, et traversées par des veines purpurines dont les principales offrent à la base quelques poils soyeux et blanchâtres. Ses fleurs répandent un doux parfum et forment une panicule très-rameuse. Le calice est pourpre, à cinq dents très-courtes; la corolle blanche, longue d'un pouce, à limbe un peu velu en-dedans. Les anthères sont bifides à leur base, cachées vers le milieu du tube, au lieu de s'élever jus- 
qu'aux parties supérieures comme dans les espèces précédentes.

Les écorces provenant de ce quinquina sont épaisses, fibreuses, d'un rouge brun, d'une saveur amère et acerbe. Leur infusion à chaud donne une teinture d'un rouge intense, assez semblable à la couleur du sang. Ce quinquina, connu sous le nom de quinquina rouge, excelle par ses propriétés toniques; on l'emploie spécialement dans les gangrènes et dans les flux produits par une grande débilité.

M. le professeur Alibert a donné, dans son Traité des fièvres pernicieuses intermittentes, la description et la figure d'une cinquième espèce de quinquina, remarquable par la grandeur de ses fruits; c'est le cinchona ovalifolia de Mutis, ou le cinchona macrocarpa de Vahl. Ses rameaux sont articulés, velus, garnis de feuilles pétiolées, elliptiques, oblongues, un peu coriaces, glabres et luisantes en dessus, pubescentes en dessous, avec des nervures pileuses. Les plus jeunes feuilles sont velues sur chaque surface, et surtout le long des nervures. La panicule est terminale, pubescente, trichotome. Les fleurs, presque sessiles sur les pédoncules des ramifications, offrent un calice campanulé, pubescent en dehors, soyeux en dedans, à cinq ou six dents peu apparentes; une corolle coriace, velue, longue d'un pouce et demi, à limbe divisé en cinq ou six découpures lancéolées, obtuses, et de la longueur du tube. Les étamines, insérées au milieu du tube, ont des filets très-courts, des anthères linéaires, s'élevant un peu au-dessus de l'orifice. L'ovaire est pentagone, le stigmate bifide, la capsule II. 
cylindrique, glabre, longue de deux pouces, un peu rétrécie à sa base.

Ce quinquina croît dans le royaume de Santa-Fé. Ses écorces, que les pharmacologistes désignent sous le nom de quinquina blanc, sont minces, recouvertes d'un épiderme grisâtre, très-fin et très-doux au toucher, blanchâtres et comme basanées intérieurement, très-cassantes, se réduisant facilement en poudre, d'une amertume désagréable, nauséabonde. D'après Mutis, elles jouissent d'une qualité savonneuse qui les rend fort utiles dans les fièvres intermittentes rebelles et dans les maladies chroniques.

Parmi les espèces dont nous venons de tracer les caractères physiques, les quatre premières et leurs variétés ont spécialement fixé l'attention et mérité la confiance des praticiens, sous le rapport de leur énergie et de leur qualité fébrifuge. La cinquième, malgré les éloges de Mutis, est très-rarement employée, du moins en France. Le genre Cinchona renferme quelques autres plantes à corolles velues, dont les écorces sont plus ou moins amères. Nous ne parlerons ici que du cinchona ovalifolia de Humboldt et Bonpland, qu'il ne faut pas confondre avec le cinchona ovalifolia de Mutis; du cinchona micrantha, et du cinchona glandulifera de Ruiz et Pavon.

La première espèce (cinchona osalifolia), découverte au Pérou, dans les forêts de la province de Cuença, par Humboldt et Bonpland, constitue un arbrisseau de huit à dix pieds de hauteur, et dont les rameaux portent des feuilles ovales, un peu obtuses, luisantes en dessus, pubescentes à la surface inférieure. 
Les fleurs sont blanches, disposées en panicule, munies de bractées linéaires et de pédoncules soyeux. La corolle est longue de six à huit lignes, à tube cylindrique, couvert de poils soyeux, ainsi que les divisions du limbe. L'écorce sèche, récoltée sur des branches de quatre à cinq ans, est un peu roulée sur les bords, gercée en tous sens et d'une manière inégale, d'un gris foncé en dehors, d'une couleur jaunâtre tirant sur le fauve intérieurement, d'une saveur astringente, un peu aromatique. Ce quinquina est connu dans le pays sous le nom de cascarilla peluda.

Le cinchona micrantha est un arbre d'un beau port, indigène des Andes du Pérou, où il a été découvert par Tafalla. Il a des feuilles luisantes en dessus, pubescentes en dessous, avec des veines pourprées. Les fleurs sont nombreuses, très-petites, presque sessiles, munies d'un calice à cinq dents aiguës, d'une corolle d'environ trois lignes de longueur, tomenteuse et rougeâtre en dehors, lanugineuse et blanchâtre intérieurement. Les étamines ont des filets très-courts, insérés au-dessous de la moitié dı tube, et des anthères linéaires un peu plus longues que les filets. Le style, presque aussi long que les étamines, se termine par un stigmate bilobé. Les capsules sont oblongues, aiguës, brunes, légèrement striées. L'écorce de ce quinquina est roussâtre à l'extérieur, rougeâtre intérieurement, et d'une saveur très-amère.

Le cinchona glandulifera est un arbrisseau de douze pieds de hauteur qu'on trouve dans les bois tempérés des Andes. Ses feuilles sont glanduleuses, 
velues en dessous, particulièrement aux nervures. Les fleurs ont une corolle d'un blanc rosé, glabre en dehors, ainsi que le tube, trois fois plus longue que le calice; des filets très-courts, et un style à stigmate bilobé. Son écorce est très-mince, parseméc de lichens grisâtres, d'une couleur fauve, rougeâtre intérieurement, et d'une amertume très-prononcée.

On trouve peu d'espèces officinales dans la section des cinchona à corolles glabres. Les plus intéressantes sont le cinchona floribunda de Swartz, et le cinchona caribcea de Jacquin, rangés parmiles exostema par le savant botaniste Persoon.

Le cinchona floribunda a un tronc élevé, des rameaux cylindriques, glabres, un peu tétragones, et d'un pourpre brun. Ses feuilles sont grandes, ovales, lancéolées, aiguës, veinées, à nervures latérales saillantes. Les fleurs sont nombreuses, longues de deux à trois pouces, d'un blanc teint de pourpre, et disposées en panicule terminale. Elles ont un calice à dents subulées, très-courtes ; une corolle cylindrique, longue d'un pouce, divisée à son limbe en longues découpures glabres et linéaires; des étamines saillantes avec des filets insérés à la base du tube; un stigmate ovale et entier. La capsule renferme des semences nombreuses émarginées à la base.

Ce quinquina a été découvert par Desportes, à SaintDomingue, en $174 \%$, et décrit ensuite par Badier sous le nom de cinchona montana. On le trouve également sur le sommet des montagnes, à Sainte-Lucie, à la Jamaïque, à la Guadeloupe, etc. Ses écorces, connues dans le commerce sous le nom de quinquina piton, 
sont minces, peu roulées, recouvertes d'un épiderme brun, très-rugueux, parsemé de lichens, d'une couleur ferrugineuse ou d'un roux plus ou moins foncé intérieurement, et d'une grande amertume. Ce quinquina n'est pas seulement doué d'une propriété fébrifuge; il excite aussi le vomissement lorsqu'on l'administre à haute dose.

Le cinchona caribara, décrit par Jacquin, est également indigène des Antilles. On le reconnaît à ses pédoncules axillaires et solitaires, chargés d'une seule

- fleur. Les rameaux sont glabres, d'un brun noirâtre, striés, souvent marqués de petites taches blanches ou jaunâtres. Les feuilles sont pétiolées, ovales, rétrécies à leurs deux extrémités, glabres, munies de bractées aiguës, très-petites et ciliées. Les fleurs naissent solitaires dans les aisselles des feuilles et vers l'extrémité des rameaux; elles offrent un petit calice glabre, à cinq dents aiguës; une corolle à tube cylindrique, à limbe divisé en cinq découpures linéaires, presque obtuses, glabres; des étamines insérées vers la base du tube, et dont les anthères sont un peu saillantes. Les capsules sont noires, ovoïdes, glabres; les semences entourées d'un rebord entier. L'écorce des branches est roulée, grisâtre en dehors, d'un jaune verdâtre intérieurement, d'une saveur d'abord mucilagineuse et sucrée, comme la réglisse, ensuite trèsamère. La poudre est d'un gris jaunâtre, d'une odeur herbacée. Suivant le professeur Alibert, ce quinquina paraît contenir un principe amer, du tannin el de l'acide gallique, mais point de résine. Ainsi que le précédent, il jouit d'une faculté émétique. 
Il existe dans le commerce beaucoup d'autres écorces appartenant soit au genre Cinchona, soit à des genres différens. On peut consulter à ce sujet les savantes recherches de M. Virey, de M. Laubert et de M. Fée.

Le quinquina n'a été connu en Europe que vers le milieu du dix-septième siècle. Linné lui a donné le nom de cinchona, en l'honneur de la comtesse de Cinchon, vice-reine du Pérou, qui fut délivrée d'une fièvre très-opiniâtre par ce remède. plus salutaires a été décrite par Charles-Marie de La Condamine; MM. de Humboldt et Bonpland l'ont consacrée à la mémoire de cet illustre voyageur.

Peu de temps après la découverte du quinquina, on lintroduisit en Espagne, d'où les jésuites le transportèrent en Italie. Son usage se répandit ensuite en France, en Angleterre, en Allemagne, et dans les autres parties de l'Europe. Nous ne parlerons point ici des discussions animées que fit naitre ce nouveau médicament; elles sont consignées dans une foule d'ouvrages, et tant s'en faut qu'elles soient encore terminées. Brown et son école, rapportant presque toutes les affections morbides à un état de faiblesse ou d'asthénie, ont donné au quinquina des éloges outrés, et personne ne conteste aujourd'hui qu'ils n'en aient fait un funeste abus. Mais ne pourrait-on pas dire également que les physiologistes de nos jours, non moins exclusif's dans leur doctrine, et ne voyant partout que des irritations, des phlegmasies, en un mot, un feu toujours prêt à s'allumer dans nos entrailles, ont frappé d'une sorte de réprobation un remède dont les effets sont ad- 
mirables dans beaucoup de maladies qui s'aggravent, au contraire, par les méthodes débilitantes? Ennemi de tous les systèmes, de toutes les doctrines qui portent le cachet de l'exagération, je vais m'occuper de l'emploi thérapeutique du quinquina, et je tâcherai d'apporter dans ce travail toute l'impartialité, toute l'indépendance d'un homme qui n'a besoin de caresser aucune opinion, de ménager aucune secte, et qui s'est voué depuis long-temps au culte de la médecine éclectique. Toutefois je commencerai par jeter un coup d'œil sur les principes qui constituent cette précieuse écorce.

\section{ANALYSE CHIMIQUE.}

Les travaux chimiques qu'on a entrepris sur le quinquina depuis sa découverte sont immenses; mais ce n'est guère que dans ces derniers temps que ce genre d'investigations a été véritablement profitable à la thérapeutique. Un grand nombre d'écorces ont été analysées par des chimistes habiles, et nous devons citer avec éloge les recherches de Fourcroy, de Bartholdi, de Westring, de Seguin, de Vauquelin, de Deschamps le jeune, de Reuss, de Gomez, etc. Toutefois nous nous arrêterons plus volontiers sur les travaux du professeur Vauquelin et de quelques autres savans, qui, en nous dévoilant les principes actifs du quinquina, nous ont fourni des armes plus sûres pour combattre la fièvre.

M. Vauquelin a cherché à déterminer les propriétés du quinquina en employant comme réactifs le tannin, la colle forte, l'émétique et le sulfate de fer. Il résulte de ses expériences que quelques écorces précipitent le 
tannin, et non la colle animale; que d'autres précipitent la colle et ne précipitent point le tannin; que d'autres précipitent le tannin, la colle et l'émétique; enfin que les plus estimées sont celles qui précipitent le tan et la noix de galle. En traitant l'écorce du cinchona pubescens de Vahl par la macération dans l'eau froide, ce chimiste a obtenu une substance colorée, amère, résiniforme. Ce principe végétal paraît avoir à peu près les mêmes caractères dans les meilleures espèces; mais, dans beaucoup d'autres, il offre des différences remarquables. Après avoir retrouvé le sel découvert par M. Deschamps, il a prouvé qu'il était une combinaison de chaux avec un acide végétal dont l'existence était encore ignorée, et à qui il a donné le nom d'acide kinique.

D'après M. Reuss, professeur de chimie à l'université de Moscou, les vertus du quinquina résident spécialement dans la combinaison de deux principes qu'il désigne sous les noms d'amer cinchonique et de rouge cinchonique. D'un autre côté, le docteur Gomez, de Lisbonne, signale un principe amer cristallisé, qu'il croit dépositaire des propriétés fébrifuges du quinquina, et auquel il donne le nom de cinchonin.

Le quinquina de Loxa (cinchona Condaminea), analysé par M. Laubert, a donné une matière verte, âcre, amère, aromatique, très-soluble dans l'éther, moins soluble dans l'alcohol; tandis que le calisaya et autres écorces de la même couleur ont fourni une matière jaune, amère, insoluble dans l'éther, soluble dans l'alcohol et dans l'eau, et ressemblant beaucoup au 
principe amer du quassia amara. Suivant cet habile chimiste, on trouve dans quelques écorces la matière cristalline observée par M. Gomez; un principe colorant d'un rouge brun, ayant les caractères d'une espèce particulière de tannin; de la gomme, de la fécule, un acide libre, et du cinchonate de chaux.

MM. Pelletier et Caventou, dont nous avons déjà signaléplus d'une fois les travaux importans, se livrent à de nouvelles recherches, et obtiennent du quinquina gris (cinchona Condaminea) le principe fébrifuge découvert par M. Gomez; mais en même temps ils constatent sa nature alcaline. Cette substance, désignée sous le nom de cinchonine, est blanche, translucide, susceptible de cristalliser en aiguilles, trèsamère, presque insoluble dans l'eau, soluble dans l'alcohol, et mieux dans un acide. Elle ne se dissout qu'en très-petite quantité dans les huiles fixes, les huiles volatiles, l'éther sulfurique. Unie aux acides, elle forme des sels neutres, dont le degré de solubilité et la forme cristalline varient suivant l'acide employé dans la combinaison. Le sulfate de cinchonine est facilement cristallisable, et très-soluble dans l'eau; il possède la vertu fébrifuge à un très-haut degré.

Ces chimistes ont reconnu, dans la composition du quinquina gris, du kinate acide de cinchonine; une matière grasse, verte; une matière colorante rouge, peu soluble (rouge cinchonique ou matière résineuse); une matière colorante rouge, soluble (tainnin); une matière colorante jaune; du kinate de chaux, de la gomme, de l'amidon et du ligneux.

Le quinquina jaune (cinchona cordifolia) leur a 
offert un principe alcalin qui a reçu le nom de quinine. Cette substance, analogue à la cinchonine, en diffère néanmoins sous certains rapports : elle est aussi blanche, mais elle n'est point susceptible de cristalliser, et sa saveur est beaucoup plus amère. Ses sels, d'un aspect nacré très-remarquable, offrent aussi en général une plus grande amertume. La quinine est très-soluble dans l'éther, tandis que la cinchonine l'est fort peu; ce qui offre un moyen non-seulement de distinguer ces deux bases, mais encore de les séparer lor'squ'elles se trouvent réunies. Le sulfate de quinine est peu soluble dans l'eau froide; mais un excès d'acide le dissout très-facilement.

Quant aux autres principes du quinquina jaune, ils ont une grande analogie avec ceux du quinquina gris; toutefois on n'y a point trouvé de matière gommeuse. Ainsi cette écorce a donné à l'analyse du kinate acide de quinine; une matière grasse, jaune; du rouge cinchonique; une matière tannante; une matière colorante jaune; du kinate de chaux; de l'amidon et du ligneux.

Le quinquina rouge (cinchona oblongifolia) a offert à la fois les deux principes alcalins, la cinchonine et la quinine. Il est composé de kinate acide de cinchonine; de kinate acide de quinine; d'une matière grasse, rougeâtre; de rouge cinchonique; d'une matière tannạnte; de kinate de chaux; d'une matière colorante jaune; d'amidon et de ligneux.

L'examen chimique du quinquina piton (exostema floribunda) a présenté les caractères suivans. Son amertume est beaucoup plus forte que celle des vrais 
quinquina ; sa décoction précipite l'émétique, la gélatine et le sulfate de fer; mais elle ne trouble que légèrement l'infusion de noix de galle. Malgré un grand nombre d'expériences, MM. Pelletier et Caventou n'ont pu découvrir aucune trace de cinchonine ou de quinine; ils ont trouvé seulement une substance brunâtre, soluble dans les acides, incristallisable seule ou combinée avec eux, amère, et ayant quelque analogie avec l'émétine. Au reste, cette matière n'a aucun rapport avec le principe alcalin qu'on obtient des vrais quinquina. Le quinquina piton contient en outre une très-petite quantité d'acide, qui paraît avoir quelque analogie avec l'acide kinique.

On a pu remarquer qu'il existe dans la composition des quinquina gris, jaune, et rouge, des principes pour ainsi dire identiques, sauf quelque différence dans leurs bases salifiables. Après un nouvel examen, MM. Pelletier et Caventou ont constaté la présence simultanée de la cinchonine et de la quinine dans ces trois espèces, avec cette particularité, que le quinquina gris contient relativement une bien plus grande quantité de cinchonine, tandis que le contraire a lieu pour le quinquina jaune. Dans cette dernière écorce, la quinine est tellement prédominante, qu'il n'est pas étonnant que la cinchonine échappe quand on opère sur de petites masses.

Enfin d'autres chimistes, iels que Henry fils, M. Robiquet, M. Colomb, pharmacien à Brest; M. Robert, pharmacien à Rouen, ont imaginé des procédés plus ou moins avantageux pour obtenir les sulfates de cinchonine et de quinine. Suivant M. Ro- 
biquet, on doit regarder la cinchonine comme un alcali plus pur que la quinine, non-seulement en raison de la propriété de cristalliser dont elle jouit, mais encore parce qu'elle exige plus d'acide pour la saturation. ll signale en même temps deux sortes de sulfate de quinine, l'une sous le nom de sulfate acide, l'autre sous le nom de sous-sulfate. Après avoir tracé leurs caractères et leur différence, il observe qu'il est plus avantageux d'employer, pour l'usage médical, la première préparation, qui est très-soluble; tandis que, pour parvenir à dissoudre le sous-sulfate, on est obligé d'y ajouter une quantité indéterminée d'acide, ce qui peut faire varier les propriétés du remède.

\section{PROPRIÉTÉS MÉDICALES.}

En nous dévoilant la constitution intime du quinquina, la chimie nous avait fait pressentir que les propriétés actives de cette écorce résident spécialement dans ses bases alcalines. De nombreuses expériences ont été entreprises; elles ont pleinement confirmé les promesses de la chimie. Parmi les praticiens qui ont fait l'application des sulfates de quinine et de cinchonine au traitement des fièvres, M. Double doit être cité le premier. Il résulte des observations publiées par cet habile médecin que le sulfate de quinine possède à un très-haut degré la vertu fébrifuge. Des faits analogues ont été recueillis par MM. Chomel, Ma-gendie, Bally, Villermé, Duval, etc., et ces préparations sont maintenant d'un usage vulgaire. Elles ont d'autant plus de prix, que quelques grains suffisent pour dissiper l'accès fébrile, tandis qu'il faut ordinai- 
rement de fortes doses de quinquina pour remplir la même indication; et cependant, il est prouvé que, dans beaucoup de circonstances, l'estomac ne saurait supporter une grande quantité de cette poudre indigeste. Au reste, nous ne pensons pas que ces alcalis puissent remplacer dans tous les cas l'écorce du Pérou et ses diverses préparations. D'ailleurs, qui pourrait se vanter de connaître à fond tous les principes d'un corps médicamenteux? La nature, plus savante que l'art, a des secrets, des combinaisons que l'analyse la plus fine, la plus déliée, ne saurait découvrir.

Placé à la tête des substances toniques, le quinquina offre dans son action toutes les propriétés attribuées à ce genre de médicamens. Mis en contact avec des organes affaiblis, et employé à des doses modérées, il augmente leur énergie vitale, ranime l'appareil circulatoire, développe la force du pouls, et ramène peu à peu les fonctions à une mesure d'activité plus naturelle. Mais, chez les personnes d'un tempérament nerveux, douées d'une grande susceptibilité, il fait naître un sentiment de chaleur et d'anxiété à l'épigastre, produit quelquefois la diarrhée ou le vomissement, provoque la céphalalgie, irrite les viscères et les dispose à l'inflammation.

Outre son action corroborante, l'écorce du Pérou jouit d'une vertu fébrifuge qui lui est propre, et qu'aucune substanse végétale n'a jamais pu égaler. Qui nous expliquera cette propriété merveilleuse de suspendre ou de dissiper le trouble périodique du cour et des artères, d'enchaîner, comme par enchantement, le frisson, le spasme, l'irritation, la chaleur, 
en un mot, tous les symptômes que l'accès fébrile traine à sa suite? Gardons-nous de vouloir résoudre une question aussi difficile, et n'imitons point nos prédécesseurs, qui n'ont pas craint de s'égarer dans un dédale d'hypothèses. Il est plus sage de se borner aux résultats de l'observation clinique : c'est elle qui nous a appris que le quinquina jouit d'une vertu spéciale contre la nature intermittente des fièvres, pourvu qu'il soit administré avec méthode et en temps opportun.

A moins de symptômes graves, on doit toujours faire précéder son emploi de quelques boissons délayantes et sédatives; combattre les complications diverses en opposant à l'irritation phlogistique des saignées générales ou locales; à l'embarras gastrique, bilieux ou muqueux, les vomitifs et les évacuans. Après avoir rempli ces indications importantes, on voit trèssouvent les accès disparaître; mais si la fièvre persiste, si d'ailleurs les voies digestives ou les viscères circonvoisins n'offrent aucun signe de phlogose, il faut avoir recours au quinquina, et l'administrer à la dose d'environ un gros, qu'on répète plusieurs fois pendant l'intermission. Malgré la suppression de l'accès, on doit néanmoins continuer le remède pendant plusieurs jours, mais à des doses un peu plus faibles, pour s'opposer au retour des mouvemens fébriles, qu'on voit ordinairement se renouveler si on l'abandonne trop tôt. Les rechutes sont souvent le résultat d'une méthode lente et faible opposée aux fièvres intermittentes, et le précepte d'attendre jusqu'au septième accès pour les combattre nous paraît pen rationnel. Au lieu 
d'affaiblir pendant plusieurs jours le malade par un torrent de boissons aqueuses, de tisanes relâchantes, apéritives; de chercher à diminuer peu à peu l'intensité des accès par des infusions amères ou de petites doses de quinquina, ne vaut-il pas mieux les combattre directement et promptement par ce fébrifuge spécifique? C'est, je crois, le vrai moyen de s'opposer aux récidives et de prévenir les affections viscérales chroniques qui en sont la suite. Il faut, en général, pour supprimer une fièvre tierce ou une fièvre quotidienne, donner, dans l'intervalle qui sépare les accès, une demi-once et quelquefois une once de quinquina. On peut diviser cette quantité en doses égales d'un demi-gros ou d'un gros, qu'on administre d'heure en heure ou de deux heures en deux heures. Les fièvres quartes, naturellement plus rebelles, en exigent une ou deux onces, et quelquefois plus.

Lorsque le malade ne peut supporter ce médicament sous la forme de poudre, on peut l'administrer en infusion ou en décoction, en y ajoutant un peu de camnelle ou toute autre substance aromatique. On a aussi employé avec succès l'extrait gommeux ou résineux, les lavemens, les applications extérieures de quinquina; mais, dans les fièvres graves, ces moyens, beaucoup moins énergiques que l'écorce pulvérisée, pourraient faire perdre un temps précieux. Le sulfate de quinine nous offre alors, sous un petit volume, la vertu active et fébrifuge du quinquina. Quinze, vingt ou vingt-quatre grains de cette préparation saline suflisent pour prévenir le retour de l'accès. On l'administre pendant l'intermission, et l'on en continue l'usage pendant 
plusieurs jours, pour détruire entièrement la fièvre.

L'engorgement de la rate, qu'on observe si souvent dans les fièvres intermittentes, ne saurait contre-indiquer l'usage du quinquina; il est au contraire puissamment combattu par le sulfate de quinine administré à hautes doses. M. le docteur Bally, qui a fait une étude spéciale des fièvres intermittentes à l'HôtelDieu, déclare que l'hypertrophie splénique, quelque considérable qu'elle soit, et qui n'est pas accompagnée d'une affection tuberculeuse, cancéreuse, etc., se dissipe rapidement par les sels de quinquina.

M. le docteur Piorry a également combattu par la même méthode, des fièvies intermittentes de tous les types, avec gonflement de la rate. Ce n'est pas en huit jours, c'est quelquefois en vingt-quatre heures que ce viscère a singulièrement diminué de volume. Des doses modérées de sulfate de quinine ont quelquefois suffi; d'autres fois il a fallu l'employer dans des proportions plus considérables ; mais, en général, il faut l'administrer à fortes doses. "On peut sans crainte, dit M. Piorry, commencer par quinze ou vingt grains et s'élever jusqu'à soixante et plus. J'ai cité ailleurs un cas où un malade avait pris, par inadvertance du pharmacien, deux cent seize grains de ce sel sans en avoir éprouvé d'accident. Il faut avoir un bien grand désir de purger pour donner des éméto-cathartiques avant de faire prendre le quinquina dans les fièvres d'accès. Je n'ai pas vu un seul cas où celles-ci ne cédassent presque immédiatement au sulfate de quinine, sans le faire précéder de purgatifs. " (Gazette médicale, juin $\mathrm{r} 8 \mathrm{r} 3$.) 
Pour mieux décrier les purgatifs, M. Piorry ajoute, d'après un fait rapporté par M. Vaidy, que des fébricitans guéris par le quinquina, ayant été purgés par un médecin, retombèrent malades. Il faut en effet avoir la manie de la purgation pour y avoir recours lorsque la fièvre est dissipée. Mais ce fait n'est ni bien nouveau, ni bien extraordinaire. Les bons praticiens ont toujours défendu l'usage des purgatifs après la cessation des accès fébriles. Sydenham a même dit qu'un simple lavement de lait et de sucre suffisait pour décider une rechute.

Mais si les évacuans sont nuisibles après la fièvre, il n'en est pas de même à son début; et nous voyons avec peine qu'un médecin aussi distingué que M. Piorry en blâme généralement l'usage. S'il avait observé les fièvres intermittentes bilieuses qui se développent au printemps, sous une chaude température, au milieu d'une armée campée dans des lieux humides, il aurait vu que leur véritable traitement consiste dans les éméto-cathartiques. J'ai guéri en très-peu de jours bon nombre de ces fièvres quotidiennes ou tierces avec l'émétique et des boissons laxatives, sans être obligé d'avoir recours au quinquina.

Il s'en faut bien que toutes les fièvres intermittentes réclament l'usage du quinquina ; il en est beaucoup que ce remède exaspère et transforme rapidement en continues. Les fièvres vernales, par exemple, se guérissent le plus souvent par des boissons humectantes et un régime rafraîchissant; lorsqu'elles persistent, quelques doses de quinquina suffisent pour les vaincre. Mais bien plus souvent elles offrent un iI. 
caractère inflammatoire qui exige la méthode antiphlogistique. Ces fièvres attaquent les jeunes gens, les sujets pleins de vigueur, d'un tempérament sanguin, qui habitent des lieux secs et montueux; les jeunes filles robustes, les femmes pléthoriques, etc. Forestus, Sydenham, Pringle, Grant, Stoll, Baumes, etc., ont observé ces fièvres s'annoncant par la violence des accès, par la couleur animée du visage, la force et la dureté du pouls, des urines ardentes, une vive céphalalgie, qui commence avec la chaleur et se prolonge pendant l'apyrexie. Cet état fébrile réclame impérieusement des boissons émollientes, acidules, et surtout la saignée, qu'on pratique ordinairement pendant l'intermission. On peut néanmoins y avoir recours dans la vigueur même de l'accès, lorsqu'un organe essentiel est fortement menacé d'une congestion inflammatoire, mais jamais pendant le frisson, car on risquerait de faire périr le malade. C'est ainsi qu'il faut entendre ce passage remarquable de Celse : Quòd si vehemens febris urget in ipso impetu, ejus sanguinem mittere, hominem jugulare est.

J'eus occasion de voir, il y a quelques années, à la campagne, un jeune homme fort et bien constitué, qui avait éprouvé de grands maux de tête pendant les trois premiers accès d'une fièvre quotidienne. Le troisième avait débuté par un frisson de peu de durée; la chaleur et la céphalalgie lui avaient bientôt succédé, mais plus violentes et accompagnées de dé-

- lire. Les yeux étaient rouges et brillans, le visage très-animé. Il fut saigné à l'instant : on lui donna une limonade légère pour boisson; on fit sur tout 
le corps des fomentations avec de l'eau vinaigrée tiède, et les symptômes d'irritation cérébrale ne tardèrent pas à s'amender. Les accès suivans, devenus beaucoup plus doux, cédèrent à une infusion de fleurs de camomille, où l'on délayait de petites doses de quinquina.

Un traitement à peu près semblable a eu le même succès chez unejeune femme brune, d'une constitution sanguine, enceinte de trois mois, et tourmentée, pendantl'accès d'unefièvretierce, d'une oppression des plus violentes avec suffocation. Le pouls était plein, vibrant, et la chaleur du corps insupportable. Une forte saignée du bras ramena le calme et fut suivie de sueurs abondantes. Du petit-lait nitré, de l'eau d'orge, un régime rafraîchissant, dissipèrent la fièvre en peu de jours sans le secours du quinquina.

Grant (Recherches sur les fièvres) fut également obligé de faire tirer du sang à un de ses malades pendant la chaleur fébrile, pour calmer une irritation excessive qui s'était manifestée par l'inflammation des yeux, le délire et une violente céphalalgie. Je voudrais, dit cet habile praticien, que nous connussions à fond la nature des maladies; nous aurions peu d'occasions d'avoir recours aux spécifiques.

Les fièvres intermittentes qui présentent des symptômes gastriques, bilieux ou muqueux, et qu'on observe fréquemment, en automne, dans les contrées basses et humides, ne doivent pas être attaquées brusquement par l'usage du quinquina, à moins qu'elles ne se compliquent de quelque épiphénomène d'une nature grave. Après avoir exploré attentivement les voies 
alimentaires, si on les trouve exemptes de phlogose ou de surexcitation, on administre un vomitif pendant l'apyrexie; on donne ensuite pendant plusieurs jours des boissons laxatives, acidules, quelquefois un ou deux purgatifs. La fièvre étant ainsi réduite à son état de simplicité, si elle persiste, on a recours au quinquina. Cette méthode, un peu surannée, s'éloigne sans doute de celle de quelques médecins modernes, qui, confondant mal à propos les affections bilieuses ou muqueuses avec la gastro-entérite, proscrivent l'emploi des évacuans; mais elle est basée sur des faits incontestables recueillis dans tous les temps et dans tous les lieux.

Nous ferons remarquer néanmoins que les signes d'embarras gastrique qui se manifestent pendant l'accès n'indiquent pas toujours les vomitifs; que souvent ils sont l'effet du spasme fébrile, et qu'ils n'ont de valeur qu'autant qu'ils se manifestent pendant l'apyrexie. Nous dirons aussi, avec M. le docteur Boisseau, que, lorsque le quinquina ne prévient pas de prime abord les accès fébriles muqueux, et bien plus encore lorsqu'il les exaspère, on doit craindre le développement d'une inflammation latente et chronique des viscères abdominaux. Alors il est sage de temporiser jusqu'au printemps, époque à laquelle les fièvres muqueuses intermittentes, presque toutes automnales, cessent trèssouvent. Mais c'est en vain qu'on espère une guérison solide, par quelque mode de traitement que ce soit, lorsque le sujet reste au milieu d'une atmosphère humide et chargée d'émanations marécageuses, cause la plus ordinaire de ces fièvres. Le changement de lieu 
est indispensable, et souvent il sutiit pour déterminer la guérison. Il en est de même pour les fièvres gastriques, lorsqu'elles proviennent de la même cause. Voilà des conseils que tous les vrais praticiens sauront apprécier, et que j'emprunte avec plaisir au savant auteur de la Prrétologie physiologique, bien que nos opinions soient parfois un peu différentes.

Le quinquina devient utile ou nuisible suivant les localités, la constitution régnante et la nature de l'affection fébrile. A Nimègue, pays sain et peu marécageux, M. Broussais n'a guère rencontré que des fièvres intermittentes simples, qui se montraient rarement rebelles et cédaient aux amers ou à de légères doses de quinquina; pendant tout un printemps, il n'a trouvé que trois fièvres qui aient résisté à cette écorce. A Udine, les fièvres tierces se guérissaient aussi très-facilement par les tisanes amères; le quinquina était réservé pour les plus rebelles, qu'il emportait ordinairement en deux ou trois jours, à la dose de deux à quatre gros. Mais, au milieu de ces succès, il survint coup sur coup deux revers qui obligèrent $\mathbf{M}$. Broussais d'étudier plus particulièrement les sujets avant de leur administrer ce médicament héroïque. Un malade, chez qui oll n'apercevait aucun signe de pléthore, était affecté d'une tierce dont les accès étaient assez intenses. A la première dose de quinquina, la fièvre devint quotidienne ; a la seconde, elle se changea en continue. Un second passa, dès la première prise du remède, de la quotidienne à la continue. Le premier, n'ayant pu être sauvé, malgré l'emploi des adoucissans, son cadavre offrit une double inflammation des poumons et de l'esto- 
mac. Le second, plus heureux, guérit par la limonade et autres relâchans et sédatifs. Comme la phlogose des voies gastriques se déclarait en même temps idiopathiquement chez un grand nombre d'autres malades, cet habile observateur comprit qu'il fallait partager les fébricitans en deux classes : $1^{\circ}$ ceux qui pouvaient supporter les amers et le quinquina $; 2^{\circ}$ ceux dont l'estomac trop délicat réclamait des moyens plus doux. Toutefois la saignée lui parut très-rarement admissible, parce que la plupart de ces phlegmasies, qui repoussaient si vivement les toniques, étaient accompagnées d'un pouls faible dans les intermissions, et semblaient se placer de préférence sur des sujets grêles, décolorés et sensibles. (Broussars, Histoire des phlegmasies chroniques.)

On voit assez souvent la fièvre intermittente s'annoncer avec les signes d'une irritation vive fixée sur la région du creur, sur le poumon, sur l'utérus, sur les organes gastriques, etc. : les émissions sanguines, l'application des sangsues sur l'organe irrité, doivent alors précéder l'emploi du quinquina; elles suffisent même quelquefois pour dissiper les mouvemens fébriles. Mais si la fièvre persévère après les saignées, sans que l'irritation locale se prolonge pendant l'apyrexie, on ne doit pas hésiter à prescrire l'écorce péruvienne. L'excellent ouvrage que nous venons de citer offre à ce sujet des faits précieux et d'utiles leçons. Toutefois il ne faut pas confondre ces phénomènes d'irritation inflammatoire avec les symptômes ataxiques qui se développent pendant l'accès, et tranchent d'une manière si grave, que les jours du malade sont dans un péril 
imminent. C'est ici que le quinquina déploie sa puissance fébrifuge, et justifie les éloges qu'on lui a prodigués.

Ces fièvres, revêtues d'un caractère pernicieux, ont reçu des noms différens, suivant les épiphénomènes qui les accompagnent. Parmi les principales variétés admises ou observées par les auteurs, on trouve la cardialgique, la syncopale, l'hépatique, la cholérique, la dysentérique, la soporeuse, la délirante, la céphalalgique, la pneumonique, la convulsive, l'épileptique, l'hydrophobique, etc. Il serait facile d'en établir encore un plus grand nombre d'après les symptômes prédominans, comme on peut s'en convaincre par les écrits de Mercado, de Morton, de T'orti, de Werlhof, de Lautter, de Sénac, de Cleghorn, de Comparetti, el surtout par l'ouvrage classique de M. le professeur Alibert.

Lorsqu'une fièvre intermittente, d'abord d'une apparence bénigne, s'aggrave au deuxième ou troisième accès, et offre quelques symptòmes jusque-là inaperçus; lorsque le stade du froid se prolonge excessivement, que le pouls, déprimé dans le frisson, se maintient plus ou moins faible dans la chaleur, que les traits du malade subissent une altération sensible, on doit se tenir en garde contre l'accès prochain : mais s'il se manifeste des signes alarmans, tels qu'une irritation vive concentrée sur l'épigastre, sur l'encéphile, sur le poumon, sur l'utérus, etc.; une oppression extrême, des vomissemens opiniâtres, des convulsions, le délire, la syncope, un profond assoupissement, on ne saurait révoquer en doute la nature pernicieuse de la fièvre. 
M. de Travanet, ancien membre du Corps législatif, âgé d'environ soixante ans, d'un tempérament bilieux, fut atteint, pendant l'été de s 8og, à l'abbaye de Royaumont, département de Seine-et-Oise, d'une fièvre intermittente tierce, dont les deux premiers accès n'avaient offert aucun symptôme saillant, si ce n'est un embarras douloureux à l'hypochondre droit. Le malade ayant été purgé immédiatement après le second accès, cette irritation locale devint plus vive, plus étendue, et fut suivie de jaunisse. Le troisième accès, qu'on n'attendait que le lendemain à midi, s'annonça brusquement à trois heures du matin par des signes du plus mauvais augure. Un parent du malade vint à Paris en toute hâte m'instruire de son état et me prier d'aller le voir. J'arrivai à neuf heures du soir à Royaumont, où le médecin de M. de Travanet m'apprit que l'accès avait débuté par un violent frisson, accompagné de vomissemens bilieux, d'une douleur aiguë dans la région du foie, et de défaillances qui se renouvelaient à chaque instant. Le malade avait le pouls faible, tremblotant, avec des intermittences rares. Il était affecté de jaunisse, avec cette particularité, que la couleur ictérique, qui était très-intense, occupait tout le côté droit du corps, tandis qu'elle se faisait à peine remarquer dans la partie latérale gauche. Le stade du froid s'était prolongé pendant presque tout le cours de la journée, et on l'avait vainement combattu par les cordiaux et les antispasmodiques.

Le médecin de Royaumont, attribuant la cause de la maladie à la diathèse bilieuse, pensait qu'il était nécessaire d'administrer un vomitif à la fin de l'accès; mais je . 
parvins à le convaincre que la fièvre devait seule être prise en considération, et qu'il fallait l'attaquer à l'instant même par un traitement direct, afin de prévenir un nouvel accès dont l'issue ne pouvait qu'être fatale. Heureusement, je m'étais pourvu d'une certaine quantité d'excellent quinquina gris. La chaleur du corps avait reparu; une sueur visqueuse répandue sur le visage et sur le thorax annonçait le déclin de l'accès. 'Toutefois la réaction artérielle était peu marquée; la voix du malade était altérée d'une manière remarquable, et sa physionomie portait l'empreinte d'une profonde tristesse. Je crus ne pas devoir différer davantage l'emploi du quinquina. La première prise fut de trois gros, qu'on délaya dans une tasse d'infusion de feuilles de menthe. Une heure après, c'est-à-dire à onze heures du soir, le malade en prit autant. A minuit, à deux heures et à quatre heures du matin, les doses furent réduites à un gros. On reprit à huit heures l'usage des poudres, à la dose d'un demi-gros seulement, et on les répéta à dix heures et à midi. Le paroxysme, qu'on avait tant redouté, ne parut point : vers cinq heures, le malade éprouva seulement quelques nausées et un peu de malaise; mais ce simulacre d'accès fébrile n'eut pas d'autre suite. Le Jendemain, de très-bonne heure, on donna trois gros de quinquina divisés en trois prises : la fièvre ne se montra plus, et avec elle cessa l'affection hépatique. Cependant, pour assurer la guérison, on continua pendant quelques jours le fébrifuge, à la dose d'un gros le matin et d'un gros le soir.

Madame Lassabathie, âgée de trente ans, d'un tempérament irritable et sanguin, était à peine rétablie 
d'une fièvre intermittente qu'elle venait d'éprouver à Bordeaux, lorsqu'elle apprit, en arrivant à Paris, que son fils était malade. Cette nouvelle lui causa une émotion si vive, qu'elle fut saisie d'un violent accès de fièvre, avec des douleurs utérines très-aiguës et perte de sang. Ces accidens cessèrent avec la fièvre, et le lendemain elle se croyait guérie, à une grande faiblesse près; mais un nouvel accès, survenu pendant la nuit, vint la jeter dans de nouvelles alarmes. Les symptômes fébriles, beaucoup moins vifs, s'étaient néanmoins prolongés jusqu'à quatre heures de l'après-midi. Une potion composée d'eau de laitue, d'éther sulfurique et de sirop d'opium, avait contribué à suspendre la douleur, ainsi que la fluxion hémorrhagique, et je me disposais à profiter de la rémission des accidens pour administrer le quinquina, lorsqu'un troisième paroxysme vint à éclater. La perte de sang était excessive ; le pouls, faible, convulsif, cédait à la plus légère pression; la prostration des forces était générale, et la face d'une couleur cadavéreuse. Application d'un large sinapisme sur la région sacro-lombaire; frictions éthérées sur les membres; emploi des cordiaux à l'intérieur. Potion préparée avec l'extrait de quinquina, la teinture de cannelle, le sirop d'éther, l'opium, et l'eau de fleurs d'oranger. Le froid et la dépression vitale persistent. Nouvelles frictions avec la teinture alcoholique de quinquina et le camphre. Ce traitement est continué avec beaucoup de persévérance.

Enfin la chaleur se rétablit, l'hémorrhagie diminue; mais le pouls se maintient faible, et la malade, qui a vu régner à Bordeaux des fièvres pernicieuses, donne 
des signes manifestes d'abattement moral. Sans attendre davantage, je prescris deux gros de quinquina rouge, réduit en poudre fine, dans un mélange d'eau et de vin de Madère. Une pareille dose est administrée deux heures après, et suivie de trois en trois heures de doses moindres. En quatre jours, la malade épuisa quatre onces de quinquina. Plus de redoublement, plus d'héinorrhagie. L'abdomen est embarrassé, un peu sensible; ce symptôme cède à des cataplasmes émolliens et à un régime doux; mais la malade éprouve une grande faiblesse, et sa convalescence se prolonge.

Madame $^{* * *}$ (voyez tome ${ }^{\text {er }}$, page ${ }^{8} 9^{8}$ ) avait éprouvé tous les symptômes de l'asphyxie, pour avoir pris un bain dans une pièce où l'on avait placé une grande quantité de jonquilles. Cet accident fut suivi, peu de jours après, d'une affection fébrile, marquée par un léger refroidissement aux extrémités inférieures, et une douleur sourde dans la région de la matrice, qui se fit sentir jusqu'à dix heures du soir. La nuit fut troublée par des rêves, un malaise universel ${ }_{i}$ et des sueurs partielles; mais la journée fut assez calme. Un second accès ramena, le troisième jour, les mêmes symptômes; seulement l'irritation utérine fut plus prononcée. Bain émollient, cataplasmes sur l'hypogastre, potion sédative. Le lendemain, l'accès devance de six heures et débute par un frisson qui frappe toute la périphérie du corps. Les douleurs sont violentes; leur intensité progressive, jointe à la faiblesse, à l'irrégularité du pouls, à la chute rapide des forces, ne laisse plus aucun doute sur le caractère pernicieux de la fièvre. Je fais renouveler les topiques émolliens et sédatifs, et je 
profite du déclin de l'accès pour administrer, dans l'espace de six heures, six gros de quinquina et deux grains d'opium, partagés èn trois prises égales. Le lendemain, les doses sont réduites de moitié; les jours suivans, la malade ne prend qu'un gros de quinquina matin et soir. Ce traitement a suffi pour dissiper la fièvre, et avec elle la surexcitation utérine qui lui était subordonnée.

M. le docteur Ducasse, de 'Toulouse, nous a donné une belle observation de fièvre intermittente cholérique. La maladie n'a offert que deux accès, et a cédé au quinquina administré à haute dose. La force et la fréquence des vomissemens et des déjections alvines avaient produit la décomposition des traits de la face, une sueur froide, une extrême petitesse du pouls et des syncopes. Appelé pendant le premier accès, M. Ducasse vit dans la maladie un choléra-morbus très-violent, contre lequel il n'employa d'abord qu'une simple boisson adoucissante. Les accidens cessèrent à cinq heures du soir. Le malade reposa toute la nuit et put vaquer le lendemain à ses affaires. Le jour suivant, c'est-à-dire le troisième jour, à la même heure que l'accès précédent, les symptômes reparurent d'une manière subite et sans avoir été précédés du plus léger malaise. Les douleurs précordiales étaient horribles, les évacuations presque sanguinolentes, et le pouls à peine sensible. L'accès dura jusqu'à sept heures du soir. M. Ducasse prescrivit quelques gouttes de liqueur d'Hoffmann avec de l'eau de fleurs d'oranger, et la nuit fut assez tranquille. Mais ce second accès l'ayant éclairé sur le caractère de la maladie, il s'enpressa le 
lendemain d'administrer le quinquina, qui prévint heureusement le troisième accès, dans lequel il est probable que le malade aurait succombé. (Ducasse, Mémoires et Observations de médecine.)

Une observation de fièvre intermittente grave, dont une sorte d'angine spasmodique était le symptôme dominant, nous a été transmise par le professeur Dumas. Les traits du malade étaient profondément altérés; il se plaignait de céphalalgie, de douleurs à la poitrine, aux hypochondres et au bas-ventre; son pouls était petit, concentré, irrégulier. Il avait la bouche amère, la langue couverte d'un enduit jaunâtre. La respiration était un peu gênée, la déglutition d'une difficulté extrême.

Dumas prescrit une boisson émétisée, mais le malade fait des efforts inutiles pour l'avaler. Le soir, la fièvre s'élève, il survient un redoublement, la difficulté d'avaler est plus considérable. Le lendemain, application de topiques irritans, afin de rompre le spasme; sinapismes au gras des jambes, et quelques heures après vésicatoire à la nuque. Le troisième jour, inquiétude plus marquée, délire sourd. On renouvelle les sinapismes; on a recours aux frictions, aux lavemens laxatifs. Point de changement dans la situation du malade. Le sixième jour, on essaie de lui faire prendre deux grains de tartre stibié dans une petite quantité d'eau; il en avale fort peu. Alors Dumas reconnait d'une manière distincte l'exacerbation du soir, caractérisée par l'augmentation de la fièvre, le délire, et une difficulté plus grande de la déglutition. Il insiste néanmoins, le huitième et le neuvième jour, sur les boissons émétisées, sur les lavemens purgatifs. La déglutition étant devenue 
plus facile, le malade prend jusqu'à quatre grains d'émétique sans en être ébranlé. Le délire, la chaleur, la fréquence du pouls, augmentent; on applique des sangsues aux tempes, on prescrit une potion composée de camphre, de nitre et de laudanum. J'avoue que je ne reconnais pas ici la sagacité de notre savant professeur; l'indication dú quinquina était évidente dès le troisième accès.

Le dixième jour, tout annonce une terminaison fâcheuse. Les symptômes s'aggravent, le délire se prolonge et devient furieux, l'assoupissement lui succède; la déglutition est impossible, la respiration s'exécute avec gêne et par des mouvemens accélérés, les forces baissent sensiblement, l'exercice des sens s'altère, l'ouïe est insensible à l'impression des sons, et l'oeil à celle de la lumière.

Cependant la marche rémittente de la maladie est bien décidée; les exacerbations, toujours croissantes, font soupçonner que la fièvre rémittente joue le principal rôle et forme l'affection dominante. Enfin le quinquina est administré en lavement à la dose d'une once, combiné avec un demi-gros de camphre, deux fois dans le même jour. Le lendemain, il y a une amélioration marquée; les douleurs du bas-ventre, loin d'avoir été accrues par le quinquina, sont diminuées sensiblement; le pouls est régulier, la déglutition moins difficile. On continue le quinquina et le camphre en lavemens matin et soir, et on fait prendre au malade deux onces de vin de quinquina. L'exacerbation de ce jour est encore sensiblement diminuée. Le lendemain, le malade paraît en voie de guérison; les forces com- 
mencent à se rétablir, la sensibilité se réveille, le pouls se développe, le délire a cessé, la déglutition devient libre, l'exacerbation du soir se fait à peine sentir. On avait administré le matin le lavement de quinquina, le vin et quelque peu d'extrait de quinquina; le soir, on continue le lavement. Les jours suivans, la convalescence se confirme sous la continuation du quinquina tant en lavemens qu'en décoction et en substance, et le malade est bientôt entièrement rétabli.

Le même professeur a observé un cas de fièvre hydrophobiquetierce, dont les deux premiers accès furent marqués par des vertiges, une céphalalgie atroce, une anxiété générale, une soif ardente, une irritation de l'arrière-bouche, avec gêne de la déglutition. Le troisième s'annonça par une chaleur violente, un délire furieux; par un mouvement convulsif des lèvres et des muscles du cou, une dysphagie considérable, avec resserrement du pharynx, augmentant à l'approche des liquides. Le jour suivant, calme, mais aversion pour les liquides, et dysphagie.

Le lendemain; convulsions générales, soubresauts des tendons, contraction violente des muscles abdominaux, dysphagie insurmontable, délire furieux, efforts pour mordre, écume à la bouche, grincement des dents, rejet volontaire de flots de salive, horreur invincible pour tous les liquides, frémissement universel par le contact de l'eau fraîche. Traité par le quinquina, le malade guérit après huit accès.

Un cas de fièvre aphonique a été observé et parfaitement décrit par M. Double. Les paroxysmes étaient caractérisés par une grande chaleur, la privation totale 
de la voix, l'agitation convulsive des muscles de la face, une langue comme brûlée, une soif extrême, un sentiment général d'inquiétude, de douleur, de pesanteur, etc. Cette fièvre, dont les accès furent peu nombreux, fut heureusement combattue à l'aide du quinquina.

La fièvre intermittente, soporeuse, carotique, léthargique, décrite par Torti, par Werlhof, et quelques autres auteurs; la fièvre céphalalgique, la fièvre convulsive de Morton; la fièvre délirante d'Alibert et de Coutanceau; la fièvre aphonique de Double; la fièvre hydrophobique de Dumas; la fièvre paralytique de Molitor; la fièvre épileptique de Lautter et de Barde ; la fièvre arthritique de Brachet; enfin toutes les fièvres intermittentes qui simulent une phlegmasie ou qui s'accompagnent d'un ou de plusieurs symptômes graves et dominans, demandent la prompte administration du. quinquina. Toutes les autres indications sont vaines, lorsque ces symptômes sont portés à un très-haut degré de violence. Le point essentiel est de combattre la fièvre d'une manière directe et de prévenir le retour d'un nouveau paroxysme. Ainsi, dès que le caractère pernicieux de la fièvre est reconnu, on doit profiter du déclin ou de la terminaison de l'accès pour administrer le quinquina en substance, d'abord à la dose d'une demi-once, et ensuite à celle d'un ou deux gros de deux en deux heures, ou à des intervalles plus ou moins éloignés, suivant le type de la fièvre. Dans les cas extrêmes, il ne faut pas craindre d'élever hardiment les doses du fébrifuge; Sims en a donné jusqu'à cinq onces. Lorsque l'accès a été supprimé, il faut le continuer 
pendant quelques jours, à la dose de deux ou trois gros, et ensuite à doses graduellement décroissantes, pendant une ou même plusieurs semaines. Lorsqu'il se manifeste des mouvemens convulsifs, une affection cholérique, une douleur vive et prédominante dans quelque organe essentiel, il est utile d'associer le quinquina à l'opinm.

Le quincuina ne doit point être administré pendant la vigueur d'un accès pernicieux; mais si la fièvre est subintrante, il faut savoir saisir habilement le temps qui approche le plus de la rémission pour donner le fébrifuge. Que la première dose soit surtout assez forte pour dompter l'accès prochain ; car les doses suivantes, quoique placées avant l'invasion de cet accès, s'en rapprochent trop pour qu'on doive compter sur leur action. Les fièvres sous-continues, les fièvres rémittentes ataxiques, qui règnent épidémiquement à la fin de l'été, et au commencement de l'automne dans les pays chauds couverts de marécages, doivent être soumises à un traitement analogue, et il faut les attaquer par le quinquina, dès la première ou seconde rémission, sans avoir égard aux signes d'irritation gastrique et' aux autres complications qui tendraient à retarder l'emploi du seul remède efficace. Lorsque ces pyrexies offrent des phénomènes graves, les moinens sont précieux, et l'indication est d'autant plus urgente, que l'accès qui va suivre sera peut-être mortel. Zimmermann a observc: une fièvre tierce épidémique dont les traits saillans étaient la céphalalgie, une dyspnée extrême, et qui faisait périr le malade au deuxième accès.

Cependant, lorsque les complications sont bien tranII. 
chées, lorsqu'il y a des signes évidens de congestions bilieuses, d'embarras gastrique, d'inflammation, de pléthore, il convient d'y porter remède avant d'administrer le fébrifuge. C'est l'opinion de Stoll et de quelques autres observateurs judicieux. Finke a combattu par les évacuans, et puis par le quinquina, une fièvre double tierce soporeuse, compliquée de symptômes gastriques. Voullonne ne fut pas si heureux dans une fièvre tierce.

M. B. , âgé d'environ soixante-dix ans, d'une constitution robuste, après avoir essuyé à la campagne quelques accès de fièvre intermittente tierce d'une nature bénigne, consulte le docteur Voullonne, qui prescrit un minoratif pour le jour libre de fièvre. Ce remède fait rendre au mılade une grande quantité de matières bilieuses. Vers six heures du soir, le frisson revint, la chaleur dura toute la nuit, et l'accès se termina dans la matinée par une sueur abondante. Le lendemain, nouveau purgatif qui opère comme la première fois. Le frisson reparaît à six heures du soir, ainsi que l'avantveille; mais l'accès est pernicieux. Le malade tombe durant la nuit dans un état apoplectique qui se prolonge jusqu'au déclin de l'accès. Voullonne prescrit sur-le-champ une once de quinquina, à prendre en quatre doses égales. Il croyait que l'accès pernicieux était éloigné de trente-six heures. Point du tout : la fièvre devint double-tierce, le frisson reparut le même jour à six heures du soir, dix heures après la première prise du fébrifuge, et cet accès subalterne fut bien plus féroce que le premier. Il se soutint sans aucune espèce de rémission jusqu'à ce que le lendemain, à l'heure 
ordinaire, un refroidissement glacial annonça l'invasion de l'accès correspondant en tierce au premier accès pernicieux. Le malade succomba au bout de quelques heures. (Voullonne, Mémoire sur les fièvres intermittentes.)

Ce triste exemple doit nous avertir que les évacuans ne sont véritablement utiles que lorsque l'indication en est précise; encore faut-il les administrer avec réserve aux vieillards, aux enfans, et à toutes les personnes nerveuses ou d'une faible complexion. Si, au lieu d'affaiblir son malade par deux purgatifs inutiles, ce médecin eût donné de prime abord le quinquina, la fièvre n'eût point contracté un caractère pernicieux.

On trouve également un exemple funeste de l'abus des évacuans dans le beau Traité des fièvres rémittentes de M. le professeur Baumes. On avait négligé le quinquina, et on le donna ensuite à trop faibles doses. Le redoublement qui suivit se termina par la mort. Le docteur Hurtado, médecin espagnol, rend compte de deux faits analogues dans un Mémoire intéressant sur les fièvres intermittentes. L'émétique et les purgatifs, administrés contre des fièvres bénignes, leur ont imprimé un caractère pernicieux. Heureusement de fortes doses de quinquina ont triomphé de tous les accidens.

Les saignées générales, l'application des sangsues et des ventouses, les antiphlogistiques, les tempérans, peuvent convenir dans quelques cas de fièvres intermittentes ataxiques, pour combattre une inflammation imminente; Lautter les a employés avec succès contre la fièvre pernicieuse épidémique de ${ }_{7} 759$. Sarcone fait 
également mention d'une fièvre sous-continue, avec phlogose de l'organe pulmonaire, oì la saignée était indispensable; mais ces cas sont rares, et nous croyons que les émissions sanguines ne peuvent être utiles que lorsque les signes d'inflammation et d'éréthisme persistent pendant l'apyrexie. Quelle que soit la violence du paroxysme, elles sont contre-indiquées, si le pouls est faible, déprimé, si la prostration des forces se prolonge pendant la rémission des phénomènes fébriles. In summo interim furientis morbi periculo, ne prceceps vitam salvandi aufugiat occasio, indicationibus aliis, quàm vitalibus, satisfacere non licet, et omne curationis punctum in futuro, facilè lethali, febris insultu per corticem avertendo, positum est. (J. P. Frank, Epitome de curandis hominum. morbis.)

M. Broussais, dont les travaux ont répandu une si vive lumière sur la doctrine des phlegmasies, se plaint de ce qu'on trouve partout le précepte de traiter avec de fortes doses de quinquina les fièvres qui sont accompagnées, durant l'accès, d'un point douloureux quelconque. On se contente, dit-il, de les ranger dans la classe des pernicieuses ou ataxiques intermittentes, et l'on menace hardiment de la mort les malheureux chez qui l'emploi du souverain fébrifuge aura été ménagé. Je conviens avec ce professeur que, dès que la phlogose gastrique existe, le quinquina et les amers deviennent des poisons. Mais quelle différence entre la gastro-entérite aiguë, qui s'accompagne de symptômes ataxiques, et une véritable fièvre pernicieuse! Il suffit d'avoir observé la marche de ces deux maladies pour ne 
pas les confondre : l'une peut se prolonger pendant plusieurs semaines, tandis que l'autre vous tue en quelques heures, si on ne la réprime promptement avec l'écorce spécifique.

Une foule d'autres maladies revêtues de la forme intermittente ou périodique se guérissent aussi trèssouvent par le quinquina. Quelques auteurs leur ont donné le nom de fièsres larvées, erratiques, anomales, etc. Casimir Médicus, qui les a rassemblées dans un traité particulier, leur attribue une origine gastrique. Il s'est convaincu, par l'ouverture des cadavres, que la cause matérielle de la maladie réside dans le tube intestinal, et non dans la partie affectée de la douleur ou du désordre. Lorsque ces fièvres larvées s'offrent sous l'empire d'une épidémie de fièvres intermittentes, leur caractère obscur et ambigu se dévoile par quelques symptômes propres à la maladie régnante. Un faible refroidissement à l'invasion de l'accès, des sueurs vers son déclin, ou bien des urines rouges, briquetées, à sa terminaison, les font reconnaître. (Voyez plusieurs observations de fièvres larvées, consignées par le docteur Dolivera dans le quatrième volume de la Revue médicale, année ı821.) Dans leurs nombreuses métamorphoses, ces maladies demandent le même traitement que les fièvres intermittentes; et lorsqu'elles offrent quelques symptômes graves ou pernicieux, il faut les attaquer brusquement par de hautes doses de quinquina.

M. le docteur Bourguet fut appelé, aux environs de Béziers, pour voir un petit garçon, âgé d'environ huit ans, qui offrait les symptômes d'une catalepsie quoti- 
dienne. A peine le soleil paraissait-il sur l'horizon, que l'enfant tombait dans un état de mort apparente, pour ne ressusciter, pour ainsi dire, qu'au soleil couchant. Arrivé auprès delui à six heures du matin, M. Bourguet le trouva endormi et tranquilte; il le réveilla, le fit parler et l'amusa. Mais aussitôt que le soleil se montra (c'était en hiver), le petit malade dit au médecin : "Monsieur, voilà que le mal me prend, " et de suite il se couche sur son lit, où il reste comme mort. Plus de respiration sensible, plus de pouls, plus de battemens de cœur, plus de sensibilité, même en le pinçant.

Le corps se refroidit considérablement pendant deux heures au moins, après lesquelles le froid diminua sans cesser tout-à-fait. M. Bourguet remarqua seulement un léger spasme de la paupière supérieure. Il souleva de force un de ses membres supérieurs, il resta soulevé; une jambe de même : ses membres étaient comme une cire molle qui prend toutes les formes qu'on lui donne. Il resta ainsi sans rien avaler; et quand le soleil quitta l'horizon, il reprit peu à peu ses sens, et se leva sans le moindre signe qui pût indiquer qu'il avait été malade.

Il avait eu déjà dix paroxysmes semblables. M. Bourguet lui fit prendre, dans le cours de la nuit, environ une once de quinquina avec du zinc sublimé. Il n'y eut point de paroxysme le lendemain matin, et depuis lors l'enfant s'est bien porté.

Une demoiselle éprouvait de deux jours l'un une affection convulsive (danse de Saint-Guy) tellement forte, qu'elle sautait continuellement pendant plus de deux heures, à un demi-pied de hauteur, se frappant, se 
débattant de toutes les manières, avec un hoquet fatigant et des grimaces continuelles, jusqu'à ce qu'enfin, excédée de fatigue, elle se laissât tomber sur un sopha, où le sommeil le plus profond terminait ce paroxysme. Son médecin ordinaire fit appliquer des sangsues, qui ne procurèrent aucun amendement. M. Bourguet, ayant considéré la maladie comme étant de même nature que la précédente, conseilla le quinquina, qui en triompha sans difficulté.

Ce médecin a guéri, par la même méthode, des hémorrhagies à type tierce, des coliques périodiques survenant tous les huit jours, et une sorte de fièvre nerveuse, dont les accès se reproduisaient tousles jours avec un rire bruyant et immodéré qui durait trois heures.

On pourrait citer des maux, des accidens de toute espèce revenant à des heures, à des jours fixes, et qui ont cédé à l'action puissante de ce remède. C'est ainsi qu'on a dissipé des tremblemens, des syncopes, des céphalalgies, des douleurs pleurétiques, des hémorrhagies, des vomissemens, des diarrhées, des oppressions, des cardialgies, etc., etc.

Mais avec quelle réserve ne faut-il pas administrer le quinquina dans plusieurs de ces affections périodiques! Par exemple, l'hémoptysie qui se reproduit avec ce caractère, bien qu'elle ne soit point accompagnée de la fréquence et de la dureté du pouls, annonce néanmoins un état de congestion de l'organe pulmonaire, une irritation locale plus ou moins vive, à laquelle le quinquina peut donner plus d'intensité, surtout si le malade est jeune et d'un tempérament sanguin. La céphalalgie périodique que Van Swiéten a domptée 
avec le quinquina, et dont on lit plusieurs exemples dans le paragraphe 746 , où il traite de la fièvre intermittente, est le plus souvent exaspérée par ce médicament. Je l'ai presque toujours vu échouer contre la migraine, et quelquefois il l'a rendu atroce; mais, lorsque cette affection rebelle est fomentée par de mauvaises digestions, par un état de langueur de l'appareil gastrique, administré après un ou deux vomitifs, il la soulage ordinairement, modifie ou éloigne les attaques, et parfois les dissipe pour toujours.

Au reste, c'est en vain qu'on aurait recours au quinquina pour vaincre ces affections périodiques, tant qu'on n'a point détruit les élémens d'où elles dérivent. C'est donc à l'investigation de ces causes primitives qu'il faut s'attacher, si l'on veut établir un traitement méthodique et rationnel.

Une femme d'un tempérament sanguin et d'une excellente santé est saisie d'une violente frayeur qui supprime ses règles. Depuis ce moment, elle est sujette à des attaques périodiques de hoquet. Cette affection spasmodique dure plusieurs mois, et résiste aux émissions sanguines, aux purgatifs, aux bains, aux antispasmodiques et au quinquina. La malade, fatiguée, renonce à toute espèce de médicamens. Les règles ayant enfin reparu, le quinquina, qui avait été impuissant contre la cause primitive, dissipa en très-peu de temps l'affection convulsive périodique à laquelle le système nerveux s'était accoutumé. (Recueil périodique de la Société de médecine de Paris, tome 3.)

Il ne suffit point d'avoir dissipé par le quinquina ou le sulfate de quinine l'impression périodique qui ra- 
mène les accès, il faut encore administrer ces médicamens pendant plusieurs jours, et même pendant plusieurs semaines, si l'on veut prévenir les récidives. D'après Sydenham, elles peuvent avoir lieu à des époques déterminées. Werlhof, qui a parfaitement développé cette observation clinique, recommande de donner le quinquina pendant la deuxième semaine qui suit la suppression des fièvres tierces, et pendant la troisième semaine pour les fièvres à type quotidien ou quarte. Ces semaines, qu'il appelle paroxystiques, sont les époques où les rechutes se font ordinairement remarquer. On continue l'écorce fébrifuge plus ou moins long-temps, suivant les forces et le tempérament du malade, suivant les lieux, la saison de l'année et le caractère de la fièvre. Pendant l'automne, et dans les pays marécageux, il faut surtout élever les doses du quinquina et prolonger son emploi; prescrire en même temps un régime tonique, et éviter avec soin les purgatifs et toutes les causes énervantes.

La crainte de favoriser l'obstruction des viscères!a souvent éloigné les médecins de l'usage du quinquina dans les fièvres quartes; mais c'est pour avoir négligé ce fébrifuge, pour l'avoir employé trop tard, ou d'une main timide, que ces fièvres réfractaires ont quelquefois produit des engorgemens, des infiltrations, des cachexies incurables. Strack, observateur habile et judicieux, a prouvé, dans un Mémoire sur les fièvres intermittentes, couronné par l'académie dȩ̣Đijon, que le quinquina, loin de produire des obstructions viscérales, en est le plus sûr remède. Toutefois il faut le prescrire avant que les altérations organiques se manifestent 
par des symptômes tels qu'il n'est plus possible de la réparer. Lorsqu'elle est parvenue à ce terme, non-seulement le quinquina est inutile, mais encore il augmente les progrès de la désorganisation. M. Baumes pense également que les pyrexies compliquées d'obstructions, d'infiltrations cellulaires, etc., peuvent être victorieusement attaquées par le quinquina. Ce n'est pas qu'il faille traiter avec cette écorce toutes les fièvres de ce genre; mais il ne faut pas se faire une idée exagérée de ce qu'on nomme obstructions des viscères. Il ne faut pas aussi ne jamais compter sur la salubrité de la fièvre; et, tout en reconnaissant que le mouvement fébrile, sagement dirigé ou abandonné à luimême, peut produire d'heureux résultats, on doit sévèrement apprécier le danger qu'il peut y avoir de. laisser la fièvre déranger les fonctions organiques, pervertir le tissu des viscères, et amener le désordre au point où la nature et l'art sont enfin hors d'état de le réparer. A ce sujet, notre illustre professeur cite un fait remarquable qui prouve les hautes propriétés du quinquina.

M. $\mathrm{Ch}^{* * * * * * *}$, l'un des médecins les plus habiles de Montpellier, éprouvait une fièvre intermittente, qui, depuis plusieurs mois, après avoir été suspendue, revenait avec une intensité nouvelle, avait pris quelquefois la forme rémittente, et avait enfin amené avec la chute des forces des accidens cachectiques bien caractérisés. En explorant l'abdomen, on avait trouvé une obstruction étendue dans les viscères, et notamment dans le foie. A la snite d'une forte péripneumonique violente que prit la maladie, les accidens s'aggravèrent, 
et la fièvre devint double-tierce. M. $\mathrm{Ch}^{* * * * * *}$ présumait que la fièvre était nécessaire pour fondre les embarras hépatiques. Les résolutifs, les sucs d'oseille et de carotte jaune, avaient été employés avec une certaine persévérance; mais la guérison n'avançait point. M. Baumes, appelé par le malade, examine l'état des viscères abdominaux, et croit reconnaître une sorte d'agrandissement du foie. Une circonstance venait renforcer son opinion, c'est que chaque accès donnait à la peau une couleur ictérique qui disparaissait pendant la rémission fébrile. La fièvre n'était donc pas subordonnée à l'état du foie, puisque c'était elle qui influait pernicieusement sur cet organe. L'avis de $\mathbf{M}$. Baumes fut de la combattre activement par l'écorce fébrifuge. Fort de son expérience, M. $\mathrm{Ch}^{* * * * * *}$ choisit sa mixture, préparée avec la résine de quinquina. Cet excellent médicament, continué avec persévérance, dissipa la fièvre, et en même temps l'état cachectique. (Baumes, Traité des fièures rémittentes, tome 2, page $52 \mathrm{r}$.)

Examinons maintenant si le quinquina peut être utile dans le traitement des pyrexies qui ont une marche continue. Généralement banni du traitement de la fièvre inflammatoire, où l'organisme est violemment excité, il a eu des succès incontestables dans les fièvres adynamiques et ataxiques, dans les affections typhoïdes, etc. Ces fièvres sont rarement simples; elles offrent souvent à leur début un état sthénique, des signes de pléthore, des irritations locales qui exigent préalablement la méthode antiphlogistique; mais lorsqu'elles se développent sous l'influence de causes puis- 
samment énervantes, comme une température chaude et humide, des effluves marécageux, des miasmes délétères, un principe actif de contagion, des fatigues excessives, des privations de toute espèce, des affections tristes, le chagrin, la crainte, la terreur; que, parmi les symptômes qui les caractérisent, on voit prédominer l'abattement moral, la stupeur, la dépression des forces vitales, enfin une adynamie réelle, l'observation clinique nous avertit d'administrer le quinquina le plus promptement possible. C'est dans les grands établissemens, dans les hôpitaux civils et militaires, dans les prisons, dans les camps, où ces maladies sévissent quelquefois avec tant de violence, que les plus grands maîtres de l'art ont éprouvé les vertus souveraines de l'écorce du Pérou.

Mais une nouvelle secte s'est élevée et a dit : Il n'y a point de fièvres adynamiques essentielles; leur cause réside dans l'irritation inflammatoire des tuniques digestives; par conséquent les toniques, les stimulans, le quinquina, sont des poisons. Qu'importe que Boerhaave, Van Swiéten, Lind, Huxham, Pringle, Smith, Stoll, Tissot, Wagler, Quarin, Frank, Barthez, Baumes, Pinel, Double, Laënnec, Chomel, Cayol, Andral, Guersent, et une foule d'autres médecins recommandables, nous aient transmis l'heureux résultat de leurs travaux cliniques, ils n'ont point connu la véritable cause des fièvres putrides, la gastro-entérite. Sans doute le mot gastro-entérite ne se trouve point à chaque ligne de leurs écrits, parce qu'ils n'ont jamais pensé que la membrane muqueuse digestive dût jouer un rôle si exclusif dans la production des maladies; mais quel 
est le médecin un peu érudit qui ignore que Sydenham, Baglivi, Pringle, Dehaën, Cullen, etc., ont recommandé les antiphlogistiques dans le premier stade des fièvres putrides et malignes, lorsqu'elles offraient des signes d'irritation et de pléthore? Et de nos jours, Hildenbrand, Hufeland, Baumes, etc., ne se sont-ils pas prononcés en faveur des saignées générales et locales, lorsque le typhus s'est montré avec le même caractère? Qu'on lise les constitutions médicales tracées, il y a déjà long-temps, avec un talent si remarquable, par M. Double, et l'on verra si ce médecin n'a point tour à tour employé les antiphlogistiques, les vomitifs, les excitans et le quinquina, suivant le mode qu'offraient les fièvres bilieuses et putrides.

Si, après des hommes d'un mérite si éminent, il m'est permis de citer des faits qui me sont propres, je dirai que le quinquina a surpassé mon attente dans plusieurs maladies fébriles où l'appareil des symptômes adynamiques et ataxiques était porté à un très-haut degré.

Madame Meggss, d'un âge moyen, d'une constitution éminemment nerveuse, avait eu le malheur de perdre son mari à Milan, à la suite d'une fièvre putride qu'on avait traitée par les antiphlogistiques et par le calomel. Livrée à une douleur profonde, elle quitte brusquement l'Italie et ne s'arrête qu'à Genève, où la fièvre la retient pendant quelques jours. En vain on lui conseille de se soigner et de prendre du repos; elle n'a qu'un désir, c'est de hâter son retour en Angleterre, sa patrie. Elle continue sa route, éprouvant, pendant tout le trajet de Genève à Paris, une céphalalgie conti- 
nuelle, de la faiblesse, des frissons, et un dégoût invincible pour toute espèce d'alimens.

A peine arrivéeà Paris, elle prend des poudres de calomel, qui la purgent abondamment et semblent lui procurer un peu de calme pendant quelques jours; mais à la suite de ces évacuations, la faiblesse augmente et le délire survient. Je fus appelé le dixième jour de la maladie, et j'observai les symptômes suivans : pouls faible, fréquent, irrégulier, accablement, tristesse, conversation incohérente, et parfois exaltation extraordinaire; langue tremblante, jaunâtre, un peu brune à la base ; épigastre tendu, légèrement sensible; déjections bilieuses d'une couleur foncée, d'une fétidité extrême. Décoction de chiendent édulcorée avec du sirop de limon; embrocations huileuses et camphrées sur l'abdomen; potion sédative à prendre par cuillerées. Le délire devient continuel, l'adynamie augmente, les traits sont profondément altérés. La malade prend toutes les heures deux onces de décoction de quinquina animée avec la teinture de cannelle, et de temps en temps un peu de vin de Madère. Ce traitement est continué jusqu'au dix-septième jour. Les idées sont moins confuses; la faiblesse diminue, ainsi que les déjections. Le vingt-troisième jour, une légère diaphorèse semble préluder à une crise favorable. La garde a l'imprudence de suspendre tous les remèdes pendant la nuit. Le lendemain adynamie plus prononcée, selles involontaires, pouls faible, évidemment spasmodique; délire, voix altérée. Vésicatoires au gras des jambes, potion préparée avec six onces d'eau de menthe, six gros d'extrait de quinquina, une once 
de sirop d'œillet, et un gros d'éther; frictions sur les membres avec la teinture de quinquina camphrée. La boisson ordinaire est une infusion de quinquina, à laquelle on ajoute un peu de vin de Bordeaux. Je surveille sévèrement l'administration des remèdes, et j'en fais élever graduellement les doses jusqu'au trentième jour. Dès ce moment, un mieux sensible se déclare, les symptômes adynamiques s'effacent peu à peu, et vers le quarantième jour la malade entre en convalescence.

M. de Fontenay, jeune officier dans les hussards du Nord, d'une faible complexion, contracta pendant l'hiver de 1816 une maladie aiguë, qui prit un caractère adynamique vers le dix-septième jour. Je fus appelé à cette époque par feu le docteur Marquis, qui lui avait donné les premiers soins. Ce jeune homme était en délire et dans un affaissement prodigieux. Il avait le pouls convulsif, à peine sensible; la langue couverte dans toute son étendue d'un mucus épais et noirâtre, ainsi que les dents et les gencives. Une éruption pétéchiale qui s'était manifestée la veille avait presque entièrement disparu; on n'en voyait que quelques faibles vestiges sur le cou et sur la poitrine. On avait appliqué des vésicatoires aux cuisses ; on donnait intérieurement de la limonade, du petit-lait vineux, des poudres composées de nitre et de camphre. La méthode thérapeutique fut modifiée de la manière suivante : toutes les trois heures une demi-tasse de décoction de quinquina et de serpentaire de Virginie avec quelques gouttes d'acide sulfurique. Dans les intervalles, quelques cuillerées d'une mixture prẹparée 
avec l'eau de cannelle simple, l'extrait de quinquina et le sirop d'écorce d'orange. De temps en temps un peu de vin de Bordeaux; topiques rubéfians sur différens points du derme. Les forces se relèvent; l'enduit noirâtre qui couvrait les parois de la bouche se détache de toutes parts; le malade expectore pendant plusieurs jours un mucus abondant et visqueux, et à la fin du quatrième septénaire il est hors de danger.

Je pourrais citer encore beaucoup d'autres observations non moins favorables au quinquina; mais je me contenterai de produire le fait suivañt, en l'abrégeant dans ses détails. M. Adolphe Geyler, âgé d'environ quinze ans, d'un tempérament lymphatique, fut atteint, dans les premiers jours de novembre 1822 , d'une fièvre muqueuse qui offrit pendant la première huitaine une irritation gastro-intestinale très-marquée. J'avais employé l'application des sangsues sur les points les plus sensibles, les embrocations émollientes, les cataplasmes, les lavemens sédlatifs, les boissons gommeuses, une diète sévère, enfin les principaux moyens dont se compose la méthode antiphlogistique; et lorsque je me flattais de la solution prochaine de la maladie, le jeune Geyler tomba dans un tel état d'asthénie, que j'en fus alarmé. La langue était tremblante, fuligineuse dans le milieu, d'un rouge pâle sur les bords. Les déjections exhalaient une odeur fétide et cadavéreuse. Je dois en faire ici l'aveu : les toniques étaient indiqués après le deuxième septénaire par l'état de faiblesse; mais je crus devoir m'en abstenir, dans la crainte de renouveler l'irritation. Je modifiai soudain le traitement, et jarrivai par 
gradation aux plus puissans toniques. Le quinquina rouge, administré à haute dose sous des formes variées, conjura l'orage et fut notre ancre de salut.

Huxham a signalé des angines, des péripneumonies qui se développent avec tous les traits caractéristiques du typhus, et qui passent rapidement à la gangrène. Pour maitriser ces inflammations d'une nature putride, asthénique, il faut, après avoir pratiqué des saignées locales au moyen des ventouses ou des sangsues, administrer sans retard les préparations de quinquina. Huxham employait de préférence sa teinture antiseptique, dont les principaux ingrédiens sont le quinquina, la serpentaire de Virginie et le safran. D’autres médecins ont préconisé le quinquina dans le traitement de la dysenterie putride, des petites véroles d'un mauvais caractère, du typhus d'Amérique, des fièvres pestilentielles.

Des faits incontestables parlent en faveur de cette méthode; mais combien en ont abusé les hommes attachés exclusivement à la théorie de Brown! Les progrès récens de l'anatomie pathologique ont prouvé que les fièvres putrides et malignes sont très-souvent produites par l'inflammation primitive d'un ou de plusieurs viscères, et particulièrement de l'encéphale et de la membrane muqueuse digestive ( $\mathbf{r}$ ). Cette considération importante devait nécessairement restreindre l'emploi des stimulans et des toniques dans le traitement des fièvres. Mais est-il vrai que ces maladies

(1) Voyez la Médecine éclairée par l'ouverlure des corps, publiée en 1804 par le docteur Prost, et le Traité des phlegmasies du professeur Broussais.

II. 
soient toujours symptomatiques d'une inflammation viscérale, comme on le prétend aujourd'hui ? et faut-il les combattre par une seule méthode, par les débilitans et les émissions sanguines répétées? Les médecins judicieux sauront toujours se garantir de cet esprit d'exagération qui n'est propre qu'à faire des fanatiques. Après avoir médité les écrits de Sydenham, de Cullen, de Stoll, de Pinel, ils puiseront avec discernement dans la doctrine de Brown et dans celle de Broussais.

Le quinquina, beaucoup moins utile dans les fièvres putrides sporadiques, est au contraire éminemment indiqué dans le typhus des camps et des prisons, dans ces épidémies qui dévastent les contrées basses et marécageuses, où l'on observe la dépression du pouls, des déjections séreuses, noirâtres, sanguinolentes, des pétéchies brunes, livides, et autres exanthèmes pernicieux. Ces maladies meurtrières attaquent les forces de la vie à la manière des poisons, et les détruisent d'une manière directe. Les inflammations qui se développent sous leur influence ne sauraient être confondues avec les phlegmasies ordinaires. Elles sont d'une nature maligne ( $\mathrm{I}$ ), comme disaient nos prédécesseurs, et elles passent rapidement à la gangrène par l'usage inconsidéré des débilitans.

Pervenit ad miseros, damno graviore, colonos

Pestis, et in magna dominatur monibus urbis.

(1) Ce point de physiologie pathologique a été savamment exposé par M. le docteur Bérard dans le $8^{\mathrm{e}}$ volume de la Revue Médicale, page 288. Examen de la doctrine de $M$. Broussais. 
Viscera torrentur primò, flammaque latentis

Indicium rubor est, et ductus anhelitus igni.

Aspera lingua tumet, tepidisque arentia ventis

Ora patent, auraeque graves captantur hiatu.

Ces symptômes si vivement exprimés par Ovide dans sa description de la peste d'Égine peignent fort bien l'espèce de phlegmasie que le typhus développe dans les entrailles. Je ne pense pas qu'on doive les combattre du prime abord par le quinquina et les stimulans; la méthode rafraîchissante me paraît plus rationnelle dans les premiers momens; mais aussitôt que les forces tombent, que le pouls s'affaiblit, la méthode stimulante sagement dirigée offre plus de chances de salut. Le typhus pestilentiel est une sorte de poison qui agit parfois avec une si grande violence, qu'aussitôt qu'on se sent frappé on est mourant, on expire.

L'indication du quinquina est bien plus évidente encore si la fièvre offre des rémissions marquées, comme cela arrive dans les affections putrides des pays marécageux. Ici, il ne faut pas craindre de l'administrer à haute dose si l'on veut éviter une terminaison funeste. C'est en parlant de semblables fièvres que le professeur Baumes a fait entendre ces paroles remarquables: Que celui qui ne croit point qu'elles soient d'une nature spéciale, qu'elles aient pour cause un miasme virulent émané des surfaces marécageuses, vienne les observer sur nos plages; que dans les fièvres rémittentes qui accablent l'homme des champs il déploie généralement la méthode délayante, antiphlogistique et affaiblissante, qui convient si bien aux phlegmasies internes, aiguës ou chroniques; et qu'il 
compare ensuite ses succès et ses revers. Une chose dont on peut l'assurer, c'est que, puisque l'anatomie pathologique est regardée par lui et ses adhérens comme le vrai pivot de la science médicale, il ne lui manquera pas de cadavres à ouvrir. Entouré de ses victimes, il pourra décrire avec enthousiasme les lésions de la muqueuse, derniers effets d'une maladie qui se termine par la mort, et sur lesquels ont influé les exhalations d'une matière morbide, les gaz gastriques et intestinaux, l'action topique des remèdes, et, plus que tout, les congestions des vaisseaux capillaires, qui, à mesure que les gros vaisseaux se vident, reçoivent cette quantité de sang qui les distend, en injecte le lacis, et donne à la surface de la membrane cet aspect rougeâtre auquel on assigne tous les caractères d'une phlegmasie dont on a méconnu les indications et le traitement. (Traité des fièvres rémittentes, tome I, page 268 .)

Après avoir montré le quinquina comme un des remèdes les plus efficaces dans le traitement des fièvres adynamiques et ataxiques, nous devons à la vérité de dire que ces maladies offrent très-souvent dans leur premier stade, et quelquefois pendant tout leur cours, des signes non équivoques d'irritation dans un ou plusieurs organes, et que cet état d'éréthisme ne peut que s'aggraver sous l'influence des toniques et des stimulans. Le docteur Mindérer a observé les mauvais effets du quinquina, de la valériane, de la serpentaire de Virginie, etc., dans une fièvre hémitritée d'une nature maligne qui régna en 1806 et 1807 dans les provinces méridionales de l'empire de Russie. Cette 
fièvre, qui débutait par des vomissemens bilieux avec un sentiment de douleur et de chaleur à l'épigastre, et un état de spasme dans le système de la veine porte, réclamait une médication tempérante, les mucilagineux, les relâchans. L'emploi prématuré des toniques transformait la maladie en fièvre continue. On ne pouvait y avoir recours que lorsque les symptômes d'adynamie ou de malignité nerveuse étaient bien prononcés; encore fallait-il alors ne les déployer qu'avec beaucoup de circonspection. Hildenbrand, qui nous a donné une histoire parfaite du typhus, se contente de prescrire dans la première période, presque toujours marquée par une excitation générale, des décoctions émollientes, des boissons légèrement acides. Dans les cas ordinaires, il recommande de n'administrer que des excitans modérés; il avoue même qu'il vaudrait peut-être mieux n'employer aucun excitant que d'en employer de trop forts.

Attaqué lui-même du typhus en $179^{5}$, il ne fit usage pendant sa maladie, à l'exception d'un vomitif qu'il prit au commencement après une saignée, que de la limonade et de la crême d'orge. Néanmoins, il surmonta heureusement la maladie, et après une crise favorable qui survint au quatorzième jour, il fut parfaitement bien, sans avoir eu recours à aucune espèce d'excitant.

C'est dans le traitement des fièvres putrides et nerveuses que la médecine des symptômes peut entraîner aux plus grands écarts. Ainsi les éruptions pétéchiales et pourprées n'indiquent point d'une manière formelle l'usage du quinquina. On a même remarqué qu'elles 
étaient assez souvent le résultat d'une médication incendiaire. Lorsque les forces vitales se maintiennent, elles ne sont point d'un mauvais augure, et n'exigent aucun remède actif; mais il n'en est pas de même lorsqu'elles se déclarent à la suite de l'abus des saignées ou de la méthode asthénique, et qu'elles se joignent à d'autres indices de la prostration des forces. Dans ce cas extrêmement grave, le quinquina, donné à grandes doses et combiné avec le vin, avec les excitans diffusibles, a quelquefois sauvé les jours du malade. Le docteur Hasenöhrl, atteint d'une fièvre maligne pétéchiale, fut promptement rétabli en prenant tous les jours une once d'extrait de quinquina, un parégorique matin et soir, et des boissons acidules. Ce traitement fut conseillé par les professeurs Dehaën, Mayer et Ernol. (ED. SANDIForT, Thesaurus dissertationum. Historia medica febris petechialis, tom. I, pag. 104.)

Le professeur Pinel, dans une fièvre ataxique qu'il avait contractée en $179^{3}$, n'échappa à la mort qu’à l'aide d'un excellent vin d'Arbois dont on lui faisait prendre de petites doses très-rapprochées.

Les diarrhées, les flux dysentériques qui compliquent ces maladies exigent la plus grande circonspection de la part du médecin. Si l'abdomen est tendu, sensible à la pression; si le pouls est vif et serré, la peau sèche et aride, le quinquina est formellement contre-indiqué, tandis que les mucilagineux, les sédatifs, les topiques émolliens produisent un effet salutaire. Il est même certains flux sans douleur, sans irritation, qu'il faut pour ainsi dire abandonner à eux- 
mêmes; lorsqu'ils coïncident avec d'autres signes favorables, ils doivent être regardés comme le produit d'une crise naturelle. Mais si la diarrhée est excessive, si elle tend à énerver de plus en plus les forces vitales, loin de la combattre par les antiphlogistiques, il faut lui opposer l'écorce du Pérou, la racine d'arnica et l'opium.

Enfin, pour traiter ces affections graves d'une manière convenable, il faut étudier avec soin leur natture, leur marche, leurs symptômes; analyser leurs élémens, leurs complications; noter l'influence des lieux, du climat, de la saison, de l'état atmosphérique, de la constitution régnante, et surtout ne point se laisser dominer par l'ascendant des nouvelles sectes ni séduire par les succès éphémères de leurs méthodes. Eh! qui ne sait que depuis vingt-cinq ou trente ans tous les systématiques nous vantent la perfection de leurs doctrines? " Brown voit la vérité sans nuages; il "l'approfondit avec toute la pénétration de son génie, " et en embrasse tous les rapports: son regard perçant " y découvre le vrai principe de la science médicale; il " le saisit dans toutes ses conséquences, et, nouvel “ Archimède, il s'écrie : Je l'ai trouvé! A lui seul ap" partient la gloire de cette belle découverte, et parti" culièrement celle d'en avoir su tirer un corps de doc" trine marqué au coin de cette solidité et de celte " simplicité qui décèlent les ouvrages de la nature. " (Lafont-Gouzi, Nouvelle Doctrine de Brown.) Les partisans de $M$. Broussais ne tiennent-ils pas à peu près ce langage? C'est toujours le même système, seulement la méthode curative est dans un sens inverse. Ceux-ci 
traitent les fièvres putrides et maligues par les mêmes moyens que les véritables inflammations, emploient les débilitans, les émissions sanguines, et surtout l'application répétée des sangsues; tandis que les autres ne veulent que des toniques et des stimulans, tels que le quinquina, le camphre, le vin, etc. Cependant ils invoquent tour à tour le témoignage de l'expérience, vantent leurs nombreux succès, et les comparent aux revers de leurs antagonistes. S'il faut en croire la nouvelle école physiologique, la méthode excitante du professeur écossais a tué plus de monde que la poudre à canon. Rasori, célèbre médecin italien, qui était jadis un des plus chauds partisans de Brown, a abjuré sa doctrine pour embrasser celle du contro-stimulus, dont il a fait le plus heureux essai dans l'épidémie pétéchiale de Gênes. Cette nouvelle méthode se compose, comme on le sait, de saignées répétées, de boissons. aqueuses abondantes, de purgatifs et de fortes doses d'émétique. Le quinquina, le vin, la serpentaire de Virginie, la valériane, etc., en sont formellement exclus. Observons néanmoins que les brillans succès de Rasori dans cette épidémie ont été niés par des témoins oculaires.

D'un autre côté, le célèbre P. Frank rapporte dix observations de typhus contagieux dont furent attaqués des médecins de l'hôpital de. Vienne : huit furent guéris promptement par la méthode excitante, et des deux autres qui moururent, l'un fut apporté presque éteint à la clinique.

Dans l'hôpital général de la même ville, sur deux cent quatre-vingt-neuf malades attaqués du typhus en 
janvier ${ }^{7797}$, il n'en mourut que quinze. Depuis l'automne de la même année jusqu'au printemps de $\mathbf{1} 79^{8}$, où la violence de la maladie était extrême, on traita dans le même hôpital deux cent cinquante-six malades; il en mourut seulement dix-neuf : tous les autres furent parfaitement rétablis par la même méthode.

Le docteur Campbell, un deș plus habiles disciples de Brown, fit la plus belle cure dont les annales de la médecine fassent mention. Ce médecin était sur un vaisseau très-malsain, appelé la Dutton, qui allait aux Indes orientales, à la latitude de 'Rio-Janeiro : une fièvre de mauvais caractère faisait périr tous les jours un grand nombre de personnes du convoi. Les registres du vaisseau la Dutton font foi qu'il arrêta les ravages de cette épidémie par l'emploi des toniques, et que, dans un espace de cinq semaines, il ne perdit pas un seul malade.

En l'an 8, il régnait à Vienne des affections de poitrine très-graves, auxquelles succombèrent le plus grand nombre des malades qu'on saigna. En suivant la méthode excitante, sur quatre-vingt-six malades on ne perdit qu'une seule femme, qui mourut quarante-huit heures après son entrée à l'hôpital.

J'ai emprunté ces détails à l'ouvrage cité de M. Lafont-Gouzi. Il est inutile d'observer qu'ils parlent hautement en faveur des remèdes toniques dans le traitement des fièvres putrides et nerveuses où la faiblesse. domine. Je doute que les sangsues et les débilitans eussent procuré de semblables succès dans les mêmes. circonstances. Les faits de ce genre (et quel est le méa. 
decin qui n'en pourrait citer ?) prouvent sans réplique que toutes les fièvres adynamiques et ataxiques ne dérivent point d'une inflammation locale. Ainsi les traitemens les plus opposés peuvent être tour à tour salutaires ou funestes, suivant la nature et les causes de la maladie. D'où il faut conclure que le praticien asservi à une seule méthode s'éloigne des règles de la médecine expérimentale, et que celui-là seul peut compter sur des succès durables qui sait profiter habilement de tous les systèmes et changer à propos de méthode. La foule, dit le professeur Laënnec, a toujours suivi le sentier tracé devant elle par l'école de son temps, et s'est toujours attachée de préférence aux doctrines les plus exclusives, et par conséquent les plus simples. Sans doute il serait plus commode de s'en tenir à une seule méthode : l'art ne serait plus long, et l'expérience aurait enfin donné un démenti à cette sagesse antique, dont le mépris est un caractère commun à tous les hérésiarques de la médecine.

$\mathrm{Au}$ reste, lorsque le danger n'est point grave, et que la nature d'une fièvre épidémique n'est pas bien caractérisée, il faut ne pas trop se presser, et surtout être avare de remèdes énergiques. Dans les cas douteux, on a pourvu plus d'une fois à sa propre réputation et à la sûreté du malade en ne faisant rien du tout; car en veillant sur la maladie, afin de trouver l'occasion favorable d'entreprendre quelque chose d'avantageux, la fièvre se dissipe insensiblement d'elle-même, ou bien elle prend un caractère qui nous fait connaitre par quelles armes il faut l'attaquer. Une chose déplorable, dit Sydenham, c'est que la plupart des malades ne sa- 
chant pas qu'il est également du devoir d'un habile médecin de ne rien faire en certaines occasions, et d'employer dans d'autres cas les plus puissans remèdes, ils attribuent à sa négligence où à son ignorance ce qu'ils devraient regarder comme un effet de sa probité et de sa bonne foi.

On a souvent recours aux préparations de quinquina dans le traitement des névroses. Cullen, Tissot, Barthez, les conseillent contre la chorée, l'épilepsie, les maladies vaporeuses atoniques, etc. Le professeur Pinel combine l'écorce du Pérou avec le camphre et la cannelle; il a essayé ce mélange sur six épileptiques, devenus tels par des frayeurs durant l'enfance. Deux de ces malades ont été guéris; un autre a eu des attaques beaucoup moins fréquentes; les trois autres n'ont point été soulagés.

J'ai administré le quinquina à un enfant épileptique, en y ajoutant un tiers ou un quart de racine de valériane, et je suis parvenu à diminuer les accidens pendant les premières années. Dans un âge plus avancé, le malade n'a pu supporter ce remède, qui rendait les attaques beaucoup plus violentes. Les bains, le petitlait, les sangsues appliquées au fondement, les saignées du pied, ont produit au contraire un soulagement remarquable. Les heureux effets de cette nouvelle méthode s'expliquent par l'état d'irritation et de pléthore qu'amène l'âge de la puberté. Il est sûr que le quinquina, la valériane, les toniques, les stimulans ne peuvent qu'aggraver les affections nerveuses qui dépendent ou se compliquent d'un état d'éréthisme et de phlogose.

L'hystérie, l'hypochondrie, l'asthme, ont pu être 
soulagés par le quinquina, ainsi que nous l'assurent plusieurs auteurs; mais qui oserait le prescrire à des sujets pléthoriques ou très-irritables? et combien n'at-on pas abusé de la méthode de Whytt dans le traitement des maladies nerveuses connues sous le nom de vapeurs! Il fut un temps où l'on rapportait ces affections à une cause unique, la faiblesse de l'appareil nerveux ; aussi prodiguait-on le quinquina, les excitans, les analeptiques. Pomme, qui ne voyait au contraire que des fibres irritées, racornies, insistait sur les relâchans, les boissons aquenses, les bains prolongés. Ces méthodes exclusives ont été jugées par Barthez avec cette supériorité de raison et de critique qui brille dans tous ses écrits. (Voyez la Science de l'homme, tome 2 , page 177 , et la note 5 , page 88 , où le traitement des maladies nerveuses a été dessiné à grands traits par cet illustre professeur. )

Personne n'ignoreles succès que Morton a obtenus du quinquina dans la phthisie pulmonaire; Van-Swieten, Pringle, Quarin, et un grand nombre d'autres praticiens distingués, ont également fait son éloge. Lorsque la diathèse inflammatoire a été combattue par les évacuations sanguines, les antiphlogistiques et un régime. convenable, si les forces diminuent d'une manière sensible, si le dépérissement fait des progrès rapides, le quinquina, administré avec sagesse, peut sans doute être d'un grand secours; mais alors il est utile de le combiner avec le lichen d'Islande, le lait, les mucilagineux, les boissons pectorales. Il faut l'abandonner ou le suspendre lorsque la peau devient brûlante et qu'il survient de l'oppression. M. de Metternich, pro- 
fesseur de médecine à Mayence, a guéri plusieurs phthisies déjà très-avancées par de fortes doses d'extrait de quinquina; il en donnait jusqu'à six gros en vingt-quatre heures. Dans le mois de février dernier, j’ai employé le même médicament à la suite d'une péripneumonie des plus graves. L'expectoration était puriforme et les forces anéanties. MM. les professeurs Portal et Landré-Beauvais avaient d'ailleurs porté sur l'issue de la maladie un pronostic fâcheux. L'extrait de quinquina, administré depuis deux gros jusqu’à demionce, dans une décoction de polygala de Virginie, et continué pendant l'espace d'un mois, a remonté les forces et dissipé des mouvemens fébriles qui se reproduisaient chaque jour à une heure fixe. J'ai en même temps prescrit la gelée de lichen d'Islande et le lait d'ânesse. En ce moment, la convalescence marche avec rapidité, et tout fait espérer une prompte et entière guérison.

Le quinquina est encore un moyen précieux dans certains catarrhes, lorsque le poumon et les organes diges-tifs sont dans un état de débilité. Si l'on prodigue alors les évacuations sanguines, les looks, les boissons relâchantes, les forces de la vie s'énervent de plus en plus, l'affection catarrhale s'aggrave, et les malades tombent dans une consomption incurable. On prescrit l'écorce du Pérou avec non moins d'avantage dans les coqueluches qui se prolongent. Ce médicament ranime les forces épuisées, en même temps qu'il détruit l'habitude des mouvemens convulsifs. On emploie alors le sirop ou la décoction de quinquina, en y ajoutant parfois une petite quantité de sirop diacode. 
Je ne veux point quitter ce sujet sans observer que l'application du quinquina est fort délicate dans les affections pectorales. Le professeur Broussais, qui a traité un grand nombre de ces maladies, ne conteste point l'utilité de ce médicament, adouci avec la gomme arabique, dans quelques cas d'anorexie; mais il pense qu'il est dangereux d'en continuer l'usage. Suivant cet habile observateur, le précepte qui s'est répandu parmi les médecins, que les catarrhes prolongés exigent l'emploi des toniques, est un des plus pernicieux qui aient jamais été donnés. J'avoue qu'il serait téméraire de combattre par les excitans toutes les maladies catarrhales, surtout dans leur état d'irritation ; mais, certes, il est des cas qui exigent impérieusement cette méthode; le point essentiel est de l'employer à propos. Il faut absolument renoncer au quinquina et à tous les remèdes toniques lorsque, après un examen approfondi, on a lieu de soupçonner une phlogose latente $\mathrm{du}$ poumon. Cet état morbide s'observe particulièrement chez les jeunes gens doués d'une constitution délicate et mobile, qui ont la poitrine étroite, comprimée, les yeux brillans, les pommettes teintes d'un rouge vif; qui éprouvent une toux sèche, avec un peu d'oppression après la moindre fatigue. Ici la véritable méthode consiste dans l'emploi judicieux des saignées, des boissons émollientes et des antiphlogistiques. Suivant la remarque de Stoll, cette phlogose lente produit beaucoup plus de phthisies que l'inflammation aiguë ordinaire.

Dans presque tous les ouvrages consacrés à l'histoire et au traitement des maladies goutteuses, le quinquina 
est tour à tour conseillé ou proscrit, suivant le système qu'ont adopté les auteurs. Tavarès, médecin portugais, Alexandre Small, le professeur Alphonse Leroy, le docteur Giannini, ont vivement recommandé ce médicament contre la goutte. Ce dernier assure, d'après un grand nombre de faits recueillis, soit en ville, soit dans les hôpitaux, qu'il est aussi utile dans la goutte que dans les fièvres intermittentes. Après avoir pris quatre ou six gros de quinquina, le malade est plus souffrant; son pouls devient plus irrité, plus tendu ; l'inquiétude et la tristesse augmentent : néanmoins tout se calme insensiblement à mesure qu'on avance dans l'administration du remède, dont les doses réunies s'élèvent de dix à quinze gros. Enfin la maladie cesse comme par enchantement dans l'espace de vingt-quatre à trente heures, à dater de l'époque à laquelle on a commencé l'usage du quinquina. Le pouls, qui était alors plein et fort, devient aussitôt petit, lent et faible ; la chaleur de la peau se trouve presque réduite à la température naturelle; il y a quelquefois une légère diaphorèse, et le malade goûte un sommeil tranquille et réparateur. Les symptômes locaux, tels que la rougeur, et souvent même la tumeur, sont dissipés, et il ne reste aux parties affectées qu'une sensibilité exquise. Il est inutile alors d'insister sur l'usage généreux du quinquina : il faut le suspendre dès l'instant qu'on a obtenu de si heureux effets, pour ensuite y revenir un ou deux jours après, quand la maladie n'est pas entièrement détruite. On l'administre alors à petites doses pendant cinq ou six jours, comme moyen préservatif contre toute rechute ultérieure; en 
un mot, on agit dans la goutte comme dans les fièvres pernicieuses, quant à la prescription du remède. L'effet du quinquina est d'autant plus prompt, plus sûr et plus durable, que l'apparence de la maladie est plus aiguë et plus inflammatoire, proposition en apparence paradoxale, mais dont la vérité résulte d'observations certaines.(Granninr, Traité c'e la nature des fièvres.) Alphonse Leroy rapporte dans son Manuel des goutteux plusieurs faits qui confirment l'efficacité du quinquina dans le traitement des maladies arthritiques. Suivant cet auteur, il faut également le donner à fortes doses pour obtenir des succès. Il est aisé de voir que cette méthode est basée sur la faiblesse indirecte de Brown. Je ne pense pas qu'un médecin prudent puisse l'adopter, à moins que la maladie ne s'annonce avec un caractère périodique et des symptômes pernicieux. Dans les affections articulaires aiguës, la méthode antiphlogistique, sagement dirigée, doit toujours obtenir la préférence. Ce n'est que dans leur état avancé, et lorsque les forces sont languissantes, qu'on peut avoir recours au quinquina. Dans la convalescence, ce remède est le tonique le plus propre à combattre la faiblesse générale et à prévenir les rechutes.

Les vertus du quínquina ont toujours été appréciées dans le traitement des affections lymphatiques, et il y a peu d'années il composait, avec la gentiane et quelques autres amers, toute la thérapeutique du rachitis, des scrophules, etc. Aujourd'hui on administre ces remèdes toniques avec un peu plus de réserve: nous devons cette sage modification à l'école physiologique. Ce n'est pas que les médecins instruits n'eus- 
sent remarqué depuis long-temps les mauvais effets du quinquina dans les scrophules qui attaquent les enfans doués d'une grande irritabilité, qui ont la peau sèche, brûlante, l'abdomen sensible ; mais la foule, toujours attachée aux méthodes nouvelles, ne voulait reconnaître dans cette affection pathologique que la faiblesse des tissus, le relâchement de la fibre; et, d'après cette théorie exclusive, elle administrait dans tous les cas des doses généreuses de vin de quinquina, dè teinture de gentiane, d'absinthe, le tout soutenu par un régime analeptique, des boissons excitantes, etc. Ce traitement a sans doute produit quelques guérisons; mais il faut convenir aussi qu'il a fait beaucoup de victimes.

Malgré les éloges prodigués au quinquina par Fordyce, Fothergill, Bond, Wihtt, etc., ce médicament est pernicieux dans l'état inflammatoire des glandes: il étend alors l'irritation jusqu'aux glandes lymphatiques encore saines, et, suivant la remarque de M. Baumes, ce sont ordinairement celles du poumon qui s'affectent. Mais on peut le donner avec confiance aux sujets d'une constitution molle, qui éprouvent une faiblesse générale, des langueurs d'estomac avec anorexie, des diarrhées provenant d'une débilité intestinale, etc. Fothergill l'a employé avec succès dans les ophthalmies scrophuleuses, en yjoignant l'usage du calomel et du soufre doré d'antimoine. On obtient aujourd'hui des effets semblables du sulfate de quinine et du calomel administrés sous la forme de pilules. J'emploie fréquemment cette précieuse combinaison dans les ophthalmies invétérées, dans l'engorgement atonique 
des glandes, les bouffissures, les cachexies muqueuses, les dartres provenant de la même source, etc. Lorsque les enfans sontirritables, je les prépare à ce remède par les bains tièdes, les boissons délayantes et un régime végétal.

On a recommandé d'avoir recours au quinquina pour réprimer les flux sanguins fomentés par la faiblesse et l'inertie des vaisseaux capillaires exhalans. Nous nous sommes déjà expliqués relativement à l'hémoptysie périodique, et nous avons fait sentir avec quel ménagement il fallait employer ce remède, malgré les faits rapportés par les auteurs. Il en est de même des autres fluxions sanguines, qu'on distingue sous le nom d'hémorrhagies passives, et qu'on observe chez les personnes faibles, nerveuses. Si quelquefois on les a combattues avec succès par le quinquina, dans d'autres circonstances on a provoqué la phlogose, et même la suppuration des tissus qui en étaient le siége. Les écoulemens muqueux, les leucorrhées chroniques qui attaquent les femmes sédentaires, d'une complexion faible, d'un tempérament lymphatique, indiquent l'usage du quinquina et des substances amères; mais qu'on se garde bien de les administrer si les voies utérines sont douloureuses ou dans un état de spasme et d'irritation, si le pouls est fébrile, la peau chaude, sèche, etc. Les flux leucorrhoïques qui surviennent à l'âge de quarante-cinq ou cinquante ans, après la cessation des règles, doivent être traités avec la plus grande réserve. Cependant, lorsque les digestions sont lentes et imparfaites, on peut prescrire les préparations de quinquina à petites doses, afin de rétablir peu à peu 
les fonctions du système gastrique. Les flueurs blanches qu'éprouvent les femmes sanguines, irritables, ainsi que les jeunes filles d'ailleurs fortement constituées et qui ne sont pas encore nubiles, contre-indiquent formellement l'emploi du quinquina. On leur oppose avec succès la méthode tempérante, les bains et les antispasmodiques. Au reste, pour triomphèr de ces maladies, il faut étudier avec soin les causes infiniment variées qui les entretiennent, faire parfois une médecine expectante, et profiter habilement des voies que la nature affecte pour en opérer la solution.

C'est dans les mêmes principes qu'il faut traiter la chlorose, l'aménorrbée, les obstructions abdominales, et quelques autres affections chroniques, où l'on prodigue quelquefois si mal à propos la méthode stimulante. Le quinquina deviendra un remède précieux dans ces maladies, si les organes sont exempts d'irritation ou de phlogose; si le pouls est lent, faible, le teint pâle, le tissu cellulaire lâche et conme bouffi; enfin, sïl existe des signes évidens d'une langueur générale.

Parlerons-nous des propriétés anthelminthiques du quinquina et de son heureuse association avec la valériane, le calomel, pour détruire la diathèse vermineuse? Dirons-nous que cette écorce a été éprouvée, avec plus ou moins d'avantage, dans les affections scorbutiques, par Lind, Cramer, Brocklesby, et que son usage est surtout réclamé par les hémorrhagies symptomatiques, les ulcères sanieux et putrides; que ses préparations diverses sont d'une application pour ainsi dire populaire, pour hâter les progrès de la con- 
valescence, à la suite des maladies de long cours, lorsque les forces vitales ont reçu une atteinte profonde; qu'elles corroborent peu à peu tous les organes, et spécialement le système gastrique, dissipent l'anorexie, les flatuosités, l'œdème des extrémités inférieures, et cet état cachectique qui, abandonné aux seules ressources de la nature affaiblie, amène si souvent des infiltrations cellulaires, des hydropisies, des obstructions incurables? On attribue également au quinquina une faculté prophylactique, et beaucoup de médecins le conseillent, concurremment avec les moyens que fournit l'hygiène, comme un préservatif des maladies contagieuses qui règnent dans les pays humides et insalubres. Toutefois, lorsqu'une épidémie offre des fièvres intermittentes ou rémittentes d'un caractère pernicieux, il faut en user sobrement, pour ne pas habituer les organes à un remède qui agirait ensuite avec beaucoup moins d'énergie, si la maladie venait à éclater.

Enfin, pour terminer le tableau, déjà si étendu des propriétés du quinquina, nous devons mentionner ici ses effets salutaires dans l'empoisonnement produit par les préparations antimoniales, et notamment par l'émétique. Lorsque cette substance saline a été avalée depuis peu de temps, l'eau tiède pure, miellée ou sucrée, prise en abondance, fait cesser pour l'ordinaire les accidens en favorisant le rejet du poison. Mais si le malade n'a point vomi, il faut lui donner une forte décoction de quinquina, afin d'opérer la décomposition de l'émétique.

Passons maintenant aux préparations qu'on fait 
subir au quinquina et à la manière de les administrer. La préparation la plus simple est la poudre qu'on obtient de cette écorce. Les uns recommandent de mêler avec le plus grand soin les premières et les dernières poudres, afin d'obtenir une poudre bien mélangée; d'autres veulent qu'on jette la première poudre, et qu'on préfère la dernière obtenue. Suivant MM. Pelletier et Caventou, celle-ci est plus résineuse, et par conséquent plus fébrifuge. Les doses varient suivant le caractère de la fièvre ou de la maladie qu'on veut combattre. On la donne seule ou associée à des aromates, à des substances amères, excitantes, etc., et délayée dans un peu d'eau, un peu de vin, ou incorporée dans un sirop, dans du miel. L'eau, le vin, l'alcohol se chargent des principes actifs du quinquina. On prépare avec ces liquides des extraits, des infusions, des décoctions, des teintures simples ou composées, etc.

On distingue trois sortes d'extraits de quinquina, deux préparés avec l'eau et un autre avec l'alcohol. Le premier est un extrait mou, préparé par la décoction de l'écorce. Suivant les chimistes que nous venons de citer, il contient non-seulement tous les principes du quinquina solubles par eux-mêmes, mais encore plusieurs substances qui se dissolvent par l'intermède des premières, lorsqu'elles ont un certain degré de concentration. Ils proposent, pour améliorer cette préparation, d'étendre de beaucoup d'eau les décoctions de quinquina, de les filtrer froides, et de les concentrer ensuite jusqu'à consistance requise : on aurait alors un extrait qui, sous une masse donnée, con- 
tiendrait beancoup plus de sel cinchonique, et qui aurait par conséquent bẻancoup plus d'activité. Le deuxième extrait est le produit de la macération : il est connu sous le nom d'extrait sec, on sel essentiel de Lagaraye. II est formé de kinate de chaux, de gomme, de matière colorante, et contient très-peu de sel cinchonique. Le troisième est également un extrait sec qu'on obtient en distillant au bain-marie la teinture alcoholique de quinquina parfaitement saturée, jusqu'à ce qu'il ṇe reste plus que le quart du liquide. On continue ensuite l'évaporation à une douce chaleur, et on conserve le produit dans des vases exactement fermés. Le docteur Chrestien, de Montpellier, emploie dans sa pratique deux préparations analogues : l'une, qu'il nomme résine, s'obtient en faisant évaporer à un feu très-doux la teinture alcoholique de quinquina; l'autre, désignée sous le nom d'extracto-résineux, est le produit d'une teinture de quinquina préparée avec l'eau-de-vie. Ces deux substances se prescrivent à la dose de dix à quinze grains dans un véhicule aquenx. La première surtout est très-fébrifnge : mêlée avec moitié dose de sel d'absinthe, elle remplace avantageusement le quinquina chez les femmes enceintes, les enfans, et en général chez les personnes qui ont une grande répugnance pour cette écorce.

Ces divers extraits, et particulièrement l'extrait mou, font partie d'une foule de prescriptions magistrales. Lorsqu'on les administre isolément pour obtenir un effet tonique, la dose est de dix, quinze ou vingt grains, et plus; mais elle doit s'élever à deux gros, et 
même jusqu'à une demi-once, lorsqu'on veut remplacer la poudre de quinquina. Toutefois, dans les fièvres intermittentes graves, cette dernière forme doit toujours être préférée à l'extrait.

Poudre fébrifuge. Prenez, quinquina gris réduit en poudre fine, une once et demie; magnésie, six gros. Mêlez exactement, et divisez en dix-huit prises égales. Cette préparation, employée par Lorentz, médecin des armées françaises, convient spécialement dans les fièvres quartes rebelles. On donne huit prises le premier jour de l'intermission, huit le lendemain, et les deux autres le jour de l'accès. On peut délayer cette poudre dans un véhicule quelconque, ou l'administrer sous la lorme d'électuaire. Dans les fièvres intermittentes pernicieuses, on donne ordinairement le quinquina sans mélange, depuis une jusqu'à deux et trois onces pendant l'apyrexie. Lorsque le danger était pressant et la récidive imminente, le docteur Coutanceau donnait jusqu'à dix onces de quinquina, et même plus, pour compléter le traitement des fièvres pernicieuses qui ont régné épidémiquement à Bordeaux en 1805. C'est ainsi que Galeazzi fut obligé de faire prendre jusqu'à une livre de cette écorce pour dompter des fièvres opiniâtres. Ces doses peuvent paraitre excessives; mais, lorsqueles circonstances sont graves, il faut, pour ainsi dire, donner le quinquina à pleines mains (1).

(1) Ces doses effrayantes de quinquina, que les estomacs les plus robustes peuvent à peine supporter, sont aujourd'hui remplacées avec un avantage incontestable par le sulfate de quinine, dont il faut aussi savoir élever les doses, lorsque le danger le commande. 
Poudre cathartique. Prenez, quinquina en poudre, carbonate de magnésie (magnésie pure), de chaque demi-once; mêlez exactement, et partagez en huit doses. On en prend une tous les matins à jeun dans une tasse de thé léger. Cette poudre est un fort bon remède contre la constipation qui ne dépend point d'une irritation intestinale; elle n'a pas l'inconvénient des purgatifs ordinaires, qui, après avoir excité les organes digestifs, les jettent dans un état d'atonie. Lorsque le ventre est paresseux, on obtient quelquefois avec un demi-gros seulement, répété plusieurs fois de suite, des selles plus faciles et plus régulières.

Quinquina tartarisé de Vogler. Prenez, écorce de quinquina choisie et finement pulvérisée, six gros; tartrate acidule de potasse, deux ou trois gros. Mêlez. pour une poudre dont on donne trente ou quarante grains deux ou trois fois par jour. Vogler la recommande comme un remède de la plus grande efficacité dans les constipations opiniâtres. Son usage a dissipé des vertiges, des spasmes, des gonflemens, des oppressions, des flatuosités, et plusieurs autres accidens occasionés par la constipation. Il a également observé les bons effets du quinquina mêlé avec quelques grains de magnésie, chez les enfans d'une constitution débile, et dont le ventre est paresseux. Ce médicament corrobore les intestins affaiblis, apaise les tranchées, les convulsions, et prévient la diathèse vermineuse. (VoGLER, Pharmacologia, page 35.)

Électuaire fébrifuge et antispasmodique. Prenez, quinquina rouge, deux onces; valériane sauvage, demi-once; extrait d'opium aqueux , trois grains; sirop 
d'écorce d'orange, quantité suffisante pour former un électuaire, qu'on divisera en douze prises à prendre toutes les deux ou trois heures. Cette préparation est consacrée au traitement des fièvres intermittentes accompagnées de dévoiement et de symptômes nerveux.

Électuaire astringent de Tissot. Prenez, conserve de roses rouges, trois onces; conserve de romarin et de quinquina pulvérisé, de chaque une once et demie; menthe, deux gros; cachou, un gros; essence de cannelle, deux gouttes. Mêlez, et faites un électuaire avec le sirop de gomme arabique. Cet électuaire dont on prend un ou deux gros, le matin et le soir, est très-propre à combattre les pollutions nocturnes, les vieilles leucorrhées, et autres flux muqueux provenant de causes débilitantes.

Infusion froide de quinquina du docteur Virey. Prenez, quinquina choisi concassé, une once; eau commune, une livre. On infuse pendant deux jours en un matras fermé; on passe, on décante. La liqueur doit être de belle couleur, comme pour faire l'extrait sec de quinquina de Lagaraye : elle se prend par verres comme tonique et fébrifuge.

Décoction antifébrile. Prenez, quinquina concassé, une once; fleurs d'arnica, un gros; eau bouillante, une livre. On fait bouillir le quinquina jusqu'à réduction de moitié; ensuite on retire du feu, et on ajoute l'arnica, qui infuse demi-heure; on passe, et on ajoute deux onces de sirop de camomille. La dose de cette décoction est de trois ou quatre cuillerées de deux heures en deux heures, dans les intervalles de la fièvre.

Décoction de quinquina duprofesseur Hufeland. 
Prenez, quinquina pulvúrisé, une once; faites bouillir dans douze onces d'eau jusqu'à réduction de moitié, et passez la décoction. Faites infuser à froid, pendant quelques heures, une demi-once de la même écorce dans huit onces d'eau; agitez de temps en temps; et filtrez. Mêlez ensuite les deux liqueurs. Cette préparation, qu'on peut édulcorer avec le sirop de cannelle ou d'écorce d'orange, est consacrée au traitement de l'affection scrophuleuse ; on en donne une ou deux cuillerées toutes les deux heures, plus ou moins, suivant l'âge du malade, lorsque les forces sont languissantes. Elle convient surtout vers la fin de la maladie, pour remédier à la faiblesse des vaisseaux lymphatiques; mais il faut s'en abstenir, s'il existe quelque inflammation particulière ou une suppuration tenant à un état inflammatoire encore existant.

Teinture alcoholique simple du docteur Chrestien. Prenez, quinquina rouge, deux onces; alcohol à trente-six degrés, vingt-quatre onces. Infusez suivant les règles de l'art, ou bien faites digérer la même quantité de quinquina dans de l'eau-de-vie à vingt-deux degrés. (Méthode iutraleptique.) En ajoutant une ou deux onces de teinture alcoholique à deux livres de vin de Roussillon, de Xérès ou de Madère, on obtient un vin de quinquina très-efficace contre les affections asthéniques.

Teinture de quinquina composée d'Huxham. Prenez, écorce de quinquina rouge, deux onces; écorce d'orange, une once et demie; racine d'aristoloche serpentaire, trois gros; safran, un gros; cochenille, deux scrupules; alcohol délayé, vingt onces. 
Laissez digérer pendant huit jours, et filtrez. La dose est d'un à quatre gros, de quatre en quatre heures, ou à des distances plus ou moins éloignées. On la donne dans du vin ou dans une eau aromatique, et on y ajoute parfois quelques gouttes d'élixir de vitriol. Huxham la recommande dans la fièvre lente nerveuse, dans les maladies putrides et malignes. D'après cet excellent praticien, elle réprime la tendance à la décomposition putride. (Essai sur les différentes espèces de fièvres.)

On peut combiner les préparations diverses de quinquina, tantôt avec des excitans diffusibles, tels que le camphre, le musc, le castoréum, l'acétate d'ammoniaque, l'éther sulfurique, la teinture anodine de Sydenham; tantôt avec des aromates, tels que la cannelle, le macis, le gérofle, etc.; enfin avec des substances amères, âcres ou astringentes, comme l'angusture, la gentiane, l'arnica, le polygala de Virginie, le cachou, la gomme kino, etc. Ces différentes mixtions sont d'un très-grand secours pour le médecin qui sait les varier à propos et les administrer avec méthode.

Potion antiseptique de Stromeyer. Faites bouillir une once de quinquina concassé dans vingt onces d'eau jusqu'à réduction de seize onces. Partagez cette décoction en deux fioles; dans la première, que vous clésignerez par le $\mathbf{n}^{\circ} \mathbf{I}$, vous mettrez un gros de carbonate de potasse; et vous ajouterez à la seconde, marquée $\mathrm{n}^{\circ} 2$, un gros d'acide sulfurique affaibli. Le malade prendra toutes les heures une cuillerée à bouche de la potion $\mathrm{n}^{\circ} \mathrm{I}$, et immédiatement après la même dose de la potion $\mathrm{n}^{\circ} 2$. 
Cette combinaison du quinquina avec le gaz acide carbonique convient surtout dans le traitement des fièvres putrides d'origine bilieuse, où l'estomac conserve une très-grande irritabilité, lorsque cette faculté semble éteinte ou considérablement diminuée dans la plupart des autres organes. Elle excite parfois une dérivation salutaire sur le gros intestin, et des selles abondantes avec turgescence hémorrhoïdale.

Potion de quinquina excitante. Prenez, quinquina réduit en poudre, une once; cannelle fine, un gros et demi ; macis, un scrupule. Faites infuser pendant deux heures dans dix onces d'eau bouillante, et ajoutez à la colature, sirop de quinquina vineux, deux onces.

Mixture de quinquina fébrifuge et antiputride. Prenez, extrait mou de quinquina, demi-once; sirop de limon, une once; teinture de quinquina, six gros; eau de menthe, cinq onces. Ainsi que la potion précédente, on l'administre par cuillerées pendant la rémission des fièvres qui s'accompagnent de symptômes adynamiques.

Mixture de quinquina du docteur Chrestien. Prenez, résine de quinquina, un gros; sel d'absinthe, demi-gros. Triturez avec soin, et ajoutez, eau de camomille, trois onces; sirop de quinquina, une once. On peut porter la dose de la résine jusqu'à deux ou trois gros, en augmentant celle du sel d'absinthe dan les mêmes proportions. On en donne une ou deux cuillerées à bouche de deux en deux heures dans le traitement des fièvres intermittentes. On pratique en même temps, pendańt l'apyrexie, des frictions sur l'ab- 
domen et dans l'intérieur des cuisses, avec la teinture alcoholique de quinquina. On emploie environ deux onces de teinture pour deux ou trois frictions. La méthode d'absorption convient surtout aux sujets d'une constitution irritable, et qui éprouvent un dégoût invincible pour le quinquina.

Des expériences nombreuses ayant confirmé la vertu antifébrile des principes alcalins extraits du quinquina, on peut employer maintenant avec confiance le sulfate de quinine ou de cinchonine dans le traitement des fièvres intermittentes (1). La dose est de dix à quinze grains, divisés en deux ou trois prises, qu'on administre, pendant l'intermission de la fièvre, dans une cuillerée d'eau très-sucrée ou dans une hostie. On augmente la dose d'un tiers, et quelquefois davantage, pour les fièvres quartes. Lorsque l'accès est dissipé, on continue l'usage de ces préparations salines, à doses décroissantes, pendant quelques jours.

$\mathrm{Au}$ reste, il est des cas où le sulfate de quinine excite vivement les organes digestifs; c'est ce qui arrive chez les enfans délicats, chez les femmes nerveuses, chez les hommes qni ont contracté la fièvre à la suite de grands travaux, ou qui sont en proie à de vives sollicitudes. Ici la méthode endermique dont nous avons déjà parlé plusieurs fois a un grand avantage sur les méthodes ordinaires. On applique le sulfate de quinine sur la peau dénudée au moyen d'un vésicatoire, ou bien on fait des

(1) Je terminais cet article en 1822 , c'est-à-dire à une époque où l'usage des sels alcalins du quinquina n'étaient pas encore généralement adopté; mais je voyais dans l'avenir tous les bienfaits de cette brillante découverte. 
frictions à la partie interne des cuisses avec une pomade dans laquelle on a incorporé ce sel.

M. Pointe, médecin de l'Hôtel-Dieu de Lyon, emploie les sels de quinine en frictions sur les gencives et sur la face muqueuse des lèvres; c'est la méthode de Clare, chirurgien anglais, à l'égard du calomel. Par ce moyen ingénieux il a guéri des fièvres de tous lestypes, et il a pu combattre avec succès celles qui étaient accompagnées d'une irritation gastro-intestinale.

On place la poudre de quinine sur l'extrémité humectée du doigt indicateur, et on frictionne les gencives, ainsi que la face interne des lèvres et des joues, pendant huit ou dix minutes, de manière à déterminer l'absorption du sel. Il faut avoir soin de ne point avaler la salive dont les frictions augmentent ordinairement la sécrétion; si elle est trop abondante, on fera mieux de la rejeter. La dose de sulfate de quinine pour chaque friction est de trois, quatre ou six grains. On peut d'ailleurs modifier ces doses suivant le caractère plus ou moins rebelle de la fièvre. La friction doit être répétée deux ou trois fois par jour. Lorsque les gencives sont molles ou saignantes, on se contente de frictionner la face intérieure des joues et des lèvres.

M. le docteur Brachet, de Lyon, a employé le même moyen pour dissiper des fièvres intermittentes dont les accès se reproduisaient, soit avec des vomissemens opiniâtres, soit avec délire et oppression. La Gazette Médicale de Paris (juillet 1830) rapporte quelqưres-unes de ces observations qui nous ont paru d'un haut intérêt pour la thérapeutique.

Sirop de quinine du docteur Magendic. Prenez, 
sirop simple, deux livres; sulfate de quinine, soixantequatre grains. On peut composer ce sirop avec la cinchonine, dans les mêmes proportions. On le donne par cuillerées, dans les cas de fièvres intermittentes, aux enfans, aux vieillards, aux personnes délicates dont l'estomac ne peut supporter le quinquina en substance. Les praticiens ont souvent constaté ses heureux effets à la suite des fièvres muqueuses et gastriques où l'on a prodigué les débilitans et les évacuations sanguines.

Teinture de quinine. Prenez, sulfate de quinine, douze grains; alcohol à trente-quatre degrés, deux onces. A l'exemple du docteur Chrestien, on pourrait employer cette teinture alcoholique en frictions sur la peau, et particulièrement sur le trajet des vaisseaux lymphatiques, pour dissiper les accès fébriles, lorsque l'estomac irrité repousse toute espèce de préparations de quinquina.

Parmi les applications médicamenteuses qu'on prépare avec cette écorce, il faut comprendre les clystères, les fomentations, les bains, les épithèmes, etc. Rosen, atteint d'une hémitritée à la suite d'une fièvre mésentérique de mauvais caractère, parvint à se guérir en appliquant, pendant huit jours sur le creux de l'estomac, une décoction saturée de quinquina : on réchauffait cet épithème dès qu'il commençait à se refroidir. Samuel Pye faisait ceindre le tronc des enfans malades avec une espèce de camisole composée de deux toiles fines mollement piquées, où l'on avait interposé cinq ou six onces de quinquina réduit en poudre. A l'aide de ce moyen ingénieux, il a dissipé des accès de fièvre, des toux, des mouvemens spasmodiques. Barthez a em- 
ployé cette méthode avec le même succès. Guillaume Alexander s'est servi des bains préparés avec la décoction de quinquina, et s'est ainsi délivré d'une fièvre intermittente. Hufeland les conseille contre la maladie scrophuleuse; trois onces de quinquina suffisent ordinairement pour un bain. On y ajoute avec avantage quelques poignées de fleurs de lavande, de camomille romaine, de feuilles de menthe, de sauge et de scordium. Ces bains médicinaux fortifient les enfans scrophuleux ou atrophiés, et qui ne peuvent supporter les remèdes intérieurement, à cause de la faiblesse ou de la grande irritabilité de leur estomac.

Enfin on a recours aux fomentations, aux lotions, aux cataplasmes préparés avec le quinquina, dans les cas de gangrène extérieure, d'ulcères putrides, atoniques, à la suite des plaies, des brûlures, des commotions violentes, etc. Il est quelquefois avantageux d'animer ces divers topiques avec le camphre, la poudre d'arnica, l'alcohol, le vin aromatique. Lorsque la gangrène se développe avec la prostration du système général des forces, on prescrit en même temps à l'intérieur de fortes doses de quinquina dans du vin généreux. 


\section{CAFIER. COFFE $A$.}

Calice très-petit, à cinq dents. Corolle en entonnoir; tube cylindrique ; orifice un peu dilaté ; limbe plane à cinq lobes. Étamines saillantes. Baie ovoïde ou arrondie, rarement oblongue, ombiliquée. Graines recouvertes d'une arille, planes d'un côté, convexes de l'autre.

Heureux le climat qui voit naître et fleurir ce noble végétal! Heureux aussi les peuples qui savourent ses graines, dont l'incomparable parfum aiguise l'esprit, rehausse le génie! Que de choses dans une tasse de café, depuis la chanson jusqu'au poëme héroïque, depuis le drame jusqu'à l'ordonnance d'une bataille!

C'est après la tasse de café que Napoléon faisait ses dispositions pour l'attaque. Le voilà sur son cheval blanc, en petit chapeau, en casaque grise, oui en casaque grise, sorte de talisman qui fait battre tous les cours. Quel contraste! Tant de simplicité et tant d'héroïsme! Son regard est calme, mais fier et pénétrant comme celui de l'aigle. Il vient de haranguer ses soldats; sa voix a retenti comme celle d'Achille; elle a porté la terreur dans les rangs ennemis.

Dans son exil, dans ses malheurs, ce doux nectar venait consoler son âme; il allégeait ces douleurs cruelles que la philosophie seule ne saurait faire supporter. Alors ses idées étaient moins sombres, moins empreintes de cette mélancolie active qui consume l'existence. Pendant ces courts instans de quiétude, sa pensée le rapprochait de cette belle France qu'il ne pouvait s'empêcher d'aimer et de regretter, de cette France où il

II. 
avait laissé de si glorieux souvenirs; où il avait terminé la guerre civile, apaisé les ressentimens, comprimé les mauvaises passions, où il avait rétabli l'ordre, reconstitué l'administration, ranimé les arts et l'industrie. Que son ombre illustre se console! Amis et ennemis, tout le monde a déploré son infortune.

Mais éloignons ces graves souvenirs qui nous attristent; revenons au café qui nous console, au café, le charme, la grâce, la vie des réunions. Surtout qu’il vienne exhalant tout son arome; qu'une autre Hébé, à la taille élégante, au bienveillant sourire, le verse de sa blanche main, vous verrez la gaîté, le bonheur agiter toutes les physionomies; les bons mots, les doux sentimens, couleront sans contrainte. La prude aura moins d'embarras, la dévote plus d'abandon, le financier moins de raideur, le savant plus de modestie, le diplomate plus de franchise. Oh! l'admirable breuvage, qui recompose ainsi le monde, et nous le fait voir à travers la gaze transparente des illusions!

Avez-vous quelquefois assisté à un déjeîner champêtre, servi dans une île formée par un beau lac, ou bien au bord d'un simple ruisseau, murmurant sur des cailloux, à l'ombre d'un vieux chêne? Des corbeilles sont remplies de fraises cueillies sur le coteau voisin, une jatte de porcelaine contient une crême épaisse d'oì s'exhalent les parfums des herbes nouvelles. Là sont de petits pains savoureux; ici fume le nectar d'Arabie préparé par la maîtresse de la maison. Dans les yeux des convives qu'un doux accord a réunis se peignent le contentement et le plaisir. La pureté de l'air, l'aspect de la nature, ont renouvelé toutes les sensations. Un vent 
frais se glisse dans le feuillage pour tempérer la chaleur du jour; la vermeille salicaire semble prendre part à la fête ; elle sourit, elle balance ses beaux épisà côté des saules dont les rameaux se reproduisent dans l'onde doucement agitée.

Une blanche nymphe s'avance, portée sur un radeau de verdure : c'est la plus belle fleur des ruisseaux; ses superbes corolles s'entr'ouvrent pour embaumer ce riant asile. Les oiseaux chantent dans les taillis, le chant des pâtres retentit au loin dans le vallon; toute cette harmonie agreste, tous ces bruits, tous ces murmures, tous ces parfums, mêlés à la paix des ombrages, à la beauté du ciel, reposent l'âme et lui font goûter un indicible charme.

CAFIER D'ARABIE. COFFEA ARABICA.

Coffea arabica. Linn. Spec. 245. Kern. Gen. Plant. v. 5. icon. Juss. Acad. 388. t. 7.

\section{(Planche 74.)}

C'est un arbrisseau toujours vert, qui s'élève jusqu'à vingt-cinq pieds de hauteur, sur une tige ordinairement droite, de trois à quatre pouces de diamètre. Ses rameaux sont presque cylindriques, opposés deux à deux, et situés de manière qu'une paire croise l'autre; une écorce fine et grisâtre les recouvre, ainsi que la tige. Les fenilles sont ovales, lancéolées, ondulées, d'un vert luisant à leur face supérieure, d'un vert pâle en dessous. On remarque vers la base de leurs pétioles, sur la face nue des rameaux, deux stipules opposées dont la pointe se termine en alène. Les fleurs sont 
blanches, d'une odeur suave, à cinq divisions, et groupées quatre ou cinq ensemble dans les aisselles des feuilles. Les fruits ont en quelque sorte la forme et la couleur de nos cerises; ils sont ombiliqués à leur sommet, et contiennent, sous une pulpe d'un goût douceâtre, deux graines ou semences ovales, aplaties et sillonnées d'un côté, convexes de l'autre, d'une consistance cornée, d'une odeur et d'une saveur aromatiques qui se développent par la torréfaction.

L'arbrisseau qui produit le café croît naturellement en Arabie et dans la Haute-Éthiopie. Celui que l'on cultive dans l'Yémen, celui d'Ouden spécialement, porte un fruit jaunâtre, d'une agréable odeur, appelé par excellence café Moka : c'est le plus parfait de l'univers. Au reste, l'arbre qui donne le café ne se trouve point à Moka; le littoral de toute cette partie de l'Arabie n'est qu'une plaine aride et sablonneuse; mais l'intérieur, ou la partie montagneuse, est entrecoupé de belles et fertiles vallées où abondent le café, les dattes, le froment, la myrrhe, et une infinité de plantes aromatiques.

Dans les lieux découverts ou exposés au midi, on entremêle les cafiers de grands arbres dont la large tête les protége contre le soleil brûlant de l'Arabie. Le Djiabal entier ( hautes terres d'Yémen), entre les sables ardens qui bordent la rive orientale de la mer Rouge et ceux de l'immense désert de l'Arabie intérieure, est comme une grande oasis avec ses bocages de cafiers et de dattiers, où bondissent les singes, où glissent les serpens verts.

Le café fut transporté de Moka à Batavia, de Batavia 
à Amsterdam, et d'Amsterdam au Jardin des Plantes de Paris. Les immenses plantations de cafiers qui enrichissent nos colonies viennent toutes de deux pieds qu'on tira des serres du Jardin du Roi. C'est Declieux, officier de marine, qui fut chargé de porter ce trésor aux Antilles. Le voyage fut long et périlleux. L'eau étant devenue rare sur le vaisseau, il partagea chaque jour avec ses arbustes chéris la faible ration qu'on lui donnait.

On cultive le cafier à Batavia, aux îles de France et de Bourbon, dans les Guyanes française et hollandaise, ainsi que dans toutes les Antilles.

Les uns les plantent en quinconce, les autres en parallélogrammes exacts, en bosquets ou en groupes; on en fait des allées prolongées en tout sens, des haies en forme de charmille, des buissons épars. Au bout de trois ans les arbrisseaux ont déjà plusieurs pieds de hauteur, et ils s'élèveraient de plus en plus, si l'usage de les étêter n'avait prévalu. Chaque arbrisseau est alors garni de branches presque depuis sa base, où les plus longues s'étendent horizontalement; celles qui les suivent ayant moins de longueur, et ainsi proportionnellement jusqu'à la cime, leur réunion forme une pyramide qui, bientôt couverte de feuilles d'un vert agréable, et d'une infinité de fleurs d'un blanc éblouissant, d'une odeur délicieuse, flatțe également la vue et l'odorat. C'est surtout un spectacle ravissant lorsque l'œil s'étend sur une plantation considérable, telle que de mille ou quinze cents cafiers, plantés en allée ou en quinconce, garnis de feuilles, de fleurs, de fruits de diverses couleurs, dont l'assemblage pré- 
sente des nuances variées, et du milieu duquel s'exhale un parfum exquis.

Ces arbres ne produisent guère dans les premières années qu'une livre de graines. Cette fructification devient de plus en plus abondante, et se prolonge pendant vingt-cinq, trente, et quelquefois quarante ans. La récolte se fait au moment où les baies ont pris une couleur foncée et presque noire. On les cueille de manière à ne ?pas confondre celles qui ne sont pas mûres, et on les fait sécher au grand air, au soleil, ou dans des étuves, car on emploie ces différentes méthodes; lorsque la pulpe a disparu et que la dessiccation est complète, on pile les coques pour en obtenir les graines.

En Arabie la principale récolte se fait au mois de mai. C'est alors une incroyable activité par tout le pays. Des milliers de montagnards aux turbans blancs, aux larges chemises rayées blanc et bleu; des femmes couvertes de vêtemens quadrillés, à peu près pareils au tartan écossais, se répandent à travers les jolis bosquets qui couvrent les revers des coteaux, étendent des pièces de toile sous les arbres qu'ils seconent légèrement, recueillent les fruits qui se détachent des rameaux, et les font sécher au soleil jusqu’à ce que la fève puisse se séparer de sa coque. On fait ensuite sécher les fèves une seconde fois, puis on les vanne.

Après le café d'Arabie, connu sous le nom de café Moka, on place ceux de la Guyane, de Bourbon et de l'île de France, ceux de Java et de quelques colonies hollandaises. Viennent ensuite les cafés de la Martinique, souvent préférés, mais beaucoup moins suaves; 
ceux de Saint-Domingue, du Brésil, et d'autres pays où la naturalisation s'est faite plus tard, et où pentêtre la culture n'a pas été aussi soignée.

Ces différens cafés se distinguent par la forme, la couleur, et surtout par le parfum des grains, qui est plus ou moins agréable. Celui de Moka est petit, jaunâtre, très-aromatique. Le café de l'île Bourbon s'offre sous la forme de grains allongés, blanchâtres, d'un parfum délicat; celui de la Martinique est verdâtre et d'une saveur un peu herbacée. Sonnini assure (V oyage en Égypte) que le café d'Arabie se trouve rarement pur dans le commerce. Une fois parvenu au Caire, où il descend par le Nil, les marchands le mêlent avec du café de l'Amérique. A Alexandrie il éprouve encore un nouveau mélange entre les mains des facteurs qui l'expédient à Marseille, où il ne manque guère d'être encore altéré; en sorte que le prétendu café moka que l'on prend en France n'est souvent que celui des colonies d'Amérique, mêlé avec un tiers et rarement avec la moitié du véritable café de l'Yémen.

En général, la couleur n indique point d'une manière sûre les qualités du café. Le moka est ordinairement blond, mais quelquefois aussi d'une teinte verdâtre. Le café de la Martinique n'a pas toujours la robe d'un vert prononcé; il est parfois d'un vert pâle ou roussâtre, sans rien perdre de sa bonne qualité. Mais il faut se méfier de toute espèce de café dont la couleur est brune ou noirâtre; c'est un indice d'un commencement de décomposition.

On croit que la figure arrondie de quelques cafés répandus dans le commerce, principalement de ceux 
qui portent le nom de Bourbon, constitue des espèces différentes; c'est une erreur. Ces grains sont le résultat des baies qui ne contiennent quelquefois qu'une graine, laquelle, n'étant point gênée et aplatie, prend une forme globuleuse en recourbant ses bords en dedans. Cette configuration ayant un coup d'œil plus agréable, on trie les grains arrondis, et on les fait passer pour un café d'une qualité supérieure. Le parfum au reste n'en est pas plus parfait, et ce choix pourrait même se faire dans toutes les balles de café qu'on nous apporte, car dans toutes on rencontre plus ou moins de ces fèves globuleuses.

Cette différence se trouve plus souvent en Arabie et à l'île de Bourbon que partout ailleurs. Les baies ne sont point monospermes naturellement; mais il arrive quelquefois que l'une des fèves avorte; alors la fève fécondée acquiert plus de volume, et s'arrondit, ne trouvant plus d'obstacle qui la gêne.

\section{ANALYSE CHIMIQUE.}

Cadet de Gassicourt, qui a soumis le café à l'analyse, y a découvert un mucilage abondant, beaucoup d'acide gallique, une matière résineuse, une huile essentielle concrète, de l'albumine, et un principe aromatique volatil. Payssé y a trouvé un acide particulier nommé cafique ou kinique. D'après Seguin, le café donne un principe amer, de l'albumine, et outre le principe acide, une huile inodore, dans le café non torréfié, indépendamment de l'huile empyreumatique amère qu'y développe la torréfaction.

M. Pelletier a extrait du café une substance parti- 
culière qu'il appelle caféine, mais qui n'est point un alcali. On l'obtient en faisant des solutions alcoholiques avec le café non torréfié; on les évapore pour en séparer l'alcohol; on traite par l'eau qui dissout la caféine et laisse la matière grasse; on sature la liqueur aqueuse par la magnésie, et on filtre. On fait ensuite évaporer jusqu'à consistance sirupeuse; on reprend par l'alcohol, qui dissout la caféine et la sépare d'une substance mucilagineuse insoluble dans l'alcohol. On filtre, et on fait évaporer.

M. Garot, sous-chef à la pharmacie centrale, obtient la caféine par le procédé suivant. On ajoute aux liqueurs filtrées et refroidies de l'acétate neutre de plomb, qui précipite les matières étrangères à la caféine; on filtre, on sépare le plomb, qui se trouve en excès dans la liqueur, par l'hydrogène sulfuré ; on filtre, et on fait bouillir pour chasser l'excès d'acide hydrosulfurique qui se trouve dans la liqueur. On sature l'acide acétique, provenant de l'acétate de plomb, par l'ammoniaque, et on fait évaporer à une douce chaleur. On continue l'évaporation jusqu'à ce qu'on aperçoive des rudimens de cristaux ; on laisse refroidir, et on obtient alors des cristaux de caféine. Ces cristaux n'ont besoin, pour être purs, que de subir une nouvelle cristallisation.

\section{USAGES ÉCONOMIQUUS.}

Le café avant la torréfaction a une saveur un peu âcre et amère : il perd la première lorsqu'on le brûle, mais il conserve encore une partie de la seconde. Le moka est moins âcre que les autres variétés. La torré- 
faction développe les principes solubles; mais elle doit être modérée, si l'on veut conserver l'arome, et ne pas décomposer l'acide, la gomme et la résine.

Il n'est personne qui n'ait vu se répandre sur chacun des grains de café torréfiés à point, une huile résineuse qu'on laisse évaporer mal à propos en faisant ce qu'on appelle suer le café. Eh bien! cette huile, très-volatile de sa nature, recèle le parfum le plus exquis du café, parfum qui s'évapore et s'affaiblit si vous brûlez votre café plusieurs jours à l'avance : vous avez beau le tenir dans une boîte bien fermée, il perd toujours un peu de son arome.

L'infusion à froid est très-aromatique, mais peu chargée de mucilage et d'acide gallique; l'infusion à chaud conserve de l'arome, et les principes dissous y sont dans des proportions qui flattent le goût. La décoction, beaucoup moins agréable que l'infusion, a peu d'arome; elle est très-chargée de gomme et d'acide gallique : la résine même peut s'y trouver suspendue. Les cafés de Bourbon et de la Martinique ne présentent pas de différence sensible entre eux ; mais celui de Moka est plus aromatique, moins gommeux et plus résineux.

Pour obtenir une infusion de café chargée de tout son arome, il faut donner des soins particuliers à sa préparation. On doit $1^{\circ}$ le torréfier dans un cylindre de tôle, jusqu'à ce qu'il ait pris une couleur dorée ou brun-marron, et qu'il ait perdu environ un sixième de son poids; $2^{\circ}$ le réduire en poudre au moulin, et mieux encore dans un mortier; $3^{\circ}$ ne brûler et infuser le café que le jour où on doit le prendre; $4^{\circ}$ faire l'infusion au 
moyen de l'appareil à filtrer de Dubelloy; $5^{\circ}$ verser quatre tasses d'eau froide sur deux onces ou quatre cuillerées de café, mettre cette infusion écoulée à part; $6^{\circ}$ verser sur le même café trois tasses d'eau bouillante, et mêler cette seconde infusion avec la première; $7^{\circ}$ faire chauffer brusquement les deux infusions réunies, et ne point les laisser bouillir, c'est-à-dire retirer le café à l'instant du frémissement qui précède l'ébullition. Si l'on désire une infusion plus substantielle, au lieu de deux onces, il faut employer trois onces de poudre.

On a inventé plusieurs appareils plus ou moins ingénieux ; mais la plupart sont trop compliqués. Le filtre en porcelaine de Dubelloy est, à notre avis, le plus simple et le meilleur.

Les Orientaux réduisent le café en poudre impalpable dans un mortier; puis ils jettent cette poudre dans l'eau bouillante. Après une infusion de quelques minutes, ils prennent le café avec le marc et ordinairement sans sucre, afin de ne rien perdre de sa force, et d'en recevoir ainsi une stimulation plus puissante. Quelques gourmets, car il y en a aussi parmi les Musulmans, le sucrent légèrement, et on assure qu'alors il est délicieux.

Ils ont également uneautresorte de café : c'est le fameux café à la sultane. On nele fait point avec la fève, mais seulement avec l'arille ou son enveloppe extérieure: on la brise, on lui donne au feu une légère couleur, puis on la jette dans l'eau bouillante sans la moudre; et le café a l'apparence de notre bière couverte d'une mousse blanchâtre. 
PROPRIÉTÉS DIÉTÉTIQUES.

Ce sont les Orientaux qui nous ont transmis l'usage du café. Le supérieur d'un monastère d'Arabie s'en servait, dit-on, pour tenir en éveil ses moines qui s'endormaient aux offices de la nuit. Suivant une autre version, ce fut un mollah qui le premier eut recours à cette boisson excitante pour se délivrer d'un assoupissement qui ne lui permettait pas de vaquer à ses prières; ses derviches l'imitèrent, et leur exemple entraîna les gens de loi. On ne tarda pas à s'apercevoir que le café donnait au sang une agréable agitation, dissipait les pesanteurs de l'estomac, égayait l'esprit; et ceux même qui n'avaient pas besoin de se tenir éveillés l'adoptèrent. Des bords de la mer Rouge il passa à Médine, à La Mecque, et, par les pélerins, dans tous les pays mahométans.

C'est en i 554, sous le règne de Soliman-le-Grand, que le café avait pris crédit à Constantinople, et ce ne fut qu'environ un siècle après qu'on l'adopta à Londres et à Paris. Aujourd'hui son usage est répandu dans le monde entier, et rien ne prouve tant en sa faveur que les efforts qu'on a faits pour le remplacer par nos productions indigènes pendant les dernières guerres maritimes : efforts malheureux qui nous ont seulement appris que rien n'est comparable au parfum de ces graines exotiques.

Le café n'est devenu populaire en France que depuis la révolution. Il fut d'abord réservé exclusivement à la haute société. L'exemple de Fontenelle répandit l'usage de ce poison lent; on sait qu'avec ce poison il a 
vécu près d'un siècle. Ce n'est pas que le café n'ait rencontré à diverses époques des ennemis et des détracteurs. Souvent condamné par les médecins, il le fut d'abord par madame de Sévigné, femme d'un excellent esprit, qui manqua pourtant deux fois de goût dans cette circonstance. Malgré sa prédiction, la ravissante poésie de Racine triompha de la cour, et le café a parcouru le monde en répandant partout ses parfums. O l'admirable breuvage, qui réveille l'esprit, console le cœur, électrise la pensée, inspire l'orateur, le poète, fait naître des fleurs sous la plume de Fontenelle, les plus beaux vers sous celle de Delille ou de Voltaire!

Délicieux moka, ta sève enchanteresse

Réveille le génie, et. vaut tout le Permesse.

Castzu, les Plantes.

C'est toi, divin café, dont l'aimable liqueur

Sans altérer la tête épanouit le cœur:

Aussi, quand mon palais est émoussé par l'âge,

Avec plaisir encor je goutte ton breuvage.

Que j'aime à préparer ton nectar précieux !

Nul n'usurpe chez moi ce soin délicieux.

Sur le réchaud brûlant moi seul tournant ta graine,

A l'or de ta couleur fais succéder l'ébène;

Moi seul contre la noix, qu'arment ses dents de fer,

Je fais, en te broyant, crier ton fruit amer;

Charmé de ton parfum, c'est moi seul qui dans l'onde

Infuse à mon foyer ta poussière féconce.

Viens donc, divin nectar, viens donc, inspire-moi.

Je ne veux qu'un désert, mon Antigone et toi.

A peine j'ai senti ta vapeur odorante,

Soudain de ton climat la chaleur pénétrante

Réveille tous mes sens; sans trouble, sans chans,

Mes pensers plus nombreux accourent à grands flots.

Mon idée était triste, aride, dépouillée ;

Elle rit, elle sort richement habillée,

Et je crois, du génie éprouvant le réveil,

Boire dans chaque goutte un rayon du soleil.

Delinte, les Trois Règnes. 
On voit que Delille aimait à préparer lui-même son café. A Paris il n'est pas rare qu'une bonne maîtresse de maison donne tous ses soins à ce breuvage digestif d'où dépendent le bonheur et la santé des convives. Une mauvaise tasse de café est une disgrâce, un malheur que ne peut faire oublier la chère la plus délicate. Demandez plutôt à M. le marquis de Cussy: il vous dira qu'un amphitryon chez qui un pareil revers se renouvelle deux fois, est comme un général d'armée qui a perdu coup sur coup deux batailles; qu'il doit dire adieu au monde et 'se condamner à la solitude. Écoutez M. Fayot, homme friand et surtout amateur de café : s'il vous décrit un repas, il glisse légèrement sur les mets les plus rares, il parle avec indifférence du dessert; mais voyez comme son œil s'anime, comme il est heureux en disant ces mots : Oh! le café était exquis.

Et moi aussi j’aime le bon café. Il m'en souvient : qu'il était délicieux celui que nous a versé madame Ségalas dans une petite réunion, composée de MM. de Beauregard, Fayot, Miquel, Gaubert et Duval ; réunion charmante où la grâce de la maîtresse de la maison, la politesse du maître, l'esprit et l'aimable causerie des convives (je n'étais là que pour écouter) m'ont fait passer les plus doux momens!

Franklin ne connaissait que la commotion électrique ou le café pour donner la plus grande énergie aux facultés intellectuelles. L'usage, pour ainsi dire, général qu'en font les gens de lettres, les savans, les artistes, ne s'est établi que d'après des observations et des expériences positives. Rien n'est plus propre surtout à 
faire cesser les angoisses d'une digestion pénible, à dissiper ces pesanteurs qui, en réagissant sur le cerveau, troublent les facultés de l'esprit, le jettent dans la tristesse et l'engourdissement. Le café n'a point les inconvéniens du vin ni des liqueurs spiritueuses; il est au contraire le moyen le plus efficace de combattre leurs funestes effets.

Et puis ne faut-il pas à l'homme quelque consolation dans ce monde si misérable? En est-il de plus douce, de plus voluptueuse que le café? La tristesse vous gagne, le temps vous tient sous son joug de plomb.... O pouvoir magique du café! Soudain l'ennui des heures se dissipe, il fuit comme un spectre devant la clarté du jour; la sérénité reparaît sur ce front, nuageux il n'y a qu'un instant; les rides du souci s'effacent, un coloris de rose vous dit que le sang a repris son cours régulier. Vous devenez bienveillant, joyeux, dispos, vous croyez aux douceurs de l'amitié, aux prestiges de l'amour; les torts de vos amis se couvrent d'un voile, et l'espérance est là avec son sourire, ses enchantemens, et la promesse d'un meilleur avenir.

Mais que le bon café est rare dans les grandes maisons! On le sert avec une sorte de pompe, avec un luxe qui fascine trop souvent l'oeil des convives, les distrait et paralyse leur goût. Il n'y a que le vrai gourmet que ce vain éclat ne saurait éblouir. Il est là, pensif, presque soucieux, en attendant le café. On va le servir, il est servi. L'élégance des porcelaines, la forme riche et neuve du plateau, où l'or étincelle, font oublier un instant le moka. Enfin un savant le déguste; il est délicieux. Une jolie femme effleure à peine sá 
tasse de ses lèvres vermeilles; oh! que ces tasses, ce plateau, sont d'un goût parfait! Un petit magistrat vide la sienne; il est grave comme lorsqu'il préside les assises. Un célèbre bibliothécaire rêve encore à ses poudreux manuscrits, il ne saurait vous dire si c'est du café ou du thé qu'il vient de prendre. L'amateur flaire, déguste, analyse le breuvage; l'émeute, la générale, le canon, rien ne saurait le distraire. Toutes ses sensations, toutes ses facultés, son âme tout entière s'élance dans sa tasse. Hélas! une sorte d'anxiété se peint dans ses yeux; le café, d'ailleurs substantiel, bien fait, limpide, d'une couleur rutilante, avait un goût de mer!

Il règne parmi les médecins un certain désaccord touchant l'usage du café. L'avis du sage Tissot ne lui est point favorable; Hahnemann le regarde comme un poison, et veut qu'il soit rayé du régime diététique. Ceux qui l'aiment ( eh! quel est le médecin de bon goût qui ne l'aime point?) sont beaucoup plus indulgens; ils le permettent à leurs malades quand il n'y a pas des raisons graves pour le leur défendre.

Le secrétaire de l'Académie royale de médecine vous dira que le café n'est jamais nuisible; que s'il le devient, c'est quand il est mal fait. Vous n'avez peut-être jamais vu M. Pariset prendre son café? Eh bien! moi qui vous parle, je l'ai vu. Sa pose, sa mimique, sont admirables. Fermement assis, il le savoure à plusieurs reprises, et chaque fois il lève au ciel ses yeux brillans comme des escarboucles. Lui si disert, il ne parle plus, il pense; il goûte, il goûte encore; il voudrait mourir en goûtant. Le nectar épuisé, il faut l'entendre : 
quelle verve! comme il étincelle d'esprit! Il raconte, il disserte; il est à Paris, à Barcelone, au Caire; il a vu les tentes des Arabes, les ruines de Thèbes. On se presse autour de lui, on recueille ses bons mots, ses saillies, ses rapides élans; on voudrait l'écouter sans cesse.

M. Bousquet, également académicien, homme d'esprit et gourmet, a une autre manière de goûter et de sentir. Ses jouissances sont plus douces, plus tranquilles; c'est Horace buvant le falerne sans penser au lendemain. Peu à peu sa figure s'anime; le plaisir brille dans son oil bleu; il se croit dans le paradis de Mahomet.

Celui-ci a la tête haute, un peu penchée : c'est l'élégant auteur des Lettres à Camille. Il hume avec bruit son nectar; il veut que les papilles de son palais s'en abreuvent, que sa vapeur rayonne physiologiquement sur le sensorium; il s'inquiète peu de son estomac, à qui les mets les plus simples suffisent.

Où êtes-vous, Bérard, Rouzet, Miquel, Dupau, confrères spirituels, savans, d'un commerce si doux? Hélas! vous aimiez aussi le moka : nous le prenions ensemble... Maintenant, je suis seul, errant dans la solitude des forêts; mais votre souvenir me suit partout : il est profondément gravé là, dans mon cœur, dans ce cœur qui vous aimait de l'amitié la plus tendre.

Les médecins les plus célébres, les plus habiles, ont du goût pour le café; ce goût leur est naturel, parce qu'il y a une sorte de sympathie entre tout ce qui est bon; et, si par hasard ils ne sont pas tous de notre avis, s'ils en diffèrent un peu avant dîner, l'heure apII. 
proche où ils deviendront indulgens. Faibles euxmêmes devant le plateau magique, ils pardonneront à notre faiblesse; que dis-je? ils applaudiront à notre enthousiasme. Et tous ces jeunes médecins, l'espoir de notre art, ils aimeront aussi le café ; car il fait aimer l'étude, il fortifie notre esprit, il nous soutient dans notre pénible carrière, il nous charme au milieu de nos travaux. Si ce breuvage brûlait le sang, s'il donnait la gastrite, comme le disent quelques observateurs peu attentifs, l'illustre chef de l'école physiologique l'eût banni à tout jamais de sa table.

“ J'ai vu dernièrement M. Broussais dans un grand repas, me disait un ancien ami : il fulminait contre les ontologistes, contre les Browniens. On sert le café à la ronde, sa tasse en est remplie, il la vide. O prodige! il hoche de contentement sa tête carrée; une aimable douceur se répand dans ses traits, une bienveillance inattendue pour ses confrères remplace ce langage amer, énergique, ces diatribes sanglantes qu'exhalait tout à l'heure sa bouche sardoniquement convulsive. L'homme de génie avait abdiqué sa colère, et, dans sa mansuétude, il eût embrassé un éclectique; il n'y en avait point dans l'assemblée. "

Nous nous arrêterons à peine à quelques alliances monstrueuses qu'on fait subir au café. Laissons le gloria aux palais d'acier, aux esprits de glace, à l'homme fatigué par une longue course, par un pénible labeur. Ce mélange n'est nullement digestif; il irrite l'estomac, il ébranle les fibres du cerveau, il détruit surtout le parfum du café, trop délicat pour lutter contre la violence de l'alcohol, et au lieu d'un souffle pur, em- 
baumé, votre bouche exhale les molécules chaudes du cognac.

Il est une association qui convient aux nerfs un peu trop sensibles. Laissez tomber dans votre tasse quelques gouttes d'une crême onctueuse, vous aurez un breuvage plus doux, plus tempéré, plus conciliant, et votre estomac pourra se livrer sans contrainte à l'acte le plus important de la vie.

Nous voici au café du matin. Cette fois, nous avons pour nous les dames, les hommes d'une complexion délicate, tous ceux enfin à qui il ne faut qu'une alimentation légère. Mais ici les avis de la Faculté ne sont pas unanimes : les uns prescrivent le café au lait, d'autres le permettent, d'autres ne veulent pas en entendre parler. Si vous êtes malade, si vous souffrez des entrailles, si vous avez des rapports acides, n'en prenez point ; mais si votre santé est en bon état, si ce déjeûner vous plaît, si vous en avez d'ailleurs contracté l'habitude, continuez: continuez surtout si vous cultivez les sciences, les lettres, les beaux-arts. Une tasse de café tempéré avec un bon laitage n'ôtera rien à votre intelligence; au contraire, votre estomac, libre de tous ces mets succulens qui l'obstruent, ne fatiguera point votre cerveau; il ne l'associera point à ses angoisses, il le laissera libre dans ses opérations. Bientôt les suaves molécules du moka agiteront agréablement votre sang sans lui donner une chaleurimmodérée; l'organe de la pensée en recevra une impression sympathique; le travail deviendra plus facile, plus fécond, et vous arriverez sans peine et sans dégoût au principal repas, qui restaurera votre corps, vous donnera une 
nuit calme, délicieuse. L'homme qui ne se livie point à de rudes travaux n'a pas besoin de deux repas substantiels dans la journée; un déjeûner frugal, un dîner confortable, lui suffisent. Il faut, au contraire, deux ou trois bons repas à l'homme affaibli par la fatigue, dont les muscles sont dans une action vive et continue. L'homme sédentaire, oisif, qui va du fauteuil à la table, qui se repaît d'osmazome, qui ne vit, qui ne respire que pour manger, boire et dormir, celui-là l'apoplexie le réclame; il lui appartient, il est son sujet, bientôt il sera sa victime.

Mais si vous pouvez vous procurer de l'excellent moka, du fin bourbon, il n'en est pas ainsi du bon lait. C'est vous surtout qui en souffrez, pauvres Parisiens, bon public, paisibles ménages, qui tenez aux vieilles coutumes de vos pères. La laitière, l'avide laitière, est aujourd'hui au nombre des charlatans qui vous trompent, qui vous dupent. C'est elle qui, de grand matin, donne le signal des falsifications ( ah! combien d'autres mensonges vous attendent dans la journée!). La fontaine du hameau a donné à son lait une teinte azurée. Il faut lui rendre sa blancheur primitive, sa moelleuse épaisseur. Vite de l'amidon, des substances féculentes : voilà ce qu'elle nomme le lait chaud. Pour la crême du banquier, du pair de France, de $\mathbf{M}$. le préfet, et autres consommateurs de haut étage, oh! il faut lui donner ce reflet doré qui vous charme dans le lait de la Basse-Normandie. Le suc de carotte, la fleur du souci des champs, le carthame des teinturiers, le sirop de mélasse, le sucre brûlé, voilà le secret de notre chimiste de la banlieue. Fasse 
le Ciel qu'elle ne veuille pas être plus habile ( $\mathrm{r}$ )! Ces substances ne sont pas précisément malfaisantes; cependant, le laitage ainsi délayé , puis épaissi par des fécules, rendu mousseux par de l'albumine, doré par des matières colorantes; ce laitage, ainsi frelaté, se coagule facilement dans l'estomac, perd ses propriétés salutaires, et devient indigeste. Les femmes délicates, nerveuses, les enfans atrophiés, les convalescens, les valétudinaires, qui vivent de laitage, n'y trouvent plus une alimentation douce et restaurante (2).

Ce n'est pas ici le lieu de décrire quelques-unes des friandises dont notre vie toute sensuelle nous fait un

(1) On a accusé les laitières de Vienne d'avoir falsifié le lait par la potasse et la chanx pour le garantir de la coagulation. $L a G a-$ zette nationale d'Allemagne de 1803 rapporte que des enfans en sont morts, et que des adultes en ont été malades.

(2) M. Gallais, habile chimiste, et l'un de nos fabricans de chocolat les plus renommés, va nous protéger contre la fraude des laitières. Nous pourrons avoir chaque jour et à tonte heure du véritable lait de Gournay ou d'Isigny. Voici comment. A force de soins et d'expériences il est parvenu à extraire et à rapprocher les principes du lait par un procédé fort ingénieux. Le lait ainsi réduit à l'état solide a reçn le nom de lacloline. Mais ce n'est point dans les campagnes des environs de Paris que M. Gallais va composer ce nouveau produit de l'industrie économique; c'est dans la vallée de Bray, au milieu des gras pâturages de la Normandie. Nous avons goûté plusieurs fois la lactoline; nous lui avons trouvé toute la saveur, tout le parfun du meilleur lait. Elle offre, à notre avis, un aliment aussi agréable que salubre aux enfans, aux vieillards et aux convalescens. On peut d'ailleurs l'ajouter au café, au chocolat, qui en deviendront plus moelleux , plus nutritifs. Voyez pour de plus amples détails le $\mathrm{n}^{\circ}$ de la Grizelte de santé de février 1835 . M. Grimaud de Caux, son principal rédacteur, a donné de justes éloges à la lactoline, dans un excellent article sur les diverses espèces de lait. 
besoin; nous abandonnons volontiers ces détails aux hommes spéciaux de l'office. Nous observerons seulement que les crêmes, les mousses, les glaces, les sorbets, se digèrent infiniment mieux lorsque la fève de Moka les a imprégnés de son parfum. Pendant les grandes chaleurs, les mouvemens de la vie se concentrent sur la surface du corps, et l'appareil digestif est presque toujours affecté d'une faiblesse relative. $\mathrm{Si}$, trop indulgent pour votre estomac, vous avez cédé à sa gourmandise; si vous lui avez accordé des mets, des ragoûts de toute espèce, laissez-le digérer en paix : il ne vous demande que quelques heures de trève. Vous êtes déjà froid, lourd, presque vertigineux; sortez, courez, faites de l'exercice en plein air; renoncez aux glaces, aux sorbets; et si vous n'avez pas le courage de vous imposer cette privation, choisissez du moins les sorbets au marasquin, au café moka, préférables aux substances végétales glacées, telles que le citron, la groseille, les fraises, qui ont quelquefois produit des symptômes cholériques, quand la digestion n'était pas accomplie.

Avant de passer aux propriétés médicales du café, hâtons-nous de répondre à un reproche grave qu'on lui adresse, et qui, s'il était fondé, diminuerait peut-être le nombre de ses partisans. On prétend, qu'en excitant les facultés de l'entendement, en exerçant uneinfluence exclusive sur l'encéphale, il affaiblit les autres sensations physiques, et surtout la sensibilité des organes de la génération. Effeminans vulgò habetur coffere potus, undè etiàm potus caponum per opprobrium dicitur. (Linn., Amcen. Academ.) Cette opinion ne 
repose sur aucun fait positif. Le docteur Hannin parle d'un homme de quarante-cinq ans, d'un tempérament sec et bilieux, qui ne prend pas de café qu'il ne se sente transporté d'une sorte de délire érotique. Au reste, il en est du café comme des autres stimulans, il peut, suivant la constitution de l'individu, produire quelquefois un effet contraire.

\section{PROPRIÉTÉS MÉDICALES.}

Lorsqu'on pense à certains breuvages que la médecine impose aux malades, on est étonné de voir qu'elle néglige l'usage du café, stimulant si agréable et en même temps si actif dans toutes les inaladies où il est nécessaire d'imprimer à la fibre une excitation vive et prompte. Ce qu'il y a de certain, c'est que le café ne le cède à aucun autre remède dans les affections des intestins, des reins et de la vessie, provenant de causes débilitantes. Cette boisson sucrée favorise l'expectoration dans les catarrhes chroniques, et dissipe quelquefois les toux les plus opiniâtres. D'après Musgrave, Pringle, Floyer, Percival, elle est un des meilleurs palliatifs de l'asthme; et, suivant le docteur Bree, elle ne dissipe pas seulement ses attaques, mais elle en prévient le retour. Laennec dit également avoir vu plusieurs asthmatiques auxquels le cafeé a été réellement utile.

Un vieux colonel avait éprouvé quelques symptômes de gravelle après la bataille de Waterloo. On lui défendit l'usage du café, auquel on substitua l'eau d'orge, l'eau de graine de lin, et un régime sévère. Son estomac devint paresseux, les fonctions de l'appareil uri- 
naire s'affaiblirent, et la maladie calculeuse s'aggrava. J'eus occasion de le voir à dîner chez un de mes amis. Il me consulta sur son état de souffrance, et il me parut regretter vivement son café. Je ne pouvais que lui donner une consultation de table; là, presque tous les médecins sont indulgens. Reprenez, lui dis-je, l'usage de cette boisson, en y ajoutant un peu de crême. On assure que la gravelle est très-rare en Orient et dans les colonies, où l'on prend du café à toutes les heures du jour. Le conseil fut suivi à la lettre, et une heure après, il prenait place parmi les bienheureux qui s'abreuvaient de café. Il continua, il réforma en même temps son régime; ses forces se rétablirent, et la gravelle disparut sans retour.

Les femmes sujettes aux suppressions menstruelles, ou chez qui les règles coulent lentement, trouvent dans le café un remède aussi agréable que salutaire. Il dissipe la mélancolie, les langueurs, les dégoûts qui tourmentent les jeunes filles chlorotiques. Cette boisson convient aussi très-bien aux personnes chargées d'embonpoint et d'obésité, qui éprouvent de l'engourdissement dans les membres, de l'assoupissement, et cette espèce de torpeur qui est quelquefois le prélude de la paralysie ou de l'apoplexie. On a quelquefois employé avec un succès rare les lavemens de café pour dissiper des symptômes apoplectiques, particulièrement chez les vieillards.

Le café est surtout d'un usage familier contre la migraine, qu'il calme assez souvent d'une manière assez prompte, bien qu'il échoue presque toujours contre le lic douloureux on la céphalalgie susorbitaire. Lorsqu'il 
agit favorablement dans ces sortes de maux, la peau, qui était d'abord froide et crispée, reprend bientôt sa chaleur naturelle, et se couvre ensuite d'une douce moiteur.

On a remarqué que le café pris avec modération était, en général, salutaire aux goutteux. Ainsi que la gravelle, la goutte est à peine connue en 'Turquie et aux Antilles où cette boisson est vulgaire.

Des faits recueillis dans plusieurs climats attestent les vertus anti-fébriles du café. Le docteur Pouqueville (Voyage en Morée) a vu rarement résister les fièvres intermittentes à un mélange de café et de suc de citron, qui est le remède général du pays. On mêle six gros de café torréfié et broyé avec deux onces de suc de citron et trois onces d'eau. Ce breuvage doit être pris chaud et à jeun pendant les intervalles de la fièvre. D’après le témoignage du docteur Coutanceau, à qui nous devons une notice intéressante sur les fièvres pernicieuses qui ont régné à Bordeaux en 1805 , une forte décoction de café, administrée au moment de l'invasion d'un paroxysme qu'on pouvait présumer devoir être très-grave, diminuait notablement son intensité. Le docteur Labonnardière s'en est servi avec avantage pour dissiper les symptômes comateux d'une fièvre ataxique subintrante. Atteint lui-même d'une fièvre catarrhale accompagnée d'une grande stupeur, il a éprouvé les plus heureux effets de cette boisson.

Suivant le docteur Grindel, conseiller aulique de l'empereur de Russie, le café non torréfié possède la propriété antiseptique et fébrifuge du quinquina. Parmi les faits que ce médecin a recueillis à la clinique de 
l'Université de Dorpat, on trouve des plaies gangréneuses à la suite de fractures, des fièvres intermittentes de diverstypes, des fièvreslentes nerveuses, qui ont cédé à l'usage du café. On le donne en poudre, en infusion, en décoction et en extrait. Les doses doivent être à peu près les mêmes que celles du quinquina. Il a fallu rarement plus de deux onces de poudre pour extirper des fièvres intermittentes opiniâtres.

M. Martin Solon a fait un heureux emploi du café dans la fièvre typhoïde avec prédominance de stupeur et d'abattement. Il l'a administré, à la dose d'une demi-once en infusion dans huit onces d'eau, à plusieurs malades de l'hôpital Beaujon, qui avaient déjà subi un traitement antiphlogistique. Cette potion stimulante, répétée pendant plusieurs jours, a relevé le pouls, diminué la céphalalgie, la somnolence, et l'affaiblissement des facultés intellectuelles, provoqué des sueurs abondantes. Les effets produits par le café ont été si rapides chez un malade, que les symptômes de prostration et de stupeur ont considérablement diminué dans la journée. Dans une autre circonstance, une forte infusion de café a ranimé la sensibilité générale, et fait disparaître graduellement le délire, la stupeur et une sorte d'état comateux. Lorsqu'on administre cette boisson, il faut choisir les momens où la réaction fébrile présente le moins d'intensité.

$\mathrm{Au}$ reste, le café ne saurait convenir dans tous les cas de fièvre typhoïde; il serait extrêmement nuisible si la fièvre était liée à l'inflammation des méninges ou à la gastro-entérite.

Dans les pays où règnent des fièvres de mauvais ca- 
ractère, dans les lieux exposés aux émanations pernicieuses de marais, le café peut être employé comme un des moyens prophylactiques les plus efficaces. Pris avec modération, il anime la circulation générale, et relève le ton du système, que tend à affaiblir de plus en plus un air chargé de vapeurs délétères.

Mais, si le café excelle lorsqu'il faut stimuler les tissus organiques, son usage aggrave toutes les affections qui s'annoncent avec des signes de phlogose ou d'une irritation vive. On sait que cette boisson trouble le sommeil, cause parfois des tremblemens, des agitations incommodes; aussi les médecins ont soin de l'interdire aux personnes nerveuses, qui ont la fibre sèche, très-irritable; à celles qui sont douées d'un tempérament pléthorique, ou sujettes à quelques hémorrhagies; qui ont des irritations viscérales, des mouvemens hémorrhoïdaux douloureux. En général, il convient peu aux enfans, surtout aux jeunes filles qui approchent de l'âge où s'établit la menstruation; aux femmes parvenues à l'âge critique, éprouvant des spasmes nerveux, une chaleur générale, des douleurs lombaires, ntérines, etc. La classe ouvrière, qui, dans ces circonstances, n'est pas assez éclairée ou assez raisonnable pour se priver de café, en éprouve un grand dommage.

D'après Tissot, il est surtout nuisible dans les maux de nerfs; il donne une agitation générale, des palpitations, quelquefois une profonde tristesse et un vrai désespoir. Pomme a vu une jeune religieuse, d'un tempérament bilioso-sanguin, attaquée subitement de cardialgie, d'évanouissemens et de spasmes, après avoir fait un usage immodéré de cette boisson. Des méde- 
cins ont observé que l'inflammation des gros vaisseaux était fort commune aux Antilles, où l'on en fait un grand usage. Je crois que l'abus des épices, et surtout la chaleur brûlante de l'atmosphère, y contribuent au moins d'une manière aussi active. A Venise, à Constantinople, à Vienne, à Londres, à Paris, à Amsterdam, enfin dans toutes les grandes villes de l'Europe, où l'on prend certainement beaucoup de café, ces inflammations ne sont pas plus fréquentes que bien d'autres maladies.

Au reste, le café est une boisson pernicieuse dans les congestions imminentes du cour, principalement lorsqu'on éprouve des palpitations fréquentes, des étouffemens, une agitation générale, une sorte de dyspnée qui se reproduit à la moindre fatigue. Dès l'apparition de quelqu'un de ces symptômes, il faut se priver de café et autres boissons stimnlantes, suivre un régime doux, humectant, peu substantiel ; c'est le seul moyen d'arrêter la marche de ces affections organiques, qui, plus tard, se jouent de toutes les ressources de l'art.

Le docteur Hahnemann, qui a publié une petite dissertation sur le café, l'a comparé aux plus affreux poisons. Quelques vérités brillent dans cet écrit; mais elles sont comme perdues dans l'exagrération et l'emphase, en sorte que les lecteurs auxquels il les adresse ne sauraient les saisir. Dès les premiéres lignes il voudrait nous condamner à l'eau de fontaine et au lait pour toute boisson.

Après la première stimulation produite par le café, viennent les bâillemens avec envie de dormir, des angoisses, des flatuosités douloureuses, le froid des extré- 
mités. Les digestions deviennent plus pénibles; la diarrhée alterne avec Ia constipation. 'Le sommeil ressemble à une sorte d'assoupissement qui ne restaure point. Les femmes sont en proie à une leucorrhée intarissable; elles ont les yeux languissans, le teint jaunâtre, terreux, les chairs molles, les seins flasques (j'adoucis beaucoup les expressions du médecin allemand). Enfin les hommes deviennent impuissans, les femmes stériles. Voilà pour le physique; le moral est encore plus maltraité.

" Le sérieux réfléchi de nos ancêtres, dit le célèbre homoopathe, la solidité des jugemens, la fermeté dans la volonté et dans les résolutions, toutes ces qualités qui distinguaient jadis le caractère national des Allemands, s'évanouissent devant cette boisson médicinale. Et qu'est-ce qui les remplace? Des épanchemens de cœur imprudens, des résolutions, des jugemens précipités et mal fondés, la légèreté, la loquacité, la vacillation, enfin une mobilité fugitive des muscles et une contenance théâtrale. Je sais bien que pour abonder en imagination luxurieuse, pour composer des romans lubriques, des poésies badines et piquantes, l'Allemand doit boire du café. Le danseur de ballet, l'improvisateur, le jongleur, le bateleur, l'escroc et le banquier au jeu de pharaon, ainsi que le virtuose-musicien moderne, avec sa vitesse extravagante, et le médecin à la mode partout présent, qui veut faire quatre-vingt-dix visites de malades en une seule matinée, tout ce monde-là a nécessairement besoin de café. "

Nous n'avons qu'effleuré les invectives que M. Hahnemann adresse aux buveurs de café, la série de maux 
dont il les menace, les anathêmes qu'il lance contre cette boisson dont il use peut-être à huis-clos; mais c'en est assez pour faire apprécier son jugement. Moins partial, plus vrai, il eût peut-être converti quelques-unes des personnes à qui le café est nuisible; mais pour avoir été trop absolu, il a prêché dans le désert.

M. le baron de Brunnow, de Dresde, qui a traduit en français la dissertation de M. Hahnemann, y a ajouté une préface et des notes où il blâme aussi l'usage du café; mais c'est toujours l'homme d'esprit, l'homme sage, indulgent et de bonne foi qui parle. Quel contraste entre le maître et le disciple! Lorsque M. de Brunnow me dit : " J'ai pris du café jusqu'à l'âge de vingt-deux ans, j'étais presque toujours dans un état de souffrance : j’ai cru reconmaître dans cet état les mauvais effets du café; j'ai renoncé à cette boisson, et ma santé, naturellement délicate, s'est raffermie; " cette simplicité de langage me persuade, et j'y crois.

Nous ne saurions terminer cet article sans faire mention des vertus du café dans l'empoisonnement produit par l'opium et les plantes narcotiques, telles que la jusquiame, la pomme épineuse, la belladone, certains champignons, etc. Après avoir éliminé la matière vénéneuse, soit par les vomitifs, soit par une abondante boisson d'eau tiède, les effets du poison peuvent subsister encore et se manifester par un état de somnolence et de stupeur, par des symptômes léthargiques ou comateux; rien n'est plus propre à combattre cette affection cérébrale qu'une forte infusion de 
café, administrée alternativement avec les boissons acides (I).

M. le général Gougeon nous a communiqué un fait qui atteste également la puissance médicinale du café contre l'asphyxie causée par la vapeur du charbon.

Au mois de janvier เ8ı, le fameux André Hoffer, chef des insurgés tyroliens, fut conduit avec son secrétaire, du Tyrol en Italie, sous l'escorte du ${ }^{\text {er }}$ bataillon du $9^{2}$ régiment. Arrivé à Ala, petite ville à huit lieues de Vérone, il fut mis dans une chambre étroite, humide et depuis long-temps inhabitée. Un brasier fut placé au milieu de la chambre, où se trouvaient deux officiers et deux sergens. Un factionnaire était debout près d'eux, séparé, par la porte fermée, d'un factionnaire extérieur. La vapeur du charbon ne tarda pas à agir sur les militaires, tous rapprochés du brasier. Les deux officiers et les deux sergens éprouvèrent d'abord quelques convulsions, et restèrent asphyxiés. La sentinelle intérieure tomba presque aussitôt. André Hoffer, couché dans la partie de la chambre la plus éloignée du brasier, veut se lever pour venir au secours de ses gardiens; mais il retombe sur son lit, où l'asphyxie le gagne, ainsi que son jeune secrétaire qui y était couché. La sentinelle extérieure, inquiète des mouvemens sourds qu'elle entendait, appelle la garde, qui enfonce la porte de la chambre. Les deux premiers qui y pénètrent tombent à l'instant même. Un caporal court à la fenêtre, l'ouvre, et y jette le

(1) Voyez notre Introduction et la famille des Solanées Voyez aussi notre Histoire des Champignons comestibles et v'énéneux. 
brasier. On porte dans la cour tous les asphyxiés, et M. le commandant Gougeon leur fait prendre plusieurs tasses de café très-fort. Cette liqueur stimulante les réveille, et peu à peu tous les accidens produits par l'asphyxie disparaissent.

Sirop de café de Ferrari. Prenez café du Levant torréfié, quatre onces; eau, deux livres; sucre raffiné, trois livres. Dans un vase fermé vous faites infuser, pendant six heures, le café avec une livre et demie d'eau froide; en le débouchant un peu, vous placez ensuite le vase au bain-marie. Quand l'eau du bain-marie bout, vous retirez le vase, vous décantez, et vous versez sur le résidu les six onces d'eau restantes. $\mathrm{Au}$ bout de quelques heures, vous décantez, et vous mêlez les liqueurs, que vous versez peu à peu sur le sucre; vous faites dissoudre au bain-marie, et vous passez à la chausse.

On prend une ou deux cuillerées à bouche de ce sirop dans du lait, ou dans tout autre véhicule. Il peut servir à édulcorer les boissons dans les maladies qui réclament une excitation douce et agréable. 


\section{CÉPHÉLIS. CEPHAELIS.}

Calice très-petit à cinq dents. Corolle en entonnoir, à cinq lobes. Cinq étamines presque sessiles, non saillantes. Un style terminé par un stigmate à deux lobes. Baie à deux loges contenant deux graines planes d'un côté, convexes de l'autre.

\section{CÉPHÉLIS IPÉCACUANHA. CEPHAELIS}

\section{IPECACUANHA.}

Cepharis ipecacuanha. Mirbet. - Cephalis emetica.

Persoon. - Callicocca ipecacuanha. Brotero.

\section{(Planche 97.)}

Cette plante a une racine arrondie, un peu rameuse, chargée d'anneaux ou de tubercules inégaux. La tige est ascendante, sarmenteuse, presque ligneuse, haute de cinq ou six pouces. Les feuilles sont opposées, ovales, lancéolées, d'un beau vert, légèrement pubescentes en dessous, placées au sommet de la tige au nombre de quatre, six ou huit; les inférieures sont caduques. Les fleurs, de couleur blanche, sont réunies en petites têtes pédonculées. Chaque fleur offre un petit calice à cinq dents obtuses ; une corolle tubulée à cinq divisions, ovales, aiguës, recourbées; cinq étamines insérées sur la gorge de la corolle, et un ovaire surmonté d'un style à deux stigmates.

On trouve le céphélis ipécacuanha dans les lieux ombragés et humides des bois, au Brésil, dans les provinces de Fernambouc, de Bahia, de Rio-Janeiro, etc. On arrache la plante, et on sépare les racines, que l'on fait 
sécher avec soin. D’après l'opinion générale, ces racines forment l'ipécacuanha gris ou du Brésil, la seule espèce employée dans nos pharmacies; elles sont cylindriques, tortueuses, annelées, recouvertes d'un épiderme rugueux, d'un gris-brun. La partie ligneuse est blanchâtre, filiforme; la partie corticale épaisse, d'une consistance ferme, d'une saveur amère, un peu âcre, d'une odeur nauséabonde. L'ipécacuanha du Brésil varie, pour la couleur, du gris au brun, et forme ainsi deux variétés qu'on emploie indistinctement. Suivant M. Mérat et M. Richard fils, ces deux variétés proviennent d'une seule et même plante, c'est-à-dire du cephcelis ipecacuanha. La différence des racines dépend probablement de la nature du terrain où on les a cueillies, et surtout de l'époque de l'année où la récolte en a été faite. Toutefois M. Virey a émis une opinion contraire, en s'appuyant de l'autorité de M. Gomez, qui rapporte l'ipécacuanha gris à une plante différente. D’après les recherches du botaniste américain, celui-ci proviendrait du richardia brasiliensis (I); il est également annelé, mais les anneaux sont un peu moins courts; son écorce est blanchâtre, également épaisse, âcre et nauséeuse. Dans les environs de Rio-Janeiro, on donne en général, suivant M. Gomez, le nom de poaia aux divers ipécacuanha. Le cephcelis est nommé poaia do mato ou cipo; le richardia est le poaia do campo ou des champs.

Il ne faut point confondre ces racines avec une autre

(1) Le genre Richardia a été dédié par Linné à Richardson, bolaniste anglais. 
espèce d'ipécacuanha très-rare dans le commerce, et qui provient du psychotria emetica de Mutis. Cette plante, indigène du Pérou, appartient aussi à la famille des Rubiacées ; mais sa racine est plus volumineuse. Au lieu d'anneaux, elle offre quelques étranglemens ou sillons circulaires assez éloignés les uns des autres. Son écorce est lisse, striée, plus mince que la partie ligneuse, et d'un gris-noir très-marqué.

M. Decandolle nous a fait connaitre des violettes, des euphorhes, des apocynées qui portent le nom d'ipécacuanha dans divers pays, et dont les racines sont douées d'une propriété émétique. D’après ce célèbre professeur, l'ipécacuanha blanc du Brésil provient d'une espèce de violette (viola ipecacuanha, Linn.). Cette racine est blanche, à peu près cylindrique, presque point fibreuse, striée plutôt que crevassée en long; son axe ligneux est plus épais que l'écorce. Le cynanchum vomitorium de Lamarck (asclepias astlımatica, Lins.) produit l'ipécacuanha blanc de l'Ile-de-France. Ses racines sont simples, cylindriques, ligneuses, blanches à l'extérieur et à l'intérieur, dépourvues d'anneaux ou de tubercules; l'axe ligneux est très-menu comparativement à l'écorce. Labillardière, qui a séjourné quelque temps à l'Ile-de-France, assure qu'on se sert non-seulement de la racine, mais de toute la plante. L'euphorbiaipecacuanha est employée comme émétique dans la Virginie, le Canada, la Caroline, et y a même reçu, dit-on, le nom d'ipécacuanha. Cette racine est à peu près cylindrique, grêle, peu rameuse, et d'un gris jaunâtre. (Mémoires de la Société médicale d'émulation, page $\mathbf{2} 38,2^{\mathrm{e}}$ édition.) 
On peut également consulter une notice de M. de Tussac sur différens végétaux dont les racines sont employées comme émétiques sousle nom d'ipécacuanhr. Voyez le Journal de botanique rédigé par M. Desvaux, cahier de décembre 1813 .

Je ne m'arrêterai pas plus long-temps sur ces racines exotiques dont les vertus ne sauraient être comparées à celles du véritable ipécacuanha. Par la même raison, je passerai sous silence un grand nombre de plantes indigènes qu'on a voulu lui substituer. J'honore les hommes dont les efforts tendent à nous affranchir du tribut que nous payons au Nouveau-Monde; mais je dois dire ici que la plupart de ces végétaux sont inertes ou peu fidèles dans leur action. Quelques-uns purgent à la manière des drastiques, d'autres excitent de violens vomissemens.

ANALYSE CHIMIQUE.

L'ipécacuanha a fixé depuis long-temps l'attention d'un grand nombre de chimistes. On a presque oublié les analyses de Boulduc, de Cartheuser, de Lassonne fils, de Cornette, etc. Celles de MM. Henry, Irvine et Masson-Four méritent une distinction particulière. Toutefois les travaux plus récens de MM. Magendie et Pelletier ont mieux fait connaitre la composition intime de ces racines. Leur faculté vomitive est due à un principe immédiat que M. Pelletier a nommé émétine.

La partie corticale de l'ipécacuanha gris (cephrelis ipecacuanha) a fourni à l'analyse une matière grasse très-âcre, d'une odeur forte; de l'émétine, une cire végétale, de la gomme, de l'amidon, du ligneux, et 
des traces d'acide gallique. La partie ligneuse a donné une très-petite quantité d'émétine, tandis que l'écorce en contient environ un sixième.

Les racines du psychotria emetica contiennent beaucoup plus de matière grasse et moins d'émétine. Elles sont d'ailleurs inusitées, et on les trouve rarement dans nos pharmacies.

L'émétine découverte par les savans que nous venons de nommer se présente sous la forme d'écailles transparentes d'un brun rougeâtre; son odeur est ì peu près nulle, sa saveur amère, mais point nauséabonde. Elle est très-déliquescente, soluble dans l'eau, et incristallisable. L'acide gallique, et surtout la teinture de noix de galle, la précipitent de sa dissolution aqueuse, et se combinent avec elle. Cette substance fait vomir les chiens et les chats, depuis un demi-grain jusqu'a deux et trois grains. A la dose de dix grains, elle produit des vomissemens répétés, et l'animal succombe ordinairement dans les vingt-quatre heures. A l'ouverture du cadavre, on découvre une violente inflammation dans le tissu pulmonaire et dans toute l'étendue de la membrane muqueuse digestive. Les résultats sont les mêmes, de quelque manière que l'émétine pénètre dans l'économie animale.

Ce médicament produit cheż l'homme les mêmes effets que l'ipécacuanha. Deux grains, pris à jeun, donnent lieu à un vomissement prolongé, suivi d'une tendance marquée au sommeil. Un quart de grain suffit quelquefois pour exciter des nausées et le vomissement. Lorsqu'on veut remplacer la poudre d'ipécacuanha par l'émétine, il faut administrer celle-ci en petite quan- 
tité. D’après les expériences tentées sur les animaux, une trop forte dose pourrait produire tous les symptômes de l'empoisonnement. Pour y remédier, il faudrait avoir recours, le plus promptement possible, à une décoction de noix de galle, qui a la propriété de décomposer l'émétine. Mais, s'il existait déjà une irritation vive ou un commencement de phlogose dans les viscères, il faudrait employer la méthode antiphlogistique.

PROPRIÉTÉS MÉDICALES.

Vers le milieu du xvir ${ }^{\mathrm{e}}$ siècle, Guillaume Pison, dans son Histoire naturelle et médicale des deux Indes, avait présenté l'ipécacuanba comme un remède employé au Brésil contre la dysenterie; mais ce ne fut guère qu'en 1686 que son usage se répandit en France, et ensuite dans le reste de l'Europe, par les soins de Jean-Adrien Helvétius. Ainsi que tous les remèdes nouveaux, cette racine jouit alors de la plus haute faveur, et le médecin qui avait fait connaître ses vertus reçut de la munificence royale mille louis d'or pour prix de son zèle (I).

(1) Un herboriste de Paris, nommé Garnier, avait fait présent à Helvétius d'une certaine quantité d'ipécacuanha. Celui-ci l'ayant essayé avec succès sur quelques malades affectès de dysenterie, de nombreuses affiches placardées au coin des rues annoncèrent tout aussitôt au public les vertus merveilleuses de ce nouveau médicament. Plusieurs gentilshommes de la cour, et le dauphin luimêıne, fils de Louis XIV, étaient à cette même époque atteints de la dysenterie. Le roi, informé par son ministre Colbert du secret. que possédait Helvétius, chargea son médecin d'Aquin et son confesseur le P. de La Chaise, d'entrer en arrangement avec lui pour la publiçation de son remède. Mille louis d'orfurent le prix 
On a mieux apprécié dans ces derniers temps ce médicament héroïque, et, malgré les éloges de Pison, d'Helvétius, etc., aucun homme de l'art ne voudrait l'employer dans tous les flux intestinaux. Quel bienfait pourrait-on espérer de l'ipécacuanha, lorsque la membrane muqueuse intestinale est en proie à une inflammation aiguë? et ne voit-on pas tous les jours des dysenteries, des cours de ventre céder aux antiphlogistiques administrés avec mesure? Il n'en est pas de même lorsque ces affections se développent avec des signes évidens de pléthore bilieuse ou d'embarras gastrique. Cette racine, administrée à la dose de quinze à vingt grains, remplit alors une indication importante. Lorsque ces flux sont devenus chroniques et opiniâtres , on la donne avec non moins d'avantage à la dose de quelques grains, qu'on réilère de temps en temps, et on l'associe, suivant les circonstances, soit avec l'opium, soit avec les mucilagineux. On a cru que les succès de l'ipécacuanha dans le traitement de la dysenterie dépendaient uniquement de sa propriété émétique : Cullen a surtout manifesté cette opinion. S'il en était ainsi, une substance émétique quelconque devrait produire

qu'il en reçut, et par la suite il fut élevé aux premières dignités nıédicales.

On voit qu'un peu de charlatanisme mène parfois à la fortune, ct que la fortune mène ensuite aux honneurs et aux dignités. Mais du moins aujourd'hui la médecine n'a pas exclusivement le monopole du charlatanisme; ce vice a filtré dans le corps social tout entier; vous ne sauriez faire un pas sans rencontrer un empirique. C'est ce qu'on appelle de l'industrie, du savoir-faire. Si cela continuc, pour ne pas êtrc dupc, tout le monde sera forcé de sc faire charlatan. 
les mêmes effets; ce qui est contraire à l'expérience. En effet, on a observé que cette racine, après avoir excité le vomissement, déployait une vertu tonique ou astringente qu'on ne retrouve point dans les préparations antimoniales.

Il est également probable que le principe alcalin ou l'émétine ne saurait remplacer l'ipécacuanha dans les mêmes circonstances; car il faut bien mettre en ligne de compte les autres matériaux qui entrent dans sa composition naturelle. La thérapeutique doit sans doute s'enrichir des nouvelles découvertes de la chimie; mais les médecins doivent, avant tout, les éprouver au creuset de l'expérience.

Dès l'invasion des fièvres bilieuses ou muqueuses, lorsque l'embarras gastrique est bien caractérisé, et que les viscères sont exempts de phlogose, les médecins qui sont restés fidèles aux lois d'une sage observation s'empressent d'employer les vomitifs, et ils donnent la préférence tantôt à l'ipécacuanha, tantôt au tartre émétique; quelquefois ils réunissent les deux substances, ainsi que le pratiquait le célèbre Stoll, et ils obtiennent ainsi des évacuations plus promptes et plus nombreuses. Nous n'examinerons point ici si les saburres, si les saletés gastriques, objet de dérision parmi les médecins modernes, sont la cause ou l'effet de l'affection fébrile. Ce qui est incontestable, c'est que les vomitifs, en éliminant hors du corps ces matières nuisibles, font quelquefois cesser comme par enchantement le dégoût, le malaise, l'agitation, la céphalalgie, etc. C'est à l'oubli des vomitifs qu'il faut souvent attribuer ces diarrhées énervantes et colliquatives qui 
sévissent vers la fin des maladies putrides. Cette observation clinique n'avait point échappé à Sydenham, à Tissot, à Huxham et à quelques autres praticiens judicieux; mais leur emploi exige du tact et de la prudence.

On est quelquefois obligé de répéter les vomitifs pour obtenir une guérison durable dans les fièvres bilieuses. Pendant la première guerre d'Espagne, nous eûmes à traiter, dans les hôpitaux de Perpignan, un grand nombre de ces maladies, qui sévissaient au printemps, sous l'influence d'une temṕérature humide et australe. Les soldats qui nous venaient de l'aile gauche de l'armée, campée dans des lieux marécageux , éprouvaient presque tous des symptômes bilieux ou gastriques parfaitement caractérisés. Un ou deux vomitifs dissipaient rarement cette diathèse bilieuse. Le foyer de la maladie étant profond, étendu, il fallait insister sur les évacuans; mais à l'aide de cette méthode on obtenait une assez prompte guérison. L'aile droite, campée sur les hauteurs, nous donnait également des affections bilieuses, mais qui cédaient à un ou deux légers vomitifs et à quelques boissons délayantes. Je peux dire qu'à aucune époque de ma carrière médicale je n'ai observé des effets aussi prompts, aussi décisifs. Les malades traités de cette manière éprouvaient rarement des récidives, tandis que ceux qui n'avaient pas été suffisamment évacués nous revenaient sous peu de jours, et alors la maladie offrait des complications qui la rendaient plus difficile. Les vomitifs quej'employais étaient ordinairement un mélange de dix à quinze graịns d'ipécacuanha et d'un à deux grains de tartre 
stibié, ou bien une potion saline composée de deux ou trois gros de sulfate de magnésie et de deux grains de tartre émétique dissous dans six onces d'eau, qu'on administrait en deux doses.

Au reste, les nausées, les vomissemens spontanés, l'amertume de la bouche, l'enduit muqueux ou jaunâtre de la langue, l'anorexie, ne sont pas toujours un indice de congestion gastrique. Ces phénomènes peuvent dépendre d'un état de phlogose des voies digestives ou des viscères voisins. Il n'y a pas à en douter, si la région abdominale est douloureuse, sensible àla pression; si la peau est brûlante, si les bords de la langue sont teints d'un rouge vif, si le pouls est dur et fréquent; etc. Cet état d'irritation exige la méthode relâchante et antiphlogistique. On en trouve de nombreux exemples dans l'Histoire des phlegmasies de M. Broussais.

On a souvent abusé de l'ipécacuanha dans les fièvres putrides et nerveuses, dans le typhus. Cependant, lorsque durant le cours de ces affections fébriles il se manifeste des signes de turgescence bilieuse, l'emploi de ce médicament est précieux. Indépendamment de sa faculté émétique, il exerce une action secondaire sur plusieurs systèmes d'organes, augmente l'activité de leurs fonctions, détruit les spasmes concentrés sur la peau, excite des sueurs, des éruptions salutaires. Bientôt après la tête devient plus libre, les accidens nerveux diminuent, les forces se relèvent, et l'on a déja rempli par là une des plus importantes indications du traitement. L'ipécacuanha mérite surtout d'être préféré aux autres vomitifs, lorsque les forces vitales sont affaiblies, et qu'il y a en même temps cours de ventre. 
Dans des cas semblables, on peut l'administrer en infusion aqueuse, à la dose de trente ou quarante grains, avec l'écorce d'orange. Je me souviens qu'une dame, tourmentée par un dévoiement opiniâtre, et réduite à un état de faiblesse extrême à la suite d'une fièvre bilieuse, fut instantanément soulagée par ce remède, qu'elle prit d'abord à la dose de deux cuillerées à houche tous les quarts d'heure jusqu'à vomissement. Les jours suivans, je me bornai à lui prescrire une cuillerée de la même infusion de trois en trois heures, afin d'exciter simplement quelques nausées, et de ranimer le ton des organes digestifs.

Les enfans sont très-sujets à des embarras muqueux, à des affections gastriques, qu'on guérit par l'usage de l'ipécacuanha et des évacuans. Cet état morbide est caractérisé par un peu d'abattement, par la pâleur du visage, le dégoût, des selles visqueuses, fétides; l'haleine est forte, la langue chargée de mucosités, un peu rouge sur les bords. Lorsque la région épigastrique n'est point douloureuse, la rougeur de la langue ne m'empêche point d'administrer quelques grains d'ipécacuanha, ou bien un peu d'eau émétisée, et je ne peux que m'applaudir de cette méthode, bien qu'elle s'éloigne des traitemens vulgaires. L'application immodérée des sangsues donne à ces affections un caractère chronique, et les rend interminables. Mademoiselle Achard, âgée d'environ douze ans, était presque expirante à la suite d'une fièvre muqueuse traitée par des émissions sanguines répétées et une diète sévère. Appelé vers le quarantième jour de la maladie, je me hâtai de prescrire le sirop de quinine pour combattre l'état 
de faiblesse. Je dirigeai ensuite mon attention sur l'affection gastrique, dont le caractère avait été méconnu, et j'administrai huit grains d'ipécacuanha. La malade vomit à plusieurs reprises des matières muqueuses, et se trouva beaucoup mieux. Une once d'huile de ricin, donnée deux jours après, procura également des évacuations salutaires. A la suite de ce nouveau traitement, l'appétit commença à renaître, et, à l'aide d'un régime convenable, la convalescence ne tarda pas à s'établir.

Personne n'ignore les succès de l'ipécacuanha dans le traitement des affections catarrhales, des toux convulsives, de la coqueluche. Lorsque ces maladies sévissent sous l'influence d'une température humide, qu'elles attaquent des sujets faibles, lymphatiques, d'une complexion molle, on donne l'ipécacuanha, à la dose de cinq ou six grains, tous les quarts d'heure, jusqu'à ce que le malade ait convenablement vomi. On est quelquefois obligé de rẻitérer ce remède lorsque la toux est entretenue par une congestion saburrale ou gastrique; mais il est rare que deux ou trois vomitifs ne produisent point une amélioration notable. On prescrit ensuite l'ipécacuanha à faibles doses, soit dans des potions, soit en sirop ou en pastilles. Dans les toux opiniâtres, on le combine avec l'opium. A l'exemple du docteur Double, je donne assez souvent un mélange de sirop d'ipécacuanha, de sirop de karabé et de sirop de quinquina dans une eau aromatique. Cette potion, douée d'une vertu antispasmodique, fortifie l'organe pulmonaire, et dissipe insensiblement la toux.

Les rhumes, le coryza, les affections catarrhales de la gorge, qu'on traite empiriquement par les tisanes 
relâchantes, par les looks, par les mucilagineux, cèdent beaucoup mieux à l'usage des vomitifs, surtout lorsque les fonctions de l'estomac sont altérées. Au lieu d'insister surles boissons aqueuses, surles pâtes pectorales, qui fatiguent et énervent de plus en plus les organes de la digestion, il faut alors avoir recours, soit à l'ipécacuanha, soit aux préparations antimoniales. Lorsque ces affections ont été négligées au point de simuler la phthisie, il est encore utile de les attaquer par les remèdes propres à leur caractère primitif. On administre pendant quelques jours l'ipécacuanha à doses nauséeuses fréquemment répétées; ensuite on fait vomir le malade en lui donnant des doses plus élevées de cette racine, et on répète le vomitif suivant l'urgence.

Il est quelquefois nécessaire d'insister sur cette méthode pour vaincre la diathèse catarrhale, en même temps qu'on emploie les révulsifs sur la surface de la peau ; on passe ensuite à l'usage intérieur des toniques. On sent bien que l'ipécacuanha, les vomitifs, les excitans doivent être soigneusement écartés lorsqu'une inflammation franche vient se joindre à l'affection catarrhale. Suivant Thomas Reid, il n'est pas de meilleur remède contre la phthisie scrophuleuse que l'ipécacuanha, administré à petites doses. D'autres médecins ont adopté cette méthode, et en ont préconisé les avantages. Les secousses produites par des nausées fréquentes, par des vomissemens modérés, doivent sans doute concourir à dégorger les glandes lymphatiques du poumon; mais il faut se tenir en garde contre l'action des vomitifs lorsque l'oppression et la vivacité du 
pouls annoncent une congestion phlogistique dirigée sur cet organe.

Des médecins ont conseillé l'usage de l'ipécacuanha dans les maladies arthritiques invétérées, et même dans l'imminence de la goutte aiguë, afin de produire un trouble général dans l'économie et d'éloigner l'attaque. Il faut abandonner ce moyen perturbateur aux praticiens dont les méthodes hardies passent, aux yeux du vulgaire, pour des inspirations cliniques. Toutefois, lorsqu'il existe un embarras gastrique, cette complication, pouvant aggraver les symptômes de la goutte, ne doit point être négligée. Scudamore cite à ce sujet un exemple digne de remarque. Un homme dont la goutte venait d'attaquer la main était en proie aux tourmens les plus cruels; sa langue était chargée, et il éprouvait en même temps des nausées. Il prit une forte dose d'ipécacuanha; et, après avoir vomi une grande quantité de mucosités et de matières acides d'une apparence verdâtre, il se sentit tellement soulagé, qu'il put immédiatement goûter un sommeil réparateur.

$\mathrm{Au}$ reste, on ne saurait être trop circonspect sur l'usage des vomitifs au début de la goutte. Dans les cas douteux, il faut explorer avec soin la région de l'estomac; et si elle est sensible, si elle s'irrite par la pression, malgré l'apparence des saburres, malgré la saleté de la langue, il faut renoncer aux vomitifs, dont l'usage inconsidéré peut être suivi d'une inflammation gangréneuse.

Granella (de Admirabili ipecacuanhce virtute in curandis febribus) a employé à petites doses la racine du Brésil dans les fièvres intermittentes de l'automne 
entretenues par des congestions saburrales, pardes obstructions du foie, de la rate, du pancréas, etc. Mais il observe avec raison que celte méthode n'est convenable que lorsque la constitution atmosphérique est humide, et que la fibre est relâchée. S'il existe des symptômes d'irritation et de phlogose, il ne faut employer l'ipécacuanha qu'après l'usage des évacuations sanguines, des émolliens et des tempérans. Ce médicament a également méritéles éloges de Stoll et de Comparetti.

L'action stimulante que cette racine déploie sur l'estomac, sur les intestins, et sympathiquement sur les autres viscères abdominaux, sur le poumon, sur le système nerveux, explique ses heureux effets dans les hémorrhagies utérines, dans l'hémoptysie, dans l'asthme convulsif, et dans quelques affections chroniques où la faiblesse se trouve unie à la mobilité excessive des nerfs. Dalberg, Bergius, Murray, ont constaté les avantages de l'ipécacuanha dans les pertes utérines, à la dose d'un tiers de grain mêlé avec du sucre, et répété toutes les deux heures. Paulisky l'a administré avec un prompt succès, à la dose d'un grain, à une femme en couches atteinte d'une violente hémorrhagie, avec syncope et mouvemens convulsifs. Quelques grains ont suffi pour arrêter cette perte, qui avait résisté à plusieurs autres moyens.

En écrivant l'histoire médicale de l'ipécacuanha, pourrions-nous oublier les succès que Doulcet a obtenus de cette substance dans le traitement de la fièvre puerpérale? Nul doute que son emploi ne soit précieux lorsque la maladie, soumise à l'influence d'une constitution bilieuse épidémique, exige le secours des 
évacuans. Mais une semblable méthode ne saurait être exclusive, car la fièvre puerpérale peut subir différentes complications, et conséquemment exiger des moyens variés. C'est ainsi yu'elle peut dépendre dc l'inflammation du péritoine, des intestins, de la matrice; présenter les phénomènes d'une véritable adynamie, ou une altération spéciale du système nerveux. Sydenham a parfaitement retracé cette dernière complication dans la lettre qu'il adresse au docteur Colle. $\mathrm{Au}$ reste, le traitement qui a valuà Doulcet une sorte de célébrité était connu, et ce médecin n'a eu d'autre mérite que d'avoir su l'appliquer dans une circonstance convenable.

Depuis quelques années, beaucoup de médecins ne veulent reconnaître dans la fièvre qui attaque les nouvelles accouchées, qu'une péritonite, et, d'après cette idée exclusive, ils ne lui opposent que la méthode antiphlogistique. Mais les faits sont là pour prouver que cette maladie n'est pas toujours produite par l'inflammation. Il y a plus : elle ne prend même quelquefois ce caractère que lorsqu'on néglige les méthodes indiquées par d'autres causes. Ainsi la diathèse bilieuse ou muqueuse existe; elle est parfaitement exprimée par les signes qui lui sont propres; si vous n'enlevez point les sucs bilieux ou muqueux, les saburres enfin, quoique ce mot sonne mal à vos oreilles, l'irritation produite par cette espèce de pléthore gastrique s'étendra de plus en plus, tous les fluides en seront viciés, et vous aurez une inflammation viscérale plus ou moins compliquée d'une affection putride ou ataxique.

Lorsqu'on lit sans prévention la fièvre puerpérale 
décrite par Stoll, il est impossible de ne pas reconnaìtre l'ellicacité des évacuans. Plusieurs femmes éprouvaient néanmoins des douleurs abdominales très-vives et s'aggravant par le plus léger toucher; mais la langue était comme hérissée de petits poils blancs jaunâtres, et quelquefois même trìs-verts. Je n'ignorais point, dit ce grand praticien, que c'est une question qui divise encore beaucoup de médecins, savoir, quelle est ordinairement la nature de la fièvre des femmes en couche? Est-elle inflammatoire, ou putride et maligne? Mais depuis long-temps les observations de Sydenham et les miennes propres m'avaient appris á connaître l'influence active de la maladie épidémique, qui, pendant tout le temps où elle règne, soumet à ses lois toutes les autres maladies, et les force ì combattre sous ses étendards. "Verum duclum et $\mathrm{Sy}$ denhamiana, et mea quoque observatione vim morbi epidemici noveram, qui omnes reliquias regritudines perid tempus quo is dictaturam exercet suce ditionis facit, suisque cogit sub vexillis militare. "(Sтоцг, Ratio medendi, febris puerperarum.)

Ce langage figuré n'a pas été employé sans dessein par Stoll; il exprime à merveille l'influence qu'exerce l'épidémie régnante sur toutes les autres affections pathologiques. Méconnue, dédaignée dans ces derniers temps par beaucoup de médecins, cette influence ne saurait pourtant être révoquée en doute; mais il ne faudrait pas lui donner une extension illimitée.

La maladie épidémique dont parle Stoll était d'une nature bilieuse et régnait en été; elle avait attaqué un grand nombre de femmes en couche. Stoll la combattit

II. 
avec le plus heureux succès par les évacuans. Il avait déjà observé cette même fièvre en Hongrie pendant deux étés. Toutes les femmes qui accouchèrent dans cette saison de l'année extrêmement chaude furent attaquées de fièvres très-bilieuses, de choléra et de dysenterie. D'abordil employa une méthode peu active; mais la longueur de la convalescence et beaucoup d'accidens qui avaient lieu au milieu même du traitement, lui firent prendre le parti de négliger toute considération relative à l'accouchement, et d'opposer au mal une méthode vigoureuse. Ainsi il employa fréquemment et hardiment les vomitifs ou les purgatifs suivant les cas, et par cette méthode la fièvre bilieuse fut guérie promptement et sans rechute.

Qu'on nous permette de placer ici une observation qui nous est propre, et qui prouve de la manière la plus évidente toute l'efficacité des évacuans.

Une dame, âgée d'environ trente ans, avait éprouvé deux mois avant sa couche, qui eut lieu vers la mijuillet, une fièvre intermittente irrégulière dont les accès furent dissipés par quelques petites doses de sulfate de quinine. Jusquà la fin de sa grossesse, cette dame fut tourmentée par des maux d'estomac et par un dégoût presque invincible pour toute sorte d'alimens. L'accouchement fut néanmoins assez facile. Le troisième jour, à six heures du snir, elle fut prise d'un frisson accompagné d'une violente céphalalgie, de nausées et de vomissemens bilieux. La fièvre redoubla dans la nuit et ne diminua qu'après des sueurs fétides. La journée du lendemain fut tranquille; mais à sept heures du soir un nouveau frisson eut lieu avec les symp- 
tômes de la veille et des douleurs aiguës dans l'abdomen. L'écoulement des lochies avait disparu, les seins étaient affaissés. On appliqua trente sangsues à la région hypogastrique; le sang coula abondamment une partie de la nuit, sans aucun soulagement remarquable.

Le lendemain, cinquième jour de l'accouchement, la malade éprouvait une grande faiblesse avec des éructations, des nausées continuelles et une sorte d'assoupissement mêlé de délire. La langue était couverte d'un muqueux épais et jaunâtre, le ventre météorisé et très-sensible. M. J., son accoucheur, était décidé à pratiquer une nouvelle saignée locale pour combattre la péritonite; heureusement je parvins à lui démontrer que la maladie ne dépendait point d'une inflammation, mais bien d'une pléthore bilieuse à laquelle il était urgent de remédier; j'ajoutai qu'on ne pouvait sauver la malade que par la méthode évacuante. On lui administra, à dix heures du matin, en deux doses, une potion préparée avec quatre onces d'eau distillée, douze grains d'ipécacuanha et un grain de tartre émétique. Ce remède fut suivi de vomissemens abondans de matières bilieuses; il y eut dans la journée plusieurs évacuations alvines, et le soirla malade était déjà très-soulagée. A dix heures du soir, elle prit demi-once de sirop diacode, mêlé avec autant d'eau de fleur d'oranger, et deux onces d'eau de laitue; ce julep anodin procura une nuit calme, et le lendemain matin les douleurs abdominales avaient presque entièrement disparu. Le septième jour, un léger frisson vint alarmer la malade; mais il fut de courte durée, ainsi que la réaction fébrile. La langue offrait encore un enduit jaunâtre, et les pa- 
rois abdominales étaient un peu douloureuses. On administra, le lendemain, deux onces de manne et trois gros de sulfate de magnésie, dissous dans quatre onces de tisane de chiendent: des matières visqueuses et d'une couleur verdâtre furent le résultat de cette purgation. Dès ce moment, tous les symptômes cédèrent, et, peu de jours après, la nouvelle accouchée fut en pleine convalescence.

La manière d'administrer l'ipécacuanha varie suivant les indications que le médecin veut remplir. L'écorce, réduite en poudre fine et dépouillée de la partie ligneuse, provoquele vomissement à la dose de huit, dix ou douze grains, qu'on peut délayer dans un peu d'eau sucrée. Si la première dose est insuffisante, on la réitère un quart d'heure après. Il est inutile, il est même dangereux de prescrire de fortes doses d'ipécacuanha. A l'exemple du docteur Pye, quelques médecins administrent maintenant cette racine à la dose de quelques grains seulement. En effet, on a remarqué qu'une faible dose faisait également vomir. Dans quelques cas d'empoisonnement, il convient néanmoins de porter la dose à vingt-quatre grains, lorsqu'on veut exciter d'une manière plus prompte les contractions de l'estomac. On pourrait même lui substituer avec avantage la substance nouvellement découverte par MM. Pelletier et Magendie. La dose de l'émétine est d'environ quatre grains, que l'on fait dissoudre dans trois ou quatre onces d'eau tiède édulcorée. On prend cette dissolution en deux fois.

Stoll, Wagler, et beaucoup d'autres praticiens, ajoutent à quinze ou vingî grains d'ipécacuanha un graiı 
de tartre stibié. Cette méthode est utile lorsqu'on a besoin d'exciter puissamment l'appareil digestif dans les affections gastriques, bilieuses ou muqueuses. D'autres mêlent à la racine du Brésil un peu d'oxymel scillitique.

On prescrit l'ipécacuanha comme altérant à la dose d'un demi-grain ou d'un grain trituré avec du sucre candi, et renouvelé toutes les deux ou trois heures. On le combine avec l'opium, avec le polygala, pour exciter les fonctions de la peau, ou favoriser l'expectoration dans les affections muqueuses de la poitrine; avec le carbonate de magnésie comme fébrifuge.

Poudre fébrifuge de Wichmann. Prenez ipécacuanha, un scrupule; magnésie pure, une once. Mêle\% exactement et divisez en vingt-quatre doses égales. On donne au malade, toutes les trois heures, une de ces doses dans une tasse de thé ou d'infusion de fleurs de coquelicot. Ainsi combiné, l'ipécacuanha ne produit point le vomissement, mais seulement quelques nausées, et surtout une sueur abondante qui emporte la fièvre. Cette préparation a quelquefois dissipé des fièvres intermittentes rebelles au quinquina.

L'eau, le vin, l'alcohol, s'emparent de ses principes, et l'on prépare avec ces liquides des médicamens plus ou moins actifs. Qui ne connaît le sirop d'ipécacuanha, si approprié aux maladies muqueuses des enfans, des vieillards, et des personnes d'une complexion délicate? Celui du Codex de Paris est préparé par la décoction aqueuse de celte racine épaissie avec du sucre; on le donne par petites cuillerées. On peut le remplacer par le sirop d'émétine de M. Pelletier. Celui-ci se prépare en faisant dissoudre un gros d'émétine dans six livres 
de sirop de sucre. Cette quantité d'émétine représente quatre onces de racine d'ipécacuanha. Une, deux ou trois cuillerées de sirop font vomir; à faible dose, il devient un doux excitant. Le sirop d'ipécacuanha alcoholique de $\mathbf{M}$. Virey contient environ dix grains de résine par once : on le donne comme vomitif à la dose d'une once à une once et demie; comme tonique, à la dose d'un ou deux gros, dans les diarrhées anciennes, la coqueluche, l'asthme, etc.

Les tablettes qu'on prépare dans nos officines sont également d'un usage familier dans les rhumes, dans les catarrhes chroniques; elles contiennent un quart de grain, un demi-grain ou un grain d'ipécacuanha. On les prend une à une toutes les deux trois ou quatre heures.

Teinture aqueuse d'ipécacuanha de Pison. Prenez, racine d’ipécacuanha pulvérisée, deux gros; eau bouillante, quatre onces. Laissez infuser, et décantez la liqueur. On donne au malade cette première infusion. On verse encore quatre onces d'eau sur la poudre restée dans le vase; et, après une nouvelle infusion, on décante la liqueur pour la donner le second jour. Enfin, cette opération réitérée fournit une autre infusion, que le malade prend le troisième jour. Ordinairement ce remède cause beaucoup de vomissemens le premier jour, moins le second, peu ou point le troisième ; mais alors il agit principalement comme tonique. Pison vante sa vertu spécifique contre la dysenterie : suivant cet auteur, on en fait un grand usage au Brésil. Aujourd'hui on est beaucoup plus réservé sur l'usage de l'ipécacuanha. Le caractère mieux connu 
de la dysenterie et des cours de ventre fait en général donner la préférence aux émolliens, aux anodins, aux antiphlogistiques.

Infusion d'ipécacuanha aromatique. Prenez, ipécacuanha, un gros; écorce d'orange, deux gros; eau bouillante, six onces. Faites infuser pendant deux heures dans un vase clos, et passez la liqueur. On prescrit cette infusion, à la dose d'une ou deux onces tous les quarts d'heure, pour provoquer le vomissement, dans les affections gastriques avec faiblesse et diarrhée. Les jours suivans, on en donne de temps en temps une cuillerée à bouche. Cette préparation m'a parfaitement réussi dans quelques dévoiemens opiniâtres.

Teinture d'ipécacuanha vineuse de Gorter. Prenez, ipécacuanha en poudre, un scrupule; vin blanc, une once; sucre, deux gros. Laissez infuser pendant la nuit, et décantez la liqueur. C'est un vomitif trèssûr et très-doux, qu'on donne aux enfans dans les cas de pléthore muqueuse, de toux convulsive, de dévoiement atonique.

Mixture anticatarrhale du docteur Double. Prenez, sirop d'ipécacuanha, sirop de quinquina, sirop de karabé, de chaque demi-once; eau de fleur d'oranger, une once et demie. La dose est d'une petite cuillerée, qu'on réitère cinq ou six fois par jour, dans la coqueluche et les affections catarrhales rebelles des enfans. 
y.9.八.y.

\section{CA PRIFOLIACEES.}

Caprifoliacece. Vent. DC.

\section{SUREAU. SAMBUCUS.}

Calice à cinq dents. Corolle en roue, à cinq lobes. Cinq étamines aiternes avec les divisions de la corolle. Trois stigmates. Baie arrondie, polysperme. Semences rugueuses, attachées vers l'axe du fruit.

\section{SUREAU YĖBLE. SAMBUCUS EBULUS.}

Sambucus ebulus. Lins. Spec. 385. DC. Fi. Fr. 3404.

$$
\text { (Planche } 76 \text {.) }
$$

Sa tige est droite, verte, un peu rameuse, cannelée, pleine de moelle, et d'une hauteur médiocre. Les feuilles sont opposées, ailées, formées de sept ou neuf folioles étroites, lancéolées, dentées en scie, glabres et d'un vert sombre. Les fleurs sont blanches, un peu rougeâtres en dehors, terminales, disposées en cime ou en manière d'ombelle. Les fruits qui leur succèdent sont des baies globuleuses, noires, remplies d'un suc d'un pourpre foncé. Cette plante croît abondamment en Europe. On la trouve dans les lieux incultes, sur le bord des chemins et des fossés humides. 
Ce petit sureau répand une odeur fétide, nauséabonde. Le suc exprimé de la racine, des jeunes pouces et des feuilles, est un violent hydragogue. L'infusion et la décoction de l'écorce intérieure de la tige purgent également avec énergie.

Le sureau noir (sambucus nigra), beaucoup plus élevé que l'espèce précédente, si commun dans les bois, dans les haies, dans les jardins, remarquable par son feuillage d'un vert foncé, par ses fleurs blanches, odorantes, et disposées en larges parasols; le sureau à grappes (sambucus racemosa), dont les baies, teintes d'un rouge vif, contribuent à l'ornement de nos bosquets, ont des propriétés analogues, et produisent des effets semblables. La médecine populaire a souvent abusé de ces plantes pour exciter des évacuations dans les cas d'hydropisie, d'anasarque, d'ascite, et autres affections œedémateuses. De même que les substances drastiques, elles peuvent produire des inflammations viscérales ou des superpurgations dangereuses; néanmoins on a des exemples de leur efficacité dans quelques hydropisies rebelles. On administre le suc exprimé de la racine et des tiges depuis plusieurs gros jusqu’à une ou deux onces, suivant la force et la constitution du malade; et on réitère cette dose pendant plusieurs jours de suite. On prescrit l'écorce moyenne des tiges à la dose d'une ou deux onces, qu'on fait bouillir légèrement dans une livre d'eau. On partage cette décoction en deux doses, à prendre à une demi-heure d'intervalle. On peut y ajouter un peu de lait, afin de tempérer sa saveur âcre et amère. Ce remède agit parfois comme un diurétique très-actif. 
A l'exemple de Sydenham, qui en fait un grand éloge, je m'en suis servi dans plusieurs circonstances, et j'en ai obtenu des effets merveilleux. Mais ces effets ne se réalisent que lorsqu'il y a de fortes et abondantes évacuations.

M. Martin Solon et M. Bonnet (Bulletin de thérapeutique); M. Birdt, de Siegburg (Gazette médicale), ont prescrit avec succès le suc de la racine de sureau contre diverses hydropisies.

Madame W. devint hydropique, en 1813 , sans cause appréciable. L'ascite et la leucophlegmatie étaient trèsconsidérables. La malade chercha en vain du secours auprès de plusieurs médecins. Son état s'aggravant de plus en plus, on lui conseilla le suc de la racine cle sureau. Elle en prit environ deux onces pendant trois jours, et l'effet en fut si prompt que l'hydropisie disparut en peu de temps.

M. le docteur Birdt rapporte qu'une autre dame fut guérie en quatorze jours, par le même remède, d'une hydropisie générale.

M. Bonnet, médecin à Graulhet (Tarn), traitait d'une ascite une demoiselle, âgée de vingt-un ans. Après avoir vainement employé tous les moyens usités dans cette maladie, il voulut essayer le suc de la racine de sureau. La malade en prit d'abord deux onces, trois jours après trois onces, et cetie dernière dose trois jours après. Des selles extrêmement abondantes et séreuses, et des vomissemens nombreux de même nature, furent chaque fois le résultat de cette médication. Après chacune de ces secousses, le ventre perdit de son volume et de sa dureté, et le dixième jour, il était tout- 
à-fait revenu à son état naturel. Cette guérison inespérée ne s'est point démentie.

M. Birdt prépare ainsice remède. On arrache les racines de sureau encore jeunes, on les lave et on enlève l'écorce noire; puis on sépare du bois de la racine l'enveloppe épaisse et molle qui vient après, et qui forme l'agent médicamenteux. On lave encore cette écorce, et on l'exprime dans un linge. Le suc abondant qui en découle a une couleur foncée, un goût amer, terreux, nauséabond. On en fait prendre une, deux et même trois tasses par jour. M. Birdt n'a pas osé en donner davantage, parce qu'il excite du dégoût et des nausées. Nous estimons que ces doses sont trop fortes pour nos malades; un Français ne saurait être traité comme un Allemand. Dans les hydropisies anciennes, liées à des désorganisations profondes, le suc de sureau ne sera sans doute pas plus efficace que d'autres; mais il soulage souvent, et c'est beaucoup dans certains cas.

Les fleurs de ces arbrisseaux répandent une odeur pénétrante, volatile; on les emploie fréquemment en infusion théiforme, pour provoquer l'exhalation cutanée dans les affections rhumatismales, les catarrhes, les exanthèmes. Cette infusion est plus eflicace si l'on y ajoute un peu d'oxymel simple. On se sert aussi extérieurement des mêmes fleurs, sous la forme de lotions, de fumigations, de cataplasmes, dans les contusions, les ecchymoses, les ophthalmies, les érysipèles, et autres phlegmasies de la peau.

La pharmacie nous offre une espèce de conserve préparée avec les fruits, qui porte le nom de roob de su- 
reau. Pris à haute dose, ce roob a, selon Bergius, une vertu laxative et sudorifique. Quarin assure également qu'il dispose le corps aux évacuations par les selles, les urines et la transpiration. C'est, dit-il, un remède puissant contre les affections rhumatiques; mais il faut en prendre trois ou quatre onces par jour.

\section{LIERRE. HEDERA.}

Calice à cinq dents. Corolle à cinq pétales élargis à la base. Cinq étamines alternes avec les pétales. Anthères bifurquées à la base, vacillantes. Stigmate simple. Baie globuleuse, à peine couronnée, à cinq lobes monospermes.

\section{LIERRE RAMPANT. HEDERA HIELIX.}

Hedera helix. Linn. Spec. 292. DC. FI. Fr. 3409.

\section{Fl. Dan. t. $102 \%$.}

Rien n'est si commun que cet arbrisseau toujours vert, dont les tiges sarmenteuses rampent à terre ou grimpent sur les arbres, sur les vieux murs, sur tous les corps voisins, et s'y attachent par des vrilles ou petits crochets radiciformes. Les feuilles sont pétiolées, luisantes, d'une texture ferme, d'un vert foncé en dessus, d'un vert pâle et sans éclat en dessous. Leur configuration varie suivant l'âge de l'arbuste : elles sont ovales, pointues, entières, ou partagées en plusieurs lobes anguleux. Les fleurs sont verdâtres, disposées en corymbe ou en forme d'ombelle globuleuse à l'extrémité des rameaux. Les fruits sont d'une teinte noirâtre, dans leur maturité. Cette plante croît naturellement dans les bois, dans les haies; elle aime les terrains frais 
et ombragés, où elle s'élève quelquefois à une grande hauteur. M. le professeur Desfontaines a observé des individus dont le tronc avait acquis la grosseur du corps d'un homme.

Dans l'arrière-saison, lorsque la campagne se dépouille et n'offre plus que des herbes flétries, le lierre nous console par sa constante verdure. Il tapisse les rochers arides, la grotte mystérieuse ; on le voit serpenter sur les vieux monumens, enlacer de ses vrilles nombreuses la statue mutilée de quelque héros, ou couvrir de ses guirlandes des colonnes, des obélisques, des chapiteaux renversés. Mais, au milieu de ces vénérables débris qui nous transportent d'admiration, un sentiment pénible vient bientôt contrister notre âme... Tout passe : les empires, les hommes et les arts.

Le lierre est une des plantes les mieux connues de l'antiquité : les naturalistes, les historiens, les poètes, en font souvent mention, et on le voit sculpté sur une foule de monumens grecs et romains. L'hedera nigra dont parle Virgile dans les Géorgiques (hederce vestigia nigrce) est celui que les Anciens qualifiaient de dionysia, et qu'ils avaient consacré à Bacchus. C'est l'hedera poetica de Bauhin, espèce conservée par Linné, comme variété. Elle servait, entrelacée avec le laurier, à couronner les poètes et les guerriers :

..... Atque hanc sine tempora circum

Inter viclrices hederam tibi serpere lauros.

Virg., Ecl. 8.

L'épithète de nigra donnée à l'hedera helix s'applique à ses baies noirâtres, et à son feuillage d'un vert 
sombre. (Conférez la Flore de Virgile publiée par M. Fée. )

Toutes les parties du lierre exhalent une odeur forte quand on les écrase. Les feuilles ont une saveur amère et nauséabonde. Les baies, d'un goût acide mêlé d'amertume, provoquent le vomissement. Elles sont même vénéneuses, ou du moins suspectes, suivant quelques auteurs : ce qui n'empêche pas les paysans d'en prendre jusqu'à dix ou douze pour obtenir d'abondantes évacuations. Vicat prétend que les oiseaux qui ont mangé de ces fruits sont tellement étourdis, qu'on peut les prendre à la main. Dans les pays chauds, il découle du lierre un suc résineux qui se condense promptement à l'air et se réunit en petites masses irrégulières. Cette substance est d'un brun roussâtre, un peu transparente, inflammable, d'une saveur âcre, résineuse et astringente. Lorsqu'on la brûle, elle donne une flamme claire, et répand une odeur pénétrante, aromatique, qui approche de celle de l'encens. Du reste, la médecine a depuis long-temps renoncé à l'usage de cette gomme-résine. 


\section{VIORNE. VIBURNUM.}

Calice à cinq dents. Corolle en cloche à cinq lobes. Cinq étamines alternes avec les découpures de la corolle. Trois stigmates. Baie monosperme, nue, ou couronnée par le calice.

\section{VIORNE LAURIER-TIN. VIBURNUM TINUS.}

Viburnum Tinus. Lins. Spec. 383. DC. FI. Fr. 3401. Curt. Magaz. t. 38.

Originaire des provinces méridionales, ce joli arbuste se distingue par sa verdure touffue et permanente, par ses rameaux opposés, tétragones, par ses feuilles nombreuses, ovales, aiguës, fermes comme celles du laurier, d'un vert luisant en dessus, garnies en dessous de nervures pubescentes. Les fleurs sont blanches ou un peu rougeâtres, surtout avant leur entier épanouissement, et disposées en corymbes terminaux : il leur succède des fruits globuleux, bleuâtres, couronnés par les dents du calice.

Le laurier-tin prospère dans nos bosquets, pourvu qu'on lui donne un abri contre les vents du nord: il aime les terres légères, fraîches et un peu ombragées. D'une taille médiocre dans les climats froids, il acquiert, dans son pays natal, jusqu'à douze pieds d'élévation. Ses baies sont âcres et délétères; elles enflamment la bouche, et purgent avec violence. On cultive plusieurs variétés dont les feuilles sont hispides en dessous, sur les bords ou sur les nervures postérieures.

Nous devons mentionner ici deux autres espèces de 
viorne. L'une porte le nom de viorne mancienne (viburnum lantana, Lins.), a des fleurs blanches, des feuilles ovales, dentées, cotonneuses en dessous : on la trouve dans les haies et dans les buissons; l'écorce moyenne de ses rameaux est irritante et épispastique. L'autre se fait remarquer par ses feuilles lobées, par ses fleurs rayonnantes, et par ses baies qui se colorent d'un rouge vif à l'époque de la maturité. Celle-ci habite les bois, les lieux montueux et humides : on la connaît sous les noms d'obier, de rose de Gueldre, de boule de neige; c'est le viburnum opulus de Linné. Le docteur Ozerets Koosky a recommandé, dans les Actes de l'Académie des Sciences de Saint Pétersbourg, les baies et les fleurs comme un remède efficace contre les maladies de la peau. D'après Willemet, les baies récentes sont émétiques.

Le genre qui a donné son nom à cette famille nous offre une espèce dont les baies sont vénéneuses : c'est le chèvrefeuille velu (lonicera $x y$ losteon). Cet arbrisseau a la forme d'un buisson très-rameux et touffu. Ses feuilles sont opposées, pétiolées, ovales, pointues, molles, d'un vert blanchâtre, pubescentes et presque cotonneuses en dessous. Les fleurs sont petites, blanches ou d'un blanc lavé de jaune, disposées deux à deux sur le même pédoncule; elles produisent des baies rouges, remplies d'un suc amer et fétide. Ces baies ont une action drastique, excitent de violens vomissemens.

Cette espèce de chèvrefeuille abonde dans les Pyrénées et dans les Alpes, au milieu des buissons et des haies : on la cultive dans les jardins où elle se montre 
sous plusieurs variétés dont les fiuits sont blancs, jaunes, bleus ou rouges. Voyez pour la culture de tous ces jolis arbustes l'Horticulteur français, publié par notre ami, M. Pirolle.

11. 


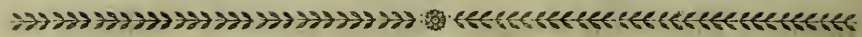

\section{OMBELLIFERES.}

Umbelliferce. Juss. - Umbellatce. Linn.

\section{ÉTHUSE. ETHUSA.}

Calice entier. Pétales courbés en cœur, inégaux. Fruit ovoïde. strié ou sillonné; semences planes d'un côté, convexes de l'autre. Collerette générale nulle; collerette partielle unilatérale, réfléchie, composée de trois à cinq folioles.

ÉTHUSE FÉTIDE. AETHUSA CYNAPIUM.

AEthusa cynapium. Linv. Spec. 36\% DG. Fl. Fr. 3436.

\section{(Planche 77.)}

Cette plante délétère porte aussi le nom de petite ciguë. Elle a une racine menue, pivotante, blanchâtre; une tige rameuse, glabre, cannelée, violacée à la base, haute d'environ deux pieds. Les feuilles ressemblent en quelque sorte à celles du persil : elles sont denx ou trois fois ailées, composées de folioles pointues, pinnatifides, ou profondément découpées, d'un vert sombre et luisant. Les fleurs, de couleur blanche, forment des ombelles planes, très-garnies, et dépourvues de collerette générale. Les fruits sont ovoïdes, arrondis, sillonnés.

La petite ciguë est commune darıs les lieux cultivés; 
on la trouve assez souvent à côté des plantes potagères, et on l'a quelquefois confondue avec le persil, ce qui a donné lieu aux plus graves accidens. Mais avec un peu d'attention on évitera une semblable erreur. Ces végétaux diffèrent non-seulement par la fructification, mais encore par l'odeur qui leur est propre. Celle du persil est aromatique, agréable; tandis que la petite ciguë, quand on la froisse entre les doigts, exhale une odeur fétide et nauséeuse; son feuillage est d'ailleurs d'un vert plus foncé. Sa racine périt tous les ans en automne; celle du persil est vivace et plus forte.

\section{PROPRIÉTÉS DÉLÉTÈRES.}

Toute la plante a une saveur âcre, alliacée, nauséeuse; son étymologie annonce sa qualité caustique. Prise intérieurement, elle déploie sur l'homme une action vénéneuse très-intense, malgré l'opinion contraire de quelques auteurs, qui prétendent qu'on l'a beaucoup exagérée. Il paraît néanmoins que les bestiaux la mangent sans inconvénient.

Le professeur Brugmans a éprouvé sur lui-même la racine de cette plante. Quelques grains pris le matin ont donné lieu aux symptômes suivans : violens maux de tête, soif, nausées sans vomissemens, douleur pongitive à l'épigastre ; bientôt après tranchées avec flatulence, disposition au sommeil; enfin un état de malaise pendant toute la journée. Le sommeil a été agité pendant les premières heures de la nuit; le lendemain, ce médecin s'est levé bien portant. (Dissertatio physico-botanica de plantis inutilibus et venenatis.

Le docteur Tournon m'écrivait, le 29 octobre r 8 I r, 
qu'il avait été empoisonné à Bordeaux par des feuilles de petite ciguë, mêlées dans une salade qu'il avait mangée à son souper. Après avoir dormi pendant quelques heures, il fut éveillé par des coliques suivies de vomissemens, de vertiges et de faiblesse. Du thé pris abondamment, et ensuite quelques petits verres de vin de Bordeaux, dissipèrent les effets du poison, à la faiblesse près, qui dura pendant deux ou trois jours. Le docteur Tournon reconnut, aux débris du triage de la salade, que cet accident avait été occasioné par la petite ciguë.

Au printemps de 1812 , je fus appelé par madame Godard, qui demeurait alors rue de Grammont, $\mathrm{n}^{0} \mathrm{n}$, et qui éprouvait depuis plusieurs heures des tranchées et des vomissemens horribles. On me rapporta que cette dame avait pris le matin trois ou quatre tasses de bouillon d'herbes pour se préparer à une purgation qu'elle devait prendre deux ou trois jours après. La violence des symptômes m'ayant fait soupçonner quelque méprise, je demandai avec quelles plantes on avait composé ce bouillon : on m'apporta aussitôt une poignée de feuilles de laitue, d'oseille et de cerfeuil qu'on avait réservées pour le lendemain. Dans ce mélange d'herbes, je découvris deux feuilles de petite ciguë, et je ne pus qu'attribuer à cette plante vénéneuse la cause des phénomènes qui se passaient sous mes yeux.

Comme la malade avait considérablement vomi, qu'elle était extrêmement faible et dans un état continuel d'angoisse, je me hâtai d'avoir recours à l'opium. En conséquence, jeprescrivis tous les quarts d'heure six gouttes de laudanum liquide dans une demi-cuillerée 
d'eau sucrée. A la troisième dose, les douleurs étaient déjà moindres; à la sixième, le vomissement, le hoquet, les faiblesses, enfin tous les symptômes alarmans avaient disparu. On donna le soir quelques cuillerées de bouillon et un peu de vin de Malaga. La petite ciguë a aussi quelque ressemblance avec le cerfenil, et cette observation prouve qu'on peut confondre ces deux plantes; mais il suffit d'interroger l'orlorat pour ne point s'y méprendre.

M. Bertrand, dans son Manuel medico-légal des poisons, nous fournit un autre exemple d'empoisonnement occasioné par un ragoût où l'on avait mis de la petite ciguë pour du persil. Un voyageur à qui l'on avait sèrvi ce ragoût dans une auberge tomba tout à coup dans un sommeil profond avec ronflement. Après avoir titillé la gorge avec une plume, et fait prendre beancoup d'eau tiède, ce qui procura plusieurs vomissemens de matières alimentaires, M. Bertrand administra une tasse dé café, qui diminua bientôt après la somnolence. On insista suir cette liqueur stimulante, et, au bout d'environ deux heures, l'état de narcotisme fut presque entièrement dissipé.

Mais voici un accident beaucoup plus funeste, dont Vicat nous a conservé le souvenir dans son Histoire des plantes vénéneuses de la Suisse. Un garçon de six ans, ayant mangéà quatre heures du soir de la petite ciguë qu'il avait prise pour du persil, commença aussitôt après à pousser des cris d'angoisse et à se plaindre de crampes d'estomac. Pendant qu'on le transportait de la campagne chez son père, tout son corps devint excessivement enflé et livide. Il mourut vers minuit. 
Enfin on lit dans les Mémoires de la Société royale de Montpellier, année 1 708, qu'une famille entière fut empoisonnée par une farce préparée avec des œufs, de la mie de pain et de la petite ciguë, qu'on avait également prise pour du persil. On ouvrit le cadavre du père, et on trouva une sérosité brunâtre dans l'estomac, le foie dur, d'une couleur jaune, la rate livide. La langue était noire; le corps n'était point enflé.

On voit, d'après les observations que nous venons de rapporter, que les effets délétères de ce végétal se manifestent par les signes propres aux poisons narcotiques âcres. Favoriser le vomissement lorsqu'on présume que le poison réside encore dans l'estomac, administrer ensuite des boissons émollientes et sédatives si l'irritation domine, des boissons acides ou stimulantes si l'on observe des symptômes de stupeur et de narcotisme, voilà les moyens les plus prompts et les plus efficaces.

Nous avons peu de choses à dire sur l'emploi médical de la petite ciguë; nous ferons seulement remarquer que des médecins ont proposé de la substituer, dans le besoin, à la ciguë commune (conium maculatum). Une pareille substitution pourrait bien n'être passans danger. 


\section{CIGUË. CICUTA.}

Calice entier. Pétales ovales, entiers, courbés au sommet, presque égaux. Fruit globuleux, sillonné; semences planes d'un côté, convexes de l'autre, et munies de cinq petites côtes. Collerette générale nulle; collerette partielle formée de trois à cinq folioles.

CIGUE VIREUSE. CICUT'A VIROSA.

Cicuta virosa. Linn. Mant. 355. Fl. Dan. t. 208. Cicutaria aquatica. DC. Fl. Fr. 3438.

(Planche 78.)

De sa racine bulbeuse, blanchâtre, divisée intérieurement en plusieurs cloisons, garnie de fibres disposées en demi-cercle, naît une tige glabre, fistuleuse, rameuse, haute de trois à quatre pieds. Les rameaux sont légèrement rougeâtres, couverts, ainsi que la tige, d'une poussière glauque. Les feuilles sont grandes, d'un vert foncé, deux ou trois fois ailées, et formées de folioles étroites, pointues, dentées en scie. Les fleurs sont blanches, disposées en ombelles lâches au sommet de la tige et des rameaux. La collerette gínérale est nulle ou à une seule foliole; la collerette partielle est composée de plusieurs folioles débordant les ombellules.

Cette plante croît dans les lieux aquatiques, sur le bord des fossés et des étangs. On la trouve en Alsace, en Dauphiné, en Suisse, en Allemagne, en Belgique, etc. Vicat l'a observée dans les étangs de Bâle, Roucel aux environs de 'T'ermonde et d'Anvers, Gili- 
bert en Lithuanie, où elle est très-commune. Elle est quelquefois désignée sous les noms de ciguë, de $c i$ cutaire ayuatique.

On regarde la ciguë vireuse comme la plus vénéneuse des ombellifères. Toutes ses parties exhalent une odeur forte, aromatique, analogue à celle du céleri sauvage (apium graveolens). Les racines, les tiges et les pétioles des feuilles radicales contiennent un suc jaunâtre ou couleur de rouille, qui est un violent poison pour l'homme et pour la plupart des animaux. On a quelquefois confondu les feuilles avec celles de l'angélique sauvage, la racine avec celle du panais, et ces méprises ont causé des accidens mortels.

La saveur de la plante n'a rien de désagréable; elle est chaude, piquante, peu différente, suivant M. Chevallier, de celle de l'angélique, que l'on cultive dans plusieurs contrées de l'Allemagne; et, si l'on ne tenait pas compte de ses effets nuisibles, on aurait de la peine à la croire aussi redoutable. La racine, plus âcre que les autres parties, se rapproche, par sa saveur, de celle du panais. Ĺes semences ont un goût analogue à celuị de l'anis ou de la coriandre.

\section{PROPRIÉTÉS DÉLÉTÈRES.}

Les expériences et les observations de Wepfer ne laissent aucun doute sur les effets pernicieux de la ciguë vireuse. Des chiens, des loups, ont été empoisonnés soit avec la racine, soit avec le suc de la plante. Ces animaux éprouvaient en général des tremblemens, des convulsions violentes, des vomissemens, de la soif, une salivation abondante et verdâtre. L'estomac et les 
intestins offraient des traces évidentes d'inflammation et de gangrène; les poumons étaient gorgés de sang et enflammés. Sproegel a essayé ce poison sur des lapins, sur des chiens, mais avec des résultats différens, puisque ces animaux ont été à peine incommodés. Il est vrai que les expériences ont été faites en automne, et l'on a remarqué que cette plante eśt beaucoup moins active dans cette saison qu'au printemps. Suivant le témoignage de Linné, elle est également funeste aux bœufs. D'autres naturalistes assurent que la chèvre, lorsqu' elle est pressée par la faim, mange la tige et les feuilles sans inconvénient.

Vers la fin de mars, huit enfans mangèrent des racines de ciguë vireuse, qu'ils prirent pour du panais. L'un d'eux, Jacob Móder, revint à la maison gai comme de coutume. Bientôt après il se plaignit d'une vive cardialgie, perdit l'usage de ses sens et tomba à la renverse. Ses urines jaillissaient avec force. Il fut ensuite saisi d'horribles convulsions, avec serrement tétanique des mâchoires et grincement des dents. Ses yeux roulaient dans les orbites d'une manière effrayante; il rendait du sang par les oreilles; il poussait des sanglots, et il était tourmenté par de vains efforts de vomissement. Il s'agitait et se tordait les membres; sa tête était renversée en arrière, son dos recourbé comme un arc. Les convulsions ayant cessé un instant pour revenir ensuite avec la même violence, les forces lui manquèrent, et il expira. La face et l'abdomén étaient tuméfiés; le contour des paupières était un peu livide, et une grande quantité d'écume verdâtre s'échappait de la bouche. 
Catherine Mneder, son aînée, se plaignit de malaise après la mort de son frère, vomit une poignée de racines, et fut agitée de convulsions épileptiques. Une dose de thériaque délayée dans du vinaigre lui fit rendre encore une certaine quantité de poison; après quoi elle resta étendue sur son lit, sans parole et presque sans vie, pendant vingt-quatre heures. Son visage était cadavéreux et sa respiration insensible. Elle revint enfin à elle-même; mais elle conserva pendant plusieurs jours une grande faiblesse et des douleurs à la région épigastrique. Une autre sœur, âgée de deux ans et demi, éprouva une violente palpitation suivie de hoquets, de cris, de rougeur à la face, de mouvemens convulsifs, de trismus et de syncope. On entr'ouvrit sa bouche de force : on lui fit avaler de la thériaque avec du vinaigre, et elle rejeta une demi-poignée de racines. Le lendemain elle était entièrement rétablie.

Mathias Graff, âgé de huit ans, éprouva plus tard l'influence du poison. Il eut d'abord des vertiges, chancela comme une personne ivre, tomba à terre, se releva pour retomber encore, et fut enfin saisi de trismus, d'opisthotonos et de violentes palpitations; peu de temps après il expira. Tout son corps était horriblement enflé. Une écume verte et abondante coulait continuellement de sa bouche.

Les autres enfans, qui avaient mangé beaucoup moins de ces racines, furent aussi moins violemment affectés, et se guérirent par le vomissement provoqué par la thériaque inêlée avec du vinaigre. Une petite fille fut promptement soulagée après avoir pris une infusion de feuilles de tabac, qui lui fit rejeter le poi- 
son.(Wepfer, Cicutce aquaticce Historia et Noxce.)

L'Histoire de l'Académie des sciences de Paris, année 1715 , renferme les détails d'un empoisonnement par la même plante. Trois soldats allemands périrent en moins d'une demi-heure. On trouva les membranes de l'estomac perforées chez l'un des trois, corrodées chez les deux autres. L'estomac était rempli d'une écume blanchâtre. Les intestins, les poumons et le cœur étaient flasques et flétris, les vaisseaux veineux pleins d'un sang très-fluide.

D'après Boerhaave (Prcelectiones academicce), huit enfans empoisonnés par la ciguë vireuse éprouvèrent des angoisses, des convulsions, des vomissemens, et le délire. Il leur fit prendre une dissolution de sulfate de zinc : tous ceux qui vomirent furent sauvés.

M. W. Schwencke rapporte que trois enfans moururent dans les convulsions, après avoir fait usage de cette plante. La tunique interne de l'estomac était phlogosée; les vaisseaux du cerveau étaient gorgés de sang.

Les faits que nous venons de rapporter nous dispensent de nous étendre sur les phénomènes physiologiques produits par la ciguë vireuse. On voit qu'elle réunit l'âcreté des substances irritantes à l'énergie des poisons stupéfians; qu'elle enflamme, corrode les tuniques digestives, en même temps qu'elle attaque le système nerveux, dont elle pervertit les fonctions. Parmi les principaux symptômes, on observe des tremblemens, des vertiges, des nausées, avec cardialgie et sécheresse de la gorge; une agitation continuelle, des angoisses, des convulsions violentes accompagnées 
de trismus, de hoquet, de syncope, etc. Dans cette espèce d'empoisonnement, le succès de la méthode curative est subordonnée au choix et à la promptitude des remèdes. Si l'on est appelé dès l'invasion des symptômes, Ja première indication à remplir est de provoquer le vomissement, soit par la titillation du larynx, soit par le tartre stibié ou les autres émétiques connus. Malgré les bons effets qu'on a obtenus de là thériaque dissoute dans du vinaigre, nous conseillons de préférence les vomitifs ordinaires, dont l'action est beaucoup plus sûre. Nous y reviendrons avant de quitter la famille des ombellifères. On prescrit ensuite des boissors adoucissantes, gommeuses, acides, suivant l'impression ressentie par les organes. L'affaiblissement du système des forces réclame l'emploi modéré des toniques.

Cette plante, beaucoup plus énergique que la ciguë ordinaire (conium maculatum, Lins.), n'est point admise dans la matière médicale. Dans le Nord, on a quelquefois employé extérieurement l'herbe fraîche et la racine contuses contre le lumbago, les douleurs arthritiques, les dartres rebelles, etc. On la substitue aussi quelquefois à la ciguë commune pour l'usage intérieur, parce que celle-ci est rare, mais cette substitution est répréhensible.

La ciguë maculée (cicutá maculata), espèce qui croît dans les lieux humides de la Virginie, figure aussi parmi les plantes délétères; mais elle est moins énergique, moins corrosive que l'espèce précédente. 


\section{OENANTHE. OENANTHE.}

Calice à cinq dents. Pétales du disque courbés en cour, presque éganx; pétales de la circonférence plus grands et irréguliers. Fruit oblong ou ovoïde, couronné par le calice. Collerette générale formée de plusieurs folioles, quelquefois nulle ; collerette partielle globuleuse.

\section{OENANTHE PHELLANDRE. OENAN'THE} PHELLANDRIUM.

OEnanthe phellandrium. DC. Fl. Fr. 3439. - Phellandrium aquaticum. Linn. Spec. 366.

(Planche 79.)

Sa racine est forte, creuse, pivotante, blanchître et garnie d'un grand nombre de fibres capillaires; elle produit une lige striée, fistuleuse, rameuse, haute de deux ou trois pieds. Les feuilles sont grandes, trois fois ailées, d'un beau vert, à pinnules écartées, à folioles extrêmement petites. Les fleurs sont blanches, disposées en ombelles sur de courts pédoncules. Il n'y a point de collerette générale; la collerette partielle se compose de six à sept folioles aiguës, de la longueur des fleurs. Les semences sont ovales, légèrement striées. Cetle plante ne croît que dans les lieux aquatiques et marécageux : je l'ai cueillie dans l'étang de Villed'Avray.

\section{PROPRIÉTÉS DÉLÉtÈres.}

On attribue généralement à cette ombellifère des qualités vénéneuses. Le bétail n'y touche point tant qu'elle est verte. Elle cause aux chevaux des convul- 
sions mortelles, une sorte de paraplégie que Linné attribuait sans motif à un charançon logé dans la tige de la plante. Bulliard, voulant constater la présence de cet animalcule, a brisé un grand nombre de tiges; mais il n'a jamais pu y découvrir le moindre insecte. Cette opinion a été également réfutée par Gmelin et quelques autres auteurs. Au reste, on assure que des enfans se sont empoisonnés en mangeant les racines de la plante, qu'on trouve ordinairement sur le bord des fossés aquatiques nouvellement nettoyés.

\section{PROPRIÉTÉS MÉDICALES.}

Cette espèce d'cenanthe, désignée sous le nom vulgaire de fenouil d'eau, exhale une odeur forte, un peu nauséabonde. Les semences sont jaunâtres, d'une saveur aromatique, âcre, vireuse; elles fournissent un principe extractif, de la résine, et un peu d'huile volatile d'une odeur pénétrante. Hers, Hufeland, Thomassen, etc., les ont employées avec avantage dans quelques affections pulmonaires avec expectoration sanglante, puriforme. Hufeland observe que ce précieux médicament convient comme moyen prophylactique et comme moyen curatif dans les phthisies chroniques, et plus particulièrement dans la phthisie muqueuse, dans les catarrhes, les toux opiniâtres occasionées par la rougeole. Dans la phthisie purulente confirmée, il devient encore un palliatif utile, lorsqu'on l'emploie conjointement avec le lichen d'Islande, les antiphlogistiques, etc. (Bibliothèque médicale, tome $3 \mathrm{I}$, page 12 . .)

M. Hannin a donné l'extrait de la plante avec beau- 
coup de succès dans une affection catarhale chronique du poumon avec anorexie, toux sèche et consomption imminente. Ce médicament, administré tous les jours à la dose de quatre à dix grains, fit cesser la toux, favorisa l'expectoration, et rendit l'appétit au malade, qui ne tarda pas à se rétablir. (Cours de matière médicale, tome 2, page 653.)

On prescrit les semences pulvérisées à la dose de quinze, vingt et trente grains, dans un véhicule aqueux ou dans du lait. Cette dose peut être réitérée deux ou trois fois par jour. Quelquefois on les administre sous la forme de teinture. Prenez, semence d'œnanthe phellandre, demi-once; esprit-de-vin, cinq onces. Laissez digérer pendant vingt-quatre heures. Ajoutez ensuite cinq onces de vin muscat, et continuez la digestion pendant vingt-quatre heures. La dose de cette teinture est d'environ un gros.

\section{OENANTHE FISTULEUSE. OENANTHE FISTULOSA.}

OEnanthe fistulosa. Linn. Spec. 365. DG. Fl. Fr. 3440.

(Planche 8o.)

Cette plante est remarquable par sa racine stolonifère, par ses feuilles d'un vert glauque, et dont le pétiole est fistuleux. Sa tige est cylindrique, striée, fistuleuse, presque nue, haute d'environ un pied. Les feuilles radicales sont alongées, deux fois ailées, à découpures fines, aiguës; les supérieures ont des folioles linéaires. Les fleurs, d'un blanc jaunâtre, for- 
ment une ombelle composée de trois ou quatre rayons, qui soutiennent chacun une ombellule plane, trèsserrée. La collerette ụniverselle est souvent nulle, ou n'a qu'une foliole. Les fruits forment une tête globuleuse, hérissée; chacun d'eux est ovoïde, couronné par le calice et par les styles persistans. On trouve cette espèce d'œnanthe dans les marais; M. Mérat l'a observée à Meudon.

\section{PROPRIÉTÉS MÉDICALES.}

La racine et les feuilles sont âcres, fétides et nauséeuses: aussi les bestiaux n'y touchent point. Un chien qui avait mangé de la racine périt en peu de jours. Ce poison, pris à hautes doses, produit l'adynamie, la syncope, la stupeur, des convulsions violentes et la mort. Les vomitifs, les boissons délayantes, mucilagineuses, forment la base du traitement. Ce n'est point à cette plante, mais à l'œnanthe safranée, ou bien à l'espèce à suc incolore (oenanthe apiifolia, Brotero), qu'il faut rapporter l'empoisonnement dont Vacher nous a transmis la relation dans l'ancien Journal de médecine.

OENANTHE SAFRANEE. OENANTHE CROCATA.

OEnanthe crocata. Linn. Spec. 365. DC. Fl. Fr. 3444. JACQ. Hort. Vind. t. 55.

(Planche 8r.)

Cette espèce, la plus vénéneuse du genre, se distingue par ses racines, composées de tubercules en 
forme de petits navets, réunis quelquefois au nombre de trois ou cinq. La tige est droite, cannelée, rameuse, d'un vert sale ou roussâtre, haute de deux ou trois pieds, remplie, ainsi que les tubercules, d'un suc fluide jaune ou couleur de safran. Les feuilles sont grandes, d'un vert sombre, deux fois ailées, à folioles cunéiformes, incisées à leur sommet. Les fleurs sont blanches, nombreuses, réunies en ombelles terminales, leémisphériques, de quinze à vingt rayons. La collerette universelle est composée de cinq ou six folioles allongées. Le fruit est oblong, terminé par les styles droits et persistans.

L'œenanthe safranée habite les lieux marécageux, les étangs, les prairies basses et humides. Elle croît dans plusieurs de nos provinces, aux environs de Versailles, de Bayeux, de Quimper, de Lorient, de Brest, d'Angers, de Dax. M. Tournon l'indique aussi aux environs de 'Toulouse, sur les bords du canal. On la trouve également en Suède, en Angleterre, en Hollande, dans la Belgique, etc.

PROPRIÉTÉS DÉLÉTÈRES.

Les naturalistes et les médecins s'accordent à dire que cєıte plante est un poison violent pour l'homme; mais il n'est pas moins essentiel de la signaler aux cultivateurs, aux grands propriétaires, comme une des plus pernicieuses qu'il y ait en Europe pour les bestiaux. Linné rapporte dans sa Flore de Laponie qu'elle a tué beaucoup de bêtes à cornes à Tornéo; d'autres auteurs citent aussi quelques faits analogues; toutefois on n'avait point encore d'observations pré- 
cises à ce sujet. Voici un événement malheureux qui doit se reproduire dans les campagnes où l'œnanthe safranée abonde, et qu'on attribue probablement à d'autres causes.

Au mois d'octobre, M. de Koreguin, propriétaire dans les environs de Quimper, fit curer les fossés de ses prairies : ce qui en fut retiré étant destiné à servir d'engrais, on le laissa le long des fossés. Il s'y trouvait une grande quantité d'œenanthe à fleurs blanches, à racines très-multipliées, pivotantes, rondes, et de la grosseur d'une carotte. Quoique dures et coriaces, ces racines contiennent une substance laiteuse, et les animaux qui en mangent ne peuvent ni les rejeter, ni les digérer; ils tombent bientôt en mugissant, écument horriblement, enflent et périssent en moins d'un quart d'heure. Ce qu'il y a de singulier, c'est que la fane (les feuilles) est une nourriture succulente et saine pour les bestiaux, tandis que la racine est pour eux un poison inortel. M. de Knereguin, s'étant aperçu que ses domestiques jetaient les racines d'œnanthe par-dessus les fossés, sur une colline où paît journellement le bétail de sa ferme (c'était un samedi), donna l'ordre de les ramasser soigneusement le lundi, de les mettre dans des sacs, et de les apporter à la maison. Cet ordre ne fut point exécuté; et le mercredi suivant, à dix heures du matin, sa fermière accourut effrayée l'avertir que trois boufs de travail périssaient. S'étant rendu sur les lieux, il les vit mourir tous les trois en moins de vingt-cinq minutes. On les ouvrit, et on trouva leur panse remplie de racines d'œnanthe. Ils rendaient par la bouche et les naseaux une grande 
quantité de matière liquide, rougeâtre et très-fétide, semblable à celle qui découle de ces racines lorsqu'on les rompt. La chair des animaux ainsi empoisonnés se putréfie très-promptement.

Quelque temps après cet accident, le même propriétaire perdit deux vaches à lait qui mangèrent des racines d'œnanthe qu'on avait laissées le long des fossés; elles périrent en un instant. Un cultivateur de ses voisins, qui avait curé les fossés d'un pré, et qui avait négligé d'enlever les racines de la même plante, ignorant qu'elles fussent un poison mortel pour les bêtes à cornes, eut le malheur de perdre également trois bœufs de travail. Ces animaux ouverts présentèrent les mêmes phénomènes.

On voit, d'après ces détails, combien il inporte aux cultivateurs de détruire avec grand soin les racines d'œnanthe lorsqu'ils font curer les fossés de leurs prairies aquatiques. Cette attention est d'autant plus nécessaire, que les bêtes à cornes en sont très-friandes, et les mangent avec une grande avidité.

L'œnanthe safranée n'est pas moins redoutable pour l'homme, d'après les exemples que nous fournissent les recueils académiques, les journaux de médecine, etc.

Au mois de juin, trente-six soldats du régiment de Berry cueillirent, dans les prairies de Belle-Ile-en-Mer, des racines d'œnanthe. Trompés par leur ressemblance avec la carotte, ils en mangèrent tous, et furent bientôt en proie aux symptômes qui accompagnent les plus violens poisons, à l'exception d'un seul, qui continua long-temps après la promenade, et fut très-gai; 
mais, sur les huit heures et demie du soir, il se sentit fort incommodé. On le transporta aussitôt à l'hôpital dans l'état le plus alarmant; il faisait des efforts incroyables pour vomir, et il était agité d'horribles convulsions, avec resserrement tétanique des mâchoires, en sorte qu'il fut impossible de lui faire avaler le moindre remède. Il mourut au bout de trois quarts d'heure dans une véritable atıaque d'épilepsie. Les autres furent sauvés par l'émétique donné en lavage, par des clystères émolliens, des potions. Néanmoins ils furent encore tourmentés par des vertiges, des nausées, des vomissemens fréquens, des syncopes. Ce ne fut qu'après l'attaque qu'ils purent rendre compte de leurs souffrances. Ils avaient tous éprouvé des douleurs inouïes dans la région du coeur et à l'orifice supérieur de l'estomac.

On ouvrit le corps du premier soldat qui avait succombé. L'estomac était vide, sans apparence d'érosion; mais les intestins étaient d'un rouge pourpre, parsemés, de distance en distance, de taches livides, gangréneuses, et enduits a'une liqueur jaune, semblable à celle qui coule de la racine d'œnanthe quand on l'incise. (Journal de médecine, par VANDermonde, année $\mathbf{I}-58$, tom. 9, pag. 43o. Observation de RocHARD. )

Le 30 mars i 758, Vacher, médecin des hôpitaux militaires, fut appelé à la citadelle d'Ajaccio pour voir dix-sept soldats du régiment de Flandre qui s'étaient empoisonnés en mangeant, à cinq heures de l'aprèsmidi, un potage préparé avec les feuilles et les racines d'une plante que l'un d'eux avait cueillie dans la cam- 
pagne. Une heure après, un de ces soldats était déjà mort, un second était expirant, et un troisième donnait pour tout signe de vie des tremblemens et des convulsions. C'est dans ce triste état que Vacher les trouva à sept heures du soir. L'activité du poison était si prompte, qu'il en vit tomber en défaillance deux qui, dans la plus grande sécurité pour eux-mêmes, s'empressaient de secourir leurs camarades. Avant de les transporter à l'hôpital, on leur avait fait avaler beaucoup d'huile. Louis Berniset, qui ne donnait aucun signe sensible de vie, mourut en y arrivant. Son corps fut ouvert. L'estomac, les intestins, et en général tous les viscères n'offrirent aucune altération remarquable.

On administra à tous les autres de l'eau émétisée, de l'huile d'olive et des lavemens. Ce traitement devint, pour ceux que le poison n'avait pas encore atteints, un préservatif aussi prompt qu'efficace.

Guillaume Trelacheau, d'un tempérament fort et robuste, âgé d'environ vingt ans, qui avait mangé copieusement de ce potage, était dans un état désespéré. Le renversement des yeux, la contraction spasmodique de la mâchoire inférieure, la faiblesse du pouls, la privation du mouvement et du sentiment, un froid glacial répandu sur tout le corps, semblaient être autant de signes certains de sa perte. Après quelques tentatives vainement réitérées pour lui faire prendre l'émétique, le docteur Vacher s'avisa de le faire rouler et fortement seconer dans une couverture. Cet exercice fut exécuté par huit hommes pendant près de deux heures, sans la moindre espérance. A la fin ce- 
pendant, le corps ainsi agité reprit de la chaleur, et recouvra insensiblement le mouvement et la vie. Il survint des efforts de vomissement, qu'on seconda à propos par l'émétique, et le malade se ranima au grand étonnement des assistans.

Étienne Garzanne, qui avait vomi plusieurs fois au quartier, et qui avait eu la force de se rendre à l'hôpital, n'en éprouva pas moins une grande partie de ces accidens. Une demi-heure après son entrée, il fut pris de violentes convulsions, avec trismus, en sorte qu'on ne put également lui rien faire avaler. On employa avec succès les mêmes moyens. Après avoir vomi, il recouvra ses sens, et au bout de trois heures il ne ressentit autre chose qu'un peu de fatigue, causée par la violence des secousses.

La plupart des autres soldats n'avaient pas encore éprouvé d'indisposition, ou n'avaient eu que de légers accidens, tels que des vertiges et de la faiblesse, principalement aux jambes. Un seul se plaignait de cardialgie; il eut un accès de fièvre qui dura près de six heures.

Après s'être assuré que tous les malades avaient vomi, Vacher leur administra des potions avec l'oxymel simple, en ajoutant, pour ceux que le vomissement avait trop fatigués, un gros ou un gros et demi de thériaque. La nuit se passa sans accidens. On donna une potion laxative à ceux que l'eau émétisée n'avait point purgés, et aux autres une seconde prise d'oxymel avec la thériaque. Tous sortirent de l'hôpital le 4 avril, parfaitement rétablis.

II ne restait que Guillaume Trelacheau, dont l'état, 
encore mal assuré, inspirait de justes craintes. Après un assoupissement de quinze heures, il éprouva des douleurs générales, une chaleur violente et des vomissemens continuels. Il prit, le 31 au soir, une troisième prise d'oxymel, avec un gros de thériaque. Le ${ }^{\mathrm{er}}$ avril, même état. On donna quelques cuillerées de bouillon avec un peu de jaune d'œuf. Le $\mathbf{2}$, les douleurs deviennent plus intenses; il survient une hémorrhagie du nez pendant la nuit. Saignée du bras le lendemain matin, potion huileuse, lavement émollient. Ces remèdes ne procurent aucun soulagement sensible; nouvelle hémorrhagie, douleur à l'hypochondre droit. On réitère les mêmes moyens dans la soirée. Le 3 , les douleurs se calment un peu; on profite de ce moment de relâche pour purger le malade. Le soir même, les douleurs et l'hémorrhagie se renouvellent, et l'on fait une troisième saignée. Le 4, le malade ayant plus souffert qu'à l'ordinaire, et ne pouvant rien prendre sans le rejeter aussitôt, on lui donna, par petites cuillerées, un mélange d'huile, de sirop et d'oxymel. Le 5, les accidens sont les mêmes; le malade se plaint, en outre, d'insomnie, de chaleur et d'altération. Julep anodin, boisson émulsionnée. Dès ce moment tous les symptômes diminuent d'une manière sensible. Les quatre jours suivans n'offrent rien de remarquable, si ce n'est le commencement de la convalescence. Enfin, le 3 r avril, le malade sort parfaitement guéri, ne se ressouvenant absolument pas de ce qui lui était arrivé pendant les trois premiers jours de son accident.

On trouva la plante dans l'endroit même où elle avait été cueillie. Vacher dit qu'elle est d'un vert très- 
foncé; que les feuilles sont embrassantes, semblables a celles du persil, mais plus rudes au toucher, plus grandes et plus étendues; que les racines ressemblent à de petits navets attachés immédiatement à la tige. Il ajoute qu'elle ne rend pas beaucoup de suc; qu'elle est d'une saveur âcre, d'une odeur qui se rapproche de celle du céleri. On la rencontre dans les ruisseaux et dans les ravins de l'île de Corse. (Ancien Journal de médecine, par Roux, année ${ }_{1} 763$, tome 18 , pag. 236 .

D'après la description de Vacher, il est évident que c'est l'oenanthe crocata, ou bien l'espèce à suc incolore, qui a donné lieu à l'empoisonnement que nous venons de rapporter, et non l'œnanthe fistulosa. Plenck a commis une erreur à ce sujet, en citant l'observation de Vacher d'après les actes helvétiques. Tissot, qui parle du même accident dans son Avis au peuple, s'est également trompé en l'attribuant à la ciguë filipendule. On donne quelquefois ce nom vulgaire à l'œnanthe fistuleuse. Lorsqu'il est question de plantes vénéneuses, il faut les distinguer avec soin, et ne point confondre les espèces, puisque la moindre méprise peut devenir fatale.

Un homme, âgé d'environ quarante ans, jouissant d'une parfaite santé, faisait défricher un pré sous ses yeux. Encore à jeun, il mangea gros comme le doigt d'une racine que ses ouvriers avaient trouvée en abondance en remuant la terre, et qu'il prit malheureusement pour des jouanettes ordinaires; c'était la racine de l'œenanthe safranée. A peine était-il rendu à son domicile qu'il se plaignit d'une grande chaleur dans la 
gorge. Une demi-heure après il perdit la parole, tomba sans connaissance, et fut pris de convulsions terribles, qui durèrent environ trois quarts d'heure et finirent par la mort, sans qu'il fût possible de lui administrer aucun secours, les dents ayant toujours été fortement serrées. Un domestique eut deux ampoules à la bouche pour avoir goûté de cette racine. Le médecin appelé auprès du malade, ayant cherché à reconnaître la plante fatale par la dégustation, fut sérieusement incommodé pendant vingt-quatre heures. Le cadavre, dont on ne put obtenir l'ouverture, exhalait une odeur putride quinze heures après la mort. Les parties génitales étaient violacées; le reste du corps n'offrait point cette couleur. (Journal général de médecine, $\mathrm{n}^{\circ} 3$ I 4 , observation de M. Bry, médecin à Angers.)

Au mois d'octobre r8ıо, M. le docteur RéveilléParise, étant à Alcaniz, dans le royaume d'Aragon, fut appelé avec un de ses confrères pour donner des soins à cinq soldats, qui, disait-on, venaient d'être empoisonnés. Comme les accidens s'étaient immédiatement déclarés après un repas, l'hôte espagnol fut arrêté, ainsi que d'autres personnes; il y eut même de la rumeur à ce sujet parmi la troupe et les habitans. Les deux médecins étaient fort indécis sur la nature du poison avalé par les malades, lorsqu'ils apprirent que ces soldats avaient été dans la campagne cueillir euxmêmes la salade qu'ils avaient mangée. Heureusement que les débris n'en avaient pas encore été jetés. On les fit apporter, et on reconnut l'cenanthe crocata, plante très-commune dans certains cantons de l'Espagne. Les feuilles et les racines de la plante avaient été man- 
gées. Les accidens furent à peu près ceux qu'on a décrits dans l'observation précédente. Tous les malades éprouvèrent une chaleur brûlante à la gorge, mais deux seulement eurent des hallucinations. On employa d'abord l'émétique, puis la limonade et autres boissons acidules. Bien que le traitement fût le même pour tous, et administré avec promptitude, trois malades succombèrent au bout de trois ou quatre heures, et les deux autres se rétablirent.

L'ouverture des cadavres, faite avec le plus grand soin, ne fit apercevoir aucune trace d'inflammation sur la membrane muqueuse de l'estomac et des intestins; cette membrane était partout d'un blanc rosé, qui en annonce l'état d'intégrité. On remarqua seulement de la rougeur et quelques points blanchâtres à la gorge. (Même journal, nº 3 I6.)

Rapprochons de cette observation deux faits qui offrent une différence frappante relativement à l'altération des tissus organiques. 'Trois soldats belges, trompés par la ressemblance des racines de l'ocnanthe safranée avec celles d'une plante dont ils font usage dans leur pays, en mangèrent en grande quantité. Peu de temps après, ils éprouvèrent un malaise général, des nausées, des vertiges et des vomissemens. Les convulsions les plus violentes se succédèrent avec tant de rapidité, qu'ils sucombèrent en moins d'une heure, et avant tout secours. Les cadavres furent ouverts à l'hôpital de la marine de Brest. On trouva l'estomac resserré et phlogosé à son cul-de-sac et à sa petite courbure; ses parois épaissies, les intestins ballonnés et injectés. Les désordres étaient les mêmes chez les trois indivi- 
dus. Les poumons d'un seul présentaient à leur surface externe quelques pétéchies. (Duval, Dissertation inaugurale.)

M. le docteur Kéraudren, médecin en chef des armées navales, a communiqué à l'Académie royale de médecine de Paris la relation d'un empoisonnement qui a eu lieu au port de Lorient parmi les détenus. Plusieurs individus étant parvenus à s'évader, et manquant de nourriture, trouvèrent dans les champs l'œnanthe safranée, dont ils mangèrent les racines; mais ils ne tardèrent pas à éprouver des accidens affreux, des douleurs, des convulsions, enfin une raideur tétanique, qui fut suivie d'un coma profond et de la mort. La plupart de ces malheureux expirèrent au bout de quatre heures; les autres furent sauvés par les soins qu'on leur prodigua à l'hôpital. A l'ouverture des cadavres, on trouva l'estomac phlogosé, et les vaisseaux de l'encéphale extrêmement gorgés de sang.

Les Transactions philosophiques renferment plusieurs autres accidens causés par le même poison : nous nous contenterons d'en extraire le fait suivant, parce qu'il offre quelques phénomènes particuliers. Huit enfans avaient mangé une grande quantité de racines d'œenanthe. Quatre ou cinq heures après, l'un d'eux tomba subitement sur le dos, et mourut dans les convulsions; quatre autres périrent dans la journée sans avoir pu proférer une seule parole. Des trois autres, l'un devint furieux, mais revint à lui le lendemain matin; un autre perdit les ongles et les cheveux; le troisième n'éprouva aucun accident. Celui-ci avait bu du lait chaud, et avait couru l'espace de deux milles, ce 
qui lui avait procuré une abondante transpiration.

Il résulte de ces différentes observations que l'œnanthe safranée n'exerce point une action constante sur l'économie animale; que, le plus souvent, elle enflamme et corrode les tissus gastriques avec lesquels elle est en contact; qu'elle irrite en même temps l'appareil nerveux, dont elle pervertit la sensibilité; mais que, dans certaines circonstances, elle attaque directement les nerfs sans laisser des traces de phlogose dans le canal alimentaire, ce qui explique l'anomalie qui règne dans les symptômes suscités par ce poison. Cependant, dans le plus grand nombre de cas , les malades éprouvent un sentiment de feu à la gorge et à la région épigastrique, des douleurs plus ou moins vives, des vertiges, des vomissemens répétés, ou de vains efforts pour vomir, des défaillances, des spasmes, quelquefois d'horribles convulsions. On observe rarement des hallucinations, des symptômes comateux comme dans l'empoisonnement produit par la ciguë, l'opium, les solanées. Les émétiques sont encore ici le secours le plus efficace; mais il n'y a pas un instant à perdre à cause du trismus, qui se manifeste quelquefois très-promptement. On donne ensuite des boissons délayantes et adoucissantes, du lait coupé, etc. Presque tous ceux qui n'ont point péri dans les premières heures ont été sanvés par cette méthode ou par des vomissemens spontanés. Dans quelques circonstances, la saignée devient indispensable pour combattre des irritations, des phlogoses imminentes.

Le genre cenanthe, qui produit de si violens poisons, renferme néanmoins quelques espèces, telles 
que l'œnanthe peucedanifolia et l'œnanthe pimpinelloides, dont on mange, dit-on, les racines sans inconvénient. On en fait usage dans quelques départemens de l'ouest sous le nom de jouanettes, d'abernotes, de méchous, etc. Ces racines croissent presque à la superficie du sol, et se composent de quelques petits tubercules allongés, ou de forme ovoïde, remarquables par leur blancheur intérieure.

Mais ne devrait-on pas renoncer à cet aliment suspect, qu'on peut d'ailleurs confondre avec les racines de l'œnanthe safranée, malgré leur différence? Cellesci sont pivotantes, rondes, multipliées, réunies ensemble, quelquefois de la grosseur d'un fort navet ou d'une forte carotte, pleines d'un suc de couleur safranée, ce qui a valu à la plante l'épithète de crocata. Il ne faudrait pourtant pas juger de leur innocuité par l'absence de cette liqueur jaune, puisque M. le docteur Mérat vient de signaler une autre espèce d'œnanthe qui en est dépourvue, et qui n'est pas moins vénéneuse. M. Brotero la désigne sous le nom d'œnanthe apiifolia. Elle ressemble beaucoup à la première espèce, avec laquelle elle a jusqu'ici été confondue; mais les feuilles sont plus divisées, les folioles plus aiguës ; la collerette générale est composée de cinq folioles, le suc des racines est aqueux et incolore. C'est donc une espèce à ajouter à la Flore Française. M. Mérat en possède un échantillon qui vient des environs de Reunes. Nous devons à ce médecin distingué d'utiles recherches sur ces végétaux délétères. (Voyez le Journal général de médecine, nos 3 i 4 et 3 i 6 .) 


\section{CERFEUIL. CHAROPHYLLUM.}

Calice entier. Pétales échancrés, inégaux. Fruit allongé, glabre ou strié à sa surface.

CERFEUIL SAUVAGE. CHAEROPHYLLUM

\section{SYLVESTRE.}

Charophyllum sylvestre. Linn. Spec. 369. DC. Fl. Fr. 3425.

JACQ. Fl. Austr. t. 149.

Sa tige est cannelée, rameuse, velue, un peu renflée sous chaque articulation, haute de deux à trois pieds. Les feuilles sont grandes, deux ou trois fois ailées, à folioles allongées, pinnatifides et pointues ; les gaînes sont recouvertes d'un duvet cotonneux d'une blancheur remarquable. Les fleurs sont blanches, et forment des ombelles médiocres, composées de huit à douze rayons. Les fruits sont lisses, luisans, d'une couleur brune d̀ leur maturité.

Cette plante ressemble beaucoup à la ciguë commune par son port et son feuillage. On la trouve dans les vergers, dans les prés couverts où elle fleurit vers le mois de mai ; elle se plaît principalement aux lieux où coulent des eaux vives. La racine est épaisse, allongée, blanchâtre, d'une saveur âcre, un peu aromatique; la tige et les feuilles ont une odeur nauséeuse et fétide.

On la regarde comme un poison pour les bestiaux lorsqu'elle est fraîche. Suivant l'auteur de la Flore de Sibérie, les vaches qui la mangent deviennent enflées et périssent. La racine, cueillie en hiver, a occa- 
sioné, d'après Bauhin, l'assoupissement, des anxiétés, le délire, etc.

On place également parmi les plantes vénéneuses ou suspectes les espèces suivantes.

Cerfeuil bulbeux. Chrerophyllum bulbosum. Cette plante, commune dans les prairies de la Suisse et de l'Allemagne, a une racine fusiforme, une tige trèsélevée, fistuleuse, renflée sous ses articulations, velue vers sa base et tachée comme celle de la ciguë (conium maculatum). Les feuilles sont trois fois ailées, à folioles incisées et dentées. Les fleurs sont blanches, les collerettes composées de cinq à sept folioles en alène.

La racine et les semences sont narcotiques; elles causent des maux de tête, des vertiges. Cette espèce de cerfeuil est quelquefois substituée à la ciguë; mais elle n'a ni ses propriétés, ni son odeur vireuse. Au reste, on a souvent confondu ces deux plantes qui ont plusieurs traces de ressemblance. La méprise est presque infaillible pour ceux qui ne sont point botanistes, le port étant à peu près le même, et les tiges étant également tachées.

Cerfeuil enivrant. Chorophyllum temulum. Celuici a une tige velue, rude au toucher, d'un pourpre noirâtre ou couleur de rouille à sa base. Ses feuilles sont velues sur les deux surfaces, à folioles découpées, obtuses. Les ombelles sont lâches, penchées avant l'épanouissement des fleurs, et composées de six à dix rayons. Les fruits sont oblongs, un peu striés. On trouve cette plante dans les haies, dans les lieux incultes; elle répand une odeur fétide quand on la froisse. 
D’après Pallas, elle est vénéneuse en Russie. Brugmans dit en avoir pris en Hollande une assez grande quantité sans accident; il l'a seulement trouvée un peu narcotique.

\section{BERLE. SIUM.}

Calice presque entier. Pétales lancéolés ou en coeur, légèrement courbés à leur sommet. Fruit ovoïde, glabre, strié. Ombelles formées en général d'un petit nombre de rayons; collerettes composées de quatre à dix folioles.

\section{BERLE A LARGES FEUILLES. SIUM}

\section{LATIFOLIUM.}

Sium latifolium. Linn. Spec. 361. DC. Fl. Fr. 3446. Fl. Dan. t. 246.

(Planche 82.)

Sa racine, noueuse, cylindrique et rampante, pousse une tige droite, rameuse, haute de deux à trois pieds. Les feuilles sont d'un vert luisant, ailées, composées de folioles ovales, lancéolées, dentées, glabres, souvent partagées en plusieurs lanières, surtout la terminale, qui est communément trifide. Les fleurs sont blanches, disposées en ombelles de douze à quinze rayons. La collerette générale est formée de cinq à six folioles linéaires, souvent incisées. Cette plante croît dans les lieux aquatiques, sur le bord des ruisseaux et des étangs.

La berle a une odeur forte, résineuse, et une saveur âcre. Sa racine, qui n'est point nuisible au printemps, se montre quelquefois très-délétère en été et 
en automne, par la détérioration de ses principes aromatiques. Elle a produit des anxiétés, des vertiges et quelquefois un délire furieux. Beyersten, cité par Vicat, observe qu'elle a fait périr des enfans et des bestiaux. Les Actes de l'Académie royale de Suède, tome 2 , année $\mathbf{r}_{7} 50$, confirment sa virulence.

Les feuilles ont un peu d'âcreté, mais elles ne sont point malfaisantes. Nos vieux auteurs font l'éloge de leur vertu antiscorbutique.

\section{HYDROCOTYLE. HYDROCOTYLE.}

Calice peu apparent, presque entier. Cinq pétales égaux, entiers. Fruit orbiculaire, comprimé, marqué de nervures.

\section{HYDROCOTYLE COMMUNE. HYDROCOTYLE VULGARIS.}

Hydrocotyle vulgaris. Linn. Spec. 338. DC. Fl. Fr. 355\%. Fl. Dan. t. 90.

C'est une petite plante qui a des tiges rampantes, grêles, longues de quatre à cinq pouces; des feuilles orbiculaires, crénelées, vertes, glabres, portées sur de longs pétioles qui s'insèrent dans le milieu de leur surface inférieure. Les fleurs naissent dans les aisselles des feuilles, le long des tiges; elles sont blanches, quelquefois rougeâtres, fort petites, ramassées cinq à huit ensemble en une ombelle simple et serrée. Le fruit est comprimé et composé de deux semences demi-orbiculaires.

On a donné à cette plante les noms de gobelet, d'écuelle d'eau; son nom botanique, dérivé du grec,

II. 
a le même sens. En effet la feuille arrondie, enfoncée dans son milieu, a presque la forme d'un petit vase. On la rencontre dans les marais, dans les étangs, dans les rivières, où elle fleurit en juillet et en août.

Elle possède une âcreté dangereuse pour le bétail. Lorsq̨u'on la déguste, elle excite la salivation, et une chaleur vive à la langue et aux parois de la bouche; bientôt après on ressent une douleur pongitive dans la gorge, dans l'œsophage et jusque dans l'estomac. Brugmans, qui en a fait l'expérience, a en outre éprouvé de temps en temps, pendant toute la journée, des vertiges avec un peu d'assoupissement.

\section{CONIUM. CONIUM.}

Calice entier. Pétales inégaux, courbés en cœur. Fruit presque globuleux; semences relevées de cinq côtes tuberculeuses, trois dorsales et deux latérales. Collerette générale à trois ou cinq folioles réfléchies; collerette partielle à trois folioles disposées du côté extérieur de l'ombelle.

\section{CONIUM MACULÉ. CONIUM MACULATUM.}

Conium maculatum. Linn. Spec. 349. J ACQ. Fl. Austr. t. 156. - Conium officinale. Chev. FI. Par. 3. 623. Cicuta major. DC. Fl. Fr. 3494.

\section{(Planche 83.)}

Sa racine est bisannuelle, pivotante, de la grosseur du doigt, d'un blanc jaunâtre, d'une odeur forte et d'un goût douceâtre. Sa tige est épaisse, fistuleuse, glabre, marquée inférieurement de taches sanglantes 
ou d'un pourpre brun; elle se ramifie et s'élève quelquefois jusqu'à la hauteur de cinq ou six pieds, suivant le terrain où elle croît. Ses feuilles sont grandes, trois fois ailées, composées de folioles pinnatifides, pointues, luisantes, d'un vert sombre, quelquefois d'une teinte glauque. Les fleurs sont blanches, disposées en ombelles très-ouvertes. Cette plante fleurit en juin et juillet. On la rencontre dans les terrains incultes, un peu frais, dans les décombres, près des habitations. Je l'ai observée dans les fossés qui entourent la petite ville d'Armentières, où elle croît abondamment.

La ciguë nous rappelle la mort de Socrate, de Phocion, de Philopémen; mais on est encore incertain sur la composition du breuvage qui a fait périr ces hommes illustres. Le suc de ciguë était-il pur? ou bien était-ce un mélange de substances vénéneuses dont on avait parfaitement calculé les effets? C'est ce que toutes les recherches des modernes n'ont pu nous apprendre. Socrate avale la ciguë, se promène, console ses amis éplorés, et, dès qu'il se sent engourdi, il se met sur son lit et s'enveloppe de son manteau. Déjà un froid mortel avait glacé son corps : il adresse quelques paroles à Criton, et, un instant après, il exhale son dernier soupir. Affaibli par une chute violente, dévoré de chagrins, chargé de chaînes, au fond d'un noir cachot, Philopémen n'a pas plus tôt appris que Lycortas et ses jeunes cavaliers sont hors de danger, qu'il se met sur son séant, prend la coupe fatale que lui offre l'exécuteur, se recouche, et s'éteint sans se plaindre. Ce n'est pas ainsi que succombent ceux qui ont fait usage de 
notre ciguë ou des plantes qui portent ce nom. Au lieu d'une mort tranquille et douce, ils éprouvent des angoisses, des douleurs, des vertiges, des convulsions, et quelquefois un délire qui va jusqu'à la fureur : d'où on peut conclure que les Athéniens tempéraient les principes âcres de la ciguë par le suc du pavot on par quelque autre substance narcotique que nous ne connaissons point.

Quoi qu'il en soit, les caractères physiques de la ciguë des anciens, son port, son odeur, ses effets pernicieux, décrits par Théophraste, Dioscoride et Pline, annoncent une parfaite analogie entre cette plante et le conium maculatum de Linné, qui est notre grande ciguë. Cependant, après avoir parlé des qualités malfaisantes des semences et des feuilles, Pline ajoute que quelques personnes étaient dans l'usage, à Rome, de manger les tiges : Caulis autem viridis estur à plerisque. L'observation du naturaliste romain se retrouve dans quelques écrits modernes. Lescale rapporte qu'en voyageant en Lombardie, il fut fort étonné de voirservir de la salade où il y avait de la ciguë ; mais il revint de sa surprise, quand il sut que les habitans du pays en mangeaient, et qu'ils n'en étaient point incommodés. M. Chevallier, dans sa thèse inaugurale sur les ciguës indigènes, observe que le vinaigre qu'on met dans la salade devient l'antidote de la ciguë commune et détruit son action sur l'économie animale. Nous verrons bientôt si l'on peut compter sur la vertu préservative du vinaigre. On pourrait, ce me semble, expliquer ce fait par la ressemblance qui existe entre un grand nombre d'ombellifères, en sorte que des yeux mal exercés 
ont bien pu confondre avec la ciguë le cerfeuil sauvage ou quelque autre plante voisine. Beaucoup de cultivateurs donnent le nom de ciguë à la plupart des scandix et des chcerophyllum, et surtout au chcerophyllum sylvestre, qui croît dans les prairies et qui lui ressemble beaucoup.

On a obtenu du conium maculatum de l'extractif, de la gomme-résine, du mucilage, une matière verte ou clorophylle, une huile volatile très-odorante, et plusieurs sels. M. Brandes y a découvert un alcali végétal composé, qu'il nomme cicutin.

\section{PROPRIÉTÉS DÉLÉTÉRES.}

La grande ciguë répand une odeur fétide et vireuse qui lui est propre. La racine, les semences, les feuilles, le suc exprimé de l'herbe fraîche, son extrait préparé avec soin, sont vénéneux pour l'homme et pour quelques animaux ( 1 ). Les feuilles ont une saveur désagréable, salée. La racine a quelquefois été confondue avec le panais, à cause de son goût douceâtre. Plusieurs exemples prouvent également qu'on a pris les feuilles naissantes pour celles du cerfeuil et du persil; on les distinguera facilement, si l'on compare leur odeur.

Mathiole raconte qu'un vigneron italien ayant cueilli des racines de ciguë pour du panais, les fit cuire, et les mangea à souper avec sa femme; que l'un et

(1) M. le professeur Delle Chiaje rapporte(Enchir. di Tossicol.) que deux ânes ayant mangé vers la fin du mois de mai une certaine quantité de ciguë, moururent en quelques heures avec un météorisme extraordinaire : Morirono dopo alquante ore con straordinario meteorismo. 
l'autre, s'étant couchés immédiatement après, se réveillèrent vers le milieu de la nuit dans un état complet de démence; qu'ils se mirent à courir çà et là dans la maison, et se heurtèrent violemment contre les murs, en sorte que le lendemain matin les voisins les. trouvèrent couverts de sang et d'horribles contusions. Mathiole s'assura que cet accident avait été causé par la ciguë; car, s'étant rendu à l'endroit même où les racines avaient été cueillies, il en trouva d'autres qui commençaient à pousser des feuilles. Il cite également l'exemple d'un franciscain qui avait mangé un ragoût où l'on avait mis des feuilles de ciguë pour du persil, et qui resta fou pendant plusieurs mois. Ces trois malades furent guéris par ses soins. (Andr. Mathioli, Comment., pag. 988.)

Étant en garnison à Torrequemada, en Espagne, M. Haaf, chirurgien aide-major, fut appelé à sept heures du soir, le 2 mars 1812 , auprès d'un grenadier qu'on disait mourant. Il le trouva profondément assoupi, sans connaissance, respirant avec une difficulté extrême, et couché par terre dans une petite chambre étroite, basse, bien fermée, remplie de monde et de fumée. Son pouls était petit, dur, et ralenti jusqu’à trente battemens par minute; les extrémités étaient froides, la face bleuâtre, regorgeant de sang comme celle d'un homme étranglé. Le malade fut placé à l'air frais. M. Haaf apprit qu'il avait mangé avec plusieurs de ses camarades une soupe dans laquelle on avait mis de la ciguë; que depuis le souper tous étaient comme ivres, et ressentaient des maux de tête et de gorge; que ce grenadier en avait mangé une plus grande 
quantité que les autres; qu'immédiatement après avoir soupé, il s'était couché et endormi; et qu'une heure et demie après on avait remarqué qu'il gémissait et respirait péniblement.

On lui donna douze grains de tartre émétique dissous dans l'eau chaude, et on lui fit respirer du vinaigre. Application sur la tête de fomentations froides; frictions sèches et chaudes sur les extrémités, pour y rappeler la circulation et diminuer la congestion cérébrale. Le malade commença à faire de vains efforts pour vomir, et bientôt son état, qui avait donné quelques espérances, s'empira visiblement. Néanmoins il parlait encore, et se plaignait d'avoir trèsfroid; mais il perdit de nouveau l'usage de la parole et de la connaissance, et ne manifesta plus que par des palpitations continuelles de la poitrine et de la région épigastrique l'extrême angoisse dont il était tourmenté. On lui fait avaler du vinaigre chaud, on le frotte sans cesse; il expire trois heures après le souper fatal.

On trouva l'estomac à moitié rempli d'une bouillie crue, avec quelques points rouges autour du pylore. Le foie était très-volumineux ; il n'y avait aucune altération dans les intestins; la veine-cave et le cour étaient vides de sang. Le lobe gauche des poumons était sain; mais le lobe droit était entièrement détruit par une suppuration précédente. A l'ouverture du crâne, il s'écoula une quantité considérable de sang; les vaisseaux du cerveau en étaient gorgés. (Journal de médecine de M. Leroux, tome 23 , page 107. )

La grande ciguë a plus ou moins d'énergie suivant 
la saison de l'année, le climat, le sol où elle végète. Ses propriétés s'exaltent pendant les chaleurs de l'été, dans les lieux exposés au soleil, dans les contrées méridionales. Elle est moins âcre, mais plus narcotique que les autres végétaux qu'on désigne quelquefois sous le même nom, tels que l'éthuse et la cicutaire. Parmi les phénomènes suscités par ce poison, on remarque l'engourdissement, la somnolence, les vertiges, le trouble des sens, l'altération de la vue, les nausées, les vomissemens, les douleurs gastriques, les défaillances, les spasmes musculaires, et quelquefois une excitation des plus violentes. On préviendra la plupart de ces accidens en provoquant le vomissement dès l'apparition des premiers symptômes; on donnera ensuite avec profusion de l'eau vinaigrée ou d'autres boissons acides. (Voyez plus bas la méthode curative générale.)

PROPRIÉTÉS MÉDICALES.

Après avoir joui d'une grande célébrité comme poison, cette plante a pris rang, vers la fin du siècle dernier, parmi les médicamens héroïques, d'après les belles expériences de Storck. Toujours guidé par les plus nobles sentimens, ce médecin fait d'abord des essais sur les animaux et sur lui-même; il choisit ensuite les affections les plus rebelles, les engorgemens squirrheux, les cancers, et il nous apprend par des observations nombreuses, fondées sur les témoignages les plus authentiques, que la ciguë peut quelquefois guérir ces maux, et presque toujours les soulager. Mais en vain de grands praticiens ont confirmé par leurs suffrages et par l'observation la plus attentive les faits 
recueillis par le médecin de Vienne; l'envie, cette rouille caustique qui s'attache aux plus belles découvertes, a voulu lui ravir ce nouveau triomphe. Qu'un critique de nos jours ait cherché à tourner en dérision jusqu'au titre si honorable d'archiatre; qu'il ait accusé les disciples et les amis de Storck d'une complaisance servile, ses traits ne sont point à craindre dans un ouvrage où l'invective se mêle si souvent aux discussions médicales ; mais que Cullen ait aussi reproché aux médecins de Vienne d'avoir prodigué les éloges à la ciguë, d'avoir surpris la foi de Storck par de faux rapports pour lui complaire et le flatter, en raison du rang qu'il occupait à la cour, c'est ce qui nous étonne dans un auteur grave, judicieux, et justement célèbre.

Parmi les médecins qui ont éprouvé l'efficacité de la ciguë contre le squirrhe, les ulcères de mauvaise nature, nous citerons Ludwig, Locher, Fothergill, Quarin, Collin, Ortega, Vivenzio, 'Tissot, Gilibert, Razous, Barthez, Fouquet, etc. Tissot avait employé l'extrait ordinaire de la plante. Ce remède calmait les douleurs du cancer, mais ne le guérissait point. Il le fit préparer ensuite d'après le procédé de Storck, et il obtint les plus heureux effets dans plusieurs cas d'écrouelles et de cancer. Lorsque le mal était incurable, il procurait toujours quelque soulagement. C'est, ditil, un remède spécifique dans plusieurs cas, qu'aucun autre ne peut remplacer, et dont il serait très-fâcheux qu'on négligeât l'usage. Gilibert, passant à Vienne à une époque où l'on répétait les expériences de Storck, vit, à l'hôpital de Pazmann, plusieurs malades qui avaient été guéris du cancer par la ciguë. Il guérit lui- 
même à Grodno, avec l'extrait de la ciguë du pays, un carcinome à la langue. A la vérité, Fothergill n'a jamais triomphé du cancer avec le secours de ce remède; mais il assure que son usage a souvent diminuéles douleurs, qu'il a arrêté les progrès de l'ulcère, et rendu la suppuration meilleure, eu égard à la couleur, à la consistance et à l'odeur. Cullen lui-même avoue que la ciguë modère les douleurs, qu'elle a guéri des ulcères survenus à des tumeurs squirrheuses, quelquefois même des ulcères approchant de la nature du cancer. Deux observations du docteur Gruelmann, insérées dans sa thèse inaugurale, De usu cicutce, etc., constatent également les vertus sédatives de la ciguë dans les ulcères carcinomateux. L'extrait, administré graduellement jusqu'à la dose de vingt à trente grains, matin et soir, a calmé les élancemens, qui étaient devenus atroces.

Toutefois des médecins très-recommandables, tant en France que dans les pays étrangers, n'ont pas obtenu les mêmes résultats; il en est même qui prétendent que ce remède aggrave la maladie et accélère le moment fatal. Sans doute on a vu périr beaucoup de personnes affectées de cancer, bien qu'on n'eût pas ménagé la ciguë; mais ces faits, quelque nombreux qu'ils soient, ne peuvent détruire d'autres faits qui attestent des guérisons. Faut-il nier qu'on a guéri des hydropisies parce qu'on voit chaque jour des hydropiques conduits au tombeau? Le professeur Pinel, qu'on n'accusera pas de trop de crédulité en fait de médicamens, dit, dans sa Nosographie, article cancer : "On ne " peut point ignorer les heureux effets que Storck a 
" retirés de l'usage interne de la ciguë; et en supposant " même un peu de partialité de sa part en faveur de ce " remède ", ce qu'il ne faut point supposer à l'égard d'un homme qui avait autant d'élévation dans le caractère, "les faits ont été si multipliés, qu'on ne peut " qu'être porté à renouveler des essais de ce genre " contre une maladie peut-être la plus déplorable dont " l'espèce humaine puisse être affligée. "

Il n'est que trop vrai que la ciguë est ordinairement impuissante contre le carcinome; mais on a remarqué qu'elle produisait au moins une meilleure suppuration de la plaie cancéreuse. Cette cruelle maladie attaque assez souvent les personnes d'une constitution ardente, irritable, tourmentées par le chagrin ou quelque autre affection morale profonde, sujettes à la colère, aux emportemens. Quel secours peut offrir la ciguë, lorsque toute l'organisation est en proie à une sorte de venin qui la consume?

\section{. . . . . Calido sub pectore mascula bilis}

Intunıit, quanı non extinxerit urna cicuta.

\section{Pers., Sat. 5.}

On a essayé la ciguë avec plus ou moins de succès dans les maladies lymphatiques, dans les affections nerveuses et convulsives. Bergius, Fothergill, Ranh, Baumes, Hufeland, et quelques autres praticiens, ont constaté ses bons effets dans les engorgemens de nature strumeuse. C'est en modifiant la sensibilité des organes, en détruisant les spasmes des vaisseaux des glandes, qu'elle améliore l'état des enfans scrophuleux. Avec ce médicament on a dissipé des névralgies, des douleurs sciatiques, des toux convulsives rebelles, des irrita- 
tions, des spasmes, etc. Guillaume Butter a recommandé l'extrait dissous dans un peu d'eau sucrée contre la coqueluche. On en donne un grain matin et soir, et on augmente peu à peu les doses. S'il y a constipation, on y ajoute de la magnésie. Sauvages (Nosologie méthodique) parle d'une fille qui éprouvait des accès fréquens d'épilepsie à la suite d'une frayeur; elle était pâle, bouffie, mal réglée, sujette auparavant à un vomissement habituel. Après avoir fait usage pendant deux mois de l'extrait deciguë, le flux menstruel reparut, les vomissemens cessèrent, et elle jouit ensuite d'une santé parfaite.

Quelques faits constatent l'utilité de la ciguë dans le traitement de la phthisie pulmonaire. Quarin a dissipé une phthisie qui avait succédé à des douleurs vagues, et qui était parvenue à un degré fort avancé. L'excellent ouvrage du professeur Baumes renferme une observation intéressante où l'extrait de ciguë a eu un succès complet.

Une demoiselle avait éprouvé à l'âge de dix-neuf ans un catarrhe aigu, qui avait donné de vives inquiétudes pour la poitrine. Deux ans après, il était survenu une toux sèche avec oppression après la moindre fatigue. Le lait, continué pendant plusieurs mois, avait dissipé ces symptômes; cependant les glandes du cou s'engorgèrent, et le flux menstruel devint irrégulier. Vers la fin de la vingt-cinquième année, la toux et l'oppression revinrent; on leur opposa inutilement l'usage du lait. La maigreur et la fièvre lente ne tardèrent pas à aggraver l'état de la malade. Quelque temps après, il se manifesta une affection aiguë de poitrine, qui fut bientôt suivie de mauvais crachats, et de tous les signes qui 
caractérisent une suppuration intérieure. Plusieurs remèdes, pris dans la classe des adoucissans, des fébrifuges et des balsamiques, furent sans effet. M. Baumes proposa à la malade l'extrait de ciguë, qu'elle prit pour la première fois à la dose de deux grains. On augmenta de deux grains tous les quatre jours, et on parvint jusqu'à deux gros par prise, qu'on réitérait matin et soir. Au bout de neuf mois, ce médicament opéra une guérison radicale. Les seuls auxiliaires furent le laitage et un régime végétal. (De la phthisie pulmonaire, tome 2, page 285.)

Les maladies cutanées, et particulièrement la teigne, les dartres, qui sont le plus souvent l'écueil de l'art, ont été traitées avec succès par les applications topiques et par l'usage intérieur de la ciguë. Murray cite un fait de teigne faveuse rebelle à tous les moyens connus, et qui céda à l'emploi de ce médicament. Le maladeportait jour et nuit un bonnet rempli de ciguë cuite à l'eau, et à chaque renouvellement de cataplasme, on faisait des lotions avec la décoction de la même plante mêlée avec du lait. On donnait en même temps l'extrait de ciguë, d'abord à la dose de deux grains, et progressivement jusqu'à un scrupule. Ce traitement fut continué pendant deux mois. On purgeait le malade de temps en temps, et on observait une grande propreté.

M. Lespine, médecin du prytanée militaire à La Flèche, a publié une observation semblable dans le $38^{e}$ volume du Journal général de médecine. L'extrait de ciguë fut porté depuis un grain jusqu'à cinquante ; mais on ne put dépasser cette dose, parce qu'alors le malade se plaignait de difficulté d'uriner, de vertiges, d'éblouis- 
semens. On continua ainsi pendant trois mois, en faisant en même temps usage de lotions et de cataplasmes de ciguë. Ce médecin a obtenu les mêmes succès dans plusieurs cas analogues; mais il a été quelquefois obligé, pour nettoyer entièrement la peau, d'employer, vers la fin, un mélange d'oxyde blanc de mercure et d'onguent rosat. Ainsi que Storck, il a observé que l'extrait de ciguë, donné même à petites doses, augmentait sensiblement le cours des urines, qui déposaient alors un sédiment épais et muqueux. A hautes doses, les urines devenaient mordicantes, et elles exhalaient assez souvent une odeur nauséabonde à peu près semblable à celle de l'écoulement de la tête.

On a consigné dans la Bibliothèque anéricaine les détails d'une affection invétérée de la vessie entretenue par un principe dartreux, et qui a été complètement guérie par l'extrait de ciguë, administré d'abord à la dose de quelques grains, et peu à peu à celle de trois gros. Le docteur Valentin, auteur de cette observation, ne dépassa point la dose d'un gros tant qu'il observa une grande propension au sommeil et quelques mouvemens convulsifs des lèvres; mais ensuite ill'augmenta graduellement jusqu'à trois gros par jour. Le malade, affecté depuis trois ans d'une strangurie douloureuse, pour laquelle il avait employé une multitude de remèdes, commença à éprouver une amélioration sensible. On diminua cependant les doses de la ciguë, à cause d'une salivation abondante qui était survenue, pour revenir ensuite peu à peu à la même quantité. Dès ce moment, le malade put rendre un verre d'urine sans interruption et sans douleur. Une dartre, qu'il 
portait à la jambe, lorsqu'il commença l'usage de ce médicament, avait entièrement disparu, et toutes les fonctions naturelles étaient rétablies. On calcula qu'on avait employé pendant l'espace d'un an près de quatre livres d'extrait de ciguë.

Les anciens plaçaient la ciguë parmi les substances froides. D'après cette hypothèse, ils l'employaient pour apaiser les irritations érotiques; ils croyaient même que son usage prolongé cansait l'impuissance virile. Mais, quand il n'existerait pas des faits contraires, il serait toujours dangereux d'avoir recours à un pareil remède, surtout si on le prenait à hautes doses. Duval raconte que l'aspect d'une jeune beauté avait allumé dans son cœur un anour violent et subit. Fatigué par les combats réitérés que lui livrait la plus fougueuse des passions, il lut un jour dans saint Jérôme que la ciguë était un antidote assuré contre elle. Charmé de cette précieuse découverte, il se fait apporter sur-le-champ une bonne quantité de cette herbe, et la mange en salade; cette imprudence pensa lui coûter la vie; il fut dangereusement malade, et il ressentit long-temps après les funestes effets du poison. (OEuures de Valentin Jamerai Duval, tome ı, page :5.)

Les effets de la ciguë varient singulièrement suivant le sol où elle a été recueillie, et surtout suivant le mode de sa préparation. Colebrook se plaint de ce quel'extrait est presque inerte en Angleterre, en sorte qu'il faut le remplacer par l'herbe elle-même fraîchement cueillie. D'après la remarque de Morris, l'extrait fourni par la ciguë de Portugal renferme plus de principe extractif résineux, et a plus d'efficacité que celui qu'on 
prépareà Vienne. Fothergill recommande de cueillir la plante lorsque les fleurs commencent à tomber et que les fruits se montrent. La meilleure est celle qui croît dans les vallées, sur un sol humide, exposé aux rayons du soleil. On peut l'administrer de plusieurs manières. Quelques médecins préfèrent le suc exprimé de l'herbe fraîche, depuis la dose de dix gouttes jusqu'à celle de soixante, et plus. Bergius dit en avoir donné jusquu'à une once chaque jour sans inconvénient. On lit aussi dans les Mélanges des curieux de la nature qu'un homme de lettres en prenait tous les matins trois onces pour dissiper des rougeurs qu'il avait au visage, sans éprouver d'autre accident qu'un peu de faiblesse. Mais, d'après les faits que nous avons recueillis, pourrait-on donner impunément d'aussi fortes doses de suc de ciguë dans tous les pays et à toutes les époques de l'année (I)?

(1) Lorsque j'écrivais ces lignes, je ne connaissais point le Formulaire médical du docteur Sainte-Marie, et je vois avec plaisir que ce praticien distingué partage mes craintes. La grande ciguë abonde dans les prairies des environs de Lyon, où sa végé-l tation est à peine suspendue pendant deux mois de l'hiver. Mais son suc est bien autrement actif en juin et en juillet, époque de sa plus parfaite maturité, que dans les mois de mars et d'octobre; et telle dose qui pourrait être donnée impunément en hiver produirait au millieu de l'été un dangereux narcotisme. M. SainteMarie préfère le suc de la plante à son extrait, et aux diverses préparations usitées dans les officines. Il l'administre principalement dans les affections strumeuses, d'abord à la dose d'une cuillerée à café, et peu à peu à celle d'une cuillerée à bouche, dans un véhicule approprié. Il est rare que l'on puisse dépasser cette dose, si le suc n'est ni filtré ni clarifié, c'est-à-dire si l'art du pharmacien ne lui a enlevé aucun de ses principes. (SaintrMARIs, Nouveau Formulaire médical.) 
D'autres prescrivent la poudre à la dose de dix ou douze grains, et ensuite à des doses plus élevées. La prudence exige qu'on débute toujours par une trèsfaible quantité, et qu'on ne l'augmente qu'à mesure que le malade se familiarise avec ce remède. Si la poudre est récente et préparée avec soin, une dose moyenne suffit pour exciter des symptômes graves. Cullen parle d'une femme affectée d'un cancer au sein, qui prenait de la poudre de ciguë, et qui était parvenue par gradation à la dose d'un gros, sans éprouver le moindre effet. Elle fit usage d'une nouvelle poudre, et débuta par vingt grains seulement; mais cette dose faillit la tuer. Au bout de quinze minutes, elle fut prise de tremblemens, de vertiges, de délire, de convulsions. Lorsque les médicamens fournis par la ciguë ne produisent it une certaine dose aucun effet sensible, il est probable qu'ils ont été mal préparés; il faut alors les changer, en commençant toujours par de faibles doses.

L'extrait de ciguë, qui est la préparation la plus employée, offre une différence étonnante dans sa qualité et dans son action. Je suis porté à croire qu'on le prépare fort mal, du moins dans certains pays, puisque le docteur Valentin, qui a beaucoup voyagé, assure en avoir souvent pris d'emblée deux ou trois gros, sans en ressentir le plus léger effet. Il faut peu compter sur les extraits qu'on prépare avec la décoction de la plante sèche.

Ainsi que nous l'avons déjà observé, on confond assez souvent la ciguë avec d'autres ombellifères, parce que les plantes de cette famille ont entre elles beaucoup de ressemblance. Cette méprise est f́réquente แ1. 
avec le cerfeuil sauvage, surtout avec le cerfeuil bulbeux dont la tige est tachée comme celle du conium maculé. Ce qui les distingue, c'est que l'ombelle de ces plantes n'a point de collerette, tandis que celle du conium en est pourvue. D'ailleurs, les fruits n'ont pas la même configuration; globuleux et relevés de côtes tuberculeuses dans la ciguë, ils sont liśses et allongés dans le cerfeuil. Cela pourrait expliquer les plaintes des médecins relativement à l'extrait de ciguë. Il est certain que cet extrait est souvent inerte, soit qu'il ait été mal préparé, soit qu'on ait employé pour sa préparation quelque autre ombellifère.

Extrait de ciguë de Storck. On choisit en juin, un peu avant la floraison, une suffisante quantité de belle ciguë, et on la pile dans un mortier de marbre ou de bois, avec quelques gouttes d'ean. On exprime à la presse son suc, que l'on passe dans un linge. Par une évaporation modérée sur le bain-marie, la fécule verte se coagule; on la passe, et on continue de faire concentrer le suc, en remuant fréquemment avec une spatule, pour qu'il ne brûle pas au fond de la bassine. Vers la fin, on retire l'extrait du feu, et l'on y incorpore la fécule verte restée sur l'étamine. Storck recommande d'y mêler une quantité suffisante de poudre de ciguë pour en former une masse propre à être divisée en pilules. Cet extrait est fétide et d'un vert noir. On le donne à la dose de trois ou quatre grains, et on augmente progressivement, suivant les effets qu'il produit. Dans les affections cancéreuses, il faut l'employer avec persévérance, et à fortes doses, pour obtenir du succès. Assez souvent les pupilles se dilatent, 
le malade éprouve des démangeaisons sur les paupières, de la raideur dans les mouvemens, quelquefois des vertiges; mais ces symptômes cessent bientôt en lavant le visage avec de l'eau fraîche, et en buvant de la limonade ou de l'oxycrat. Lorsque les douleurs sont atroces, il est utile de combiner la ciguë avec l'opium. Ce mélange produit quelquefois des effets sédatifs qu'on n'obtient point des deux substances administrées isolément.

On emploie l'extrait de ciguë dans la syphilis invétérée, accompagnée de douleurs ostéocopes, d'exostoses, etc.; dans les obstructions abdoninales, dans les engorgemens de la rate, à la suite des fièvres quartes. On augmente son action en l'unissant au calomel, au kermès minéral, au soufre doré d'antimoine, au tartre stibié. Ces combinaisons deviennent quelquefois très-elficaces dans les affections scrophuleuses, les maladies de la peau, les dartres rebelles.

Pilules de ciguë contre les dartres. Prenez, extrait de ciguë, deux gros; oxyde d'antimoine sulfuré orangé, depuis douze jusqu'à trente grains. Faites des pilules de quatre grains chacune. Lorsqu'on allie le tartrate antimonié de potasse à l'extrait de ciguë, la dose est d'un ou deux grains par gros d'extrait.

Pilules de ciguë contre la jaunisse chronique. Prenez, extrait de ciguë, demi-once; aloës, deux gros. Mêlez exactement, et faites des pilules de quatre grains chacune. On en prend une le matin, une à midi et une autre le soir, en buvant après chaque pilule une tasse de décoction de chiendent ou de saponaire bien miellée. 
Pilules de ciguë de Stoll. Prenez, extrait de ciguë, demi-once; extrait d'aconit, un gros; mercure sublimé corrosif, quinze grains; sirop de cannelle, suffisante quantité pour former trois cents pilules. La dose est de quatre pilules par jour. On boit en même temps quelques tasses de tisane de douce-amère ou de salsepareille. C'est un remède hérö̈que contre les vieilles dartres, contre les affections strumeuses ou syphilitiques invétérées.

On prépare avec les feuilles fraîches de ciguë des cataplasmes, des fomentations, des bains qu'on prescrit avantageusement contre les ulcères de mauvais caractère, contre les tumeurs des articulations, l'engorgement des glandes et des testicules. Le docteur Hannin a vu guérir, en Suisse, un montagnard couvert d'ulcères vénériens, profonds et douloureux, par l'usage des topiques de ciguë.

Les bains préparés avec cinq ou six poignées de ciguë fraîche ont été vivement recommandés par le professeur Hufeland contre la maladie scrophuleuse. On y joint quelques poignées de menthe, de fleurs de camomille, et une livre de son de froment. On met le tout dans un sac de toile, et on le fait bouillir pendant quelques minutes dans une quantité d'eau suffisante, en ayant soin d'exprimer plusieurs fois le sac. On verse ensuite cette décoction dans l'eau du bain, où le malade ne reste d'abord qu'un quart d'heure. On le garantit des vapeurs de la décoction en étendant un drap sur la baignoire, et en lui faisant respirer du vinaigre. Il faut continuer l'usage de ces bains pendant quelques semaines; ce n'est qu'au bout d'un certain temps qu'ils 
opèrent. Mais alors ils ont quelquefois des effets surprenans. Ils fondent l'engorgement rebelle des glandes, dissipent les éruptions, et guérissent les ulcères, ainsi que les tumeurs douloureuses qui se forment sur les os.

\section{ANGÉLIQUE. ANGELICA.}

Calice à cinq dents peu marquées. Pétales lancéolés, courbés au sommet. Styles réfléchis. Fruit arrondi ou ovale, anguleux ; semences creusées sur la face interne d'une strie longitudinale, convexes en dehors et relevées de cinq côtes. Collerette générale à trois ou cinq folioles; collerette partielle à cinq ou huit folioles.

Qu'elle est douce la mélancolie à laquelle on s'abandonne au déclin d'un beau jour! Les coteaux qui m'entourent réfléchissent la pourpre du couchant; les fleurs de la prairie, négligemment penchẹes, confient leurs parfums aux brises du soir qui les répandent dans toute la vallée.

Que de belles plantes au bord de ce ruisseau! C'est l'angélique sauvage, déployant sur sa haute et vigourense tige une vaste ombelle ornée de fleurs d'un blanc mêlé de rose. Comme cette nuance délicate contraste harmonieusement avec la douce verdure des feuilles et des rameaux! C'est la salicaire vive, fraîche, vermeille, qui se balance et se mire dans l'onde. C'est la spirée ulmaire, reine des prés par sa taille imposante, par ses superbes corymbes de fleurs blanches et suaves.

Le palais des rois est là devant moi, silencieux, désert, s'élevant de toute sa grandeur sur la triste cité de 
Versailles; il n'y a plus que de vieux souvenirs......... Mais quelle pompe vient charmer mes regards! Le nymphaca nage tranquillement sur les eaux, porté comme en triomphe sur un tapis de verdure. Quelle richesse dans cette corolle formée d'un triple rang de pétales d'albâtre où se mêle l'or d'un nombre infini d'étamines! Quel doux parfum s'exhale de son sein ! Le soleil va bientôt quitter l'horizon; cette belle fleur ne tardera pas à se plonger et s'endormir dans l'onde. Les premières clartés du jour la ramèneront à la surface du ruisseau. O nature! ô. Providence! qui pourrait approfondir vos mystères!

ANGÉLIQUE ARCHANGÉLIQUE. ANGELICA ARCHANGELICA.

Angelica archangelica. Lins. Spec. 360. DC. FI. Fr. $345 \%$.

Fl. Dan. t. 206.

\section{(Planche 84.)}

Cette plante, dont le nom un peu fastueux annonce les qualités bienfaisantes, est généralement cultivée dans les jardins, où elle s'élève à la hauteur de trois ou quatre pieds. Sa racine est volumineuse, charnue, brune en dehors, blanche intérieurement. Sa tige est épaisse, fistuleuse, rameuse, un peu rougeâtre, garnie de feuilles très-amples, deux fois ailées, à folioles ovales, lancéolées, dentées et quelquefois lobées. Les fleurs sont d'une teinte verdâtre, disposées en ombelles épaisses et terminales. Les fruits sont cannelés et bordés d'une aile membraneuse. L'angélique est ori- 
ginaire des Alpes européennes; elle croìt dans les montagnes du midi de la France, en Italie, en Allemagne, etc.

Toutes ses parties, et principalement les racines, sont imprégnées d'huile essentielle et d'une gommerésine très-aromatique, un peu musquée. L'odeur en est pénétrante, la saveur chaude, légèrement amère. Ce précieux végétal, qui pourrait remplacer avec avantage plusieurs substances stimulantes qui nous viennent des pays étrangers, est rarement employé en France; il est depuis long-temps relégué dans l'officine du confiseur. La racine et les semences ont des propriétés médicales très-énergiques; on peut les prescrire dans toutes les affections qui réclament l'usage des aromates et des excitans, dans les dyspepsies, les flatulences, l'aménorrhée, la chlorose, etc. L'angélique est surtout un excellent remède pour les goutteux faibles, d'un âge avancé, et qui digèrent péniblement. Tissot la conseille dans les affections nerveuses où la lenteur du pouls, et en général celle des fonctions, se joint à la faiblesse de la fibre. Mais cet habile praticien observe qu'il ne faut point abuser des toniques; que, lorsqu'ils ne soulagent point, il faut changer de méthode, et ne point s'obstiner à suivre un traitement dont l'abandon est quelquefois le seul moyen de guérir le malade.

On administre utilement l'angélique mêlée avec la gentiane, ou avec quelque autre substance amère, à la suite des fièvres muqueuses et gastriques, pour dissiper la faiblesse des organes digestifs, assurer la convalescence, et prévenir les rechutes. C'est une heureuse 
pratique à laquelle il ne faut point renoncer, malgré les menaces des théoriciens modernes. Les esprits mal affermis dans leurs principes peuvent se rassurer en lisant les observations de Sydenham, de Boerhaave, de Van Swiéten, de Tissot, de Stoll, etc.

Nous ne répèterons point ici ce que nous avons dit ailleurs relativement à l'usage de la serpentaire de Virginie, de la valériane, etc., dans le traitement des fièvres de mauvais caractère, des maladies putrides et ataxiques, du typhus. La racine d'angélique partage les propriétés de ces remèdes excitans; elle convient dans les mêmes circonstances, et son emploi réclame les mêmes précautions. Avant d'y avoir recours, on explorera attentivement l'état des viscères, et il faudra s'en abstenir, s'il existe des signes d'irritation ou de phlogose:

On emploie les racines et les semences d'angélique en infusion aqueuse, ou bien on les fait digérer dans du vin, dans del'alcohol. Quelquefois on ajoute à ces compositions médicinales des excitans, des antispasmodiques, tels que la valériane, le camphre, l'éther sulfurique, l'opium, etc. Ces moyens énergiques, dont on a tant abusé dans les fièvres, dans le typhus, doivent être réservés pour la dernière période.

Infusion d'angélique composée. Prenez, racine d'angélique et de valériane, de chaque, trois gros. Faites infuser pendant une heure dans douze onces d'eau bouillante. Passez, et ajoutez à la colature, sirop d'écorce d'orange, une once. La dose est d'environ deux onces d'heure en heure dans les maladies asthéniques. 
ANGÉLIQUE SAUVAGE. ANGELICA SYLVESTRIS.

Angelica sylvestris. Linn. Spec. 361. - Imperatoria syluestris. DC. Fl. Fr. 3422.

Cette plante, d'une belle et vigoureuse végétation, s'élève à quatre ou cinq pieds sur une tige épaisse, lisse, cylindrique, rameuse, couverte d'une poussière glauque. Ses feuilles sont deux fois ailées, à folioles ovales, lancéolées, dentées en scie ; leur pétiole forme à sa base une gaîne large et ventrue. Les ombelles sont grandes, hémisphériques, composées d'ombellules de fleurs nombreuses, blanches, ou d'une couleur rosée.

On l'appelle angélique des prés. Elle est très-commune et fleurit, en juillet et août, dans les lieux humides, au bord des bois, des prairies et des ruisseaux. Sa racine estépaisse, blanchâtre, d'une saveur amère, aromatique, un peu âcre; elle contient de la gomme, de la résine et un peu d'huile essentielle. Moins agréable, moins aromatique que l'espèce précédente, cette plante possède néanmoins des propriétés toniques qui ne sont pas à dédaigner. On peut l'employer en infusion aqueuse ou vineuse pour exciter l'appareil gastrique et faciliter la digestion. Ses graines sont âcres et stimulantes comme celles de la plupart des ombellifères. L'impératoire (imperatoria ostruthium) jouit des mêmes vertus.

L'angélique pourprée (angelica atro-purpurea) est imprégnée d'un suc délétère très-énergique. D'après Puinh, c'est un poison indomptable. Cette plante croît dans l'Amérique septentrionale, particulièrement au Canada; on la cultive au Jardin du Roi. 


\section{THAPSIE. THAPSIA.}

Calice entier. Pétales lancéolés, courbés à leur sommet. Fruit oblong, comprimé, échancré aux deux extrémités, muni sur ses côtés de deux ailes membraneuses.

\section{THAPSIE VELUE. THAPSIA VILLOSA.}

Thapsia villosa. Linn. Spec. 375. DC. Fl. Fr. $352 \%$.

Lapeyr.' Hist. Plant. Pyr. 1. 163. Lam. Illustr. t. 206.

Cette plante a une racine épaisse, un peu noueuse, d'un blanc jaunâtre, d'où s'élève une tige presque simple, haute de deux à trois pieds, cylindrique, striée, glabre, chargée d'une poussière glauque. Les feuilles sont amples, pétiolées, velues, d'un vert foncé en dessus, blanchâtres en dessous, deux fois ailées, à folioles dentées, pinnatifides et cohérentes à leur base. Les fleurs sont jaunes, disposées en ombelles lâches, fort amples, composées d'une vingtaine de rayons.

On la trouve dans les lieux stériles, ombragés et montueux des provinces méridionales. Elle croît aussi surles côtes d'Afrique, où le prof́esseur Desfontaines et M. Poiret l'ont observée.

La racine est imprégnée d'un suc laiteux, amer, nauséeux, très-âcre. Lorsqu'elle est fraîche, elle purge avec une extrême violence. On l'a quelquefois employée extérieurement pour guérir les dartres; mais ce topique est dangereux, il enflamme et corrode la peau. 
THAPSIE TURBITH. THAPSIA GARGANICA.

Thapsia garganica. Linn. Mant. 57. Porr. Voyag. B BRB. 2. 138. Desf. Fl. Atlant. 2. 262. Gouan. Illustr. 18. t. 10.

Sa racine est épaisse, allongée, grisâtre, remplie d'un suc laiteux, très-caustique. Sa tige est forte, droite, légèrement striée, fistuleuse, haute d'un pied et plus; elle se divise en rameaux lîches, étalés, garnis de feuilles pétiolées, deux ou trois fois ailées, glabres, à folioles lancéolées, aiguës, d'un vert luisant en dessus, plus pâles, nerveuses et ridées en dessous; les pétioles s'élargissent à leur base en une gaîne ample et membraneuse. Les fleurs, d'un jaune pâle, forment plusieurs ombelles composées de huit à douze rayons.

Cette belle espèce, cultivée au Jardin du Roi, croît également en Afrique. On l'appelle vulgairement turbith des anciens, turbith de montagne, turbith bâtard, faux turbith. On lui a donné le nom de turbith parce que ses racines ont quelque ressemblance avec celles du turbith, espèce de liseron; mais elles sontplus âcres, plus énergiques.

La thapsie fétide (thapsia foetida), la thapsie de la Pouille (thapsia asclepium) partagent les propriétés actives des espèces congénères. La première espèce paraît être la thapsia des anciens; elle porte des feuilles presque semblables à celles de la carotte; on la trouve en Espagne et en Italie. Sa racine contient un suc fétide, très-îcre, qui enflamme les entrailles. La seconde espèce croît dans la Pouille et en Orient. Toutes ces plantes sont vénéneuses, corrosives. 


\section{FÉRULE. FERULA.}

Calice entier. Pétales oblongs, presque égaux, courbés au sommet. Fruit ovale, comprimé; semences elliptiques, à trois nervures. Collerettes à plusieurs folioles courtes et caduques.

FÉRULE DE PERSE. FERULA ASSA-FOETIDA.

Ferula assa-fatida. Linn. Spec. 356. Kемpғ. Amaen. exot. 535. Cum icone.

Cette plante, figurée dans le $75^{\mathrm{e}}$ volume des Transactions philosophiques, diffère beaucoup de l'assafoxtida de Kompfer; elle est cultivée dans le jardin botanique d'Édimbourg.

Sa tige est rameuse, droite, haute d'environ deux pieds, glabre, légèrement striée. Les feuilles sont deux ou trois fois ailées, pinnatifides, à folioles incisées. Les fleurs sont d'un blanc jaunâtre, disposées en ombelles terminales de vingt à trente rayons. Toute la plante répand une odeur alliacée. Il découle des incisions pratiquées sur la racine, la tige et les rameaux, un suc laiteux, dont l'odeur et la saveur ressemblent à celles de l'assa-foetida.

La substance gommo-résineuse, connue sous le nom d'assa-foetida, provient probablement de plusieurs espèces de férules qui croissent en Perse et dans les Indes orientales. On l'obtient, suivant Kompfer, en coupant transversalement la racine de la plante. Après chaque section, il se ramasse sur la partie tronquée un suc épais, lactescent, qu'on laisse sécher à l'air et qu'on enlève ensuite avec soin. On trouve dans le com- 
merce l'assa-fœtida en larmes jaunâtres et en masses solicles, formées de divers grumeaux d'une couleur brune ou fauve, d'une odeur fétide, alliacée, d'une saveur amère un peu âcre. M. Pelletier a obtenu de cette substance une résine qui se colore en rouge à la lumière; une huile volatile, à laquelle elle doit son odeur et son âcreté; une gomme semblable à la gomme arabique; une matière analogıe à la gomme de Bassora et du malate acide de chaux.

L'assa-foetida, que sa qualité nauséabonde a fait apappeler stercus diaboli, est pour les Indiens un agréable assaisonnement et un très-bon stomachique. Les médecins ont cru trouver dans cette substance fétide un remède spécifique contre certaines affections du système nerveux, telles que l'hystérie, les spasmes, les convulsions, etc. Whitt et Tissot, qui se sont spécialement occupés des maux de nerfs, en font un grand éloge. Mais il ne faut pas oublier que ce médicament est très-actif; que les maladies nerveuses sont très-souvent accompagnées d'un état d'irritation, d'un excès de chaleur, ou d'une sensibilité vive de l'estomac; que les antispasmodiques, pris dans la classe des excitans, aggravent, tandis que l'usage des bains tièdes, des boissons tempérantes et sédatives produisent un soulagement remarquable. Lorsqu'on a combattu cet état morbide par les moyens appropriés, on peut avoir recours aux antispasmodiques, et particulicrement à l'assa-foetida, qui a une influence spéciale sur les nerf́s, et dissipe quelquefois très-promptement les palpitations, les étouffemens, les spasmes, et une foule d'autres symptômes qui dérivent d'une sensibilité dépravée. 
Dans les attaques violentes d'hystérie, avec resserrement spasmodique de la gorge et suffocation imminente, il suffit souvent d'un clystère avec l'assa-foetida pour faire disparaître ces accidens. Le docteur Wauters, qui lui a dû de nombreux succès dans les affections convulsives, dans la chorée, ou danse de Saint-Guy, l'administrait, sous la forme d'émulsion, avec le sirop de violette. Il est certain que les goinmes fétides sont de précieux médicamens dans les maladies nerveuses, quand on peut vaincre la répugnance des malades, et les leur donner à fortes doses. Égo sanè, à quo tempore assam foetidam liberaliùs ingessi, sanatos aliquoties lcetus villi morbos nervosi generis, multium diùque incassùm per exquisitissima remedia sollicitatos. (Voltelen, Pharmacologia universa.) Cet auteur distingué rapporte deux exemples très-remarquables des vertus de l'assa-foetida dans le traitement des névroses.

Une jeune fille, effrayée par l'aspect d'un incendie, poussa des cris continuels pendant un quart d'heure, et s'évanouit. Dès ce moment, elle fut sujette à des accès de vapeurs, qui commençaient par des cris aigus, et se terminaient ordinairement par une syncope, quelquefois par des ris immodérés. Elle resta pendant deux ans dans cet état fâcheux. Après une foule de moyens tentés sans succès, Voltelen eut recoursàl'assafoetida, dont il donnait chaque jour un gros et demi et plus sous la forme d'émulsion. Ce médicament diminua d'abord la fréquence des paroxysmes, et bientôt après il les fit disparaître entièrement. Un effet digne de remarque, c'est une salivation très-abondante exci- 
tée par l'assa-foetida, en sorte qu'on fut obligé d'en suspendre l'usage ou d'en diminuer les doses pendant quelques jours. Une autre demoiselle, âgée de vingttrois ans, fut prise de convulsions épileptiques à la suite d'une frayeur. Les accès, qui étaient très-violens, avaient lieu surtout pendant la nuit, et revenaient toutes les deux ou trois semaines. Un médecin habile avait inutilement essayé pendant trois ans les meilleurs remèdes. On employa l'assa-foetida, d'après le conseil de Voltelen. Le premier effet de ce médicament fut un intervalle de six semaines entre les paroxysmes. La malade en continua l'usage pendant dix mois à doses peu à peu décroissantes, et elle obtint enfin un parfait rétablissement.

Le docteur Vieusseus, de Genève, a éprouvé les bons effets de l'assa-foetida dans le croup, aecompagné de symptômes spasmodiques. Une petite fille, affectée de cette maladie, était presque guérie au troisième jour. A cette époque, tous les accidens revinrent avec la même violence. L'application des sangsues à la gorge diminua la fièvre, mais l'état du conduit aérien était le même. On administra l'assa-fortida pendant huit jours, et l'on obtint une entière guérison. L'asthme aigu de Millar, dont Wichmann a tracé le diagnostic avec une grande précision, et quil regarde comme une affection purement spasmodique, a été traité de la manière la plus heureuse par le premier avec l'assa-foetida; et par le second avec le musc, uni à cette gomme-résine. Plusieurs de nos médecins, et particalièrement M. Double et M. Giraudy, admettent également une espèce de croup d'une nature nerveuse, où les antispasmo- 
diques doivent former la base de la méthode curative. Barthez recommande également l'assa-foetida comme un moyen précieux dans l'asthme convulsif, l'angine de poitrine d'une nature goutteuse ou rhumatique.

D'autres praticiens ont signalé sa faculté vermifuge, et tout le monde connaît les pilules de Frédéric Hoffmann, préparation excellente, où cette gomme fétide est combinée avec le calomel, la myrrhe et le safran. La teinture d'assa-foetida, administrée le matin à jeun dans du vin, est délétère pour les vers lombricoïdes.

On donnel'assa-foetida en bols, en pilules, en émulsion, depuis la dose de dix grains jusqu'à celle d'un gros. La teinture alcoholique se prescrit depuis trente ou quarante gouttes jusqu'à un ou deux gros, qu'on ajoute aux potions excitantes et antispasmodiques. L'esprit ammoniacal fétide est une solution d'assafoetida dans l'ammoniaque liquide, qu'on administre par gouttes dans les affections hystériques.

Teinture antispasmodique. Prenez, assa-f’etida, un scrupule; liqueur de corne de cerf succinée (ammoniaque succinée), une once. Mêlez et opérez une parfaite solution. La dose est de dix, quinze ou vingt gouttes dans un demi-verre d'eau froide, trois fois par jour. On a guéri l'épilepsie avec ce seul remède.

Bol antispasmodique. Prenez, assa-fœetida, demigros; camphre, douze grains; musc, six grains. Préparez huit bols suivant les règles de l'art. On en prend un de deux en deux heures dans les affections nerveuses avec asthénie.

Pilules fétides sédatives de Gorter. Prenez, assafœetida, un scrupule; castoréum, six grains; extrait 
d'opium, un grain. Formez des pilules de quatre grains. La dose est d'une ou deux pilules matin et soir.

Emulsion d'assa-foetida de Wauters. Prenez, assafoetida, trois gros. Triturez avec six onces d'eau de fontaine, et ajoutez une once de sirop de fleurs de violette. On prescrit cette émulsion par cuillerées dans les maladies convulsives.

Mixture antispasmodique de Kopp. Prenez, assafoetida, un gros; mucilage de gomme arabique et sirop de guimauve, de chaque, une once. Le docteur Kopp a obtenu de très-bons effets de ce mélange dans la coquelúche. On en donne une cuillerée à café, de deux en deux heures, aux enfans de trois à quatre ans. Il faut en continuer l'usage pendant plusieurs semaines.

Nous venons de parcourir une famille féconde en plantes actives. Celles qui habitent des lieux humides, marécageux, sont âcres, et pour la plupart vénéneuses. Les ombellifères qui croissent dans des terrains secs, élevés, sont stimulantes, aromatiques, rarement nuisibles; mais elles peuvent le devenir hors de leur habitation naturelle : les eaux stagnantes, bourbeuses, détériorent leurs principes, et les rendent quelquefois délétères.

Parmi les ombellifères suspectes, nous rangerons le sélin sauvage ( selinum sylvestre) et le sélin des marais (selinum palustre), qui, d'après L'Écluse, ont quelquefois produit des convulsions, des irritations gastriques, etc. Leurs tiges, brisées, donnent un suc

II. 
laiteux amer, un peu âcre. La berce (heracleum sphondylium) infeste les prés des collines et des montagnes; elle acquiert des qualités âcres lorsqu'elle végète dans des terrains fangeux. Sa racine est fusiforme, remplie d'un suc jaunâtre; son écorce enflamme la peau. Les peuples du Nord retirent, par la fermentation des tiges dans l'eau, un alcohol qui devient pernicieux, si l'on n'a pas eu soin de les dépouiller de leur enveloppe corticale. Quelques observations prouvent que les racines du panais cultivé (pastinaca sativa) peuvent acquérir en vieillissant des qualités nuisibles; elles ont produit le délire, des vertiges, des anxiétés, etc.

SYMPTOMES ET PHéNOMÈnEs GéNéraUX. PRODUITS PAR LES OMBELLIFÈRES.

Les poisons tirés des ombellifères se distinguent, en général, par une action complexe sur l'économie animale; ils attaquent le système nerveux, et ils produisent en même temps sur les tuniques digestives une inflammation plus ou moins intense. Cependant, dans quelques cas, ils agissent à la manière des narcotiques, et l'on ne trouve après la mort aucune trace de phlogose dans toute l'étendue du conduit alimentaire. Lorsque leurs principes âcres dominent et se concentrent sur les entrailles, cette agression est marquée par des vomissemens, des angoisses, des douleurs déchirantes, une chaleur vive répandue depuis l'œesophage jusqu'aux intestins. La somnolence, les vertiges, le délire, le coma, les tremblemens, les spasmes, les convulsions, expriment l'altération spéciale du cerveau et de l'appareil nerveux. Assez souvent ces différens 
symptômes alternent, se mêlent, se confondent. II survient des hémorrhagies, un trismus invincible, la tuméfaction du ventre, le hoquet, des faiblesses, une sueur glaciale, et la mort. Tout le corps est quelquefois enflé d'une manière horrible; les paupières sont marquées de taches livides; une écume verdâtre, sanglante, coule de la bouche.

\section{MÉTHODE CURATIṼ GÉNÉRALE.}

Les indications curatives reposent entièrement sur l'état pathologique des organes qui ont ressenti les atteintes du poison. Les faits que nous avons recueillis prouvent d'une manière incontestable que le vomissement, excité dès les premiers momens, peut dissiper les symptônes les plus funestes. Il faut donc le favoriser par des boissons délayantes, par le chatouillement de la gorge ou par les émétiques. Des enfans empoisonnés par la cicutaire aquatique furent sauvés par le vomissement, tandis que ceux qu'on ne put faire vomir périrent. (Voyez les obsérvations de Wepfer, que nous avons rapportées, page 362 de ce volume.) Mais on préfèrera le tartre émétique, et on le donnera sans retard, afin de prévenir le resserrement spasmodique des mâchoires. Si l'on n'a point sous la main du tartre stibié ou de l'ipécacuanha, on pourra administrer une infusion légère de tabac à fumer ou en poudre; une pincée suffit pour une petite tasse d'eau. On provoquera ensuite les évacuations intestinales par des lavemens laxatifs, par une solution de manne, de crême de tartre, etc. Les traces d'inflammation et de gangrène qu'on a trouvées dans l'estomac ou dans les 
intestins ne doivent point faire renoncer aux vomitifs. Il y a plus : dans la plupart des empoisonnemens, ils sont la base essentielle de la méthode curative. Administrés dans la première période, ils préviennent la phlogose et les autres accidens consécutifs. Mais, à une certaine époque, il n'est plus permis d'y avoir recours : c'est lorsqu'une violente irritation, des douleurs aiguës, annoncent l'état phlegmasique des viscères. Les fomentations émollientes, les embrocations sédatives, lesbains tièdes, les lavemens, les boissons adoucissantes, l'application des sangsues sur les parties de l'abdomen les plus sensibles, les saignées générales, si la force du pouls le permet, voilà les moyens convenables, les seuls qui puissent encore sauver le malade. Lorsque le danger est dissipé, il faut surtout se tenir en garde contre les purgatifs, car rien n'est plus propre à rallumer l'inflammation gastrique, à peine éteinte. Comme les exemples instruisent mieux que les préceptes, on peut voir, page 375 , à quel danger fut réduit un malade qu'on purgea au moment où le calme commençait à renaître.

L'affection spasmodique de l'estomac, les vomissemens opiniâtres, la cardialgie, les crampes et autres accidens nerveux qui survivent à l'emploi des antiphlogistiques, doivent être combattus par l'opium. Ce médicament agit alors d'une manière spécifique, pourvu qu'on en donne des doses sulfisantes.

La méthode doit être modifiée, si le poison excite des symptômes de stupeur, d'engourdissement, de narcotisme. Ainsi on donnera, immédiatement après les vomitifs, des boissons acidulées avec le vinaigre ou avec 
le suc de citron, une infusion de café, des potions excitantes. La rougeur de la face et des conjonctives, la plénitude et la dureté du pouls, le coma, annoncent une congestion cérébrale qu'il faut combattre non par l'émétique, qui pourrait causer une véritable apoplexie, mais par la saignée, par l'application des sangsues aux tempes ou sur le trajet des jugulaires, par des pédiluves irritans. Dans les cas de trismus avec faiblesse et insensibilité, on cherchera à opérer une réaction vitale par les rubéfians, par des frictions alcoholiques, par des secousses réitérées. Ces moyens d'excitation, continués avec persévérance pendant plusieurs heures, ont quelquefois produit des effets inattendus. Pendant la convalescence, on donne quelques toniques, du vin, des bouillons restaurans; mais le régime doit être plus sévère, si le poison a particulièrement affecté les tuniques digestives. 


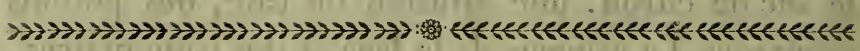

\section{RENONCULACÉES.}

\section{Ranunculacece. Juss. DC.}

\section{RENONCULE. RANUNCULUS.}

Calice à cinq folioles. Corolles à cinq pétales, munis d'une petite écaille à la base. Capsules nombreuses, comprimées, réunies en tête, terminées par une petite pointẹ.

Quel beau temps! quelle saison délicieuse! Le soleil se montre avec son globe de feu sur la hauteur des collines, chassant devant lui quelques légers nuages tout brillans d'or et d'azur. Les champs, les prés, les ruisseaux, les rochers mêmes, sont tapissés de plantes qui saluent en souriant le dieu de la lumière, et semblent tressaillir de volupté sur leurs tiges. Un réseau de fleurs enlace la terre, la rajeunit, lui donne une nouvelle vie.

Me voici sous un antique chêne dont le vaste ombrage couvre un buisson tout riant de verdure, paré de guirlandes de chèvrefeuille, dont la senteur se mêle au souffle des vents; un papillon aux ailes diaprées s'enivre de leur miel : il est immobile, on dirait qu'il sommeille. A côté de ces guirlandes si fraîches, un rustique arbrisseau ose montrer ses petits bouquets de fleurs verdâtres, taillées en étoiles : c'est l'évonyme 
d'Europe. Un nid se balance au milieu de ses légers rameaux; il porte l'oiseau du printemps et tonte sa postérité.

Dans le lointain apparaît le château de Vanvres, retraite fondée par la médecine et la philosophie. La prairie étale à mes yeux une moisson de renoncules et de trèfles : c'est comme une tapisserie semée d'or, de pourpre et d'émeraudes. Comme elles sont jolies, ces renoncules avec leurs corolles si fraîches où la rosée du matin a laissé ses perles transparentes! Ah! méfiez-vous de cette fleur hypocrite: un feu dévorant est caché au fond de sa coupe qui vous paraît si séduisante. Voyez ce pauvre agneau qui bondissait, il n'y a qu'un instant, sur la pelouse, à côté de sa mère. Comme il souffre! comme tout son corps est en convulsions! En vain elle le caresse, le réchauffe, lui présente sa mamelle pleine de nectar; il pousse à peine quelques cris plaintifs, il meurt empoisonné par des renoncules.

\section{RENONCULE SCÉLÉRATE. RANUNCULUS} SCELERATUS.

Ranunculus sceleratus. Linn. Spec. 776. DC. FI. Fr. 4639.

FI. Dan. t. 311.

\section{(Planche 85.)}

Cette espèce, dont le nom indique l'âcreté vénéneuse, a des tiges droites, épaisses, feuillées, rameuses, hautes d'un à deux pieds. Les feuilles radicales sont d'un vert jaunâtre, pétiolées, palmées, divisées en lobes arrondis;, celles de la tige ont des incisions plus. 
profondes et plus étroites. Les fleurs sont d'un jaune pâle, pédonculées, très-petites et terminales. Les ovaires se développent dès l'épanouissement de la corolle, et forment une tête oblongue, un peu conique. Les semences sont nombreuses, lisses, presque orbiculaires, un peu comprimées latéralement.

La renoncule scélérate habite les lieux humides, les marais, les étangs. On la nomme vulgairement renoncule des marais, grenouillette d'eau. Sa puissance délétère réside dans un principe âcre très-volatil. Les racines sont beaucoup moins âcres que les autres parties de la plante. Les feuilles, les fleurs, et surtout les ovaires et les jeunes graines, sont extrêmement caustiques. Si on les soumet à la plus légère mastication, on éprouve à l'instant un sentiment de feu dans toute la bouche; et si l'on répète cette expérience, la langue s'enflamme, s'excorie, se couvre d'ampoules, de fissures, accompagnées d'une douleur insupportable. Les feuilles récentes appliquées sur la peau l'enflamment, et la déchirent très-promptement.

PROPRIÉTÉS DÉLÉTÈRES.

Krapf ayant avalé immédiatement après son dîner une seule fleur contuse, éprouva bientôt des défaillances, des douleurs aiguës et des spasmes dans plusieurs parties de l'abdomen. Il se guérit en prenant quinze gouttes de baume du Pérou et trois ou quatre verres d'eau froide. Deux gouttes de suc exprimé de la plante firent naitre les mêmes symptômes, avec cette différence, qu'une douleur brûlante et convulsive se faisait sentir dans toute l'étendue de l'osophage. Le 
baume du Pérou exaspéra la douleur; mais elle s'apaisa en partie par l'eau froide. L'œsophage, légèrement excorié, fut douloureux pendant six jours.

Un chien fut empoisonné avec une demi-once du suc de la renoncule scélérate. La tunique interne de l'estomac était enflammée, corrodée sur différens points. Le pylore était enflé, extrêmement rétréci, et d'un rouge livide.

Si l'animal boit une grande quantité d'eau immédiatement après qu'on lui a fait avaler le poison, il n'en éprouve aucun effet sensible. L'alcohol, le vin, la bière et surtout le vinaigre, par leur mélange avec ce suc, en augmentent singulièrement l'âcreté, L'eau affaiblit tellement son action délétère, qu'on peut avaler impunément un demi-gros de suc mêlé avec six onces de ce liquide. Le suc, épaissi jusqu'à consistance d'extrait, devient insipide et inerte. La plante, desséchée à l'air, ne conserve aucune âcreté ; on peut la mâcher, en avaler même une forte dose sans aucun inconvénient. Deux pincées de feuilles et de fleurs récentes bouillies dans une livre d'eau pendant l'espace de deux heures, perdent toute leur énergie, en sorte qu'on peut les manger en les assaisonnant comme les plantes potagères; l'eau elle-même est dépourvue de toute espèce d'âcreté. L'infusion est au contraire très-âcre, elle brûle et corrode la langue : mais, si on la prolonge pendant cinq ou six jours, elle perd peu à peu ses principes caustiques.

D’après les expériences réitérées de Krapf, les feuilles d'oseille détruisent la causticité de l'herbe frầche ; les groseilles non mûres possèdent la même vertu, mais à un degré moins éminent. Le suc du.melisso- 
phyllum, le vinaigre, antidotes vantés par les anciens, le sucre, le miel, le sel, développent son énergie. (Caroli Krapf, Experimenta de nonnullorum ranunculorum venenatâ qualitate. Viennæ Austriæ, i 766.)

Les médecins, les naturalistes, les agronomes de tous les pays ont observé les effets délétères de cette renoncule sur les bestiaux ; elle est surtout funeste aux moutons, dont elle ronge et gangrène les intestins. Ce poison, pris intérieurement, cause la cardialgie, des angoisses, des douleurs inexprimables, des syncopes, des mouvemens convulsifs, le rire sardonique. Les meilleurs remèdes sont l'eau pure, les boissons émollientes, oléagineuses, le lait coupé, qu’il faut prendre à grandes doses.

\section{RENONCULE SARDONIQUE. RANUNCULUS SARDOUS.}

Ranunculus sardous. $\mathbf{C}_{\mathrm{R} a \mathrm{ntz}}$. Stirp. Austr. p. 84. - Ranunculus apii folio lanuginosus. C. Bачн. Pin. 180.

Cette espèce a de grands rapports avec la renoncule scélérate: elle en diffère par ses feuilles plus larges, plus divisées, hispides; par ses fleurs un peu plus grandes, et par ses épis beaucoup plus courts. Les calices sont velus, réfléchis, colorés; la corolle est d'un jaune luisant. Les semences sont petites, comprimées, terminées à leur sommet par une petite pointe droite, aiguë, qui n'existe point dans la renoncule scélérate. Au reste, soit: qu'on la considère comme une espèce distincte, ou comme une simple variété, elle n'est pas 
moins corrosive. On la trouve au bord des étangs, dans les marais, en Autriche, dans l'île de Sardaigne, et dans nos provinces méridionales.

Est-ce la plante que les anciens appelaient herbe de Sardaigne, herba Sardoa, laquelle produisait une sorte de mouvement convulsif des lèvres (rire sardonique)? Virgile fait mention de cette plante vénéneuse dans sa septième églogue :

\section{Inı̀ ego sardois videar tibi amarior herbis.}

La plupart des renoncules, surtout les deux espèces ou variétés que nous venons de décrire, causent des contractions, des mouvemens spasmodiques des muscles de la face et des lèvres, une sorte de rire forcé et convulsifqu'on a appelé rire sardonien, rire sardonique.

RENONCULE ACRE. RANUNCULUS ACRIS.

-Ranunculus acris. LinN. Spec. 779. DC. Fl. Fr. 4643. Curt. Bot. Mag. t. 215.

(Planche 86.)

Lestiges sont droites, fistuleuses, rameuses, presque nues, hautes d'un à deux pieds. Les feuilles radicales sont pétiolées, un peu velues, quèlquefois maçuléeś, palmées, anguleuses, dẹ́coupées en lobes pointus et incisés; les supérieures sont sessiles, à trois ou cinq divisions linéaires, entières. Les fleurs sont assez grandes, d'un jaune luisant, portées sur de longs pédoncules à l'extrémité des tiges et des ranieaux. Le calice est ouvert et velu. Cette plante abonde dans les 
pâturages, les prés humides. On la cultive dans les parterres sous le nom de bouton d'or.

PROPRIÉTÉS DÉLÉTÈRES.

Elle s'adoucit par la culture, mais, dans son lieu natal, elle est presque aussi dangereuse que l'espèce précédente. Toutes ses parties, et particulièrement les fruits, sont très-caustiques. Les racines, les feuilles et les tiges produisent sur la peau une douleur brûlante, suivie de gonflement, d'inflammation et de phlyctènes. On les employait anciennement à la place des cantharides, après les avoir réduites en une espèce de pulpe, contre les maladies goutteuses invétérées, la névralgie sciatique, les vieux rhumatismes, les céphalalgies opiniâtres. On appliquait aussi ce topique sur le carpe, pour supprimer les accès des fièvres intermittentes : la chaleur qui s'ensuivait était quelquefois si intense, que le froid fébrile n'avait point lieu. Ces moyens perturbateurs bien dirigés ont eu sans doute d'heureux résultats dans plusieurs circonstances : on pourrait même substituer avec avantage aux cantharides la plupart des renoncules, lorsqu'on craint l'action irritante des épispastiques ordinaires sur les reins ; mais les charlatans ont quelquefois abusé de ces plantes d'une manière déplorable. Plusieurs faits prouvent qu'elles ont produit la fièvre, le délire, des douleurs atroces, des ulcérations profondes, et même le sphacèle. 


\section{RENONCULE BULBEUSE. RANUNCULUS} $B U L B O S U S$.

Ranunculus bulbosus. Linn. Spec. 778. DG. Fl. Fr. 4648. Fl. Dan. t. 651.

\section{(Planche 87.)}

Cette renoncule est remarquable par sa racine bulbeuse, arrondie, blanchâtre, d'où naissent des tiges plus ou moins velues, un peu rameuses, hautes d'environ un pied, et quelquefois beaucoup plus. Les feuilles inférieures sont pétiolées, divisées en trois parties, crénelées, incisées ou trilobées, d'un vert obscur. Les feuilles supérieures sont presque sessiles, à découpures plus étroites. Les fleurs sont d'un beau jaune, terminales, peu nombreuses, portées sur des pédoncules pubescens. Le calice est velu, à cinq divisions ovales, colorées, réfléchies à l'épanouissement des fleurs. Les fruits forment une petite tête globuleuse.

On trouve cette plante partout, dans les prés, le long des haies, dans les jardins; les prairies de Vanvres, de Meudon, en sont couvertes. Elle varie pour la configuration des feuilles, et surtout pour la hauteur. Dans les terrains secs, la tige est peu élevée, mais très-velue, et quelquefois un peu violette à la base.

La renoncule bulbeuse, qu'on appelle vulgairement grenouillette, pied de coq, pied de corbin, égale en causticité la renoncule scélérate. Avant la floraison, les tiges et les feuilles sont très-vénéneuses, et la bulbe beaucoup moins; mais, pendant la floraison, celle-ci 
a une âcreté remarquable, tandis que les parties herbacées perdent leur énergie.

Les fruits se distinguent également par leur qualité caustique. Les enfans peuvent s'empoisonner avec la bulbe, qui, par sa forme arrondie, ressemble à une petite rave. Cette partie de la plante a quelquefois remplacé les cantharides pour l'usage extérieur; mais elle enflamme violemment la peau, produit des ulcérations longues et douloureuses.

RENONCULE LANGUE. RANUNCULUS LINGUA.

Ranunculus lingua. Linn. Spec. 773. DC. FI. Fr. 4657. FI. Dan. t. 755 .

\section{(Planche 88.)}

Cette espèce se distingue par ses tiges droites, cylindriques, velues, un peu rameuses, hautes de deux à trois pieds, garnies de feuilles fort longues, étroites, lancéolées, pointues, embrassantes, légèrement dentées, et munies de petits poils très-courts. Les fleurs sont grandes, terminales, d'un beau jaune; le calice est un peu velu. Les semences sont glabres, réunies en une tête ovale, presque arrondie. On trouve cette renoncule dans les lieux aquatiques, sur le bord des étangs, autour des lacs, dans les forêts où il y a beaucoup d'eau stagnante. On la désigne quelquefois sous le nom vulgaire de grande douve.

Ses propriétés caustiques résident spécialement dans les feuilles et dans les fruits. Lorsqu'elle est verte, elle est très-dangereuse pour les bestiaux, et surtout 
pour le menu bétail. Le docteur Giulo, qui a signalé les mauvaises plantes qui croissent dans les pâturages du Piémont, assure qu'elle est encore plus âcre que l'espèce suivante.

\section{RENONCULE FLAMMÉTE. RANUNCULUS}

\section{FLAMMULA.}

Ranunculus flammula. Lisn. Spec. 772 . DC. FI. Fr, 4658. Fl. Dan. t. 575 .

\section{(Planche 89.)}

Sa racine, composée de fibres menues, fasciculées, pousse une tige glabre, striée, rameuse, fléchie, quẹquefois rampante à la base, haute d'environ deux pieds. Les feuilles inférieures sont ovales, entières ou un peu dentées, et munies d'un pétiole qui embrasse la tige par une gaîne membraneuse ; les supérieures sont lạncéolées, étroites, presque sessiles. Les fleurs sont pédonculées, terminales, d'un jaune brillant. Cette es: pèce, connue sous le nom de petite douve, a plusieurs variétés plus ou moins remarquables, qu'on trouve dans les marais, dans les prairies humides; elles:sont toutes imprégnées d'un suc caustique.

La renoncule flammète, ainși qualifiée à cause de son action rubéfiante sur la peau, est une des plus vénéneuses. D'après les observations de Linné, Haller, Gmelin, Giulo, Brugmans, etc., les bestiaux qui brontent l'herbe naissante dans les pâturages où elle ahonde périssent ou éprouvent de graves accidens. Elle cause aux chevaux l'enflure, la gangrène, la pa- 
ralysie; aux moutons, l'inflammation du foie, la phthisie.

\section{RENONCULE THORA. RANUNCULUS THORA.}

Ranunculus thora. Linn. Spec. 775. DC. FI. Fr. 4654. LApeyr. Hist. Plant. Pyr. 1. 315. JacQ. Fl. Austr. t. 442.

Cette espèce a une racine composée de plusieurs petits tubercules fusiformes, réunis en faisceau. Sa tige, médiocrement élevée, grêle, droite, simple, quelquefois ramifiée, glabre, porte une ou deux feuilles sessiles, assez grandes, arrondies, réniformes, veinées, crénelées, et se termine par une, deux ou trois petites fleurs jaunes, au-dessous desquelles on trouve souvent une bractée ou une petite feuille découpée en trois ou quatre lobes. Les fruits sont un peu ovales, réunis en tête, surmontés d'une petite pointe recourbée.

Elle croît dans les Vosges, dans les Alpes, dans les Pyrénées, etc. Son suc est très-caustique; les anciens ${ }^{\circ}$ Gaulois s'en servaient pour empoisonner leurs flèches. Cueillie dans son habitation propre, elle surpasse peutêtre en virulence la renoncule scélérate. Toutes ses parties sont également corrosives. Allioni la met au nombre des plus violens poisons. Dalechamp rapporte qu'un pigeon qu'il avait légèrement blessé avec une épingle trempée dans le suc de cette renoncule, mourut en peu d'instans. 
RENONCULE DES CHAMPS. RANUNCULUS ARVENSIS.

Ranunculus arvensis. Lins. Spec. 780. DC. Fl. Fr. 4652. Fl. Dan. t. 219. - Ranunculus echinatus. Crantz. Stirp. Austr. p. 95. n. 13.

Sa tige est cylindrique, droite, rameuse, légèrement pubescente, haute d'environ un pied, garnie de feuilles glabres, pétiolées, finement découpées : les feuilles inférieures ont les découpures moins étroites, et les radicales sont simplement partagées en trois lobes oblongs et trifides. Les fleurs, assez nombreuses, et d'un jaune pâle, terminent les rameaux, et sont attachées à des pédoncules filiformes, pubescens. Les semences sont comprimées, hérissées latéralement de pointes nombreuses.

Cette plante est commune dans les champs, au milieu des moissons. La racine a beaucoup moins d'âcreté que les feuilles et les fleurs. Le suc exprimé de l'herbe récente brûle, corrode la langue, fait enfler les lèvres, excite une douleur vive et permanente dans toutes les parties de la bouche. Ce suc est mortel pour les chiens, à la dose d'une once. En ouvrant ces animaux, on trouve l'osophage enflammé, la tunique interne de l'estomac rouge, livide, corrodée sur différens points. Le docteur Giulo, qui l'a observée dans les plaines du Piémont, dit qu'elle est encore plus pernicieuse que la renoncule âcre.

Presque toutes les renoncules sont âcres et vénéneuses. Après celles que nous venons de décrire, nous II. 
devons signaler les espèces suivantes comme les plus remarquables.

Renoncule graminée. Ranunculus gramineus. Linn. Sa tige, droite, cylindrique, glabre, porte ì son sommet deux à quatre fleurs d'un jaune brillant. Ses feuilles sont linéaires, aiguës, assez semblables à celles des graminées. On la rencontre dans les pâturages secs et montagneux du midi de la France, dans les landes sablonneuses de la forêt de Fontainebleau, où elle fleurit en juin. Elle est presque aussi âcre que les espèces précédentes.

Renoncule d'Illyrie. Ranunculus Illyricus. Linn. On la distingue à sa racine, composée de tubercules allongés, fasciculés; à ses feuilles soyeuses, terminées ou divisées en trois lobes profonds, à lanières étroites, linéaires, aiguës. Les fleurs sont d'un jaune d'or, terminales, soutenues par des pédoncules pubescens. Elle croît en Allemagne et dans nos provinces méridionales. Ses propriétés se rapprochent de celles de la renoncule bulbeuse.

Renoncule des glaciers. Ranunculus glacialis. Lrns. Sa tige, peu garnie de feuilles, porte ordinairement des fleurs assez grandes, blanches ou teintes de pourpre. Les feuilles radicales sont un peu velues, très-découpées, soutenues par de longs pétioles. Elle habite les Pyrénées, les Alpes củ Dauphiné et de la Suisse. Ces deux dernières renoncules sont très-âcres. M. Vaivolet, le Nestor des botanistes de Lyon, qui a bien voulu nous en envoyer plusieurs échantillons cueillis dans les Alpes, a été témoin de leurs funestes effets. 
Renoncule à feuilles d'aconit. Ranunculus aconitifolius. Linn. Cette espèce a une tige élevée, droite, cylindrique, rameuse; des feuilles amples, palmées, à trois ou cinq lobes pointus et dentés en scie; des fleurs d'un blanc pur et fort jolies. Elle croît dans les Alpes, dans les Pyrénées et dans plusieurs de nos départemens méridionaux. On la cultive dans les jardins sous le nom de bouton d'argent. Elle est aussi âcre que la renoncule bulbeuse. Lorsqu'on la déguste, on éprouve aussitôt un sentiment de feu qui se répand dans toute la bouche, et qui est bientôt suivi d'une douleur persistante. L'herbe et les fleurs appliquées sur la peau y excitent promptement des ampoules. Cultivée dans les jardins, et même dans certaines localités, cette plante est beaucoup moins corrosive.

Renoncule aquatique. Ranunculus aquatilis. Linv. Cette renoncule a de nombreuses variétés. Ses feuilles sont tantôt divisées en lobes cunéiformes, tantôt finement découpées. Les fleurs ont une corolle blanche, ouverte, à pétales arrondis, marqués d'un onglet jaune. Les fruits sont petits, nombreux, un peu comprimés, ovoïdes et ridés à leurs deux faces. On trouve cette plante dans les lieux inondés, dans les étangs, dans les rivières; elle a plus ou moins d'acrimonie, suivant son habitation. Dans les eaux stagnantes, elle devient très-délétère; ses principes actifs résident spécialement dans les fleurs.

On cultive une infinité de renoncules, et surtont la renoncule d'Asie, qui se reproduit sous des variétés si brillantes dans les parterres. Toutes ces fleurs s'a- 
doucissent par la culture, mais elles ne sont pas entièrement dépourvues d'âcreté.

Nous avons dit que les renoncules étaient pernicieuses pour le bétail; nous devons ajouter ici que ces plantes âcres ravagent quelquefois au printemps des troupeaux entiers, et que la véritable cause de ce désastre est ordinairement ignorée des cultivateurs. Dès que la pointe des herbes commence à paraitre dans les prairies, on se hâte d'y conduire les bestiaux; et , comme les fourrages secs ont été leur principale nourriture pendant presque tout l'hiver, ils sont tellement affanés d'herbes fraîches, qu'ils dévorent indistinctement tout ce qu'ils rencontrent. Les renoncules, qui jouissent alors de toute leur force corrosive, leur causent des tranchées, des inflammations viscérales, et les tuent même assez promptement. Les remèdes les plus utiles sont alors une décoction de son, dont il faut gorger ces animaux, et des lavemens émolliens répétés.

Lorsqu'on a avalé par imprudence ou par mégarde quelqu'un de ces poisons, il faut également employer la méthode adoucissante et antiphlogistique; boire avec profusion du lait coupé, des décoctions mucilagineuses. Les ulcères profonds, opiniâtres, causés par l'application extérieure des renoncules, se guérissent par le baume du Pérou. 


\section{ANÉMONE. ANEMONE.}

Calice remplacé par un involucre caulinaire de deux ou trois folioles simples ou divisées. Corolle de cinq à neuf pétales. Capsules surmontées d'une longue queue soyeuse ou d'une simple pointe.

Anémone (Hippocr. Théophr. Plin.), dérivé d'un mot grec qui signifie vent. Cette fleur, dit Pline, ne s'épanouit que lorsque le vent souffle; c'est de là que vient son nom : Flos nunquàm se aperit nisi vento spirante, unde est nomen ejus. L'espèce suivante porte le nom de pulsatille ou herbe au vent, parce que le moindre souffle agite ses fleurs.

\section{ANÉMONE PULSATILLE. ANEMONE}

\section{PULSATILLA.}

Anemone pulsatilla. Linn. Spec. 759. DC. 4608. Fl. Dan. t. 153. Ghev. Fl. Par. 3. 944.

\section{(Planche $9^{\text {o.) }}$}

Sa racine est une espèce de souche ligneuse, noirâtre, d'où s'élève une tige cylindrique, couverte d'un duvet blanchâtre, haute de six à huit pouces, portant à son sommet une fleur violette, assez grande, munie de pétales oblongs, droits, et un peu velus en dehors. $\mathrm{Au}$-dessous de la fleur, on distingue une espèce de collerette profondément découpée en lanières velues et étroites. Les feuilles sont radicales, pétiolées, allongées, deux fois ailées, à découpures très-fines, plus 
ou moins velues. Cette plante habite les collines, les pâturages secs : on la trouve aux environs de Lyon et de Paris, en Suisse, en Allemagne, et dans la plupart des régions tempérées de l'Europe. Elle est connue sous le nom vulgaire de coquelourde.

Toutes ses parties ont une action caustique. Les feuilles, dans leur état de fraîcheur, sont délétères pour les bestiaux; elles enflamment et corrodent les membranes du tube digestif.

ANÉMONE DES PRÉS. ANEMONE PRATENSIS.

Anemone pratensis. Linn. Spec. 760. DC. Fl. Fr. 4609. Fl. Dan. t. 611 .

(Planche 91.)

Cette plante a une racine allongée et fibreuse. Les feuilles, attachées à de très-longs pétioles, sont deux fois ailées, à folioles étroites, aiguës, inégalement divisées, et d'un vert foncé. Les tiges, velues, faibles, hautes de quatre à six pouces et d'un brun verdâtre, se terminent par une fleur d'ụn violet foncé on d'un rouge-brun, penchée, un peu velue en dehors, et dont les pétales sont réfléchis au sommet. La collerette qui ceint la tige est distante de la fleur d'environ un pouce, et divisée en plusieurs lanières inégales, étroites et velues. Cette anémone croît sur les pelouses sèches, exposées au soleil. On la trouve dans plusieurs départemens de la France, en Suisse, en Allemagne, etc. 
Propriétés DÉLÉTĖres.

L'anémone des prés est aussi âcre que l'espèce précédente. Si l'on mâche l'herbe fraîche, elle enflamme toutes les parties de la bouche. Appliquée sur la pean, elle y produit un effet vésicant très-prompt. Heyer en a obtenu une substance particulière qu'il a désignée sous le nom d'anémonine. Elle s'offre sous la forme d'une poudre blanche, cristalline, insipide, volatile, inflammable, analogue au camphre. D'après Storck, l'eau distillée d'anémone dépose des cristaux blancs, d'une âcreté extrême.

\section{PROPRIÉTÉS MÉDICALES.}

Cette plante vénéneuse a été l'objet d'un grand nombre d'expériences. Storck a fait les premiers essais; parmi les observations qu'il a recueillies, il en est qui constatent d'une manière évidente son efficacité dans quelques cas de paralysie des membres et d'affections chroniques des yeux. Elle a guéri des cataractes commençantes, des maladies cutanées rebelles, de vieux ulcères, des douleurs invétérées, etc. Pendant l'usage de ce remède, les urines coulaient avec plus d'abondance; quelquefois il excitait des tranchées et une légère diarrhée, qui était ordinairement salutaire. Storck administrait l'infusion, l'eau distillée et l'extrait de la plante. L'eau distillée, donnée depuis deux gros jusqu'à une once, deux ou trois fois par jour, produisait quelquefois des nausées, des vomissemens; mais, lorsqu'on pouvait la supporter, elle se montrait salutaire contre la paralysie, les tophus vénériens, les douleurs. 
nocturnes des membres. Il prescrivait l'extrait, réduit en poudre avec du sucre, de la manière suivante : Prenez, extrait de pulsatille (anemone pratensis), quinze grains; sucre blanc, un gros; mêlez et triturez exactement. On prenait cette poudre d'abord à la dose de deux grains, deux ou trois fois par jour, et on parvenait peu à peu jusqu’à trente grains et davantage en vingt - quatre heures. On préparait l'infusion de la plante d'après le mode suivant : Prenez, herbe sèche de pulsatille incisée, un gros; faites infuser pendant un quart d'heure avec une livre d'eau bouillante dans un vase exactement fermé. Le malade prenait trois fois par jour trois ou quatre onces de cette infusion, légèrement sucrée. On élevait quelquefois la dose des feuilles jusqu’à demi-once; mais, ainsi concentrée, elle causait du malaise. Ce remède, employé intérieurement et en lotion sur les ulcères sordides, produisait quelquefois d'excellens effets. On essaya les mêmes lotions contre la teigne, mais il fallut y renoncer; elles enflammaient la peau, et causaient de violens maux de tête.

Depuis les expériences de Storck, on a essayé l'infusion et l'extrait soit de l'anémone pulsatille, soit de l'anémone des prés; mais tant s'en faut qu'on ait obtenu les mêmes succès. Plusieurs malades n'ont pu supporter l'action irritante de ces médicamens, qui leur causaient des douleurs d'entrailles, des mouvemens spasmodiques, de violentes céphalalgies. Dans d'autres circonstances, l'extrait n'a paru produire, même à fortes doses, aucun effet sensible. Storck recommande expressément de ne point employer la pre- 
mière espèce (anemone pulsatilla), dont l'action médicamenteuse n'est point la même. Suivant Gilibert, on n'employait à Lyon que l'extrait de celle-ci, qui est beaucoup plus commune, et qui a des propriétés analogues. Au reste, les expériences négatives ne suffisent point pour détruire les faits que Storck a recueillis. Avant de prononcer définitivement sur ces plantes énergiques, il faudrait se livrer à de nouveaux essais, administrer comparativement les deux espèces, et surtout n'employer que des extraits préparés avec soin.

ANÉMONE SAUVAGE. ANEMONE SYLVESTRIS.

Anemone syluestris. Linn. Spec. 761. DC. Fl. Fr. 4614.

\section{(Planche 92.)}

De sa racine allongée, fibreuse, un peu traçante, naît une tige de six à huit pouces, velue, cylindrique, entourée à sa partie supérieure par une collerette calicinale formée de trois à cinq feuilles pétiolées et découpées en plusieurs lobes profonds. Une grande fleur, composée de six pétales blancs, un peu velus en dehors, termine la tige. Les feuilles radicales sont vertes, pétiolées, à cinq digitations incisées et anguleuses. Les semences sont entourées d'un duvet laineux.

Cette anémone croît sur les collines, dans les haies, dans les bois, en Alsace, en Lorraine, en Dauphiné, en Provence; on la trouve également en Suisse, en Allemagne, en Suède, et sur les montagnes de la Si- 
bérie. Ses feuilles sont très-âcres, vésicantes; les bestiaux qui les broutent dans les pâturages éprouvent des diarrhées sanguinolentes, et tombent dans une espèce de phthisie. Bulliard rapporte que la décoction de cette plante a causé à un malade d'horribles convulsions. On lui avait fait prendre du lait et de l'huile sans aucun soulagement; il fut sauvé en buvant une forte dissolution de miel dans de l'eau, qui excita la diarrhée.

\section{ANÉMONE SYLVIE. ANEMONE NEMOROSA.}

Anemone nemorosa. Lins. Spec. 762. DC. Fl. Fr. 4616.

(Planche 93.)

Sa racine, horizontale et noirâtre, pousse une ou deux feuilles pétiolées, à trois folioles ovales, découpées, incisées. La tige est simple, grêle, munie, vers les deux tiers de sa longueur, d'une collerette de trois feuilles pétiolées, incisées, lobées, dentées, vertes, un peu velues sur les bords. La fleur qui termine la tige est légèrement inclinée, blanche, teinte de rose extérieurement, et formée de cinq ou six pétales ovoïdes, lancéolés. Ses semences sont velues, terminées par une pointe courte, sétacée. Cette anémone fleurit dès les premiers jours du printemps; elle est commune dans les bois, dans les lieux incultes et couverts.

\section{PROPRIÉTÉS DÉLÉTÈRES.}

Elle est généralement regardée comme une plante très-pernicieuse pour le bétail, qu'elle fait périr en 
lui occasionant l'hématurie, des flux dysentériques, des inflammations violentes. $L$ 'herbe fraîche, appliquée sur la peau, y développe une action vésicante très-prompte. Quelques charlatans ont la témérité de l'appliquer sur les parties atteintes de goutte ou de rhumatisme. Dans les campagnes, on l'a également employée en topique sur les poignets, pour interrompre les accès des fièvres intermittentes. Ces applications sont dangereuses; si on les maintient trop longtemps sur les membres, elles peuvent y. exciter la gangrène. Les onctions pratiquées sur la tête des teigneux avec des pommades où l'on faisait entrer la pulpe de cette plante ont été suivies de violens maux de tête, de convulsions, de syncopes alarmantes.

Anémone renoncule. Anemone ran unculoides. Elle partage les propriétés vénéneuses de l'espèce précédente : on la croit même plus délétère. Sa tige, grêle, porte à son sommet une ou deux fleurs jaunes, dont les pétales sont arrondis, et un peu velus en dehors. La collerette est composée de trois feuilles à lobes profonds, incisés ou dentés. On la rencontre dans les bois et les prés couverts. Toute la plante est très-âcre; elle cause aux bestiaux des inflammations et des hémorrhagies.

PROMENADE A SAINT-CLOUD.

Par une belle matinée, j'avais gagné le plateau de Saint-Cloud. C'était vers la mi-avril, saison d'espérance et d'amour. Une chaleur bienfaisante était répandue dans l'air, la terre souriait, l'aubépine commençait à 
fleurir, l'anémone sylvie se balançait avec grâce sur la pelouse, la violette embaumait les buissons, et la primevère inclinait çà et là sa corolle d'or encore humide des pleurs du matin.

Les coteaux qui bordent la Seine resplendissaient des feux du soleil. A travers la cime à peine colorée des arbres, on voyait le fleuve se dessiner au loin comme un lac; et ses ondes, paisibles, presque immobiles, semblaient s'éloigner à regret de la terre classique des arts.

Délivrée du joug des vanités de la terre, plongée dans une vague rêverie, mon âme goûtait ce calme, cette paix si délicieuse des bois, au milieu du frémissement des feuilles naissantes, du parfum des fleurs et de la mélodie des oiseaux.

Charmant asile, témoin muet des plus étranges métamorphoses, tu as vu passer comme un songe des consuls, des empereurs, des rois; mais au milieu de tous ces débris des grandeurs humaines, tu as du moins conservé tes ombrages. Ah! puissé-je, sous leur abri tutélaire, me livrer encore aux études que j’aime, admirer cette divine harmonie qui préside à la création, rapproche et unit par des liens naturels tous les êtres qui peuplent l'univers, et bénir l'auteur suprême de tant de merveilles! 


\section{ADONIS. ADONIS.}

Calice à cinq folioles. Corolle à cinq pétales ou plus. Capsules nombreuses, ovoïdes, surmontées d'une petite pointe recourbée.

Nom poétique donné par Linné à ce genre de plantes. Une espèce (adonis annua) se fait remarquer au milieu des moissons par ses fleurs d'un rouge éclatant. C'est probablement à cette plante, et non à l'anémone des jardins, qu'on doit appliquer les vers d'Ovide touchant la métamorphose du sang d'Adonis en une fleur.

"Ayant ainsi parlé, Vénus répand du nectar sur ce sang. La liqueur céleste ne l'a pas plus tôt touché, qu'il s'enfle pareil à ces boules d'eau que forme la pluie en tombant sur la terre. Dans l'espace de moins d'une heure, il en sort une plante avec une couleur semblable à celle du sang, ou au grain que la grenade enferme sous son écorce. Cette fleur cependant est d'une courte durée. A peine est-elle attachée à la terre, la trop grande finesse de sa tige en fait la faiblesse, et le même vent qui la fait éclore et qui lui donne son nom, la renverse. "

............. Sic fala cruorem

Nectare odorato spargit, qui taclus ab illo

Intumuit, sicut pluvio perlucida coelo

Surgere bulla solet. Nec plená longior hora

Facta mora est, cùm flos de sanguine concolor ortus,

Qualem, quce lento celant sub cortice granum,

Punica ferre solent : brevis est tamen usus in illo:

Namque male haventem, et nimiá levilate caducum,

Excutiunt idenı, qui prcestant nomina, venti.

Metamorph., lib. x. 
ADONIS PRINTANIER. ADONIS VERNALIS.

Adonis vernalis. Linn. Spec. 771. DC. Fl. Fr. 4622.

Lapeyr. Hist. Plant. Pyr. 1. 312.

(Planche 94.)

Sa racine, épaisse, fibreuse et noirâtre, pousse une tige simple ou peu rameuse, faible, haute d'environ un pied. Les feuilles sont nombreuses, sessiles, à découpures très-menues, très-rapprochées de la tige. Les fleurs sont grandes, terminales, jaunes, composées de douze à quinze pétales, oblongs, finement striés dans leur longueur. Les capsules sont velues et disposées en une tête ovale. Une variété se distingue par ses pétales plus étroits et par les découpures un peu moins fines de son feuillage. Cette jolie plante habite les collines des provinces méridionales de la France; on la trouve aussi dans les Alpes de la Suisse, d'où elle m'a été envoyée par $\mathbf{M}$. Watt, botaniste trèsdistingué de Délémont. Je possède un échantillon des deux variétés.

On a cru pendant long-temps que cet adonis était l'hellébore noir des anciens; Schulze (Toxicologia veterum) et Vogel (Historia materia medice) lui attribuent les mêmes propriétés. Ses racines ont une odeur forte, nauséeuse, et une saveur âcre mêlée d'amertume. Lorsqu'elles sont fraîches, elles purgent violemment, et peuvent enflammer les organes gastriques à la manière des hellébores et des renoncules. Dans quelques pays, on les substitue à celles de notre hellébore à fleurs roses (helleborus niger. Linn.). 
Adonis de l'Apennin, adonis Apennina. C'est une superbe espèce qui ressemble beaucoup à l'adonis printanier; mais elle en diffère par sa tige plus élevée, par ses feuilles à découpures moins étroites, à pétioles beaucoup plus longs. Ses fleurs sont grandes, terminales, d'un beau jaune, portées par un pédicule nu et strié. Les capsules sont glabres, anguleuses, pointues, réunies en une tête ovale. Gilibert et Lapeyrouse ont cueilli cet adonis aux Pyrénées, dans la vallée d'Eynes. Tous les bestiaux évitent avec soin ces plantes âcres. Quelques amateurs les cultivent dans les jardins, à une exposition un peu humide.

Voyez, pour la culture des adonis, des anémones et des renoncules, le livre de M. Pirolle, l'Horticulteur français ou le Jardinier amateur.

\section{CLÉMATITE. CLEMATIS.}

Calice nul. Corolle à quatre ou cinq pétales. Capsules surmontées d'une longue queue plumeuse.

\section{CLÉMATITE BRULANTE. CLEMATIS VITALBA.}

Clematis vitalba. Lins. Spec. 766. DC. FI. Fr. 4590.

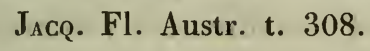

(Planche 95.)

Cette plante caustique est connue sous le nom vulgaire d'herbe aux gueux. Ses tiges, anguleuses, un peu ligneuses, grimpantes, montent jusqu'à douze ou quinze pieds lorsqu elles rencontrent un appui. Ses feuilles sont glabres, ailées, composées ordinairement 
de cinq folioles un peu en cœur, pointues, plus ou moins dentées, marquées de trois nervures; les pétioles s'accrochent à tous les corps voisins, autour desquels ils se roulent en manière de vrille. Les fleurs sont blanches, un peu odorantes, disposées en grappes latérales sur des pédoncules pubescens, plusieurs fois trifides. Les semences forment, par la réunion de leurs aigrettes, des houppes argentées d'un effet trèsagréable. Ces aigrettes durent une partie de l'année, et font donner à la plante, par les Anglais, le surnom de plaisir des voyageurs.

Cet arbuste croît dans les haies et sur la lisière des bois : on le cultive pour l'ornement des jardins.

\section{PROPRIÉTÉS DÉLÉTÈRES.}

Toutes ses parties ont une saveur brûlante et caustique. Les feuilles fraîches, ainsi que l'écorce des tiges, appliquées sur la peau, l'enflamment et l'ulcèrent. Les jeunes pousses, les feuilles naissantes, dont les sucs ne sont pas encore bien élaborés, sont beaucoup moins âcres. Dans quelques parties de l'Italie on mange même les bourgeons, cuits à l'eau ou confits dans du vinaigre. Mais lorsque la plante a acquis toute sa force, elle est certainement vénéneuse, et les bestiaux qui la mangent alors dans les pâturages éprouvent des tranchées violentes, des flux dysentériques.

Les feuilles sèches, analysées par le docteur Mueller, ont fourni une huile essentielle, flavescente, d'un goût caustique, surnageant sur l'eau à la distillation ; une huile butyracée, de l'extractif et de la résine. L'eau distillée a une saveur très-âcre. 


\section{CLEMMATITE DROITE. CLEMATIS ERECTA.}

Clematis erecta. Lisn. Spec. 767. DC. FI. Fr. 4592. J ${ }_{\Lambda C Q}$. Fl. Austr. t. 291.

\section{(Planche 96.)}

Ses tiges, droites, feuillées, verdâtres, hautes d'environ trois pieds, portent des feuilles ailées, composées de folioles ovales, pointues, entières, pétiolées, d'un vert prononcé en dessus, plus pâles et pubescentes en dessous. Les fleurs sont blanches, terminales, disposées en ombelle formée par des pédoncules droits, plusieurs fois ternés ou trifides. Les semences sont peu nombreuses. Cette plante croît en Suisse, en Hongrie, en Espagne, et dans les lieux stériles et incultes de nos provinces méridionales. On la cultive dans nos jardins, dans nos bosquets; mais actuellement elle s'est comme naturalisée dans le parc de Saint-Cloud et dans le bois de Vincennes.

Cette espèce ne le cède point en âcreté à la précédente. Si l'on mâche les fleurs et les feuilles récentes, on éprouve un instant après une chaleur brûlante à la langue, aux parois de la bouche, et jusque dans l'œsophage. Leurs principes âcres se dissipent en partie pàr la dessiccation.

\section{PROPRIÉTÉS MÉDICALES.}

Storck a soumis à de nombreuses expériences cette plante énergique. D'après les faits qu'il a consignés dans son écrit ( Libellus de flammulâ Jovis), elle a 
dissipé des affections syphilitiques opiniâtres, des nodus, des douleurs ostéocopes, des ulcères avec carie, des carcinomes, des maladies dartreuses, des gales invétérées, etc. Dans un autre de ses ouvrages il cite la guérison d'un cancer mammaire obtenue par le professeur Leber. Cette cruelle maladie, qui avait résisté à tous les autres médicamens, fut entièrement dissipée par le seul usage de la clématite droite. $\mathrm{Fer}$ dinandus Leber, chirurgice professor, cancrum exulceratum mamme, qui nec cicutâ nec aliis medicamentis mitigari poterat, solâ flammula Jovis radicitùs percuravit publicè corain suis discipulis et quibusdam medicis.

Il administrait intérieurement cette plante sous la forme d'infusion, de poudre et d'extrait. L'infusion était préparée avec deux gros de feuilles sèches pour une livre d'eau bouillante. Il augmentait la force de l'infusion, qui devait être faite dans un vase bien clos, en portant peu à peu la dose des feuilles jusqu'à demionce. Les fleurs étaient employées de la même manière. La dose de ces infusions était d'environ quatre onces, deux, trois ou quatre fois par jour. Storck préparait l'extrait avec l'herbe récente; il en donnait tous les jours depuis un grain jusqu'à trois. Il prescrivait la poudre des feuilles à la dose de deux ou trois grains triturés avec un peu de sucre, et pris dans l'espace de vingt-quatre heures. Quelquefois il angmentait peu à peu les doses jusqu'à trente grains pour trois prises. Chez quelques malades, ces médicamens excitaient le cours des urines; chez d'autres, ils provoquaient des sueurs copieuses; chez d'autres, la purgation. On sau- 
poudrait de temps en temps les ulcères avec la poudre des feuilles : cette application causait parfois une ardeur locale; mais ensuite elle réprimait les chairs baveuses, et détergeait l'ulcère, qui prenait bientôt un aspect plus favorable.

A l'exemple de Storck, le docteur Mueller a essayé la clématite brûlante dans quelques affections chroniques. Il a surtout observé ses propriétés énergiques dans un cas de syphilis extrêmement grave. Une jeune fille était affectée de cette maladie depuis deux ans; elle avait perdu la luette et une partie du voile du palais, lorsqu'elle se présenta à l'Institut clinique d'Erlang. Plusieurs préparations mercurielles n'avaient produit aucun effet. On lui administra une infusion de clématite brûlante pendant quelques semaines, et tous les symptômes se dissipèrent peu à peu. Ce même remède guérit une autre femme qui éprouvait depuis six mois de violentes attaques de céphalalgie à la suite d'un rhumatisme. Dans ces deux cas, l'infusion de clématite avait particulièrement excité les fonctions de l'appareil urinaire.

Le docteur Mueller recommande de cueillir les feuilles un peu avant l'épanouissement des fleurs, de les faire sécher à l'ombre, de les conserver dans un lieu sec, et de les renouveler tous les ans. Leurs parties volatiles se dissipent par la vétusté. (Dissertatio de clematide vitalbâ ejusque usu medico. )

Le professeur Wendt a donné avec succès l'une et l'autre clématite dans plusieurs cas de scrophules; de syphilis et de rhumatisme d'un caractère rebelle. Il les a aussi employées utilement contre les maladies 
cutanées. Les expériences de cet habile praticien sont consignées dans les Annales de l'Institut clinique d'Erlang, année 1808.

Toutes les clématites sont empreintes de principes âcres. La clématite flammule, qui exhale une odeur si douce dans nos jardins, n'en est point exempte.

Clématite flammule. Clematis flammula. On la reconnaît à ses tiges grêles, nombreuses, ràmpantes ou grimpantes; à ses feuilles ailées, composées de folioles fort petites, lancéolées : les inférieures échancrées, les supérieures entières. Les fleurs sont blanches, petites, un peu velues sur le bord des pétales. Les ovaires se terminent par un appendice bordé de soies. Cette plante croît spontanément dans les provinces méridionales. Les feuilles fraîches sont un poison pour les bestiaux.

Clématite à feuilles entières. Clematis integrifolia. Cette espèce est remarquable par ses feuilles simples et par la beauté de ses fleurs. Ses tiges sont hautes d'environ deux pieds, simples, anguleuses, striées et presque glabres. Ses feuilles sont opposées, sessiles, entières, ovales, pointues, pubescentes en leurs bords. Ses fleurs sont grandes, terminales, penchées, d'un beau bleu, bordées d'une membrane ondée et blanchâtre. Les étamines sont plumeuses ainsi que les semences; elles forment ensemble une espèce de houppe argentée. Cette clématite croît en Italie, en Autriche, en Sibérie; on la cultive comme plante d'ornement sous le nom de clématite bleue. Elle n'est pas moins délétère que les espèces précédentes. 
Tarzioni Tozzeti rapporte, dans un mémoire lu à l'académie de Florence, en ${ }_{1} 766$, que le baron de Bassoord, directeur de la pharmacie du grand-duc de Toscane, étant en Hongrie avec l'armée du prince Eugène, observa parmi les chevaux du maréchal de Palfy un flux dysentérique occasioné par la clématite bleue, qui croissait abondamment dans les prairies de la Pannonie, où ces chevaux paissaient, et où l'on recueillait le foin pour l'hiver. Ce poison caustique rongeait la tunique intérieure des intestins, et produisait cette dysenterie terrible, qu'on fit cesser en arrachant la plante qui infestait les prairies.

Ces plantes âcres recèlent sans doute des propriétés énergiques; mais elles appartiennent à la classe des poisons. C'est ce qu'il ne faudrait pas oublier, si l'on voulait renouveler les expériences de Storck, de Wendt et de Mueller. On remédie à leurs effets délétères par les antiphlogistiques, les boissons délayantes et adoucissantes. 


\section{TROLLE. TROLLIUS.}

Calice formé d'environ quatorze folioles. Corolle à neuf pétales tubuleux, beaucoup plus courts que le calice. Capsules nombreuses, presque cylindriques, rapprochées en tête.

\section{TROLLE D'EUROPE. TROLIIUS EUROPAEUS.}

Trollius europaeus. Linñ. Spec. 782. DC. Fl. Fr. 4661. Fl. Dan. t. 133.

\section{(Planche 97.)}

Sa racine, composée de fibres noirâtres, cylindriques, réunies en faisceau, produit une tige feuillée, ordinairement simple, haute de huit à quinze pouces, portant au sommet une seule fleur. Ses feuilles sont palmées, anguleuses, d'un vert foncé, à cinq lobes pointus, incisés et dentés; elles ont quelque ressemblance avec celles de la renoncule âcre. La fleur est grande, globuleuse, de couleur jaune ou safranée, d'une odeur assez agréable. Le calice est formé d'environ quatorze folioles ovales, glabres, veinées, réunies en boule.

Cette belle plante croît sur les hautes montagnes des provinces méridionales. M. Fée m'en a communiqué un bel échantillon, qu'il a cueilli dans les pâturages du Mont-d'Or. Je l'ai observée moi-même, en 1834 , dans les hautes prairies de Barèges, au bord du chemin qui conduit à la montagne du 'Tourmalet.

Les bestiaux broutent les feuilles du trolle d'Europe, dont la racine est néanmoins empreinte d'une 
âcreté vénéneuse. Tournefort l'avait placé parmi les hellébores; il s'en rapproche par ses caractères botaniques, et surtout par l'énergie de ses racines, qu'on a souvent substituées à celles de l'hellébore noir. Le trollius asiaticus, assez semblable à l'espèce précédente, mais dont les fleurs ne sont point globuleuses, a des propriétés analogues. On cultive ces plantes sus= pectes dans quelques jardins.

\section{HELLÉBORE. HE LLEBORUS.}

Calice à cinq folioles, presque toujours persistantes. Corolle de cinq à douze pétales ou plus, beaucoup plus courts que le calice, à deux lèvres ou à trois lobes. Trois à six capsules comprimées, terminées par une pointe.

\section{HELLÉBORE ORIENTAL. HELLEBORUS ORIENTALIS.}

Helleborus orientalis. Lam. Encycl. méthod. 3. 96. Desf. Choix de plant. cum icone.

Cette plante, qu'on trouve dans les îles d'Anticyre, sur les bords du Pont-Euxin, au pied du mont Olympe, etc., est, selon Tournefort, l'hellébore noir des anciens. Sa racine est brune, tubéreuse, composée d'un grand nombre de fibres rapprochées et noirâtres. Ses feuilles sont amples, divisées jusqu'aux pétioles en plusieurs lanières ovales, lancéolées, dentées, et d'un vert foncé. La tige est cylindrique, rameuse, feuillée dans sa partie supérieure, et terminée par des fleurs d'un vert triste, un peu jaunâtre. Il leur succède quatre 
ou cinq capsules larges, courtes, mucronćes, renfermant plusieurs semences.

Ainsi que nous l'avons déjà dit en traçant l'histoire des vératres, les anciens employaient sous le nom d'hellébore dẹx plantes douées de propriétés énergiques. L'une a été rapportée au veratrum album; l'autre paraît être un véritable hellébore : c'est l'helleborus orientalis, que Tournefort a fait connaitre dans son voyage au Levant. Désigné par les anciens sous le nom d'hellébore noir, il croissait spontanément dans les îles d'Anticyre, dans la Béotie, dans l'Eubée, sur le mont Hélicon, et autres lieux circonvoisins, où on le recueillait pour l'usage de la médecine. Tournefort, qui l'a retrouvé dans ces mêmes contrées, et qui en a observé les effets, dit qu'à la dose d'un demi-gros il a produit des nausées, des douleurs d'entrailles, une impression de feu et d'âcreté dans l'œsophage et l'estomac, accompagnée de mouvemens convulsifs et d'élancemens dans la tête, qui se sont renouvelés pendant quelques jours. (Choix de plantes du Corollaire des instituts de Tournefort, par le professeur Desfontaines. Paris, 1808 .)

L'espèce suivante a des propriétés non moins actives; elle remplace dans nos pharmacies l'hellébore oriental. 


\section{HELLÉBORE NOIR. HELLEBORUS NIGER.}

Helleborus niger. Linn. Spec. 783. DC. Fl. Fr. 4664.

JACQ. Fl. Aust. t. 201.

(Planche 98.)

Sa racine est vivace, composée d'une espèce de souche d'où s'échappent plusieurs fibres noirâtres. Ses feuilles sont radicales, grandes, luisantes, d'un vert foncé, attachées à des pétioles longs de cinq ou six pouces, composées de sept à onze folioles ou digitations lancéolées, pointues, dentées en scie. Les tiges sont nues, cylindriques, hautes de six à huit pouces, terminées par une ou deux fleurs d'une belle dimension et d'un blanc teint de rose. Les pétales, ainsi que les étamines, sont deux fois plus courı̣s que les folioles du calice.

Cet hellébore croît dans les lieux ombragés des Vosges, des Alpes, des Pyrénées. Nous l'avons cueilli au pied du Canigou. On le trouve en Italie, en Autriche, et dans les provinces australes de la Russie. On le cultive dans les jardins, où ses fleurs s'épanouissent lorsque la neige couvre encore la terre, d'où lui vient le nom de rose de Noël.

\section{ANALYSE CHIMIQUE.}

La racine récente de notre hellébore noir manifeste une odeur nauséeuse, une saveur âcre qui pique vivement la langue et la frappe ensuite de stupeur. Appliquée sur la peau, elle l'enflamme et l'excorie. D'après 
les expériences chimiques de MM. Capron et Feneulle, ses propriétés actives résident dans une huile particulière, qui se dissout principalement dans l'éther. Cette huile a une odeur et une saveur qui caractérisent la racine d'hellébore, et que l'on attribue à la présence d'un acide très-volatil. M. Schabel pense que l'action délétère de l'hellébore noir est due spécialement à une matière résineuse.

\section{PROPRIÉTÉS DÉLÉTÈRES.}

Les animaux empoisonnés par cette substance végétale éprouvent des vomissemens, des vertiges, une grande faiblesse dans les extrémités postérieures, des convulsions plus ou moins violentes. Lorsqu'ils succombent, la tunique interne de l'estomac et des intestins offre ordinairement des traces évidentes de phlogose.

L'hellébore noir est également funeste aux hommes, lorsqu'il est administré sans précaution. La racine pulvérisée, son infusion aqueuse, sa teinture alcoholique, son extrait, excitent le vomissement ou purgent avec violence, produisent des vertiges, des tremblemens, des mouvemens convulsifs. D'après le témoignage de Morgagni, un demi-gros d'extrait fit périr un malade à l'hôpital de Padoue dans l'espace de huit heures. Lecanal alimentaire était enflammé dans toute sa longueur.

Cet empoisonnement exige l'emploi des boissons délayantes et mucilagineuses. On évitera avec soin toutes les substances qui pourraient augmenter l'irritation des parties déjà affectées. Le docteur Valkiers, dans une dissertation sur l'usage et le choix des vomi- 
tifs, conseille comme contre-poison l'eau d'orge tiède avec un ou deux jaunes d'œuf et un peu d'alcohol. On calmera les contractions spasmodiques, les vomissemens rebelles par de petites doses d'opium; mais, si l'on remarque des signes de stupeur et d'abattement, on aura recours aux boissons acides, à une infusion de café, aux potions excitantes.

\section{PROPRIÉTÉS MÉDICALES.}

On sait avec quels soins, avec quelle circonspection les anciens prescrivaient l'hellébore, et les fastes de l'art attestent qu'ils opéraient beaucoup de guérisons avec ce remède héroïque. Ils l'employaient particulièrement contre la folie; et nous voyons par plusieurs passages de Juvénal que le médecin Archigène était renommé pour le traitement de ce genre d'affections:

\section{..... Pauper locupletem optare podagram Nec dubilet Ladas, si non eget anticyrá nec Archigene.}

On disait proverbialement d'un homme qu'il avait besoin d'Archigène, Archigenis indiget, lorsqu'il avait perdu la raison.

Notre hellébore noir, presque aussi actif que celui des Grecs, a des propriétés analogues. Cependant la médecine moderne en fait rarement usage. Peu confiante dans une substance dont on a sans doute exagéré les vertus contre les affections mentales, elle préfère avec raison des remèdes moins violens, secondés par les secours de l'hygiène. Cependant, s'il est démontré que le tube intestinal est le foyer d'un grand nombre de maladies opiniâtres, que l'abdomen 
exerce une influence active sur l'encéphale, on ne doit pas être surpris que l'hellébore ait quelquefois dissipé la manie en excitant fortement l'appareil gastrique, et en produisant ainsi une révulsion forte et soutenue. Les évacuans des organes abdominaux sont aujourd'hui trop négligés, et l'on a tort de ne voir dans les affections mentales, dans la manie, la mélancolie, l'hypochondrie, qu'une affection essentielle et primitive du cerveau. On peut, je pense, se plaindre de ce système exclusif, sans être accusé de vouloir faire revivre l'atrabile des anciens. J'ai quelquefois administré avec un grand avantage l'extrait d'hellébore, combiné avec le calomel, pour combattre le délire fébrile, après avoir pratiqué les émissions sanguines convenables. Dans quelques circonstances, j’ai employé seulement le muriate de mercure doux. M. le docteur Miquel a fait mention, dans la Gazette de santé, d'un délire phrénétique que j’ai dissipé comme par enchantement par cette substance, donnée à la dose de trois grains toutes les heures. Les saignées, les pédiluves révulsifs, l'application de la glace sur la tête, n'avaient produit aucun effet appréciable, lorsque j'eus recours au calomel. Trente-six grains, administrés dans l'espace de quelques heures, amenèrent des évacuations abondantes; et dès ce moment le malade recouvra la raison.

C'est encore par son action stimulante et purgative que l'hellébore a produit d'heureux effets dans les fièvres intermittentes rebelles, dans l'aménorrhée, les hydropisies, les affections dartreuses, etc. Fabrice de Hilden, atteint d'une fièvre quarte, employa ce médicament avec succès. Il le prescrivait également dans sa 
pratique. Mead se servait de la teinture alcoliolique pour exciter l'écoulement des règles. Cette préparation, administrée deux fois par jour, à la dose d'une petite cuillerée dans une demi-tasse d'eau tiède, trompait rarement son attente. J'observerai néanmoins que les remèdes âcres et fortement excitans ne conviennent que lorsque la nature n'a pas assez d'énergie pour préparer et soutenir la fluxion menstruelle; encore faut-il craindre d'en abuser. Les anciens, qui employaient en pareil cas des substances d'une nature chaude, ne manquaient jamais d'en tempérer l'activité par un régime doux, des boissons émulsives et délayantes.

Bacher a recueilli une série d'observations où l'extrait d'hellébore, combiné avec la myrrhe, a déployé de puissantes vertus dans le traitement de diverses hydropisies, en excitant tantôt des évacuations séreuses, tantôt une émission abondante d'urines, des sueurs, des éruptions cutanées. Mais, pour en modifier l'action, il faut administrer en même temps quelques boissons délayantes et apéritives, telles que la limonade, le petit-lait, etc. Ce remède héroïque ne doit pas être employé trop tard, c'est-à-dire lorsque l'hydropisie a produit des altérations organiques graves; en pareil cas, le système ne saurait recevoir sans défaillir des secousses aussi violentes.

Elleborum frustrà, cùm jam cutis agra tumebit, Poscentes videas. Venienti occurrite norbo.

Pers., Sat. 3.

'Tous les hellébores sont nuisibles dans les hydropisies accompagnées d'irritation ou de pléthore sanguine. Il y a quelques années, je fus consulté par un 
homme très-robuste qui avait tout le corps enflé, l'appétit nul et la langue extrêmement sale. Je lui conseillai un vomitif, et ensuite les pilules de Bacher. Après cinq ou six jours de ce traitement, la fièvre devint très-vive; le malade était altéré, et il respirait avec une peine extrême. Je me hâtai de réparer mon erreur en changeant de méthode. Une forte saignée du bras, de la limonade nitrée pour boisson, et puis une dissolution légère de crême de tartre, dont il fit usage pendant plusieurs jours, firent disparaitre entièrement l'enflure. Ces hydropisies actives, beaucoup moins rares qu'on ne pense, s'exaspèrent par l'usage des échauffans, des drastiques, et peuvent se terminer par des inflammations mortelles. (Conférez l'article Scille, tome I, page 164.)

On donne l'hellébore noir en substance pulvérisée, et plus souvent en extrait. La dose est de dix, quinze, vingt et trente grains. Observons néanmoins que, lorsque l'extrait a été préparé avec soin, il peut, à cette dernière dose, causer aux sujets nerveux des vomissemens opiniâtres, des évacuations douloureuses, des spasmes, etc. Il faut donc prescrire ce médicament énergique avec beaucoup de réserve, et débuter par de faibles doses. On prépare avec quatre onces de racine d'hellébore, qu'on met en digestion dans une livre de vin, ou dans une égale quantité d'alcohol, des teintures actives, dont la dose est de quarante à cinquante gouttes et plus dans un véhicule approprié. Le docteur Burtin a proposé de remplacer le jalap par notre hellébore noir ; cette substitution nous paraît dangereuse, et nous ne saurions l'accueillir. 
Infusion d'hellébore contre l'hydropisie. Prenez, racine d'hellébore noir récente, une once; armoise absinthe, une poignée. Faites infuser dans deux pintes de bière ou de vin blanc. On en prend une ou deux tasses dans la journée. Cette infusion a également dissipé des fièvres intermittentes opiniâtres.

Gouttes emménagogues. Prenez, teinture alcoholique d'hellébore noir, teinture de safran, teinture de castoréum, de chaque, demi-once. Ce mélange, pris à la dose de trente ou quarante gouttes, deux ou trois fois par jour, dans une tasse d'infusion de feuilles de menthe ou de fleurs de camomille romaine, provoque puissamment le flux menstruel.

Pilules toniques de Bacher. Prenez, extrait alcoholique d'hellébore noir, extrait aqueux de myrrhe, de chaque une once; poudre de feuilles sèches de chardon bénit, trois gros; réduisez le tout en masse, et formez des pilules d'un grain. On a recours à ces pilules dans les hydropisies, où l'on a besoin d'exciter le système lymphatique d'une manière vive et permanente. On en donne depuis trois jusqu'à dix , matin et soir; c'est-à-dire qu'il faut en régler le nombre d'après le degré d'excitation qu'elles produisent, et les continuer à petites doses pendant la convalescence, afin de prévenir le retour de l'hydropisie. On les a quelquefois employées avec succès contre l'engorgement des viscères abdominaux, les fièvres quartes, les affections vermineuses, et les maladies de la peau invétérées. 


\section{HELLÉBORE VERT. HELLEBORUS VIRIDIS.}

Helleborus viridis. Linn. Spec. 784. DC. Fl. Fr. 4665.

LAPEYK. Hist. Plant. Pyr. JaCQ. Fl. Austr. 1. 106.

\section{(Planche 99.)}

Ses racines, noirâtres et fibreuses, poussent quelques tiges nues, hautes d'environ un pied, divisées, vers leur partie supérieure, en deux ou trois rameaux. Ses feuilles radicales sont glabres, partagées jusqu'au pétiole en sept ou neuf lobes étroits, lancéolés, aigus, fortement dentés en scie. Les feuilles situées à la base des rameaux sont sessiles et composées de trois à cinq lobes ou digitations. Les fleurs sont terminales, penchées, ouvertes, d'un vert jaunâtre. Les étamines sont beaucoup plus courtes que le calice.

Cet hellébore croît dans les montagnes des provinces méridionales. Nous l'avons observé aux Pyrénées à la descente du Tourmalet. Toutes ses parties sont nauséeuses et très-âcres. Le suc exprimé des feuilles et de la racine purge avec beaucoup de violence. On a souvent substitué son extrait aqueux à celui de l'hellébore noir.

HELLÉBORE FÉTIDE. HELLEBORUS FOE TIDUS.

Helleborus foetidus. Lins. Spec. 784. DC. Fl. Fr. 4662.

(Planche r oo.)

De sâ racine, composée de fibres longues, épaisses; s'échappe une tyge cylindrique, assez forte, feuillée, 
haute d'environ un pied et demi, et d'un vert blanchâtre. Les feuilles sont pétiolées, luisantes, d'un vert sombre, à digitations allongées, pointues, dentées en scie. Les fleurs sont verdâtres, bordées de pourpre, inclinées, soutenues par des pédoncules pubescens, et disposées au sommet de la tige en manière de panicule. Les folioles du calice sont arrondies, redressées, presque conniventes.

Cette plante, connue sous le nom vulgaire de piedde-griffon, se trouve en France, en Suisse, en Allemagne, en Angleterre, etc. Elle se plaît dans les lieux ombragés, pierreux, sur la lisière des bois. Nous l'avons observée aux Pyrénées, dans la vallée d'Argelès, sur le plateau du Larzac, et à la côte Saint-Pierre, non loin de Lodève; elle est très-commune au Mont-d'Or.

Son feuillage sombre, son odeur repoussante, sa saveur âcre, annoncent un véritable poison. La décoction de la racine, des feuilles et des fleurs, déploie une action purgative très-intense. Son usage immodéré a produit des anxiétés précordiales, le choléra, des inflammations gastriques, et même la mort. On a cependant conseillé cet hellébore comme un excellent vermifuge. Bisset et quelques autres praticiens ont donné la poudre et la décoction des feuilles; d'autres en ont fait préparer une teinture alcoholique. Ces médicamens doivent être administrés avec beaucoup de réserve, surtout aux enfans. J'accorderais plus de confiance à l'huile de ricin et à quelques autres anthelminthiques, dont les effets sont beaucoup moins suspects. 


\section{HELLÉBORE D'HIVER. HELLEBORUS} HYEMALIS.

Helleborus hyemalis. Lins. Spec. 783. DC. Fl. Fr. 4666.

(Planche ıог.)

Ses racines, tubéreuses, noirâtres, garnies de fibres menues, poussent, après la fonte des neiges, des pétioles longs, fermes, droits, portant des feuilles arrondies, profondément divisées en sept lobes en forme de coin, incisés au sommet. Plus tard s'élèvent des tiges simples, terminées par une collerette foliacée, découpée en huit à dix lanières, et d'où sort une fleur de couleur jaune. Le calice est composé de six folioles oblongues, obtuses et caduques. Les pétales sont tubuleux à leur base, et comme labiés au sommet.

Cette plante croît en France, en Suisse, dans les lieux humides et couverts. Ses racines, nouvellement cueillies, sont âcres et vénéneuses; d'après l'analyse de M. le professeur Vauquelin, leurs principes actifs sont dus à une huile particulière. Cette plante, que quelques botanistes ont détachée des hellébores, partage leur action énergique; son extrait aqueux purge vivement à la dose de dix à quinze grains. En général, tous ces végétaux recèlent de grandes vertus; mais ils demandent à être administrés par une main prudente, puisqu'une dose immodérée peut susciter tous les symptômes de l'empoisonnement. 


\section{DAUPHIN. DELPHINIUM.}

Calice à cinq ou six divisions colorées; la supérieure prolongée en éperon à sa base. Pétales au nombre de deux à quatre, dont un ou deux se terminent également en éperon. Une à trois capsules oblongues, renfermant plusieurs semences anguleuses.

\section{DAUPHIN STAPHISAIGRE. DELPFINIUM}

STAPHISAGRIA.

Delphinium staphisagria. Linn. Spec. 750. DC. Fl. Fr. 4678.

\section{(Planche ro2.)}

Sa tige est droite, cylindrique, peu rameuse, plus ou moins velue, haute d'un à deux pieds. Ses feuilles sont grandes, pétiolées, vertes, souvent tachées de brun, profondément découpées en cinq ou sept lobes divergens, lancéolés, pointus, entiers ou quelquefois bifurqués. Les fleurs, d'un bleu pâle ou pourpre, disposées en grappe au sommet de la tige et des rameaux, offrent une corolle à quatre pétales irréguliers. Cette plante croît dans nos départemens méridionaux; on la trouve parmi les décombres, dans les lieux un peu couverts. Les capsules contiennent des semences triangulaires, ridées, d'une couleur brunâtre, d'une saveur amère et très-âcre.

Ces graines sont vénéneuses. Quinze ou vingt grains excitent le vomissement ou purgent avec violence; une plus forte dose peut causer l'inflammation du canal alimentaire, et la mort. Ainsi que la cévadille, leur application sur des parties ulcérées a produit des 
accidens fâcheux. L'activité délétère des semences de staphisaigre réside spécialement dans un principe alcalin désigné sous le nom de delphine par MM. Lassaigne et Feneulle. Cette substance est blanche, âcre, extrêmement amère, peu soluble dans l'eau, très-soluble dans l'alcohol et l'éther.

\section{ACONIT. ACONITUM.}

Calice à cinq folioles colorées; la supérieure concave, en forme de casque. Pétales nombreux, très-petits, en forme d'écailles; les deux supérieurs (nectaires, Livn. ) allongés, cachés sous le casque, munis d'un long onglet, coudés à l'extrémité, ayant le limbe réfléchi, en forme de lèvre, et l'extrémité épaisse, obtuse, en forme de crosse. Trois à cinq capsules oblongues, droites, pointues.

\section{ACONIT NAPEL., ACONITUM NAPELLUS.}

Aconitum napellus. Lins. Spec. 751. DC. FI. Fr. 4682.

Lapeyr. Hist. Plant. Pyr. 1. 305. Chev. Fl. Par. 3. 926.

JAC. Fl. Austr. t. 381.

\section{(Planche io3.)}

De sa racine noirâtre, tubéreuse, allongée en forme de navet, s'élève une tige cylindrique, droite, simple, haute d'environ deux pieds, terminée par un long épi de fleurs solitaires sur leur pédoncule et d'un bleu violet. Les feuilles sont pétiolées, palmées, multifides, à découpures linéaires, luisantes et d'un vert sombre en dessus. Le casque des fleurs est convexe; les deux pétales cachés sous le casque ont la sommité obtuse, ten- 
dant très-légèrement à se rouler en dehors. Les fruits sont composés de trois capsules.

On trouve cette belle plante dans les pâturages, dans les lieux ombragés et humides des Vosges, des Alpes, des Pyrénées, etc.; elle croît dans le cirque de Gavarnie. Ce poison sied bien à ces lieux austères et sauvages; sa superbe attitude, son feuillage noirâtre, vernissé, d'une odeur virulente, le sombre azur de son casque, tout cela est en harmonie avec la nudité des rochers, avec la colère du torrent.

Les anciens donnaient le nom d'aconit aux poisons en général, comme on le voit dans plusieurs passages de Virgile, d'Ovide et de Juvénal.

"Quoi ! cet empoisonneur qui fit périr trois de ses oncles sera, dans sa litière, mollement assis sur le duvet, d'où le monstre laissera tomber sur moi ses regards méprisans?"

Qui dedit ergo tribus patruis aconita, vehatur Pensilibus plumis, atque illine despiciet nos?

$$
\text { Juv., sat. } \mathrm{I} \text {. }
$$

ANALYSE CHIMIQUE.

M. Brandes a découvert dans le suc du napel un alcali végétal cristallisable, qu'il a nommé aconitine.

En $183_{2}, M$. Geiger avait conclu de quelques expériences physiologiques que l'aconit renferme, outre le principe âcre et volatil, une substance narcotique toutà-fait différente ; il avait observé en effet que des feuilles d'aconitum napellus dont la saveur n'était pas du tout âcre jouissaient d'une action narcotique énergique. Les recherches de M. Hisse sont venues à l'appui de 
cette conclusion. Ce chimiste a extrait l'aconitine des feuilles sèches de l'aconit napel par le même procédé qui a servi à préparer l'atropine avec la racine de belladone.

L'aconitine est blanche, grenue, transparente, présentant l'éclat du verre, inaltérableà l'air, inodore, d'une saveur amère, puis âcre; mais cette âcreté n'est ni aussi forte, ni aussi persistante que celle de la plante. Le principe âcre est intimement uni à l'aconitine impure; mais en combinant à plusieurs reprises cet alcali avec les acides, et décomposant le sel formé, on enlève peu à peu l'âcreté. L'aconitine pure est extrêmement vénéneuse : un dixième de grain tue un moineau avec la rapidité de l'éclair. Portée sur l'œil, elle produit une dilatation momentanée de la pupille. Elle est facilement fusible, non volatile, et fournit des produits ammoniacaux à la distillation sèche. Elle est peu soluble dans l'eau, et se dissout au contraire en abondance dans l'alcohol ou l'éther. Ses solutions sont alcalines. La solution aqueuse n'est pas précipitée par l'hydrochlorate de platine. L'acide nitrique dissout l'aconitine sans la colorer. L'acide sulphurique la colore d'abord en jaune, puis en rouge amaranthe sale. Elle neutralise complètement les acides, et forme des sels qui ont paru incristallisables comme l'aconitine elle-même. (Journ. de Pharm., mars i 834.)

\section{PROPRIÉTÉS DÉLÉTÈRES.}

Toutes les parties de l'aconit napel sont âcres et vénéneuses. Lorsqu'on mâche les racines ou les feuilles dans leur état de fraîcheur, on éprouve, suivant Rein- 
hold (Dissert. de aconito napello), une sorte d'engourdissement à la langue, aux lèvres, aux gencives et au palais ; cet engourdissement est mêlé d'une chaleur brûlante, qui se fait particulièrement sentir à la base de la langue pendant plusieurs heures.

D'après les expériences tentées sur les animaux par Wepfer, Sproegel, Brodie, Orfila, le baron Larrey, la racine de l'aconit napel, le suc exprimé de la plante, ou son extrait préparé avec soin, attaquent spécialement l'appareil nerveux, produisent une irritation plus ou moins vive, quelquefois une inflammation intense des parties avec lesquelles ils sont en contact.

" Nous fîmes avaler un demi-gros d'extrait d'aconit à un chien épagneul de moyenne taille et adulte. Il s'assoupit peu de momens après, puis s'éveilla en sursaut, jeta quelques cris, grinça des dents, s'agita en tous sens, éprouva des mouvemens convulsifs, et tomba dans un assoupissement léthargique, interrompu, à des distances plus ou moins éloignées, par des soubresauts dans les membres; le lendemain matin, nous le trouvâmes mort et raide, les membres étendus, les mâchoires serrées, et le ventre ballonné. L'ouverture de cet animal nous présenta les vaisseaux du cerveau gorgés de sang noir et coagulé, les substances du cerveau colorées et d'une consistance plus ferme que dans l'état naturel; les poumons affaissés, d'un gris terne, vides d'air et de sang. Les cavités gauches du cœur étaient remplies d'un sang noir et presque concret; les cavités droites, au contraire, en contenaient fort peu. Les intestins étaient boursoufflés et d'un rouge verdâtre à l'extérieur; la membrane mu- 
queuse del'estomac était crispée, de couleur brune, et se détachait par lambeaux; la vessie était pleine d'une urine de couleur brune, et donnant une odeur fétide. " (D.-J. Larrex, Mém. de chirurg.militaire,t. 3,p. 216.)

L'aconit napel exerce sur l'homme une influence non moins funeste, et la culture modifie très-peu ses facultés délétères, comme on peut s'en convaincre par l'observation suivante.

Une dame anglaise avait invité sa nombreuse famille à diner le jour de Noël. Au moment de se mettre à table (il était trois heures), quelqu'un ayant parlé de raifort, elle envoya un de ses domestiques en chercher dans le jardin, en lui indiquant le lieu où il en trouverait. Celui-ci cueillit par méprise la racine d'aconit. Pendant le dìner, on fit quelques observations sur le goût du prétendu raifort, et un des convives s'imagina qu'on y avait mis du poivre de Cayenne. Toutefois on ne se doutait point de l'erreur jusqu'au moment où la dame de la maison se plaignit de malaise et de faiblesse dans les jambes. Bientôt après elle éprouva des maux de cœur qui furent suivis de vomissemens. A l'arrivée du médecin, la malade était très-agitée et couverte d'une sueur froide; son cœur semblait avoir cessé de battre, ainsi que son pouls; il survint ensuite de fortes convulsions. Les spasmes ayant cessé un instant, on lui administra l'émétique; mais ce remède et tous les autres secours furent vains, elle expira à six heures du soir. Son beau-frère, qui avait mangé très-peu de la même racine, fut aussi malade; mais son accident n'eut aucune suite fầcheuse. (Extrait du Courrier anglais du io janvier 1832.) 
A la même époque, un événement non moins déplorable avait lieu à Halluin, village situé sur la frontière, à deux lieues de Lille. Une femme sexagénaire, son fils, son gendre et une voisine, prirent chacun un verre à liqueur d'esprit de grain, dans lequel on avait fait macérer par erreur de la racine d'aconit napel, coupée par tranches, au lieu de la racine de livêche. Trois de ces malheureux succombèrent deux heures après. Le fils seul ne mourut point; il dut sa conservation au hasard, qui voulut que son verre ne fût pas aussi rempli que celui des autres, et aux soins qu'on lui prodigua. M. le docteur Pallas, qui rend compte de cet accident dans sa thèse inaugurale sur la classification des poisons, dit qu'ils éprouvèrent tous une sensation de brûlure dans la gorge, l'oesophage et l'abdomen, des envies de vomir, bientôt après des vomissemens et des selles accompagnés de cardialgie et de coliques violentes. Ils avaient le visage gonflé et l'abdomen fortement ballonné.

L'œesophage, l'estomac et les intestins étaient rouges et très-enflammés. Les vaisseaux sanguins du conduit digestif étaient très-apparens, surtout les veines, qui semblaient être injectées. L'inflammation était bornée au cœcum exclusivement; les gros intestins contenaient une grande quantité de gaz. Le mésentère participait aussi à l'état inflammatoire. Le péritoine renfermait une grande quantité de sérosité jaunâtre. Les poumons étaient bleuâtres, violets en arrière, peu. crépitans, et gorgés de sang. Le péricarde contenait une once environ de sérosité tirant sur le jaune. Le cœur ne présentait rien de remarquable, de même 
que les gros vaisseaux qui s'y rendent. (Extrait du rapport fait à $\mathbf{M}$. le procureur du roi par $\mathbf{M}$. Degland, docteur en médecine à Lille. )

Bien que les fleurs d'aconit ne soient point odorantes, il est dangereux de les respirer, de les manier, d'en faire des bouquets, parce qu'elles contiennent un principe gazeux qui en s'exhalant peut affecter les nerf's et provoquer des symptômes graves, comme le démontre le fait suivant.

Plusieurs jeunes filles, en allant sur la Dent de Vaulion (le point le plus élevé du Jura), cueillirent des fleurs de napel, et en firent des bouquets. Peu de temps après, elles éprouvèrent un sentiment de lassitude et d'extrême faiblesse. Elles furent obligées de s'asseoir, ne pouvant plus marcher; elles eurent des maux de cceur, des défaillances. Heureusement pour ces pauvres filles, il survint un voyageur qui, ayant reconnu la cause de leur mal, s'empressa de jeter au loin les bouquets de fleurs, et leur donna ensuite un peu de vin. (Viridet, de Morte subitâ ex nimio violarum odore.)

Au rapport de $\mathbf{M}$. le professeur Fodéré, une femme affectée d'un ulcère à la matrice éprouva des accidens fâcheux après avoir fait usage pendant plusieurs jours de l'extrait d'aconit, d'abord à la close d'un quart de grain, et graduellement à celle de deux grains et demi. Ces faibles doses suffirent pour déterminer des éblouissemens, des défaillances, le météorisme du bas-ventre, des douleurs utérines avec gonflement des glandes inguinales, et enfin une perte très-abondante. (Traité de médecine légale, tome 3 , page 46ij.) 
On trouve des faits analogues dans les Commentaires de Mathiole, dans les Transactions philosophiques, etc. Waller (de Fundamentis agriculturce chemicis) observe que l'aconit napel a moins de virulence dans le Nord que dans les pays méridionaux. Cela nous paraît assez probable; mais nous ne saurions néanmoins partager l'opinion de quelques auteurs qui prétendent qu'on le mange sans inconvénient en Pologne, en Russie, et même en Angleterre. En nous élevant contre la témérité de semblables témoignages, nous recommandons d'écarter avec soin cette plante des jardins potagers.

ACONIT CAMMARUM. ACONITUM CAMMARUM.

Aconitum cammarum. LINN. Spec. 751. JAcQ. Fl. Austr. t. 424.

(Planche 104.)

Cet aconit a beaucoup de rapport avec l'espèce précédente. Sa racine est tubéreuse, napiforme, garnie de fibres noirâtres. Sa tige, un peu rameuse à sa partie supérieure, atteint quelquefois la hauteur de quatre à cinq pieds. Les feuilles sont palmées, assez grandes, d'un vert foncé, à découpures oblongues, cunéiformes, trifides et dentées. Les fleurs sont d'un bleu un peu rougeâtre, presque disposées en panicule au sommet de la tige et des rameaux; leur casque est conique et allongé, les pédoncules portent plusieurs fleurs. L'aconit canmarum croît en Allemagne et dans plusieurs 
cantons de la Suisse. Haller observe avec raison que la figure de Storck exprime cette espèce, et non le napel.

C'est encore un dangerereux poison qu'on cultive dans quelques jardins. On l'a souvent confondu avec le napel, et l'on a attribué tantôt à l'un, tantôt à l'autre, les empoisonnemens dont les livres de médecine et d'histoire naturelle abondent. Ce qu'il y a de certain, c'est que ces deux espèces différentes sont également délétères. Il en est de même de l'aconitum nueomontanum de Koelle, espèce assez commune en Allemagne, et qui a plusieurs traits de ressemblance avec l'aconit napel.

\section{PROPRIÉTÉS MÉDICALES.}

Les observations recueillies par Storck nous ont prouvé que ces poisons, maniés prudemment, pouvaient être d'un grand secours dans quelques affections chroniques rebelles aux méthodes ordinaires. Après plusieurs essais sur ses propres organes, ce philanthrope administra avec un succès remarquable l'extrait de l'aconitum napellus, ou plutôt celui de l'aconitum cainmarum, si l'on s'en rapporte à la figure qui accompagne ses observations, à divers malades attaqués de rhumatismes chroniques, de douleurs goutteuses violentes, d'engorgemens squirrheux des glandes, etc. Qui pourrait suspecter la véracité de Storck? Il était bien moins occupé de sa gloire que du soulagement des malheureux. D'ailleurs les faits qu'il a recueillis ont eu pour témoins un grand nombre d'élèves, plusieurs médecins d'un mérite éminent, et le célèbre Van Swieten lui-même, qui applaudissait à de si nobles travaux. 
Les témoignages des médecins de Strasbourg, Guérin , Ehrmann, Ehrhart, etc., ne sont pas moins favorables à l'aconit napel, dont l'extrait a dissipé des gouttes invétérées, des nodus, des tumeurs articulaires, des névralgies sciatiques, des rhumatismes accompagnés de douleurs atroces. Ce remède augmentait ordinairement la transpiration cutanée ; quelquefois il agissait comme diurétique ou comme laxatif. (RerNноцо, Dissert. de Aconito napello.)

En effet, des observations ultérieures ont prouvé que l'aconit napel excite les fonctions des reins, provoque les sueurs, et quelquefois des irritations cutanées, des éruptions miliaires, qui contribuent à la guérison de la goutte ou du rhumatisme. Ces mouvemens critiques doivent être secondés par des boissons délayantes, apéritives, diaphorétiques, et par un régime approprié. Mais, indépendamment de ces excrétions, qui d'ailleurs n'ont pas toujours lieu, l'extrait d'aconit ne se montre pas moins salutaire dans les maladies goutteuses les plus graves; ce qui dépend peut-être d'une vertu spécifique qui lui est propre : aussi Barthez le regardait comme un antigoutteux des plus puissans. Ce professeur dit avoir vu très-souvent cette substance vénéneuse dissiper les gouttes les plus opiniâtres sans produire des sueurs ni aucune autre évacuation sensible. Storck et Van Swieten avaient déjà fait la même remarque.

Le docteur Busch (Recherches sur la nature et le traiteinent de la phthisie pulmonaire) a proposé l'extrait d'aconit comme un moyen propre à calmer l'état de spasme des vaisseaux exhalans et absorbans 
des organes de la respiration. En combattant cet état nerveux, qui se manifeste dans la première période de la phthisie pulmonaire, on parvient à arrêter les progrès de cette cruelle maladie. Ces vues thérapeutiques sont conformes à celles d'un médecin ( I) que ses vastes

(1) M. Double est peut-être un des médecins qui ont le plus manié l'aconit. Il emploie de préférence l'extrait que l'on fait venir de la Suisse. C'est plus particulièrement dans les maladies chroniques qu'il l'administre, et très-précisément pour remplir une indication générale fort commune dans cet ordre de maladies, laquelle a pour objet de calmer l'exaltation de la sensibilité, de diminuer l'irritation spéciale du système nerveux. Il remarque que cette excitation du système nervenx existe souvent dans l'économie indépendamment de l'excitation des autres systèmes, et indépendamment de l'excitation du système sanģuin surtout. Cette distinction devient capitale en médecine clinique. C'est à ce titre qu'il a donné l'aconit avec avantage à certaine époque et dans certains cas de la phthisie pulmonaire, lorsque toute la maladie consiste encore dans l'élément nerveux fixé sur l'organe de la respiration. L'aconit convient dans les cas où il y a lésion du système lymphatique, ce qui est si commun dans les phthisies. C'est aussi en vertu des mêmes données qu'il obtient de grands succès de ce moyen, opposé à quelques cas d'affection rhumatismale aiguë, mais le plus ordinairement chronique. Ici les effets sont quelquefois surprenans. Enfin il a combattu avec le même avantage un grand nombre de maladies vénériennes rebelles, et même des écoulemens gonorrhö̈qnes très-opiniâtres. Dans ces circonstances, il a quelquefois combiné l'aconit avec le sublimé, le plus souvent avec l'extrait de salsepareille, et avec l'extrait de douce-amère. Les cas où cette association lui a complètement réussi sont très-nombreux, et se répètent chaque jour dans sa pratique.

C'est le plus ordinairement sous la forme d'extrait que M. Double conseille l'aconit, et alors il le donne depuis un demi-grain, et en augmentant graduellement et lentement les doses, jusqu'à trois grains. Si les malades se plaignent de légers maux de tête, de frissons vagues, plus particulièrement ressentis au nez, à la langue et aux doigts, avec fourmillement, ou même l'engour- 
connaissances, la pureté de sa doctrine, et surtout son esprit observateur, ont placé parmi nos praticiens les plus habiles.

Les remèdes tirés des poisons, et particulièrement l'aconit, ont quelquefois vaincu des affections syphilitiques rebelles aux préparations mercurielles les plus actives. Ce médicament est spécialement indiqué par la funeste alliance de la goutte avec la vérole. Il est dangereux d'insister alors sur le mercure, qui fait dégénérer la goutte et la rend incurable, en prolongeant ses attaques. Barthez a combattu cette complication, qui avait résisté aux antivénériens et aux antigoutteux ordinaires, en donnant l'extrait d'aconit seul, ou combiné avec la tisane des bois sudorifiques, et avec les préparations d'antimoine.

On trouve parmi les faits recueillis par Storck des exemples de tumeurs squirrheuses, d'ulcérations mammaires où l'extrait d'aconit a déployé une action thérapeutique peu commune. D'autres praticiens l'ont prescrit utilement contre les engorgemens de nature

- dissement de ces parties, on doit ou suspendre l'usage de ce médicament, ou en diminuer les doses. Si le vertige devient manifeste, il faut recourir anx acides végétaux. Toutefois si, par ses bons effets, on éprouve le besoin de continuer l'aconit, il faut le donner avec assez de mesure pour éviter ces inconvéniens; car, une fois qu'ils ont eu lieu, il suffit des plus légères doses pour les faire reparaître de nouveaı. L'exaltation directe du système sanguin est une puissante contre indication de l'aconit. C'est surtout alors qu'il détermine le vertige, que l'on doit si soigneusement éviter. Lorsque M. Double n'est pas sûr de la nature et des qualités de l'extrait, il emploie l'aconit en substance et en poudre, trois ou quatre grains soir et matin, et en élevant successivement les doses jusqu'à vingt ou vingt-quatre grains. 
scrophuleuse, les obstructions abdominales, les dartres invétérées, la paralysie, l'amaurose, etc. Administré à petites doses, il a presque entièrement dissipé en peu de jours une nyctalopie qui durait depuis plusieurs mois. (Voyez le Bulletin des sciences médicales, tome 4, page 393 .)

On a également guéri des fièvres intermittentes invétérées avec l'aconit napel. Un jeune homme affecté depuis trois années d'une fièvre quarte, devenu maigre et cachectique, éprouvait dans les membres des douleurs lancinantes à chaque accès fébrile : on lui administra le napel, qui fit cesser la fièvre et les douleurs. Mais on n'est point d'accord sur les doses qu'il convient de prescrire. Bergius faisait prendre cinq grains d'extrait toutes les deux heures; Collin en a donné jusqu'à un demi-gros par jour; et d'autres médecins n'ont pas craint d'administrer la racine de la plante pulvérisée depuis un gros jusqu'à deux. Reinhold s'élève avec raison contre cette pratique téméraire, qui peut occasioner les plus graves accidens.

On administre rarement l'aconit en poudre, mais on donne son extrait et sa teinture alcoholique. On peut employer indifféremment l'aconitum napellus ou l'aconitum cammarum. L'extrait doit être préparé au bain-marie avec le suc exprimé de la plante, récoltée avant la floraison dans sa station naturelle, et non dans les jardins. La dose est d'abord d'un demi-grain ou d'un grain par jour, trituré avec du sucre; ensuite on parvient insensiblement jusqu’à huit ou dix grains. Quelques médecins l'ont prescrit à de bien plus hautes doses sans inconvénient. Nysten en a donné trente- 
deux grains en une seule prise; Stoll, jusqu’à sept scrupules dans l'espace de vingt-quatre heures. Lorsque l'extrait est récent et bien fait, il serait extrêmement dangereux de le donner à des doses aussi élevées. Mais la plupart des extraits obtenus des plantes vireuses sont inertes, soit par leur vétusté, soit par le peu de soin qu'on a mis à leur préparation, en sorte que, dans quelques officines, ils diffèrent à peine du roob de sureau brûlé ( $\mathrm{I}$ ).

La teinture alcoholique d'aconit se prépare en faisant digérer une once de feuilles récentes dans six onces d'esprit de vin. On en donne d'abord huit ou dix gouttes, et graduellement jusqu’à quarante, et plus.

Teinture d'aconit éthérée de Trommsdorff. Prenez, feuilles récentes et incisées d'aconit, deux onces;

(1) J'avais conseillé l'extrait de la pomme épineuse (datura stramonium) à une jeune dame affectée d'une névralgie de la face Elle en avait pris jusqu'à quinze et vingt grains à la fois sans aucun effet sensible. Je fis préparer par le pharmacien qui avait fourni ce médicament un nouvel extrait avec les semences de la plante. Les premières doses, qui n'étaient pourtant que de deux à trois grains, déterminèrent une chaleur âcre à la gorge, et lia malade éprouva les jours suivans un tel état de malaise, d'engourdissement et de stupeur, qu'elle fut obligée de renoncer à ce remède. Il en est de même de l'extrait de jusquiame, qu'on a quelquefois administré à des doses effrayantes, et qui néanmoins a produit dernièrement, à la dose de quelques grains, des suffocations, des vertiges et des accidens nerveux, d'après le témoignage de M. le docteur Miquel, qui l'avait prescrit à un de ses malades. Les praticiens ne doivent pas oublier ces anomalies qu'on remarque dans l'action des extraits vénéneux; elles peuvent sans doute dépendre de l'idiosyncrasie individuelle, mais elles proviennent aussi de la mauvaise préparation de ces médicamens. 
alcohol, trois onces; faites digérer pendant huit jours dans un vase hermétiquement fermé. Passez avec expression, filtrez, et ajoutez ensute une once d'éther acétique.

Solution d'extrait d'aconit stibiée de Richter. Prenez, extrait d'aconit, demi-gros; vin stibié, une once. La dose est de vingt à trente gouttes, et plus, qu'on prend matin et soir dans une tasse de tisane de salsepareille, de gayac, de sassafras, ou autre boissön appropriée.

Pilules d'extrait d'aconit de Stoll. Prenez, extrait d'aconit, oxyde d'antimoine hydro-sulfuré orangé, de chaque, un gros. Mêlez et incorporez avec suffisante quantité de sirop d'oillet pour former une masse, que vous diviserez en pilules du poids de deux grains chacune. On les emploie contre les douleurs rhumatismales, les dartres et les affections syphilitiques invétérées. La dose est de deux pilules, trois fois par jour. Immédiatement après chaque dose, on boit une tasse de décoction de bardane, de patience, de douce-amère ou de salsepareille. Cette composition provoque des sueurs grasses et fétides, et quelquefois aussi des selles. Lorsqu'elle excite le vomissement, on ne donne qu'une pilule chaque fois.

L'aconit napel tient une des premières places dans la pharmacopée homøopathique; c'est avec son extrait que la nouvelle secte prépare ses atomes médicinaux, atomes d'une action merveilleuse contre l'inflamınation aiguë du poumon. Qu'on les applique à certaines aberrations nerveuses, à quelques affections vagues, indéterminées, à la bonne heure; le temps et 
la nature peuvent venir à l'aide du malade; mais en présence d'une violente pneumonie donner un décillionième de grain d'aconit, c'est-à-dire s'en rapporter à l'énergie vitale pour dégorger le poumon, c'est le comble de l'extravagance. Sans doute le malade peut ne pas mourir, la nature a des ressources infinies; mais, lorsque cela arrive, comment osez-vous proclamer ce succès? Vous l'avez dérobé à la nature.

ACONIT TUE-LOUP. ACONITUM LYCOCTONUM.

Aconitum lycoctonum. Linn. Spec. 750. DC. Fl. Fr. 4679. JACQ. Fl. Austr. t. 380.

\section{(Planche 105.)}

Cette espèce a une tige cylindrique, feuillée, un peu rameuse, haute de deux ou trois pieds. Les feuilles sont très-larges, arrondies, pétiolées, palmées, pubescentes, à trois ou cinq lobes pointus, incisés et dentés, d'un vert sombre ou un peu noirâtre. Les fleurs sont velues, d'une couleur jaunâtre, disposées en grappes terminales. La division supérieure du calice est allongée en manière de toque ou de bonnet presque conique, obtus à son sommet, pubescent et anguleux, ou ridé; les autres sont légèrement pubescentes en dehors, et fortement barbues en dedans vers leur sommet. Les deux pétales supérieurs sont cachés dans le casque, qu'ils traversent en diagonale; leur sommité se roule en arrière en forme de spirale; le limbe du pétale est oblong, presque entier.

L'aconit tue-loup croît dans les montagnes de l'Al- 
sace, de l'Auvergne, du Dauphiné, et des provinces méridionales de la France. On le rencontre fréquemment dans les lieux couverts et montueux de la Suisse.

D’après les recherches chimiques de M. le docteur Pallas, la racine de cette espèce d'aconit a donné une matière huileuse noire; une matière verte ayant de l'analogie avec celle du quinquina; une matière ayant de l'analogie avec les alcalis végétaux; de l'albumine végétale; du muriate, du sulfate, du malate de chaux, et de l'amidon.

Cet aconit est vénéneux pour l'homme et la plupart des animaux; il fait périr les loups, les chiens, les chats, etc. Suivant Mandoza, écrivain espagnol, les chasseurs des montagnes de Grenade empoisonnent leurs flèches avec l'aconit tue-loup, qu'ils appellent yerva de baleste, herbe par excellence. Les animaux blessés avec ces flèches éprouvent un engourdissement subit, accompagné d'une prostration extrême des forces, qui se termine par la mort.

\section{ACONIT ANTHORA. ACONITUM AN'THORA.}

Aconitum anthora. Livs. Spec. 751. DC. Fl. Fr. 4681. JACQ. FI. Austr. t. 382.

(Planche 106.)

Sa racine, composée de tubercules anguleux, pousse une tige cylindrique, droite, rameuse, feuillée, pubescente, haute d'environ un pied. Les feuilles sont palmées, à cinq ou sept lobes divisés en segmens profonds, linéaires, pointus et divergens. Les fleurs sont 
jaunes, pédonculées, disposées en petites grappes au sommet de la tige et des rameaux. Le calice est jaunâtre, velu en dehors; le casque est très-convexe en dessus; les deux pétales supérieurs (nectaires, Linn.) sont allongés, suivent la courbure du casque, se terminent par une crosse roulée en dehors, et portent en dedans un limbe qui a la forme d'un cœur renversé. Les fruits sont composés de cinq capsules.

Cette plante croît dans les Pyrénées, dans les montagnes de la Provence, de la Suisse, etc. Les anciens avaient présenté sa racine comme l'antidote du ranunculus thora; mais plusieurs faits recueillis par des auteurs modernes prouvent que cet aconit est lui-même un poison.

\section{ACONIT DES PYRÉNÉES. ACONITUM PYRENAICUM.}

Aconitum Pyrenaicum. Linn. Spec. 751. Lapeyr. Fl. Pyr. t. 115. DC. Fl. Fr. 4680.

Cette espèce a beaucoup de ressemblance avec l'aconit tue-loup, mais elle est beaucoup plus grande dans toutes ses parties. Son port, sa tête penchée, l'ampleur de ses feuilles, la forme et la disposition de leurs lanières qui se recouvrent, la figure de l'éperon, suffisent pour séparer ces deux espèces. Les feuilles inférieures. sont très-amples, divisées en sept ou onze lobes principaux, découpés eux-mêmes en trois ou cinq lanières palmées, divergentes et incisées. Les fleurs sont disposées en grappe rameuse à la base. Le casque est long, comparé à la longueur des autres parties; son hord an- 
térieur se prolonge en un bec aigu et peu saillant; l'éperon du capuchon est roulé en spirale.

On trouve cet aconit dans les Pyrénées; il est aussi vénénenx que l'aconit tue-loup, auquel il ressemble.

\section{ACONIT DE NEUBOURG. ACONITUM} NEOMONTANUM.

Aconitum neomontanum. WilLd. Spec. 2. p. 1236. Koell. Aconit. 16. Lapeyr. Hist. Plant. Pyr. 1. 305. Porr. Encycl. Suppl. 1. p. 114. - Aconitum napellus. $\mathrm{J}_{\mathrm{AcQ}}$. Fl. Austr. t. 381 .

On avait confondu cette espèce avec l'aconit napel ; elle en diffère par plusieurs caractères pris surtout dans ses fleurs. Ses tiges sont fermes, droites, allongées, garnies de feuilles amples, presque palmées, à découpures élargies, lancéolées, luisantes, d'un vert foncé en dessus, plus clair en dessous. Les fleurs, d'un violet foncé, forment un long épi lâche, rameux à sa base, presque en grappe; les pédoncules sont glabres, uniflores; le capuchon est muni d'un éperon court, recourbé, obtus; la lèvre lancéolée, roulée, bifide; le casque glabre et convexe.

On trouve cette plante dans les forêts en Allemagne, dans la Carinthie, la Carniole, etc.; elle croît aussi dans les Pyrénées, au Canigou, au port de Paillères, sur la montagne d'Averan, mais surtout à Saint-Sauveur et à Gavarnie, où elle a été observée par Lapeyrouse. D'après ce botaniste, elle se reproduit, ainsi que le napel, sous une variété à fleurs blanches.

Toutes ces variétés sont délétères, ainsi que l'aconit 
paniculé de Lamarck (aconitum tauricum, WiLlo.), à feuilles palmées, à cinq divisons profondes, à lanières trifides, incisées, à fleurs bleues ou violettes, munies d'un casque convexe. Cette dernière espèce croît en Hongrie et dans quelques contrées de l'Allemagne.

Toutes les espèces, variétés ou sous-variétés d'aconit sont plus ou moins vénéneuses; nous n'exceptons pas même celles qu'on soumet à la culture. Un père de famille ne devrait jamais avoir de ces plantes dans son jardin. Nous avons vu dernièrement un pauvre petit enfant qui avait cueilli plusieurs fleurs de napel et qui allait les porter à sa bouche. D'après notre avertissement, une heure après tous les pieds d'aconit étaient arrachés.

Malgré la beauté de leurs fleurs, ces plantes ont quelque chose qui repousse la main prête à les cueillir. Leur odeur virulente et nauséabonde, leur feuillage velu, teint d'un vert lugubre, nous avertissent de les éviter. "Je ne sais, dit Bernardin de Saint-Pierre, si les embryons de leurs fruits ne présentent pas, dès les premiers instans de leur développement, des oppositions dures qui annoncent leurs caractères malfaisans : si cela est, ils ont encore cette ressemblance commune avec les petits des bêtes féroces. "

\section{MÉTHODE CURATIVE.}

Toutes les parties des aconits, leur suc, leur extrait, convenablement préparés, peuvent donner lieu à l'empoisonnement. Leur impression délétère se porte à la fois sur les tuniques digestives, sur le cerveau et sur les nerfs. Les symptômes excités par ces poisons sont: 
une chaleur brûlante dans la gorge et dans les parties intérieures de la bouche, des nausées, des vomissemens, des douleurs viscérales plus ou moins vives, des dé-. faillances, des sueurs froides, des vertiges, des mouvemens convulsifs, le trouble des facultés mentales, etc. Lorsque l'empoisonnement est récent, et que le malade n'a point vomi, il faut provoquer les contractions de l'estomac par des boissons délayantes émétisées. Si, au contraire, il y a eu des vomissemens abondans, et si l'appareil gastrique est violemment irrité, on s'en tiendra aux boissons adoucissantes, au lait coupé, aux lavemens émolliens, aux potions anodines. Les saignées générales ou locales, pratiquées avec sagesse, serviront à combattre les congestions imminentes. On opposera à la prostration des forces les toniques et les excitans.

\section{AC'CEE. $A C T A E A$.}

Calice à quatre folioles caduques. Corolle à quatre pétales. Un seul ovaire surnonté d'un stigmate sessile. Baie à une loge, renfermant plusieurs graines.

ACTÉE EN ÉPI. ACTAEA SPICATA.

Actcea spicata. Linn. Spec. 722. DC. Fl. Fr. 4686.

FI. Dan. t. 498.

(Planche 107.)

Sa racine, droite, herbacée, un peu rameuse, a un ou deux pieds d'élévation. Ses feuilles sont glabres, d'un vert un peu luisant, deux ou trois fois ai- 
lées, à folioles ovales, lancéolées, dentées en scie, et plus ou moins incisées. Les fleurs sont blanches, petites, pédonculées, disposées en épi court et ovale; les étamines sont plus longues que la corolle. Les fruits sont des baies noirâtres dans leur maturité. Cette plante croît dans les bois montagneux de presque toute la France. Ses racines, noirâtres, un peu ligneuses, sont quelquefois substituées à celles de l'hellébore noir.

L'actée en épi, qu'on appelait autrefois herbe de saint Christophe, jouit de propriétés vénéneuses trèsénergiques. Les feuilles exhalent une odeur fétide lorsqu'on les froisse entre les doigts; elles sont amères, âcres et vésicantes. La racine, récemment cueillie, purge à la manière des hellébores. Administrée à forte dose, elle peut donner lieu aux plus graves accidens. Les fruits sont narcotiques; ils ont produit le délire et la mort.

L'actée à grappes (actcea racemosa, Lisis.), qui croît dans les lieux humides du Canada, de la Floride, de la Virginie, est également délétère. Schœpf dit que les Américains se servent de la racine pour purger les chevaux. 


\section{POPULAGE. CALTHA.}

Calice nul. Pétales au nombre de cinq, ou davantage. Cinq à douze capsules comprimées, pointues, ouvertes.

POPULAGE DES MARAIS. CALTHA PALUSTRIS.

Caltha palustris. Linn. Spec. 784. DC. FI. Fr. 4684.

Fl. Dan. t. 668.

(Planche 108.)

Voici le mois d'avril. L'hirondelle revient des régions australes, portée sur les vents embaumés. Déjà le coucou fait entendre sur les collines son chant monotone ; les pelouses reverdissent près des ruisseaux, et au milieu des cressons, des menthes, des cardamines, de toutes ces herbes pleines de vie, de santé, de fraîcheur, le souci des prés vient étaler ses corolles d'or.

Cette p'ante, d'un extérieur robuste, fort commune le long des ruisseaux, dans les lieux marécageux, dans les pâturages humides, a dẹs racines blanchâtres et fibreuses, d'où s'élèvent des tiges cylindriques, creuses, un peu rougeâtres, hautes d'environ un pied. Les feuilles, attachées à de longs pétioles, sont d'un vert glacé, grandes, arrondies, réniformes, crénelées, quelquefois simplement ondulées, et presque entières. Les fleurs sont d'un beau jaune lustré, composées de cinq pétales oblongs, d'un grand nombre d'étamines , et de dix à douze ovaires, qui se convertissent en capsules polyspermes.

On la désigne sous différens noms. Celui de popu- 
lage dérive de populus, peuplier, c'est-à-dire plante qui croît aux lieux humides parmi les peupliers. Le nom de souci des prés lui vient de la couleur de sa corolle. Celui de caltha est syncopé d'un mot grec qui signifie corbeille; en effet sa fleur ressemble en quelque sorte à une corbeille d'or. On l'appelle en anglais mary-gold, or de Marie, parce qu'elle parait au printemps, vers la fête de la Vierge. On la cultive pour ses belles fleurs d'un jaune satiné; elle réclame un sol un peu humide.

On doit ranger cette plante parmi les poisons âcres. Haller, Ehrhart, Allioni, Giulo, Caels, Brugmans, assurent qu'elle est dangereuse pour les bestiaux. Toutefois Gmelin dit que les chèvres, les moutons, les bœufs la mangent sans inconvénient, ce qu'il faut peut-être attribuer à la nature du sol ou à l'âge de la plante. Lorsqu'elle sort de terre, elle n'a presque point d'âcreté; mais elle devient virulente et corrosive à mesure qu'elle approche de la floraison. Les bestiaux qui la broutent alors éprouvent des tranchées, des phlogoses viscérales. Caels observe que, dans la grande disette des fourrages, les vaches y touchent à peine, et que, si elles en mangent, elles sont attaquées d'une inflammation violente dans l'oesophage et le ventricule, qui les fait périr. (Dissertatio de plantis Belgii venenatis.)

Brugmans a éprouvé sur lui-même l'herbe naissante, à forte dose, sans en être incommodé; mais une trèsfaible quantité de la plante adulte lui a causé un si grand malaise, qu'il a craint de continuer ses expériences. (Dissertatio physico botanica.) 


\section{PIVOINE. P $A E O N I A$.}

Calice à cinq folioles persistantes. Corolle à cinq pétales, ou plus. Deux à cinq ovaires, chargés de stigmates épais. Capsules ovales, ventrues, cotonneuses, contenant plusieurs semences arrondies et luisantes.

PIVOINE OFFICINALE. PAEONIA OF FICINALIS.

Preonia officinalis. Lins. Spec. 747. DC. Fl. Fr. 4685. Lapeyr. Hist. Plant. Pyr. 1. 304. Bonpl. Malm. t. 1.

(Planche rog.)

Ses tiges sont hautes d'un à deux pieds, rameuses, striées, quelquefois un peu rougeâtres, garnies de feuilles presque deux fois ailées, divisées en folioles ou en espèces de lobes oblongs, elliptiques ou lancéolés, d'un vert gai en dessus, plus pâles en dessous. Les fleurs sont grandes, d'un rouge vif, solitaires à l'extrémité de la tige et des rameaux. Les fruits sont formés par deux ou trois capsules ovales et velues. La variété qui porte le nom de pivoine mále a des feuilles plus larges, plus épaisses, à lobes entiers et non divisés. Les capsules sont un peu courbées à leur sommet.

La pivoine officinale croît dans les bois et dans les montagnes des provinces méridionales de la France. On cultive dans les parterres plusieurs variétés à fleurs doubles.

Cette plante a des racines tuberculeuses, charnues, napiformes, recouvertes d'un épiderme rougeâtre, blanches intérieurement. Ces racines ont, dans leur 
fraîcheur, une odeur forte, nauséeuse, un peu narcotique, une saveur âcre et amère. En séchant, elles perdent leur odeur, mais elles conservent leur amertume. L'usage de la pivoine remonte à la plus haute antiquité. Suivant les poètes, elle tire son nom du médecin Pæon, qui s'en servit pour guérir Pluton blessé par Hercule.

Galien a beaucoup trop loué les vertus de cette plante, et l'on ne croit point à la guérison qu'il dit avoir opérée sur un enfant sujet à des mouvemens convulsifs, en lui faisant porter un collier de racines de pivoine. Le fait avancé par le médecin de Pergame est sans doute extraordinaire ; cependant, loin de partager l'opinion de quelques auteurs modernes, qui prétendent que la pivoine est dénuée de toute espèce de propriétés, je pense, au contraire, que les racines fraîches contiennent un principe volatil dont l'impression doit être énergique sur le système nerveux. J'en trouve la preuve dans un exemple que me fournit le professeur Fodéré. Un de ses malades, attaqué d'une maladie convulsive, perdit tout à coup le sentiment et le mouvement après avoir avalé une tasse d'infusion de deux gros de racine de pivoine. On ne parvint à le rendre à la vie qu'après un long séjour dans un bain chaud. Je lis également dans les Êphémérides d'Allemagne (décur. 2, ann. 7) qu'un jeune militaire ne pouvait respirer l'odeur forte et volatile de la pivoine sans être affecté de syncope et de sueurs froides.

On peut conclure de ces faits que la racine de pivoine n'est point une substance indifférente; qu'elle est au contraire pourvue de principes très-actifs, surtout lorsqu'elle est fraîche; mais qu'on a besoin de nou- 
velles expériences qui constatent ses facultés thèrapeutiques. Hippocrate la prescrivait contre l'hystérie et l'engorgement des viscères. Quelques modernes assurent l'avoir employée utilement dans les affections convulsives. Venel lui-même, après avoir traité Galien de charlatan, ne refuse point à la pivoine des propriétés actives, et Peyrilhe la met au nombre des médicamens héroïques.

SYMPTỐMES ET PHÉNOMÈNES GÉNÉRAUX PRODUITS PAR LES RENONCULACÉES.

La famille des renonculacées se compose d'un grand nombre de poisons dont l'activité semble dépendre, en grande partie, d'un principe âcre, volatil, et comme gazeux. Quelques-uns sont tellement irritans (les clématites, les renoncules), que leur application extérieure suftit pour excorier la peau. Pris intérieurement, ils produisent une chaleur brûlante dans l'intérieur de la bouche, dans l'œesophage et dans l'estomac; des douleurs plus ou moins vives, quelquefois atroces, dans toute l'étendue du canal alimentaire; des nausées, des vomissemens opiniâtres, des déjections accompagnées de tranchées, de ténesme; une soif intense; la fréquence, la dépression, l'irrégıllarité du pouls; quelquefois une fièvre ardente. A ces premiers symptômes succèdent des défaillances répétées, une anxiété inexprimable, des tremblemens, des mouvemens convulsifs, le rire sardonique (les renoncules), le refroidissement des extrémités, des sueurs gḷaciales, une pâleur cadavéreuse, un abaltement extrême. Les hellébores et less aconits attaquent en même temps d'une manière 
directe l'appareil nerveux, excitent le délire, des vertiges, et quelquefois une stupeur profonde. Leur action est plus prompte lorsqu'on les applique sur des plaies saignantes, que lorsqu'on les introduit dans le canal alimentaire.

MÉTHODE CURATIVE GÉNÉRALE.

Les toxicologistes blâment avec raison l'emploi des vomitif's, et surtout du tartre émétique, dans l'empoisonnement produit par les renoncules, par les substances végétales irritantes, caustiques. En effet, il est bien plus rationnel d'administrer des boissons aqueuses abondantes, qui, en même temps qu'elles favorisent le vomissement, divisent les molécules du poison, préviennent ou modifient la phlogose des tuniques digestives. Toutefois, lorsque ces premiers moyens sont insuffisans, et qu'il n'existe point encore de signes d'inflammation gastrique, il faut se hâter d'expulser hors du corps le foyer vénéneux, par les vomitif's, par l'ipécacuanha ou le tartre stibié. Mais, si l'irritation inflammatoire des premières voies est déjà caractérisée par des douleurs aiguës, déchirantes, par des vomissemens répétés, des déjections séreuses, etc., on n'a d'autre espoir de salut que dans une méthode adoucissante et antiphlogistique; là sont compris les bains entiers, les demi-bains, les lavemens émolliens, les boissons gommées, oléagineuses, anodines, le lait, les fomentations appliquées sur l'abdomen, les saignées générales ou locales. On combat l'irritation nerveuse, les crampes, les mouvemens convulsifs, les douleurs, les vomissemens opiniâtres, par les préparations opiacées. L'abat- 
tement, la faiblesse, l'état de stupeur réclament des remèdes excitans; mais il ne faut pas perdre de vue l'action irritante, presque corrosive, de la plupart des renonculacées: l'usage prématuré des toniques peut rallumer l'inflammation à peine éteinte du canal alimentaire. Pendant la convalescence, on doit surtout insister sur une alimentation douce, sur le bouillon de poulet, le laitage, les panades légères, les substances amilacées. 


\title{
PAPAVÉRACÉES. PAP AVERACE AE.
}

\author{
Papaveracece. Vent. - Juss. DC.
}

\section{PAVOT. PAPAVER.}

Calice à deux folioles caduques. Corolle à quatre pétales ouverts, presque ronds, plus étroits à leur base. Étamines trèsnombreuses. Stigmate orbiculaire, étoilé. Capsule globuleuse ou oblongue, à plusieurs loges imparfaites, s'ouvrant, par des trous, sous la couronne du stigmate. Graines très-nombreuses, adhérentes à des placenta insérés sur les parois de la capsule.

PAVOT SOMNIFÉRE. PAPAVER SOMNIFERUM.

Papaver somniferum. Linn. Spec. 626. Wood. Med. Bot.

$$
\text { t. } 185 .
$$

\section{(Planche rio.)}

Sa tige, droite, cylindrique, plus ou moins rameuse, haute de trois à quatre pieds, porte des feuilles glabres, embrassantes, ondulées, incisées, inégalement dentées, et d'un vert glauque. Les fleurs sont grandes, terminales, penchées sur la tige avant leur épanouissement. Elles se colorent de différentes nuances, depuis le blanc le plus pur jusqu'au pourpre le plus vif; l'onglet des pétales est marqué d'une tache d'un violet foncé. Originaire des contrées orientales, le pavot 
somnifère abonde dans les jardins et dans tous les lieux cultivés. On en distingue deux variétés : l'une, qu'on nomme pavot blanc, a des capsules ovoïdes et des semences blanches; l'autre s'appelle pavot noir, et produit des capsules globuleuses avec des semences noires.

La connaissance de cette plante remonte à la plus haute antiquité. Homère compare le jeune guerrier mourant dans les combats au pavot qui penche sa tête chargée de fruit et des rosées du printemps. Virgile fait la même comparaison, et la rend encore plus touchante dans son admirable épisode de Nisus et Euryale. Mais les anciens n'avaient pas seulement remarqué la grâce et l'élégance du pavot, ils connaissaient également ses propriétés narcotiques, et ils savaient qu'il pouvait donner la mort. Aussi Virgile lui donne quelquefois l'épithète de lethceum; Ovide, celle de soporiferum. On croit même que le nepenthes d'Homère n'est autre chose que l'opium, ou le suc tiré, par incision, des capsules de la même plante.

Ovide fait fleurir le pavot devant la caverne du Som'meil. La Nuit humide en cueille les sucs assoupissans, et les répand dans tout l'univers.

Ante fores antri fecunda papavera florent

Innumeraque herba, quarum de lacte soporem

Nox legit, et spargit per opacas hamida terras.

On cultive le pavot sommifère dans les jardins, où il se reproduit sous les formes les plus pittoresques. Ses fleurs varient dans toutes les nuances; il y en a de blanches, de roses, d'un rouge pourpre, de panachées; d'autres dont les bords se colorent de rose, de 
violet ou d'un rouge plus ou moins vif sur un fond blanc. Toutes ces fleurs passent vite, ne durent qu'un jour, mais elles se renouvellent successivement sur la même tige; et rien n'est plus agréable à l'oil qu'une vaste plate-bande ornée de pavots de diverses teintes.

Les propriétés narcotiques du pavot résident dans un suc laiteux très-amer, d'une odeur vireuse, contenu dans les feuilles, les pédoncules, la tige, et principalement dans le fruit. Les semences, bien mûres, donnent une huile douce, agréable, qui ne partage point la qualité narcotique des capsules. Elle est connue sous le nom d'huile d'ceillet (1), et forme une branche importante de commerce pour la Flandre.

Dans les contrées orientales, dans la Natolie, dans la Perse, dans les provinces voisines de l'Égypte, la récolte du suc de pavot se fait ordinairement vers la fin de l'été. Ón l'obtient en pratiquant le soir plusieurs incisions sur la superficie des capsules avant leur parfaite maturité. Il découle de ces blessures une liqueur d'un jaune pâle, qui se condense pendant la nuit par l'action de l'air atmosphérique, et qu'on recueille le lendemain. Ce suc forme l'opium en larmes, substance précieuse que les riches orientaux réservent pour leur usage particulier, et qui est presque inconnue en $\mathrm{Eu}$ rope. On pile ensuite dans un mortier toutes les parties du pavot, et on en exprime le suc, que l'on fait évaporer au soleil ou au feu jusqu'à consistance requise.

(1) On donne dans le commerce le nom d'ceillet ou oeillette à la plus grande espèce de pavot, dont la graine produit une huile douce, blanche, bonne à manger. Ce mot est altéré d'olliele, son véritable nom. Celui-ci dérive d'oleum, huile. 
Cet opium, nommé méconium, bien inférieur au précédent, est le seul qu'on trouve dans le commerce. II est ordinairement réuni en masses orbiculaires, aplaties, recouvertes de feuilles de différens végétaux, rongeâtres à l'extérieur, d'un brun noirâtre intérieurement, d'une cassure brillante et compacte, d'une odeur nauséabonde, vireuse, d'une saveur âcre et amère. On peut également extraire l'opium des pavots indigènes ; mais il a beaucoup moins d'énergie.

\section{ANALYSE CHIMIQUE.}

Les principes qui constituent l'opium n'ont été bien appréciés que par les chimistes de nos jours. En I 8o3, M. Derosne reconnut dans ce produit végétal une substance particulière qui reçut d'abord le nom de sel d'opium, ensuite celui de narcotine. Elle fut regardée par ce chimiste comme le principe le plus actif de l'opium.

En décembre 1804, M. Séguin communiqua à l'Institut un mémoire où il annonçait avoir obtenu de l'opium cinq substances distinctes : $\mathrm{I}^{\circ}$ une matière cristalline considérée comme une substance nouvelle; $2^{0}$ un acide nouveau jouissant de propriétés particulières; $3^{\circ}$ une matière insoluble dans l'eau, soluble dans l'alcohol, les acides et les alcalis, qu'il appelle principe amer insoluble de l'opium; $4^{\circ}$ une substance soluble dans l'eau et dans l'alcohol, qui n'est précipitée par aucun réactif, et qu'il nomme principe amer soluble de l'opium; $5^{\circ}$ de l'acide acétique.

Dans un travail également remarquable sur l'opium, M. Sertuerner, pharmacien à Eimbeck, dans 
le royaume d'Hanovre, a signalé : $\mathbf{I}^{\circ}$ un principe alcalin cristallisable, insoluble dans l'eau, soluble dans l'alcohol et l'éther, à qui il a donné le nom de morphine; $2^{\circ}$ un acide particulier qu'il a nommé acide méconique. Les recherches de ces deux derniers chimistes offrent des résultats tellement conformes, relativement à la découverte de la morphine et de l'acide méconique, que M. le professeur Vauquelin a réclamé la priorité en faveur de cellès de M. Séguin. Cependant il faut avouer qu'on doit particulièrement à M. Sertuerner d'avoir appelé l'attention sur ces nouveaux produits.

Les expériences ultérieures de M. Robiquet ont encore perfectionné l'analyse de l'opium. Ce chimiste a démontré qu'indépendamment de l'acide méconique, cette substance contient un autre acide qui n'a point reçu de dénomination particulière; que le sel de Derosne n'est point du méconate de morphine; que ce sel et la morphine existent ensemble, et peuvent être séparés par l'éther.

D'après les analyses chimiques les plus récentes, l'opium contient de l'huile fixe, du caoutchouc, une substance végéto-animale, du mucilage, de la fécule, de la résine, des débris de fibres végétales, de la narcotine, de l'acide méconique, un acide nouveau découvert par M. Robiquet, et une substance, jouissant des mêmes propriétés que les alcalis, désignée sous le nom de morphine.

On ne trouve point ce dernier principe dans l'opium extrait de nos pavots indigènes; tandis que l'opium des pavots cultivés dans le territoire de Naples en con- 
tient une certaine quantité, et se rapproche de l'opium d'Égypte. (Boudet, Journal de pharmacie.)

On obtient la morphine en faisant bouillir une solution aqueuse d'opium avec de la magnésie. On lave et on dissout le dépôt avec l'alcohol chaud, qui enlève la morphine. Dans son état de pureté, elle est blanche, transparente, cristallisable, peu soluble dans l'eau bouillante, très-soluble, à l'aide de la chaleur, dans l'éther et dans l'alcohol, auxquels elle communique une saveur très-amère. Elle se dissout facilement dans les acides, et forme des sels neutres solubles dans l'eau, qui agissent, à très-petite dose, avec la même intensité que l'extrait aqueux d'opium. On connaît particulièrement l'acétate, le sulfate et l'hydrochlorate, ou muriate de morphine.

Depuis la première édition de notre Phytographie, l'opium a été l'objet de nouvelles recherches. D'après un mémoire lu à l'Académie des Sciences, le 18 décembre 1832 , par M. Robiqùet, les chimistes n'ont point connu jusqử présent le véritable acide de l'opium; ce qu'il ont désigné sous le nom d'acide méconique n'est que le résultat d'une altération de cet acide. Pour l'obtenir tel qu'il préexiste, il faut soigneusement éviter la chaleur de l'ébullition, parce qu'à cette température l'acide se décompose. Le véritable acide méconique est parfaitement blanc; il cristallise en belles écailles micacées qui s'effleurissent au contact de l'air chaud, et prennent alors l'aspect du gypse calciné. Cet acide est soluble dans quatre parties environ d'eau bouillante. Il cristallise par refroidissement, et se reproduit identique à lui-même, si on n’a pas soutenu la 
température de l'ébullition; mais dans le cas contraire, il se décompose, donne lieu à une émission d'acide carbonique, devient fort peu soluble dans l'eau, et ne retient plus d'eau de cristallisation.

La codéine, nouvelle base de l'opium, a été découverte par cet habile chimiste. Le moyen de l'extraire consiste à préparer du muriate de morphine par le procédé de William Gregory , c'est-à-dire en ajoutant, dans une solution aqueuse d'opium, une dissolution concentrée de muriate de chaux. Il se produit alors du méconate de chaux qui se précipite, et du muriate de morphine qui reste en dissolution. On filtre, on évapore, on fait cristalliser, et après plusieurs cristallisations successives, on obtient un muriate de morphine très-blanc, qu'on redissout de nouveau pour le décomposer par l'ammoniaque. La morphine se précipite ; la majeure partie de la codéine reste en dissolution avec un peu de morphine. On évapore ces eauxmères; on obtient une première cristallisation formée de petites aiguilles groupées en mamelons radiés; on redissout ces cristaux, qui sont formés de l'union triple de l'acide muriatique, de la morphine et de la codéine.

Quand ils sont suffisamment purifiés, on les comprime fortement pour en séparer les eaux-mères ; puis on les traite par une solution de potasse caustique un peu étendue, mais employée en léger excès. La morphine est retenue en dissolution, la codéine se précipite sous la forme d'une pâte qui peu à peu acquiert de la consistance, se tuméfie et finit par devenir pulvérulente. On broie cette poudre, on la lave avec un. 
peu d'eau froide; on la fait sécher et on la traite ensuite par de l'éther bouillant. Lorsque cette dissolution est suffisamment concentrée, on obtient par refroidissement de belles aiguilles blanches, aplaties et assez consistantes, plus larges à leur base qu'à leưr sommet. C'est la codéine; elle jouit des propriétés suivantes: elle est très-soluble dans l'eau houillante; elle cristallise par refroidissement en beaux polyèdres réguliers, parfaitement transparens et incolores.

Cette solution, même froide, a une réaction alcaline très-prononcée. Elle précipite abondamment par l'infusion de noix de galle, propriété dont ne jouit pas la morphine quand elle est très-pure, et il est bien à présumer que cette propriété accidentelle ne lui est communiquée que par son union avec la codéine. Cette base nouvelle ne rougit point par l'addition de l'acide nitrique. Les dissolutions de fer au maximum ne lui font pas prendre, comme à la morphine, une teinte bleue. En un mot, ce sont deux bases tont-à-fait distinctes. Plusieurs physiologistes ont fait remarquer que la morphine ne représentait pas à elle seule toutes les propriétés caractéristiques de l'opium. Il devient donc probable que la codéine viendra compléter le cadre. Ce qu'il y a de certain, c'est qu'elle est vénéneuse, qu'elle agit fortement sur la moelle épinière, et qu'elle ne paralyse point le train de derrière comme la morphine.

M. William Gregory a fait connaître à M. Robiquet le résultat de quelques expériences qu'il a tentées sur les propriétés du nitrate de codéine. Ce sel, à la dose de trois grains, n'a produit aucun effet ni sur lui-ınême, 
ni sur plusieurs de ses élèves; mais à la dose de quatre à six grains, il a donné lieu aux symptômes suivans. D'abord, accélération du pouls, chaleur dans la tête et dans la face, ensuite excitation remarquable de l'esprit analogue à celle que produisent les liqueurs enivrantes. Cette excitation agréable et d'assez longue durée fut accompagnée d'une forte démangeaison qui commença à la tête et se répandit dans tout le corps. Après quelques heures, cet état fut suivi d'une dépression désagréable, avec des nausées et quelquefois des vomissemens. On n'a observé aucune tendance au sommeil, excepté après l'état de dépression.

D'un autre côté, le docteur Kunkel a constaté, par des expériences, que la codéine pure avait une action beaucoup plus vive sur les organes que lorsqu'on l'employait combinée aux acides. Il est vraisemblable qu'on obtiendrait des résultats plus prononcés que ceux de M. Gregory, en faisant usage d'une simple solution aqueuse de codéine. Au reste, cette nouvelle substance peut représenter, ainsi que l'avait annoncé M. Robiquet, certaines propriétés de l'opium qui n'avaient point encore été retrouvées dans les produits connus de son analyse.

Nos grands chimistes sont infatigables. M. Pelletier se livre en ce moment à un nouvel examen de l'opium, mais il n'a pas encore publié le résultat de ses recherches.

PROPRIÉTÉS DÉLÉTĖRES DE L'OPIUM ET DE SES PRODUITS.

D'après les expériences de M. le professeur Orfila, la morphine est presque sans effet, si on l'administre 
seule aux animaux. Douze grains qu'on a fait avaler à un chien n'ont donné lieu à aucun des symptômes qui caractérisent l'empoisonnement par l'opium. Cette nullité d'action de la morphine dépend, selon M. Orfila, de son peu de solubilité, et de la difficulté avec laquelle elle est attaquée par lesi sucs de l'estomac. Mais Sœmmering a obtenu d'autres effets; il résulte de ses expériences que la morphine, administrée à des chiens sous forme solide et à la dose de quatre à dix grains, a produit des effets narcotiques. L'un de ces animaux s'est endormi de suite, et est resté vingtquatre heures dans cet état. La morphine exerce sur l'homme une action très-intense. M. Sertuerner prit, de concert avec trois jeunes gens, et par doses de demi-grain, de quart d'heure en quart d'heure, un grain et demi de morphine dissous dans l'alcohol, et étendu de plusieurs onces d'eau distillée. Après la première dose, les quatre expérimentateurs éprouvèrent une surexcitation des forces vitales, avec rougeur de la face. Après la seconde dose, il se manifesta des nausées et des vertiges. Ces symptômes devinrent plus intenses après la troisième. Chez tous il se développa subitement une vive douleur dans l'estomac, un engourdissement général. M. Sertuerner était près de s'évanouir; il tomba dans un état de rêverie, et sentit dans les extrémités, surtout dans les bras, une sorte de palpitation. Après avoir pris une assez forte dose de vinaigre, ils eurent tous de violens vomissemens. L'un d'eux, s'étant trouvé ensuite dans un état fort douloureux, prit du carbonate de magnésie; les vomissemens furent calmés, mais se reproduisirent le 
lendemain, et cessèrent de nouveau après l'administration du même sel. Pendant quelques jours encore il y eut manque d'appétit, constipation, céphalalgie et mal d'estomac.

Les sels formés par la combinaison de la morphine avec les acides sont de violens'poisons, pris à une certaine dose. Le plus connu et le plus employé de tous, l'acétate de morphine, produit les mêmes effets que l'extrait aqueux d'opium, et devient sédatif depuis un sixième de grain jusqu'à un grain. On l'obtient en combinant directement l'acide acétique avec la morphine, et en faisant ensuite cristalliser.

M. de Lens (Dict. des sciences médicales) a observé l'effet narcotique de l'acétate de morphine chez une femme qui en avait pris, en deux fois, un grain et un quart. La première dose produisit de l'agitation, la deuxième des étourdissemens, un état d'ivresse, des bouffées de chaleur, des battemens dans la tête, des palpitations dans les membres. La malade éprouva tour à tour un sentiment pénible de chaleur et des sueurs froides, un malaise inexprimable, des nausées et des vomissemens de matières d'apparence muqueuse; son visage était pâle, décomposé; elle était comme anéantie. Cet état, qui ne fut combattu qu'au bout de cinq ou six heures, et seulement par l'usage d'une infusion antispasmodique acidulée, se prolongea pendant presque tout le cours de la journée; vers le soir tous les symptômes avaient disparu. Il ne resta qu'un état de fatigue et de malaise pendant deux ou trois jours.

En juin 1829 , un médecin, voulant prescrire dix 
grains de sulfate de quinine à une petite fille, eut le malheur d'être distrait, et il écrivit, par méprise, sur son ordonnance, sulfate de morphine. Malgré l'observation que le pharmacien en fit à la mère de la malade, la dose indiquée pour un lavement fut administrée. Au bout de dix minutes, l'enfant s'assoupit; bientôt des convulsions violentes se manifestèrent, et, alors seulement, le médecin fut instruit de son erreur. En vain les lavemens purgatifs, le café, les boissons vinaigrées, les révulsifs, furent employés, la petite malade expira le même jour, à neuf heures du soir.

Voici les principaux phénomènes que présenta cet affreux accident : face injectée, pupille contractée, immobile; trismus de temps en temps, craquement des dents; souvent des convulsions épileptiformes; respiration gênée, entrecoupée, spasmodique, stortoreuse; pouls petit, fréquent, variable néanmoins sous le rapport de sa force et de sa fréquence; muscles du bas-ventre extrêmement contractés; grande difficulté pour administrer les lavemens; persistance de la chaleur jusqu'au dernier moment.

Un élève en pharmacie, sanguin, velu, bien constitué, et offrant à l'extérieur tous les caractères de la meilleure santé, avait pris., le 5 juin, dix grains de narcotine pour constater sur lui-même les effets de cette substance. Le lendemain il éprouva une courbature générale avec lassitude et mal de tête. Le 7 , son état s'aggrava, et le 8 au soir il tomba dans un délire continu mais calme. On appliqua vingt-quatre sangsues aux cuisses, et dix aux hypochondres qui étaient devenus douloureux. Le 9 , il y eut des vomissemens de 
matière verdâtre, qui se répétaient à chaque gorgée de tisane prise par le malade. Le 10 , le mal ayant empiré, quarante sangsues furent appliquées à l'anus.

Le i juin, ce malheureux fut transporté à l'HôtelDieu, où l'on constata l'état suivant : coucher en supination, peau chaude, pouls petit, serré, dur, fréquent; balbutiement, divagation, pupilles contractées; langue large, molle, couverte au centre d'un enduit muqueux, faiblement rouge sur les bords; ventre volumineux, ballonné, résonnant; épigastre douloureux à la pression, soif, point de selles. Quarante sangsues à l'épigastre, eau de gomme. Le soir, même état; saignée de quatre palettes. Le sang se recouvre d'une couenne, mais le caillot est noir et diffluent. Après la saignée, pouls plus petit, également fréquent; le délire paraît augmenter. Pendant la nuit rêvasserie calme, comme interrompue par des questions.

Le I 2 , état de plus en plus grave; pouls vermiculaire, filiforme, irrégulier ; membres froids, violacés; stupeur, coma profond; ballonnement considérable du ventre; mort à midi.

Autopsie faite le r 3 . Vive congestion de l'encéphale. La pie-mère est fortement injectée, surtout entre les circonvolutions; son tissu aréolaire est soulevé par une sérosité opaque, gélatiforme. La substance cérébrale, après sa section, est ponctuée en rouge. Les ventricules contiennent beaucoup de sérosité. Le cœur et les poumons sont entièrement sains. La membrane muqueuse gastrique est d'un brun noir, parsemée de points rougeâtres, dans le voisinage du cardia, épais- 
sie, évidemment le siége d'une forte inflammation. La tunique interne des intestins grêles, dans l'étendue de plusieurs pieds au dessus et jusqu'auprès de la valvule iléo-coecale, est couverte de grandes plaques ovalaires, saillantes, et de granulations confluentes comme dans une éruption de variole. Plusieurs de ces plaques sont ulcérées à leur surface. Entre elles, la membrane muqueuse est parsemée de points noirâtres. Les ganglions mésentériques, rouges à leur surface et dans leur épaisseur, offrent un volume double et même triple de l'état naturel. (Guérin, Toxicol. p. 289. Observ. de M. Dance. )

L'opium pur, son extrait aqueux, ses teintures, sont aussi des poisons pour l'homme et pour les animaux. Il résulte des expériences tentées par Méad, Sproegel, Courten, Alston, Freind, Nysten, Orfila, que l'opium est mortel pour les chiens, soit qu'on l'introduise dans l'estomac, dans le rectum, dans le tissu cellulaire ou dans les veines. Ces animaux éprouvent des tremblemens dans les membres; les extrémités postérieures sont quelquefois comme paralysées. Il survient un assoupissement plus ou moins profond, des mouvemens convulsifs, et la mort.

Un homme avait pris trois grains d'opium et autant de safran vers minuit. Ce narcotique donna lieu aux phénomènes suivans : d'abord sommeil agité, et, un quart d'heure après, perte de mouvement, aridité de la langue, impossibilité d'articuler les sons. On chercha à dissiper son sommeil en lui parlant et en le forçant de répondre. Après une heure, vertiges, trouble de la tête; il lui semblait que son lit était suspendu 
dans l'air, yu'il volait, et que tout tournait autour de lui. On le fit sortir du lit; il se promena en vacillant : à peine conservait-il le sentiment de son existence; cependant il répondait avec justesse. Une demi-heure après, perte des fonctions des sens, excepté de la vue et de l'ouie; on lui faisait flairer en vain le vinaigre et l'ammoniaque. Ensuite froid des pieds et des mains, avec une sorte d'insensibilité. Se reposait-il, il semblait éprouver les langueurs de la mort, en sorte qu'on le faisait promener sans cesse, bien que ses genoux pussent à peine le soutenir. Vers la troisième heure à dater de la prise de l'opium, il semblait que les ténèbres de son entendement commençaient à se dissiper: le pouls s'était relevé; mais, si on le laissait à lui-même, il retombait dans une affection comateuse. Enfin quelques cuillerées d'eau de mélisse et d'eau de menthe, et ensuite des frictions répétées sur tout le corps, dissipèrent cet état de stupeur et d'engourdissement. Le malade paraissait conserver le souvenir de ce qui s'était passé; il lui semblait que ses yeux avaient acquis un volume immense. L'action de ce narcotique ne parut pas se prolonger'au-delà de six heures (Branchi, Historia hepatica).

Un jeune homme âgé de vingt-huit ans, plongé dans la plus noire mélancolie, prit, dans l'intention de se donner la mort, environ cent vingt grains d'opium du commerce après un repas très-copieux. Au bout d'une heure il tomba dans un profond sommeil, et, six heures après, il fut réveillé par des tourmens affreux. Il perdit l'usage de la parole; ses yeux étaient immobiles, ses paupières noires, ses lèvres livides, et son 
pouls presque insensible. On essaya de le faire vomir; mais, pour y parvenir, il ne fallut pas moins de trente grains d'émétique en trois doses assez rapprochées; ensuite on lui fit avaler en quantité des boissons acidulées avec le vinaigre. Il commençait à reprendre l'usage de la parole et des sens lorsqu'il fut pris de violentes convulsions : on le saigna du bras, et aussitôt ces accidens se dissipèrent. Ils se renouvelèrent quatre fois de suite dans l'espace de quelques heures, et chaque fois on fit une nouvelle saignée du bras, qui les calma toujours très-promptement. Après la dernière saignée, il survint des palpitations de cœur très-fortes, accompagnées d'une sensation de brúlure dans la poitrine : le malade demanda lui-même qu'on lui fit des aspersions d'eau froide sur la poitrine, ce qui fit cesser les palpitations. En même temps un dévoiement considérable s'étant déclaré, le malade fut tout-à-fait soulagé : il dormit paisiblement pendant douze heures, et en s'éveillant il se trouva guéri, à cela près qu'il eut pendant plusieurs mois les yeux très-enflammés et la vue très-affaiblie. Depuis ce temps il ne fut plus dominé par ses idées mélancoliques (Bibliothèque médicale, tom. 34. Observation du docteur de Sanctis, professeur de mathématiques à Rome ).

Une jeune dame enceinte de son premier enfant, étant arrivée au terme ordinaire de sa grossesse, éprouva les douleurs del'accouchement, et bientôt après des convulsions. Pour les modérer, on donna la teinture d'opium par doses graduellement augmentées et trop rapprochées. Un état de stupeur s'empare de la malade, et elle accouche sans s'en apercevoir. Toute 
sensibilité disparait; il en est de même ensuite de la chaleur. Enfin cette dame meurt empoisonnée sans avoir formé aucune plainte, et sans souffrance. Son enfant, venu naturellement, était mort et d'un rougebrun par tout le corps. (Bertrand, Manuel médicolégal des poisons. Observation du docteur Desgranges.)

Madame $\mathbf{L}^{* * *}$ donna, vers huit heures du matin, à son petit-fils, âgé de dix-sept mois, une demi-cuillerée de laudanum, croyant lui faire prendre du sirop anthelmintique. Le docteur Suchet, appelé au secours de l'enfant, le trouva dans un assoupissement profond. Sa langue exécutait de bas en haut des mouvemens oscillatoires d'une étonnante vitesse. Les pupilles étaient très-resserrées, contre l'observation des auteurs; le globe oculaire immobile, les paupières sans contractilité. Cependant le pouls avait conservé son rhythme et sa force, la surface cutanée sa chaleur, et la face sa couleur naturelle; la respiration se faisait librement. On administra au petit malade un grain de tartrate antimonié de potasse dissous dans un tiers de verre d'eau sucrée. Cet émétique n'ayant excité au bout d'un quart d'heure aucun vomissement, le docteur Suchet prescrivit alternativement toutes les cinq minutes de l'eau sucrée tiède, acidulée avec le jus de citron et une infusion de café. On donna en même temps des clystères avec l'eau tiède vinaigrée, et on chatouilla la gorge de l'enfant avec la barbe d'une plume huilée. Ces moyens procurèrent d'abondantes évacuations par haut et par bas.

A neuf heures, convulsions générales, gonflement II. 
de la face et du cou; yeux fixes, proéminens; bouche écumeuse, pouls successivement lent, fréquent, irrégulier, régulier, fort, petit, intermittent : toute la périphérie du corps prend une teinte violacée, qui disparait presque aussitôt.

A dix heures et demie, mêmes symptômes; de plus, élévation et tension légère des parois abdominales. Continuation des mêmes médicamens, qui produisent des effets semblables. Application de huit sangsues sur la région épigastrique et autour de l'ombilic. Nonobstant l'usage non interrompu des boissons et des lavemens précités, la tension et l'élévation de l'abdomen augmentent; les oscillations de la langue restent aussi fréquentes; les convulsions se rapprochent; le pouls s'affaiblit graduellement, la respiration devient haute, pénible, lente, entrecoupée par de profonds soupirs; une abondante quantité de matières visqueuses, sanguinolentes, sort parla bouche et la fosse nasale gauche; l'enfant, triste victime d'une méprise, meurt à quatre heures du soir, à l'instant où le ventre commence à diminuer de volume, ce qui était un signe certain de la gangrène de la tunique interne de l'estomac et des intestins. On ne put obtenir des parens la permission de faire la section cadavérique. (Gazette de santé, rédigée par le docteur Miquel.)

M. ${ }^{* * * *}$ avait conseillé à un militaire l'usage du laudanum pour combattre une irritation nerveuse, accompagnée d'insomnie, qui le tourmentait depuis plusieurs mois. La formule du médecin indiquait un gros de laudanum de Rousseau, à prendre, tous les soirs, à la dose de dix à quinze gouttes, à l'heure du sommeil. 
Les premières gouttes n'ayant vraisemblablement pas produit l'effet désiré, le malade épuisa le même soir la dose entière du narcotique. Le lendemain, il fut trouvé mort dans son lit. La poitrine, le cou, et surtout la face, étaient d'une couleur livide. L'ouverture du cadavre, ordonnée par l'autorité, ne fit découvrir aucune altération dans les organes digestifs; mais les vaisseaux du cerveau étaient extrêmement gorgés de sang. On déclara que le malade avait succombé à une attaque d'apoplexie.

Une femme, âgée de trente-cinq ans, enceinte de sept mois, avala, pour s'empoisonner, le 19 décembre 1823 , vers une heure après midi, une once et demie environ de laudanum. Les signes de narcotisme ne tardèrent pas à s'annoncer.

Sur les huit heures du soir, M. le docteur Dukes introduisit dans l'estomac un long tube de gomme élastique, et, au moyen d'une seringue dont ce tube était muni, il injecta et retira successivement de l'eau tiède à plusieurs reprises, jusqu'à ce que le liquide retiré, qui répandait d'abord fortement l'odeur du laudanum, n'eût plus cette odeur. L'opération ne dura pas plus de dix minutes. Le lendemain la malade fut prise de fièvre, mais les symptômes de narcotisme s'étaient dissipés, et le 2 I, elle put reprendre ses occupations ordinaires.

Pouple, jeune pharmacien employé à l'armée de Saint-Domingue, éprouvait un flux dysentérique rebelle, qu'on lui conseilla de combattre par des lavemens opiacés. N'ayant obtenu qu'un faible soulagement de quarante gouttes de laudanum liquide, il crut pouvoir doubler le lendemain la dose; mais ce second 
lavement le jeta dans un état de torpeur qui finit par une léthargie mortelle.

Je fus consulté, il y a quelques années, par un vieux domestique d'un tempérament sanguin, et sujet à des douleurs lombaires, à qui on avait donné un lavement préparé avec une solution de trois grains d'extrait d'opium. Deux heures après avoir pris ce clystère, il éprouva un engourdissement général et des vertiges accompagnés d'une illusion de la vue, qui faisait paraître tous les corps environnans couverts d'un voile sombre; il était tourmenté par des nausées fréquentes, et il parlait avec une difficulté extrême. Plusieurs tasses d'eau fraîche acidulée avec le suc de citron, et des lavemens vinaigrés, dissipèrent en partie l'affection narcotique. Cependant la nuit fut agitée par des rêves. Le lendemain matin, le pouls était plein, la face vivement colorée. Cet état de congestion céda à l'application de quinze sangsues au fondement, et à quelques pédiluves sinapisés.

Les applications extérieures de l'opium ne sont pas sans danger. On lit dans la Nosologie de Sauvages, qu'une personne tomba dans un assoupissement carotique après s'être frictionné la poitrine avec la teinture d'opium. D'après Lieutaud (Mat. méd.), deux grains d'opium, appliqués sur la tempe, ont produit un délire furieux. Guérin dit qu'un cataplasme arrosé de laudanum liquide et appliqué sur un érysipèle phlegmoneux occupant la partie externe de la jambe droite, causa la mort à un soldat. Le médecin avait prescrit seulement quinze gouttes de laudanum; mais l'infirmier, pour mieux calmer les souffrances du ma- 
lade, en versa environ une demi-once sur le cataplasme ; une pareille dose lui servit à imbiber les compresses. Cette application fut suivie de mouvemens convulsif's des membres supérieurs et inférieurs, de la contraction des pupilles, de la distorsion de la bouche, enfin d'un profond assoupissement. Tous les remèdes furent inutiles; le malade expira le lendemain, à cinq heures du soir.

A l'autopsie, quelques points de l'arachnoïde parurent rouges et assez fortement engorgés. L'encéphale, le cœur, le tube gastro-intestinal, n'offraient rien de remarquable; mais toutes ces parties exhalaient une forte odeur d'opium, sans cependant qu'on pût trouver dans les vaisseaux aucune trace du narcotique.

Si l'on recueille les symptômes généraux qui naissent de l'empoisonnement causé par l'opium et ses préparations diverses, on voit que c'est presque toujours une sorte de stupeur ou d'engourdissement qui en est le prélude. La tête devient pesante, embarrassée, quelquefois un peu douloureuse. On éprouve une lassitude générale, des frissonnemens, des nausées, des vertiges, une somnolence invincible. Les yeux sont gonflés, ouverts, saillans, quelquefois à demi fermés et abattus ; la face est bouffie, pâle, souvent d'un rougeviolet. Les membres sont faibles, pendans, comme frappés de paralysie. Le pouls est tantôt plein, régulier; tantôt inégal, déprimé, intermittent. La respiration devient haute, bruyante, quelquefois presque insensible. Les secousses les plus fortes suffisent à peine pour retirer le malade de l'état de torpeur dans lequel 
il est plongé; et, s'il se réveille, c'est pour retomber aussitôt dans l'assoupissement. Quelquefois les effets du poison s'annoncent par un délire gai ou sombre, par un état de fureur et d'exaltation extrême, par des convulsions violentes, des vomissemens, des angoisses, des douleurs atroces, etc.; ce qui prouve que l'opium ne procure pas toujours, comme on le croit vulgairement, une mort douce et tranquille.

Cette anomalie de symptômes est due au tempérament individuel, aux doses de l'opium, et quelquefois aussi aux substances avec lesquelles il a été combiné. Pour accomplir de criminels desseins, on a quelquefois recours à de semblables mélanges, afin de masquer l'effet de l'opium; mais si l'on analyse avec soin les phénomènes physiologiques produits par ces combinaisons délétères, on doit observer par intervalles, surtout lorsque les périodes de l'empoisonnement se prolongent, quelques - uns des signes propres aux compositions opiacées, tels que l'engourdissement, la stupeur, la somnolence, etc.

On remarque assez souvent après la mort des taches extérieures d'un rouge livide. Les vaisseaux du cerveau sont distendus, gorgés de sang. Le canal alimentaire offre rarement des traces d'inflammation. Cependant le docteur Desgranges, en ouvrant le corps d'un jeune homme empoisonné par l'opium, a trouvé la membrane muqueuse de l'estomac épaissie, avec des taches noirâtres vers sa grande courbure et près du pylore. Lindestolpe et Loeseke ont aussi trouvé l'estomac enflammé dans des animaux qu'avait fait périr l'opium, pris à la dose d'un ou deux gros. M. Mérat a 
vu les viscères de la poitrine atteints d'une inflammation presque générale.

MÉTHODE CURATIVE.

On ne connaît point de véritable antidote de l'opium; et malgré qu'on ait donné de grands éloges aux vomitifs, aux acides végétaux, au vinaigre, au suc de citron, aux évacuations sanguines, au café, à l'ammoniaque, aux boissons excitantes, on est toujours forcé d'avoir recours à une méthode rationnelle, si l'on veut obtenir d'heureux résultats; d'autant mieux qu'il est des circonstances où les moyens que nous venons d'énumérer ne font qu'aggraver l'empoisonnement. Lorsque l'embarras de la tête, l'engourdissement, les nausées, annoncent les premières atteintes du poison, il faut l'expulser promptement des voies alimentaires par des évacuans énergiques, afin de prévenir ses effets ultérieurs. Une solution de quatre ou cinq grains de tartrate antimonié de potasse dans huit ou dix onces d'eau, dont on donne la moitié ou le tiers de dix en dix minutes, remplit cette indication importante. On favorise d'ailleurs le vomissement par l'irritation mécanique du larynx, et on donne encore un ou deux grains d'émétique, si les contractions de l'estomac s'opèrent avec lenteur. Lorsque la stupeur est profonde, il ne faut pas craindre d'élever les doses de l'émétique; on peut même remplacer avantageusement cette préparation antimoniale par le sulfate de zinc, le sulfate de cuivre, comme plus propres à réveiller l'action engourdie des organes gastriques. Quelquefois unclégère infusion de tabac à fumer ou en poudre a excité le 
vomissement de la manière la plus prompte, lorsque tous les autres vomitif's avaient échoué.

M. Marcet (Transactions médico-chirurgicales) a administré avec succès une solution de trente grains de sulfate de cuivre dans un cas d'empoisonnement où un gros et demi de vitriol blanc n'avait produit aucun effet. Le malade, qui avait avalé environ six onces de laudanum, était dans une insensibilité complète. Ce puissant émétique lui fit rejeter environ deux pintes d'un fluide brunâtre exhalant une forte odeur d'opium. Les purgatifs, les lavemens préparés avec le sulfate de soude ou de magnésie, doivent être administrés, lorsqu'on présume que le poịson a pénétré dans les intestins.

L'expulsion de la matière vénéneuse est sans doute d'un avantage immense; toutefois on voit assez souvent la stupéfaction, l'engourdissement lui survivre; alors rien n'est plus propre à dissiper ces symptômes que les boissons acides. On dorne en conséquence, à des intervalles rapprochés, de l'eau acidulée avec un cinquième de vinaigre, de suc de citron, d'orange, de groseille, etc. Les lavemens, les fomentations d'eau vinaigrée sur la région abdominale, sont également convenables : on les emploie particulièrement lorsque la déglutition est impossible ou très-difficile. Le café, par son action stimulante, est quelquefois aussi d'un grand secours après l'usage des vomitifs : on peut donner son infusion ou sa décoction concentrée alternativement avec les acides. Le docteur Niemann (Pharmacopcea batava) a consommé dans l'espace de quelques heures une livre et demie de café torréfié, et il a 
sauvé la vie à un homme qui, dans un accès de délire érotique, avait avalé au-delà de deux onces de teinture d'opium. La stupeur étantà peu près dissipée, il a prescrit ensuite une infusion de fleurs d'arnica et de racine de valériane animée avec l'éther sulphurique, afin de redonner de l'énergie au système nerveux.

Les vertiges, le délire, la torpeur générale, enfin les signes qui indiquent une congestion violente vers le cerveau, réclament impérieusement les émissions sanguines, répétées suivant l'âge, la force et l'état pléthorique du sujet. C'est le moyen le plus sûr de prévenir ou de combattre l'assoupissement apoplectique. Joignons l'exemple au précepte.

Un homme très-robuste prit deux onces de laudanum liquide de Sydenham pour se donner la mort. Appelé à son secours, le chirurgien Ross lui donna un émétique de sulfate de zinc, qui produisit un vomissement trèsabondant. Deux heures après, le malade fut en proie à un état comateux tout-à-fait semblable à celui que détermine la compression du cerveau. Cette circonstance engagea $M$. Ross à pratiquer une saignée de seize onces. Aussitôt que la veine eut été ouverte, l'assoupissement se dissipa, et le malade, au bout de deux heures, jouit d'un mieux extrêmement marqué. On lui fit prendre quelques délayans, entremêlés, de temps à autre, de nouvelles doses de sulfate de zinc. Ce traitement réussit parfaitement bien. Les acides ne furent pas employés. (Revue médicale, tome i i, page 331.)

Les saignées locales ne doivent point être négligées lorsque la congestion du cerveau ne cède point aux saignées générales : on peut les pratiquer aux tempes, 
au cou ou derrière les oreilles, à l'aide des sangsues ou de la ventouse à pompe du docteur Gondret, qu'on applique plusieurs fois sur les parties profondément scarifiées. Si les symptômes cérébraux persistent, malgré les évacuations sanguines, on appliquera de la glace sur la tête ( 1 ); on fera des aspersions d'eau vinaigrée sur la surface du corps; enfin, on aura recours aux lavemens âcres, aux pédiluves irritans, aux vésicatoires, aux sinapismes, dont l'action révulsive est si propre à rompre les mouvemens fluxionnaires concentrés sur l'encéphale. Dans les cas d'insensibilité profonde, on donnera les excitans les plus actifs. A l'aide de l'alcali volatil, Riedlin a rappelé à la vie un homme qui était dans un état désespéré après avoir pris une forte dose d'opium.

Voilà les moyens les plus efficaces contre ce genre d'empoisonnement. Mais n'a-t-on pas souvent abusé des vomitifs, de la saignée, des acides, des stimulans? Lorsque l'empoisonnement est très - avancé, et que tout décèle une affection cérébrale profonde, les émé-

(1) Une jeune fille, qui avait avalé deux onces de laudanum, était plongée dans un coma invincible. Tartre stibié, ipécacuanha, sulfate de zinc, lavemens irritans, tout cela n'avait produit aucun effet. Le docteur Jackson fit apporter un baquet plein d'eau froide, et, ayant fait soutenir par des aides la tête le la malade audessus de ce baquet, il commença à lui verser de l'eau sur la tête avec un gobelet ordinaire. La malade ne sentit pas les premières affusions; mais la quatrième occasiona un léger soupir, qui devint de plus en plus profond à chacune des suivantes, jusqu'à ce qu'enfin elle poussa de grands cris. La sensibilité étant rétablie, on lui administra un vomitif qui évacua complètement l'estomac. On appliqua des sinapismes aux pieds, et le lendemain elle était si bien rétablie, qu'elle put se lever et s'habiller seule. 
tiques ne peuvent qu'aggraver cet état fâcheux ; tandis que la saignée, pratiquée avec hardiesse, peut arracher le malade au trépas, en combattant d'une manière directe l'engorgement sanguin du cerveau. Elle a même quelquefois opéré le vomissement en dissipant l'état de spasme concentré sur la région épigastrique. Mais les évacuations sanguines sont elles-mêmes contreindiquées lorsque le refroidissement des extrémités, la langueur du pouls, annoncent la prostration du système des forces. Dans cette circonstance, la saignée peut causer instantanément la mort. Il faut même en user avec modération, bien qu'il se manifeste une excitation vive, à l'égard des sujets plus irritables que sanguins, chez qui la réaction vitale est de courte durée,

Les acides végétaux, administrés lorsque l'opium est encore dans l'estomac, dissolvent ses principes actifs, favorisent leur absorption, et aggravent l'empoisonnement. C'est ainsi qu'il faut expliquer la mort prompte que se donnent les Perses en avalant un verre de vinaigre immédiatement après avoir pris de l'opium. Il ne faut donc avoir recours aux boissons acides que lorsqu'il y a eu des vomissemens, soit spontanés, soit provoqués par l'art, ou que la période avancée de l'empoisonnement fait présumer que l'absorption est accomplie.

On a souvent employé avec un succès évident l'infusion de café pour combattre les poisons narcotiques, et plus particulièrement l'opium. Mais ne doit-on pas s'abstenir de cette liqueur stimulante lorsque la dureté du pouls, la rougeur et le gonflement de la face, an- 
noncent l'engorgement inflammatoire des vaisseaux cérébraux ? Il en est de même des autres moyens excitans, tels que le camphre, l'ammoniaque, les frictions, les secousses répétées, etc. Ils sont utiles sans doute pour ranimerl'excitabilité, pour dissiper l'engourdissement, la somnolence; mais ils peuvent aussi déterminer un état apoplectique, si on les emploie avant d'avoir combattu la pléthore cérébrale par des évacuations sanguines suffisantes $(\mathrm{I})$.

Nous venons de considérer l'opium sous le rapport de ses propriétés vénéneuses; et nous avons vu qu'une assez faible dose a suscité dans quelques circonstances les symptômes les plus graves. Toutefois il faut convenir que notre art serait souvent réduit à une malheureuse impuissance sans le secours de ce médica-

(1) On a fait à Londres des expériences dont la réussite assure un secours prompt et efficace aux personnes empoisonnées. On a éprouvé à l'hôpital de Guy, en présence de sir Astley Cooper, un instrument avec lequel on parvient à retirer les liquides introduits dans l'estomac. On a fait avaler à un clien une certaine dose d'opium étendu dans un verre d'eau. Aussitôt que l'effet du poison s'est manifesté, on a introduit l'appareil en question dans l'estomac de cet animal , et l'on est parvenu à retirer tout le liquide. Les symptômes ont cessé sur-le-champ. Sur la demande du docteur Payne, un instrument à peu près semblable a été employé avec succès à extraire une certaine quantité de laudanun de l'estomac d'une femme qui éprouvait des souffrances très-vives, et chez laquelle le soulagement a été aussi prompt que dans la première expérience. M. Williams, aidé de M. Ward, a fait l'application de cet instrument sans éprouver la moindre difficulté. (Voyez une semblable observation rapportée plus haut) 
ment. Mais, avant de passer à son emploi thérapeutique, voyons un peu comment on explique son action sur l'organisme.

MODE D'ACTION DE L'OPIUM.

L'opium doit-il être rangé parmi les substances excitantes ou parmi les substances sédatives ? Cette question a été longuement agitée par des physiologistes et des médecins d'un grand mérite, et elle n'est pas encore résolue. Vanhelmont, Ettmuller, Sydenham, Boerhaave, Young, Tralles, Jean Leig, Bontius, Plater, Berger, Haller, Tissot, Ferdinand Schulze, Pierre Frank, Sprengel, etc., lui accordent une vertu stimulante. Ludwig compare son action à celle du vin, et Mead à celle de l'alcali volatil.

Sennert (Prax. med.) a surtout fort bien peintla puissance excitante de l'opium dans le passage suivant : $S_{i}$ ejus qualitates et vires diligenter perpendamus, calidum esse animadvertemus : est enim amarum et acre, linguam veilicat, fauces incendit, sitim excitat, odorem gravem habet, facilè inflammat, animum effert, venerem concitat, pruritum excitat, sudorem ciet, dura emollit et discutit.

Freind attribue l'état de langueur qui suit l'usage de l'opium à l'épuisement qu'entraînent ses premiers effets, épuisement que rien ne répare comme une nouvelle dose de ce même cordial.

Le professeurJoseph Frank, qui a embrassé la même opinion (Ratioinstituticliniciticinensis), observeque l'opium, loin de provoquer le sommeil, produit, dans bien des cas, un effet contraire. A ce sujet, il cite un 
exemple de léthargie occasionée par des champignons, avec froid aux extrémités et autres accidens qui annonçaient une fin prochaine, où le malade fut rappelé à la vie au moyen de sept gros de laudanum liquide, qu'on lui administra dans l'espace de quarante-huit heures. Si l'opium est vraiment sédatif, comment se fait-il que tous les médecins s'accordent à condamner son usage dans les maladies où il y a excès de forces vitales, dans celles qui tiennent à une disposition inflammatoire, à un état de pléthore, à trop de vivacité dans la circulation? Ses mauvais effets dans tous les cas de cette nature ne prouvent-ils pas son action stimulante, comme la démontrent ses effets salutaires chez les individus dont les forces sont tout-à-fait épuisées? Mais, dira-t-on, l'opium calme les douleurs, les spasnies et divers autres symptômes. Sans doute il les calme ; mais c'est en diminuant la cause de ces accidens, l'affaiblissement des pouvoirs vitaux qui a déterminé leur formation.

Cette théorie est en tout point conforme à celle du célèbre professeur écossais. Suivant Brown, l'opium remplit les mêmes indications que le vin, l'eau-devie et les stimulans les plus actifs, dans les cas de spasmes et de convulsions, dans le délire, etc. C'est à sa vertu excitante qu'il attribue ses effets soporifiques; ainsi l'opium amène d'abord la diathèse sthénique pour un temps plus ou moins considérable, et ensuite l'asthénie indirecte, qui produit le sommeil. S'il calme l'insomnie, c'est qu'elle dépend ordinairement d'un état de faiblesse. Chez les gens en santé, il excite la gaîté, augmente le courage, et peut même écarter 
le sommeil (1). Avant de commencer sa leçon, Brown prenait quelquefois quarante ou cinquante gouttes de laudanum dans un verre d'eau-de-vie, et lorsqu'il se sentait fatigué, il en répétait la dose jusqu'à quatre ou cinq fois, ce qui montait son imagination presque jusqu’à la phrénésie.

M. Philibert-Joseph Roux pense que l'opium est à la fois stimulant et sédatif, qu'il excite violemment les forces organiques, notamment celles qui président à la circulation générale et capillaire, ce que dénotent la force et la vitesse du pouls, l'état de la respiration, l'augmentation générale des forces, etc.; qu'il diminue, engourdit ou anéantit même l'action cérébrale suivant la quantité qui a été prise. L'affaissement général, l'assoupissement plus ou moins profond, la suspension des fonctions intellectuelles et de la vie de relation, la mort même, dans certains cas, tout prouve qu'il dirige sur le cerveau une action stupéfiante après avoir exercé sa vertu stimulante sur les propriétés organiques. (Réflexions médicales sur les effets sensibles de l'opium.)

D'après les expériences tentées sur divers animaux par M. le docteur Constancio, médecin portugais, l'application de l'opium sur une partie quel-

(1) Weikard rapporte qu'une dame dont le mari s'enivrait tous les soirs recevait souvent la visite d'un officier. Afin de n'avoir rien à craindre pour leurs amours, ils versèrent du laudanum liquide dans la dernière bouteille qu'on servit à l'époux à la fin du repas. Celui-ci but la liqueur avec avidité. Mais ils furent loin d'obtenir le résultat qu'ils se promettaient de leur ruse; car le mari ne put absolument dormir, et fut instruit du rendez-vous. (Lafont-Gouzı, Nouvelle doctrine de Brown.) 
conque ne présente rien qui diffère essentiellement de toute autre irritation. Une petite dose augmente la sensibilité et l'irritabilité locales, une plus forte les apaise, et une dose excessive cause quelquefois la mort, quand l'application est faite sur une grande surface. Injecté dans les vaisseaux sanguins, il en augmente l'action, si la dose est modérée ; il la diminue, et finit même par l'anéantir, si la quantité est trop considérable. L'opium agit de la même manière sur le cœur; mais il faut l'y introduire directement pour qu'on puisse parvenir à détruire les mouvemens de cet organe. Toutefois il paraît n'exercer aucune influence sur le cœur par une autre voie que celle de la circulation. Mis en contact avec le cerveau, même à une très-faible dose, il diminue la sensibilité générale, produit la langueur et la léthargie. A une plus forte dose, il excite, comme tout autre stimulant, des convulsions violentes, qui cependant ne sont pas toujours mortelles, et finit enfin par tuer l'animal, si l'on insiste davantage. Ces convulsions causées par l'opium ont un caractère qui leur est propre et qui les distingue de celles que produisent d'autres substances. Ce n'est que par la violence de ces convulsions que l'opium parvient à affecter l'irritabilité des muscles soumis à l'empire de la volonté. Danš tous les autres cas, cette faculté ne souffre aucune altération, malgré la mort générale causée par l'application de l'opium au cerveau ( 1 ).

(1) M. Flourens a fait de belles expériences sur l'opiun et autres substances vénénenses. Il résulte des recherches de cet habile 
L'opium agit toujours sur les nerfs, et non sur les fluides, comme Fontana l'a prétendu; mais ce n'est que par la circulation et l'absorption qu'il produit des effets sur des parties éloignées, sur lesquelles il ne saurait agir, s'il n'est en contact avec elles, car son influence ne se communique nullement par la voie des nerfs. S'il paraît quelquefois produire des effets sur des parties auxquelles il est impossible qu'il ait déjà été porté par la circulation, cela tient à l'importance des fonctions de l'organe lésé, dont l'altération locale donne lieu à une foule de phénomènes dans le cercle plus ou moins étendu de ses dépendances. (De l'action de l'opium sur l'économie animale, par F. S. ConSTANCIO.)

Suivant Barthez, l'opium agit d'abord sur l'estomac; mais son action s'étend ensuite à tout le système des vaisseaux sanguins, où elle affaiblit généralement l'irritabilité, ou bien l'influence des forces sensitives

physiologiste : $1^{\circ}$ que l'opium, à une dose et sous une forme déterminée, agit exclusivement sur les lobes cérébraux; $2^{\circ}$ que l'action spécifique de l'opium sur ces lobes reproduit exactement tous les phéuomènes qui dérivent de leurs lésions mécaniques; $3^{\circ}$ qu'en agissant exclusivement sur ces organes, l'opium n'altère ou n'abolit que les fonctions qui leur sont départies; $4^{\circ}$ que l'action de l'opium sur les lobes cérébraux laisse toujours après elle des traces qui peuvent servir à la constater; $5^{\circ}$ qu'il y a telle dose qui n'agit que sur les lobes cérébraux, et laisse complètement intactes les parties même les plus voisines; $6^{\circ}$ enfin que, chez les petits oiseaux, on peut suivre à l'œil, et à travers les parois du crâne, la formation et le développement de l'altération organique de la partie produite par l'action de l'opium. (Recherches expérintentales sur les propriétés et les fonctions du système nerveux dans les animaux vertébrés.) 
sur les forces motrices. Les vertus contraires de ce médicament tiennent spécialement à la différence des doses et à celle de ses préparations. C'est ainsi que sa qualité irritante est effacée par sa vertu sédative, lorsqu'on l'administre à des doses extrêmement fortes. Pris à des doses modérées, il accélère les battemens du pouls et produit d'autres effets d'excitation. Quand il est donné à une très-grande dose, il affaiblit la sensibilité au point de diminuer extrêmement l'irritabilité du coeur et des artères, dont il rend les pulsations moins fréquentes, de même qu'il diminue alors la fréquence des mouvemens de la respiration. (Nouveaux élémens de la science de l'homme.)

Cabanis prétend que l'opium produit deux effets distincts très-remarquables : l'un, de diminuer la sensibilité ; l'autre, d'augmenter la force de la circulation, et par elle, ou, plus directement encore, par l'état du système nerveux, celle des organes moteurs. C'est uniquement à raison de ce dernier effet que l'opium doit être considéré comme stimulant. Mais, pour accroître véritablement les forces musculaires, l'opium doit être employé à doses modérées : car, à mesure qu'on augmente la dose, l'engourdissement des nerfs augmente lui-même; et le cerveau, comprimé de plus en plus par l'afflux extraordinaire du sang, transmet de moins en moins et peut finir par cesser entièrement de transmettre aux muscles les principes d'excitabilité. (Rapports du physique et du moral de l'homme).

D'après l'opinion du professeur Moreau (Encyclopédie méthodique), l'opium, donné à petites doses, produit un premier degré d'irritation. Mais les moyens 
d'irritation et d'excitement ne portent pas également sur toutes les parties de l'organisme. L'opium est caractérisé par cette sorte d'affinité élective : il se dirige, se concentre vers le cerveau; il n'apparaît comme excitant général qu'en donnant momentanément plus de force et d'étendue à l'influence et à la sphère d'activité de cet organe. D'autres médecins, et particulièrement le docteur Barbier (Traité de matière médicale), pensent que l'opium exerce une action sédative sur le cerveau, qu'il affaiblit la puissance vivifiante que ce centre exerce sur toutes les parties du corps. Le professeur Alibert (Nouveaux élémens de thérapeutique ) reconnaît également l'action sédative de l'opium; toutefois il avoue que ce médicament, introduit dans les voies digestives, manifeste d'abord un effet irritant qui semble être le résultat de son application immédiate.

D'après les expériences de M. Broussais (Histoire des phlegmasies ), l'opium, appliqué sur des pustules ou sur des boutons rouges, commence par exciter vivement l'activité organique des parties qu'il touche; mais il engourdit l'instant d'après les mêmes capillaires qu'il avait excités, les resserre et les condense en les engourdissant. Pris intérieurement, l'opium, après avoir excité la sensibilité et la contractilité organiques dans l'estomac, y produit une stupeur de quelque durée, pendant laquelle la sécrétion muqueuse diminue et les oscillations péristaltiques sont ralenties. L'opium a donc en même temps un effet calmant et un effet astringent. Au reste, ce grand physiologiste recommande de ne jamais donner de laudanum lorsqu'il 
existe une affection inflammatoire générale, parce que cette diathèse s'alimente de toutes les excitations, quelque légères qu'elles soient.

L'opium, employé à forte dose, ne doit être rangé, d'après le professeur Orfila, ni parmi les narcotiques ni parmi les excitans ; il exerce un mode d'action particulier qui ne saurait être désigné exactement par aucune des dénominations actuellement en usage dans la matière médicale. Employé à petite dose, l’opium paraît borner son action au développement des symptômes qui annoncent la stupéfaction; quelquefois cependant il produit une excitation très-intense, effet qui dépend de l'idiosyncrasie.

Le nouvelle école italienne range l'opium parmi les excitans diffusibles. Suivant le professeur Rolando de Turin, ce médicament agit sur l'excitabilité moléculaire, et l'insensibilité qu'il produit, lorsqu'on l'administre à fortes doses, est le résultat de l'augmentation trop considérable des molécules. C'est ainsi qu'il explique l'assoupissement qui a lieu par son usage. ( Inductions physiologiques et pathologiques.)

$\mathrm{Au}$ milieu de ces opinions contradictoires, quelle est celle que le praticien doit adopter pour ne point compromettre le sort des malades confiés à ses soins? L'observation attentive des phénomènes produits par l'usage de l'opium doit surtout lui servir de guide; mais, en interrogeant l'expérience, il faut qu'il renonce aux théories vaines et subtiles qu'on a si souvent agitées au sein de l'école. L'opium, introduit en petite quantité dans l'estomac, provoque une excitation prompte, mais passagère. Si l'on réitère la dose, le pouls s'élève, 
le visage se colore, l'imagination s'éveille, la respiration est moins libre, les fonctions cutanées sont plus actives; et à ces phénomènes succède un sommeil tranquille, ou plus ou moins agité. $\Lambda$ dministré à grandes doses, il produit une excitation extrême, quelquefois une immobilité universelle, le délire, la stupeur, la sédation de l'encéphale, et la mort.

L'empire de l'habitude, le tempérament, le climat, peuvent néanmoins modifier son action, au point qu'on peut en avaler impunément des doses effrayantes; et l'on sait que les Orientaux font leurs délices de cette production végétale, qui les jette dans une voluptueuse ivresse et leur fait goûter un bonheur ineffable. Animé par sa vertu stimulante, le Turc brave le terrible appareil des combats et se précipite avec audace au milieu des rangs ennemis. Veut-il signaler ses exploits sur un thêâtre moins périlleux, il a également recours à l'influence active de l'opium; et alors, brûlant de désir et d'amour, il paraît fièrement au sein de son sérail, où , après avoir satisfait ses appétits sensuels, calmé ses irritations érotiques, il s'endort dans les bras de la volupté.

D'après le témoignage des voyageurs, les Indiens ont aussi le goût le plus vif pour l'opium, qui les enivre, leur procure des visions agréables, exalte leur imagination jusqu'à l'enthousiasme, et même jusqu'à la fureur.

Ceux qui veulent tenter quelque action désespérée en avalent de fortes doses; alors, dans leur ivresse, ils se jettent sur le premier objet qui se présente, sur un homme qu'ils n'ont jamais vu comme sur l'ennemi le plus implacable. Lorsqu'un Indien ainsi enivré d'o- 
pium court les rues en criant : amok! amok! il est proscrit par la loi, et qui que ce soit à le droit de le tuer.

Dans toutes les villes de Perse, il y a des cabarets où l'on vend une boisson faite avec les capsules de pavots, comme l'on vend du vin en Europe. Quand les buveurs entrent dans ces cabarets, ils sont mornes, défaits et languissans; mais après avoir pris deux ou trois tasses de ce breuvage, leur figure s'épanouit, ils se livrent à une gaité désordonnée, font et disent mille extravagances. Quelques-uns sont à moitié endormis; d'autres plongés dans une sorte d'extase et d'enchantement; d'autres se pâment de rire en gesticulant comme des maniaques.

Le marché de Theriaki-Tchachissy, près de la mosquée de Solymania, estl'endroit où les amateurs d'opium vont satisfaire leur goût pour ce délicieux poison. Les cafés où les theriaky (preneurs d'opium) ont coutume de se réunir sont distribués sur une grande place. Là ils attendent, sur un banc intérieur, les rêveries qui présentent à leur imagination enflammée les houris célestes et les jouissances dont elles doivent les enivrer dans le paradis de Mahomet. Le docteur Madden, qui a observé les thériaky, dit que leurs gestes sont effrayans. Ceux qui sont entièrement sous l'influence de l'opium poussent des cris, parlent d'une manière incohérente; leur visage est en feu, leurs yeux ont un éclat extraordinaire, et l'on aperçoit, dans tout l'ensemble de leur personne, quelque chose de sauvage et de terrible.

L'effet se manifeste ordinairement au bout de deux 
heures, et dure quatre ou cinq. Les doses d'opium varient depuis trois grains jusqu'à une drachme. L'affaiblissement moral et physique qui résulte de son usage est une chose effrayante; mais lorsqu'on s'est livré à cette funeste habitude, il est impossible d'y renoncer. Les théricky sont misérables et languissans jusqu'au moment où l'heure arrive de prendre leur dose quotidienne; mais des que l'influence de l'opium commence à se faire sentir, toutes leurs facultés assoupies se réveillent. Quelques-uns composent, dans cet état, d'excellens vers, adressent aux personnes présentes d'éloquens discours; d'autres, convaincus qu'ils sont en possession de l'empire, croient que tous les harems de l'Asie sont à leurs pieds.

Le docteur Madden, se trouvant dans un café, voulut essayer sur lui-même l'action de cette substance. II en prit un grain sans éprouver aucun effet sensible; il augmenta peu à peu jusqu'à la dose de quatre grains, et il ne tarda pas à éprouver une excitation très-vive. Ses facultés étaient agrandies; tout ce qu'il regardait semblait avoir augmenté de volume. Il ne ressentait pas le même plaisir quand il fermait les yeux. Il se hâta de retourner chez lui, craignant à chaque instant de faire quelque extravagance. " En marchant, je sentais à peine, dit-il, le sol sur lequel je m'avançais; il me semblait que je le rasais légèrement, poussé par l'impulsion de quelque agent invisible. On eût dit qu'une substance éthérée avait remplacé le sang dans mes veines, et me rendait plus léger que l'air. "

Dès qu'il fut rentré, il se mit au lit. Pendant toute la nuit, son imagination fut absorbée par des visions déli- 
cieuses. Le lendemain matin, il se leva avec un violent mal de tête; il était pâle et tellement affaibli, qu'il fut obligé de rester tout le jour étendu sur un sopha. Ce fut ainsi qu'il expia le premier essai qüil avait fait des voluptés des thériaky.

Darwin rapporte que dans l'Inde les voyageurs font souvent de longues routes sans se reposer, et sans autre nourriture qu'une petite boule de pâte préparée avec de l'opium, et une plus grosse pour leur cheval.

Nous avons cité dans l'introduction de cet ouvrage l'exemple d'une dame de Baltimore qui s'était habituée à l'usage de l'opium, et qui prenait tous les jours deux onces de laudanum liquide de Sydenham; cette dose était nécessaire pour ranimer ses forces et son courage, qui disparaissaient avec l'effet du laudanum. Une autre Américaine résidant à Paris, âgée d'environ soixante ans, très-maigre, très-pâle, d'une haute taille, d'une constitution nerveuse, prend tous les trois ou quatre jours une once d'opium; et elle en consommerait bien davantage, si cette drogne était d'un prix moins élevé. Lorsque sa provision est épuisée, elle est morose, triste, faible, abattue; mais une nouvelle dose la rend vive, alerte, et lui fait retrouver son énergie. Elle prend aussi beaucoup de café sans sucre; toutefois cette liqueur ne saurait remplacér l'opium, dont elle ressent plus efficacement la vertu excitante.

Dans l'état de maladie, l'opium, pris à des doses modérées, calme les douleurs, les convulsions et autres accidens spasmodiques qui dérivent de l'irritation et $\mathrm{du}$ trouble du système nerveux. Si, au contraire, les douleurs, les spasmes, sont causés par l'inflammation de 
quelque organe, l'opium, loin d'agir comme calmant, exaspère tous les symptômes, et ce n'est qu'après des doses très-fortes, ou souvent répétées, qu'il parvient à émousser et même à détruire la sensibilité, comme cela arrive après l'application immodérée de tout violent stimulus; mais alors l'action sédative de l'opium n'est que temporaire; et l'on voit ordinairement tous les accidens se renouveler, si toutefois la vitalité des parties n'est pas entièrement anéantie. C'est ainsi qu'on voit quelquefois la gangrène se manifester dans les inflammations où l'on a abusé des remèdes opiacés pour calmer les douleurs.

Ces effets de l'opium sembleraient prouver qu'il possède une action complexe, c'est-à-dire qu'il peut être à la fois excitant par l'action qu'il exerce sur le système vasculaire, et sédatif par l'impression qu'il communique au système nerveux. Cette opinion a été émise par Haller, Murray, Cabanis, Dumas; et l'observation clinique l'a souvent confirmée. Au reste, le tempérament, l'habitude, le climat, les doses plus ou moins élevées de l'opium, et surtout la nature de la maladie, doivent singulièrement modifier ses effets, et faire prévaloir tantôt son action stimulante, tantôt son action sédative. C'est ainsi qu'un estomac phlogosé ou disposé à l'inflammation ne supporte point ce médicament, qui agit alors par sa propriété stimulante, augmente la douleur et l'irritation.

PROPRIÉTÉS MÉDICALES.

De même que toutes les substances énergiques, l'opium a eu des partisans outrés, et en même temps 
d'injustes détracteurs. A la pratique téméraire de $\mathrm{Pa}$ racelse et des empiriques de tous les pays qui en ont fait un abus répréhensible, aux préventions de StahI, qui l'a frappé d'une sorte d'anathême dans sa fameuse dissertation De imposturá opii, nous opposerons les éloges d'un grand nombre de praticiens distingués, et surtout les brillans succès de Sydenham. C'est contre les douleurs, les irritations, les spasmes, l'éréthisme nerveux, qu'il faut d'abord invoquer l'influence sédative de l'opium. Lorsque la douleur est violente, continue ou souvent répétée, qu'elle dépend d'une irritation nerveuse plutôt que d'une irritation inflammatoire, l'opium en est le souverain remède; il la combat d'une manière directe, prompte, et comme spécifique. Les ouvrages de Sydenham, de Sarcone, de Stoll, etc., nous en fournissent de nombreux exemples. Un homme atteint du choléra-morbus éprouvait des vomissemens affreux avec des convulsions violentes, des sueurs fioides, et un pouls à peine sensible. Sydenham lui donna vingt-cinq gouttes de laudanum dans une cuillerée d'eau de cannelle. Ce mélange n'ayant point suffi, il le réitéra plusieurs fois, et il augmenta la dose du narcotique jusqu'à ce que l'irritation fût calmée.

M. Vaidy, médecin en chef de l'hôpital militaire de Lille, a reconnu les bons effets de l'opium contre cette maladie d'une manière si évidente, qu'il ne la combat jamais par un autre remède. Dans un cas très-grave, l'application des sangsues à l'épigastre augmenta notablement l'anxiété. Les évacuations avaient continué toute la nuit. Le lendemain matin, le pouls était entièrement déprimé, la peau froide et couverte d'une sueur 
visqueuse, le visage d'une pâleur extrême; les vomissemens duraient encore, et une crampe très-douloureuse se faisait sentir dans une jambe. M. Vaidy prescrivit six gouttes de laudanum dans une cuillerée de potion gommeuse, tous les quarts d'heure, jusqu'à cessation du vomissement. Ce remède arrêta promptement tous les accidens, et au quatrième jour la convalescence était confirmée. (Revue médicale, tome ir.)

Nous avons parlé dans notre introduction d'une affection cholérique des plus violentes, provoquée par deux tranches de melon, et qui céda promptement à une assez forte dose de laudanum liquide. Dans tous les cas où dominent une sensibilité vive, une sorte d'éréthisme nerveux, les remèdes opiacés sont en général d'un grand secours; mais leur emploi devient plus difficile, plus délicat, dans le choléra épidémique, et beaucoup de médecins ont pu s'en convaincre, en 1832 , lorsque ce fléau ravageait la capitale. Les uns écartaient soigneusementl'opium comme un médicament dangereux ; les autres, au contraire, en faisaient la base de leur traitement. Dans beaucoup de cas , ce puissant remède calmait momentanément les vomissemens, les évacuations intestinales, les crampes; mais la maladie n'était point domptée, et il fallait une méthode plus large, plus générale, comme l'observent fort bien les rédacteurs de la Gazette médicale de Paris. Le professeur Broussais, qui opposait presque toujours à cette maladie la glace et les saignées générales ou locales, employait cependant, après les évacuations sanguines, les lavemens opiacés pour apaiser la sensibilité du bas-ventre, les crampes, le malaise, l'agitation. "On 
en obtient alors, dit-il, un très-grand succès ; mais il n'en est pas de même lorsqu'on les applique prématurément. La quantité de l'opium dépend du sentiment du médecin : il y en a qui ne craignent point ce narcotique. Je ne suis pas de ce nombre, ajoute $\mathbf{M}$. Broussais ; je donne cinq, six gouttes de laudanum dans un demilavement, et je porte peu à peu la dose jusqu'à quarante, quand le malade est très-convulsé. "

Les médecins anglais sont ceux qui ont le plus insisté sur l'usage de l'opium dans le traitement du choléra, et ils citent de nombreux succèsà l'appui de leur méthode. Celle du docteur Robinson nous a paru très-remarquable; nous croyons devoir la faire connaître à nos lecteurs.

Choléra violent. Sinapisme de deux pouces d'épaisseur, préparé à l'eau bouillante, et appliqué sur la surface antérieure du corps, depuis le cou jusqu'aux. chevilles. Lavement préparé avec deux onces de mucilage d'amidon, et quatre-vingts à cent gouttes de laudanum. En même temps que le lavement, on donne deux pilules ainsi composées : opium pulvérisé, trois grains; proto-chlorure de mercure (calomel), dix-huit grains; camphre pulvérisé, douze grains. Faites six pilules égales. On prend une pilule chaque demi-heure jusqu'à ce que les vomissemens cessent et que les spasmes de l'estomac se calment. Cet effet a ordinairement lieu à la quatrième pilule, quelquefois même auparavant; d'autres fois au contraire il en faut davantage. On les casse en cinq ou six morceaux qu'on avale. dans une cuillerée d'eau fraîche pure.

Cas moins grave. Lavement; une pilule d'abord, 
puis une autre chaque demi-heure. Si le sujet est jeune et d'une forte constitution, on essaiera de faire une saignée de quinze à dix-huit onces. Limonade pour boisson, fraîche, mais non glacée; elle désaltère promptement, et elle est en même temps un des meilleurs anti-émétiques.

Les pilules sont rarement rejetées par le vomissement; elles diminuent l'irritabilité des organes, réveillent les faibles restes de l'action vitale, raniment la circulation, poussent fortement à la peau, qui participe ainsi à la stimulation générale. La moutarde fait sentir alors son influence révulsive, appelle l'irritation de l'intérieur à la surface du corps et le sang dans les vaisseaux cutanés, dégorge ainsi les viscères, débarrasse le cour et les poumons de l'oppression qui les paralysait. Peu à peu la chaleur et le pouls reparaissent; la soif cesse, et le malade commence à ressentir l'influence de l'opium; mais cette influence n'est nullement en rapport avec les doses du médicament. L'assoupissement survient bientôt, suivi d'un sommeil profond qui dure ordinairement jusqu'au lendemain matin, si c'est dans la journée que le traitement a été commencé. Pendant le sommeil, on voit se manifester sur tout le corps une douce transpiration qui quelquefois est trèsabondante.

I $^{\text {er }}$ degré du choléra. Dévoiement plus ou moins abondant, avec vomissemens. Quelquefois les vomissemens n'ont pas lieu.

$2^{\mathrm{e}}$ degré. Vomissemens et diarrhée, face glacée, lèvres bleues, glacées, langue blanche, froide, nez cyanosé, figure d'une teinte bleuâtre, plombée, etc. 
3 - degré. Choléra-asphyxie. Crampes; tout le corps glacé, cyanosé; pas le moindre frémissement dans les artères du bras; voix caverneuse, cholérique, sépulcrale ; soif dévorante.

Le traitement que nous venons d'exposer a guéri, d'après le docteur Robinson, un grand nombre de cholériques; il en a arraché plusieurs à une mort imminente. Une fois les carotides ne donnaient aucune pulsation; il y avait suppression totale de l'urine, évacuations involontaires, crampes violentes, face ridée, glacée, cyanosée, tout le corps raide, sans mouvement, haleine effleurant à peine la main placée devant la bouche, sueur froide, abondante, visqueuse, adhérente à la peau comme une dissolution de gonme.

Malgré les succès de cette méthode, nous ne saurions la conseiller aux cholériques jeunes, vigoureux, surexcités, aux personnes d'un tempérament pléthorique, disposées aux congestions sanguines. Les praticiens attentifs savent bien que l'opium ne calme pas toujours les mouvemens spasmodiques, les crampes, les vomissemens, etc. Cette surexcitation est souvent provoquée par quelque phlegmasie viscérale, et surtout par l'état inflammatoire des organes digestifs : les véritables calmans sont alors les émissions sanguines, les boissons gommeuses, les topiques émolliens. Au reste, iln'y a pas de symptôme qui ne puisse exiger, suivant les circonstances, des remèdes différens, et cette vérité est généralement reconnue en théorie; mais il faut avouer que dans la pratique elle ne sert de règle qu'à un petit nombre. Ainsi on a pu combattre tour à tour, et quel- 
quefois avec succès, les crampes, le vomissement, la diarrhée, par l'opium, par les sangsues, par les vomitifs, etc. ; et la cyanose, comme tout autre symptôme, a pu se dissiper tantôt par les stimulans, tantôt par les relâchans.

Mais une méthode qui a prévalu au commencement de l'épidémie, et qui a dû faire beaucoup de victimes, c'est la méthode sudorifique soutenue par les médicamens opiacés. Elle pouvait sans doute être favorable à quelques sujets lymphatiques, faibles, inertes, froids, glacés; mais les cholériques robustes, ardens, déjà enflammés, surexcités, qu'on frictionnait de la tête aux pieds, qu'on irritait, qu'on brûlait avec des briques rougies au feu, avec des fers presque incandescens, qu'on étouffait par des vapeurs aromatiques ou sous un amas de couvertures! oh! pour ceux-là, il fallait un miracle du Ciel pour les sauver.

Sarcone opposait aux affections pleurétiques dont l'invasion était marquée par une douleur violente, par un éréthisme nerveux dominant, les évacuations sanguines, et, immédiatement après, l'extrait d'opium. Huxham employait ce traitement avec le même succès.

Dans plusieurs cas d'empoisonnemens produits par des champignons ou des substances irritantes, j’ai donné moi-même l'opium à fortes doses, et j'ai dissipé des douleurs atroces, des crampes, des vomissemens, des cardialgies qui simulaient la gastro-entérite. J'ai observé dernièrement une néphrite du côté droit des plus violentes, qui a été combattue pendant huit jours par des saignées locales réitérées, des topiques émolliens, 
des bains, des potions huileuses et sédatives. Le malade, d'un tempérament très-irritable, a éprouvé des douleurs horribles pendant les huit premıers jours; le neuvième jour, elles ont paru s'apaiser, et le lendemain elles avaient presque entièrement disparu. Mais vers neuf heures du soir l'irritation s'est portée au rein gauche avec une violence extrême. Cette fois j'ai renoncé aux sangsues, et j’ai prescrit une saignée du bras, qui a été pratiquée sous mes yeux par M. Dechastelus, jeune chirurgien attaché au premier dispensaire. Une heure après la saignée, les douleurs étant les mêmes, le malade a pris trente-six gouttes de laudanum de Rousseau en deux doses. Vers minuit, il était déjà plus calme, et le lendemain matin toute sensation doulourense avait disparu. On a insisté cependant sur la méthode calmante pendant plusieurs jours.

Les douleurs spasmodiques, utérines, intestinales, etc., cèdent également à l'usage de l'opium; mais il ne faut pas attendre, pour l'administrer, que cet état nerveux soit transformé en phlegmasie. En général, on donne l'opium avec trop de timidité dans toutes ces affections où la douleur domine d'une manière pernicieuse. Administré à faibles doses ou à de trop longs intervalles, il agit comme stimulant, et tous les symptômes s'aggravent; il déploie, au contraire, une vertu sédative, si l'on en donne un ou deux grains toutes les deux ou trois heures.

Camérarius a recueilli un fait qui vient à l'appui de notre opinion. Un homme que de violentes douleurs de tête avaient rendu tout-à-coup aveugle, recouvra promptement la vue, après avoir pris quelques doses 
de laudanum qui dissipèrent les douleurs et ramenèrent le sommeil.

J'ai parlé ailleurs d'un homme de lettres sujet à une violente céphalalgie, dont les attaques s'annonçaient par des vomissemens et un spasme douloureux de l'é. pigastre. Cette affection nerveuse avait été vainement combattue par divers remèdes, par les bains, le quinquina, l'opium à petites doses, etc. Malgré le peu de succès de cette dernière substance, je lui conseillai d'insister sur son usage, et d'en augmenter graduellement les doses, afin de réprimer l'éréthisme nerveux, qui semblait s'accroître par l'impuissance des moyens qu'on lui avait opposés jusqu'alors. Le malade prit régulièrement pendant l'espace de huit jours, et toutes les vingt-quatre heures, trois grains d'extrait aqueux d'opium. Le neuvième jour, la céphalalgie reparut avec force, et cette nouvelle attaque fut accompagnée de spasmes violens. Le dixième jour, je prescrivis quatre grains d'opium; et cette dose, augmentée d'un grain tous les deux jours, fut enfin portée à celle de quinze grains. Cette méthode ayant été couronnée d'un plein succès, le malade diminua peu à peu la dose de l'opium, et en cessa tout-à-fait l'usage après deux mois d'intervalle.

On observe des irritations abdominales chroniques qui tiennent à un état de spasme des intestins, et qui se dissipent par l'opium, donné sous la forme de lavemens. M. Chopin cite un fait remarquable où l'application réitérée des sangsues et les bains ne produisirent qu'un très-faible soulagement. La sensibilité de l'estomac était tellement exaltée, qu'il pouvait à peine sup- 
porter l'alimentation la plus douce. Deux demi-lavemens pris le soir, et contenant chacun un demi-grain d'opium, procurèrent un sommeil paisible qui dura toute la nuit. On continua ainsi l'usage du narcotique, dont on augmenta peu à peu la dose, et tous les symptômes d'irritation s'évanouirent. (Recherches historiques et médicales sur l'opium.)

L'usage de l'opium dans les pyrexies exige la plus grande réserve. En général, tous les praticiens atlentifs ont pu observer qu'il est nuisible dans la première période des fièvres continues, surtout lorsque la diathèse inflammatoire prédomine. Il est également contre-indiqué dans les affections fébriles déterminées par la phlogose des membranes de l'estomac et des intestins : son application immédiate sur les tissus gastriques augmente la congestion sanguine dans les vaisseaux capillaires, et cette surexcitation peut être suivie de gangrène. Mais lorsqu'on a combattu la cause essentielle et primitive par les adoucissans et les antiphlogistiques, l'opium est très-utile pour calmer les anxiétés précordiales, les inquiétudes, les veilles opiniâtres, les spasmes et autres symptômes qui pervertissent la maladie et en retardent la solution. C'est ainsi que, dans la période nerveuse du typhus, Hildenbrand indique l'opium pour réprimer le délire furieux, la phrénésie, les diarrhées énervantes. Demian, qui le conseille aussi dans la fièvre lente nerveuse, dit qu'il convient surtout dans cette affection particulière des nerfs qui se manifeste par un état d'inquiétude et de crainte, en sorte que le malade ne peut gonter un seul instant de repos. Administré toutes les heures à la dose 
de cinq à dix gouttes, ce médicament favorise la transpiration, rend la circulation du sang plus libre, plus égale, dissipe le délire, ranime les forces, et procure un sommeil rëparateur. ( Снrist. Gotтl. DEmiani Dissertatio de febre lentâ nervosâ. ) Avouons toutefois qu'il n'est pas très-facile de distinguer si le délire, les mouvemens convulsifs qui se manifestent dans le cours du typhus, tiennent à un état nerveux ou à une congestion inflammatoire du cerveau. Lorsqu'on observe ces symptômes ataxiques, et que les forces ne sont pas épuisées, il est plus sage de les combattre par des boissons rafraîchissantes, par l'application des sangsues ou des ventouses scarifiées, par les pédiluves, les topiques révulsifs : on donne ensuite l'opium combiné avec les antispasmodiques, si ces premiers moyens sont insuffisans.

On a préconisé les avantages de l'opium dans le traitement d'une affection cérébrale causée par l'abus des liqueurs spiritueuses, à laquelle on a donné le nom de delirium tremens, parce que le tremblement des mains en est un signe constant. Le docteur Sutton, médecin anglais, rapporte plusieurs observations favorables à ce médicament administré à haute dose. Dans l'espace de six jours, un malade en a consommé soixante-onze grains. Un autre malade affecté de délire avec paralysie prit toutes les trois heures trois. grains d'opium; le lendemain il put exécuter des mouvemens avec le membre paralysé. Les évacuations sanguines, si utiles dans la plupart des affections cérébrales, ne doivent être employées ici qu'aves la plus grande restriction. Ce n'est que dans le cas de plé- 
thore, et au commencement de la maladie, que l'on doit pratiquer la saignée. Immédiatement après, le docteur Sutton conseille de donner l'opium en quantité suffisante : la tranquillité du malade et le sommeil sont les premiers effets de ce traitement. M. Ehrart a vu deux exeinples de lelirium tremens survenu après la scarlatine où l'opium a eu le même succès. Le docteur Albers, qui a également observé cette maladie, conseille de commencer le traitement par la saignée chez les sujets pléthoriques; il pense aussi que, dans la plupart des cas, on doit débuter par de petites doses d'opiun. Un phénomène qui l'a frappé, c'est l'appétit prodigieux que le malade éprouve après ce médicament. (Nouvelle bibliothèque germanique.)

On trouve dans la Gazette médicale de Paris (octobre 1832 ) une belle observation de delirium tremens recueillie par le docteur Robert, médecin en chef des hôpitaux de Lanğres.

Un portefaix, jeune encore et d'une forte constitution, est pris de délire avec tremblement des extrémités thoraciques et d'une partie du corps, mais surtout des mains. Malgré les pédiluves, les émulsions, les boissons rafiaîchissantes et la diète, le délire augmente. Le malade est dans un état d'angoisse et d'hallucination. L'agitation des extrémités supérieures et même de presque tout le corps augmente; la face s'altère excessivement. On applique un vésicatoire au bras, et on administre vingt gouttes de laudanum liquide avec autant d'éther sulphurique. Le délire devient furieux ; le tremblement est violent et continuel. Le malade pousse de grands cris, et cause beaucoup 
de trouble dans la salle où il est couché; toutefois son pouls est presque dans un état naturel. En proie à de fréquentes hallucinations, il croit voir des personnes avec lesquelles il avait eu des démêlés dans un cabaret, quelques jours avant son entrée à l'hôpital, et, dans cette excessive agitation, il sort de son lit, parcourt la salle, ouvre une des fenêtres, saute dans la cour et se dirige vers une grande porte qui donnait sur la rue, afin de se sauver; mais trouvant cette porte fermée, il grimpe après le mur pour atteindre la sonnette, qu'il agite vigoureusement, jusqu'à ce qu'on vienne le reconduire à son lit. A ces désordres cérébraux se joignait la décomposition des traits du visage. Les yeux offraient un aspect extraordinaire, beaucoup plus facile à saisir qu'à décrire.

Le lendemain il y eut une espèce de rémission; mais le tremblement des extrémités supérieures, l'altération de la face et le trouble des facultés mentales étaient toujours portés à un assez haut degré d'intensité. On avait remarqué pendant la nuit des soubresauts. A raison des accidens de la veille, et en même temps pour prévenir la violence de la réaction qui pouvait avoir lieu, M. Robert prescrivit soixantequinze gouttes de laudanum liquide à prendre pendant la journée, en trois doses, dans une infusion de fleurs de tilleul. C'était principalement durant la nuit que le délire et le tremblement se déclaraient avec le plus de force. Le matin, le malade était plus paisible. Après la potion sédative il éprouva un soulagement marqué; il avait pu dormir, et le délire, quoique persévérant, était moins violent', moins verbeux. Quant 
au tremblement, il ne paraissait pas avoir diminué. La face, sans être colorée, offrait encore un aspect extraordinaire, avec un mélange d'étonnement et de rire sardonique. Le pouls était un peu serré, lent toutefois et point fébrile. On donna un lavement et cinquante gouttes de laudanum liquide en deux doses, durant le cours de la journée.

La nuit fut moins agitée, et le malade eut plusieurs heures de sommeil. Le délire et le tremblement avaient beaucoup diminué. On administra encore cinquante gouttes de laudanum liquide de Sydenham en deux doses égales. La diète fut moins stricte.

Le jour suivant, M. Robert ne remarqua à la visite du matin qu'un léger tremblement des mains. Les idées étaient beaucoup plus nettes, et le pouls n'annonçait aucun degré de fièvre. On donna des boissons délayantes, des émulsions, et vingt gouttes de laudanum liquide en une seule fois. Enfin il ne restait plus qu'un tremblement des mains imperceptible. Le délire était dissipé, ainsi que les hallucinations. Le sommeil avait été tranquille et prolongé; le pouls était lent, et la peau offrait pour la première fois un peu de moiteur. Malgré ces changemens favorables, on donna encore vingt gouttes de laudanum en une seule dose. Le $i^{\mathrm{e}}$ jour, la maladie parut entièrement terminée, sans laisser apercevoir aucun accident consécutif. La convalescence s'accompagna néanmoins d'une sorte de débilité qui céda à l'usage des toniqnes.

Les anciens faisaient un fréquent usage de l'opium dans le traitement des fièvres intermittentes. Galien, Alexandre de Tralles, Aëtius, Paul d'Égine, les mé- 
decins arabes ont employé la thériaque et autres compositions opiacées. Dans un temps beaucoup plus rapproché de nous, Plater, Rivière, Horst, Ettmuller, Wédel, etc., ont suivi cette méthode avec plus ou moins d'avantage. Toutefois on avait à peu près abandonné l'opium, lorsque Berryat l'a proclamé comme un fébrifuge nouveau dans les Mémoires de l'académie des Sciences de Paris, ce qui lui a attiré une critique sévère de la part de Cullen. C'est d'après une série d'expériences renouvelées pendant l'espace de six ans, que Berryat s'est convaincu de l'efficacité de l'opium. Sa méthode consiste à donner, une heure avant l'accès, dix-huit à trente gouttes de teinture anodine de Sydenham dans une demi-tasse d'infusion de petite centaurée: cette dose est pour les adultes. Les enfans de trois à cinq ans doivent prendre cinq, six ou huit gouttes de laudanum; ceux de dix à douze ans, dix ou douze gouttes. Une heure après l'administration de ce médicament, le pouls se relève, la peau se détend, s'humecte, et le sommeil survient; rarement il est nécessaire de le répéter. Un enfant atteint depuis trois ans d'une fièvre double tierce qui avait résisté à tous les remèdes fut radicalement guéri en prenant quinze gouttes de laudanum une heure avant la période du froid. Lind a confirméles propriétés antifébriles du laudanum sur plus de trois cents malades; mais il veut qu'on l'administre, une demi-heure après le développement de la chaleur, à la dose de quinze à vingt gouttes mêlées avec deux gros de sirop diacode. Lorsque ce médicament ne diminue pas d'une manière sensible les symptômes fébriles, il rend du moins l'apyrexie plus parfaite, et on 
n'a besoin ensuite que de quelques faibles doses de quirrquina pour dissiper la fièvre. Ce médecin recommande de frictionner, au commencement du paroxysme, l'épine dorsale des enfans avec la teinture thébaïque mêlée avec suffisante quantité de liniment savonneux. Lorsque ces frictions ne produisent point l'effet désiré, on leur donne, pendant le stade de la chaleur, deux ou trois petites cuillerées de sirop diacode. Pour obtenir une guérison parfaite, il est quelquefois nécessaire de donner des lavemens où l'on fait entrer de l'extrait de quinquina et quelques gouttes de laudanum.

Odier de Genève, le docteur Grégory, M. Hegewisch, médecin à Kiel, et quelques autres praticiens, ont adopté la méthode de Lind. Le docteur Hegewisch, qui a observé un grand nombre de fièvres intermittentes, préfère donner l'opium en substance à la dose d'un grain dans la seconde période de l'accès, c'est-àdire lorsque le malade n'éprouve plus aucun sentiment de froid. Le professeur Hallé, dont la perte se fait chaque jour plus vivement sentir, employait souvent l'opium comme fébrifuge; il donnait le laudanum de Sydenham ou les gouttes de Rousseau avec l'éther ou l'eau de menthe. Cette mixture était administrée au malade au moment même du frisson. Ensuite il augmentait graduellement d'accès en accès la dose de l'opium, jusqu'à ce qu'il eût obtenu l'effet antispasmodique qu'il voulait produire, et que le frisson, diminué d'abord, fût entièrement effacé. M. Guilbert a donné la même potion, et il a vu les symptômes fébriles se dissiper peu à peu pendant les deux premiers 
accès. Le troisième, à peine sensible, a signalé la guérison complète de la fièvre.

D’autres médecins ont recommandé la combinaisonde l'opium avec l'émétique, comme un moyen fébrifuge très-efficace. Cette méthode, employée d'abord par le docteur Peysson, a été mise ensuite à l'épreuve avec beaucoup de succès par M. Jourdain, médecin en chef de l'hôpital militaire de Dax, dans le traitement des fièvres intermittentes quotidiennes, tierces et double-tierces ordinaires; mais elle a rarement réussi dans les fièvres quartes et dans les fièvres dont les accès présentaient des symptômes graves ou pernicieux. Ce nouveau fébrifuge, essayé dans le Nord, n'a point produit, à beaucoup près, les mêmes avantages, et le docteur Varlet, médecin à Mons en Belgique, annonce qu'il a été obligé de l'abandonner pour avoir recours au quinquina seul ou uni à l'opium, selon les circonstances.

Au reste, long-temps avant M. Peysson, un médecin de. l'École de Montpellier, M. Arnal, avait recommandé comme un excellent fébrifuge la combinaison de la thériaque avec l'émétique. Ce fut à l'hôpital de Castelnaudary qu'il employa ce mélange. Il faisait prendre dans la journée trois ou quatre pilules contenant chacune un quart de grain de tartre stibié et quatre ou cinq grains de thériaque. Cette méthode fut suivie pour toutes les fièvres intermittentes, et elle procura des succès constans et presque inattendus, même au milieu de l'hiver.

On convient généralement que les fièvres intermittentes simplesqui attaquent des sujets nerveux et d'une 
grande susceptibilité se guérissent par les remèdes les plus doux; que le quinquina aggrave celles qui s'accompagnent d'une irritation vive, locale ou générale; tandis qu'on les voit céder aux antiphlogistiques, aux tempérans, aux sédatifs; que, dans les cas où elles se montrent rebelles, il est toujours prudent, afin de ménager la sensibilité, d'associer les calmans à l'écorce du Pérou; mais l'emploi de l'opium, préconisé dans les fièvresintermittentes pernicieuses, offre de plus grandes difficultés, surtout lorsque les symptômes ataxiques se concentrent vers l'encéphale; et malgré l'heureuse hardiesse de Rivière, de Hoffmann de Munster, et de quelques autres médecins, je n'oserais le conseiller contre la fièvre soporeuse.

La pratique de notre Barthez dans ces fièvres graves ne saurait être oubliée ici. D'après les observations de cet illustre professeur, l'opium, administré à haute dose, pendant l'accès même des fièvres intermittentes malignes où prédomine un état spasmodique, peut sauver les malades d'une mort presque certaine. Si le spasme de l'œsophage s'oppose à la déglutition, il faut administrer l'opium en lavement, ou bien frictionner le rachis, l'abdomen et la partie inférieure des cuisses avec un mélange de laudanum et d'éther. Le danger étant dissipé, on profite des premiers instans de l'apyrexie pour donner le quinquina, et prévenir ainsi le paroxysme suivant. Toutefois, comme le remarque Barthez, l'opium serait un remède dangereux, s'il existait dans les viscères, et particulièrement dans le cerveau et dans le poumon, une lésion organique ou une disposition antérieure à la fièvre intermittente maligne 
qui rendît la circulation difficile, et qui, avec le concours de l'état spasmodique fébrile, pût déterminer la formation d'une affection apoplectique ou inflammatoire.

Malgré les éloges accordés à ce remède héroïque, son emploi dans les fièvres intermittentes exige la plus grande circonspection. Les fastes de l'art renferment plus d'un exemple de ses pernicieux effets. Morton parle, dans sa Pyrétologie, d'un malade qui, ayant pris un médicament opiacé au commencement du paroxysme, fut frappé d'apoplexie, et mourut dans l'espace de vingt-quatre heures. Au rapport d'Eller ( $\mathrm{Ob}$ servationes de cognoscendis et curandis morbis), le laudanum, administré également dès l'invasion de l'accès, a causế d'abord un état comateux, et ensuite une phrénésie mortelle. Pris au forl de l'accès, l'opium n'a pas les mêmes inconvéniens, parce que l'éréthisme nerveux lui oppose alors une vive résistance et enchaîne son action narcotique; mais il n'en est pas de même lorsqu'on l'administre pendant l'apyrexie ou à une époque trop éloignée da retour de l'accès. Le docteur Mérat a vu périr à la clinique de la Faculté une femme à qui on avait donné le matin par mégarde quatre-vingts gouttes de laudanum pour combattre une fièvre intermittente grave dont l'accès ne devait avoir lieu que le soir.

Fallope rapporte un fait analogue. Un criminel prit deux drachmes d'opium au commencement d'un accès de fièvre quarte; mais cette même dose prise pendant l'intermission de la fièvre lui causa la mort.

L'excellence de l'opium se fait surtout remarquer 
dans le traitement des maladies convulsives. La plus redoutable de ces névroses, le tétanos, cède quelquefois à ce puissant narcotique; mais alors il faut en élever les doses jusqu'à un demi-gros, et même plus, en vingt-quatre heures. Chalmers a donné, dans le même espace de temps, une once de teinture d'opium sans produire d'effet stupéfiant; mais, certes, personne n'a été aussi audacieux qu'un médecin anglais dont parle Murray, qui fit prendre dans une nuit vingt onces de laudanum à un malade affecté de tétanos. Ces doses énormes ne calmèrent ni le spasme ni l'insomnie; cependant il parvint à guérir l'affection convulsive en continuant l'usage de l'opium uni au quinquina. Il est bien plus sage de débuter par des doses modérées, qu'on renouvelle suivant la violence des symptômes. C'est ainsi que M. le docteur Delens a recueilli à l'hôpital des Enfans une observation de laquelle il résulte que l'opium, administré d'abord à la dose de trois ou quatre grains par jour, et porté successivement à celle d'un demi-gros, a guéri dans l'espace d'environ un mois une affection tétanique survenue à un enfant adonné à la masturbation et très-irritable.

L'opium n'a point la même efficacité contre le tétanos traumatique; on a beaucoup vanté néanmoins la méthode de Stutz, laquelle consiste dans l'usage simultané de l'opium et du carbonate de potasse. On assure que ces deux substances ainsi combinées ont une action particulière contre cette terrible maladie.

Marcus, médecin de l'hôpital de Bamberg, a dissipé un trismus rebelle en variant les préparations d'opium, dont on augmentait chaque jour les doses. D'abord le 
laudanum liquide procura un peu de relâchement dans les muscles de la mâchoire. On substitua au laudanum des poudres composées de quatre à six grains d'opium et de six à huit grains de camphre, qu'on renouvelait trois fois par jour. L'extrême dégoût, la tristesse, la constipation que le malade éprouvait, firent suspendre l'usage des poudres pendant trente-six heures, et l'on profita de cet intervalle pour administrer des bains chauds et d'autres émolliens. Mais la raideur des muscles devint plus intense, et il s'y joignit des mouvemens spasmodiques qui se communiqquèrent à tout le corps. Alors on crut devoir remplacer les poudres par un mélange d'une once de laudanum liquide et de trois onces de teinture de valériane, dont on donna de soixante à cent gouttes toutes les heures. On fit en même temps des frictions sur le cou et sur les épaules avec un liniment composé d'une once de teinture thébaïque, d'une demi-once de camphre et de quatre onces d'esprit de vin. Le malade ne tarda pas à être mieux après l'usage de ces remèdes. On continua ainsi pendant quelques jours encore, et il sortit enfin de l'hôpital parfaitement guéri. (Bibliothèque germanique.)

L'usage de l'opium a quelquefois été avantageux contre l'épilepsie. Dehaën et Morgagni citent des guérisons opérées par ce médicament. En effet, il doit agir comme un puissant antispasmodique dans les cas où l'épilepsie dépend de quelque affection morale ou d'une sensibilité exquise des nerfs ; mais certainement il est pernicieux lorsque la maladie est occasionée par l'engorgement sanguin de l'organe cérébral. Il en 
est de même de la manie, de l'hystérie, de l'hypochondrie, et autres affections nerveuses contre lesquelles on emploie journellement l'opium sans distinguer les causes morbifiques. Que de maux entraîne l'usage inconsidéré des narcotiques, lorsque ces névroses dépendent d'un état d'inflammation et de pléthore, d'une congestion bilieuse ou muqueuse du système abdominal ( I)!

Mais l'opium est d'un puissant secours dans les aberrations nerveuses qui dérivent de causes morales, qui sont fomentées par des passions vives, exaltées, et qui s'accompagnent d'une sorte de désordre dans les organes du sentiment. On doit alors préférer les préparations les plus douces, telles que le sirop composé avec les capsules du pavot, et prescrire en même temps des émulsions, des boissons tempérantes et anodines.

(1) C'est sans doute cette variété dans les complications des maladies nerveuses qui a fait employer un si grand nombre de moyens thérapeutiques, tous préconisés outre mesure, et tous utiles, lorsqu'ils ont été administrés dans des cas convenables. On a voulu généraliser une seule méthode, et on n'a point senti que la diversité des élémens associés devait établir une différence analogue dans leur traitement, puisque chacun d'eux exigeait des remèdes particuliers, et souvent fort opposés. Cette partie de la médecine a été presque entièrement assujettie à l'esprit de système, ou, pour mieux dire, à l'influence de la mode. (Dupau, De l'Eréthisme nerveux, ou Analyse des affections nerveuses.) Cette monographie, écrite dans les meilleurs principes, annonce dans son jeune auteur beaucoup d'instruction et de goùt. M. Dupau analyse surtout avec beaucoup de sagacité les caractères propres à l'éréthisme nerveux et à l'irritation inflammatoire, distinction très-importante, sur laquelle reposent les méthodes curatives. Ce praticien distingué est aujourd'hui professeur agrégé à la faculté de médecine de Montpellier, et médecin en chef de l'hôpital Lagrave, à Toulouse. 
Les maux de nerf's, autrefois si fréquens, ensuite beaucoup plus rares, se montrent aujourd'hui sous des formes très-variées, et font souvent le désespoir des malades et des médecins. Parmi les causes qui leur donnent naissance, il faut surtout compter les commotions politiques, les discordes civiles. Ici l'ambition, l'orgueil, une sorte de fanatisme philosophique, une perfectibilité indéfinie, tourmentent quelques têtes ardentes, séduisent quelques optimistes de bonne foi ; là des sentimens moins élevés, la cupidité, la soif des richesses, l'amour du luxe, la vanité avec toutes ses faiblesses, l'intrigue avec ses mensonges, sa corruption, son immoralité, poussent le plus grand nombre. Les uns, exaltés, enivrés par un succès inespéré, tombent dans une sorte de délire fébrile qui fausse leur jugement, les livre à toutes les folies d'un orgueil sans frein, et les rend presque mécontens d'un revirement de fortune qui les a placés si haut; les autres, déçus de leurs espérances, trompés dans leur ambition, réduits à une vie simple, à des privations qu'ils n'ont pas le courage de supporter, s'irritent, s'enflamment, s'abreuvent de fiel, le répandent dans leurs écrits, et se consument dans l'attente de changemens qui n'arrivent point.

Hors de la sphère politique, c'est l'envie qui se repaît de désirs, de chagrin et de colère, l'envie qui pâlit, qui frissonne au moindre succès d'autrui, qu'une fièvre lente, habituelle, ronge, dévore. Tout le monde veut être riche, faire du fracas, vivre au milieu des jouissances. La médiocrité, qui a tant de charmes pour l'homme sage, est aujourd'hui méprisée et presque un 
objet d'horreur. Eh ! qui ne connaît les effets de la colère, des emportemens habituels? Lisez Sénèque, ce philosophe éloquent, quelquefois sublime, qui a sondé toutes les profondeurs du cœur humain. La colère est un ouragan qui détruit, renverse tout sur son passage; un feu qui brûle, consume, anéantit; un poison qui dévore le cour où il a pris naissance. Tous les vaisseaux se gonflent, les yeux sortent de leurs orbites, ils étincellent de fureur. Tout le corps s'agite, les lèvres sont tremblantes, convulsives; la menace et l'injure sortent de la bouche avec des flots d'écume; le visage se couvre tour à tour d'une rougeur livide et d'une pâleur cadavéreuse. A ces explosions violentes succède une sorte d'abattement moral escorté des phénomènes nerveux les plus étranges. Les organes de la sensibilité se dépravent; la bile, le sang, tous les fluides s'altèrent, se décomposent.

Dans les lettres, dans les sciences, dan:s les arts, on voit des hommes profonds, habiles, mais bizarres, ardens, exagérés, que des méditations fortes et soutenues conduisent quelquefois aux plus déplorables visions, à des frayeurs ridicules, à des tremblemens nerveux, à des mouvemens convulsifs. L'homme que l'orgueil égare se complaît dans son propre mérite; il . l'exagère, il le prône partout, mais il ne saurait se contenter de son propre suffrage; il exige impérieusement ou il mendie celui des autres, et il s'irrite quand il ne peut l'obtenir. Toute une vie passée dans des méditations peu fécondes, dans des lectures, des travaux sans fruit; des prétentions frustrées, les regrets tardifs d'un temps perdu, dissipé sans gloire, le décourage- 
ment, le chagrin, puis l'inaction, l'ennui, la paresse, enfin, à titre de compensation, l'abus des plaisirs sensuels : voilà l'origine d'une foule de maladies, d'affections indéterminées, qui éludent toute espèce de traitement, et que les remèdes vulgaires rendent encore plus douloureuses.

Nous ne parlons point des cercles, des réunions à la mode, assemblage bizarre de goûts, de passions, de vertus et de vices, où règnent la vanité, le luxe, l'anbition, la joie, l'ennui ; où naissent et s'évanouissent des liaisons éphémères; où la cupidité, l'amour du jeu, épient les chances du hasard, brillent d'une joie expansive quand la fortune les favorise, s'attristent, souffrent, s'irritent, quand elle leur est contraire. Nous passons également sous silence mille autres causes, nées de notre état social, source inépuisable d'anomalies nerveuses, se développant avec plus ou moins de rapidité, affectant des formes si bizarres, si diverses. Quelques-unes de ces affections se lient à des irritations, à des phlegmasies viscérales chroniques; beaucoup d'autres tiennent seulement à une lésion spéciale du système nerveux, et demandent, pour être traitées avec succès, tantôt une méthode anodine et relâchante, lorsque le spasme et l'irritation dominent, tantôt l'emploi des toniques et des excitans modérés, lorsque la faiblesse se révèle dans tout le système et que les actes de la vie se font avec une sorte de lenteur. Ici le tempérament du sujet, son âge, ses habitudes, ses passions, sa manière de vivre, peuvent jeter une vive lumière sur le diagnostic, et conduire le médecin à une méthode sage, rationnelle, indépendante de toute théorie exclusive. 
C'est dans les souffrances morales, dans ces maux de l'âme qui répandent sur la vie tant d'amertume, éloignent le sommeil, et font les nuits si longues, si douloureuses, que l'opium donné par une main intelligente produit quelquefois un bien inespéré. Le médecin doit alors seconder les effets de cette substance par un langage consolant, plein d'une tendre et généreuse pitié; éloigner du malade tous les objets qui pourraient irriter son chagrin, déployer toutes les ressources d'une hygiène rationnelle, prescrire un régime frais, adoucissant, des lectures philosophiques qui relèvent le courage, des promenades dans les champs, sur des coteaux entourés de paysages d'un aspect gracieux; en un mot, procurer au malade tout ce qui peut le distraire, le calmer, faire entendre à son oreille une douce mélodie, des sons qui captivent son esprit, charment ses douleurs. N'a-t-on pas vu le bruit monotone de l'eau qui tombe goutte à goutte dans un bassin provoquer un sommeil paisible? C'est ainsi que le frémissement des feuilles dans la forêt ou le murmure d'un ruisseau fuyant sur des cailloux, portent le calme dans notre âme, endorment nos douleurs.

\section{......... Cum nilurmure labens \\ Invitat somnos crepitantibus unda lapillis. \\ Ovin.}

Dans les grandes perturbations de l'esprit, dans les angoisses du cour, procurer un peu de sommeil au malade, lui faire onblier un instant la vie, c'est commencer sa guérison.

Ces soins, qui peuvent paraître minutieux, ridicules 
même ì certains esprits forts, aux hommes positif's, ne se trouvent point dans la pratique ordinaire; ils sont inspirés par une médecine plus élevée. Les anciens qu'on dénigre tant aujourd'hui nous en ont donné l'exemple.

Il est peu de névralgies où l'opium ne soit employé journellement avec plus ou moins d'avantage. J'en ai éprouvé moi-même de très-bons effets à une époque où j'étais cruellement tourmenté par une névralgie sciatique. Les antiphlogistiques, l'application des sangsues, des ventouses scarifiées, des vésicatoires, les fumigations, les douches, les bains de toute espèce, rien ne pouvait adoucir mes souffrances. J'éprouvais tous les soirs un paroxysme s'annonçant par des élancemens douloureux et rapides, qui se répétaient successivement depuis l'origine du nerf sciatique jusque dans ses ramifications. De toutes les préparations d'opium dont je fis usage, le laudanum liquide fut constamment celle qui me donna le plus de calme. J'en prenais vingt-cinq gouttes, dans un peu d'eau de fleur d'orange sucrée, une heure avant le paroxysme. Peu à peu les douleurs s'apaisèrent, et je n'éprouvai plus ces angoisses qui accompagnent cette espèce de névralgie, et vont quelquefois jusqu'à la syncope. On pratiquait en même temps des onctions douces sur la région sacro-lombaire et sur toute l'étendue du rachis avec deux onces d'huile de camomille et deux gros de laudanum. Ces parties étaient, inmédiatement après, recouvertes de flanelles chaudes.

J'ai vu M. le professeur Boyer guérir en très-peu de temps, à l'aide de l'opium employé intérieurement et 
sous la forme de lotions, des névralgies mammaires qui avaient résisté aux saignées locales et à la méthode antiphlogistique.

D'après les observations de Stoll, l'opium, donné à hautes doses, exerce une action spécifique contre l'affection du canal alimentaire connue sous le nom de colique de plomb. Un de ses malades, éprouvant un vomissement violent, en prit treize grains dans l'espace d'une seule nuit. Il avait soin d'en faire continuer l'usage pendant la convalescence, et d'en prescrire tous les jours six ou huit grains, divisés en plusieurs doses. Mais une remarque qui n'a point échappé à la sagacité de ce grand praticien, c'est que la colique saturnine peut se compliquer avec un état bilieux ou inflammatoire, d'après la nature de la constitution régnante. Dans le premier cas, il est nécessaire d'administrer les évacuans avant de recourir à l'opium; dans le second, la saignée est indispensable : on la réitère, si l'inflammation l'exige, et on donne en même temps des boissons tièdes, émollientes. On passe ensuite aux préparations d'opium, lorsque la diathèse inflammatoire est réduite. Ce procédé clinique diffère beaucoup de celui qu'on emploie vulgairement à l'hôpital de la Charité. On sait que la colique de plomb est combattue dans cet établissement par les vomitifs, les évacuans, les tisanes de toute espèce, combinés avec l'opium; mais cette méthode porte évidemment le cachet d'une dégoûtante polypharmacie; et si elle est utile lorsque l'affection des intestins est compliquée d'un état bilieux, elle doit être meurtrière dans les cas d'inflammation viscérale, et lorsque l'irritation nerveuse est portée au plus haut 
degré. Stoll a vu des malheureux se rouler dans leur lit par l'excès de la douleur. Qui voudrait alors prescrire les drastiques les plus violens? Lorsque les évacuans sont indiqués, nous avons dans le tartre émétique et dans l'huile de ricin deux médicamens d'une activité convenable.

Le docteur Sainte-Marie emploie avec un heureux succès l'huile de ricin, à la dose de deux ou trois onces, tous les matins; il donne ensuite le soir un à trois grains d'extrait gommeux d'opium. A l'aide de cette méthode, remarquable par sa simplicité, il est parvenu à dissiper en vingt jours, et quelquefois beaucoup plus tôt, ces affreuses coliques. Le professeur Fodéré (Traité de médecine légale) observe avec raison qu'il faut distinguer dans cette espèce d'empoisonnement le temps du paroxysme pour placer alors les huileux, les émolliens, combinés avecle laudanum. Hors du paroxysme, on administre l'huile de ricin ou tout autre évacuant assez actif pour débarrasser le conduit alimentaire. Toutefois, on réussit rarement si l'on ne réunit l'opium aux purgatifs.

Depuis que Sydenham a constaté les bons effets de l'opium dans le traitement de la dysenterie, on a vu des médecins prescrire cette substance dans toutes les périodes de la maladie, sans distinguer son caractère, ses causes, ses complications. Lorsque la fluxion établie sur les intestins est encore sous l'influence nerveuse, on peut sans contredit la combattre par l'opium, les boissons délayantes et diaphorétiques. Cette méthode, qui a pour but d'apaiser l'irritation intestinale et de rappeler les mouvemens vers la périphérie du corps, 
a été employée avec succès par Stoll dans les mêmes circonstances. Le docteur Jacobs, médecin belge, l'a imitée, et lui a donné une bien plus grande extension, puisqu'il n'a pas craint d'avoir recours à l'opium dans la dysenterie parvenue au plus haut degré d'intensité. Une religieuse était en proie à un flux dysentérique accompagné de douleurs atroces : on lui prescrivit toutes les six heures seize gouttes de laudanum liquide de Sydenham. Ce lieême remède fut administré chaque fois que les douleurs reparurent, et la guérison eut lieu le septième jour. Un autre malade, âgé de trente ans, très-fort et très-robuste, éprouvait des épreintes cruelles et des tranchées violentes; les selles n'entraînaient qu'un peu de mucus teint de sang. L'usage d'une mixture composée de six grains d'opium, de deux onces de sirop de pavot, et de six onces d'eau distillée, dont on donnait deux cuillerées de demi-heure en demiheure, calma la violence des symptômes. Le malade buvait abondamment de l'eau d'orge. La mixture fut répétée le troisième jour; 'le neuvième, la guérison fut complète. Suivant le docteur Jacobs, l'effet de l'opium est si merveilleux, si prompt, șon usage si facile, qu'il peut être considéré comme l'antidote le plus sûr contre la dysenterie. (Traité de la dysenterie en général, contenant une nouvelle inéthode curative.)

Le docteur Rademacher a donné la relation d'une dysenterie qui régna à Cologne dans le mois d'aon̂t de 1802 , et contre laquelle l'opium manifesta une vertu spécifique. Cette dysenterie dépendait d'un état d'irritation ou de spasme fixé sur les intestins. Les émétiques, les purgatifs, même les plus doux, étaient nui- 
sibles, tandis que l'opium faisait ordinairement cesser les vomissemens, les tranchées, le ténesme et les autres symptômes d'irritation qui accompagnaient l'épidémie. (Libellus de dysenteriâ.)

M. Latour, qui a publié un excellent mémoire sur la dysenterie dans le premier volume du Bulletin des sciences physiques d'Orléans, a également constaté les hautes vertus de l'opium administré au commencement de la maladie. Ordinairement ce remède calmait non-seulement les tranchées et les déjections, mais il les faisait disparaitre en vingt-quatre heures. Plusieurs médecins d'Orléans ont employé la même méthode avec un égal succès, soit en ville, soit dans les villages circonvoisins où régnait une dysenterie épidémique. Mais l'opium, qui était si utile le premier, le second ou le troisième jour, c'est-à-dire lorsque la fluxion était encore dans toute sa simplicité, ne produisait plus les mêmes effets lorsque la phlegmasie nuembraneuse avait jeté de profondes racines.

En effet, lorsque la tunique interne des intestins est dans un véritable état d'inflammation, que la peau est chande, sèche, le pouls fébrile, le ventre tendu, douloureux, les remèdes opiacés ne peuvent qu'accroître cet appareil phlogistique; et si l'on insiste sur cette médication intempestive, on provoque la gangrène des parties enflammées. Les évacuations sanguines, les bains, les demi-lavemens, les fomentations émollientes, les boissons tièdes, mucilagineuses, prises en petite quantité, nais souvent renouvelées, sont alors les seuls moyens avoués par une saine thérapeutique. Cependant, si l'irritation intestinale, les tranchées, les épreintes, se 
prolongent, si le malade est tourmenté par une insomnie opiniâtre, il faut combiner les antiphlogistiques avec les sédatifs.

On s'est élevé avec raison contre l'usage prématuré de l'opium dans certaines dysenteries où prédominent la diathèse bilieuse, les symptômes gastriques. Ces complications, admises par les plus habiles observateurs, exigent la méthode évacuante, dirigée avec ménagement. Si l'irritation est vive, il faut préalablement la calmer par des boissons tempérantes, par l'application de quelques sangsues au fondement ou surles parties sensibles de l'abdomen. On donne ensuite un ou deux vomitifs, des boissons laxatives, des purgatifs légers, afin d'expulser les matières bilieuses dont le séjour provoque l'éréthisme des intestins et ranime la fluxion dysentérique. Mais, qu'on ne s'y trompe point, les signes qui manifestent l'état saburral, tels que les nausées, les vomissemens, les éructations, l'anorexie, dépendent très-souvent d'une disposition inflammatoire, et cette disposition existe, si leventre est météorisé, si les douleurs sont fixes, continues, etc. Il est inutile de dire que la méthode antiphlogistique est alors la seule convenable. On n'ignore pas non plus que, dans beaicoup de circonstances, l'irritation locale, d'abord très-modérée, devient promptement inflammatoire par l'emploi des remèdes évacuans, et surtout des purgatifs; mais, parce que la médecine humorale en a souvent abusé, parce qu'ils ont été formellement proscrits, d'abord par les browniens, ensuite par les physiologistes, faut-il admettre qu'ils sont nuisibles dans toutes les dysenteries? Tissot, Pringle, 
Monro, Stoll, Zimmermann, Grimaud, etc., ont prouvé leur utilité par des faits incontestables. Les docteurs Brassier et Rampon, médecins des hôpitaux militaires, ont employé avec beaucoup de succès les émétiques et les doux laxatifs dans la dysenterie bilieuse, et surtout dans celle qui régna à Mayence pendant le siége de cette place. Après l'usage des vomitifs, il fallait insister sur les boissons acidulées et prescrire une ou deux fois la manne avec le sulfate de magnésie, les tamarins, etc. Alors seulement la fièvre diminuait, les épreintes cessaient, et les amers, les préparations d'opium, le vin, terminaient promptement la cure. 'Toute autre méthode avait un succès incertain, les convalescences étaient longues ou se terminaient par des affections chroniques incurables. (НвскеR, Manuel de médecine militaire.)

Quoique les symptômes adynamiques et ataxiques qui se développent dans le cours de la dysenterie soient maintenant considérés comme le résultat d'une irritation locale, et principalement de l'irritation inflammatoire du colon; quoiqu'il ne faille point perdre de vue cette affection primitive, élémentaire, de laquelle découlent des indications importantes, l'expérience clinique a prouvé, et prouvera encore très-souvent aux esprits qui sauront l'interroger avec calme et sans prévention, qu'il est des dysenteries qu'on ne saurait vaincre par les débilitans et les antiphlogistiques; que, sous l'influence de certaines épidémies, l'inflammation intestinale est d'une nature septique, qu'elle tend rapidement à la gangrène, et que la méthode débilitante favorise cette terminaison malheureuse. Dans ces épi- 
démies qui ravagent les camps, les hôpitaux, les prisons, et quelquefois des contrées entières, la dysenterie se manifeste par une soudaine prostration des forces, par un pouls accéléré, tremblotant, presque insensible; par la faiblesse re la voix, un regard fixe et éteint, des éruptions pétéchiales d'une nuance livide ou noirâtre, des déjections fréquentes, putrides; enfin par un tel affaissement de l'énergie vitale, que le sort des malades est souvent décidé en deux ou trois jours. Quel est le médecin assez dominé par l'esprit de système pour ne voir dans ces épidémies formidables qu'une simple gastro-entérite? Les moyens les plus propres à combattre cet état de prostration et de putridité sont les toniques et les excitans, combinés avec l'opium. C'est ainsi qu'on emploie la décoction de quinquina rouge ou de racine d'arnica, à laquelle on ajoute quelques gouttes de laudanum liquide. D'autres prescrivent des mixtures de camphre, de cachou, de cannelle, d'extrait d'opium; d'autres, la poudre de Dover ou des compositions analogues. On fait en même temps des fomentations chaudes sur la région abdominale avec des flenrs et des herbes aromatiques cuites dans du vin, et on donne des lavemens préparés avec cinq ou six onces d'une décoction mucilagineuse et quinze ou vingt gouttes de teinture anodine. On irrite, on rubéfie la peau avec les sinapismes, les ventouses, le liniment ammoniacal camphré.

Les dysenteries, les diarrhées chroniques, entretenues par l'irritation ou par l'inflammation lente de la membrane muqueuse du colon, exigent l'usage des antiphlogistiques, des boissons adoucissantes, aux- 
quelles on ajoute de petites doses de teinture anodine de Sydenham. Lorsque les malades sont très-nerveux et passent de mauvaises nuits, on peut porter la dose jusqu'à trente gouttes, et même davantage. M. Broussais en a prescrit jusqu'à cinquante et soixante gouttes sans inconvénient; mais il observe avec raison que ces médicamens doivent être secondés par un régime sévère. Dans toutes les diarrhées, ses disciples rejettent l'emploi des toniques et des astringens. M. Broussais ne conteste pas absolument leur succès; toutefois il leur préfère l'opium, parce qu'il agit plus efficacement que toute autre substance sur l'action péristaltique des intestins irrités. Mais est-il vrai que toutes les diarrhées qui succèdent aux affections gastriques ne puissent être combattues que par le traitement indiqué contre la gastro-entérite, c'est-à-dire par l'application des sangsues au fondement ou sur l'abdomen, par les boissons adoucissantes, les potions gommeuses, etc.? L'observation repousse cette théorie exclusive. Il y a plus : le dévoiement n'offre quelquefois un caractère rebelle que parce qu'on a méconnu la véritable cause de l'affection primitive, la pléthore bilieuse ou muqueuse, qu'on eût pu enlever par quelques évacuans administrés à propos. Lorsque les forces ne sont pas tout-ifait ruinées, on peut encore espérer de vaincre ces diarrhées consécutives par l'ipécacuanha, administré comme vomitif, ensuite par quelques toniques légers, par de petites doses d'opium ou de thériaque, et par un régime convenable $(\mathrm{r})$.

(1) En général, l'opium supprime ou diminue les évacuations 
Brown et son école ont donné de grands éloges à l'opium dans les hémorrhagies actives; mais aujourd'hui qu'on rapproche cet ordre de maladies des inflammations, on est très-réservé sur l'usage des narcotiques, et on emploie avec beaucoup plus d'avantage les antiphlogistiques et les débilitans, dont l'effet est de modérer l'activité des mouvemens fluxionnaires. Cependant, lorsqu'une hémorrhagie violente se déclare chez des sujets faibles et d'un tempérament nerveux , les remèdes opiacés, unis aux antispasmodiques, sont d'un grand secours. L'emploi de l'opium ne doit point être négligé dans les hémorrhagies pectorales entretenues par une irritation vive, une toux sèche et fréquente, surtout après avoir employé vainement les émissions sanguines, les remèdes adoucissans, les potions gommeuses, les émulsions, etc. On prescrit en même temps des pédiluves, des frictions sur les membres inférieurs, des boissons diaphorétiques, afin de rompre

alvines; cependant il dissipe quelquefois aussi la constipation, lorsqu'elle est occasionée par un spasme chronique des intestins. L'observation suivante en est un exemple remarquable. Une dame était sujette depuis quinze ans à une constipation habituelle; elle n'allait à la garde-robe que toutes les trois semaines ou tous les mois, et cette évacuation était toujours précédée d'une fièvre d'un ou deux jours Une circonstance particulière d'une maladie qu'elle éprouva fit qu'on lui administra l'opium. L'usage de ce remède fut suivi d'évacuations alvines faciles et répétées chaque fois qu'elle le renouvela. D'après cet heureux effet de l'opium, on l'essaya contre la constipation habituelle avec un succès complet. Depuis ce temps-là cette dame prend un demi-grain d'opium trois ou quatre fois la semaine, et l'usage de ce médicament est suivi chaque fois d'une évacuation facile et plus ou moins abondante. (Vengu, Précis de malière médicale.) 
les mouvemens fluxionnaires concentrés sur les organes de la respiration, et de les rappeler à la surface du corps. Les hémorrhagies de la matrice qui surviennent pendant la gestation chez les femmes d'une complexion délicate, mobile, irritable, et qui ne cèdent point aux saignées pratiquées avec modération, au repos et aux autres moyens diététiques, exigent l'usage des antispasmodiques, des calmans, et surtout de l'opium. Ces remèdes, en combattant l'irritation nerveuse fixée sur la matrice, font cesser l'hémorrhagie et préviennent l'avortement. Les pertes de sang qui se manifestent à la suite des couches sous la même influence indiquent les mêmes moyens; l'emploi de l'opium est surtout très-urgent lorsqu'il survient des spasmes, des mouvemens convulsifs, des faiblesses, etc. Le docteur Miquel a reproduit, dans son Traité des convulsions, couronné par la Société de médecine de Paris (I), une observation de Mauriceau où les convulsions devinrent promptement mortelles après une perte de sang excessive. Dans une circonstance aussi grave, qui doit décider en quelques instans du sort de la femme, je n'hésiterais pas à donner de fortes doses d'opium, sans contredit le plus puissant des antispasmodiques; j’y joindrais en même temps la teinture de cannelle, qui jouit d'une vertu spéciale contre les hémorrhagies asthéniques. (Voyez notre article cannelle, dans le premier volume.)

Mais une règle de la plus haute importance dans le

(1) Traite' des convulsions chez les ferimes enceintes, in travail et en couche, mémoire qui a remporté le prix proposé par la Société de médecine de Paris pour l'année 1820. 
traitement des hémorrhagies, c'est de ne point confondre les flux qui ont un caractère critique, et qui peuvent être salutaires, avec ceux qu'il importe de réprimer le plus promptement possible. Les hémorrhagies qui cö̈ncident avec la plénitude des vaisseaux et qui la diminuent, avec une surexcitation plus ou moins considérable et qui la dissipent, sont le résultat d'une crise salutaire. Ainsi il ne faut pas trop s'inquiéter des hémorrhagies nasales qui ont lieu dans les maladies inflammatoires, quelque abondantes qu'elles soient, puisque ces évacuations, poussées jusqu’à la syncope, font quelquefois cesser les épiphénomènes les plus graves, le délire, la phrénésie, les convulsions, etc. (Voyez le bel article de M. Double, sur les hémorrhagies, dans sa Sémeiologie générale.) On peut consulter également le Traité des hémorrhagies, de M. le professeur Lordat, excellent ouvrage où le traitement de cet ordre d'affections est envisagé sous un point de vue très-philosophique.

Dans les affections de la poitrine, les rhumes, les catarrhes, etc., l'opium est journellement employé, soit pour ranimer la transpiration insensible et provoquer une douce diaphorèse, soit pour calmer la toux et ramener le sommeil. Mais on convient généralement qu'il est nuisible dans la première période clu catarrhe aigu ; qu'il augmente la chaleur fébrile, la clyspnée, et provoque l'irritation inflanınatoire des bronches. M. Broussais, dont les écrits ont jeté une si vive lumière sur les inflammations chroniques, recommandel'opium comme un sédatif précieux dans l'état avancé du catarrhe pulmonaire et de la pleurésie aiguë. Il regarde ce mć- 
dicament comme la meilleure ressource contre les irritations de la poitrine qui refusent de céder aux antiphlogistiques, et qui sont exaspérées par les irritans révulsifs. Parmi les auteurs qui ont parlé de l'opium dans le traitement de la phthisie, il en est qui ne sauraient assez louer ses puissantes vertus, tandis que beaucoup d'autres le regardent comme un remède qui procure un calme trompeur, et qui accélère le dépérissement du malade. Après les saignées indiquées par l'activité du système sanguin, par la disposition phlogistique de l'organe pulmonaire, De Meza (De opio phthiseos proplyylactico) arrêtait la marche de la phthisie en donnant matin et soir de petites doses d'opium. Cette méthode est particulièrement utile lorsque le poumon est dans un état habituel de spasme et d'irritation, caractère qui a fait donner par quelques auteurs à cette espèce de phthisie le nom de phthisie nerveuse. Les sujets d'une sensibilité vive, d'une complexion délicate, d'un tempérament mélancolique, y sont les plus disposés. Ici les évacuations sanguines sont moins nécessaires; elles peuvent même hâter les progrès de la consomption, lorsqu'on les pratique sans ménagement ; tandis que les tempérans, les anodins, les préparations d'opium les plus douces, telles que son extrait aqueux, le sirop diacode, produisent les meilleurs effets. Dans l'état avancé de la phthisie, les médicamens opiacés servent encore à dissiper l'insomnie, à calmer, à suspendre la toux, dont les secousses répétées augmentent l'éréthisme et l'engorgement du poumon.Van Swieten veut surtout qu'on les administre le soir. Sed procipuum auxilium pendet $a b$ anodynis circa 
vesperam datis.... ab his sedatur tussis, blandus somnus conciliatur, undè vires reficiuntur, et matutino tempore sputa cocta leni tussi educuntur quàm facillimè. Enfin la diarrhée des phthisiques, ce symptôme redoutable, qui met le comble à leur épuisement, demande à être modérée par les potions mucilagineuses avec le laudanum, par la conserve de roses rouges avec le sirop diacode, par des lavemens préparés avec la décoction des capsules du pavot, avec l'extrait d'opium ou avec la thériaque. Ainsi, lorsque toute espérance est perdue, lorsque le malade marche à grands pas vers le terme de son existence, l'opium peut encore retarder l'heure fatale.

L'opium a été recommandé dans quelques autres affections pectorales, telies que la coqueluche, l'asthme convulsif, l'angine de poitrine. Le docteur Muller a. observé une toux convulsive épidémique où ce médicament a eu le plus grand succès. Il employait particulièrement la teinture d'Eckart, préparation analogue à la teinture thébaïque, à la dose d'une, deux ou trois gouttes, toutes les deux heures, suivant l'âge des enfans malades. L'opium, administré de cette manière, ne produisait jamais d'effet narcotique. Guillaume Heberden (Comment. de morborum historia et curatione) ne connaît pas de meilleur remède contre l'asthme convulsif. Il a vu des asthmatiques près de rendre le dernier soupir, qui étaient promptement soulagés en prenant deux ou trois grains d'opium. Fothergill a également indiquéles anodins pour combattre l'excès d'éréthisme qui accompagne l'angine de poitrine; il prescrivait vingt-cinq gouttes de teinture thébaïque 
avec une égale quantité de vin d'antimoine, et il répétait ce mélange suivant la violence des symptômes.

Lorsque ces maladies se présentent avec un caractère purement nerveux ou spasmodique, nul doute que les anodins, et surtout l'opium, ne soient d'un grand secours, soit pour apaiser des irritations dominantes, soit pour prévenir le retour des paroxysmes; mais le médecin n'a-t-il pas d'autres indications à remplir lorsque les organes de la respiration sont atteints de phlogose, lorsque la force et la dureté du pouls, la rougeur de la face, une oppression vive, annoncent un état pléthorique? (Voyez le Traité de l'angine de poitrine publié en 18 I I par le docteur Desportes.)

D'après l'autorité de Sydenham, presque tous les auteurs de matière médicale ont parlé des avantages de l'opium contre les phlegmasies cutanées, et particulièrement contre la variole. Cet illustre médecin recommande, en effet, les narcotiques dans l'état avancé de la petite vérole confluente, pour apaiser, dit-il, la fermentation du sang, et entretenir la salivation, qui s'affaiblit quelquefois vers le dixième ou onzième jour avec un grand danger pour le malade. Il prescrit en conséquence tous les soirs, jusqu’à la fin de la maladie, quatorze gouttes de laudanum liquide ou une once de sirop diacode dans de l'eau distillée de fleurs de primevère. Cette potion, administrée à six ou sept heures du soir, éloigne les agitations de la nuit. Cullen s'est prononcé en faveur de la méthode de Sydenham, et il a toujours observé qu'elle était éminemment utile lorsqu'on avait soin de prévenir la constipation par des lavemens laxatifs. Hufeland a dé-

II. 
crit une épidémie variolique accompagnée de symptômes nerveux où l'opium a sauvé la vie à plusieurs enfans qui étaient dans un état désespéré. Peu d'heures après l'usage de ce médicament, le pouls se ranimait, le visage reprenait des couleurs, les urines devenaient rouges, brillantes, la peau se gonflait, enfin les boutons s'élevaient et se remplissaient de pus. D'après le témoignage du docteur Barbier, l'opium a produit un effet très-remarquable dans un cas de petite vérole confluente. Un jeune homme de dix-huit ans éprouvait, vers le dixième jour de la maladie, un sentiment intolérable de chaleur à la peau, qui était alors gouflée, rouge, sensible. Ce médecin lui prescrivit le matin et le soir une demi-once de sirop d'opium. Chaque fois que le malade prenait ce remède, il éprouvait subitement un calme marqué ; ses douleurs diminuaient, son agitation cessait, et il rendait bientôt après une quantité assez forte d'urine; il n'urinait que très-peu dans? l'intervalle. Ces effets s'observèrent tant que la maladie resta violente, et qu'elle exigea l'administration cu narcotique.

Lorsque la petite vérole se complique, dans son cours, de phénomènes adynamiques ou ataxiques, que les pustules s'affaissent et présentent un aspect décoloré, livide; que les malades, agités de mouvemens spasmodiques, ont des selles fréquentes, putrides, le pouls faible, irrégulier, intermittent, on ne doit pas craindre d'administrer l'opium uni au quinquina, au camphre, malgré le peu de faveur dont jouissent ces vieux médicamens dans la nouvelle école physiologique. Malheur à celui qui ne verrait dans ce groupe 
de symptômes que l'effet d'une simple gastro-entérite qu'il s'obstinerait à combattre par une méthode débilitante! Il est impossible qu'un praticien habitué à observer avec calme, sans passion, sans préjugés, ne reconnaisse point dans cet état pathologique une affection de tout le système qui réclame assurément d'autres moyens que l'application des sangsues et quelques tasses d'eau de gomme. Il y a plus : la méthode antiphlogistique, si utile dans la première période de la petite vérole inflammatoire, devient funeste, si elle n'est circonscrite dans de justes bornes; elle entrave les mouvemens naturels, et peut donner lieu à des métastases, à des abcès d'une mauvaise nature, enfin à des accidens qui démontrent que l'éruption a été troublée.

Avouons toutefois que des médecins non moins exclusifs ont étrangement abusé des préparations d'opium dans le premier stade de la petite vérole. Ces médicamens, si utiles aux sujets très-faibles, irritables, et lorsque l'organe cutané est frappé d'un spasme douloureux qui s'oppose à l'éruption des pustules, augmentent dans d'autres circonstances l'excitation artérielle, font affluer le sang vers les parties supérieures, favorisent les congestions du cerveau, et peuvent déterminer un état comateux ou quelque inflammation viscérale. Le docteur Harris raconte que Marie, reine d'Angleterre, prenait habituellement, lorsqu'elle éprouvait de la fièvre, une dose assez considérable de thériaque pour exciter les sueurs. Il avait plusieurs fois averti la reine de se cléfier de l'usage d'un pareil remède; mais elle avait tant de confiance en son ancien médecin, le fameux docteur Lower, qui le lui avait 
conseillé, que, la nuit même où elle sentit les premières atteintes de la petite vérole, elle prit la dose ordinaire de thériaque, et le lendemain matin une donble dose. Ce médicament opiacé lui causa une si violente agitation, que, lorsque la petite vérole parut, il se manifesta en même temps un crachement de sang, des taches pourprées, et d'autres symptômes du plus mauvais augure, qui furent suivis de la mort au bout de quelques jours. (GuIldaume Grant, Recherches sur les fièvres.)

On peut appliquer la plupart de ces réflexions à la rougeole. Sydenham, qu'on doit presque toujours citer lorsqu'il est question de faits pratiques, insiste fortement sur la méthode rafraîchissante, sur la saignée; mais il prescrit les calmans, le sirop diacode, pendant tout le cours de la maladie pour apaiser l'irritation pulmonaire. On pourrait lui reprocher néanmoins d'avoir un peu trop prodigué l'opium dans le traitement des exanthêmes fébriles. Ce remède doit être employé avec beaucoup de réserve chez les enfans pléthoriques et d'une forte complexion; mais qu'on ne craigne pas d'y avoir recours pour les sujets délicats et d'une sensibilité exquise : combiné avec les boissons adoucissantes, il apaisera plus sûrement la toux, les anxiétés précordiales, que l'application réitérée des sangsues, dont on use si libéralement depuis qu'on veut à toute force, et malgré l'évidence des faits, localiser tous les exanthêmes et les faire dépendre de l'inflammation des tissus gastriques ou pulmonaires.

On dit que l'opium ne convient point dans les affections arthritiques, qu'on ne saurait calmer avec ce mé- 
dicament les douleurs qui accompagnent la goutte et le rhumatisme, et que son emploi dans ces maladies est toujours dangereux. Cette opinion, émise par quelques auteurs modernes, est évidemment exagérée. Sydenham, qui a traité de la goutte, et qui a été lui-même goutteux presque toute sa vie, veut qu'on prenne tous les soirs un peu de laudanum, lorsque les douleurs articulaires sont insupportables. Il le conseille aussi lorsqu'il survient des tranchẻes violentes, une diarrhée excessive, des vomissemens accompagnés de faiblesses. Cullen n'a pas craint d'administrer de fortes doses d'opium lorsque la goutte affectait vivement l'estomac. Scudamore se prononce également en faveur de l'opium, dont il prescrit un grain toutes les deux heures, mêlé avec moitié dose de poudre antimoniale, lorsque les douleurs arthritiques sont très-intenses. Ce médecin recommande en même temps, l'usage du black drop (gouttes noires), préparation concentrée d'opium, qui réussit beaucoup mieux à certaines personnes que les médicamens opiacés ordinaires. Mais personne n'a mieux connu les véritables indications de l'opium dans les maladies goutteuses que le professeur Barthez. Dans les attaques simples et régulières de la goutte des articulations, un régime doux , des boissons relâchantes et diaphorétiques, sont les moyens les plus convenables, puisqu'ils tendent à favoriser les mouvemens salutaires de la nature; mais, lorsque la douleur est violente et soutenue, qu'elle épuise les forces et s'oppose à une terminaison salutaire, les préparations opiacées, dont on règle les doses suivant le degré d'irritation, l'âge et le tempérament du malade, produisent quelquefois les 
plus heureux effets. L'opium n'est pas moins avantageux lorsque la goutte, fixée sur l'estomac ou sur les intestins, détermine sympathiquement un état convulsif dans les viscères précordiaux ; mais il faut s'en abstenir lorsque l'irritation goutteuse semble déjà disposée à se porter sur les articulations, lorsqu'elle se complique d'une affection cérébrale ou de symptômes bilieux bien prononcés. On prescrit également l'opium dans l'asthme spasmodique des goutteux, en le combinant avec l'éther, le musc, le camphre on l'assa-foetida. Ces combinaisons conviennent spécialement pendant les accès qui se développent avec des douleurs atroces, une suffocation imminente, après avoir toutefois suffisamment affaibli l'état de pléthore ou la disposition inflammatoire par la saignée, par l'application des ventouses ou des sangsues sur les parties les plus douloureuses de la poitrine. On applique en même temps des sinapismes, des vésicatoires sur les articulations qui étaient le siége de la goutte. Lorsque cette redoutable maladie offre des paroxysmes bien dessinés, on doit avoir recours au quinquina, et l'administrer de la même manièreque dans les fièvres intermittentes pernicicuses.

Le rhumatisme aigu, qui s'accompagne d'anxiétés, d'une insomnie constante, de souffrances excessives, réclame l'usage de l'opium, surtout lorsqu'ón a combattu la diathèse inflammatoire par les rafraîchissans et les antiphlogistiques. Dans l'état chronique, on a quelquefois donné avec un rare succès un mélange d'opium et de muriate de mercure doux. Le docteur Fischer vante cette combinaison comme un moyen infaillible, lorsque le rhumatisme est caractérisé par 
des tiraillemens et des douleurs insupportables des membres, avec impossibilité de les mouvoir. Il prescrit soir et matin un grain d'opium et un grain de calomel, triturés avec du sucre et de la magnésie. On varie d'ailleurs les doses de cette poudre suivant les effets observés. D'autres praticiens donnent tous les soirs un grain d'opium et cinq ou six grains de calomel, jusqu'à ce qu'ils aient obtenu une salivation modérée. Ce traitement a quelquefois dissipé les rhumatismes les plus réfractaires. D'autres enfin unissent l'opium à l'ipécacuanha, aux préparations antimloniales, aux purgatifs. Je conviens qu'on doit accueillir ces méthodes empiriques avec réserve; cependant, dans quelques circonstances difficiles, je ne me suis pas mal trouvé de les avoir suivies. J'ai surtout employé avec beaucoup de succès la poudre de Dover, en interposant un purgatif tous les trois ou quatre jours, dans un cas de rhumatisme extrêmement grave.

Un ancien militaire, d'un tempérament nerveux, sujet depuis la campagne de 1814 à des attaques d'un rhumatisme articulaire, qu'il dissipait ordinairement avec le secours des bains et d'une boisson humectante, éprouva une attaque beaucoup plus vive l'automne dernier. Pendant l'espace de deux mois, on n'épargna ni les saignées générales, ni l'application des sangsues. Les bains, les cataplasmes émolliens, n'avaient pas été plus favorables. Lorsque je vis le malade, il était entièrement perclus des membres inférieurs, où il éprouvait une douleur rongeante par le moindre attonchement; sa physionomie portait l'empreinte d'une profonde tristesse. Il fut mis à l'usage de la poudre 
de Dover, dont il prenait tous les matins environ quinze grains; il buvait ensuite dans la matinée cinq ou six tasses de thé léger, afin de seconder son action sudorifique. Tous les trois ou quatre jours on suspendait l'usage de la poudre, pour administrer un bol purgatif, composé de huit grains de calomel et de douze grains d'aloès. Cette méthode perturbatrice, suivie avec une grande exactitude pendant une vingtaine de jours, produisit de si heureux effets, que le malade put marcher sans appui.

Vers la fin du siècle dernier, on crut trouver dans l'opium un nouveau moyen de combattre l'affection vénérienne. Schoepf et Michaëlis lui prodiguèrent surtout des éloges outrés; mais Grant et Hagstroem en bornèrent avec raison l'emploi à certains cas où la sensibilité est exaltée, et sauvèrent en même temps, dit Sprengel, l'honneur du mercure dans le traitement de la syphilis. En effet, il est douteux que l'opium suffise pour extirper entièrement cette maladie ; mais il devient un puissant auxiliaire du mercure en calmant l'excès de la douleur et de la sensibilité chez les personnes très-irritables. Boerhaave soignait un jeune homme couvert d'ulcères syphilitiques, et tourmenté toutes les nuits par des douleurs ostéocopes. Après avoir employé vainement les moyens ordinaires, il prescrivit l'usage de l'opium, qui rappela le sommeil et dissipa tous les symptômes. Associé aux préparations mercurielles, l'opium modifie leur action irritante, et prévient les accidens qui accompagnent fréquemment leur usage.

En traçant le tableau des vertus médicinales de l'opium, pourrions-nous passer sous silence ses heureux 
effets dans le traitement d'une espèce particulière de gangrène, dont l'invasion est marquée par des douleurs vives qui se font ressentir aux extrémités inférieures, et surtout aux orteils? D'après l'observation de Percival Pott, on peut arrêter les ravages de cette maladie avec le secours de l'opium, administré à hautes doses et combiné avec le musc. On a également constaté ses avantages dans la gangrène produite par l'usage du seigle ergoté : il est spécialement indiqué par la douleur, les crampes, et l'état convulsif des membres.

Enfin nous devons signaler l'opium comme un moyen précieux pour combattre une foule d'accidens causés par les poisons. C'est une sorte de compensation des pernicieux effets qu'il produit lui-même dans quelques circonstances. Nous avons rapporté dans le cours de cet ouvrage des faits nombreux en faveur de ce médicament. Ainsi nous l'avons vu dissiper les irritations, les douleurs les plus intenses, le hoquet, la cardialgie, les spasmes, les convulsions, les mouvemens épileptiques qui succèdent à l'empoisonnement par les champignons, la petite ciguë, etc. Nous pourrions également rappeler ici avec quel avantage nous l'avons administré à une jeune et très-intéressante dame, empoisonnée le jour des Rois 18 r 2 avec un gâteau où l'on avait introduit du sublimé corrosif. Depuis ce déplorable événement, dont l'auteur, par une fatalité bien étrange, est toujours resté ignoré, madame de $\mathrm{M}^{* * *}$ avait conservé pendant plusieurs années une telle susceptibilité d'entrailles, que la moindre irritation, le plus léger motifde chagrin, provoquaient instantanément une tuméfaction considérable des parois abdomi- 
nales, suivie de hoquet, de vomissemens, et d'une douleur vive dans toute la région hépatique. La teinture anodine de Sydenham, prise à la dose de dix à douze gouttes toutes les trois heures, a constamment dissipé ces symptômes. Cette dame, jouit maintenant d'une assez bonne santé.

On ne saurait méconnaître la puissance sédative de l'opium dans les cas d'empoisonnement par les cantharides. Ce médicament est surtout indispensable lorsque l'irritation de l'appareil urinaire résiste à l'usage des bains, des émolliens et des antiphlogistiques. Lanzoni cite l'histoire d'une femme qui fut prise de douleurs atroces après avoir avalé une forte dose de cantharides. Deux gros de laudanum liquide firent cesser tous les accidens, et procurèrent un sommeil paisible.

Je trouve dans mes notes un fait qui m'a paru digne d'être conservé. Un négociant de Philadelphie, demeurant à l'hôtel d'Angleterre, rue des Filles-SaintThomas, avait mangé une certaine quantité de moules. Peu de temps après, il éprouva une chaleur vive à l'épigastre avec des vomissemens répétés. Toute la surface du corps était rouge, gonflée, fortement tendue, et couverte d'une éruption vésiculaire. Ces premiers symptômes furent bientôt suivis d'étouffemens, d'une anxiété extrême, de mouvemens convulsifs et d'une raideur universelle. Appelé presqu'en même temps que le docteur Vergez, qui m’avait précédé auprès du malade, et qui lui avait déjà fait prendre sans aucun résultat avantageux une potion éthérée et du thé acidulé avec le suc de citron, je proposai l'usage du laudanum liquide. Ce médicament fut administré de suite à la dose de 
vingt-quatre gouttes dans une cuillerée d'eau de menthe avec un peu de sucre, et répété une heure après. Dès ce moment le malade, dont la respiration et la voix étaient presque éteintes, commença à se ranimer. Il continua néanmoins la teinture anodine à la dose de sept ou huit gouttes toutes les trois heures, et le lendemain il ne lui restait que le souvenir de ses souffrances et un peu de gêne dans les membres inférieurs.

Nous avons disserté sur les propriétés de l'opium avec toute l'étendue convenable à un sujet aussi important; nous avons surtout signalé l'immense avantage que peut en retirer dans les exercices cliniques un médecin à la fois sage et instruit; mais notre amour pour cette substance héroïque ne va point jusqu'à un aveugle enthousiasme. Ainsi, d'après un examen impartial et sévère, nous voyons que son usage habituel émousse la sensibilité, paralyse les facultés de l'esprit et contribue puissamment à hâter cette vieillesse précoce, si commune dans les pays chauds. Suivant le docteur Pouqueville (Voyage en Morée), les thériaky, ou mangeurs d'opium, tombent dans un marasme général. En proie à des douleurs atroces, tourmentés par un satyriasis incommode, ils ne peuvent assouvir leurs désirs. Enfin devenus hideux, déformés par de nombreuses périostoses, privés de leurs dents, les yeux presque éteints au fond des orbites, agités d'un tremblement involontaire, ils cessent d'exister long-temps avant d'avoir fini de vivre.

On a également remarqué que l'abus de l'opium dispose à l'hypochondrie, aux affections maniaques, aux 
congestions sanguines, à l'apoplexie. C'est surtout dans l'enfance, dans cet âge où domine la mobilité de tout le système des forces, qu'on observe les mauvais effets de l'opium. Hoffmann a vu le fréquent usage du sirop diacode provoquer une épilepsie mortelle. Barthez rapporte aussi l'exemple d'un enfantà qui l'abus du même remède avait causé des palpitations pendant plusieurs années. On a observé que les enfansà qui les nourices donnent habituellement de la thériaque ou dusirop de pavot pour les endormir, deviennent stupides. Dans les fièvres gastriques et bilieuses, dans les affections inflammatoires, et principalement dans celles del'encéphale, on doit être extrêmement réservé sur l'usage des médicamens fournis par l'opium, malgré l'insomnie et l'exaltation de la sensibilité. Quce, licet veteribus arriderent medicamenta, vix, nisi devicto inflammationis impetu, ob continuas vigilias nimiainque sensibilitatem, indicare queunt. (Frank, Epitome, lib.2, pag. 57.$)$ Dans l'état avancé des maladies aiguës, lorsque la nature coordonne ses mouvemens, prépare une crise salutaire, tous les symptômes prennent quelquefois une intensité nouvelle; la fièvre, la douleur, l'anxiété, augmentent. L'observateur haljile ne cherchera point alors à calmer ce trouble passager, à détruire cette réaction vitale en administrant l'opium; mais il s'attachera à l'application raisonnée de la méthode expectante. Nous ferons remarquer en passant que, si les crises sont moins fréquentes aujourd'hui, il faut en chercher la cause dans les méthodes de traitement. En effet, les uns troublent la marche de la nature, pervertissent ses actespar une foule de médicamens 
inutiles ou trop actifs; les autres paralysent ses efforts par l'abus des relâchans et de la saignée. Aussi la nouvelle école, méprisant les traditions les plus saines, range-t-elle la doctrine des crises parmi les vieilles rêveries de la médecine dogmatique.

Au reste, les mauvais effets de l'opium ne doivent être imputés qu'à la main inhabile qui le donne sans mesure ; et ceux-là même qui le déprécient par prévention ou par esprit de système sont souvent forcés d'y avoir recours, ne fût-ce que pour adoucir des maux qu'ils ont peut-être irrités par un traitement peu convenable. Quand bien même l'opium ne serait qu'un palliatif, ainsi que le prétendent quelques médecins qui ont étudié légèrement ses propriétés, ne faudraitil pas remercier la Providence de nous avoir donné un remède capable d'apaiser la douleur? Lorsque notre art ne peut guérir, il faut du moins qu'il console. Qui n'a pas été témoin du tableau déchirant qu'offre à nos regards le malheureux en proie à une maladie incurable et douloureuse? Qui n'a pas entendu ses plaintes, ses gémissemens? Hâtons-nous d'adoucir des jours remplis d'amertume; donnons à l'homme qui attend la mort comme la fin de ses misères ce calmant, ce baume magique qui suspend ses souffrances et lui fait goûter le calme des nuits : il supportera avec plus de courage les angoisses de la journée. Interim hurnanitas poscit ut succurramus miseris, de quorum salute etiam desperamus; ut leniamus mala qua eraiticari nequeunt; ut placidè magis peragatur pauculum illud, quod cle vitce curriculo superest, donec mors his rerumnis finem imponat. (Van Swieten.) 
On administre l'opium de plusieurs manières. Lorsque l'estomac est très-irritable, on l'injecte dans le rectum, en commençant toujours par une petite quantité, et non en doublant et triplant les doses, comme le conseillent quelques auteurs de matière médicale. Employé sans ménagement par cette voie, il produit des vomissemens, des vertiges et un état comateux. On peut aussi l'administrer avec avantage, sousla forme de frictions, sur la surface du corps, à l'exemple de Chiarenti de Florence, de Brera, d'Alibert, de Chrestien de Montpellier, etc. Les préparations qu'on fait subir à l'opium sont très-variées; la plus simple est celle de son extrait, appelé extrait aqueux d'opium. On y procède en faisant dissoudre dans l'eau les parties de l'opium solubles dans ce liquide; on fait ensuite évaporer jusqu'à consistance d'extrait. On distingue un autre extrait préparé par la fermentation d'après la méthode de M. Deyeux. Pour l'obtenir, on ajoute de la levure à l'eau qui tient l'opium en dissolution; on expose ce mélange à une douce température; on laișse fermenter jusqu'à ce que la liqueur se clarifie, et on réduit ensuite en extrait. L'extrait d'opium vineux se prépare en faisant dissoudre l'opium dans du vin blanc à la chaleur du bain-marie, et en procédant ensuite à l'évaporation du véhicule.

L'extrait d'opium jouit d'une propriété sédative plus marquée lorsqu'il est dépouillé de la narcotine, ou sel de Derosne. M. Robiquet propose d'adopter pour l'usage médical la préparation suivante : on fait macérer dans de l'eau froide de l'opium ordinaire, divisé en petits morceaux, comme pour obtenirl'extrait 
aqueux ; on filtre, on évapore en consistance de sirop épais, et on traite en vase convenable par de l'éther rectifié. On agite le tout un grand nombre de fois avant de décanter la teinture éthérée, et, lorsque celle-ci est séparée, on la soumet à la distillation pour en retirer l'éther. On réitère cette opération tant qu'on obtient des cristaux de narcotine pour résidu de la distillation. Quand l'éther est sans action, on évapore la solution d'opium jusqu'à consistance pilulaire, et on obtient par ce moyen un extrait toutà-fait exempt de narcotine. Ces divers extraits se prescrivent depuis un demi-grain jusqu'à deux grains, et même plus, suivant la nature etl'intensité de la maladie. On les administre, soit sous la forme de pilules, soit dissous dans une eau distillée quelconque, dansles potions, dans les mixtures calmantes et antispasmodiques.

On prépare avec l'opium des infusions aqueuses ou vineuses, des teintures alcoholiques simples ou composées, des poudres, des électuaires, etc.

Infiusion aqueuse d'opium du professeur Chaussier. Prenez, opium du commerce, une once; eau distillée, neuf onces. Après avoir pulvérisé grossièrement l'opium, on le laisse infuser à froid pendant trois ou quatre jours; ensuite on filtre la liqueur à travers un papier gris, et on ajoute, pour la conserver, une once d'alcohol. Cette infusion aqueuse d'opium peut s'employer par gouttes dans des potions depuis seize jusqu'à vingt-quatre ou trente. On s'en sert également à la dose de cinquante à quatre-vingts gouttes, sur deux onces d'infusion de fleurs de mauve, dans les inflammations des yeux, et surtout dans les maladies des 
mamelons. (Ratier, Formulaire pratique des hòpitaux civils de Paris.)

Le docteur Demangeon emploie avec succès contre les ophthalmies aiguës ou chroniques, accompagnées d'une vive irritation, une infusion d'un gros d'opium gommeux dans une pinte d'eau bouillante. On fomente fréquemment les yeux avec cette liqueur refroidie, et on ne tarde pas à voir diminuer l'inflammation et la douleur. L'usage de ce remède est d'autant plus sûr que l'ophthalmie tient plus particulièrement à la sensibilité anomale des organes de lá vue, ou à une irritation produite par une cause accidentelle, comme un coup de fouet ou de baguette, un courant d'air, une lumière trop vive, une chaleur ardente. Voyez les observations publiées par ce praticien distingué dans le Journal général de médecine, tome $3 \mathrm{I}$, page $\mathrm{s}$ 3. Long-temps après $\mathrm{M}$. Demangeon, le docteur Gendrin a publié dans le même journal un mémoire sur l'usage des topiques opiacés dans les ophthalmies. Lorsque l'inflammation est aiguë, il fait précéder les fomentations d'opium de la saignée et des antiphlogistiques. Dans les ophthalmies chroniques, il donne la préférence à l'emploi du laudanum ou de la teinture thébaïque de la pharmacopée de Londres. Le célèbre Scarpa prescrit aussi les applications opiacées dans les ophthalmies aiguës graves, mais seulement après la première période de l'inflammation, et après avoir pratiqué des saignées générales ou locales.

Le professeur Lallemand conseille, pour faire disparaître les taies des yeux, de les toucher deux ou trois fois par jour, pendant environ un mois, avec 
du laudanum liquide; ce temps sulfit pour la guérison radicale des taies même les plus anciennes. Ce procédé, employé depuis long-temps en Pologne, a été communiqué à M. Lallemand par un Polonais. Le professeur de Montpellier dit en avoir obtenu les effets les plus extraordinaires. " J'ai vu, dit-il, l'application " du laudanum dissiper des taies si profondes et si " dangereuses, que je suis aussi affligé qu'étonné de " voir entièrement ignorée l'efficacité d'un agent si "précieux."

$V$ in d'opium, teinture anodine, ou laudanum liquide de Sydenham. Ce précieux médicament se prépare de la manière suivante : prenez, opium choisi, deux onces; safran, une once; cannelle et clous de gérofle en poudre, de chaque un gros. Faites digérer au bain-marie pendant cinq ou six jours dans une livre de vin d'Espagne; passez avec expression, et filtrez ensuite la liqueur. Dix-huit ou vingt gouttes contiennent un grain d'opium. La dose ordinaire est de dix à vingt gouttes. Cette composition se trouve plus ou moins modifiée dans certaines pharmacopées : quelques médecins voudraient même qu'on supprimât les aromates. Nous avons donné la véritable formule de l'auteur, et nous croyons qu'elle doit être respectée. Sydenham, qui avait observé ses effets dans les maladies avec une sagacité admirable, l'administrait nonseulement pour concilier le sommeil et calmer les irritations, mais encore pour relever les forces languissantes. On emploie fréquemment le laudanum liquide dans les potions antispasmodiques, les mixtures sédatives, en le combinant avec le sirop dia- 
code, l'éther alcoholisé, l'eau de fleur d'orange, etc. Il convient d'observer que, dans les affections cholériques, les vomissemens violens, qui exigent l'emploi de cette teinture, on doit l'administrer dans un véhicule peu étendu, afin de ne pas augmenter la susceptibilité de l'estomac. On peut en donner huit, dix ou douze gouttes dans, une cuillerée à café d'eau de menthe, et renouveler ce mélange deux ou trois fois, et même davantage, suivant l'intensité des symptômes, en mettant un quart d'heure ou une demi-heure d'intervalle entre les doses. Dans les convulsions générales, dans le tétanos et autres affections graves du système nerveux, non-seulement on n'obtient aucun effet de cette teinture, mais encore on augmente les accidens, si l'on n'en proportionne les doses à la violence du spasme et de la douleur. On l'emploie aussi à l'extérieur sous la forme de lotions, de linimens, de pommades, dans les ophthalmies, les affections cancéreuses, les douleurs rhumatismales, les brûlures, les hémorrhoïdes, les ulcères vénériens, etc.

Dans la pharmacopée de Russie, le laudanum liquide est préparé, sous le nom de teinture d'opium, de la manière suivante : prẹnez, opium thébaïque, une once; safran oriental, demi-once; vin d'Espagne, neuf onces. Faites digérer à une douce température pendant trois jours, et passez. Un gros de ce liquide contient environ six grains d'opium.

Le vin d'opium de la pharmacopée de Suède est simplement composé d'une partie d'opium pulvérisé et de six parties de vin blanc de France. On prolonge la macération pendant une semaine sans chaleur. 
Teinture d'opium d'Eckard. Prenez, opium purifié, deux onces; gérofle, un gros; eau de cannelle, huit onces; alcohol, quatre onces. Faites digérer pendant six jours dans un endroit chaud ou au hain-marie. Passez ensuite la liqueur avec expression, et filtrez. Dix gouttes de cette teinture contiennent à peu près un grain d'opium. Elle a été pendant quelque temps l'ancre sacrée des partisans fanatiques de la doctrine de Brown.

On prépare l'opium, ou les gouttes de l'abbé Rousseau, en faisant dissoudre de l'opium dans de l'eau miellée en fermentation. On laisse fermenter pendant un mois dans un lieu bien chaud, puis on filtre, et on fait évaporer une partie de la liqueur à l'air libre. Sept gouttes équivalent à un grain d'opium. Quelques praticiens emploient fréquemment cette teinture, qu'ils préfèrent aux autres préparations opiacées.

Black drops, ou gouttes noires. Prenez, opium, demi-livre; verjus, trois pintes; noix muscade, une once et demie; safran, demi-once. Réduisez le tout à consistance convenable au moyen de l'ébullition. Ajoutez ensuite quatre onces de sucre et deux cuillerées de levure. Placez le mélange dans un endroit chaud, près du feu, pendant six ou huit semaines, puis à l'air jusqu'à ce qu'il se convertisse en sirop; enfin décantéz et filtrez. Cette composition est très-active; quatre ou cinq gouttes représentent à peu près un grain d'opium.

Teinture d'opium, teinture thébaique de la pharmacopée de Londres. Prenez, opium pur, deux onces; alcohol rectifié, deux livres. Faites digérer pendant 
quatorze jours, et passez. Vingt-cinq gouttes contiennent un grain d'opium en dissolution.

Teinture d'opium ammoniacée, ou élixir parégorique de la pharmacopée d'Édimbourg. Prenez, opium, deux gros; safran broyé, acide benzoïque, de chaque trois gros; huile volatile d'anis, demi-gros; alcohol ammoniacé, seize onces. Faites digérer pendant sept jours à vaisseau clos, et filtrez. Un gros de cette liqueur contient un grain d'opium. Elle est regardée comme un puissant antispasmodique; on la donne aussi pour exciter la transpiration dans les maladies catarrhales, après avoir dissipé l'état d'irritation ou de phlogose par les moyens convenables. La dose est d'environ un gros. La teinture d'opium camphrée de la pharmacopée de Dublin porte aussi le nom d'élixir parégorique. Elle est composée de deux gros de camphre, d'un gros d'opium, d'un gros d'acide benzoïque, d'un gros d'huile volatile d'anis, et de deux livres d'alcohol. On la prescrit à la dose de cinquante à cent gouttes.

Le sirop diacode ou de pavot blanc est préparé avec la décoction ou l'infusion prolongée des capsules. C'est un doux somnifere, qu'on prescrit depuis deux gros jusqu'à une once. Dans la plupart des officines, on le remplace par une solution aqueuse d'extrait d'opium, à laquelle on donne la consistance requise à l'aide du sucre. Le sirop d'opium du Codex de Paris contient environ deux grains d'extrait par once. La dose est d'un à huit gros. Celui de la pharmacopée de Prusse est composé de vingt-cinq grains d'extrait d'opium dissous dans une once de vin de Malaga, qu'on 
mêle ensuite avec vingt-quatre onces de sirop de sucre ou de réglisse. Une once de sirop contient un grain d'extrait d'opium. Enfin on peut préparer à l'instant un sirop d'opium, en mêlant, d'après la pharmacopée de Suède, seize gouttes de teinture thébaïque à une once de sirop de sucre. Toutes ces préparations ont des propriétés plus constantes que le sirop de pavot; mais celui-ci est plus doux et moins narcotique; il convient mieux aux enfans.

Tous nos pharmaciens ne préparent pas de la même manière le sirop diacode. Pour quelques-uns, c'est le sirop de pavot blanc qu'ils préparent simplement avec les capsules de la plante; pour le plus grand nombre, c'est le sirop d'opium du Codex, et alors cette préparation contient deux grains d'extrait d'opium par once; mais quelquefois aussi elle n'en contient qu'un grain, d'après les modifications que certains pharmaciens lui font subir. Ce désaccord dans la composition d'un médicament dont on fait un si fréquent usage est préjudiciable non-seulement aux malades, mais encore aux médecins et aux pharmaciens. Dans beaucoup de cas le simple sirop de pavot ne saurait remplacer le sirop diacode ou le sirop d'opium; et, dans quelques circonstances, une once de sirop diacode contenant deux grains d'opium, lorsque le médecin croit n'en prescrire qu'un grain, peut produire de graves accidens.

Le sirop de karabé est tout simplement un sirop d'opium où l'on a mêlé une certaine quantité d'esprit de succin. On le prescrit à la même dose dans les potions sédatives et antispasmodiques. Il contient environ un grain d'opium par once. 
En parlant des médicamens opiacés, il est impossible de passer sous silence la thériaque d'Andromaque, composition bizarre, sans doute, par le nombre prodigieux de ses ingrédiens, mais dont l'efficacité est tellement reconnue, qu'elle figure encore dans la plupart des dispensaires. Néron, inquiet pour sa vie, avait chargé Andromaque de Crète, son médecin, de lui trouver un remède capable de résister à l'effet des poisons; les craintes d'un tyran nous ont valı la thériaque. Nous nous garderons bien de présenter cette espèce d'électuaire comme un antidote contre les substances vénéneuses; mais on ne saurait contester ses vertus cordiales, stomachiques et sudorifiques. Dans quelques cas, il agit, à la dose d'un à deux gros, comme un calmant, comme un somnifère très-efficace. On s'en sert contre les diarrhées rebelles, les flux dysentériques, la débilité de l'estomac, l'inappétence; vers la fin des rhumes, des catarrhes, lorsque le sommeil est troublé par la toux, et lorsqu'on a besoin de ranimer la transpiration insensible.

Que dirons-nous d'une composition analogue qui a reçule nom de Mithridate, son inventeur, et que Pompée fit connaître à Rome, après avoir triomphé de cet implacable ennemi? Ainsi que la thériaque, cet électuaire doit ses principales vertus à la combinaison de l'opium avec plusieurs substances toniques et excitantes; mais il est entièrement tombé en désuétude.

Le diascordium de Fracastor, autre médicament opiacé, jouit encore de quelque estime; on l'emploie particulièrement dans les flux intestinaux avec débilité locale. Il nous a été parfaitement utile pour com- 
battre un dévoiement opiniâtre qui se reproduisait sans cesse chez une dame qui avait éprouvé des accidens cholériques en 1832. La diarrhée durait depuis environ six mois, et la malade, dont l'estomac ne pouvait d'ailleurs supporter aucune substance tonique, était réduite à un tel état de maigreur et de faiblesse que toute sa famille désespérait de sa guérison. Les lavemens préparés avecl'extrait de rathania, le cachou et autres astringens, où l'on ajoutait soit de l'extrait d'opium, soit du laudanum liquide, n'étaient que d'un faible secours. D'après une consultation à laquelle avaient assisté MM. Chomel, Cayol, Dubois d'Amiens et moi, on lui donna pendant plusieurs jours de petits lavemens où entrait depuis un scrupule jusqu'à un demi-gros de diascordium. Ces lavemens répétés deux ou trois fois en vingt-quatre heures firent cesser complètement la diarrhée en moins de huit jours. La malade, ayant repris un peu de force, fut transportée à la campagne, et deux mois après elle était parfaitement rétablie.

Poudie de Dover. En Angleterre et dans le Nord, on fait un fréquent usage de cette poudre, qui est un mélange d'opium, d'ipécacuanha, de nitre et de sulfate de potasse. Mais les doses et les ingrédiens varient dans les différentes pharmacopées qui ont recueilli cette composition. Dans les pharmacopées d'Édimbourg, de Londres, de Suède et de Russie, on supprime le nitrate de potasse. Du reste, comme cette poudre s'altère en vieillissant, il vaut mieux la préparer au moment où l'on veut en faire usage. Prenez, opium, ipécacuanha, de chaque deux grains; sulfate de potasse, nitrate de potasse, de chaque huit grains. Mêlez 
exactement, pour une ou deux doses à prendre le matin à jeun. Cette poudre est un sudorifique très-efficace dans les maladies goutteuses et rhumatiques, dans quelчues affections catarrhales. D'après l'intensité des symptômes et la constitution du malade, on peut élever les doses de l'opium et de l'ipécacuanha jusqu'à quatre, cincI et six grains. Il faut s'abstenir de boire immédiatement après avoir pris cette poudre, pour ne pas provoquer le vomissement. Après une heure d'intervalle, on fait usage de quelque boisson délayante, comme une infusion de thé, de fleur de tilleul, de feuilles d'oranger ou de sauge. On s'enveloppe de flanelle, et on se tient chaudement dans le lit. Si l'on supporte aisément les sueurs, il est bon de les entretenir pendant plusieurs heures; après quoion s'essuie le corps et on se couvre de flanelle sèche. Lorsqu'on prend la poudre de Dover, il est nécessaire de garder la chambre et d'éviter avec beaucoup de soin de s'exposer au froid. Si elle produit des sueurs abondantes sans causer un grand échauffement ni d'autres symptômes fâcheux, on en continue l'usage à des doses modérées, et on tient le ventre libre. Au reste, cette méthode est contre-indiquée par une chaleur brûlante, une grande soif, une anxiété vive, par la fréquence et la dureté du pouls, la céphalalyie, le délire imminent.

On remplace la poudre de Dover par un mélange de trente à quarante gouttes de laudanum liquide, et de quarante à cinquante gouttes de teinture d'ipécacuanha ou de vin stibié, qu'on donne sous la forme de julep, avec une once d'eau de rose et deux gros de sucre. Ces remèdes sont utiles aux personnes affectées de douleurs rhumatismales, de catarrhes habituels, et chez qui la 
transpiration se supprime facilement. Par leur usage méthodique, on obtient une distribution plus régulière des forces sur l'organe de la peau, dont ils réveillent l'énergie et l'activité.

Enfin nous mentionnerons en passant les pilules de cynoglosse, préparation assez estimée de quelques praticiens, mais dont il faudrait supprimer les ingrédiens inutiles en n'y laissant que l'opium et les semences de jusquiame. On les donne à la dose de quatre, six et huit grains, pour calmer la toux et les irritations pectorales.

Emploi des sels de morphine. Le docteur Magendie a proposé de remplacer le sirop de pavot, le sirop diacode par la préparation suivante :

Sirop de morphine. Prenez, sirop de sucre parfaitement clarifié, une livre; acétate de morphine, quatre grains. Ce sirop est maintenant employé par beaucoup de praticiens comme un calmant très-efficace, à la dose d'une à deux onces. Le sirop de sulfate de morphine se prépare dans les mêmes proportions, et se prescrit aux mêmes doses.

Gouttes calmantes. Prenez, acétate de morphine, seize grains; eau distillée, une once; ajoutez trois ou quatre gouttes d'acide acétique, et un gros d'alcohol, afin de maintenir le sel dissous. On peut employer le sulfate de morphine au lieu de l'acétate. La dose de ces gouttes est de six à vingt-quatre.

D'ailleurs l'acétate et le sulfate de morphine s'emploient en pilules ou bien dans les potions, dans les juleps, depuis un huitième de grain jusqu'à un grain. Le docteur Magendie a reconnu que ces sels jouis- 
sent de tous les avantages qu'on désire trouver dans l'opium, sans en avoir les inconvéniens. Il a donné avec succès l'acétate de morphine à une demoiselle atteinte d'un anévrisme de l'aorte pectorale. La malade, ayant épuisé tous les secours de la médecine et toutes les recettes du charlatanisme, a trouvé enfin dans cette nouvelle préparation, administrée à la dose d'un quart de grain à un demi-grain par jour, un remède efficace contre les insomnies continuelles et les vives douleurs qui la tourmentaient depuis long-temps. Chez une dame portant un cancer au sein, le même sel, donné à la dose d'un quart de grain, a singulièrement diminué les douleurs lancinantes dont cet organe était le siége.

D'autres praticiens ont constaté par de nouveaux faits la vertu éminemment calmante de l'acétate de morphine. D'après l'observation de M. le docteur De Lens, il a constamment diminué l'extrême susceptibilité nerveuse d'une malade qui en a fait un long usage. Les nuits sont devenues plus calmes, les jours moins agités; il n'y a jamais eu ni céphalalgie, ni assoupissement profond, ni constipation; et l'on n'a pas vu non plus se développer cet enduit de la langue que produit ordinairement l'usage des médicamens opiacés. Une autre dame atteinte d'une angine de poitrine, maladie fort rare chez les femmes, a été d'abord, et pour ainsi dire subitement, délivrée de ses douleurs, mais cette amélioration ne s'est point soutenue.

Une femme affectée d'un squirrhe éprouvait des douleurs violentes qui l'empêchaient de goûter les douceurs du sommeil. M. le docteur Vincent Duval lui avait plusieurs fois administré, à Chaillot, l'extrait gom- 
meux d'opium, à la dose d'un à deux grains, sans pouvoir lui procurer le moindre soulagement. L'acétate de morphine, donné à la dose d'un demi-grain, apaisa chaque fois ses souffrances et la fit reposer pendant quatre ou cinq heures. L'opium causait des rêvasseries et de l'oppression à une dame phthisique au dernier degré. M. Duval est parvenu à la calmer et à lui procurer plusieurs heures de sommeil pendant un mois, en lui faisant prendre tous les soirs un demi-grain d'acétate de morphine. Une jeune fille atteinte d'une petite vérole confluente avait passé neuf jours sans dormir. Le même médecin lui donna le soir un julep anodin avec un grain d'extrait d'opium : point de sommeil, agitation, mouvemens spasmodiques. Le lendemain, un grain et demi d'opium produit les mêmes effets. M. Duval prescrit le jour suivant, à huit heures du soir, un demi-grain d'acétate de morphine, et, une heure après, la malade s'endort pour ne se réveiller que le lendemain à onze heures du matin. Dès ce moment, la fièvre, l'agitation, les spasmes cessent, et la convalescence marche rapidement.

Dans certains cas, il est indispensable d'élever les doses des sels de morphine, si l'on veut en obtenir un effet prompt et efficace. Un demi-grain, un quart de grain, et même des doses plus faibles, peuvent calmer une irritation légère, mais ne sauraient réprimer des douleurs violentes, un état d'exaltation extrême. M. le docteur Charles Prost a donné progressivement jusqu'à quatre grains d'acétate de morphine, en une seule dose, pour apaiser un délire maniaque et rappeler le sommeil. 
M. le docteur Bally, qui a fait à l'hôpital de la Pitié de nombreuses expériences sur l'acétate de morphine, en a particulièrement obtenu d'heureux effets dans les diarrhées chroniques. Parmi les faits dont il a rendu compte dans une des dernières séances de l'Académie de médecine, il en est un qui a surtout fixé notre attention. Un homme âgé de soixante ans, d'une constitution pléthorique et sanguine, avait éprouvé subitement une attaque d'apoplexie, suivie immédiatement d'hémiplégie du côté gauche. Le mouvement, deux mois après, commença à se rétablir; le malade marcha, et finit par n'avoir plus qu'un peu de gêne dans la progression. Il resta douze ans dans cet état, pendant lesquels le bras s'atrophia. Enfin la faculté de se mouvoir diminua progressivement, et lorsqu'il se décida à entrer à l'hôpital, il avait un air d'idiotisme, parlait peu, articulait assez mal, et se tenait toujours couché sur le côté gauche. On pratiqua quelques saignées, qui ne produisirent aucun effet. On eut recours aux bains tièdes, à l'application de la glace sur la tête, et en même temps à l'acétate de morphine, administré d'abord à la dose d'un quart de grain matin et soir, et peu à peu à un grain trois quarts. Des symptômes fâcheux signalèrent les mauvais effets de la médication. L'insomnie, le délire, la céphalalgie, le désir de fuir, les. efforts pour s'échapper de son lit, annoncèrent un danger pressant. Il fallut se hâter de suspendre le traitement, et revenir à la saignée. Le lendemain, tous les symptômes nouveaux étaient dissipés. Ce dernier résultat démontrait suffisamment que la médication était la cause réelle des accidens. 
Lorsque l'état du tube intestinal ne permet pas l'usage intérieur de l'acétate de morphine, ou que cette substance administrée par cette voie ne produit aucun effet remarquable, on a recours à la méthode endermique. Des faits nombreux ont constaté les avantages de ce nouveau procédé. Nous croyons que les observations suivantes méritent de fixer l'attention des praticiens.

Le docteur Gaspard Cerioli, de Crémone, fut appelé pour donner des soins à une dame affectée de tétanos à la suite d'une blessure au front, au-dessus du sourcil droit. On employa d'abord la saignée, les bains tièdes prolongés; on appliqua des calmans sur le cou et les articulations de la mâchoire; on administra l'acétate de morphine à l'intérieur et des lavemens purgatifs. Tous ces moyens n'avaient produit aucune amélioration, et la maladie faisait des progrès sensibles. La saignée réitérée et l'ipécacuanha pris comme sudorifique aggravèrent encore les accidens. On appliqua enfin un vésicatoireà la nuque, on enleva l'épiderme de la vésicule, et on recouvrit la plaie avec un linge enduit d'onguent d'althæa, qu'on saupoudra d'un quart de grain d'acétate de morphine. La même application fut répétée dans la journée, et l'effet en fut si remarquable, que, quelques heures après, les spasmes cloniques s'affaiblirent, les mouvemens de la mâchoire devinrent un peu libres, les contractions des traits de la face s'effacèrent, les douleurs du cou et du dos diminuèrent sensiblement, et la malade eut un sommeil tranquille, quoique interrompu. On continua le lendemain l'usage de ce médicament, à la dose d'un tiers de grain, deux 
fois par jour, et le mieux fit des progrès tellement rapides, que, quinze jours après, la malade était parfaitement guérie.

Le même médecin rapporte l'histoire d'une dame affectée de névralgie maxillaire rémittente, qui avait résisté aux saignées locales et générales, aux topiques de toute espèce, aux antispasmodiques, à la jusquiame, à la laitue vireuse, à la valériane, au sulfate de quinine, etc., et yui céda à l'application extérieure de l'acétate de morphine. On l'employa d'abord à la dose d'un quart de grain, puis à celle d'un tiers de grain, et les accidens se dissipèrent promptement.

Le docteur Bonnet a guéri par le même moyen une demoiselle de vingt-cinq ans, atteinte depuis environ huit mois d'une névralgie faciale se reproduisant ì des intervalles variables avec des souffrances inouies. Une compresse de plusieurs doubles, de la forme et de la grandeur d'une pièce de dix sous, fut trempée dans de l'ammoniaque caustique, et appliquée sur la tempe douloureuse. Au bout de trois minutes on put enlever l'épiderme. Alors on saupoudra la plaie avec un demi-grain d'acétate de morphine en poudre, et en moins de cinq minutes, la douleur ayant disparu complètement, la malade passa d'un état de désespoir à une satisfaction inexprimable.

On a également dompté, par l'acétate de morphine employé à l'extérieur, des névralgies sciatiques et lombaires; mais on a remarqué que lorsque le tube digestif était surexcité, lorsqu'il y avait gastro-entérite, ce médicament, bien qu'il ne fût appliqué que sur la peau, augmentait l'irritation des membranes digestives. 
Au reste, les jeunes praticiens ne doivent pas oublier que l'acétate et le sulfate de morphine sont des poisons très-actifs; qu'il faut les manier avec prudence, et surtout ne les administrer, même à l'extérieur, qque d'après des indications bien précises, d'autant mieux que l'habitude n'en affaiblit pas beaucoup l'énergie. Nous observerons aussi qu'il est peu probable que ces médicamens puissent remplacer, dans toutes les circonstances, les autres préparations opiacées.

M. Barbier, d'Amiens, a soumis la codéine à des essais cliniques qui l'ont convaincu de l'effet vraiment sédatif de ce nouveau principe de l'opium. Une femme tourmentée depuis environ deux mois d'anxiétés épigastriques, de douleurs gastro-spinales, arriva à l'Hôtel-Dieu d'Amiens dans un état d'accablement, avec plaintes, soupirs, pouls petit, irrégulier, vomissemens. La codéine la soulagea instantanément et rétablit sa santé en trois jours. Ce médecin a comparé les effets de la codéine et de la morphine employées intérieurement; voici les résultats qu'il a obtenus.

La codéine, administrée de cette manière, produit des sensations agréables; elle fait habituellement naitre une douce chaleur qui se répand dans l'épigastre, dans la poitrine, dans l'abdomen, et amène le sommeil après avoir calmé les malades. Ce sommeil a un caractère qui lui est propre, et qui diffère beaucoup de celui que provoquent la morphine et ses sels. Réveillés au milieu de leur sommeil, les malades qui ont pris la codéine ont l'encéphale parfaitement libre; ils sont gais, causeurs; leur figure est ouverte et rosée. Au contraire, les personnes qui sont sous l'influence de la 
morphine ont la tête lourde, les paupières pesantes, une certaine pâleur. Elles se plaignent d'engourdissement, de vertiges, d'accablement.

Outre la morphine et la codéine, l'opium offre dans sa composition beaucoup d'autres principes qui doivent nécessairement modifier ses propriétés générales; et, quelque précieuses que soient les nouvelles découvertes de la chimie, il ne faut pas trop se hâter d'abandonner des remèdes dont l'expérience atteste encore chaque jour les nombreux avantages ( 1 ).

Dans les prescriptions magistrales, on combine l'opium avec une foule de corps médicamenteux, suivant les indications thérapeutiques qu'on se propose de remplir. Ainsi on l'associe aux substances gommeuses et adoucissantes, aux évacuans, aux astringens, aux

(1) Depuis peu, l'acétate de morphine a causé un si grand effroi dans le monde, qu'on s'est empressé de multiplier les expériences sur divers animaux, dans le but de découvrir les traces de ce poison végétal, soit dans les voies alimentaires avant son absorption, solt dans le sang après qu'il a été absorbé. D'après les recherches de MM. Dupuy, professeur à l'École vétérinaire d'Alfort, Deguise fils et Leuret, l'acétate de morphine ne détermine aucune altération visible dans les tuniques digestives des chiens et des chats. On a retrouvé plusieurs fois le poison dans l'estomac, mais pas encore dans les intestins. Les expériences chimiques qu'on a faites sur le sang ont été infructueuses; on n'a pu retrouver dans ce liquide la moindre trace du poison absorbé. Le professeur Barthélemy a injecté dans la veine jugulaire d'un cheval une solution de trente grains d'acétate de morphine. Cinq quarts d'heure après cette opération, et lorsque l'animal était sous l'influence du poison, il a tiré de la jugulaire opposée environ un litre de saug. Ce fluide, analysé par M. Lassaigne, préparateur du cours de chimie à l'École vétérinaire, $n$ 'a offert aucune trace d'acétate de morphiue. 
toniques, aux excitans, aux antispasmodiques, aux plantes vireuses, afin de changer ou de modifier leur action réciproque. Il n'est pas toujours facile d'expliquer d'une manière satisfaisante les heureux effets de ces mélanges, de ces combinaisons; mais on ne saurait. les révoquer en doute lorsqu'ils sont garantis par l'observation clinique, par des expériences répétées.

Poudresédative. Prenez, opium purifié, deux grains; sucre, vingt-quatre grains. Triturez exactement, et divisez en quatre ou six prises. On en donne une de deux en deux heures, ou à des intervalles plus rapprochés.

Poudre parégorique de Vogler. Prenez, sucre blanc, amidon, de chaque, deux gros; opium cru, quatre grains. Mêlez et triturez avec soin. On l'administre, mêlée avec un peu de lait, à la dose de huit, dix ou quinze grains, plusieurs fois par jour, dans les diarrhées invétérées, les flux dysentériques rebelles. Il est quelquefois utile d'ajouter à chaque prise un demigrain ou un grain d'ipécacuanha.

Pilules antihystériques de l'hôpital Saint - Antoine. Prenez, extrait d'opium, extrait de valériane, musc, de chaque, vingt-quatre grains.

Pilules calmantes du professeur Récamier. Prenez, extrait d'opium, oxyde d'antimoine hydro-sulfuré rouge, de chaque, deux grains; nitrate de potasse, quatre grains. On les emploie à l'Hôtel-Dieu, dans les affections rhumatismales, pour diminuer les douleurs et provoquer en même temps une diaphorèse salutaire. On trouve dans ce composé quelque analogie avec la poudre de Dover. (Ratier, Formulaire des hôpitaux civils de Paris.) 
Pilules antispasmodiques du professeur Dumas. Prenez, assa-fœetida, deux gros; castoréum, camphre, de chaque, un gros; opium gommeux, vingt grains. Faites des pilules de quatre grains chacune, avec suffisante quantité de mucilage. On en prend deux ou trois matin et soir.

Prenez, castoréum, un gros; opium gommeux , demi-gros; extrait de jusquiame, vingt grains; sirop de Stochas, suffisante quantité pour former des pilules de trois grains. On donne d'abord une pilule matin et soir. Le troisième jour on augmente d'une pilule, et six jours après on porte la dose à trois pilules pour chaque prise. (Consultations et observations de médecine de feu $\mathrm{C}_{\text {h. L. Dumas, publiées par le docteur Rouzer.) }}$

Potion calmante. Prenez, eau distillée de laitue, trois onces; eau de fleur d'orange, sirop diacode, de chaque, une once; laudanum de Rousseau, dix gouttes. On prescrit cette potion par cuillerées, pour apaiser des irritations nerveuses, pour dissiper les spasmes de la matrice qui s'opposent à l'écoulement périodique. Elle soulage presque instantanément les femmes très-irritables chez qui la menstruation est difficile ou accompagnée de vives souffrances. On augmente les doses du laudanum dans les maladies où la douleur est extrême, où elle prédomine d'une manière pernicieuse ( 1 ). Il ne faut pas craindre alors d'élever les doses

(1) Dans certains cas, l'inflammation porte spécialement sur la sensibilité animale, et plus généralement sur l'action nerveuse. Alors elle prend une tournure particulière dans sa première origine, dans sa marche, dans ses symptômes; elle se montre subordonnée à l'affection de la sensibilité, de telle sorte que 
de l'opium; l'influence de ce remède sur le système nerveux est si puissamment modifié par la douleur, qu'il faut le donner d'une manière active pour qu'il devienne réellement efficace.

Potion contre les vomissemens spasmodiques. Prenez, eau de menthe, deux onces; sirop de limon, une once; laudanum liquide de Sydenham, éther alcoholisé, de chaque, trente gouttes. Donnez-en une cuillerée à bouche toutes les heures, ou plus souvent, suivant l'urgence. Nous devons observer que, che\% quelques individus, toutes les préparations d'opium excitent le vomissement au lieu de le calmer. Elles le provoquent aussi lorsqu'on les donne dans les lavemens.

c'est la douleur qui décide la série de tous les autres phénomènes de l'inflammation, qui les tient sous sa dépendance pendant plus ou moins long-temps, et d'une manière si décisive, que, si , par des moyens appropriés, on parvient à détrnire cette affection de la sensibilité, la phlegmasie s'évanouit. Il est incontestable que certaines inflammations sont heureusement traitées par les narcotiques, et notamment par l'opium. Cette circonstance est d'autant plus remarquable pour l'observateur réfléchi, qu'en général l'opium est un remède irritant qui augmente l'inflammation simple et ordinaire, ou qui, se bornant à la masquer sous un calme trompeur, la conduit rapidement à la gangrène. Tous les observateurs ont noté ces deux ordres de faits : or, deux ordres de faits si différens ne peuvent pas se rattacher à deux états morbides identiques. Celui qui cultive la médecine pour l'appliquer aux besoins de l'humanité doit chercher à connaître la source d'une contradiction si formelle. S'il est éclairé par une saine physiologie; si, pénétré de l'importance de sa mission, il ne se laisse point arrêter par le vain reproche de s'attacher à de prétendues distinctions subtiles d'où dépend le salut des malades, reproche d'autant plus ridicule qu'il vient de la part de médecins qui mettent une laute importance à des distinctions anatomiques 
Potion contre les hémorrhagies utérines avec faihlesse. Prenez, eau distillée de cannelle, cinq onces; sirop de gomme arabique, une once et demie; nitrate de potasse, vingt grains; acide sulfurique alcoholisé, laudanum liquide, de chaque, demi-gros. La dose est d'une ou deux cuillerées, qu'on réitère de demi-heure en demi-heure, ou toutes les heures. On l'emploie aussi dans quelques autres flux sanguins, dans certains crachemens de sang qui dépendent d'une congestion passive sur l'organe pulmonaire.

Gouttes volatiles. Prenez, laudanum liquide, éther sulfurique, de chaque, un gros; esprit de corne de cerf succiné, deux gros. La dose de cette liqueur stimulante est de vingt à trente gouttes dans une demi-cuil-

qui ne peuvent que modifier secondairement le traitement; si, dis-je, il est fort de ses intentions et ferme dans sa logique, il ne manquera pas de reconnaître que, dans le premier cas, l'inflammation porte spécialement sur la sensibilité et l'action nerveuse; que la douleur a paru la première et persiste pendant long temps; que les autres phénomènes de l'inflammation y sont moins marqués, disproportionnés avec la douleur sous le rapport de l'intensité ; qu'ils ne sont que les effets de cette affection; qu'ils sont sous sa dépendance d'une manière plus ou moins absolue ; et que, dans le second cas, la douleur n'est qu'un simple phénomène de l'inflammation, qu'elle n'indique qu'une affection de la sensibilité égale à celle des autres propriétés, avec lesquelles elle conserve la plus grande harmonie; qu'il serait absurde et dangereux de la combattre d'une manière directe, et qu'on s'exposerait par là à augmenter l'inflammation, dont elle est un des résultats. Dès-lors il s'explique à lui-même comment, dans le premier cas, l'opium ne peut avoir que les plus heureux effets, tandis que, dans le second, il ne peut avoir que les suites les plus funestes, et il peut utiliser ce fait pour diriger sa pratique. (BÉRARD, Examen de la doctrine de M. Broussais; Revue médicale, tome 8 , page 285.) 
lerée d'eau de menthe sucrée; on la répète toutes les heures ou plus souvent dans les accès hystériques, les syncopes, les convulsions, les affections paralytiques qui ne dépendent point d'une congestion sanguine. Les gouttes volatiles conviennent dans la période avancée des fièvres ataxiques, du typhus irrégulier, pour dissiper le trouble de l'action nerveuse, pour ranimer la circulation, relever les forces abattues, et provoquer une diaphorèse salutaire. On ne doit pas les employer lorsqu'il existe des signes d'inflammation viscérale, lorsque le pouls est fréquent et dur, la peau chaude, la figure animée, etc. Au reste, lorsque les excitans sont indiqués, et ils le sont assez souvent dans les fièvres typhoïdes, malgré l'opinion contraire de la nouvelle école, il ne faut pas attendre le plus haut période du mal, c'est-à-dire que l'organisme ne soit plus excitable. Il est un état de débilité profonde où rien ne saurait ranimer les fonctions vitales. Que pourrait-on espérer de l'usage des stimulans lorsque l'excitabilité est pour ainsi dire épuisée, soit par.l'effet de la maladie, soit par l'abus des évacuations sanguines et de la méthode antiphlogistique?

Mixture antifébrile du docteur Peysson. Prenez, tartre stibié, un grain. Faites dissoudre dans huit onces d'eau, ajoutez ensuite, sirop diacode, une once; gommeadragant, un scrupule; eau de fleur d'orange, deux gros. C'est une nouvelle combinaison que le docteur Peysson et après lui le docteur Jourdain ont employée avec succès contre les fièvres intermittentes. On l'administre de deux manières. Si le malade est fort, et ne peut se passer d'alimens solides, ce qui vaudrait mieux, 
on lui donne entre les accès une cuillerée la prenière heure, deux la seconde, trois la troisième, et ainsi de suite jusqu'aux repas. On la suspend alors, pour la reprendre une heure et demie ou deux heures après, en recornmençant par deux cuillerées, et augmentant de nouveau par degrés. Lorsquie le malade est faible, délicat, et qu'il peut se passer d'alimens solides, on la donne, comme les autres potions, par cuillerées ; seulement, au lieu d'en augmenter graduellement la dose, on rapproche insensiblement les intervalles, de manière qu'il en prenne une cuillerée tous les quarts d'heure, ou au moins chaque demi-heure. Dans l'un et l'autre mode, on n'en cesse entièrement l'usage que pendant la violence des accès. Après leur suppression, il faut continuer pendant quelque temps le remède, pour prévenir les rechutes. Il faut qu'il ne fatigue point, que l'action en soit insensible. S'il provoquait des vomissemens ou la diarrhée, il faudrait aussitôt en diminuer la dose, soit en modifiant la composition, soit en éloignant davantage les cuillerées.

On peut remplacer le sirop diacode par l'extrait aqueux d'opium ou par le laudanum liquide, en ajoutant du sirop simple. La poudre de Dover, ou un mélange de vin stibié et de teinture thébaïque, ont quelquefois produit les mêmes effets. Ces compositions dissipent les fièvres intermittentes en modifiant l'action nerveuse, en dirigeant les mouvemens vitaux du centre à la circonférence. Lorsque la fièvre se complique, et surtout lorsqu'elle dépend d'une phlegmasie viscérale, il faut préalablement combattre l'irritation inflammatoire par les émolliens, les antiphlogistiques. 
Teinture antispasmodique du docteur Chrestien. Prenez, opium, demi-gros. Faites dissoudre dans quatre onces d'alcohol affaibli. On y ajoute quelquefois un demi-gros de camphre. On administre cette teinture sous la forme de frictions, pratiquées plusieurs fois par jour sur la partie interne des cuisses, et quelquefois aussi sur le bas-ventre et sur le rachis, lorsque le spasme de l'œsophage ou la susceptibilité de l'estomac ne permettent point de donner l'opium à l'intérieur. Par ce procédé, M. Chrestien a guéri des fièvres intermittentes et quelques autres affections entretenues par un état spasmodique. On emploie ordinairement pour chaque friction environ une once de teinture. Lorsqu'on frictionne les parties voisines de la tête, il faut surveiller l'effet narcotique de l'opium.

Teintures antifébriles. Prenez, opium, dix grains; camphre, demi-gros. Faites dissoudre dans cinq onces de teinture alcoholique de quinquina.

Prenez, opium, quinze grains; camphre, demi-gros; succin, un gros; alcohol affaibli, huit onces.

Dumas (ouvrage cité) prescrit ces teintures, en friction, sur toute l'habitude du corps dans les fièvres intermittentes qui se prolongent chez les sujets faibles, nerveux et très-sensibles. On fait plusieurs fois par jour des frictions sur les extrémités supérieures et inférieures, et le long de la colonne épinière. On administre en même temps, matin et soir, un demi-lavement préparé avec une infusion de racine de valériane sauvage et de fleur de camomille romaine, où l'on fait dissoudre quelques grains de camphre et d'assa-fretida.

Liniment sédatif: Prenez, haume tranquille, 
baume de Fioraventi, de chaque, une once; teinture thébaïque, deux à quatre gros. Mêlez, et pratiquez de temps en temps des frictions sur les parties douloureuses.

Lotion narcotique. Prenez, opium purifié, deux gros. Faites dissoudre dans nne livre d'eau. On calme les douleurs du cancer par l'application souvent répétée de compresses imbibées de cette liqueur.

Pour remplir le même but, le docteur Sainte-Marie (Nouveau formulaire médical) fait ajouter une once d'ammoniaque (alcali volatil) à une livre de décoction de têtes de pavot. Avec le secours de cette fomentation, il dit avoir soulagé des douleurs atroces qu'aucun autre topique n'avait pu calmer.

\section{CHÉLIDOINE. CHELIDONIUM.}

Calice caduc, à deux folioles. Corolle à quatre pétales. Étamines nombreuses. Ovaire cylindrique, surmonté d'un stigmate bifide. Capsule allongée semblable à une silique, à une loge, à deux valves.

CHÉLIDOINE ÉCLAIRE. CHELIDONIUM MAJUS.

Chelidonium majus. Lins. Spec. 723. DC. Fl. Fr. 4093.

Fl. Dan. t. 542 .

(Planche irr.)

Sa racine, fusiforme, fibreuse, d'un jaune foncé, pousse des tiges cylindriques, rameuses, hautes d'un à deux pieds, quelquefois un peu velues. Les feuilles sont alternes, molles, découpées, ailées ou profon- 
dément pinnatifides, à lobes arrondis, d'un vert foncé en dessus, d'un vert glauque en dessous. Les fleurs ont quatre pétales presque ronds, ouverts et d'une nuance jaune; leurs pédoncules particuliers sont réunis sur les pédoncules communs en manière d'ombelle. Le fruit est une silique grêle, longue de quinze à vingt lignes, renfermant plusieurs semences arrondies, noires et luisantes.

Cette plante, qu'on désigne aussi sous le nom de grande chélidoine, abonde dans les haies, dans les lieux frais et ombragés. On la rencontre f:équemment dans les fentes des vieux murs, dans les décombres, autour des villages, où elle fleurit en juin et juillet.

Elle donne à l'analyse chimique une matière gommorésineuse jaune, nauséabonde, de l'acide malique libre, du mucilage, de l'albumine, des cirrate et phosphate de chaux, etc. Lorsqu'on brise la tige ou les feuilles, il s'en écoule aussitôt un suc jaunâtre, amer, caustique, d'une odeur vireuse. Ce suc est un poison irritant qui enflamme les tuniques digestives, et tue les chiens à la dose de deux ou trois onces. L'extrait aqueux, préparé avec la plante fraîche, jouit d'une action analogue. Si l'on était appelé pour remédier aux accidens produits par la grande chélidoine, il faudrait mettre en usage la méthode curative que nous avons plusieurs tois indiquée en traitant des poisons âcres. (Voyez la famille des Daphnoïdes, celle des Renonculacées, etc.)

Dioscoride et Galien ont employé cette plante énergique. Parmi les modernes, Linné, Lange, et quelques autres médecins du Nord ont particulièrement 
loué sa vertu antifébrile. Le peuple de Brunswick se sert contre les fièvres intermittentes soit de la racine en poudre, soit du suc de la plante, mêlé avec le vinaigre. Des sueurs copieuses paraissent être l'effet immédiat de ce médicament. On a également conseillé la grande chélidoine contre la jaunisse, l'hydropisie ascite, les maladies vénériennes, les scrophules, la goutte, les dartres, etc.; mais on cherche en vain quelques observations qui garantissent son heureux emploi. Quant à son usage extérieur, personne n'ignore que la chélidoine était autrefois fort usitée dans le traitement des maladies des yeux. Le suc, étendu à la dose d'environ un gros dans deux ou trois onces d'eau fraîche ou d'eau distillée de rose, forme un collyre efficace contre l'ulcération chronique des panpières, les ophthalmies scrophuleuses, pourvu que l'inflammation soit modérée.

\section{CHÉLIDOINE GLAUQUE. CHELIDONIUM GLAUCIUM.}

Chelidonium glaucium. Linn. Spec. 724. Fl. Dan. 1. 585.

- Glaucium flavum. Crantz. Fl. Austr. 2. 141. Lapevr. Hist. Plant. Pyr. 1. 295.

\section{(Planche i r.)}

Cette plante se fait remarquer par la couleur blenàtre de sa tige et de ses feuilles, et par ses fleurs d'un jaune d'or. La tige est cylindrique, rameuse, glabre, quelquefois un peu velue vers sa partie supérieure. Les feuilles sont alternes, cmbrassantes, sinuées, 
pinnatifides, hérissées de poils courts, droits et écartés. Les fleurs sont grandes, solitaires, assez semblables à celles des pavots. Il leur succède des siliques longues de quatre à cinq pouces, légèrement aplaties, rudes au toucher, bivalves et biloculaires.

Elle est commune en été dans les lieux sablonneux et découverts du Roussillon; dans les bois secs et rocailleux, à Saint-Germain, au bois de Boulogne, etc. On l'appelle vulgairement pavot cornu.

Les feuilles et les tiges:ąsont remplies d'un suc jaune, fétide, amer, et âcre comme celui de l'espèce précédente. On attribue en même temps à ce suc une qualité narcotique. L'usage de la racine a été suivi de délire et d'hallucinations.

On lit dans l'Abrégé des Transactions philosophiques, que M. Charles Worth, ayant mangé d'un pâté où l'on avait mis des racines de chélidoine glauque pour celles du chou marin (cynocrambe maritima), fut subitement attaqué d'une sorte d'aliénation mentale. Ses domestiques, qui en avaient mangé comme lui, furent tous plus ou moins incommodés. Mais un effet qui leur fut commun à tous, c'est une altération de leurs sens, une illusion de leur esprit, qui leur faisait prendre pour de l'or tout ce qu'ils touchaient, et les avait, pour ainsi dire, changés en Midas.

La chélidoine à fleurs rouges (cheliclonium corniculatum, Linn.) passe également pour une plante suspecte. Elle a causé le délire et des convulsions. On la reconnaît à ses tiges rameuses, très-velues; à ses feuilles sessiles, presque embrassantes, profondément pinnatifides, hérissées de poils blancs; à ses pétales 
rouges, avec, une tache violette ou noirâtre à leur onglet; à ses siliques droites, linéaires, longues de quatre ou cinq pouces. On distingue une variété dont la tige et les feuilles sont glabres. Cette plante croît dans les champs, parmi les moissons; on la trouve dans les provinces méridionales de la France.

'Toutes les chélidoines sont plus ou moins imprégnées d'un principe âcre, virulent. On a depuis longtemps renoncé à l'usage intérieur de ces plantes; mais on peut les employer extérieurement avec quelque utilité. Un de nos zélés correspondans, M. le docteur Dupont, nous écrit qu'il a guéri une dartre rongeante en la bassinant plusieurs fois par jour, d'abord avec une forte décoction de grande chélidoine, et ensuite avec le suc de la même plante étendu dans une infusion de fleurs de sureau. On appliquait en même temps sur la partie ulcérée des compresses imbibées de ce liquide. Le premier effet de ces applications fut de calmer un horrible prurit que le malade éprouvait aux bords de la dartre.

FIN DU DEUXIEME VOLUME. 


